\title{
AgroEcological Transitions
}

Changes and Breakthroughs in the Making

Edited by

Boelie Elzen

Anna Maria Augustyn

Marc Barbier

Barbara van Mierlo 



\section{AgroEcological Transitions}

Changes and Breakthroughs in the Making

Edited by Boelie Elzen, Anna Maria Augustyn,

Marc Barbier and Barbara van Mierlo 
() Boelie Elzen, Anna Maria Augustyn, Marc Barbier and Barbara van Mierlo, 2017

\section{(1) $(1) \Theta$}

This work is licensed under a Creative Commons Attribution-NonCommercial-NoDerivatives 4.0 International License.

ISBN: 978-94-6343-114-9

Published by Wageningen University \& Research, Applied Arable and Vegetable Research https://www.wur.nl/en/Expertise-Services/Research-Institutes/plant-research/Applied-Arable-and-VegetableResearch.htm

Cover design by Françoise Maxime

Document available at DOI: http://dx.doi.org/10.18174/407609

Citing this document

Elzen, B., A. Augustyn, M. Barbier and B. van Mierlo, 2017. AgroEcological Transitions: Changes and Breakthroughs in the Making. DOI: http://dx.doi.org/10.18174/407609 


\section{Contents}

PREFACE

ACKNOWLEDGEMENTS

AGROECOLOGICAL TRANSITIONS: CHANGES AND BREAKTHROUGHS IN THE MAKING

\section{Part A: Learning in niches}

Bart Bremmer and Bram Bos, "Creating Niches by applying Reflexive Interactive Design"

Julie Ingram and Damian Maye, "Niche knowledge systems-challenging or invigorating the AKS? An analysis of the Permaculture community in England"

Claire Lamine, "Multi-actors transition arenas in the fruit breeding system: a pathway towards sustainability, or a new veil over lasting power relationships?"

Bálint Balázs, György Pataki and Orsolya Lazányi, "Socio-Economics of CSAs in Hungary"

Boldizsár Megyesi, "Agri-food production in a Hungarian micro-region: Factors influencing farmers' practices"

Marcia R. Ostrom, "Understanding Trends in Consumer Food System Participation: Implications for Agri-food Movement Mobilization and Systems Change in the Northwestern United States"

\section{Part B: Niche-regime interactions}

George Vlahos, Pavlos Karanikolas and Alex Koutsouris, "Identifying transition patterns at the regional scale. A Greek case study"

Shambu Prasad Chebrolu and Debashish Sen, "Exploring Diversity, Networks and Knowledge Regimes: Transitions and System Building in SRI in India"

Paul Swagemakers, Pierluigi Milone and Flaminia Ventura, "Resilient farmers' strategies and policy regulations: The quest for modernization on Dutch and Italian dairy farms"

Boelie Elzen, Arni Janssen and Bram Bos, "Portfolio of promises: Designing and testing a new tool to stimulate transition towards sustainable agriculture"

Jan Buurma, Anne-Charlotte Hoes, Karel de Greef and Volkert Beekman, "Role of NGOs in system innovation towards animal friendly pork production in the Netherlands"

Allison Loconto, Anne Sophie Poisot and Pilar Santacoloma, "Sustainable Practices,

Sustainable Markets? Institutional innovations in agri-food systems" 


\section{Part C: Regime transformations}

Erika Quendler, "Sustainable development in education: are we ready for change? System innovation and higher education in life sciences"

Frank Nevens, Erik Mathijs and Philippe Vandenbroeck, "From systematic to systemic: An experiment in systems analysis for agriculture and food"

Pieter J. Beers, Barbara van Mierlo, "Reflexivity, reflection and learning in the context of system innovation: Prying loose entangled concepts"

Patrick Steyaert, Marc Barbier, Marianne Cerf, Alix Levain and Allison Loconto, "Role of intermediation in the management of complex socio-technical transitions"

Conclusion: A CURIOSITY CABINET OF AGROECOLOGICAL TRANSITION STUDIES 


\section{Preface}

Around the year 2010, the research field of "transition studies" was gaining increasing attention and was developing into a true research community with the advent of the "Sustainability Transitions Research Network" (STRN), the organisation of annual international sustainability transition (IST) conferences, and the launch of a scientific journal, named "Environmental Innovation and Societal Transitions". Concerning the topics addressed within this emerging field, the domain of agriculture was studied by only a small number scholars. This constituted an important omission given the major role this domain plays in global challenges like food provision, depletion of minerals, curbing $\mathrm{CO}_{2}$ emissions, etc. Seeking to fill this gap, researchers from 'Wageningen University \& Research' in the Netherlands (WUR) and the 'Institut National de la Recherche Agronomique' in France (INRA) took the initiative to organize a first international workshop on the topic of "System Innovation towards Sustainable Agriculture" (SISA). This first SISA workshop was held in June 2010 in Lelystad, the Netherlands, and its proceedings were published online in $2012 .{ }^{1}$

From the beginning, the idea was to develop a permanent network of transition researchers with interest in the domain of agriculture. To give the network that emerged from the first workshop a more permanent character, a second SISA workshop was held in Paris in 2014. This volume provides a collection of the papers that were presented and discussed at this workshop.

The objective of the workshop was to bring research insights and practical experiences together, and to discuss papers in depth to create a basis for effective strategies to stimulate transitions towards sustainable agro-food systems. The papers presented provided an overview of analytical methods, experiences and scientific insights on the main issues at stake in a variety of sustainability initiatives, projects and programmes. More specifically, the workshop sought to contribute to:

- Comparing various approaches towards analysing sustainability transitions in agriculture;

- Comparing various approaches towards governance of innovation in agriculture in various European countries, as well as some examples from outside Europe;

- Providing input for rethinking government policies, socio-professional strategies and civic concerns, seeking to contribute to sustainable development in the agro-food systems on the basis of existing research and experiences;

- Identifying main topics for future research.

Contributions to the workshop were expected to have either a strong analytical component (to analyse the relevant processes), or a strong constructive component, i.e. seeking to play a role in co-operation with other stakeholders in the development of sustainable alternatives. The topics addressed should cover several agricultural subsectors (including animal production, arable farming, (glasshouse) horticulture, biomass production for fuels and fibres) and target emerging innovations in agro-food systems, knowledge regimes in transition, or design practices.

Two main issues were proposed to the participants:

- Analyse the ongoing dynamics in agro-food systems, including system innovations, knowledge regimes and design practices.

- Investigate how government agencies and other actors can position themselves and what they can do to stimulate and influence such system innovations, knowledge regimes and design settings, seeking to make agro-food systems more sustainable.

The INRA Science in Society unit organized the second SISA workshop in Paris from 22-23 May 2014 that was hosted by AgroParisTech. Financial support was received from INRA, IFRIS and WUR. A scientific and

\footnotetext{
${ }^{1}$ Marc Barbier and Boelie Elzen (Eds.), 2012. Proceedings of the first international workshop on System Innovations, Knowledge Regimes, and Design Practices towards Sustainable Agriculture. Paris: INRA. Downloadable from: http://www.inra-ifris.org/activites/open-science/system-innovations-knowledge-regimes-and-design-practices-towardstransitions-for-sustainable.html
} 
organizational committee was set up under the coordination of Marc Barbier that was composed of Marc Barbier, Marianne Cerf and Claire Lamine from INRA SAD, Boelie Elzen from Wageningen Research and Barbara van Mierlo from Wageningen University. A call for papers was launched through the scientific networks of the committee members, including agricultural research communities and the STRN. Fifty-five paper proposals were submitted of which eighteen were selected for presentation. The format of the meeting was designed to stimulate in-depth discussions of various issues, rather than having many presentations and only brief discussions. Papers were not presented but were assumed to be read beforehand and to stimulate the interaction, two discussants kicked off the discussion of each paper. All participants played an active role, either as paper authors or discussants or both.

Participation in the workshop was by invitation only on the basis of submitted abstracts. The invited participants came from a variety of disciplinary backgrounds such as innovation studies, economics, science \& technology studies (including constructive and interactive technology assessment studies), policy studies (including studies of network governance, learning and the impact of regulation), organisation studies (including studies focusing on management of structural change and leadership) and practice based studies.

The authors were encouraged to improve their papers on the basis of the discussions at the workshop. After further review (two reviewers per paper), sixteen contributions were considered mature enough to be published in this volume.

We wish to thank all participants for their stimulating contributions, their commitment to improve their papers, and their critical comments and suggestions which enhanced the quality of all the papers through the reviewing process.

Boelie Elzen, Anna Maria Augustyn, Marc Barbier and Barbara van Mierlo 


\section{Acknowledgements}

We thank INRA for organizing the international workshop at which the papers in the present volume were presented and discussed. Our further thanks go to WUR, Applied Arable and Vegetable Research that provided managerial and secretarial assistance in the production of this volume. Furthermore, we are grateful to the WUR Knowledge, Technology and Innovation Group, the INRA Research Unit Science in Society, and the Groupe de Bruges for their strong in kind support. We also like to thank AgroParisTech who has kindly hosted the workshop.

Furthermore, we thank the following institutions and their representatives for their financial support: INRA (SAD department and SAE2 Department) that provided the initial funding; further financial contributions were made by UR INRA SenS, the IFRIS consortium, and Wageningen University and Research (from the knowledge base program 'Transition \& innovation' - KB VI).

A special word of thanks goes to Iran Veiga (INRA) for minutes of the workshop and Lieneke Voorbij (WUR) for her excellent work in editing the text of the chapters and creating a consistent lay-out.

Finally, we thank all colleagues that took part in this enchanting Paris workshop. All participants played an active role, either as author or commentator, while some also gave kick-off presentations at 'harvesting' sessions. Furthermore, almost all of them reviewed the draft versions of papers before publishing them in this volume (two reviewers per paper). This teamwork been very stimulating and effective in raising the quality of the present volume.

\section{Workshop participants:}

Alyakova, Mira, University of National and World Economy, Sofia, Bulgaria

Augustyn, Anna Maria, Groupe de Bruges, Netherlands

Barbier, Marc, INRA, UMR LISIS (INRA, UPEM, CNRS, ESIEE), Marne-La-Vallée, France

Boldizsar, Megyesi, Hungarian Academy of Sciences, Budapest, Hungary

Bos, Bram, WUR, Wageningen, Netherlands

Bremmer, Bart, Independent Innovation Sociologist, Renkum, Netherlands

Buurma, Jan, WUR, The Hague, Netherlands

Cerf, Marianne, INRA, UMR LISIS (INRA, UPEM, CNRS, ESIEE), Marne-La-Vallée, France

Cittadini, Roberto, INTA, UMR Innovation (INRA, CIRAD, SUPAGRO), Montpellier, France

Cucco, Ivan, University of Naples Federico II, Napels, Italy

Elzen, Boelie, WUR, Lelystad, Netherlands

Garçon, Lucile, University of Lyon, Lyon, France

Häring, Anna Maria, Hochschule für nachhaltige Entwicklung, Eberswalde, Germany

Hermans, Frans, Leibniz Institute of Agricultural Development in Transition Economies Structural Development of Farms and Rural Areas, Leibniz, Germany

Ingram, Julie, University of Gloucestershire, Cheltenham, UK

Kitti, Laura, Academy of Finland, Helsinki, Finland

Koutsouris, Alex, Agricultural University of Athens, Athens, Greece

Lamine, Claire, INRA, UR Eco-développement, Avignon, France

Lazanyi, Orsolya, St. István University, Budapest, Hungary

Levidow, Les, The Open University, Milton Keynes, UK

Loconto, Allison, INRA, UMR LISIS (INRA, UPEM, CNRS, ESIEE), Marne-La-Vallée, France

Nevens, Frank, Leuven University, Leuven, Belgium

Ostrom, Marcia, University of Washington, Wenatchee, WA, USA

Pinel, Bertrand, TERRENA, Ancenis, Paris, France

Probst, Lorenz, Centre for Development Research, BOKU Universität, Vienna, Austria

Quendler, Erika, Federal Institute of Agricultural Economic, Wien, Austria

Ramonteu, Sonia, ACTA, Paris, France

Sen, Debashish, Xavier Institute of Management, Bhubaneswar, Orissa, India 
Steyaert, Patrick, INRA, UMR LISIS (INRA, UPEM, CNRS, ESIEE), Marne-La-Vallée, France Swagemakers, Paul, University of Vigo, Vigo, Spain

Tardivo, Caroline, SUPAGRO Montpellier, Montpellier, France

Van Mierlo, Barbara, WUR, Wageningen, Netherlands

Veiga, Iran, INRA, UMR LISIS (INRA, UPEM, CNRS, ESIEE), Marne-La-Vallée, France

Vermeulen, Tycho, WUR, Bleiswijk, Netherlands 


\title{
AgroEcological Transitions: Changes and breakthroughs in the making
}

\author{
Barbara van Mierloํ․ Anna Maria Augustyn², Boelie Elzen ${ }^{3}$ and Marc \\ Barbier $^{4}$
}

\section{Introduction}

In 2010, the initiative was taken to organise international workshops with scientists from different disciplines with the aim of improving system innovation processes in agriculture. The first workshop about SISA (system innovation towards sustainable agriculture) was held in Lelystad, the Netherlands. At the time, the European research agenda on agricultural innovation was largely characterized by two visions on innovation in agriculture. The first was based on the emerging Knowledge-Based Bio-Economy (KBBE) paradigm with the overall objective of combining life sciences with techno-scientific innovations to develop the means for an efficient use of agricultural resources. The alternative vision built on the Agricultural Knowledge Systems paradigm with the objective of developing ('co-creating') relationships between all relevant knowledge producers and stakeholders, including the farmers.

In that situation, the SISA initiative aimed to foster scientific reflection on "Transitions for Sustainable Agriculture", as expressed in the title of the edited volume of the first SISA workshop (Barbier and Elzen 2012). Our starting point was that making agriculture more sustainable was not simply a matter of choosing one vision over the other, but paying attention to, understanding and reflecting on processes in dominant socio-technological systems, knowledge regimes, and design practices. We concluded that it was key to analyse ongoing developments, practices, actions, projects, while paying attention to the development of 'novelties' in niches, and how niche developments start and contribute to transformation processes in the agricultural system (or 'regime') at large. The second SISA workshop, held in Paris from 22-23 May 2014, built further on these understandings and intended to seek synergies between the fields of sustainability transitions and agroecological thinking. The present volume brings together the papers discussed at the workshop.

Over the past five years, the notion of 'transitions' has gained much wider recognition in agricultural research and policy. The challenges and opportunities of sustainable agriculture have been addressed in the work of many organizations, including government bodies, NGOs, professional organizations and research institutions. Various publications, including White Papers by the EU (e.g. EU 2009) and different national governments, as well as FAO reports (e.g. FAO 2010, 2014) define future targets and objectives to improve sustainability in various agricultural sub-sectors like animal production, arable farming, or glasshouse horticulture. Furthermore, the take-off of the KBBE vision (e.g. EU 2012) has sparked growing concerns about the sustainability of heavily promoted technologies, like biomass for fuel, feed and fibres (e.g. EUSCAR 2015). This has also led to public and policy debates on ethical and economic issues related to the multi-functionality of agriculture.

But are these debates and increasing concerns translated into concrete actions? And do actions lead to changes towards a more sustainable agriculture? Many scholars are sceptical about agroecological

\footnotetext{
${ }^{1}$ Knowledge, Technology and Innovation Group, Wageningen University, Netherlands. Email: barbara.vanmierlo@wur.nl

${ }^{2}$ Groupe de Bruges, the Netherlands. Email: annamaria.augustyn@yahoo.com

${ }^{3}$ Applied Arable and Vegetable Research, WUR, the Netherlands. Email: boelie.elzen@wur.nl

${ }^{4}$ INRA, UR1326 Laboratoire Interdisciplinaire Sciences Innovations et Sociétés (LISIS), Champs-sur-Marne, France.

Email: Marc.barbier@grignon.inra.fr
} 
transitions, expecting emerging examples of greenwashing in agriculture as have been demonstrated in various other domains.

The differentiating expectations concerning the possibilities of agroecological transitions are not only due to differences in visions about desirable futures, but also to diverging levels of confidence in possibilities to govern the development of agri-food systems in a sustainable direction. Furthermore, and not least important, there is no precise definition or shared understanding of what sustainability entails. The term sustainability is commonly used while involving a diversity of stakeholders' expectations. Yet, increasingly the public as well as various policy arenas demand changes to agricultural production so as to be able to feed a growing world population in a sustainable way. This is visible in the rapidly growing number of alternative approaches, while social movements and civil society initiatives are increasingly pressing for changes of the agricultural system at large. In public debates, the current ways of food provisioning are questioned and debated by a broad variety of stakeholders. Jointly, these can be seen as a movement towards a reflexive governance (Voss et al. 2006) of food systems that include the conditions of producing as well as consuming food products, recycling and avoiding food waste.

Two "Grand Challenges" have gained recognition in policy arenas: climate change and loss of biodiversity. Especially after the Paris COP 21 climate conference in 2015, it has become widely recognized that the development of industrial societies has seriously harmed the planet and there is an urgent need to move in a different direction. In the domain of agriculture, this has led to an increasing attention to the concept of agroecology that features in the title of this volume. Agroecology has been coined by scientists with the intention to open up scientific preoccupations and to contest technocratic governance of agricultural innovation, oriented towards agricultural intensification, commercial benefits and expansion of global trade (such as the Mansholt Plan to promote land consolidation and agricultural intensification in order to conquer the markets; Mansholt 1952).

While the negative effects of such intensification and globalization became more and more visible in association with the socio-economic vulnerability of many rural zones, agricultural research started offering an alternative vision. Altieri (2002; 2009) and Gliessman (2006) proposed to orient research more towards the needs of peasants harmed by technocratic farming systems. Dalgaard et al. (2003) considered agroecology as the study of interactions between plants, animals, humans and the environment within agricultural systems. Gliessman (2006) and Francis et al. (2003) further expanded the understanding of agroecology by putting a stronger emphasis on the notion of sustainable food systems. Moreover, the unique character of single farms has increasingly been recognised by scholars. Specifically, small farms and food sovereignty gained momentum in the overall discourse (Altieri 2009).

As a notion travelling between many arenas, agroecology became ambiguous, with an inter- and transdisciplinary character. Hence, it is a buzzword (Tittonell 2015) describing relations between humans, ecosystems, traditional farming, innovation and technology to trigger practical actions. Many prominent global players, scientists and practitioners have attempted to define agroecology. For instance, the OECD views agroecology mainly in connection with the environmental challenges, i.e. as 'the study of the relation of agricultural crops and environment' (OECD Glossary), while FAO defines it as an 'integrative study of the ecology of the entire food system, encompassing ecological, economic and social dimensions' (FAO 2015). The latter definition proposes to focus on interactions in virtuous cycles and ecosystem services that underpin agricultural production. These relate to multiple aspects of farming systems including pollination, natural pest control, crop-livestock integration, soil biodiversity, nitrogen fixation, drought resistance, agroforestry, water management, aquaculture (including ponds and wetlands on farms), cover crops and crop rotation, perennial cultivation, wildlife, energy and building communities. Due to the complexity of agroecological farming systems, this list is anything but exhaustive.

Civil society organisations and peasants movements (e.g. Via Campesina) have proposed agroecology as an alternative to mitigate negative impacts of the growth-oriented innovation system and as a way of life (Rosset and Martinez-Torres 2013). These organisations typically combine ecological and human-rights based values, which are expressed in new forms of societal organisation. For instance, Community Supported Agriculture, seed savers and food sovereignty groups have emerged from these principles. The 
wellbeing of peasants, family farmers, indigenous people and rural workers, typically marginalised in the technocratic innovation system, has also gained more attention. The need for social innovation has been emphasized as opposite or complementary to technological progress. Thus, the focus is placed on the biopolitics of not only nourishing humanity, but also access to resources and distributive justice, defining people in their humanity (Coll 2014).

Currently, agroecological thinking captures a critique of the agro-food regime at large rather than the critique of the green revolution dominating the early days of agroecological thinking. It targets new ways of doing research and producing knowledge, new ways to fulfil needs and secure access to resources and to engage various stakeholders in decision-making on issues related to the production and consumption of food (Holt-Giménez and Altieri, 2013). Furthermore, it puts a strong emphasis on inclusion of actors who are usually marginalised within the dominating socio-technical regime.

Although the interest in agroecology is rising, a large divide exists between those who think that we should and can change our ways of producing and consuming food, and those who doubt about the potential of alternative ways of farming to halt climate change and radically reduce environmental risks. The latter perspective is evidently dominant and leads to a variety of incremental changes that leave the overall agrifood system basically intact. While most governments' adopted the notion of sustainable development as a basic policy principle, it has become increasingly obvious that a 'post-industrial' society will not necessarily result in a more sustainable society, i.e. a society that is characterized by a better balance between economic, social and ecological goals. Ensuring that ongoing transformation processes lead to more sustainability is a major challenge for societies in general and for agri-food systems in particular. In this context, the relations between agronomic science, agricultural technologies, and public and private expectations are at stake. Agroecology, as a concept, acknowledges this by questioning actual research practices (Francis et al., 2016).

To underline the need for radical, systemic changes, we have chosen the term "AgroEcological Transitions" for the title of this volume. It stresses that a transition towards sustainable agriculture requires more than improving agribusiness as usual. To us, agroecology refers to broad and varied processes of experimentation and innovation that often start in niches and have the potential of transforming the dominant agri-food system into a more sustainable one. Analysing these ongoing processes will increase our understanding of transformative change. The chapters of this book reflect the need for such insights by analysing a broad variety of agroecological 'breakthroughs-in-the-making'.

\section{Presentation of the volume}

All chapters in the book are concerned with pathways of transformative change, highlighting different aspects of these processes. Using the vocabulary of the multi-level perspective on sustainability transitions (Geels 2002), the portfolio of the agroecological transition studies in this book is organised in three parts. They each aim to address a specific dimension of transition processes: learning in niches, niche-regime interactions, and regime transformations.

\subsection{Part A: Learning in niches}

The six chapters in Part A focus on how various actors are tinkering with new agricultural practices that involve social, technological or institutional novelties. These new practices are varied, ranging from new ways of producing meat or rice, to permaculture communities. The chapters give an account of a diversity of experimental places, re-design approaches and change initiatives in animal production, permaculture, cultivar breeding, and various other agricultural domains.

Stimulating reflexivity is a key feature of the re-design projects described by Bart Bremmer and Bram Bos in their chapter. This design approach by the name of RIO (a Dutch acronym for Reflexive Interactive 
Design) aims to undertake a complete re-design of Dutch animal husbandry systems. Over the past 15 years, it has been applied to a variety of animal sectors, three of which are analysed in this study. In a RIO project, a variety of stakeholders (ranging from farmers to NGOs) designs a new animal husbandry system that is integrally sustainable, i.e. sustainable on a variety of dimensions. Although the heterogeneity of the stakeholder groups made interaction difficult initially, the reflexive nature of RIO projects, by which taken-forgranted perceptions and tacit routines are made explicit and scrutinized, eventually resulted in shared learning, a better mutual understanding, network formation and the articulation of promises. This formed the basis to design new animal husbandry systems that are radically different from the present.

The chapter by Julie Ingram and Damian Maye describes the Permaculture community in England, an emerging group or sub-niche that questions the operations of the mainstream agricultural regime. The community advocates a radical shift in patterns of thinking and acting towards new agri-food systems framed around agroecological principles. Sites include home gardens, community gardens and farms, public spaces, allotments and smallholdings. The question of the study is how knowledge systems within these alternative innovative agricultural groups develop and interact with the mainstream Agricultural Knowledge System (AKS), using the notion of boundary-work. The chapter shows how many members of the permaculture community question the operations of the mainstream agricultural regime and advocate a radical shift in patterns of thinking and action towards new agri-food systems, particularly in smart cities.

Claire Lamine starts with a counterfactual question: why did societal pressures for sustainability virtually not influence cultivar breeding in the French peach and apricot industry? Breeding strategies hardly change, although modern cultivars often taste badly, have a poor environmental performance (pesticides issues) and negatively impact prices and hence producers' future perspective. The chapter provides a socio-historical analysis of changes in cultivar breeding in the peach and apricot sectors since the 1960s, analysing innovation strategies in niches of sustainable cultivars. It combines evolutionary economics and multi-level frameworks with an ethnographic analysis of ongoing changes, based on an approach anchored in the French pragmatic sociology. A study of recent changes in public research and in cultivars' evaluation and registration while uncovering the controversies in several "mainstream" or "transition" arenas leads to a balanced answer to the research question.

In their chapter on 'Community Supported Agriculture' (CSA) in Hungary, Bálint Balázs, György Pataki and Orsolya Lazányi describe an interesting inversion. While CSA is rather new in Hungary, it has a longer history in other parts of the world. This inversion underlines that in a state of societal crisis, agricultural activities that are supported by a community of practice, might catalyse social change and enhance consumer-producer cooperation in order to regain control over the ways in which food is supplied. The authors describe how CSA farmers pursue a set of socio-economic practices (in production, assortment and delivery of boxes, investments and pricing, and community building) to reach beneficial socio-ecological outcomes at the community level. They introduce the term 'agriculture supported community' as a specific but previously unexamined form of moral economy whereby farmers create communities by relying on external financial resources and reaching out to trust-based personal networks or ethical consumers.

The chapter by Boldizsár Megyesi describes different models-in-use of agri-food production in a Hungarian rural micro-region. Building on the concept of 'alternative food networks', the author explores the factors and resources that determine farming technologies and specific practices that inspire different models of agri-food production. The research arrives at a distinction of three forms of knowledge (local/traditional, managerial and scientific knowledge) and four types of farming within the studied area (agricultural companies, medium-size farms, small-size farms and social farming).

The chapter by Marcia Ostrom analyses trends in the attitudes and behaviours regarding food consumption and food sourcing in the north-western United States. A theoretical framework on social movements is utilized to investigate the role of consumers' ideological orientations and the effectiveness of local agri-food initiatives in driving larger food system innovation and institutional change. The way food is framed by many residents in the regions has expanded beyond personal health and culinary preferences and started to include the economic and agro-ecological challenges of farmers and farm workers and the 
need for equitable food access. The study thus shows how alternative agri-food movements have succeeded in opening up the public discourse about food.

\subsection{Part B: Niche-regime interactions}

The six chapters in Part B focus on interaction processes between niches and regimes. In various concrete cases, including fruit production, dairy farming, alternative food networks, the authors analyse how the innovating actors position themselves vis-à-vis the actors operating in the dominant regime. Driving forces that govern gradual sustainable transformations either through public support and policy making or through organised action and initiatives from the stakeholders involved are explored.

George Vlahos, Pavlos Karanikolas and Alex Koutsouris explore the pattern of transformative change in an emerging transition from an intensive, towards an integrated farming system for canned peach production in Northern Greece. They use the concepts of niche and regime to analyse how integrated farming has originated from within the incumbent regime. A major driving force behind the change was a policy change at the EU level that led to the development of a new entity, a 'niche-regime', that was facilitated by the launching of an integrated farming standard. Central to this change process were the innovative activities of Agrocert, a standardisation and certification organisation that operated under the Greek Ministry of Agriculture.

The chapter by C. Shambu Prasad and Debashish Sen describes a case in which a global niche became established firmly. The study explores transition and system innovation theory in a non-European context with the System of Rice Intensification (SRI) in India. Proposed as an integrated and agroecological approach to rice production, SRI has received much attention from its early uptake in the 1980s in Madagascar. Balancing between critical assessment and celebration of extraordinary yields, this study focuses on the dynamic evolution of SRI in India, by comparing three different states to highlight the diversity of technical and institutional arrangements in system innovation. The comparison shows the role of networks in complex and multi-actor innovation systems. It provides a better understanding of the politics of knowledge and contestations among actors that accompany the management of sustainability transitions in developing countries, specifically when knowledge hierarchies are strong.

Paul Swagemakers, Pierluigi Milone and Flaminia Ventura address the interdependence between niches and regimes. In two case-studies on 'alternative practices' in dairy farming in the Netherlands and Italy, they analyse the organization of projects and the practices developed by farmers and government intermediaries. They illustrate how newly evolving institutional arrangements help farmers to adopt resilient strategies. The alternative farm optimization trajectories root in the experience and skills of pioneers, and the capacity of hybrid actors (i.e. actors who operate in the regime as well as the niche) like farmers, government representatives, and researchers, to create and adapt organizational structures that improve the optimization of agricultural production, food chains and environmental concerns. The Common Agricultural Policy for the period 2014-2020 stimulates farmers to develop alternative practices.

The chapter by Boelie Elzen, Arni Janssen and Bram Bos presents a tool that can be used to stimulate transition processes. It builds on the recognition of a wide range of 'bottom-up' innovation initiatives by entrepreneurial farmers in agricultural practice. In the tool, the 'Learning and Experimentation Strategy' (LES), the central unit is a 'promise'. A promise describes a novelty in terms of its attractive features from specific sustainability perspectives, as well as its problematic or unknown features. In this chapter, the tool is developed further by presenting a 'portfolio of promises' which is basically a database with a variety of novelties that provides information on their sustainability potential as well as their weaknesses. It can be used by farmers to take decisions on changes they want to make on their farm, as well as by strategic actors and policy makers to inform a broader innovation strategy. The authors describe how they tested the tool in a number of different situations in the domain of animal production.

Jan Buurma, Karel de Greef and Volkert Beekman address how social movements trigger change processes in a regime by analysing the dynamics between NGOs, researchers and sector organisations in 
the domain of Dutch pork production in the period 2005-2012. An activist NGO, that primarily raised normative pressure on the current production and consumption system, is contrasted with a moderate NGO engaged in partnerships with the pork sector to experiment with alternatives. While the activist NGO sought to stimulate consumers to buy less meat, the moderate group developed better housing systems and an intermediate market segment for animal-friendly pork. This implies that the NGO's addressed different areas in terms of the multi-level perspective: in one case the area between niche and regime and in the other case the area between regime and landscape.

Allison Loconto, Anne Sophie Poisot and Pilar Santacoloma combine social movement theories with the sociology of innovation. This combination, the authors argue, allows a better understanding of the diversity as well as the similarities of dynamics in the case studies. The fourteen case studies analysed in the chapter concern the creation of various market arrangements in developing countries, based on local networks linking sustainable agricultural practices to (global) markets. Standards facilitated this linking. The study shows that in many cases, the market arrangements rely upon technological innovations ascribed to capital-intensive production systems, which illustrates that they merely concern incremental innovations within the sustainable intensification paradigm. The findings also suggest that both community and international dynamics influence the development of institutional innovations in developing countries, even in the cases which focus primarily on local network building.

\subsection{Part C: Regime transformations}

This final part addresses the role of knowledge in regime transformations through diverse lenses. The chapters present different types of social-scientific research: sociology of education, system thinking, communication studies and practices-based approaches.

Erika Quendler studies the role of education on sustainable development by analysing how education entities and employers train students on the manifold aspects of sustainable development from a systemic perspective. The chapter enriches the transition research agenda with a number of insights from the sociology of education and knowledge systems with a brief overview of the discussions about: (i) the need for change in Higher Education Institutions (HEI); (ii) the ways to make the labour market regarding competences, skills and knowledge for sustainable development in the field of life sciences more transparent; and (iii) the role of system innovation in education towards developing reflexive skills, and elaborating guidelines for further research. An general key observation is that HEI training programmes suffer from the same inertia as incumbent socio-technological systems: there is a strong tendency to continue business as usual and only incremental changes take place.

In their study drawing on concepts of system thinking and transition management, Frank Nevens, Erik Mathijs and Philippe Vandenbroeck describe the interactive research process in which they have crafted an analysis of the agri-food system in Flanders, while exchanging intermediary results with a multistakeholder reflection group. They combine the multi-level perspective as a general interpretative framework with system thinking methodology to visualise underlying system narratives and enhance reflexive thinking as a test case for the actual workability of integrated systemic approaches in transitions. The process resulted in a description and analysis of the central regime of the agri-food system in Flanders, highlighting a number of 'systemic hotspots', i.e. loci of tensions that cause sustainability concerns.

Pieter J. Beers and Barbara van Mierlo present a study on the reflexivity of initiatives that aim to contribute to socio-technological regime change. Reflexivity is defined as an emergent systemic property of an initiative, i.e. its ability to interact with and affect the institutional context in which it operates. They start their analysis by observing that reflexivity is seldom clarified conceptually although mentioned very often. As a consequence, its relation with learning and reflection are unclear and rarely studied empirically. In the study reflexivity is operationalised as changes in rules, discourse, practices and relations in order to be able to critically study the relation between learning in and reflexivity in a case study in the Dutch greenhouse sector. It was found that, as often assumed, learning indeed sometimes appears to increase reflexivity. The 
authors, however, also provide evidence of situations in which reflexivity changes preceded learning and situations in which there was no relationship at all.

The chapter by Patrick Steyaert, Marianne Cerf, Marc Barbier, Alix Levain and Allison Loconto focuses on intermediation activities at play in situations of sustainability transitions in relation to what the authors call the 'environmental paradox'. The chapter draws upon four case studies of intermediation activities in complex situations. Based on a comprehensive analysis, the chapter identifies key functions of intermediation activities, involving a strong articulation of objectification and inter-subjectification processes. The authors suggest that these activities are a combination of three properties of intermediation, which they term contextualization, performativity and reflexivity. By comparing the case studies they observe that, while sustainability transitions are driven by expectations in terms of efficiency and measurement, they are also characterized by generic attributes of 'wicked problems' that make these expectations hard to fulfil.

\section{References}

Altieri, M. A., 2002. Agroecology: the science of natural resource management for poor farmers in marginal environments. Agriculture, Ecosystems \& Environment, 93 (1), 1-24.

Altieri, M. A., 2009. Agroecology, small farms, and food sovereignty. Monthly review, 61(3), 102.

Barbier, M. and Elzen, B., 2012. System innovations, knowledge regimes, and design practices towards transitions for sustainable agriculture. Published online under a Creative Commons Licence. http://www.inra-ifris.org/activites/open-science/system-innovations-knowledge-regimes-and-designpractices-towards-transitions-for-sustainable.html

Coll, 2014. Scientists' support letter for the international symposium on agroecology, 18-19 September 2014. http://www.iatp.org/files/2014.09.17_AgroecologyFAOLetter.pdf

Dalgaard, T., Hutchings, N. and Porter, J., 2003. Agroecology, Scaling and interdisciplinarity. Agriculture Ecosystems and Environment 100 (2003): 39-51.

EU, 2009. Adapting to climate change: the challenge for European agriculture and rural areas. Commission staff working document accompanying the White Paper adapting to climate change: Towards a European framework for action. http://webcache.googleusercontent.com/search?q=cache:w2Uu QD2evcJ:ec.europa.eu/danmark/ documents/alle emner/miljo/090401 work doc landbrug en.pdf $+\& c d=2 \& h l=p l \& c t=c l n k \& g l=h u$

EU, 2012. Innovating for Sustainable Growth: A Bioeconomy for Europe. http://ec.europa.eu/research/bioeconomy/pdf/official-strategy en.pdf

EU SCAR, 2015. Sustainable agriculture, forestry and fisheries in the bioeconomy. A challenge for Europe: 4th SCAR foresight exercise. http://bookshop.europa.eu/en/sustainable-agriculture-forestry-andfisheries-in-the-bioeconomypbKI0115295/;pgid=GSPefJMEtXBSROdT6jbGakZD0000COuO2ZTI;sid=FehJ9XVRfg9J_COXjJvXUhd Otys 1pdeSabg=?CatalogCategoryID=1 uwKABstHaoAAAEjB5EY4e5L

FAO, 2010. 'Climate-Smart' Agriculture: Policies, Practices and Financing for Food Security, Adaptation and Mitigation. http://www.fao.org/docrep/013/i1881e/i1881e00.pdf

FAO, 2014. Building a common vision for sustainable food and agriculture. Principles and Approaches. http://www.fao.org/3/a-i3940e.pdf

FAO 2015. Agroecology for Food Security and Nutrition Proceedings of the FAO International Symposium, 18 and 19 September 2014, Rome. http://www.fao.org/3/a-i4327e.pdf

Francis, F., Haubruge, É., Garré, S., Stassart, P. M., Dufrêne, M., Monty, A., \& Boeraeve, F., 2016. Towards sustainable food systems: the concept of agroecology and how it questions current research practices. A review. Biotechnol. Agron. Soc. Environ, 20 (S1).

Francis, C., Lieblein, G., Gliessman, S., Breland, T. A., Creamer, N., Harwood, R., \& Wiedenhoeft, M., 2003. Agroecology: the ecology of food systems. Journal of Sustainable Agriculture, 22(3), 99-118.

Geels, F. W., 2002. Technological transitions as evolutionary reconfiguration processes: a multi-level perspective and a case-study. Research policy, 31(8), 1257-1274.

Gliessman, S. R., 2006. Agroecology: the ecology of sustainable food systems. CRC Press.

Holt-Giménez, E., \& Altieri, M. A., 2013. Agroecology, food sovereignty, and the new green revolution. Agroecology and Sustainable Food Systems, 37(1): 90-102. 
Mansholt, S.L., 1952. Toward European Integration: Beginnings in Agriculture. Foreign Affairs, Vol. 31, No. 1 (Oct.), pp. 106-113. http://www.jstor.org/stable/20030945?seq=1\#fndtnpage_scan_tab_contents

OECD Glossary. https://stats.oecd.org/glossary/detail.asp?ID=81

Rosset, P., \& Martinez-Torres, M. E., 2013. La Via Campesina and agroecology. La Via Campesina's open book: Celebrating, 20, 1-22.

Tittonell, P., 2015. Food Security and Ecosystem Services in a Changing world, Agroecology for Food Security, Agroecology for Food Security and Nutrition Proceedings of the FAO International Symposium, 18 and 19 September 2014, Rome. http://www.fao.org/3/a-i4327e.pdf

Voss J.P., D. Bauknecht and R. Kemp, 2006. Reflexive Governance for Sustainable Development. Cheltenham: Edward Elgar. 
Part A

\section{Learning in niches}




\title{
Creating Niches by applying Reflexive Interactive Design
}

\author{
Bart Bremmer ${ }^{1}$ and Bram Bos ${ }^{2}$
}

\section{Abstract}

Reflexive Interactive Design (RIO) is an approach that aims to contribute to a transition towards more sustainable animal production systems. In this chapter three projects that use the RIO approach are evaluated: Pork Opportunities (pigs), Broilers with Taste (broilers) and New Livestock Husbandry (covering all sectors). In the evaluation, there is a specific focus on niche development and the interaction with the regime. The chapter shows the role of articulation of promises, building networks and learning in these projects, and in what way these led to shielding, nurturing and empowerment. All projects were successful in igniting and facilitating niche development, but to varying degrees and using different strategies. Until the time of writing (early 2015), no global niches were developed, but several local niches, that stem from these projects, are still in the process of shielding and nurturing. Although they are not powerful enough (yet) to compete with the regime, they slowly increase their potential to do so in the future. The analysis shows that the success of RIO can be equally attributed to its three essential aspects: design, interaction and reflexivity.

Keywords: system innovation, sustainable animal husbandry, redesign, structured design, co-creation, niche-development.

\section{Introduction}

Contemporary Dutch (and European) agriculture is in a threefold crisis (Van der Ploeg 2003; Swagemakers 2008):

- An economic crisis of stagnating revenues and increasing costs for farm households, putting their incomes under pressure.

- An ecological crisis of environmental pollution, deconstruction of natural habitats and loss of biodiversity.

- A social crisis of growing distrust in the food production system and an increasing demand for performance of more diversified functions in rural areas.

The agricultural sector, policy makers and scholars have been trying to tackle these problems since the 1980s. At some points, this has been successful, but most of the problems have exacerbated and new issues have emerged. The problems are embedded in the system, they have been institutionalized (Marsden 2003), and for the most part they are caused by modernization itself. Scholars have concluded that a transition in agriculture is needed. As a response the Dutch government started to promote a transition towards a sustainable agriculture in the 1990s (Slingerland \& Rabbinge 2009).

Nowhere else is the crisis in agriculture more noticeable than in animal production chains. On top of the problems mentioned above, these systems are confronted with animal welfare issues, animal diseases, the risk of zoonosis, food scandals and (as a result) negative societal attention. Back in 2001, an appeal was made for a redesign of the animal husbandry sector (Commission Wijfels 2001).

One of the initiatives following this call was a series of projects, under the overarching programme title Designs for System Innovation (2001-2013), financed by the Dutch Ministry of Agriculture. Each project in

\footnotetext{
${ }^{1}$ Self-employed Innovation Sociologist, Renkum, Netherlands. Bart.Bremmer@innovatiesocioloog.nl

2 Wageningen UR Livestock Research, Wageningen, Netherlands. Bram.Bos@WUR.nl
} 
this programme aimed for the interactive redesign of a specific animal production sector. In the course of this programme, a specific approach was developed called Reflexive Interactive Design (called RIO, in a Dutch acronym; Bos et al., 2011, Bos et al., 2009). This approach is characterized by a combination of system analysis, structured (co)design, stakeholder management and niche formation. The overall goal is to redesign husbandry systems, starting from a heterogeneous set of values and goals. These projects had the explicit ambition to contribute to a transition in animal husbandry, i.e. to ignite and facilitate 'system innovation'.

Very explicitly, RIO does not try to optimize the current system. Therefore, it starts with a critical reflection upon assumptions that are normally taken for granted in the current system. It follows the doctrine that, to tackle the problems that are institutionalized in the current system, actors have to break with existing routines. To do so, technical change is not enough. Therefore, RIO also focuses on cultural and institutional change. Furthermore, the projects make use of knowledge from multiple scientific disciplines, which is scrutinized and enriched with knowledge and experience from the field.

A central concept within the method is 'integral sustainability', meaning that an improvement on one sustainability aspect may not lead to a regression on other aspects. RIO strives for synthesis and congruency, instead of compromise (Bos 2008). To achieve this, an analysis is made of the needs and requirements of the most important actors involved in the production system: the animal, farmer, environment and consumer/citizen. These needs are summarized in so-called 'Briefs of Requirements', which form the basis for the actual redesign process.

The procedure for redesign is based on a structured design method, which is normally used to design machines and technical systems (Siers 2004; see also: Groot Koerkamp \& Bos 2008; Bos \& Groot Koerkamp 2009). In this approach, functions are identified to fulfill the needs that are determined in the Briefs of Requirements. Subsequently, existing and new solutions to serve these functions are generated, and combinations of selected solutions are used to design new systems. This is done in close interaction with stakeholders to stimulate implementation of the results, as a stepping stone towards igniting actual change.

One of the first projects in the Designs for System Innovation programme was Houden van Hennen (Keeping and Loving Hens; addressing laying hen husbandry, 2002-2004). This project has been extensively studied and reported (Zwartkruis et al. 2010; Klerkx et al. 2010; Groot Koerkamp and Bos 2008; Bos 2008; Spoelstra et al., 2013). In the following years, over ten RIO projects have been executed within this programme, and various changes have been made regarding the operationalization of the general approach. The most essential changes are:

- A larger emphasis on integral sustainability. In earlier projects, the main focus was on farmer's income and animal welfare. In more recent projects, the environment gets equal attention and new issues like public health are addressed as well.

- The projects have become more interactive, especially in the design phase itself. Farmers and other stakeholders are participating in more phases of the projects while the group of participating stakeholders has become more heterogeneous.

Although the general response among participants and others appears to be very positive, thorough evaluation has been limited. In this chapter we want to focus on three of the more recent design projects, all of which used the RIO approach but with varying methodical set-ups and styles. These projects are Pork Opportunities (pigs: sows, piglets and fatteners), Broilers with Taste (chickens for meat production), and New Livestock Husbandry ('Het Nieuwe Veehouden', covering all livestock sectors).

We will use the multi-level perspective to carry out this evaluation, analysing to what extent and in what way niche development and niche-regime interaction has taken place. The analysis does not only lead to a better understanding of the three projects in terms of system innovation, but can also give some important clues for future redesign projects and other initiatives that try to stimulate transitions in the making. 


\section{Theoretical framework}

RIO tries to tackle institutionalized problems by 'doing' reflexive modernization (Grin et al. 2004; Bos \& Grin 2008; based on Beck 1997). This is based on the assumption that contemporary problems cannot be tackled by incremental changes within the system, because the problems are rooted in structural features of the system. For structural change, the whole system - which is normally taken for granted - has to be scrutinized, so that system failures can be addressed instead of treating the symptoms.

This kind of structural change can be understood by using the multi-level perspective (MLP) on sociotechnical transitions. MLP distinguishes three analytical levels, namely (1) the socio-technical landscape of the external environment which is relatively static, (2) socio-technical regimes that comprise established practices which are produced and reproduced by a set of rules shaping and reshaping the current system, and (3) niches where novelties that break with the existing routines of the regime can develop (Geels 2002; 2005). The MLP clarifies how these levels interact with each other and how different transition pathways may develop, thus transforming or replacing an existing socio-technical regime (Geels \& Schot 2007).

System innovation may result from the interaction between these three layers, and cannot be initiated or steered in a deliberate way because it stems from a complex interdependent whole of events and developments in which numerous actors are involved. One route to deliberately make a contribution to system innovation, is by niche development, i.e. creating protective spaces for path-breaking innovations (meaning innovations incompatible to and infringing with the regime). Another route is to make structural changes at the regime level, e.g. by new governmental regulations. RIO addresses the first route, taking niche development as an explicit goal (Bos et al. 2009), although (advise for) institutional interventions (like new regulations) are not ruled out.

A niche can be conceptualized at two levels that interact with each other (Geels \& Schot 2010). First there are local niches: local projects or initiatives in which certain innovations are developed that challenge existing routines. These initiatives are supported by local actors, and their progress depends on local circumstances. The other level is that of global niches: the emergence of a community with shared rules as a counterpart of the regime. Local initiatives can be part of such a community. In the literature on transitions, a niche is usually understood as a global niche.

Niche development can be understood as combination of three processes that take place simultaneously (Smith \& Raven 2012):

1. Shielding: creating protective space, so that the innovations are not directly evaluated (and rejected because of lock-ins and path dependency) against prevailing selection criteria. Shielding can take place by situating an innovation in a (geographical, social or economic) context that deviates from the mainstream selection criteria, or by introducing purposeful financial or regulatory arrangements.

2. Nurturing: shaping possibilities for the development of path-breaking innovations; building a novel innovation system by e.g. resource mobilization, knowledge development, market formation and creating positive externalities (Hekkert et al. 2007; Bergek et al. 2008).

3. Empowering: finding more enduring forms of institutionalization, so that 'shields' can be removed. Innovations can become competitive in an unchanged selection environment - without changing the rules of the game - labeled 'fit and conform'. Or the empowerment can take place by affecting the selection environment in ways that are favorable to path-breaking niche innovations: 'stretch and transform' (Hoogma 2000).

These processes can be stimulated by three kinds of activities (Kemp et al. 1998; Schot \& Geels 2008):

1. Articulation of promises. Promises can attract the attention of a diversity of actors, it provides direction for further development and learning, it legitimates the protection provided, and it stimulates people to proceed. 
2. Building networks. A variety of actors is needed to acquire the necessary knowledge, power and resources. The interaction between the actors increases the capacities of the total network.

3. Assisting learning processes. Niche development not only requires learning on how a technology functions in a technical way, but also how the technology relates to government policies, cultural and psychological meaning, functioning of markets and production chains, adequacy of infrastructure and the relation to society and environment.

All three kinds of activities are important for all three processes of niche development. Promises, for instance, are important to legitimize shielding, to keep the development going (nurturing), and by persuading influential actors to support the path-breaking innovation in its empowerment.

Smith \& Raven (2012) emphasize that regime change does not come about by bottom-up processes only, or that it is simply the sum of niche developments (see also: Berkhout et al. 2004). Regime changes require interaction between niche and regime. This means that ongoing niche development - that is moving beyond local initiatives, and affecting the regime - requires outward orientation, focused on the changing interdependency of the niche and the wider social world.

On the basis of the above conceptualization, we derived the following four questions to analyse nichedevelopment in the three projects mentioned above:

- How did the articulation of promises, building networks and learning take place in these projects?

- To what extend did (global) niche development take place?

- In what way did these activities lead to shielding, nurturing and empowerment?

- To what extent and how did the RIO approach contribute (or not) to these effects?

\section{Methods}

To examine the results of the projects in terms of niche development, in-depth interviews were carried out with people who participated in the projects. Per project three or four participants were interviewed. They were selected on the basis of their (expected) attempts to initiate change on their farm and on their (expected) knowledge of the progress of other participants. Most respondents were farmers, but also builders of housing systems and agricultural advisors who attended one of the workshops.

In the interviews, farmers were asked to explain the developments on their farm and plans for the future. The connection between the developments and plans, and their participation in the project was reviewed. The respondents were also asked to discuss the effects of their participation on their opinions, motivation and contacts.

After the interviews, a first analysis was made of the effects resulting from the projects, leading to a first overview of the differences in effects between the three projects. Subsequently, in-depth interviews were held with seven project team members. Most of them had been involved in more than one of the three projects in question and, therefore, were able to compare the projects with each other. In these interviews the results of the analysis of the first interviews were critically reviewed and checked. Furthermore the similarities and differences in effects between the projects were discussed, as well as the similarities and differences in the set-up and execution of the projects.

After these interviews a second analysis took place. This was done by scrutinizing the story lines of the various respondents leading to a meta-narrative of the projects: putting the events in chronological order, outlining different views and accompanying causalities, and identifying the most frequently mentioned similarities and differences between the projects. This meta-narrative was analysed, specifically focusing on articulation of promises, network building and learning, as well as shielding, nurturing and empowerment. Finally, we analysed to what extent the effects can be related to the RIO approach. 


\section{$4 \quad$ Results}

\subsection{Pork opportunities}

Pork Opportunities was carried out from 2008-2010 with the aim to redesign the pig husbandry system. The project team was asked to come up with new ideas to 'produce pork in a way that is good for People, Planet, Profit and Pigs'. As most RIO projects, it started with a system analysis: the needs of the pig, pig farmers, environment and consumer/citizen were assessed. Furthermore, the key challenges in the current system were identified, as were the possibilities for change. After the system analysis and a trial design workshop for researchers only, two three-day-workshops for around twelve people were organized, with an ascending heterogeneity in group composition:

- In the first workshop, researchers and pig farmers participated. They worked together on three designs for a new way of keeping pigs.

- In the second workshop, researchers were only present to facilitate. The actual design process was carried out by participating pig farmers, builders of housing systems, agricultural advisors and civil servants. At the end of the third day, three designs were produced of radically different systems for pig husbandry.

In the workshops, design goals were formulated, key functions were identified and solutions to these functions were generated to fulfill the needs of all actors. We combined a selection of these solutions to render new designs of pig husbandry systems. After the two workshops, the project team made a wrap-up of all solutions and designs to construct three final designs which were published in an attractive brochure for a wide audience. Figure 1 shows one of the resulting designs.

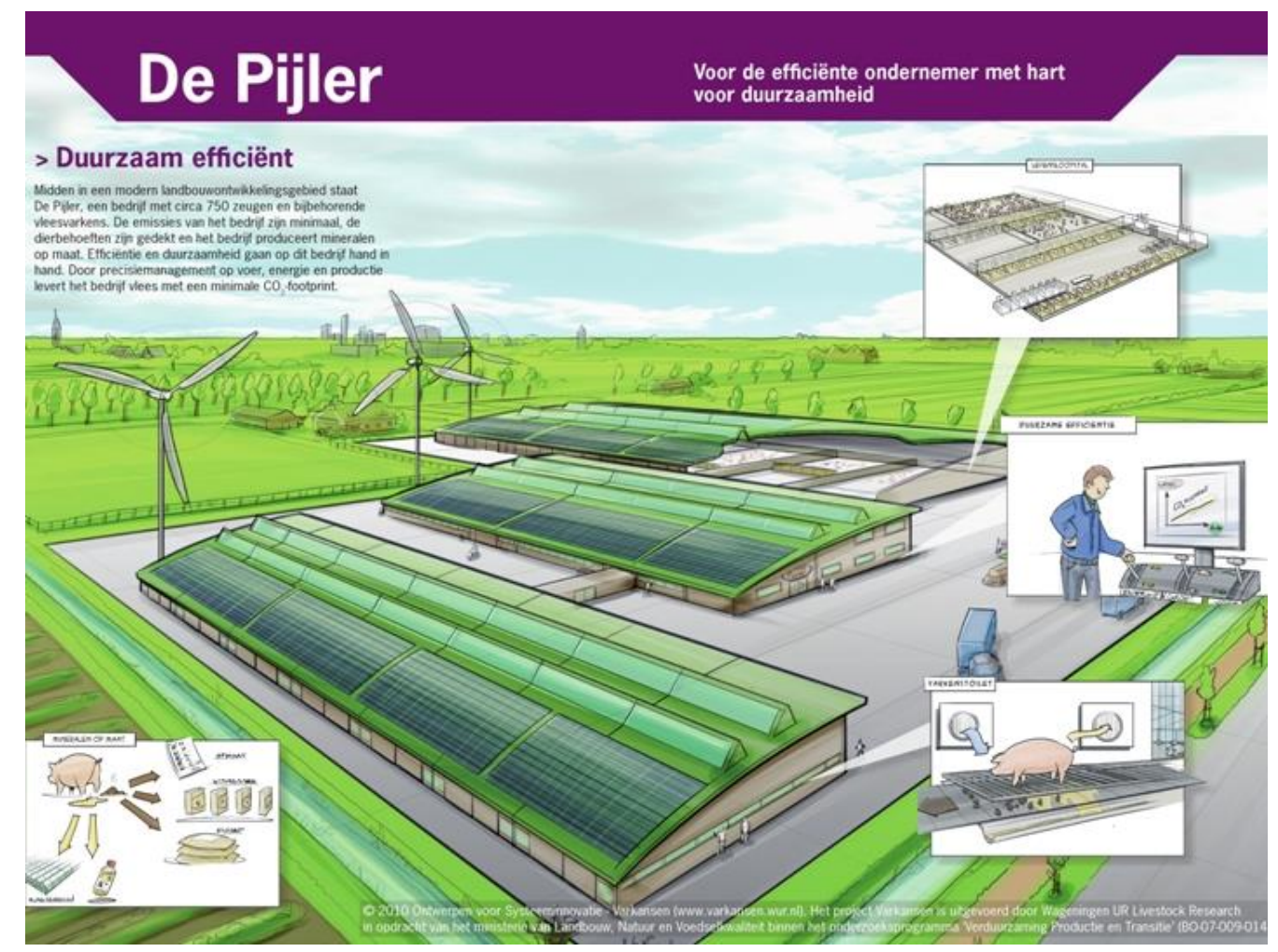

Figure 1: Resulting design from Pork Opporunities (The header reads: "The Pillar: For the efficient farmer with a drive for sustainability") 
As can be observed in Figure 1, various 'partial solutions' are highlighted by 'zooming in' on the overall design. This leaves room for pig farmers and others to tinker with the constituting elements themselves. The designs of Pork Opportunities are mainly meant as source of inspiration. Technically and economically, they have not been worked out in any detail. These designs express a strong focus on the level of the farm and the keeping of pigs, while attention for the wider production chain and market is limited.

\subsubsection{Effects and their causes}

The visible effects, that stem directly from Pork Opportunities, are limited to one initiative. After the second workshop one of the participating pig farmers immediately started with a realization process. She formed a consortium consisting of project participants and 'outsiders', and she was granted money from a Small Business Innovation Research (SBIR) tender (a national innovation stimulation fund). After three more years of further development and construction, a new type of farm (called 'Vair Varkenshuis', meaning 'Fair Pig Home') was realized, using several elements that were proposed in the Pork Opportunities project.

Next to this direct effect, the indirect influence of Pork Opportunities is far greater. According to the respondents, the project affected the pig husbandry sector as a wole. The intellectual legacy - in terms of ambitions, key solutions and changes of perspective communicated in brochures and presentations - has not only been adopted by a number of pig farmers, but also by other parties, including actors that can be considered representatives of the regime.

The legacy of Pork Opportunities has been especially appealing to the members of the steering group of the project. They represent the governmental Department of Agriculture, the Dutch Animal Protection Society and the Dutch farmers association. They have been involved during the whole project, and at the end of the project they decided to proceed with the existing steering group of the project, with the aim of further develop and spread the resulting ideas. Furthermore, these actors and other representatives of the regime changed the allocation of (applied) research funds, developed the tender structure for Small Business Innovation Research (that helped to realize the 'Vair Varkenshuis' above), and made a case for the adoption of elements of the Pork Opportunities method in other projects. Although these developments cannot be fully attributed to the project, Pork Opportunities did play a significant role.

Due to the initiatives mentioned above, this alternative view reached a lot of pig farmers and inspired a substantial number of them to implement minor or major changes on their farm that are related to or derived from Pork Opportunities. These include adaptations in existing pig pens, building new pens, changes in farm management and novel value chain development. These local initiatives illustrate that the regime is opening up to create more space for alternatives. However, this new space does not (yet) represent structural, institutional change. It mainly comprises add-ons to existing regulations, subsidies, research programmes and procedures.

A further analysis of these changes makes clear that part of the explanation for these further reaching effects lies in the interactive character of the RIO project, in which not only pig farmers actively participated, but also the earlier mentioned representatives of the regime. The project team discussed results of workshops and other activities with the steering group in detail, and this group also had some influence on the final designs. A result of this process was that they felt the (co-)owner of the resulting designs and became ambassadors for their further uptake.

Moreover Pork Opportunities resulted in a powerful story, decorated with appealing illustrations in an attractive brochure. But these results are not blueprints: the outcomes of Pork Opportunities offer quite some freedom. The essence is to be found in the ambitions and the changes in perspective, which respond to existing bottlenecks felt by many pigfarmers and upcoming societal needs. The resulting designs and solutions are not worked out in detail and mainly offer new directions to think about pig husbandry systems. As a result, the presented outcomes are neither compulsory, nor threatening for a variety of stakeholders in pig production. This makes it interesting for representatives of the regime, many of whom do feel that there are serious problems with current ways of doing things. It offers them space for their own interpretation and implementation of the outcomes. So it enables a lot of actors to relate to Pork Opportunities in their own way. 
Arguably, the most influential factor for explaning the effects of Pork Opportunites is the (accidental) timing of the project. Respondents remark that 'something' was going on already in the pig husbandry sector. The status quo had been challenged for years, also from inside the regime, due to an outbreak of classical swine fever (1997), food and mouth disease (2001) and pressure from animal protection groups. In this situation, Pork Opportunities offered a welcome alternative: it showed that there are other possible ways to keep pigs and organise production.

\subsection{Broilers with Taste}

Broilers with Taste was carried out from 2010-2012 to redesign the broiler production system (broiler is the industry term for chickens raised for meat production). The project started with a system analysis, similar to the one of Pork Opportunities. After this first phase, two workshops were organised:

- The first was a three-day workshop with a heterogenous group (over 15 people), in which the whole production chain and some outsiders (e.g. NGOs) were represented. At the end of the third day, two alternative designs for broiler husbandry were realized, in terms of concreteness comparable to the designs made in Pork Opportunities

- The second was a seven-day workshop, stretched out over a period of several months. This design group was considerably smaller: a broiler keeper, a veterinarian, a builder of housing systems, an architect and two researchers. They started again from goals and functions, re-using results from the first workshop which they found useful. Two elaborate designs were made in architectural software, and subsequently converted to artist's impressions by visual designers. A drawing of one of these ('Windstreek' in Dutch, meaning 'Cardinal Point') is presented in Figure 2 below.

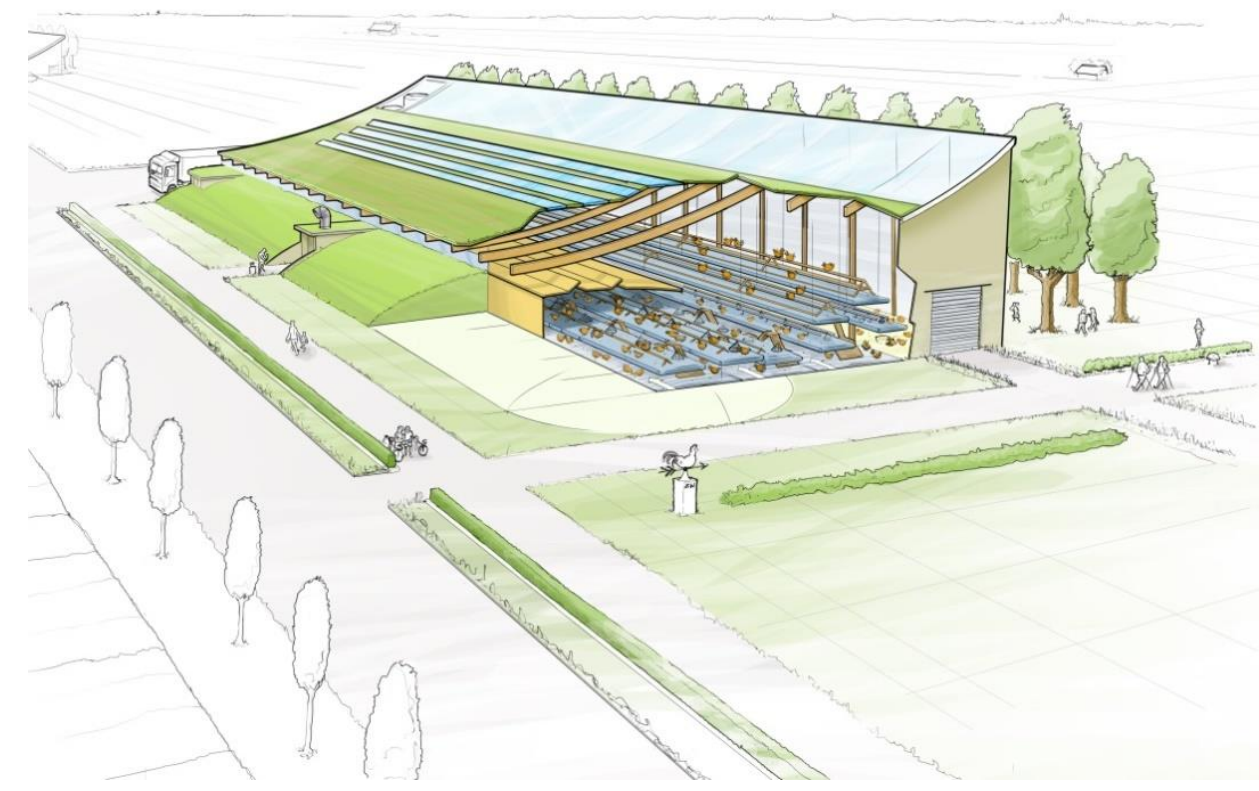

Figure 2. Windstreek (Cardinal Point) henhouse.

The final designs in Broilers with Taste are worked out in considerable detail (more than in Pork Opportunities): economic and technical calculations have been made, and the equipment of the system has been thought out more thoroughly. The designs of this project are not primarily meant as source of inspiration; they offer a complete and concrete interpretation of 'what might be'. The designs are also set-up as a coherent big picture, not as a loose inspirational image to trigger the creativity of farmers or system builders. An important aspect of Broilers with Taste, which is not clear from the Figure above, is that the designs are broader than the farm. They cover various aspects of the whole production chain. 


\subsubsection{Effects and their causes}

The effects of Broilers with Taste are limited to the activities in connection with Windstreek, one of the designs that form the output of the project. Broilers with Taste led to participants forming a consortium, consisting of a farmer, enterprises and a knowledge institute. Jointly, they develop Windstreek further, investing considerably in R\&D of innovative key parts like the climate system and the 'mother clock' or 'brooder hood'. This consortium does so with the help of SBIR: the same tender arrangement that was used by the consortium that resulted from Pork Opportunties. At the time of writing (spring 2015), the first prototype of Windstreek is being built, aided by the support of a $€ 460,000$ sustainable innovation grant.

According to our interviewees, Windstreek has the potential to become competetive with the incumbent system. Windstreek tackles several sustainability issues while the consumer price of the meat will only be slightly higher than regular (no more than 20\%). This potential is not only acknowledged by consortium partners, but also by outsiders. Various actors in the broiler husbandry sector are closely following developments in connection with Windstreek.

Representatives of the regime were involved in a steering group, although their involvement was more lowprofile in comparision to Pork Opportunities, and they do not play an active role in the realisation of Windstreek. Here, the regime created space for further development mainly from a distance, most importantly by providing the SBIR grant, but also via some regulative support. The regime at large hardly seems to be affected.

The potential of Broilers with Taste lies mainly in the strength of the design of Windstreek. It was conceived in reaction to a regime with huge barriers for change, coming from the whole production chain and part of the periphery. The project offers the potential to tackle problems in a comprehensive and fundamental way, problems that cannot be tackled by individuals or single organisations. Solutions that were generated and applied were technically thought out in depth and underpinned by calculation. The technical aspects are relatively simple and foremost functional (for example the barn is equipped with a natural ventilation system). The design is elaborated in detail which makes it plausible that it can be built in the way presented. Compared to traditional housing systems, it is a radically different way of keeping broilers. For many actors this is very interesting and attractive, but for others it seems rather odd or even threatening.

The strength of Windstreek is also its weakness: for its realization larger parts of the production chain have to be mobilized and institutional changes may be required. Because of its radical character, Windstreek is 'hard to sell' to actors that play important roles in the dominant selection environment.

Consortium partners and other enthusiasts are generally people who were already struggling with the routines of the incumbent regime, prior to the project and the SBIR trajectory. For them, Windstreek is a way to express their ambitions for a more sustainable way of producing chicken meat.

Wider attention of a variety of actors can partly be explained by contextual factors, like an increased pressure from animal protection groups, particularly on the broiler sector. Another factor is the recent public discussion on the use of antibiotics in animal husbandry at large. The negative environmental effects of the organic way of keeping broilers also plays a role. It will depend largely on the actual performance of Windstreek whether these actors will actively support scaling-up in the future.

\subsection{New Livestock Husbandry}

The 'New Livestock Husbandry' project does not focus on a particular animal sector. Several five-day workshops were organized, each of them focussing on a specific sector. In each of these workshops, between five and eight farmers and the same number of agricultural advisors are present. The workshops are split in three phases. In the first phase, the farmers are stimulated to identify their individual ambitions. The second phase focuses on the challenges that interfere with the accomplishment of these ambitions, while solutions are generated to address these challenges. In the third phase, solutions are selected and combined to a new design and an action plan is set up. This results in a personal fit with the ambitions and 
situation of the individual farmer. One of the posters that was made in New Livestock Husbandry is presented in Figure 3.

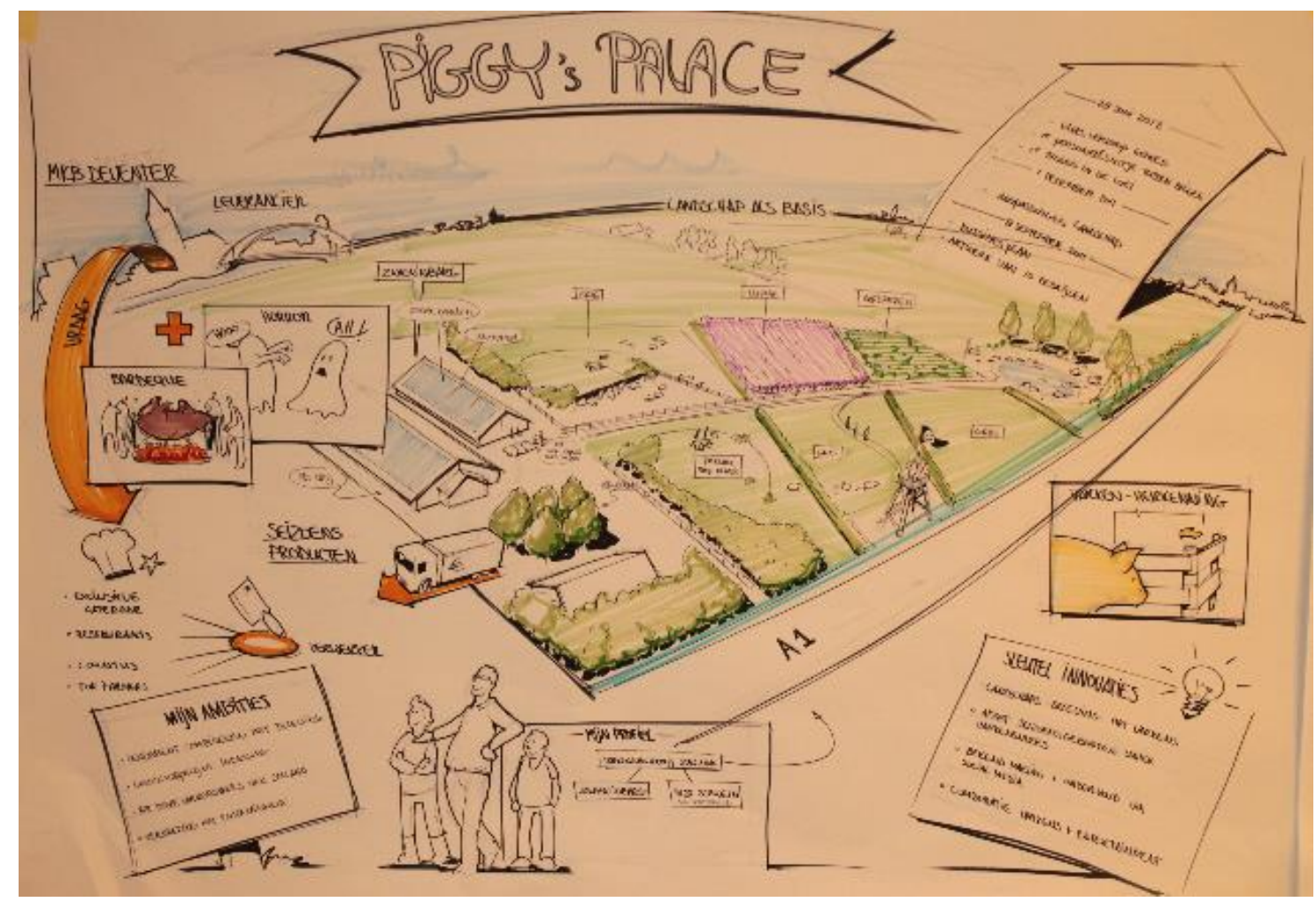

Figure 3: Piggy's Palace: Poster by one of the participants in New Livestock Husbandry

As can be observed in Figure 3, the focus of the design is on the farmer and his familiy, rather than the system. The plan is very personal with specific emphasis on the context of the farm, with a link to the present situation. The focus is mostly on the farm and its direct environment, i.e. the sphere of influence of the farmer. Some aspects of the plan are technical, but most are not and address issues like management, organisation, communication and collaboration.

\subsubsection{Effects and their causes}

The short-term effects of New Livestock Husbandry are far greater than those of the other two projects: two thirds of the participating farmers (over 40 in total) seriously start with the plans that they developed in the workshop. Some of the participants did already realize their plans, or are in the middle of realization. Others are improving their plans and make preparations for realization. The radicality of the things they realize varies to a large extent. Some farmers choose adjustments within the present system; others build a completely new farm and develop their own supply chain. Also the degree of success differs between the participants.

Despite the large number of initiatives, there is hardly any cooperation between the farmers. They all gather their own resources, build their own network, develop their own knowledge and create their own markets. They try to achieve their own goals, without any relation to the innovation trajectories of others.

To realize their plan, the participants often require various forms of support. In some cases, government and other institutional actors offer special subsidies or exemptions to rules and procedures. However, the majority of the innovation trajectories makes use of existing space for development. 
Besides the individual innovation trajectories of the farmers, agricultural advisors are involved in the project, so that they can use the tools and ideas of New Livestock Husbandry in their everyday practice. A number of agricultural advisors explicitly stressed the enriching character of the project for their advisory work. Others find it hard to take the ideas and tools with them back to their own organisation. These advisors do see the added value of (for example) searching for the ambitions of the farmer and involving neighbours in the innovation trajectories, but this does not seem to fit in with their daily work.

A third way in which the outcome of New Livestock Husbandry was propagated was via presentations by project team members for representatives of the regime. Although many of these actors were enthusiastic about the presentations, none of them was prepared to actively support the farmers in their innovation trajectories, and none of them was prepared to change their behaviour to facilitate innovation in general.

An important explanation for the specific results of New Livestock Husbandry and the differences with the two other projects, can be found in the central focus on individual farmers. This focus leads to a strong sense of ownership among the participants and a strong motivation and endurance to realize their plans. Thus, the projects that are initiated can be traced back to the ambitions, personalities and circumstances of the participants. This implies that innovations are not always new (although they are new to the farmer in his/her context) and that ambitions are often far from radical, sometimes not even really breaking with existing routines. As a result, further development stops when the local project is finished. Because the participants are only interested in their own farm, the initiated change will not reach further than their farm.

This does not mean, however, that New Livestock Husbandry structurally failed in stimulating system innovation. Not only is the project - in terms of numbers - the most succesful of the three in initiating and stimulating innovation amongst farmers; it also helped the farmers to look critically at themselves and the system in which they operate. This does not only help them in their current innovation trajectory, but also in dealing with future challenges and makes them more receptive for change. Moreover, some farmers in New Livestock Husbandry were very ambitious in their innovation trajectories, creating path-breaking innovations with which they inspire others.

In their attempts to deploy and apply their experiences in practice, the agricultural advisors and project team members struggle with the focus on the individual farmers in the project. As the solutions and designs are all developed with a specific local farm in mind, these are not easy to communicate to others. Furthermore, although the tools are generally applicable, they are hard to transfer outside New Livestock Husbandry, because without a context they are too vague and too abstract.

\section{Evaluation}

\subsection{Articulation of promises}

All three projects clearly articulate expectations and promises, but they do so in widely diverging ways. In Pork Opportunities, a very general future vision is conceived, that reflects a sense of urgency and promises potential improvements on many aspects. It is a vision that many can agree upon, as it only sketches rough contours and leaves a lot of room for different implementations. It invites actors to reflect on the way they think about the pig sector and articulate their own promises. This appears to work for a large number of pig farmers as well as for representatives of the regime. Various stakeholders create their own future vision of the pig sector, using building blocks from Pork Opportunities. A central element in all of these future visions is the awareness that it is possible to improve several aspects at the same time. The 'pig toilet' is the most illustrative example of this: by using the natural cleanliness of the pig, animal welfare is improved, ammonia emissions are decreased and the quality of manure rises (manure is more suitable for arable farming).

In Broilers with Taste the designs are much more technical, underpinned by calculation and meant to be build in the way they are presented. It features a clear set of closely related promises, free of context. There is little room for differing interpretations, so the promises are appealling to a limited group of actors. 
At the same time, raising high expectations - technically and visually powerful designs that are strongly deviating from the status quo - is attractive for several others.

In New Livestock Husbandry participants create a future vision on the basis of what they learn about themselves and the context in which they operate. This gives them a very concrete and user-friendly set of promises, as they are personal and related to their own context. Although all of these visions are quite deviant in comparison with the average business plan of a Dutch farmer, most participants easily adapt to the rules of the regime. Ultimately, most of them wish to transform their own farm and their direct environment, not a complete production sector. Because of the personal character and the contextspecificity of the designs, the promises of most of them are not very appealing to others.

\subsection{Network building}

With respect to network building, it is critical who are involved in the project. The consortia that initiated change in response to Broilers With Taste and Pork Opportunities are for the greater part formed during these projects. Thus, a larger variety of actors in the project leads to a higher potential for network building afterwards. This is important as almost all initiatives require a range of actors to realize their plans and overcome obstacles. Participants of New Livestock Husbandry are clearly disadvantaged here, because there were no market parties, NGOs or governments involved in their workshops. They are encouraged to build their own network, but this turns out to be troublesome for most of them. Likewise, initiatives that stem from Pork Opportunities suffer from the absence of market parties.

Furthermore, network building strongly depends on the articulation of promises discussed above. Again, the farmers in New Livestock Husbandry are in a disadvantaged position, as their promises are personal and strongly contextualized. The promises made by Broilers with Taste and Windstreek are especially appealing to actors who want to structurally change the current system, building a strong network that disassociates itself from the status quo. The promises made by Pork Opportunities, on the other hand, are appealing to a broad range of actors, including representatives of the regime, building a loosely structured network (or interconnected networks) that offers a range of opportunities for a variety of activities.

\subsection{Learning}

All three projects facilitate learning, but in different ways and at different levels. Broilers with Taste helps participants to gain a thorough understanding of the current system, its sustainability problems, and the possibilities to overcome these, including the technical and economic dimensions. The same kind of 'system learning' takes place in Pork Opportunities, but at a more general level without too much details. The primary learning experience by participants in Pork Opportunities is that the current system can be changed, and that each actor can have a role in this change process. New Livestock Husbandry specifically focusses on personal learning: not only the system itself is discussed, but specifically how the thinking of the participants shapes their opportunities (second-order learning). In Broilers with Taste, joint learning focused on designing, and realizing a path-breaking husbandry system was more important than individual learning processes.

Pork Opportunities is the only project that successfully facilitates a learning process for actors outside the workshops. The designs get others thinking about the future of the sector, directly by the brochure and presentations, or through follow-up initiatives.

\subsection{Local initiatives versus global niches}

Although RIO is aiming for global niche-development, it primarily facilitates local initiatives and projects. This is most clear for New Livestock Husbandry. Most of the participants in this project solely focus on realizing change on their own farm, without making use of or contributing to a global niche. Because of this 
fragmentation, the project itself cannot be considered a niche (or niche-in-the-making) either. It only functions as a temporary platform for farmers to reach their goals. Some of the participants do interact with a global niche outside New Livestock Husbandry. For instance, some of them became part of the organic agriculture niche, while some others associated with certain forms of multifunctional agriculture.

This is slightly different for Pork Opportunities. Just like New Livestock Husbandry, it stimulated local projects, but at the same time these are part of a greater change trajectory in the pig sector. Changes occur (partly as a consequence of Pork Opportunities) in regulations, procedures, future visions, research programs, etc. However, this does not constitute a niche for two reasons. First, these activities very loosely structured, not forming a new 'community', which Geels \& Schot (2010) see as a necessary characteristic of a niche. Second, there is no clear distinction between this niche and the regime, resulting in a great influence of the regime on the niche-developments, often neglecting and isolating radical local initiatives. Actually, it appears that a selection of the local initiatives is embraced by the incumbent regime, leading to incremental changes. The development of more radical change is still troublesome, despite the influence of Pork Opportunities.

The Windstreek-initiative, originating from Broilers with Taste, can also be considered a local initiative, but it does have the potential of becoming a niche. Not only is Windstreek designed without a specific context in mind, so that it can also be built in other places, it also has broad support of a variety of stakeholders. If it can fulfill its promises, in terms of technical, economic and sustainablility performances, these actors might well be able to form a community around Windstreek, countervailing the incumbent regime.

\subsection{Niche development processes}

\subsubsection{Shielding}

In many of the initiatives stemming from the three projects, some form of shielding takes place. In Pork Opportunities this is most prevalent, as there are various regime initiatives that create space for development of local initiatives. These include expectations on regulation and procedures, subsidies, and innovation projects, which all function as shields for these initiatives, protecting them from the selection criteria of the regime. However, this direct niche-regime relationship raises barriers for radical changes. The innovations have to fit the terms and conditions set by the regime or they will not be supported sufficiently. If innovations do not fit, pig farmers risk losing their protection. Here, the absence of a global niche is felt: protection from such a niche would offer more possibilities, especially for path-breaking innovations.

The same holds for New Livestock Husbandry, where the only shielding for most farmers also comes from the regime. Here the struggle for protection is even stronger, as the network building and articulation of promises has been limited, and no representatives of the regime were involved in the project. Whereas, for instance, the relation of an initiative with Pork Opportunities can be a legitimation for a subsidy, New Livestock Husbandry does not have the same effect, as the general promises are not shared.

Until now, shielding of Windstreek has taken place in the same way as with the other two projects: the regime offers some space for this kind of initiative, in this case by facilitating a specific SBIR tender. However, there is a difference with the other projects. Because of the future potential of the system, several groups have started to support its development. These include specific consumer groups, who stress sustainability issues, and local or regional governments that seek to distinguish themselves as facilitators of sustainable innovation. Because of the power of the total concept, Windstreek has more potential than the other initiatives to yield this kind of shielding. And specifically this kind of shielding offers much more space for radical innovation, because it is independent of the regime.

\subsubsection{Nurturing}

Nurturing is understood as shaping possibilities for the development of path-breaking innovations by creating a new Innovation System (Smith \& Raven 2012). Using this definition, little nurturing takes place in the initiatives that stem from Pork Opportunities and New Livestock Husbandry. The initiators mainly focus 
on implementation and realization, without considering changing the context in which this takes place. This results from the fact that many of these initiatives are carried out by single farmers, which does not cause problems for them as long as their plans are not really path-breaking. As a result, no further protection is needed.

However, there are several exceptions: several farmers, who develop new knowledge, create new markets and reinvent the way in which they interact with their (natural and social) environment. This requires new network building and a thorough learning process, while engaging actors that can contribute to (and profit from) the innovation trajectory. When asked for the underlying reasons of their particular innovation trajectory, these farmers all refer to Pork Opportunities or New Livestock Husbandry as turning points in their development. At the same time it must be noted that these farmers are non-typical in terms of their creativity, visioning, endurance and communication skills. This enables them to do new things that others can or will not.

For Broilers with Taste most of the nurturing has yet to come. As the promise of Windstreek can only be fulfilled if the embedded novelties are realized in combination, further development will require comprehensive R\&D. Moreover, Windstreek requires a wider system change to function, relating to the value chain and the market. As the goals of Broilers with Taste are more ambitious than those of the other projects, this will require more nurturing of the required developments.

\subsubsection{Empowerment}

Empowering is understood as strengthening the niche to become competitive with the regime (Smith \& Raven 2012). It is not very likely then, that empowerment would result from projects that have finished only recently. Nevertheless, since Pork Opportunities and New Livestock Husbandry primarily created local initiatives (in the absence of a global niche) that follow quite short innovation trajectories, there are quite some initiatives that already have been empowered. All of them fall within 'fit and conform' empowerment (Hoogma 2000), which means that they have become competitive within an unchanged selection environment. This implies that these initiatives result in incremental changes, although there are also several initiatives that tinkered with path-breaking innovations. In these cases, the empowerment of the niche in the sense of competiveness with the regime, at the same time lead to disempowerment with respect to sustainability (Smith \& Raven 2012). Thus they dropped the path-breaking aspects they entailed, as these farmers do not have the ability nor the will to change the selection environment.

Other initiatives, that stem from Pork Opportunities and New Livestock Husbandry, continue developing their local niche, creating their own local niche market, both as shielding and nurturing mechanism, sometimes succeeding to scale up to a regional market. These initiatives seem to postpone their moment of empowerment. They are not ready for a confrontation with the regime as they lack the strength of a mature global niche. To survive and maintain their path-breaking aspects, they have to keep operating as a local niche. If a global niche develops in the future, their possibilities will be extended and 'stretch and transform' empowerment (Hoogma 2000) might become feasible.

For Broilers with Taste, the moment of confrontation with the regime is still far away. Because of its radical and encompassing changes, it has to follow a 'stretch and transform' path, leading to structural changes in the selection environment. To make this possible, first a more global niche has to be developed, implying that the initial focus has to be on shielding and nurturing.

\section{Discussion and conclusion}

We studied the first effects of three recent projects in redesigning animal production systems. Although many initiatives have been identified that build on these projects, none of them has yet established a global niche. The initiatives follow their own local innovation trajectory (for Pork Opportunities and New Livestock Husbandry) or they are still in the phase of niche-in-the-making (Broilers with Taste). 
Although global niches are (still) absent, all three projects have actively stimulated articulation of promises, network building and learning, resulting in diverse configurations of shielding, nurturing and empowering. By doing so, they have all facilitated new developments that are normally out of reach for the average farmer.

It can be argued that innovations, that are carried out by individual farmers, are not likely to result in niche development, as innovative farmers generally aim for changes on their own farm, not in the system. In practice, in many of these initiatives, that were initially path-breaking, farmers chose to decrease their level of ambition, thus adapting to an unchanged selection environment. As Broilers with Taste has wider goals and is carried by a diversified group of actors, this project still has the potential to develop into a global niche. At the same time Pork Opportunities and New Livestock Husbandry have engendered some initiatives that have become local niches, where the initiators are motivated and able to keep this niche alive, further shielding and nurturing their path-breaking innovations. Furthermore, following Pork Opportunities also institutional players have started changing their behaviour. Although these changes are not radical, Pork Opportunties has altered the direction and speed of incremental transformation for the regime, thereby providing more space and support for niches based on path-breaking innovations.

We conclude that all three projects have contributed to system innovation in one way or another, but that, until now, path-breaking changes have only been realized on a very small scale in local initiatives. The largest promise for future regime changes lies in the potential of Broilers with Taste. However, the ability of Pork Opportunities to alter the research agenda and create more space for sustainable production and commercialization alternatives, and the achievements of Pork Opportunities and New Livestock Husbandry in producing initiatives that retain as local niches, also have their value in terms of transitions. Although in the current state of regime and landscape, this is not likely to lead to wider structural change, the projects do offer alternative pathways for the future, if circumstances might change and the tension between landscape and regime increases.

We therefore conclude that RIO can ignite and facilitate niche innovation, which, depending upon regime and landscape characteristics, may eventually lead to a transition of the regime. In answering how the RIO approach may contribute to the perceived effects (the last question formulated at the end of the theoretical framework), three aspects stand out: design, interaction and reflexivity.

Concerning design, in all projects, the newly developed designs provided people with a strong and tangible visualization of possible alternatives, opening them up for more solutions and possibilities than they initially thought. This is due to the focus on goals and functions, thereby avoiding short-term conflicts and perceived problems, before solutions are generated. The designs are not only important for articulation of promises, they also facilitate network building. Whether this contributes to global niche development, depends on several design process conditions, especially the ambitions of the project, the system barriers that are addressed and the heterogeneity of participants. Initiators and design are in a constant interaction with each other. An appealing design is able to attract a capable group of actors, and a capable group of actors is able to create and develop a powerful design. A strong design facilitates a joint focus and spark a consortium to start and grow, using its capacity to enthuse and enroll new actors, and to provide a common vision.

Concerning interaction, all projects illustrate that involving a heterogeneous group of stakeholders is essential. A heterogeneous group increases diversity, enables the conciliation of perspectives, enhances heterogeneous network building, and opens up possibilities that are unattainable for stakeholders alone. In aspiring system innovation, chain parties need each other, just like niche players and institutional parties need each other.

Stimulating reflexivity is the third important aspect of RIO. The primary focus of RIO on goals and functions, rather than on solutions, stimulates reflection on what has to be done, rather than how. Furthermore, the process stimulates a critical attitude towards participants' biases, as well as towards the rules of the game from the regime. This turns out to be a powerful way to scrutinize taken-for-granted perceptions and tacit routines, which in turn results in shared learning, a better mutual understanding, network formation and the articulation of promises that are seen as such by a wider array of stakeholders. 
The combination of design, interaction and reflexivity enables the shielding, nurturing and empowerment of path-breaking niche innovations, and is a distinguishing feature of RIO compared to other stakeholder approaches. As this chapter has made clear, this is not a straight-forward exercise: niche development and system innovation are man-made processes in a continuously changing environment. It is the combination of the planned activities in the RIO projects, and the unplanned and often unforeseeable responses to this from the regime, that determines whether this will eventually contribute to a transition.

Acknowledgements: This chapter is based on research conducted within the Programme KB-16 Transitie \& Innovatie (KB-16-002.05-007), financed by the Dutch Ministry of Economic Affairs.

\section{References}

Beck, U. (1997). The reinvention of politics: Rethinking modernity in the global social order. Polity Press: Cambridge.

Bergek, A., S. Jacobsson, B. Carlsson, S. Lindmark \& A. Rickne (2008). Analyzing the functional dynamics of technological innovation systems: A scheme for analysis. Research Policy 37 (3): 407-429.

Berkhout, F., A. Smith \& A. Stirling (2004). Socio-technical regimes and transition contexts. In: B. Elzen, F.W. Geels \& K. Green (eds.). System Innovation and the transition to sustainability: Theory, evidence and policy. Edward Elgar: Cheltenham.

Bos, A.P. (2008). Instrumentalization theory and Reflexive Design in animal husbandry. Social Epistemology 22, $29-50$

Bos, A.P. \& J. Grin (2008). 'Doing' reflexive modernization in pig husbandry: The hard work of changing the course of a river. Science, Technology \& Human Values 33: 480-507.

Bos, A.P. \& P.W.G. Groot Koerkamp (2009). Synthesising needs in system innovation through structured design: A methodical outline of the role of needs in reflexive interactive design (RIO). In: K.J. Poppe,

C. Termeer \& M. Slingerland (eds.) Transitions towards sustainable agriculture and food chains in peri-urban areas. Wageningen Academic Publishers: Wageningen.

Bos, A.P., P.W.G. Groot Koerkamp, J.M.J. Gosselink, \& S.J. Bokma (2009). Reflexive Interactive Design and its application in a project on sustainable dairy husbandry systems. Outlook on Agriculture 38, 137145.

Bos, A.P., S.F. Spoelstra, P.W.G. Groot Koerkamp, K.H. de Greef \& O.N.M. van Eijk (2011). Reflexive design for sustainable animal husbandry: mediating between niche and regime. In: Spaargaren, G., Loeber, A. \& Oosterveer, P. (eds.) A transition perspective on sustainable food and agriculture. Routledge: London.

Commission Wijfels (2001). Toekomst voor de veehouderij: Agenda voor een herontwerp van de sector. LNV: Den Haag.

Geels, F.W. (2002). Technological transitions as evolutionary reconfiguration processes: a multi-level perspective and a case-study. Research Policy 31 (8-9), 1257-1274.

Geels, F.W. (2005). Technological transitions and system innovations: A co-evolutionary and socio-technical analysis. Elgar: Cheltenham.

Geels, F.W. \& J.W. Schot (2007). Typology of sociotechnical transition pathways. Research Policy 36 (3), 399-417.

Geels, F.W. \& J. Schot (2010). The dynamics of transitions: A socio-technical perspective. In: J. Grin, J. Rotmans \& J. Schot (Eds.). Transitions to Sustainable development: New directions in the study of long term transformative change. Routledge: New York.

Grin, J., F. Felix, A.P. Bos \& S.F. Spoelstra (2004). Practices for reflexive design: Lessons from a Dutch programme on sustainable agriculture. International Journal of Foresight and Innovation Policy 1 (12): $126-149$.

Groot Koerkamp, P.W.G. \& A.P. Bos (2008). Designing complex and sustainable agricultural production systems: An integrated and reflexive approach for the case of table egg production in the Netherlands. NJAS 55, 113-138.

Hekkert, M.P., R.A.A. Suurs, S.O. Negro, S. Kuhlmann \& R.E.H.M. Smits (2007). Functions of innovation systems: A new approach for analysing technological change. Technological Forecasting \& Social Change 74: 413-432. 
Hoogma, R. (2000). Exploiting technological niches: Strategies for experimental introduction of electric vehicles. Twente University Press: Enschede.

Kemp, R., J. Schot \& R. Hoogma (1998). Regime shifts to sustainability through processes of niche formation: The approach of Strategic Niche management. Technology Analysis \& Strategic Management 10 (2): 175-195.

Klerkx, L., N. Aarts \& C. Leeuwis (2010). Adaptive management in agricultural innovation systems: The interactions between innovation networks and their environment. Agricultural Systems 103, 390400.

Marsden (2003). The condition of rural sustainability. Van Gorcum: Assen.

Schot, J. \& F.W. Geels (2008). Strategic niche management and sustainable innovation journeys: Theory, findings, research agenda and policy. Technology Analysis \& Strategic Management 20 (5): 537 554.

Siers (2004). Methodisch ontwerpen volgens H.H. van den Kroonenberg. Wolters-Noordhoff: Amsterdam.

Slingerland, M. \& R. Rabbinge (2009). Introduction. In: K.J. Poppe, C.J.A.M. Termeer \& M. Slingerland (Eds.). Transitions towards sustainable agriculture and food chains in peri-urban areas. Wageningen Academic Publishers: Wageningen.

Smith, A. \& R. Raven (2012). What is protective space? Reconsidering niches in transitions to sustainability. Research Policy 41: 1025-1036.

Spoelstra, S.F., P.W.G. Groot Koerkamp, A.P. Bos, B.E. Elzen \& F. Leenstra (2013). Innovation for sustainable egg production: realigning production with societal demands in The Netherlands. World's Poultry Science Journal, 69, 279-298.

Swagemakers, P. (2008). Ecologisch kapitaal: Over het belang van aanpassingsvermogen, flexibiliteit en oordeelkundigheid. Wageningen UR: Wageningen.

Van der Ploeg, J.D. (2003). The virtual farmer: Past, present and future of the Dutch peasantry. Van Gorcum: Assen.

Zwartkruis, J., L. Klerkx, E. Moors, J. Farla \& R.E. Smits (2010). Co-innovation in Sustainable Laying Hen Husbandry Systems: Investigating the interactive framing of sustainability. 9th European IFSA Symposium. Vienna, Austria. 


\title{
Niche knowledge systems-challenging or invigorating the AKS? An analysis of the Permaculture community in England
}

\author{
Julie Ingram ${ }^{1}$ and Damian Maye ${ }^{2}$
}

\section{Abstract}

This paper examines how knowledge systems within alternative innovative agricultural groups (niches) develop and interact with the mainstream AKS using the notion of boundaries. It draws on empirical data from a study of the Permaculture community in England, a sub-niche entity. Members of this community question the operations of the mainstream agricultural regime and advocate a radical shift in patterns of thinking and action towards new agri-food systems. Analysis shows that a distinctive knowledge system has emerged to support learning in the community independently of the AKS. This is strongly associated with, and coheres around, the community's social system. The boundary between this KS and the mainstream AKS can be characterised in terms of differing sets of beliefs and values, epistemologies, ways of facilitating and supporting learning, approaches to research and modes of development. However, despite these epistemic divides, there is evidence of some interaction across the boundary. The paper explores the potential for the Permaculture's KS to potentially invigorate and transform the AKS.

Keywords: Permaculture; AKS; AKIS; niche; regime; boundaries; innovation; agro-ecology

\section{Introduction}

The complex problems facing agriculture require approaches that go beyond "traditional" sectorial agricultural boundaries. Innovative forms of agriculture are emerging, often associated with groups and networks where the actors advocate sustainable alternatives to mainstream agro-food systems and challenge the existing socio-technical regime built around industrialised agriculture (Goodman, 2014; Marsden, 2004; Seyfang and Smith, 2007; Whatmore and Thorne, 1997). Such innovative groups, which operate outside or on the fringes of conventional agricultural contexts and outside public funding and established institutional and policy frameworks, can be thought of as synonymous with socio-technical niche $^{3}$ (or sub-niche) entities. These groups are typically self-organising; they share common goals and interests; and they learn together to create new ideas and innovative practices (Knickel et al., 2009). Moreover, they follow distinctive modes of development, frequently emerging out of bottom-up processes or socio-technical processes of social innovation rather than the outcomes of the implementation of topdown technological projects.

Knowledge is one of the most relevant resources circulating in such groups or niches. This has been notably revealed, for example, in analysis of transition towns (Seyfang and Haxeltine, 2012), organic farming (Morgan, 2011), agri-environmental action (Lockie, 2006), and Permaculture (Ingram et al., 2014a).

\footnotetext{
1 Countryside and Community Research Institute, University of Gloucestershire, Gloucester, UK. Email: ingram@glos.ac.uk

2 Countryside and Community Research Institute, University of Gloucestershire, Gloucester, UK. Email: dmaye@glos.ac.uk

${ }^{3}$ Originally used to describe technological innovations, the niche concept has also been used to capture sociallyoriented innovations based upon different values from the mainstream (Geels, 2004; Kemp et al., 1998 Seyfang and Smith, 2007).
} 
They develop their own distinctive knowledge systems (KS) and collaborative modes of learning in the absence of support from the formal Agricultural Knowledge System ${ }^{1}$ (AKS) (Brunori et al., 2013). These KS confront the AKS, which is charged with fostering innovation but is locked into old approaches or trajectories of the incumbent regime. Equally, however, learning and experimentation in niche may enhance the regime's AKS, contributing to its diversity and adaptation, and creating opportunities for innovation and learning.

Understanding potential interaction across the boundaries between the KS of these groups and the established mainstream AKS is important to identify opportunities for mutual learning and for boundary work (Cash et al., 2002; Tisenkopfs et al., 2015). Support of alternative agricultural innovations by the AKS, and provision of an enabling environment to accommodate them, is an emerging theme in European policy. This emphasises the reform of the AKS in the context of the demands of sustainable agriculture and the evolution of a more responsive Agricultural Knowledge and Innovation System (AKIS) (EU SCAR, 2012, 2014).

Despite the centrality of knowledge to innovation, there is little understanding of how KS in emerging innovative niches interact with the AKS of the incumbent regime. This paper addresses this using the notion of boundaries. It frames the analysis around transition, knowledge systems and boundaries literatures and draws on empirical data from a study of the Permaculture community in England, a sub-niche entity studied within the SOLINSA ${ }^{2}$ project. The paper explores the potential for this Permaculture community's KS to potentially challenge or invigorate the AKS of the mainstream regime.

\section{$2 \quad$ Niche knowledge systems - challenging or invigorating the AKS?}

The exchange and combination of knowledge has always been an important element of alternative agricultures, which develop largely through bottom-up processes or socio-technical processes of social innovation (Barbier and Elzen, 2012; Geels, 2004; Roling and Wagemakers, 2000). This distinguishes them from top down solutions typical of mainstream agricultural development and supported by AKS where a technology-oriented definition rather than social innovation predominates (Boch, 2012).

\subsection{The Agricultural Knowledge System}

The incumbent socio-technical food regime built around industrialised agriculture has developed a dedicated knowledge base and institutional arrangements to promote and sustain it. In agriculture the notion of Agricultural Knowledge Systems (AKS) emerged to describe the formal set of institutes and actors charged with fostering innovation, and to capture the stable actor networks, which support agricultural innovation and learning (Roling and Engel, 1991). Today it encompasses powerful actor networks (comprising agricultural scientists, extension officials, and agro-chemical suppliers and technologically innovative farmers), and can be thought of a key apparatus of the incumbent mainstream agricultural regime. The AKS is an institution that has co-evolved as part of the regime, conferring legitimacy and scientific authority, reinforcing existing trajectories (the 'agricultural treadmill') and contributing to its path dependency (Leeuwis, 2004). As a core element of the knowledge dimension, it is central to the conventions, rules, and norms that guide the uses of particular technologies and the everyday practices of regime actors (Geels, 2004; Smith, 2007).

\footnotetext{
${ }^{1}$ Agricultural Knowledge System is understood here to mean the formal set of institutes and actors: researchers, advisory services, supply industries and progressive farmers.

${ }^{2}$ SOLINSA - Support of Learning and Innovation in Sustainable Agriculture.
} 
Alternative food producer groups can be thought of as socio-technical niches or sub-niche entities where innovation occurs and where social networks are built by those who desire to advance more sustainable alternatives to those present in the existing socio-technical regime. Knowledge is one of the key resources devoted to alternative socio-technical practices, and learning processes are central to niche development and management (Geels and Schot, 2007; Hoogma et al., 2002; Kemp et al., 1998; Smith, 2007). Niches tend to develop their own distinctive KS (e.g. Morgan, 2011; Seyfang and Haxeltine, 2012). The social nature of knowledge in these systems is a central theme particularly in social or grassroots innovations, which are applied to a wider goal of sustainability (Seyfang and Smith, 2007). In these innovations KS cohere around social systems, they are ".a network of actors connected by social relationships, formal or informal, that dynamically combine knowing, doing, and learning to bring about specific actions for sustainable development" (van Kerkhoff and Szleza, 2010, p1). This has been described for the Organic, Transition and Permaculture social movements (Seyfang and Haxeltine, 2012; Smith, 2007; Veteto and Lockyer, 2008).

\subsection{Challenging or invigorating the AKS?}

Emerging groups with new co-learning approaches and advocating more sustainable activities are said to challenge the assumptions and rules of the AKS (Brunori et al., 2013). Through the development of raised levels of awareness, empowerment and capacity building they follow a 'second order' innovation and learning. This questions and confronts the fixed rule set (or paradigm) of first order innovation of the mainstream AKS which is dependent on technical efficiency and innovations from science and technology (Brunori et al., 2007; Kemp et al., 1998; Seyfang and Smith, 2007). The KS of alternative groups or niches therefore potentially challenge the dominance of the AKS actors and structures and seek to change it through diffusion of more radical ideas and practices. Learning, and in particular social learning, nurtured through the process of experimentation, is considered to be at the core of niche development and very important in overcoming stable and difficult-to-change socio-technical systems. The process is, however, contested, as like the overall niche-regime relationship, niche KSs struggle to find and maintain a viable space within the AKS.

However, it is simplistic to describe the AKS as a coherent system. It is increasingly heterogeneous with diverse actors, entities, coalition networks and organizational structures (Aarts et al., 2007). Some argue the AKS has become more a creative and flexible space arguably less bounded and more accessible to outside initiatives (Garforth et al., 2003). Scholars describe an evolving AKS. They envisage a role for alternative groups in invigorating and strengthening the AKS and helping its transformation into an AKIS comprising all types of public, private and civil society actors, such as inputs and processing industry actors, agricultural traders, retailers, policymakers, consumers and NGOs (EU SCAR, 2012, 2014; Hermans et al., 2015). This analysis suggests that, from one perspective, the KS of niches and the mainstream are opposed and disconnected, and that the niche KS challenges, confronts or aims to transform the incumbent AKS. However, from another perspective, the niche KS can potentially strengthen and invigorate the AKS by bringing in new perspectives and opportunities for innovation.

\subsection{Conceptualising connection and disconnection}

The notion of boundaries captures the dialectic interaction or tension between AKS and niche KS suggested above, it provides a frame for conceptualising any disjuncture or potential connection between them. Absence of common knowledge is a defining feature at the boundary between different knowledge domains. In KS boundaries demarcate the socially constructed and negotiated borders between disciplines, sectors and communities (Cash et al., 2002). Boundaries delimit functions such as knowledge generation as well as different types of knowledge (e.g., western scientific, traditional, situated, or local). Structural and cognitive barriers can restrict bridging between different KSs (Berkes, 2009) and where they become impermeable, boundaries at the interface between knowledge domains can prevent any meaningful communication taking place across them (Clark et al., 2011; Robinson and Wallington, 2012). 
Certain sorts of knowledge, learning and practice are associated with specific groups or communities where social bonds are strengthened by sharing the same knowledge, language, practice, values and repertoires (Wenger, 2000). As Castree (2005, p12) notes "typically, knowledge exists as more or less established bodies of knowledge that distinct groups of people share in common." Boundaries are maintained by such groups to steward and protect critical competence. In the science community boundaries play a role, they are maintained against threats to its cognitive authority from, for example, pseudo-science (Cash et al., 2002).

However, communities or groups can be so tightly knit that they become, insular, defensive, closed in, and oriented to their own focus. Boundaries around them can create divisions and be a source of separation, fragmentation, disconnection, and misunderstanding (Wenger, 2000). Where these coincide with different sorts of knowledge and epistemological language they have been described as epistemic divides (O'Kane et al., 2008). Scholars suggest that, where boundaries exist, this can constrain knowledge flows between communities (Tagliaventi and Mattarelli, 2006). This has implications for niche innovations. For niches to emerge and develop they need to communicate effectively with wider audiences. However, internal learning and networking within some niches has become principally an 'insider' activity, supporting the niches' own development but not translating it beyond its boundaries (Seyfang and Haxeltine, 2012).

The literature on knowledge in organisations recognises knowledge boundaries between specialised domains (Carlile, 2004). With respect to emerging innovations this author argues that there is often a lack of common knowledge to adequately share and access domain-specific knowledge at a boundary. He describes the "curse of knowledge" which recognises the difficulty that actors have in abandoning previous knowledge as an important property of knowledge at a boundary when a novelty or sub-niche appears (Carlile, 2004, p557). Where knowledge is invested within a given practice-it should be seen as "at stake," indicating the significant costs associated with giving it up and acquiring different knowledge (Carlile, 2004, p556). Finding common knowledge therefore is key to promoting effective exchange. This is often the basis of boundary processes (Roberts, 2006) and boundary work, which helps to manage all kinds of demarcations between and within different actors (Clark et al., 2011). Tisenkopfs et al. (2015) provide examples of boundary work in a number of sustainable agriculture networks where individual knowledge stocks are translated into collectively shared knowledge and innovations for sustainable agriculture.

As well as boundaries marking spaces of disconnect, commentators have argued that where boundaries interact they become spaces of unusual learning, where fresh perspectives meet and new opportunities arise (Wenger, 2000). Exposure to new information "creates an environment in which 'creative abrasion', the synthesis that is developed from multiple points of view, is more likely to occur" (Powell and Grodal, 2005, p. 59). Thus, according to Carlile (2004) knowledge is seen, both a source of, and a barrier to innovation.

These different perspectives on boundaries can be drawn on to inform and examine the dialectic interactions between KSs of innovative groups and the mainstream AKS and to frame the analysis of whether niche KS challenge or invigorate the AKS.

\section{Methodology}

\subsection{The context - Permaculture in England}

The Permaculture community in England is an emerging group or sub-niche ${ }^{1}$ that questions the operations of the mainstream agricultural regime. It advocates a radical shift in patterns of thinking and action towards

\footnotetext{
${ }^{1}$ The Permaculture community in England cannot be classified as a complete niche. Instead it is a sub-niche entity developing in a value space (agro-ecological niche) distinct from the mainstream agricultural regime.
} 
new agri-food systems framed around agro-ecological principles. It can be described as a diffuse network of diverse individuals or communities sharing a common approach and vision. Sites include home gardens, community gardens/farms, public spaces, allotments and smallholdings. The community coheres around the Permaculture Association (PA) a membership organisation (over 1200 individual, 67 groups, and 18 businesses) (Permaculture Association, 2011a).

Permaculture is an approach to the design of community and agricultural systems according to the principles that mimic ecological systems (Holmgren, 2002; Mollison and Holmgren 1978; Mollison, 1988). A central theme in Permaculture is the design of ecological landscapes that produce food. As the emphasis is on design principles, it does not prescribe a specific practice of food production, although it is often referred to as agro-ecological production. The movement advocates a paradigm shift from "business as usual' agriculture by putting community at the centre of agriculture, as this statement from the PA website reveals:

"Many researchers, including myself, believe that permaculture should form the basis of agricultural and social development. The establishment of a large number of small, permaculture type farms serving local communities and adapted to local conditions, would create tremendous cultural as well as biological diversity, because farming would no longer be geared to uniform global production. Permaculture based minifarms could be the key to agricultural and community regeneration." Dr. John Zarb, Newcastle University [PA, 2011b]

Its goals in this sense are transformative, in that it reframes how agri-food systems should be organised. Permaculture can be described as a second order innovation, it represents a sub-niche entity that is radically different from the incumbent agricultural or food regime.

\subsection{Methods}

The research was carried out as part of the three year EU funded project SOLINSA (Support of Learning and Innovation in Sustainable Agriculture). This project was underpinned by transdisciplinary approaches and five participatory workshops were carried out over the project period. Participants (15-20 in each workshop) were selected to represent the diverse range of actors who engage with Permaculture in England including practitioners and PA representatives. Interviews were also carried out with 14 individuals from the community to supplement the workshop data. The workshops and the interviews focused on understanding the community's learning and innovation networks including the emergence of its KS. One workshop specifically looked at the interaction between KS of mainstream and agro-ecological KSs and included a range of participants from both. Further information is available in Ingram et al. (2013) and Home and Rump (2015).

\section{Results - the Permaculture Knowledge System boundary interactions}

\subsection{The Permaculture Knowledge System (PKS)}

In England a distinctive Permaculture Knowledge System (PKS) has emerged around the Permaculture community to support learning. This is characterised by a broad community of individuals and groups, a social learning system, who learn experientially, and share and validate their knowledge through multiple social networks, supported by a formal set of structures and activities run by the PA.

Knowledge and learning are at the centre of the Permaculture movement. Learning is guided by a belief in Permaculture design, self-reliance and a trust in the system of production. The ethos is one of mutual 
support through shared learning, both in terms of helping people change their perspective on life according to the three core ethics, but also with respect to practical knowledge about Permaculture design tools and techniques. Permaculture is underpinned by a certain set of values and understandings of what constitutes valid and relevant knowledge. However, there are multiple personal understandings of what Permaculture means and, as such, approaches to learning vary: for some it is a scientific process, for some practical, for others it is a philosophical or even a spiritual one.

The PA has developed a set of frameworks, ideas, tools and information that the community can share. It aims to promote the understanding of the theory and practice of Permaculture in England by educating the public, providing individuals and groups with access to advice, support, information and training and researching Permaculture. The PA legitimises the design principles, provides accredited training courses, supports a website and newsletters and runs events for members, and coordinates research. It also coordinates the 'Learning And Network Demonstration' (LAND) and FarmLAND initiatives.

\subsection{Individual learning and networking}

The nature of Permaculture means that practitioners learn experientially on their own sites combining knowing and doing. There is an acceptance that people have different knowledges, that "It is so sitespecific; so people specific" and that there is "no right or wrong". There is a considerable personal investment in experimental learning and a significant level of individual, local, context-specific knowledge is built up. There are codified resources that individuals refer to, most commonly the Designers Manual (Mollison, 1988), However, knowledge also tends to be personified, there is a lot of knowledge embedded in inspirational and charismatic individuals who act as advocates for Permaculture. Practitioners welcome the chance to network and connect to others (virtually or at events) and share and validate their learning. This sharing is enabled by people having the same sort of "ethical mindset", or being on "the same page", according to some respondents. The significance given to this tacit or 'unspoken' knowledge generated and circulated within the community, and the allegiance to those who share the same identity, beliefs and values, serves to strengthen internal ties and networks but can restrict external linkages.

Many practitioners also seek out information to complement and support their experimental learning, they need to enhance their discovery driven learning by absorbing knowledge from others. They cultivate personal channels and networks and seek information and training from a range of sources outside of the PA. This networking reveals, what some described as the "magpie" tendencies of Permaculture actors who seek out and use different aspects of knowledge and practice from a number of sources. The breadth of networking also reflects the wide and multiple interpretations of Permaculture design that the diverse constituency subscribes to, as well as their variable sites and personal motivations. Thus a dynamic exists between the strong internal ties, which reinforce the boundaries of the PKS and the weaker ties some actors make connecting across the boundaries.

Although personal links are made with individual AKS actors, for some in Permaculture, their enthusiasm for unorthodox approaches means that they participate in, and draw inspiration and information from, a number of communities in the 'alternative' social learning system operating on the fringes of the AKS (e.g. local Community Supported Agriculture and Transition groups). In this sense there is a tendency to operate outside of the usual farm AKS information and advisory sources. Often this is linked to their belief and conviction in Permaculture as a system of production and their principles of self-sufficiency. They distinguish themselves from farmers who they perceive as reliant on subsidies and needing formal certification for their food products. Although some respondents said they had good social networks with local farmers, these were not used to share knowledge about food production. A lack of understanding seems to be the main barrier to communication, one problem being that Permaculture is a hard concept to describe, as this farmer applying Permaculture principles explained. Such comments reveal a critical lack of common knowledge. 
"Even to the closest farmers that we work with, if you said do you know what Permaculture means, if they do, it will be nothing to do with us. They know that we're organic, and they know that we're grass fed". Organic farmer

\subsection{Permaculture Association actor networking}

The PA staff have a strong allegiance to the Permaculture community and to the PA's vision (PA, 2011a); they reinforce the community's boundaries through a number of internal activities. However, PA staff members are also active in building partnerships with external organisations. These tend to be like-minded organisations such as Campaign for Real Farming and the Organic Growers Alliance suggesting that, as with individuals, interaction is mainly with those in the same 'alternative' social learning system. Whilst some connections are made with mainstream AKS organisations, PA actors tend to view these as dissemination, rather than learning, opportunities. They also identify mainstream concepts, which resonate with Permaculture principles (e.g. sustainable intensification, catchment based approaches), as a means of accessing AKS knowledge and funds. These concepts, however are often re-interpreted through a Permaculture lens; such re-framing of knowledge is characteristic of boundary processes. These boundary interactions are essentially informal connections, with most boundary work done at the individual level rather than by any recognised boundary organisations. Indeed respondents pointed to a lack of structures and funding for boundary work, which restrict opportunities for sharing knowledge between KSs.

\subsection{Permaculture Association training and supporting learning}

Running alongside and supporting individual experiential learning is a well-developed training programme coordinated by the PA delivering the Permaculture Design Course (PDC) (with more than 3500 graduates), viewed by many as an essential route into Permaculture, and the higher level Diploma in Applied Permaculture Design. The training style emphasises co-learning, reflecting the Permaculture ethos and culture of sharing. One participant reflected on the training: "The [tutor] was there as a facilitator to draw out of you and out of the group what the ideas they had and so on...". Another commented: "it is quite inspiring and transformative to be working with a group of like-minded people and to be learning about something". This mutual learning does create some problems in reconciling it with mainstream learning systems - it is difficult to standardise curricula, and to monitor, evaluate and certificate the courses. This limits the transferability of courses to outside the PKS. As with the individual experiential learning, the training element of the PKS appears to strengthen internal ties. Attaining the course qualifications confers some level of cognitive authority on the participants and builds a critical competence, which reinforces boundaries. It also represents a level of investment in knowledge both by trainer and trainee, since the courses can be demanding on time and money.

However, the recent accreditation of some PDC courses and modules (e.g. level one mulching module) by the Open College Network (a credit awarding organisation), marks the first stage in making the courses accessible to a wider audience and provides common fora for knowledge sharing. Thus although training reinforces a closed knowledge system, there is an element of boundary crossing, with educational structures.

\subsection{Permaculture Association outreach and dissemination}

One of the aims in the PA strategy is to reach out to new groups and sectors (PA, 2011a). The LAND and FarmLAND initiatives in particular are opportunities for diffusion of Permaculture ideas into the AKS. LAND is a network of some 80 demonstration sites for Permaculture practitioners and the general public. Some managers of Permaculture LAND sites interact with their local community, as one participant remarked "We have contacts on many fronts, farmers, local government, architects, urban food growers, we're reaching out to a lot of people". However, respondents remarked on the difficulties in explaining Permaculture to 
these people. There is also resistance from conventional farming bodies, one LAND practitioner described attempts to communicate with local farming union representatives: "We have been trying to knock on door of the NFU [National Farmers Union] for ages without success...NFU is a hard nut to crack".

FarmLAND aims to promote Permaculture design at the farm scale by working with farmers and AKS partner/training organisations. This initiative is ambitious and largely aspirational, it reflects the PA vision to transform the food production system. So far it has attracted interest mainly from smallholders already interested in Permaculture. A few larger scale mainstream farms have engaged, either attracted by the Permaculture approach or by training events on certain selected practices, such as mob grazing, which can be implemented on conventional farms. Attempts to take some of these events out to a wider farming community have met some resistance. One large scale dairy farmer, who is using Permaculture design, described an organised farm walk led by a well-known expert in mob grazing:

"The meeting attracted some local farmers. All the people for Permaculture design course also came. Some of the farmers thought they were a bit weird and one described them as 'fanatical'. I thought I can see what you're saying. But you're looking at it purely from a farming point of view and not listening to what they are saying. Sometimes we can come over as quite fanatical'. Dairy farmer

\subsection{Permaculture Association Research}

The PA regards research as important, both in providing feedback to the community about best practice, but also as providing evidence to outsiders. There is a wider interest in the Permaculture community to prove that Permaculture works (Perkins, 2012) and to gain some credibility. As Holgrem (2011, p 23) noted, there is a "perception of lack of intellectual rigour, which has continued to inhibit the concept being taken seriously in academia".

The PA supported by a Research Advisory Board (RAB) (which includes a number of interested academics) is in the early stages of developing and implementing a research strategy for the PA (PA, 2011c). The Permaculture principles underpin the PA's approach to research with co-production of knowledge, a systems approach and participatory methodologies at the core. The PA views its network of practitioners as a ready-made research resource, they are referred to as the Practitioner Research Network (PRN) and are seen to have the potential to carry out small scale, technologically simple research into a wide range of topics, as one of the RAB explained:

"One characteristic of Permaculture is a large number of amateur practitioners in the field, in terms of practice the knowledge lives with the practitioners, so the structures we've created around research are intended to gather momentum, not reinvent the wheel, just do a few case studies... we have started some participatory trials, so people can try things at home and report in a format that we can aggregate". RAB member

Advocates also argue that Permaculture's systems approach is better equipped to tackle complex issues compared to single issue research communities. Permaculture is also seen to provide a novel approach and to offer freedom for researchers. The PA's ambition is to bring together the data available from a number of plots and to produce a published research evidence base.

"So a few years down the line we will put out paper to prove that Permaculture works and draw on evidence of applying principles to a plot from all continents, we will have 10-20 examples from the main ecosystems on the planet, we will go granular. We can offer evidence that Permaculture design works, the approach is working." RAB member

In this sense the PA are seeking credibility with AKS actors and looking for validation by using a common knowledge and language (peer reviewed publication). However, they are doing this on their own terms, using methodologies (small scale participatory trials of wheat and poly vegetable production) which some 
consider will not be acceptable because they will not be written up "scientifically". Furthermore the PRN lacks research skills and equipment and there are inadequate systems for measuring and recording, since the PA has not historically carried out research in the traditional sense. They anticipate problems in communicating their findings to the AKS due to their non-conventional approach and different views about what constitutes valid knowledge. One RAB member described the "difficulty of sticking your head above the parapet when you don't fit with the norm".

There are, however, areas of common understanding and knowledge between PKS and AKS research. Some respondents pointed to fundamental knowledge and principles shared between the mainstream and Permaculture KS (for example, an understanding of the carbon and nitrogen cycles). This is regarded as value-neutral knowledge that all systems could draw on as a baseline. Furthermore agro-ecology and systems thinking, central tenets of Permaculture, are recognised approaches in the AKS, and underpin many practices in mainstream farming. PKS and AKS actors are exploiting this potential commonality and the emerging interest in mainstreaming agro-ecological farming, by collaborating in partnerships to explore and access associated new streams of research and project funding.

\section{Discussion}

It is apparent that in each of main elements of the PKS there is a tension between internal facing activities which create and reinforce PKS boundaries, and external facing activities that cross these boundaries (Figure 1). Challenges to the AKS, that is activities that aim to persuade AKS actors that Permaculture is a suitable alternative to conventional agricultural, are often limited by boundaries around the PKS and AKS. However, tensions at the PKS-AKS interface arguably also lead to new opportunities and perspectives. Thus, the distinction drawn between challenging and invigorating is more subtle that previously hypothesised.

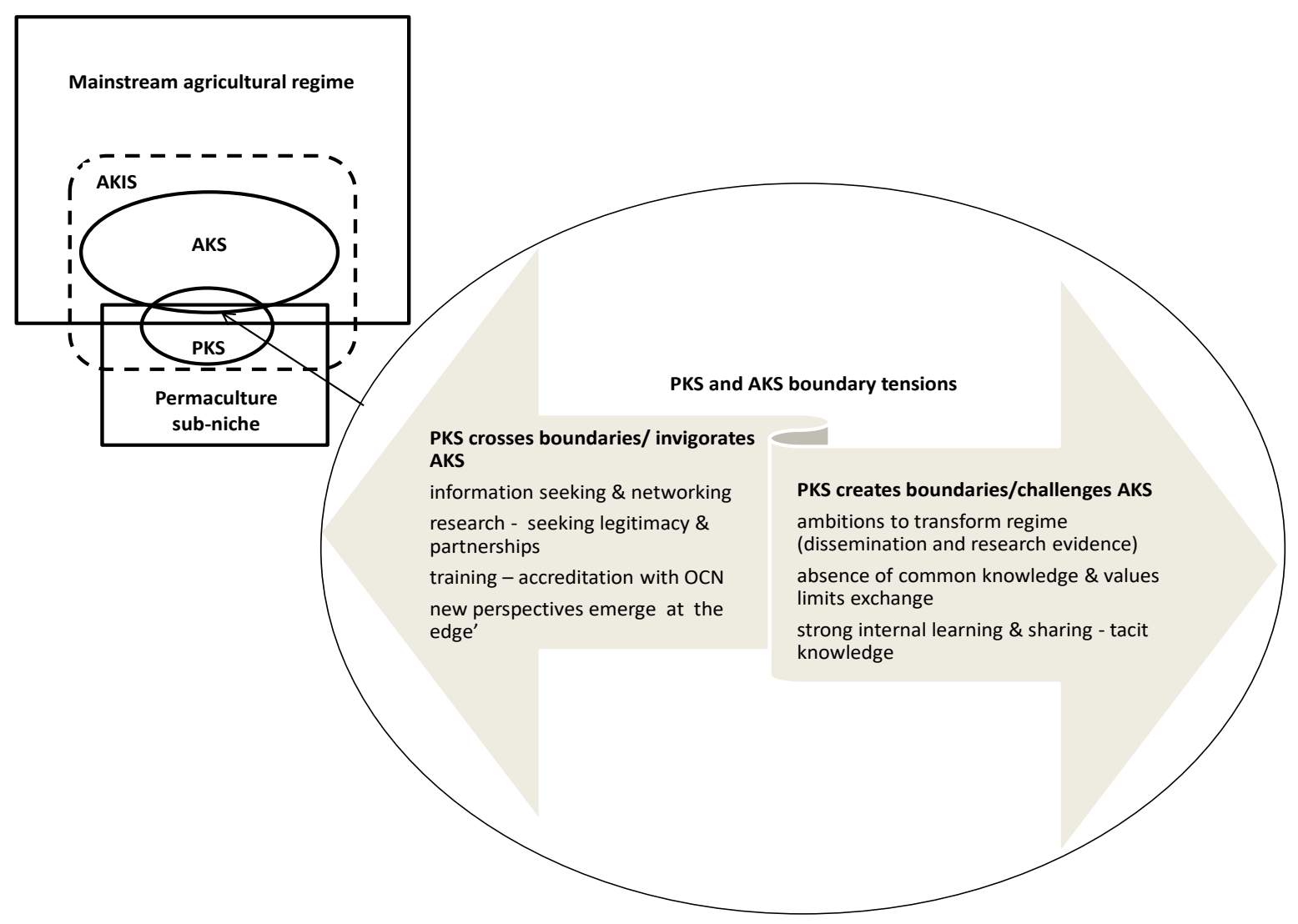


Figure 1: PKS and AKS boundary tensions in the context of the mainstream agricultural regime and Permaculture sub-niche

In many ways Permaculture and mainstream agriculture actors inhabit different worlds. Consequently, there are different views of what constitutes reliable or useful knowledge. Fundamentally, absence of common knowledge is a defining feature at the boundary between the respective knowledge systems. Every component of the PKS (individual learning, training, networking, dissemination and research) is centred around values, beliefs and co-produced through experience and mutual support. Such tacit knowledge is hard to standardise and codify and lacks a means of validating it according to the rules and assumptions of the AKS. This is further hampered by the perception from the outside that its knowledge base, and associated claims, lack rigour or evidence. Conversely, the universal knowledge of the AKS is not seen as relevant to the local context in which Permaculture actors operate, nor does it address the more complex problems they face at the systems level. Furthermore the commodified knowledge of the AKS is not always accessible to them.

In the PKS knowledge has a tendency to circulate internally and boundaries are maintained by shared internal understandings, invested knowledge, and the cognitive authority attached to personified knowledge and to Permaculture qualifications. Learning within the sub-niche is primarily an internal activity. However to counter this tendency Permaculture actors, both as individuals and as representatives of the PA, are starting to make connections and communicate with wider audiences 'outside' of the PKS boundaries. This inside/outside dynamic is being played out at all levels of the PKS as actors endeavour to, both maintain a cohesive PKS true to Permaculture values and ethos, and cross boundaries to challenge the regime, and seek information and legitimacy from the AKS. This interaction across the boundary, although still in the early stages, arguably provides opportunities for generative tension (Wenger, 2000) or creative abrasion (Powell and Grodal, 2005).

At the level of the individual, tacit learning strengthens internal ties. However, this is balanced by the weaker external ties some actors make by networking, disseminating and seeking information outside of the PKS boundary. These informal interactions seed connections across the PKS-AKS boundary. According to the idea of the "strength of weak ties", it is often people loosely linked to several communities who facilitate the flow of knowledge among them (Granovetter, 1973). Furthermore the importance of individual actors in the networking, negotiation, adaptation and translation processes in linking niches and regime has been demonstrated in other studies (Ingram et al., 2014b; Klerkx et al., 2010; Smith, 2007). At the PA level some staff members possess bridge building qualities and competences. They are not intermediaries, 'innovation brokers' or 'boundary spanners' (Swan et al., 2002) in the strictest sense, as their motivations and intentions are not value-free, nevertheless they are starting a dialogue with actors in the AKS. These people are able to operate in a different world and look for opportunities to advance the interests of Permaculture, to appropriate or reframe knowledge, ideas and associated resources from the AKS, and to enter partnerships where knowledge stocks might be translated into collectively shared or new knowledge, as described in other contexts (Tisenkopfs et al., 2015). At the same time they are also prepared to defend Permaculture and the validity of evidence to support it. As argued in this book (Steyaert et al., 2015) such intermediation cannot be described as a strictly functional role, as it involves navigating between different social worlds where values are at stake. In this case those navigating have done so by finding their own meanings to disputed concepts.

Reconciling the PA's internal training processes and legitimisation with its efforts to accredit the courses in the OCN further demonstrates efforts to balance strong internal learning with recognition in the wider community. This connection potentially exposes both the Permaculture and the wider education community to fresh perspectives. Furthermore the boundary interaction at the Permaculture-farming interface is providing new learning experiences (about novel practices: mob grazing, polyculture, agroforestry) for both mainstream and Permaculture producers. It is also providing common fora, such as farm walks and workshop events, where interaction can take place. The PA's efforts to seek legitimacy for Permaculture by publishing research according to the rules and routines of the AKS shows an attempt at bridge building. 
Such exchanges may help to create a common platform for knowledge sharing and potentially innovative research methodologies. However, using evidence from participatory research may be resisted by the AKS, as described by the organic movement who faced problems establishing scientific proof due to the ecological philosophy held by activists and the need to understand the full system (Smith, 2007).

Despite a tendency to operate in an alternative social learning system, the many ways in which Permaculture is interpreted, and the overlapping networks practitioners and PA staff engage in, do help to create learning opportunities across boundaries with the AKS. Thus, the communities are following one of their own design principles, the edge effect, an ecological concept that describes how there is a greater diversity of life at the boundary or interface between two biological communities (Holmgren, 2002; Turner et al., 2003). Tensions within the regime open up opportunities for niche boundary crossing as well. Respondents argue that as the different KS deal with common problems and goals, more partnership opportunities and synergies will emerge. The need for integrated approaches to tackle complex problems of the modern food system can also be seen as a window of opportunity for the systems approach of Permaculture research, as one participant remarked Permaculture's "time has come". Thus the PKS can potentially strengthen the AKS by bringing in new perspectives and opportunities for innovation.

\section{Conclusion}

Sustainable transitions are inevitably disputed and controversial because they lead to confrontations of systems of knowledge, interest and value. This is revealed in this research which describes the boundary between the PKS and the AKS where differing sets of beliefs and values, epistemologies, ways of facilitating and supporting learning, approaches to research and modes of development confront each other. The interaction between the knowledge systems is characterised by the tension between the strong learning processes which reinforce the PKS boundaries and the tentative external links being forged in an attempt to connect across PKS-AKS boundaries. This tension reveals the complex nature of processes involved. Rather than a dichotomy of the PKS challenging or invigorating the AKS, there is a subtle set of overlapping processes that involve some contested diffusion of Permaculture ideas into the AKS, as well as some potential co-learning and emergence of fresh perspectives and opportunities for innovation

Scholars propose the need for boundary work to negotiate interactions between different knowledge systems while maintaining the integrity of each knowledge system. Such work would enable the interactional space between PKS and the AKS to develop further. It is argued that such activities could be fostered in an AKIS, and so offer a more comprehensive concept for accommodating the newly emerging coalitions of actors, which are pursuing different, sometimes competing goals (EU SCAR, 2012).

However, the essence of this boundary work, and who performs it, have not been widely considered in a situation where niche KS are linked to such transformative ambitions for the food system. In such situations intermediaries between KS, rather than a purely functional role of communicating objective knowledge, have to negotiate, interpret and represent different values, epistemologies and visions for the future. In the case of Permaculture these intermediary processes have been ad hoc and opportunistic and shaped by individuals; there have been no formal attempts to align actors' cognitive frames, perceptions and motivations. The relative merits of such emergent and adaptive interactions, compared to formalised approaches, needs further consideration in the context of sustainable transitions.

Acknowledgement: We would like to acknowledge and thank all the stakeholders from the Permaculture community who participated in this research.

\section{References}

Barbier, M. ,Elzen, B., 2012. System Innovations, Knowledge Regimes, and Design Practices towards Transitions for Sustainable Agriculture. INRA - Science for Action and Development, E-book, Paris, 86-100. 
Berkes, F., 2009. Evolution of co-management: role of knowledge generation, bridging organizations and social learning. Journal of Environmental Management 90 (5), 1692-1702.

Boch, B., 2012. Social innovation and sustainability: how to disentangle the buzzword and its application in the field of agriculture and rural development. Studies in Agricultural Economics 114, 57-63

Brunori, G., Barjolle, D., Dockes, A., Helmle, S., Ingram, J., Klerkx, L., Moschitz,, H., Nemes, G., Tisenkopfs, T., 2013. CAP Reform and Innovation: The Role of Learning and Innovation Networks. Eurochoices 12 (2), 27-33.

Cash, D., Clark, W., Alcock, F., Dickson, N., Eckley, N., Jäger, J., 2003. Knowledge systems for sustainable development. Proceedings of the National Academy of Sciences 100 (14), 8086-8091.

Carlile, P. R., 2004. Transferring, Translating, and Transforming: An Integrative Framework for Managing Knowledge Across Boundaries. Organization Science, 15 (5), 555-568.

Castree, N., 2005. Nature. Routlegde, London.

Clark, W.C., Tomich, T. P. van Noordwijk, M., Guston , D., Catacutan, D., Dickson, N. M., McNie, E., 2011. Boundary work for sustainable development. Natural Resource Management at the CGIAR. Proceedings of the National Academy of Sciences August 15, 2011.

Elzen, B. van Mierlo, B., Leeuwis, C., 2012. Achoring of innovations; Assessing Dutch efforts to harvest energy from glasshouses. Environmental Innovations and Societal Transitions 5, 1-8.

EU SCAR, 2012. Agricultural Knowledge and Innovation Systems in Transition - A Reflection. Paper. Brussels: European Union

EU SCAR, 2014. Agricultural Knowledge and Innovation Systems Towards 2020. An orientation paper on linking innovation and research. Luxembourg Publications Office of the European Union

Garforth, C., Angell, B., Archer, J., Green, K., 2003. Fragmentation or creative diversity? Options in the provision of land management advisory services. Land Use Policy 20, 323-333.

Geels, F., 2004. From Sectoral Systems of Innovation to Socio-Technical Systems. Insights About Dynamics and Change from Sociology and Institutional Theory, Research Policy, 33, 897-920.

Geels, F., Schot, J., 2007. Typology of sociotechnical transition pathways. Research Policy 36, 399-417.

Goodman, D., 2004. Rural Europe redux? Reflections on alternative agro-food networks and paradigm change. Sociologia Ruralis, 44 (1), 3-16.

Granovetter, M.S., 1973. The Strength of weak ties. American Journal of Sociology 78 (6), 1360-1380.

Hermans, F, Klerkx, L., Roep, D., 2015. Structural conditions for collaboration and learning in innovation networks: using an innovation system performance lens to analyse Agricultural Knowledge Systems. Journal of Agricultural Education and Extension 21 (1) 35-54

Holmgren, D., 2002. Permaculture: Principles and Pathways beyond Sustainability. Hepburn, VIC: Holmgren Design Services.

Holmgren, D., 2005. The End of Suburbia or the Beginning of Mainstream Permaculture? Permaculture Magazine 46, 7-9. Creek, Tasmania.

Home, R. Rump, N., 2015. Evaluation of a multi-case participatory action research project: The case of SOLINSA. Journal of Agricultural Education and Extension 21 (1), 73-89.

Hoogma, R., Kemp, R., Schot, J., Truffer, B., 2002. Experimenting for sustainable transport: the approach of strategic niche management. Spon Press, London, UK.

Ingram, J., Curry, N., Kirwan, J., Maye, D., Kubinakova, K., 2013. WP4 Synthesis Report. SOLINSA project Deliverable 4.2a, October 2013. Available at www.solinsa.net

Ingram, J., Curry, N., Kirwan, J., Maye, D., Kubinakova, K., 2014a. Learning in the Permaculture Community of Practice in England: An Analysis of the Relationship between Core Practices and Boundary Processes. Journal of Agricultural Education and Extension 20 (3), 1-16.

Ingram, J., Curry, N., Kirwan, J., Maye, D., Kubinakova, K., 2014b. Interactions between niche and regime: an analysis of learning and innovation networks for sustainable agriculture across Europe. Journal of Agricultural Education and Extension 21 (1), 55-71.

Kemp, R., Schot, J., Hoogma, R., 1998. Regime shifts to sustainability through processes of niche formation: the approach of Strategic Niche Management. Technology Analysis and Strategic Management 10 (2), 175-195.

Klerkx, L., Aarts, N., Leeuwis, C., 2010. Adaptive management in agricultural innovation systems The interactions between innovation networks and their environment. Agricultural Systems 103, 390400 . 
Knickel K., Brunori, G., Rand, S., Proost, J., 2009. Towards a Better Conceptual Framework for Innovation Processes in Agriculture and Rural Development: From Linear Models to Systemic Approaches. The Journal of Agricultural Education and Extension, 15 (2), 131-146.

Leeuwis, C.. van den Ban, A., 2004. Communication for Rural Innovation: Rethinking Agricultural Extension. Oxford: Blackwell Science.

Lockie, S., 2006. Networks of Agri-Environmental Action: Temporality, Spatiality and Identity in Agricultural Environments. Sociologia Ruralis, 46 (1), 22-39.

Marsden T., 2004. The quest for ecological modernisation: re-spacing rural development and agri-food studies. Sociologia Ruralis, 44 (2), 129-146.

Mollison, B., 1988. Permaculture - A Designer's Manual. Tyalgum, New South Wales, Tagari Publications.

Mollison, B., Holmgren, D., 1978. Permaculture One. A Perennial Agriculture for Human Settlements. Melbourne: Trasworld.

Morgan, S. L., 2011. Social Learning among Organic Farmers and the Application of the Communities of Practice Framework. Journal of Agricultural Education and Extension 17 (1), 99-112.

O'Kane, M. P., Paine, M. S., King B. J., 2008. Context, Participation and Discourse: The Role of the Communities of Practice Concept in Understanding Farmer Decision-Making. Journal of Agricultural Education and Extension 14 (3), 187-201.

Perkins, R., 2012. Why permaculture needs accurate data and measurement to persuade the mainstream. Permaculture. Wednesday, 2nd May 2012 http://www.permaculture.co.uk/articles/whypermaculture-needs-accurate-data-and-measurement-persuade-mainstream [viewed November 6 2014]

Permaculture Association, 2011a. Permaculture Association Britain Research Strategy 2010 - 2014. Leeds: Permaculture Association.

Permaculture Association, 2011b. Strategic Plan. 2011-2018. Leeds: Permaculture Association.

Permaculture Association, 2011c. The Origins of Permaculture. http://www.permaculture.org.uk/sites/default/files/page/education/2011pack-web.pdf [viewed 7 may, 2014]

Powell, W., Grodal, S., 2005. Networks of innovators. In: Fagerberg, J., Mowery, D. C., Nelson., R. (eds), The Oxford Handbook of Innovation. Oxford: Oxford University Press, pp. 56-85.

Roberts, J., 2006. Limits to Communities of Practice. Journal of Management Studies 43 (3), 623-639.

Robinson, C. J., Wallington, T. J., 2012. Boundary work: engaging knowledge systems in comanagement of feral animals on Indigenous lands. Ecology and Society 17(2), 16.

Roling, N., Engel, P., 1991. The development of the concept of agricultural knowledge and information systems. In: Rivera, W. and Gustafson, M. (Eds), Agricultural Extension: Worldwide Institutional Evolution and Forces for Change. Elsevier, Amsterdam, 125-137.

Roling, N., Wagemakers, M. A. E. (Eds.), 2000. Facilitating Sustainable Agriculture: Participatory Learning and Adaptive Management in Times of Environmental Uncertainty. Cambridge: Cambridge University Press.

Seyfang, G., Haxeltine, T., 2012. Growing grassroots innovations: exploring the role of community-based initiatives in governing sustainable energy transitions. Environment and Planning C: Government and Policy 30, 381-400.

Seyfang, G., Smith, A., 2007. Grassroots Innovations for Sustainable Development: Towards a New Research and Policy Agenda. Environmental Politics 16, $584-603$.

Smith, A., 2007., Translating Sustainabilities between Green Niches and Socio-Technical Regimes. Technology Analysis \& Strategic Management 19 (4), 427-450.

Smith, A., Raven, R., 2012. What is protective space? Reconsidering niches in transitions to sustainability. Research Policy 41, 1025-1036.

Steyaert, P., Barbier, M., Cerf, M., Levain, A., Loconto, A., 2015. Role of intermediation in the management of complex socio-technical transitions. This book

Swan, J., Scarbrough, H., Robertson, M., 2002. The Construction of Communities of Practice in the Management of Innovation. Management Learning 33, 476-496.

Tagliaventi, M. R., Mattarelli, E., 2006. The Role of Networks of Practice, Value Sharing, and Operational Proximity in Knowledge Flows between Professional Groups. Human Relations 59 (3), 291-319. 
Tisenkopfs, T., Kunda, I., Sumane, S., Brunori, G., Klerkx, L., Moschitz, H., Berti, G., 2015. Learning and innovation in agriculture and rural development: the use of the concepts of boundary work and boundary objects. The Journal of Agricultural Education and Extension 21 (1), 13-33.

Turner, N., Davidson-Hunt, I. J. and O'Flaherty, M., 2003. Living on the Edge: ecological and cultural edges as sources of diversity for social-ecological resilience. Human Ecology 31 (3), 439-461.

van Kerkhoff, L., Szlezak, N., 2010. The role of innovative global institutions in linking knowledge and action. Proceedings of the National Academy of Sciences of the United States of America, 200900541.

Veteto, J. R., Lockyer J., 2008. Environmental Anthropology Engaging Permaculture: Moving Theory and Practice Toward Sustainability. Culture \& Agriculture 30, 47-58.

Wenger, E., 2000. Communities of Practice and Social Learning Systems. Organization 7 (2),225-246.

Whatmore, S., Thorne, L., 1997, Nourishing Networks: Alternative Geographies of Food. In: Goodman D and Watts M.J. (Eds.), Globalising Food. Agrarian Questions and Global Restructuring, Routledge, London/New York pp. 287-304. 


\title{
Multi-actor transition arenas in the fruit breeding system: a pathway towards sustainability, or a new veil over lasting power relationships?
}

\author{
Claire Lamine ${ }^{1}$
}

\section{Abstract}

This study is based on a socio-historical analysis of changes in the French peach and apricot industry since the 1960s, and focuses on the place of genetics and cultivar breeding in this development. The chapter describes the shift from an innovation model based on production criteria, to one based on marketing criteria (product segmentation, fruits' ability to be transported and stored, fruit appearance), and explores the consequences of this shift. Although modern cultivars are often disappointing for consumers in terms of taste and not always a good choice neither for the environment nor for the producers in the long term, a nagging question is why societal pressure for sustainability has continuously failed in significantly impacting the breeding system? Based on an analysis of recent changes in public research and in cultivars' evaluation and registration, with a focus on the controversies in diverse public arenas, we develop a nuanced answer to this question: due to the strong inertia (partly as a result of long lead times) and prevailing power relationships in the fruit breeding industry, a combination of advocacy and co-construction strategies within "mainstream", "alternative" and "transition" arenas, could provide a good starting point for collective pathways towards sustainability.

Keywords: Socio-Historical Analysis, Sustainable Agriculture, Genetics and Breeding, Pragmatic Sociology, Transition Arenas

\section{Introduction}

The peach and apricot industry, which will be our focus here, like the fruit sector in general, is characterised by intense international competition and strong marketing constraints that are both contradictory to and interdependent with consumers' and society's expectations. For example, while retailers impose diverse constraints regarding fruits' appearance and storage properties, which are achievable only with inputintensive agricultural practices, consumers prefer a fruit that is free of pesticide residues and society at large increasingly demands a more ecological type of agriculture as well as variation in landscapes. In the region under study, the middle Rhône Valley (Drôme and Ardèche, two French départements), the economic context of repeated and then structural crises since the early 1990s, combined with sanitary problems such as the development of plum pox virus - a disease due to a quarantine virus which required the infested trees in peach orchards to be uprooted (although its actual direct impact seems to be quite limited) ${ }^{2}-$

\footnotetext{
${ }^{1}$ INRA Ecodéveloppement, Avignon, France. Email: Claire.Lamine@avignon.inra.fr

2 The decrease in the peach orchard surface area is only partly directly due to the plum pox virus through production damages and uprooting obligations (set up by public sanitary policies from 2006 onwards). The institution in charge of the control of this disease estimates that since 2000 , around $25 \%$ of uprooted areas were actually uprooted because of the legal obligations set up by public sanitary policies from 2006 onwards (FDGEDON26, in Gillet and Schost, 2013. "Bilan sanitaire et économique et analyse du dispositif de lutte contre l'agent causal de la maladie de la Sharka", CGAAER, report $\left.n^{\circ} 12164,53 p.\right)$. However, its indirect impact has probably been higher and still has to be assessed
} 
caused a sharp decrease in the total surface area of peach production. In the Drôme alone, the peach orchard surface area decreased by about 66\%, from 6400ha in 2000 to 2100 ha in 2010 . Peaches have been partially replaced by apricots on some farms, and in the same period apricot orchards roughly maintained the same surface area (7,000ha and 6,400ha in 2000 and 2010, respectively, according to the RGA - Recensement Général Agricole, 2010).

This chapter is based on the first results of an ongoing research project which studies the past, current and possible future transition pathways in the peach and apricot industry. This research is carried out by an interdisciplinary network of scientists (sociologists, economists, agronomists and geneticists), using an integrated approach that aims at linking breeding issues with production and marketing ones, and sociohistorical perspectives with more prospective ones. ${ }^{1}$ This chapter is based on the first phase of the project, devoted to a socio-historical analysis of the changes in this industry since the 1960s and more specifically to the place of genetics and cultivar breeding in this trajectory.

The current breeding strategies focus mainly on improving yields and fruit's technological quality for packaging, storage and transport, and on creating "varietal series" in order to offer retailers continuity in each product type (see below) over a production period which has been extended from 3 to nearly 6 months for peach production. These objectives neglect the environmental aspects (even if substantial work has been done for decades on resistant cultivars, as we will see), and lead to create cultivars and then market fruits that are easy to store and transport, but are often disappointing in terms of taste and nutritional quality. In a context of increasingly stringent production constraints, producers have to keep up with the constant renewal of cultivars, and grow those that will allow them to remain on the market. Why have these changes occurred and why have public policies not been able to act effectively in this respect? Is there any sign of change in recent years? These are the main empirical questions that will be addressed in this chapter.

This chapter rests on a framework (presented in Section 1) that combines a socio-historical analysis, based on key concepts stemming from evolutionary economics and MLP frameworks (the notions of landscape pressures, socio-technical trajectories and interdependencies within the socio-technical system) with a more ethnographical analysis of ongoing changes, based on an approach anchored in the French pragmatic sociology (analysis of enrolment processes and alliances, and of controversies). The chapter first presents the trajectory of the peach and apricot socio-technical system and describes the shift from a genetic innovation model based on criteria linked to the production stage, to an innovation model based on marketing criteria (fruits' abilities to be transported and stored, much more than taste) (Section 2). The next section analyses recent and ongoing changes, interactions and controversies within both public research and fruit cultivars' evaluation and registration procedures, as both are our focus here (Section 3), and finally the emergence of a few new arenas linking these two fields. This leads to a balanced answer to the core question, i.e. why have societal pressures for sustainability continuously failed in really impacting the breeding system so far, and are there any signs of recent change? Based on this analysis of changes, interactions and controversies in several arenas, my suggestion is that despite (and maybe because of) a strong inertia (largely due to long growing and breeding time spans) and lasting power relationships in the fruit breeding industry, a double combination of advocacy and co-construction strategies in mainstream, alternative but also new transition arenas might be a basis for pathways towards sustainability.

and analysed, an issue which we plan to tackle within our ARDU research project (Métaprogramme SMASH, INRA) in 2015.

${ }^{1}$ Prunus project (Programme Pesticides, MEDDE), 2013-2015. For further details on this context, see Lamine et al., $2014 a$. 


\section{State of the art and theoretical framework}

In the social sciences, the literature about the fruit industry rarely considers breeding issues, as we will see, which makes it necessary to turn to a literature mostly based on annual plants breeding issues (rather than perennial plants such as fruit trees), and of course to take into account the crucial difference between perennial and annual crops, due to the growing and breeding time spans.

Regarding the fruit sector, social scientists have mainly investigated the combined processes of concentration, industrialisation and standardisation within fruit production and distribution, along with the changes in modes of coordination in the food chain. Theoretically, this work has been based on Actor Network Theory (Collet and Mormont, 2003) and/or the Sociology of Organisations (Dubuisson-Quellier et al., 2006; Bernard de Raymond, 2013; Praly et Chazoule, 2013). As the need for a flexible and fast supply of fruit and its transport and distribution to the market requires specific organisational forms, these authors study the types of coordination between the actors, and how new components or entities enter the system. ${ }^{1}$ They focus primarily on the production and marketing stages and actors, and do not investigate some other important components of the socio-technical system, such as genetics and breeding strategies, which are our focus here.

In the social sciences, or within interdisciplinary approaches, breeding issues have so far mainly been addressed in relation to annual crops, and from two main perspectives: either critical perspectives, which focus on the negative impacts of globalisation over the last century or decades; or research-action perspectives based on current participatory plant breeding projects and networks. ${ }^{2}$ Within the first kind of perspective, some authors have adopted the political economy framework of "food regimes" and/or "accumulation by dispossession" to analyse and denounce farmers' loss of their "seed sovereignty", especially in the global South (Kloppenburg, 2010). Other authors have developed a historical analysis of the French breeding system and of the role of power relationships in impeding the development of more environmentally-friendly breeding schemes as well as in the progressive exclusion of farmers interests (Bonneuil et Hochereau, 2008; Bonneuil et Thomas, 2009). Studying recent changes in seed regulations and intellectual property rights over seeds in Canada, B. Müller has similarly shown that these regulations have become the tools of multinational seed corporations and that "the governance of seeds has shifted from an emphasis on controlling the quality of seed, in the interest of farmers, to rendering each seed identifiable, in the interest of the owner of the intellectual property" (Müller, 2014: 40). Vanloqueren and Baret (2008) have used the evolutionary economics perspective on technological trajectories and its notions of lock-in effects or path-dependency to study why multi-resistant wheat cultivars (available since the late 1980s) were slow to develop commercially. They argue that the "yield cost" of these multi-resistant cultivars, often put forward by some specialists, cannot be the only explanatory factor, and that this situation is the consequence of a set of intertwined factors at different levels of the agri-food system (farmers, market, extension services, research, public regulations and policies), and of conflicts of interest between its main actors. The same authors have also applied the concepts of technological paradigms and trajectories to the larger case of agricultural science and technology, to analyse the factors that influence research choices and to explain why genetic engineering as a technological paradigm has influenced agricultural research much more successfully than has agro-ecology, despite the recommendations of several international scientific assessments (Vanloqueren and Baret, 2009).

Within the second type of perspective, Chiffoleau and Desclaux (2006) have combined their respective sociology of science and genetics backgrounds to argue, in the case of durum wheat, that conventional breeding methods do not generally provide fitting responses to the diversity of both environmental

\footnotetext{
${ }^{1}$ In terms of the economy of conventions (Thévenot, "Le régime de familiarité; des choses en personnes"), these phenomena can also be analysed as a change in the convention which links the actors, and as a shift from a domestic convention to a market one, from a regime of familiarity to an industrial regime characterized by long-distance transport and standardized quality assessment.

${ }^{2}$ Here we focus on plant genetics; social sciences literature dealing with animal breeding and genetics might well have different characteristics.
} 
conditions and end-users' needs. This has led them to develop a participatory plant breeding approach bringing together researchers, producers and firms and leading to the identification of common relevant criteria for breeding schemes. These authors question the ability of "conventional" breeding programmes to ensure agricultural sustainability, because these programmes fail to take into account environmental interactions, especially if the socio-economic dimensions of the "environment" are to be taken into account, including farms' viability or social interest in local varieties, for example. All these authors and, more generally, most studies focus on the case of cereals, while the case of tree fruit breeding, which differs considerably in many respects (and especially the time span of fruit growing and breeding), has attracted little interest from social scientists - with the exception of rare interdisciplinary approaches such as one regarding the case of apple cultivars (Vanloqueren et Baret, 2004) which shows that marketing criteria and strategies may explain to some degree the limited success of non-transgenic resistant apple cultivars.

In this study on the place of genetics and cultivar breeding in the peach and apricot industry, the framework used combines a socio-historical approach inspired by the evolutionary economics perspective on technological trajectories and the MLP (Multi-Level Perspective) theory, with a more ethnographical analysis of ongoing changes within the breeding system more specifically, focusing on the analysis of enrolment processes and alliances and of controversies, and anchored in the French pragmatic sociology. ${ }^{1}$ The (agrifood) socio-technical system, which is the key concept here, is defined as the network of actors, rules and artefacts involved in the production, processing, distribution and consumption of food (farmers, market operators, extension services, inputs - and seed - industry, research, public regulations and policies, civil society). This work builds on previous research that, based on the application of a path-dependency approach to the case of plant protection practices in wheat and apple production, demonstrated through a socio-historical analysis the coherence of this socio-technical system, and the irreversibilities created by the specific and interdependent trajectories of its different components, which impede the development of more sustainable plant protection practices (Lamine and al., 2010; Ricci et al., 2011). In previous papers we have discussed the interdependencies and lock-in effects within this socio-technical system that go along with a "regime" shift from a regime of proximity, prevailing until the early 1980s, to a regime characterised by both distance and intensification (Lamine et al., 2014, a, b), as I will summarise it in the following section. In this chapter on the breeding system, I focus on recent changes in public research and in the procedures of fruit cultivars' evaluation and registration, and on current debates and controversies in several public arenas. I studied a number of specific arenas dealing with fruit genetic research and in the registration and evaluation of cultivars. This study includes a description of the stakeholders involved in these arenas (as well as those who were not), the components of the socio-technical system that were taken into account (or not), and the debates and controversies between these stakeholders.

This sociological analysis is built on a variety of sources, notably (1) professional, technical and scientific documents (lists of varieties and technical guidelines, commissions' and working groups' reports, scientific projects, etc.); (2) twenty interviews with key actors (researchers, members of diverse commissions, foodchain intermediaries, farmers with collective responsibilities, advisors) carried out in 2013 and 2014; (3) the analysis of a qualitative survey with 35 farmers; ${ }^{2}$ (4) participation in several institutional bodies involved in agricultural innovation, and (5) stakeholders' meetings organised by various actors within the fruit industry. The different meetings of our Prunus project group, which includes not only the scientific team, but also six other members who embody different components of the socio-technical system (farmers, advisors, market intermediaries, sanitary bodies), were an important place for feedback. This group discussed, and re-constructed parts of the socio-historical analysis in the second section, and that is further

\footnotetext{
${ }^{1}$ Barthe et al., 2001; Chateauraynaud, 2002.

2 Through two master thesis supervised by C. Lamine, S. Penvern and S. Simon, members of our Prunus research project: (1) Ruynat L. (2014). Analyse des pratiques de protection actuelles en verger de Prunus (pêcher, abricotier) en Rhône-Alpes: mise en perspective par rapport aux trajectoires d'exploitation et potentiel de progrès pour réduire l'utilisation de pesticides. Mémoire de fin d'études, diplôme d'Ingénieur Agronome, Spécialité Production Végétale Durable, Montpellier SupAgro, 49 p. ; and (2) Kouchner C. (2014). Analyse des stratégies de protection dans un contexte de changement d'espèce fruitière Prunus (pêcher, abricotier) en Rhônes-Alpes : mise en perspective par rapport aux trajectoires et influences du système socio-technique. Mémoire de fin d'études, diplôme d'Ingénieur Agronome, Spécialité Protection des Plantes et Environnement, AgroParisTech, 73 p.
} 
developed in two other papers, of which one has been co-authored by all these partners (Lamine et al., $2014, a, b)$.

\section{The socio-technical life of peaches and apricots: how breeding strategies are embedded in a wider system}

Based on analyses of the changes over the last five decades at the different levels of the socio-technical system of the peach and apricot industry, four phases have been identified (Lamine et al., 2014b): ${ }^{1}$ This shows that the main changes in this socio-technical system have led to a profound redefinition of breeding strategies.

- Until the 1970s, the peach and apricot industry was strongly structured by close and direct relationships between its stakeholders. Marketing channels were rather short in terms of number of intermediaries and time, and these intermediaries, such as wholesalers or brokers, were thoroughly familiar with the products, their specific properties, and the various cultivars. In those days, research and experimentation seemed to be relatively close to producers, as we will see later on. Breeding strategies were mostly centred on yield and production regularity.

- As in other food industries, the 1980s were the decade of the "intensification turn" (Lamine, 2011), characterised in this case by a significant extension of cultivated areas (partly to new regions and largely due to large public land planning projects such as Rhône Valley dams), an extension of the production period, and a strong increase in the diversity of grown cultivars. At the same time, the corporate retailing sector was getting off the ground. Breeding criteria were adapted to this new context and started to focus more on an extension of the production period (early and late cultivars), while experimentation was reorganised around regional "stations" which mainly worked on intensive production systems, in close cooperation with the advisory system.

- In the early 1990s, the fruit sector entered a structural crisis due to the concentration of the retailing sector and its consequences, and to the growing competition of imports, mainly from Spain (after it joined the European Community) and Italy. To adapt to this new context, producers had to provide retailers with a safe and consistent flow of fruit over a longer season. This led the breeding industry to pursue its strategy of developing "varietal series", to guarantee enough continuity in each type of product over this extended season.

- In the current period (the past 10 years), there is clearly both an intensification of the previous trends and a diversification of farming and marketing systems. This makes many stakeholders wonder whether the economic, social and environmental sustainability of their industry may rely on a combination of complementary pathways. Regarding genetic innovation, while in the early 2000s French public genetic research was profoundly restructured to focus on a limited range of species, and to prioritise fundamental research, more recently an apparently contradictory trend has appeared, with the intention to take more fully into account stakeholders' expectations, as well as the impacts of innovations (as we will see in the third section).

We recognise in this trajectory the combined processes of intensification (of production techniques), of concentration (of production, and even more so of the retailing sectors), and of a lengthening of the distance from production to consumption, which characterise the whole food sector and have been amply described in the literature (Allaire et Boyer, 1995; Friedmann et McMichael, 1989). As a result of these processes, Allaire and Wolf 2004) describe two emerging paradigms within food innovation: the first one corresponds to the segmentation of products, mainly within supermarkets and long food chains, and the second one to the valorisation of strong identities, mainly in short food chains, like farmer markets.

In previous papers (Lamine et al., 2014 a, b) we have shown that this socio-technical system and its trajectory are determined by a range of interconnected interdependencies that generate lock-in effects: interdependencies between land planning, on the one hand, and the extension of cultivated areas along with

\footnotetext{
${ }^{1}$ This paper presents the 4 periods in detail and also underlines important differences between the two species - peach and apricot - which are beyond the scope of this chapter.
} 
the intensification of (mainly irrigated) agriculture (in the 1970s and 1980s), on the other; interdependencies between the restructuring of the advisory system and this intensification of practices; interdependencies between the organisation of marketing and the supply of cultivars ("varietal series"); and so on. For instance, from the 1990s onward, because producers were increasingly organised into producers' groups to market their fruits (a requirement to be eligible for EU-related public subsidies), they were urged to adopt the new "varietal series" (as well as to abandon some old varieties). In fact, they had to choose their cultivars from a more or less formal list drawn up by their groups and cooperatives to satisfy the market intermediaries and retailers' demands of storable and good-looking fruits, as well as of continuity during the season. These lists appear as obligatory passage points impeding transitions towards more sustainable practices (Callon, 1986, Wiskerke and Oerlemans, 2004). These structures also often set up a graduated price policy supposed to incite producers to plant the "best" cultivars. Considering the long time span which characterizes fruit growing, and the rapid changes on the market of both fruits and cultivars, such incentives tend to make producers more vulnerable. As recognized one of these cooperative's director "This generates instantaneous reactions on things that are going to be planted for a long time, which is actually a bit contradictory."]

Of course, such interdependencies (and others) not only link one element of the socio-technical system to another, they actually tie all the elements together. The increasing competition in retailing and production, due to these combined processes of intensification, concentration and distance, have progressively led to a segmentation of the product types (white/yellow peach, peach/ nectarine, etc.), to an extension of the peach and apricot season and production period (from 3 to nearly 6 months for peach production), and to a redefinition of quality criteria and, in turn, of breeding strategies, which will be our focus here.

Whereas, until the 1950s, peaches from the middle Rhône Valley were picked ripe, carefully packed and quickly transported directly to the big markets and cities where they would be sold just one day after being picked (Praly, 2010), they are currently picked unripe and often sold several days later, after transiting through several platforms. To adapt to these changes, quality criteria imposed on producers by the marketing operators (often through their producers' groups and cooperatives) were progressively redefined. The aim was to adapt to long distances and to multiple and delayed steps in the marketing process. It was also to satisfy what were considered to be consumers' expectations, such as colour (today apricots, for example, are considered more attractive if they are not only orange but also have a nice blush of red). ${ }^{2}$ The main criteria have turned out to be resistance to shocks, shelf life, firmness, appearance (including fruit grade and colour), and taste, in addition to the usual production criteria (mainly yield and regularity). The changes in these criteria also coincide with the technological development of measurement tools that allow products to be assessed "objectively", and to be assigned to specific categories (with set prices). For example, as taste is a composite criterion that is difficult to assess objectively, it has progressively been codified into measurable criteria such as sugar content or acidity, along with the development of such measurement tools. These criteria have been imposed on producers through market intermediaries and material procedures such as contracts and fruit control at the collecting stage. In the vocabulary of the Actor-Network Theory, market demands and criteria redefine growers' practices through a process of alignment of a series of practical intermediaries and technical instruments (Callon, 1986), such as those used to grade the fruits or to measure the sugar content or firmness (Haynes et al., 2010).

These changes in the socio-technical system (segmentation of product type, extension of the production period, redefinition of quality criteria) have not only impacted the production and marketing sectors, but have also redefined the objectives of breeding strategies over the past decades. Like the fruit industry in general, the private breeding industry is also subject to powerful processes of competition and concentration and has to put new cultivars on the market as quickly as possible. It was urged to adapt its innovation schemes to these new criteria, and to develop early and late cultivars and "varietal series" to offer retailers continuity in each product type over the extended season. Over the last decades, along with

\footnotetext{
${ }^{1}$ Cooperative's director, interviewed during a former research project (PSDR), 2003.

${ }^{2}$ In a former project we showed that such statements can be challenged, as consumers buy what they actually find and many of them buy less "perfect" fruit on market stalls or through direct sales. Consumers could be much more flexible in their fruit choice than what supermarket representatives suggest, as shown by some results of the focus groups that we organized around this issue (Haynes et al., 2010).
} 
the process of specialisation and intensification, breeding strategies increasingly focused on improving not only yield, but also suitability of fruit for packaging, storage and transport, and on extending the production period (from 3 to 6 months for peach production) for each "segment" through these varietal series. This led to the current situation of an endless "race for innovation", where $80 \%$ of the peach cultivars proposed for registration and development are removed before the end of their evaluation phase. Most fruit growers complain about this race ("when we see a cultivar in the trials and they tell us there is a limited number of available trees, we are tempted. We believe in an Eldorado and we pay for it sooner or later, as the resistance to disease has not been evaluated', as puts one of them), and about the disappointing taste of the new cultivars ("we have too many cultivars, and many are awfully tasteless" as says another one). ${ }^{1}$

We can therefore say that there was a shift from a genetic innovation model based on objectives and criteria linked to the production stage (regularity, yield), to an innovation model based on the marketing stage and the characteristics of the product (product type, sugar content, acidity, appearance and firmness), including its ability to withstand transport and storage (e.g. resistance to shocks, post-harvest behaviour). These objectives and criteria led to the creation and then marketing of fruits that were easier to store and transport, but disappointing for consumers in terms of taste and quality. Environmental criteria such as adaptation to low-input practices have also been neglected within breeding strategies. Many new cultivars, especially the late harvest ones, require more intensive practices and pesticide use, because the extension of the production period requires them to be cultivated well outside the species' "natural" season.

\section{$4 \quad$ Why 'landscape pressures' for sustainability could not influence breeding strategies}

If we apply a key concept of Multi-Level Perspective (MLP), notably the notion of regime, all these changes in the norms and rules governing the peach and apricot socio-technical system, in the modes of coordination between its actors, and in the predominant innovation model in the breeding sector, suggest a regime shift from a regime of proximity, prevailing until the early 1980s, to a regime characterised by both distance and intensification, as we have seen above. However, this current regime is increasingly challenged by emerging niches or new technological innovations and is subject to landscape pressures (two other key concepts of MLP), to which we will now turn to examine their possible effects.

Since the 1960s, successive sanitary problems have affected the peach and apricot industry, threatening it with significant losses in production and, in the case of some diseases (such as plum pox virus), with obligations to uproot trees in orchards. These difficulties, combined with the lasting economic crisis and the broader societal demand for sustainability, could have prompted the stakeholders to profoundly redefine their priorities. Yet, this has not been the case. Why have this economic and sanitary context, and what most policy makers and economic stakeholders call the "societal demand", not strongly influenced fruit breeding strategies? A first and partial answer is that, until recently, more attention was given to other challenges, such as food security and food traceability, than to chemical inputs reduction. In France, despite the presence of critics over the decades in civil society (Jas, 2007), it was only very recently that the societal demand for more environmentally-friendly practices started to have some influence on public policies. It was not until 2005, that a collective scientific initiative was taken to assess current practices and pathways for pesticide reduction ("Expertise Pesticides"; Aubertot et al., 2005). Although the first agroenvironmental policies at the European level were set up as early as the mid-eighties, and reinforced in the following decade, it was also only quite recently that breeding strategies started to be tackled from this perspective. We will see that in France this started with the "Grenelle de l'Environnement" conferences in 2007-08 and the subsequent regulation issued in 2009. Since the mid-2000s, several international

\footnotetext{
1 These two producers took part to a meeting we organized in October 2014 in order to present the results of our survey with 35 fruit growers. Of course some fruit growers escape this race and the constraining marketing criteria and take other trajectories towards organic farming and/or short circuits and/or a higher diversification (as well as try to find old cultivars through "alternative" networks or nurseries - see below), but these are a minority.
} 
scientific assessments have also demonstrated the need for a reorientation of agricultural science and technology towards more sustainable approaches, but regulation in many countries does not seem to follow this path.

In this "new" context of greater environmental concern, noting that in France breeding activities are still controlled to a large degree by the state (through public research in genetics and through the system of certification and registration of new cultivars), it might be expected that public authorities would facilitate or even stimulate the inclusion of more environmentally-friendly criteria in the breeding industry, such as the adaptation to low-input practices. We will focus here on these two components (public genetic research, and evaluation and registration of fruit cultivars), keeping in mind that they are embedded in the wider sociotechnical system whose trajectory has been described in the previous section.

\subsection{Successive reconfigurations in public genetic research}

In the case of the peach and apricot industry, there is a major "landscape" factor (in the MLP terminology) that probably had a greater impact on the socio-technical system and its actors and institutions, than did the societal demand for environmental sustainability: the sanitary crises that deeply impacted the peach industry, particularly through high rates of tree mortality and uprooting obligations. These crises were due to bacterial infection (from the 1960s onwards for peaches) and plum pox virus (especially in the 1990s). From the 1960s onwards, these issues prompted research on resistant cultivars, the first results of which were published in the late 1980s (Dosba et al., 1988). What might appear today as a successful adaptation of public research (as a whole) to environmental issues, seems rather to have stemmed from real proximity of some researchers to producers, probably combined with an authentic environmental concern by the same researchers. At least, this is suggested from interviews held with some of the researchers who were involved in these programmes in the 1960s and 1970s. With a hint of nostalgia one of these pathologists would mention the "country laboratories" ( "laboratoires de campagne") where they would spend long periods and analyse the bacterium samples collected in the producers' orchards, as well as the "direct contact with producers that would allow the researcher to understand their problems". ${ }^{1}$ This approach embodies a vision of research that is close to producers and to their needs and situations, which appears more as a vision of individual researchers than as that of the institution as a whole. However, the creation of the INRA "Mediterranean Fruit Research Station" in Avignon in 1982 resulted from a strategic orientation of the institution (as a whole) and the intention to develop an interdisciplinary approach to fruit production. Although this interdisciplinarity would not include the social sciences (nor "systemic agronomy"), it allowed different disciplines to work together around common research objects such as peach and apricot: "In the early 1990s, the apricot tree had become the plant that would bring together pathologists, zoologists, geneticists, specialists of fruit quality, and specialists of tree architecture. All aspects were represented" (ibid.).

Regarding resistance to plum pox, a resistant selection was obtained by the identification of the gene carrying this resistance in the late 1980s and then by an hybridisation process. It was then evaluated in terms of resistance, regularity and quality, which led to the official registration of the first apricot resistant cultivar in 2008 (A3902, commercial name Shamade). This cultivar has been available to producers since 2009 through a convention between INRA and a federation of plant nurseries (CEP Innovation), that is in charge of developing INRA's cultivars. However, the processes of adoption of these resistant cultivars are still to be assessed. ${ }^{2}$

We could wonder if these resistant cultivars can be considered as "niches", to use MLP vocabulary, or whether they constitute a real alternative pathway. They do not really give rise to collective dynamics where proponents would try to learn on this novelty in practical situations, and it is difficult to say whether they represent a radical innovation within genetic research, as some researchers argue that they focus only on one disease and fail to address various diseases and pests in a systemic way. However, the main point here is that the development process of these cultivars (during the 1980s and 1990s) did not really involve

\footnotetext{
1 JP. Prunier, interview, Archorales INRA.

${ }^{2}$ An aspect which we will also explore in the next step of our project.
} 
any other stakeholders from the socio-technical system than researchers (no farmers, economic agents, civil society, etc.), despite the first period of proximity between researchers and producers described above. Put differently, while pathologists had to go into the "real world" of the orchards, and talk with the farmers to understand the diseases, geneticists are more likely to work only in their laboratory, to use a Latourian image. In that sense they did not provide loci within the wider socio-technical system for learning about technical specifications, user preferences, public policies, etc. (Geels, 2004). In simpler words, these cultivars are a research innovation, but do not constitute a niche in MLP terms.

Besides these resistant cultivars, do we find any other types of niches? Old (local) varieties might also appear as niches or alternative pathways. However, even though local cultivars may subsist and be disseminated in some alternative networks with collective learning processes (Bonneuil and Thomas, 2009), as for other species, they have not really impacted the production level until now. Participatory breeding projects constitute another type of niche. In the case of cereals, participatory breeding projects have been implemented, bringing together researchers, producers and firms to identify relevant criteria for breeding schemes (Chiffoleau and Desclaux, 2006). This corresponds better with the MLP definition of a niche (a radical innovation giving place to learning processes in practical situations) while it also addresses our concern here regarding the inclusion of the different components of the socio-technical system. However, such participatory breeding projects appear to be absent in the case of peach and apricot species, ${ }^{1}$ although there have been some participatory cultivar evaluation projects. The main problem raised by researchers and experimenters, when asked about this, deals with the time span of breeding schemes for fruit species. While 3 years is the usual length of public research financing, for fruit cultivars this is not enough to obtain reliable results. It is also problematic to mobilise producers who will not be able to see the results of their commitment and their trials for at least ten years (in contrast with cereals and other annual crops). Another difficulty lies in the sanitary regulations for the stone fruit industry, which oblige to uproot entire orchards above a certain degree of contamination, which in turn makes it impossible to consider field selection, as in the case of some annual crops in participatory breeding schemes. As one producer puts it, "[the plum pox virus controlers] found apricot orchards with up to $96 \%$ of contamination. And I did not understand, I thought for myself, why did they have the remaining 4\% uprooted? Why did not they leave these trees and try to graft them and then see whether the trees coming out of this would carry the plum pox virus or not. In a given orchard, I think that some trees can get immunized against the virus, it is like human beings..."

A large reconfiguration of French public genetic research occurred in 2003 when the strategy of the INRA Plant and Biology Department was redefined, aiming to prioritise the production of "generic knowledge", and invest less directly in breeding activities. ${ }^{2}$ Public research in genetics subsequently withdrew from many species and INRA has now concentrated its forces on 6 fruit species, as opposed to 19 in the 1980s. It has progressively focused its efforts on more fundamental research, mainly molecular biology and genomics. In this vision and in this report, the other components of the socio-technical system are not given a very significant place.

However, the context has slightly changed in the last 10 years which could lead to a more progressive or subtle reconfiguration. As INRA's scientific director put it, in 2003 "the priority for French research was to remain at the forefront of the emergence of genomics, which made it necessary to concentrate the efforts within the Plant and Biology Department. Moreover, in hindsight, we could say that we had not expected environmental issues to take on so much importance in public policies." ${ }^{3}$ Today, within this Plant and Biology Department, the research unit devoted to stone fruit species shows a firm intention to "integrate" not only production and quality criteria, but also resistance criteria "with the aim to set up a sustainable

\footnotetext{
${ }^{1}$ Yet, some stakeholders involved in organic agriculture consider that the fruit industry should set up such participative breeding processes: "A participative selection with (and by) fruit growers could be a useful tool for modern and reliable fruit cultivar selection. Results obtained so far with wheat or cabbage are promising, and drove us towards such process" (Warlop and Sunt, 2006).

${ }^{2}$ Lefort M., Riba G., 2003. Quelles perspectives pour l'innovation variétale à L'INRA ?, report, 107p.

${ }^{3}$ Interview with the INRA's scientific director, May 2014. This environmental turn within public policies is seen by most stakeholders as linked to the "Grenelle de l'environnement" forums (2007) and consequent Law (2009), see below.
} 
orchard". ${ }^{\prime}$ Moreover, a recent reorientation of INRA (around 2010) as a whole, extending beyond genetic research, incorporated more attention for its own research impact (eg. a specific study - Asirpa - was carried out recently, aiming to assess the impacts of INRA's major recent innovations). ${ }^{2}$ In the same perspective, the "Fruit" GIS (Groupement d'Intérêt Scientifique / scientific interest network), founded in 2011, involves research institutes, industry representatives and the advisory sector, and aims to help the fruit industry to reconcile different objectives usually perceived as contradictory: "deliver quality fruit at an acceptable price to consumers, while integrating new environmental demands and, more generally, applying lower input practices as aimed for [in the national pesticide reduction plan], in a context of climate change that is already effective in French fruit production areas." ${ }^{3}$ A recent public commitment by INRA towards the fruit industry stakeholders appears to be in line with this "new" perspective ("Let's work together towards the co-construction of a sustainable fruit production", Journée FNPF, French federation of fruit producers 31/1/2014). Of course, the question it raises is how to translate such commitments into constructive partnerships, and whether this really allows different stakeholders' visions and interests to be taken into account within the socio-technical system, or, knowing that some stakeholders demands are not primarily focused on sustainability issues, how these issues and therefore the interdependencies within this system can be introduced, discussed and addressed. We will address this point through the study of some emerging "transition arenas" in section 4.

\subsection{The evaluation and registration of new fruit cultivars: an environmental turn impeded by prevailing power relationships?}

This section addresses recent changes in discourses and regulations, as well as debates and controversies over the evaluation and registration of fruit cultivars, seeking to understand why, despite strong "landscape pressures", these changes have been quite limited so far.

Under European and French law, seed and plant production and marketing rules are based on two main pillars: the registration of new cultivars (in national official catalogues) and the certification of marketable seeds and plants. In France, the decision to register a new cultivar is taken by the Ministry of Agriculture, based on advice from the CTPS (standing technical breeding committee) which is a consultative "privatepublic" committee composed of representatives from the sector's main stakeholders: administrations, researchers, industry representatives (mainly breeders and nurseries), as well as NGOs. ${ }^{4}$ In interaction with this plenary committee, CTPS is organised into 14 sections devoted to the main species, one of them being fruit trees. This section has about 30 members "representing the public and private sector and involved in the creation, distribution and use of varieties, seeds and plants" (CTPS website). Another institution, "GEVES" (group for the study and inspection of varieties and seeds), is in charge of cultivar studies, which are required for their registration in the official catalogue. While CTPS coordinates the registration of cultivars with the help of GEVES, the varietal and health certification of fruit trees is coordinated by another institution, CTIFL (national technical institute for fruits and vegetables). To be registered, a new variety has to be distinct (D) from varieties already registered, homogenous $(H)$, and stable $(S)$, i.e. maintain the same phenotypic characteristics from generation to generation (DHS criteria). Some species (but not fruits) also have a VCU (value for cultivation and use) evaluation, which states it has a significant improvement over reference varieties already widely used. ${ }^{5}$ This evaluation procedure allows public and private stakeholders to agree on the "most appropriate cultivars", based on a common metrological system and on a shared paradigm of agricultural modernisation (Bonneuil et al., 2006) in which possible "improvement" is mainly evaluated in terms of yields.

\footnotetext{
${ }^{1}$ GAFL/G2IP website http://w3.avignon.inra.fr/gafl/fr/recherches/G2IP

${ }^{2}$ http://www6.inra.fr/asirpa

${ }^{3}$ Gis Fruits website, http://www.gis-fruits.org/Le-GIS-Fruits

${ }^{4}$ Whereas in most countries the decisions are taken by the Ministry of Agriculture without such a "private-public" organisation, which in the case of France was set up in 1942.

${ }^{5}$ Geves website, accessed $9^{\text {th }}$ of September, 2014:

http://www.geves.fr/index.php?option=com content\&view=article\&id=106\&ltemid=394\&lang=en
} 
The main objective of these rules is to guarantee fair transactions, transparency in competition among breeders, and a "uniform and recognised quality". This "fair competition" and "emulation" (as it is often called in the official texts) is seen as contributing to an increase of cultivar supply and the selection processes, so that they integrate the expectations of the food chain and of consumers. Of course, many stakeholders challenge these positions and demand better consideration of low input and organic farming, and of local varieties. In France, as in other countries, the organic sector, which is generally unsatisfied with the available conventional cultivars, is one of the main loci of advocacy for new rules and innovation pathways in the breeding industry. ${ }^{1}$ Organic stakeholders tend to be more concerned with social and environmental sustainability, which is of course due to the strength of organic values, but also to a different sociology of stakeholders, in the sense that dominant firms are less present while smaller private breeders, public breeders and farmer groups are much more active.

These alternative stakeholders' claims for more sustainability were voiced during the "Grenelle de l'Environnement" discussions in 2007 and 2008. In 2009, this resulted in a new law (Law n²009-967, Article 31 ) in which the breeding sector was urged to contribute to more sustainable and productive schemes. The law has also enlarged CTPS to include environmental organisations, consumer representatives and organic farmers (whereas previously, only consumer representatives were involved). Of course, involving stakeholders in such "mainstream arenas" does not necessarily lead to really take their concerns into account, as is evident from the case of the revision of regulatory processes of variety registration in Canada, where consultation procedures were actually designed to silence politically motivated dissent as non-technical, and thus irrelevant (Müller, 2014). Therefore, it is necessary to carefully assess how the arguments and criteria of different stakeholders are taken into account in the discussions and resulting documents.

Following this new law, a commission was established within CTPS to work on "seeds and sustainable agriculture". Each CTPS section (such as the fruit section) was asked to contribute, which resulted in a report, published in 2011, entitled "Seeds and sustainable agriculture action plan". ${ }^{2}$ This report defined new key issues for the breeding sector, including the "environmental qualities" of cultivars, the input reduction objectives, the necessity to meet more diversified demands such as organic farming, the adaptation to climate change, the development of cultivated biodiversity, and the importance of long-term genetic resources conservation. Regarding breeding activities specifically, one of the seven main objectives of this action plan is to "orientate genetic progress towards creating cultivars adapted to diversified cultivation methods and to input reduction public policies," an aim that would require changes in breeding schemes.

However, the CTPS fruit commission mentions in its specific report that fruit breeding faces intrinsic difficulties, such as the length of breeding cycles, the dominant place of private companies, and public research's withdrawal from breeding (in favour of more fundamental work), as well as methodological difficulties concerning ideotype design ${ }^{3}$ (see Brun et al., 2011). However, this report does not present a specific action plan regarding selection issues, even though it mentions that "it will be necessary to generate multicriteria breeding strategies with more participative networks." 4 The first stage is considered to be the evaluation of available cultivars based on resistance to pest and diseases.

In this context, the main proposed action concerns the extension of VCU ("Value for Cultivation and Use" in European regulations) to VCUS (S for Sustainability). ${ }^{5}$ This means that the evaluation should take into

\footnotetext{
${ }^{1}$ At the European scale, a consortium called Eco-PB was created in 2001, which gathers research institutes, individual researchers, organic breeders, farm seeds networks, in order to tackle these issues, but it has not worked much on perennial plants until now.

${ }^{2}$ http://agriculture.gouv.fr/IMG/pdf/Semences_agriculture_durable_rapport_2012_cle8754f1-1.pdf, accessed 15th of September, 2014.

${ }^{3}$ An ideotype is "a system of aims and constraints defined ahead of the breeding process" (Desclaux D., Chiffoleau Y., Nolot JM., 2013. Du concept d'Ideotype à celui de Realtype : Gestion dynamique des Innovations Variétales par une approche transdisciplinaire et partenariale. Exemple du blé dur pour l'AB. Innovations Agronomiques 32 (2013), 455466.

${ }^{4}$ p. 49 in the Seeds and sustainable agriculture action plan of 2011.

${ }^{5}$ In French, VAT (agronomic and technological value) and VATE (E for Environment).
} 
account sustainability criteria such as adaptation to climatic conditions and to lower input crop management systems. A second action was to adapt and extend the cultivar evaluation networks to better take into account the genotype-environment interactions. Each CTPS section (such as the fruit commission) was asked to work in accordance with VCUS and the questions it raised. However, until now there is still no VCU for fruit species, unlike cereals and other groups of species, which deprives the state of a direct means of action in the fruit cultivar supply. ${ }^{1}$ For fruits, the evaluation process is organised within a "national fruit experimentation charter" which has brought together the fruit industry, nurseries, research and CTIFL since 1998 to implement "only' the DHS (Distinction, Homogeneity, Stability) evaluation of cultivars, which is compulsory for all species. According to the new public orientations (as presented in the 2011 report), this system should evolve towards a better agronomic and environmental characterisation of cultivars' resistance to pests and diseases, and their adaptation to specific cultivation methods.

In 2011, a specific working group was set up within the CTPS fruit commission with the aim to study the possibility of establishing an agronomic and environmental evaluation (VCUS) for fruit species. However, as one of the members of this commission put it, "few people in the section are interested by this discussion over the VCUS because most, such as the nurserymen or those who represent international breeders, are not leaders on this question, and besides, those who take part in the meetings are often not decision makers". This context of lasting power relationships also explains why in the fruit section report, some statements have been "played down", probably in order not to blame or oppose certain stakeholders or readers, as a comparison of a draft version of report with the final one shows. For example, some sentences have been deleted which stated that "consumers might turn away from fruits they would no longer consider as safe and healthy", or that the current system of cultivar evaluation was efficient to "select cultivars able to produce industrially, for long circuits, under an efficient chemical protection". Most of the available fruit cultivars are indeed unsuited to low-input or organic systems as they have been developed and selected under high-input cultivation methods. In the CTPS fruit commission, the representative of organic agriculture argues that reducing the inputs in the experimental protocols for variety testing is not enough, and that some experimental trials should completely eliminate the inputs. The official answer to such a claim and the justification for excluding such an alternative pathway (for cultivars' evaluation), is generally that it would represent unacceptable costs for the experimental network. However, the main reason is probably related to the fact that conventional agriculture remains the main market for both breeders and advisors, breeding issues being embedded in the wider socio-technical system described above (Vanloqueren and Baret, 2009). Another issue and claim is the adaptation to local conditions. Whereas the French fruit experimentation network has been progressively centralised (although to a lesser extent than for other species), currently some stakeholders make a plea towards some decentralisation to better take into account local conditions ( "terroir" effects), as well as the adaptation of cultivars to the climate changes affecting the different areas of production in various ways. ${ }^{2}$

In the case of other species like cereals, the turn towards the inclusion of environmental criteria (and low input trials) was taken much earlier than for fruit species. How were the stakeholders convinced in that case? It seems to have been the result: (i) of a long trajectory of progressive legitimisation of low input trials, carried out and collectively analysed by a network of researchers, experimenters and advisors for more than 10 years (Rolland et al., 2003); and (ii) of the more recent involvement of key French stakeholders in intense negotiations which highlighted the necessity to be at the forefront of future changes at European level. ${ }^{3}$ These two processes are likely to have reinforced each other in affecting stakeholders' visions. The first process initially occurs in an "alternative arena" but is progressively acknowledged by a larger range of scientists and stakeholders, including more mainstream ones, although with great difficulties, for example when trying to publish the results of these low-input trials in professional journals. The second process takes place primarily within mainstream arenas (CTPS commissions, Ministry of

\footnotetext{
1 VAT was abolished in 1994 for fruit cultivars.

2 Interview with an INRA researcher. This plea for decentralisation is also made in the organic sector and in participatory breeding schemes, especially in southern countries, based on the argument that a decentralised model better allows taking into account, not only the local conditions, but also farmers needs and knowledge (Cecarelli, 2006).

${ }^{3}$ Interview with a former member of the Ministry of Agriculture who took part in these negotiations on new seed regulations at the European level.
} 
Agriculture, European policy circles), but under pressure of alternative stakeholders (mainly NGOs) and societal demand (in a context which is largely impacted by lasting controversies around GMOs).

\section{The emergence of new 'transition arenas'}

The preceding section has shown the complementary role of co-construction strategies, bringing together different stakeholders of the socio-technical system in alternative arenas, and of more classical advocacy strategies within mainstream arenas such as those linked to the evaluation and registration of cultivars. Indeed, in the case of cereals, the network of researchers, experimenters and advisors, who have worked on the co-construction or co-conception of low-input trials for resistant wheat cultivars, can be considered as an alternative arena. Other examples are networks within participatory breeding projects where researchers, producers and firms discuss their respective needs and try to elaborate common breeding criteria (Chiffoleau and Desclaux, 2006, see above). ${ }^{1}$ In the CTPS fruit commission, which can be considered as a mainstream arena, different stakeholders representing breeders, nurseries, the organic sector and other actors from the socio-technical system, discuss and try to impose their claims. However, in this mainstream arena, the weak position of certain actors compared to others, and the prevailing power relationships between actors, have impeded or slowed down an ecologisation of these processes. This does not mean that the recent inclusion of new stakeholders has no effect at all. The interviewed stakeholders considered it rather positive that the issue of more environmental evaluation and selection protocols was now in everyone's mind, which was not the case only 10 years ago. Of course, the fact that within the different CTPS commissions (both plenary committee and species commissions) the mainstream stakeholders have had to listen to the claims of some more alternative actors, whose place was effectively reinforced in these commissions, contributes to a gradual acknowledgement and legitimisation of new visions and new perspectives (just like the work of the resistant wheat cultivars network was gradually acknowledged by larger numbers of scientists and stakeholders, including more mainstream ones). Therefore, the boundary between mainstream and alternative arenas and actors is clearly unstable and changes over time.

A third kind of arena can also be identified in the breeding sector. In 2013, some stakeholders from public research and evaluation bodies and networks, disappointed by the way the above CTPS fruit commission had addressed sustainability issues, decided to launch another group, which is more informal in the sense that it is not linked to any official and institutional process as in the case of the CTPS commission. This new working group, named the "Medieval" group, is to focus on fruit cultivars and methods for evaluating them, and was created with the support of the newly created interest consortium "GIS fruit" (cf. above).

This informal "Medieval" group is not only devoted to evaluation methods for fruit cultivars but also to the coconstruction or co-design of experiments. At the same time, advocacy strategies are never very far, as most participants belonged to specific interest groups and, de facto, in most cases to major mainstream arenas as well. Therefore, it differs from the mainstream as well as the alternative arenas described above, but mobilizes their specific modes of action and also actors that often belong to different kinds of arenas (not in the least, because breeding issues are very complex and specialists are not numerous). This is why I suggest considering this group as a "transition arena". This concept is borrowed from Loorbach and Rotmans (2006) although I give it a slightly different meaning. These authors developed it within a transition management framework (anchored in the Multi-Level Perspective) and defined transition arenas as "networks of innovators and visionaries that develop long-term visions and images that, in turn, are the basis for the development of transition-agendas and transition-experiments, involving growing numbers of actors" (p. 9). In their case, the transition arena is deliberately created by the stakeholders who launch and coordinate a transition process with specific "goals" (often, public authorities or researchers who assist them). In our case, transition arenas can be formed by newly emerging groups, not necessarily initiated (nor controlled) by the stakeholders who launch and coordinate transition processes (which in our case would be governmental bodies like CTPS or specific services from the Ministry of agriculture). They also originate 1 At the European scale, but once again for annual plants, see the Solibam project,
http://www.solibam.eu/modules/addresses/viewcat.php?cid=1, accessed $26^{\text {th }}$ of May, 2015 
mainly from researchers or members of public bodies, as in the case of the Medieval Group, and of others that will be presented below, but the interesting feature is that they try to escape the classical power relationships by either leaving aside the most powerful actors (such as the main private breeders or the larger producers), or by choosing, within these structures, key persons who are considered to be "more open". This interpretation of "transition arenas" is perhaps closer to Jorgensen's notion of "arenas of development' (Jorgensen, 2012), in the sense that it relies on a flatter approach towards networks. These transition arenas overlap with institutional boundaries as well as with the three classical MLP levels, as they are composed of actors who may belong to what could be referred to the "regime" level (such as public institutions) or to "niches" (in the case of organic stakeholders), and may embody "landscape pressures" (in the case of social movements in general), or even navigate across these levels. Moreover, the boundaries of these arenas may expand and shrink, depending on the aims and performances of these actors, who may have multiple identities and engagements and be enrolled in several arenas at the same time (ibid.).

Other "transition arenas" are currently emerging in the field of genetic innovation. Some are intended to be long-lasting while others are multi-stakeholders working sessions that can happen once, although they may turn into regular events, as in the case of a seminar co-organized by the same GIS fruit and another similar multi-stakeholders consortium devoted to arable crops, intended to bring different actors to work together on the elaboration of selection processes for sustainable agriculture. ${ }^{1}$ This is also the case of a few recent or ongoing research projects. A breeding research project (in general) brings together researchers, experimenters and possibly other actors from the socio-technical system (producers, advisors, breeders, nurseries etc.) around shared aims. In the French system of public research financing, it also allows public decision makers to support certain innovation pathways. Regarding breeding issues, until a few years ago most research projects would bring together either (i) essentially "mainstream" actors, often from research institutes, experimentation networks and the breeding sector (without really involving other stakeholders such as growers, economic stakeholders or policy makers) or (ii) essentially alternative stakeholders at all levels of the sociotechnical system, aiming to develop systemic and multi-actor perspectives on breeding issues (such as in participatory breeding projects in organic annual crops, as we saw above). Today, however, new types of projects seem to be emerging. For example, in the 'Innovafruit' project launched by the INRA in 2013, the aim is to develop an "integrated" vision of breeding that could lead to cultivars adapted to low input practices, based not only on alliances between researchers, experimentation networks and breeders, but also with professional or economic stakeholders. This is also the case for our Prunus project, where breeding strategies appear as one of the intertwined issues within a more systemic and integrated approach, rather than as the core issue. It is not only a wider range of stakeholders that are involved, but also, because these stakeholders embody the different components of the socio-technical system (research, experimentation networks, breeders, economic stakeholders, policy makers, sometimes civil society and consumers), a wider part of this system.

Involving the different components of the socio-technical system is also the role of some mainstream arenas, like the CTPS commission. However, while in mainstream arenas these stakeholders are asked to represent the different institutions and actors in an official, mandatory way, in the emerging transition arenas they are asked to embody and "translate" the various components of the socio-technical system in a perspective that aims to collectively tackle the interdependencies between these components (and within this system). In the case of our Prunus project group, this is done through both shared analysis of the past and existing situation, and co-construction of future collective goals and actions.

Currently, such systemic approaches are actually developing into a new framework imposed on public research through research calls and programmes. For example, the new action plan for seeds and sustainable agriculture (2011) specifies new systemic approaches, which combine complementary protection methods (including functional biodiversity), involving industry stakeholders. ${ }^{2}$ The future effects of this institutionalisation of systemic and participatory approaches - although still a minority in the French agronomic public research system - need to be carefully assessed in the future. This trend might lead to the "neutralization" of more radical options, pathways and stakeholders, whose key role in questioning and

\footnotetext{
${ }^{1}$ Séminaire Idéotypes variétaux, https://colloque6.inra.fr/gchp2e_ideotypes_varietaux, accessed 20/4/2015.

${ }^{2}$ http://agriculture.gouv.fr/MMG/pdf/Semences _ agriculture_durable_rapport_2012_cle8754f1-1.pdf, accessed 15th of September, 2014, p. 104
} 
criticizing the incumbent system has to be acknowledged and supported. Therefore, multi-actor strategies deployed within "transition arenas" (such as the group or the research projects mentioned here) have to be combined with more radical options to be explored in more alternative arenas, as well as with advocacy strategies within more mainstream arenas (such as the CTPS commissions described above). In that sense, the emergence of other types of transition arenas, that originate from civil society organizations and "alternative" geneticists rather than, as for those which were described here, from more "classical" geneticists (or other researchers) or members of public bodies, also need further examination. ${ }^{1}$

\section{Conclusion}

The core question in this chapter was: why have societal pressures for sustainability continuously failed in really impacting the fruit breeding system so far, and are there any recent signs of change? The sociohistorical analysis of the evolution of the fruit industry and of breeding strategies suggests that we observe a process of intensification (with an endless "race for innovation"), rather than an ecologisation of this breeding system. However, the analysis of interactions, debates and controversies in the two fields of public genetic research and fruit cultivars' evaluation and registration procedures within several kinds of arenas has led to acknowledge the emergence of new multi-actor "transition arenas", in addition to mainstream arenas where advocacy strategies are favoured, and to alternative arenas where coconstruction is rather favoured. This suggests that despite inertia and prevailing power relationships, a combination of co-construction strategies and advocacy strategies within these three different kinds of arena (mainstream, alternative and transition arenas) might form a basis for a collective design of pathways towards sustainability. These emerging transition arenas stem from alliances between a diversity of stakeholders who embody the different components of the socio-technical system (research, experimentation networks, breeders, economic stakeholders, policy makers, civil society), although they do not represent them in an official, mandatory way. This co-presence can be a way to try to tackle (or to redefine) the interdependencies that tie them together. Of course, a question for further research is how these three types of arenas will continue to co-exist, how they will relate to each other and how this coexistence and these interactions between them will influence the resulting dynamic.

These transitions arenas are often initiated by public researchers, and their future impacts will highly depend upon future orientations within public research. However, within public research, lasting tensions have developed between a trend towards more fundamental research, and a wish to interact with civil society, professional and economic stakeholders. At the intersection of these two trends, the issue of sustainable agriculture (or since 2012, agroecology in France) appears as a catchword that might, next to reconcile different stakeholders, also reflect visions that are more contradictory than compatible. In that sense, "whose sustainability?" is probably the right question to ask, as Smith and Stirling (2010) have suggested, and to ask collectively. Are we talking about the fruit growers' sustainability? Of the fruit industry's sustainability? Or the private breeders' sustainability? The private breeders clearly seek to sell their cultivars and promote a high turnover of these cultivars, ${ }^{2}$ rather than to work on more sustainable and more resistant cultivars, ${ }^{3}$ for which public research will have to take the lead.

Moreover, we should be aware of the processes of exclusion that these transition arenas themselves reproduce or maintain. For example, producers or producer groups are rarely involved in them, and the historical choice of public research to collaborate mainly with breeders (rather than producers) is

\footnotetext{
${ }^{1}$ I could so far identify one such experience, which is the case of the Resoriv netwotk (for Social acknowledgment and genetic innovation regulation through participatory selection for organic and peasant farming), a network launched in 2009 by V. Chable and the FSC (Foundation for science and citizenship), which organized a workshop in 2013 with actors of their close networks but also with some of the "mainstream" actors we mentioned here, such as the CTPS and the Ministry of Agriculture, in order to discuss possible strategies to support "peasant innovation" (www.sciencescitoyennes.org/wp-content/uploads/2013/07/plaquette ReSoRIV.pdf, accessed 10/3/2015).

${ }^{2} \mathrm{~A}$ phenomenon that is reinforced by the system of public subsidies for plantations, aimed at supporting producers in their adaptation to market demands, but that seem to mainly benefit breeders.

${ }^{3}$ With probably a few exceptions that would be worth studying of course.
} 
questioned to a limited extent only. Consumers are also most often excluded from these arenas. While recent changes in French public policies for more sustainability criteria in breeding and in cultivar evaluation express a will to connect agriculture and the environment more closely, a future challenge is to (re)connect them to food and consumption as well. Even though many stakeholders and texts claim to take consumer demand into account (as in the case in the recent governmental "Seeds and sustainable agriculture action plan" described above), this demand is typically conflated with or reduced to marketing criteria (such as visual aspects or storage capacity), without the numerous different stakeholders for whom these criteria are relevant (producers, marketing operators, retailers, consumers themselves) having any opportunity to really compare and discuss their views and constraints.

Participatory breeding projects do try to take these criteria into account and redesign breeding schemes, but these are only developed for annual crops. The long time span that characterizes fruit breeding, as opposed to annual plants breeding, is a significant obstacle that makes it more risky for researchers to engage in alternative programmes that are less motivating or risky for farmers, or inacceptable for civil society. This does not mean that fruit cultivars do not mobilize social movements, but these movements focus on the conservation of old and local varieties, and much less on breeding issues. There is also another important, often overlooked difference, which is the metabolic trajectory of products: the processing stage, for cereals and possibly for some fruits, holds specific constraints but also opens up new possibilities. For instance, wheat cultivars with a low baking quality may fit "alternative" processing technologies (Wiskerke and Oerlemans, 2004; Lamine et al., 2010), while fruits are mainly sold and consumed as fresh produce, implying that, apart from direct sales, it is very difficult to circumvent the prevailing quality criteria. Therefore, another topic for further research is to analyse the absence, the failure or the emergence of specific breeding schemes devoted to canned fruit production.

The main difference of our approach, compared to former studies dealing with cereal breeding strategies in France, lies in the role we play as researchers, emphasizing interaction with other disciplines and with other stakeholders. The analyses of the organisation and activities of the breeding system have generally remained the realm of social scientists, either working "alone" within historical or STS approaches, or with only "alternative" geneticists. Our approach, however, covers a variety of disciplines and we try to involve a broad range of stakeholders. ${ }^{1}$ Both types of "enrolment" (disciplines and stakeholders), have specific consequences, which we need to be reflexive about. Trying to elaborate a shared analysis of the current situation and of the trajectory that led to it, along with the actors who were and are involved, implies that some scientists or stakeholders might be grieved by or disagree with some of our interpretations. It is therefore necessary to trace and accept possible controversies both in the field (in the real world) and in our network of concerned scientists and stakeholders. Moreover, our approach tends to involve leaders instead of a broader range of the "concerned" actors (Barbier et al., 2013). Doing so, however, and by focussing on a rather 'small' territory (only two French départements), will facilitate a comprehensive approach to the peach and apricot socio-system's complexity and specificity.

Acknowledgements: This work was carried out under the Prunus project (supported by the research programme "Assessing and reducing environmental risks from plant protection products" funded by the French Ministries in charge of Ecology and Agriculture) and the ARDU network (Métaprogramme SMASH, INRA). I would like to thank all the participants involved in the discussions within or around this project, both researchers and stakeholders: JM Audergon, S. Penvern, S. Simon, J. Pluvinage, S. Bui, L. Garçon, S. Tabouret, G. Clauzel, R. Aubenas, S. Stévenin, S. Buléon, V. Faugier, M. Lamberet. I am also grateful to all SISA2 conference participants who gave me useful comments on this chapter, to I. Cucco and B. Megyesi who reviewed this chapter before publication, to Boelie Elzen who read and commented several versions of it, to a Research Policy anonymous reviewer, as well as to Liz Libbrecht for her efficient language editing.

\footnotetext{
${ }^{1}$ This last point was also made in an IFSA paper (Lamine et al., 2014)
} 


\section{References}

Allaire, Gilles, et Robert Boyer (1995) La grande transformation de l'agriculture. Paris: INRA Economica,.

Allaire G., Wolf S. (2004). Cognitive representation and institutional Hybridity in Agrofood Systems of Innovation. Sci. Technol. Hum. Value 29, pp 431- 458

Aubertot J.N., Barbier J.M., Carpentier A., Gril J.J., Guichard L., Lucas P., Savary S., Savini I., Voltz M. (2005) Pesticides, agriculture et environnement, Réduire l'utilisation des pesticides et limiter leurs impacts environnementaux, Expertise scientifique collective, synthèse du rapport, INRA \& Cemagref, France, $64 \mathrm{p}$.

Barbier, M., L. Cauchard, P-B Joly, C Paradeise, et D. Vinck. (2013) "Towards pragmatic, ecological and political approaches to expertise ». Revue d'anthropologie des connaissances 7, $\mathrm{n}^{\circ} 1$.

Barthe, Yannick, Michel Callon, et Pierre Lascoumes (2001) Agir dans un monde incertain. Essai sur la démocratie technique. Paris: Seuil.

Bernard de Raymond, A. (2013) En toute saison. Le marché des fruits et légumes en France. Rennes: PUR.

Bonneuil, C., Demeulenaere, E., Thomas, F., P-B. Joly, G. Allaire, et Goldringer, I. Innover autrement? La recherche face à l'avènement d'un nouveau régime de production et de régulation des savoirs en génétique végétale. Gasselin P., Clément 0. (coords.), 2006. Quelles variétés et semences pour des agricultures paysannes durables? Les Dossiers de l'environnement de I'INRA n³0, Paris, 186 p., 2006.

Bonneuil, C., et F. Hochereau (2008). Gouverner le "progrès génétique. Biopolitique et métrologie de la construction d'un standard variétal dans la France agricole d'après-guerre ». Annales HSS 6 : 1305 -40 .

Bonneuil, C., et F. Thomas (2009) Gènes, pouvoirs et profits. Recherche publique et régimes de production des savoirs de Mendel aux OGM. Quae.

Brun L., Warlop, F., Mercier, V., Broquaire, JM, Clauzel, G., Gomez C., Parveaud, CE, Audergon, JM. (2011). Quelle sélection fruitière pour une production durable, à faible niveau d'intrants ? Méthodologie pour un réseau de sélection variétale décentralisée. CIAG Innovations Agronomiques $15,105-115$.

Callon, M. (1986)Éléments pour une sociologie de la traduction. La domestication des coquilles SaintJacques dans la Baie de Saint-Brieuc. L'Année Sociologique, $n^{\circ} 36$.

Ceccarelli, S. (2006). Decentralized - Participatory Plant Breeding: Lessons from the South - Perspectives in the North, Pp. 8-17. In Dominique Desclaux, Marianne Hédont (Eds), 2006. Proceedings of the ECO-PB Workshop on Participatory Plant Breeding: Relevance for Organic Agriculture, held in Domaine de la Besse (Camon, Ariège), France, 11-13 June 2006. ITAB, Paris, France, 112 pages

Chateauraynaud, F. (2002) Prospero, une méthode d'analyse des controverses publiques. Cahiers Politiques, 61-84.

Chiffoleau, Y., et D. Desclaux. (2006) Participatory plant breeding: the best way to breed for sustainable agriculture?. International Journal of Sustainable Agriculture 4, n 2: 119-30.

Collet, E., et M. Mormont (2003). Managing pests, consumers, and commitments: the case of apple growers and pear growers in Belgium's Lower Meuse region. Environment and Planning, A 35, 413 $-427$.

Dosba F., Lansac M., Audergon J.M., Maison P., Massonie G. (1988). Tolerance to plum pox virus in Apricot. ISHS Congress Thessaloniky, Acta Horticulturae, 235, 275-281

Dubuisson-Quellier, S., M Navarrete, et J Pluvinage (2006) Les organisations de producteurs au coeur de la valorisation de la qualité des fruits. Economie Rurale, $n^{\circ} 292$ : 18-34.

Friedmann, H., et McMichael. (1989) Agriculture and the state system: the rise and fall of national agricultures, 1870 to the present. Sociologia Ruralis $29, \mathrm{n}^{\circ} 2: 93-117$.

Geels, F.W. (2004) From sectoral systems of innovation to socio-technical systems. Insights about dynamics and change from sociology and institutional theory. Research Policy, 33: 897-920.

Haynes I., C. Lamine, R. Paratte, A. Wierzbicka, S. Zoltan, J. Lehota, J. Buurma, I. Vandenberg, E. Maraccini and C. Moonen, S. Williamson (2010). Are supermarkets a tool facilitating the transition to low input farming practices? IFSA congress, Vienna, July 2010. available at http://ifsa.boku.ac.at/cms/fileadmin/Proceeding2010/2010_WS4.4_Haynes.pdf 
Jas, N. (2007) Public Health and Pesticides Regulation in France before and after Silent Spring, in Soraya B. et N. Jas (dir), Risk Society in Historical Perspective, History and Technology, 23, 4, 369-388

Jorgensen, U. (2012). Mapping and navigating transitions - The multi-level perspective compared with arenas of development, Research Policy, 41, 996-110

Kloppenburg J., (2010) Impeding Dispossession, Enabling Repossession: Biological Open Source and the Recovery of Seed Sovereignty. Journal of Agrarian Change, vol. 10 (3), p. 367-388.

Lamine C., M.Barbier, J.Blanc, J. Buurma, I.Haynes, J. Lehota, E.Marracini, E.Noe, R.Paratte, Z. Szabo, A. Wierzbicka (2010) Reducing the dependence on pesticides: a matter of transitions within the whole agro-food system, IFSA congress, Vienna, July 2010. available at http://ifsa.boku.ac.at/cms/fileadmin/Proceeding2010/2010_WS4.4_Lamine.pdf

Lamine C., 2011. Transition pathways towards a robust ecologization of agriculture and the need for system redesign. Cases from organic farming and IPM, Journal of Rural Studies, 27, 209-219

Lamine, C., Audergon, JM., Penvern, S., Simon, S., Pluvinage, J. (2014a) From genetics to marketing (... and through complex connexions and interdependencies): an integrative approach of the ecologisation of fruit production. IFSA congress, April 2014, Berlin

Lamine, C., Pluvinage, J., Aubenas, R. Faugier, V., Simon, S., Clauzel, G., Lamberet, M., Penvern, S., Stévenin S., Buléon S., Garçon, L., Bui, S., Audergon, JM. (2014b). Innovation variétale en Prunus, 1960-2013: les enseignements d'une analyse socio-historique co-construite avec les acteurs. Deliverable, Prunus project

Müller, B. (2104). The seed and the citizen. Biosocial networks of confiscation and destruction in Canada, Journal of Global and Historical Anthropology 69 : 28-44

Praly, C. (2010) Nouvelles formes de valorisations territoriales en agriculture, le cas de l'arboriculture de la moyenne vallée du Rhône. thèse en géographie, Lyon 2, sous la direction de C.Delfosse et J.Pluvinage.

Praly, C., et C. Chazoule (2013). Les circuits de proximité en fruits, une économie de la variabilité complémentaire de l'expédition. Revue d'Études en Agriculture et Environnement 94: 39-64.

Ricci, P., Bui, S., Lamine, C. (2011). Repenser la protection des cultures. Paris, QUAE.

Rolland, B., Bouchard, C., Loyce, C., Meynard, J.M., Guyomard, H., Lonnet, P., Doussinault, G. (2003). Des itinéraires techniques à bas niveaux d'intrants pour des variétés rustiques de blé tendre: une alternative pour concilier économie et environnement. Courr. Environ. 49, 47-62

Thévenot, L., 1994. Le régime de familiarité; des choses en personnes. Genèses, nº 17 (1994): 72-101.

Vanloqueren, G., Baret, P.V. (2004). Les pommiers transgéniques résistants à la tavelure -Analyse systémique d'une plante transgénique de "seconde génération". Courr. Environ. 52: 5-22.

Vanloqueren, G., Baret, P.V. (2008). Why are ecological, low-input, multi-resistant wheat cultivars slow to develop commercially? A Belgian agricultural "lock-in" case study. Ecol. Econ. 66: 436-446.

Vanloqueren, G., Baret, P.V. (2009). How agricultural research systems shape a technological regime that develops genetic engineering but locks out agroecological innovations. Res. Policy 38: 971-983

Warlop, F., et Sunt, C. (2006) Providing suitable tolerant fruit cultivars for facilitating low input strategies: what is the situation? In Dominique Desclaux, Marianne Hédont (Eds), 2006. Proceedings of the ECO-PB Workshop : Participatory Plant Breeding : Relevance for Organic Agriculture? 11 - 13 June 2006 La Besse, France

Wiskerke, J.S.C., Oerlemans, N.J., (2004) Zeeuwse Vlegel: a promising niche for sustainable wheat production, in Wiskerke, J.S.C. and Van der Ploeg, J.D., ed., Seeds of Transition: Essays on novelty production, niches and regimes in agriculture (European Perspectives on Rural Development). Assen, The Netherlands: Van Gorcum 


\title{
Socio-Economics of CSAs in Hungary
}

\author{
Bálint Balázs, ${ }^{1}$ György Pataki ${ }^{2}$ and Orsolya Lazányi ${ }^{3}$
}

\section{Abstract}

The chapter presents a case study of a developing Hungarian "Community-Supported Agriculture" (CSA) sector which gained recognition in recent crisis driven times to examine uncertainties of farmers and consumers for running or joining a CSA. Research findings are based on in-depth interviews, data from stakeholder workshops and consumer (member) survey. Evidence demonstrates how CSAs catalyse social change to enhance consumer-producer cooperation and regain control over the ways in which food is supplied. The research also found that current share prices do not transparently reflect real production cost, and that farmers rely on an altruistic coping strategy to invest into deepening their operations by a trusted community base. This fundamental deviation from the original economic principle of sharing all risks and rewards and from the usual practice in North American and Western European CSAs has not received much attention from scholars. In the Hungarian context of weak community engagement, CSA farmers take on the extra work to bring together and nurture bonds of affinity in their customer base and educate members about sustainable diets. To highlight this socio-economic paradox, the term "agriculture supported communities" will be suggested to summarize the set of practices that CSA farmers pursue to reach beneficial socio-ecological outcomes.

Keywords: Local Food System, Community-Supported Agriculture, Qualitative Research, Socio-Economic Characteristics

\section{Introduction}

"Community Supported Agriculture" (CSA) is a specific form of local food system (LFS; Renting et al. 2012) that is based on long-term partnership and risk-sharing between one or, in some instances, several producers and their consumers. A CSA relationship implies the capacity to extend beyond economic exchange to include social roles, motivations and benefits for both farmers and consumers. CSA, in an institutional sense, attempts to turn economic roles (of producer and consumer) into social ones (of members of a community) and, consequently, non-price considerations take on greater importance (Hinrichs 2000; Henderson 2003).

While the literature on expansion of the CSA movement in so-called developed countries is extensive, not much evidence is available on the situation concerning so-called post-socialist countries, such as the ones in Central and Eastern Europe (CEE). This chapter attempts to partially fill this gap and examine the CSA movement as experienced in Hungary, a CEE country still in its post-socialist cultural transformation phase. In 2012, the National Agricultural and Rural Development Strategy initiated institutional changes to localize the food system in Hungary. The strategy provides a source of legitimacy for the CSAs but the full institutional support is missing. True, locally grown food is in general more valorised, and more and more market opportunities are created for small-scale family farmers.

\footnotetext{
${ }^{1}$ Environmental Social Science Research Group (ESSRG), Szent Istvan University, Gödöll, Hungary. Email: balazs.balint@essrg.hu

${ }^{2}$ Environmental Social Science Research Group (ESSRG), Corvinus University, Budapest, Hungary. Email: gyorgy.pataki@uni-corvinus.hu

${ }^{3}$ Environmental Social Science Research Group (ESSRG), Corvinus University, Budapest, Hungary. Email: orsolya.lazanyi@essrg.hu
} 
This chapter draws upon prior experience of the authors from their personal involvement in the Hungarian CSA movement. Authors belonging to the Environmental Social Science Research Group established research relationship with farmer-led CSAs through previous studies: one farmer is a former student taking part in classes and graduating on alternative food systems, another farmer is a former colleague of the authors. In our sampling strategy we sought to trace the dominant or typical Hungarian form of CSA, where farmers collect trusted customer base for their box scheme and initiate the formulation of the CSA group. We consider this study an engaged scholarship, where authors are also constitutive parts of the system as experts, facilitators, in dialogue with the CSAs, activists, advocates and practitioners under study.

On this basis, in 2012-13 we conducted a qualitative research on vegetable box schemes operated by farmers in Hungary, in order to explore CSA development pathways in a Central European context and reflect upon the underlying mechanisms and processes.

\begin{tabular}{llllllll}
\hline & $\begin{array}{l}\text { Opera- } \\
\text { tion } \\
\text { (yrs) }\end{array}$ & produce & $\begin{array}{l}\text { land } \\
\text { (ha) }\end{array}$ & locality & members & $\begin{array}{l}\text { Emplo- } \\
\text { yees }\end{array}$ & $\begin{array}{l}\text { Organi- } \\
\text { sational } \\
\text { form }\end{array}$ \\
\hline $\begin{array}{l}\text { Évkerék } \\
\text { EcoFarm }\end{array}$ & 3 & $\begin{array}{l}\text { fruit, veg, } \\
\text { cereals, meat }\end{array}$ & 7 ha & $\begin{array}{l}\text { Szeged } \\
\text { (Kistelek) }\end{array}$ & 50 boxes & 2 & $\begin{array}{l}\text { family } \\
\text { farmer }\end{array}$ \\
\hline $\begin{array}{l}\text { Háromkaptár } \\
\text { Organic } \\
\text { Garden }\end{array}$ & 3 & $\begin{array}{l}\text { vegetables } \\
\text { and organic }\end{array}$ & $\begin{array}{l}1,5 \\
\text { ha } \\
\text { food shop }\end{array}$ & Tahitót-falu & 80 boxes & 1 & limited \\
company \\
$\begin{array}{l}\text { Biokert } \\
\text { Szigetmonost } \\
\text { or }\end{array}$ & 7 & $\begin{array}{l}\text { vegetables, } \\
\text { cereals, } \\
\text { legumes }\end{array}$ & 5 ha & Szigetmo- & 60 boxes & 2 & nostor \\
\hline $\begin{array}{l}\text { Matthews } \\
\text { farm }\end{array}$ & 3 & $\begin{array}{l}\text { vegetables, } \\
\text { egg, poultry }\end{array}$ & 4 ha & Zsámbok & 53 boxes & 4 & company \\
\hline $\begin{array}{l}\text { Bioéléskamra } \\
\text { (Eleven Föld } \\
\text { coopera-tive) }\end{array}$ & 8 & $\begin{array}{l}\text { vegetables, } \\
\text { pumpkin seed }\end{array}$ & 7 ha & $\begin{array}{l}\text { Hét } \\
\text { (Miskolc) }\end{array}$ & 47 boxes & 2 & fompany \\
\hline
\end{tabular}

Table 1: Features of producer-operated CSAs

According to the research design, the empirical data was collected and analysed in three stages. Firstly, in total 21 semi-structured interviews were analysed: 5 CSA producers, 13 CSA members/consumers, and 3 policymakers and experts. Interview participants were all contacts of the farmers, while a selection was made to reflect the heterogeneity of stakeholders in local food communities. Interviews lasted between 60 and 90 minutes, took place at the farms and in interviewees own environment (Patton 2002). All interviews were tape-recorded and transcribed verbatim before data analysis. The data analysis used thematic coding, a combination of meaning-condensation, categorisation and meaning-interpretation of the relevant themes (Kvale 1996). Secondly, to cross-check the findings data was collected through desk research (newspaper articles, advocacy literature) and participant observations related to the box schemes (e.g. delivery and distribution of the boxes and interactions between farmers and consumers). Providing further context, the evolution of the Hungarian CSA platform was observed through participation at the Vision to Action Forums of CSAs in Gödöllö in February 2012 and in Budapest in April 2013. Third, a consumer (member) attitude survey was carried out in 2013 among the members of four CSAs exploring their initial motivation for joining a CSA and their experience being exposed for at least one year to the operation of a box scheme. Altogether 83 responses were collected out of 226 members of the four CSA farms and presented through basic statistical distributions and crosstabs.

By applying a relational-interpretivist approach (Whatmore 2002, Goodman et al. 2010), the present analysis turns to the socio-economics of food supply through CSAs. More specifically, the following research questions were addressed: How farmers and consumers construct their motivations around CSAs? What ambitions and concerns are present in their stories and how they maintain the development of CSAs? For the interpretation of results, theories of alternative food networks and transition theories (Roep \& Wiskerke 2006; Dupuis \& Gillon 2009; Izumi et al. 2010) will be drawn upon. 
The chapter is divided into three sections. First, a brief literature review is provided to contextualise everyday practices of farmers and consumers around the CSAs. Second, the chapter outlines CSA development in Hungary with regard to the policy context. Next, results are presented on farmers' and consumers' attitudes towards socio-technical, cultural, and economic mechanisms of CSAs. In the final discussion, it will be argued that, to consolidate their operations and sustain (financially) successful farm activities, CSA farmers tend to rely on an altruistic copying strategy and refrain from sharing full range of costs. We regard this as a fundamental difference from the North American and Western European CSAs, a deviation from the original economic principle of sharing all risks and rewards. In the CEE context of weak civic engagement and difficulties to trust others, CSA farmers take on the extra work to bring together members of the local community, nurture bonds of affinity and teach members about sustainable diets and local food systems. To highlight this socio-technical, cultural, economic paradox, the term "agriculture supported communities" will be suggested to summarise the set of socio-economic practices that CSA farmers pursued to reach beneficial socio-ecological outcomes.

\section{The concept of Community Supported Agriculture}

The literature on contemporary alternative agri-food economic practices depicts specific forms ranging from residential food production, buying groups, CSAs, farmers' markets, urban food councils, local food systems, farm to school programs, etc. (see for example Cooley \& Lass 1996; DeLind 1999; Verhaegen \& Van Huylenbroeck 2001; Stagl 2002; Lamine 2005, Mariola 2008; Izumi et al. 2010; Kortwright \& Wakefield 2011). Among highly diverse conceptualisations, most analysts consider CSAs as important part of alternative food supply chains that strengthen the local economy and preserve agricultural diversity (Hinrichs 2000; DeLind 2002; Stagl 2002; Lyson 2004).

While CSAs can appear in many configurations (producer-led or subscription-based, community-led or cooperative, collaborative, producer-community partnership, and community-owned farm enterprises), by definition all are devoted to shorten the distance between farmers and consumers. This shortening is realised in practice by sharing the risks and the rewards of food production and results in creating a more local and socially just food system (DeLind 1998; Henderson 2003).

Farmers and consumers need to act together to achieve the balance of supply and demand (Flora and Bregendahl 2012). Consumers reduce their qualitative uncertainties (safeness, taste, origin, etc.) while in exchange farmers reduce their uncertainties of quantitative nature (sales and prices) (Lamine 2005). In this way, Psarikidou and Szerszynski (2012) argue that CSAs constitute a moral economy around relations of solidarity and justice, and ethical concern for land and the global environment.

Studies that focus more on the demand side are mostly concerned with the motivation behind members' participation, the practices of consumer engagement in a CSA, the induced behavioural change, and the social inclusivity of the initiatives. Supply side researches investigate sustainability from the standpoint of producers. As for the analytical approach of this chapter, a socio-technical transition approach was taken that attempts to understand the box scheme as a technical artefact, a central piece of the strategic niche management that farmers employ to manage socio-technical innovations around the farm (Brunori et al. 2012, Witkamp et al. 2011). Specifically, by following a transition approach (Brunori et al. 2012), this chapter depicts the complex experiences of CSA activities governed by coherent systems of rules and principles ('regimes'). In such circumstances, innovation emerges as reconfiguration or transformation in the socio-technical 'niches' that experience radically different cognitive frames, resource bases, relational patterns. The main players are CSA operators who manage a complex socio-technical network consisting of humans and technical devices. Actors are guided by socio-technical and normative rules while the operator orchestrates social innovation. The box as a non-human element renders different social components. 


\section{Institutional context for re-localizing food systems in Hungary}

In Hungary the remnants of informal economy, which is the continuation of the second economy, as a compensation for some faults of the planned economy (Sík 1992) helped to maintain a strong local food culture and sustainable agriculture in traditional agricultural family households. Food provision is still often served by non-market mechanisms and through high level of food self-sufficiency. Recent simplification of food legislation on SFSCs and LFSs facilitated some alternative food supply systems (farmers' markets, farm gate sales, pick-your-own, local food festivals, food trails) to get widespread attention, whereas other forms, typically initiated by urban non-farmers (local food shops, buying groups, CSAs) gained only rudimentary success. Although less than one-fifths of the agricultural farms are involved in direct sales activities the national level agricultural and rural development policy provides increasingly important institutional support for this sector. Exemptions and flexibility rules were successfully implemented to facilitate change in the local food sector. The foresight policy document, New Agricultural and Rural Development Strategy 2020, which is often regarded as a new constitution of rural Hungary, also provides proportionately much higher allocation of resources for LFSs and SFSCs than any previous high level policy document (Darányi Ignác Plan 2012). Clearly top-down policy processes under the framework of the New Agricultural and Rural Development Strategy 2020 opened a window of opportunity for this sector and especially bottom-up initiatives.

In scholarly literature the evolution of the first CSA project, the organic box scheme of Open Garden in Gödöllö, Hungary, initiated by Matthew Hayes from 1998 to 2006 have already been widely examined in various qualitative studies (Hayes \& Milánkovics 2001; Vadovics \& Hayes 2010; Zsolnai \& Podmaniczky 2010). Evaluations of the pathway of the pioneer CSA movement record a constant restructuring to reach an economically viable, community-supported sales model. It all seems that the Open Garden Foundation could not comply with the principle of transparent budget planning. Following such precedents, a series of new CSA-projects were started in 2005 and 2011. The necessary impulse to found new CSAs came from the social expectations of the improving institutional-regulatory framework; and practical training courses, networking opportunities media/marketing services and policy advocacy offered by the Hungarian CSA platform in 2012 and 2013.

CSAs were practically unknown in Hungary a decade ago. Popular press and advocacy literature helped to give such production and distribution systems wide recognition. CSAs have been depicted as some of the hot food trends in the last few years that give a socially innovative panacea to the multiple crises. Most articles emphasized how CSAs support a group of farmers by providing them with a fair wage for healthy food. Similarly, in public policy CSAs have been regarded as a community form of direct sales and therefore a tool for the local economic development. In this policy context, the National Agricultural Advisory, Educational and Rural Development Institute, as the main body to implement the Rural Development Strategy financed the organisation of the Hungarian CSA platform in 2012 and 2013. Initiated by the Association of Conscious Consumers, the Research Institute of Organic Agriculture and the Environmental Social Science Research Group the CSA platform provides networking opportunities, media/marketing services and policy advocacy to CSAs in Hungary. In the European Union's new agricultural and rural development policy 2014-2020, SFSCs may be subject to thematic sub-programmes within rural development programmes and CSAs expect to get further public funding to extend their services (Kneafsey et al. 2013). Therefore, it is helpful to investigate the main challenges related to production, investment and sales, as well as community management in CSAs.

\subsection{Uncertainties of production}

Planting and cultivation in investigated farmer-led CSAs is mostly non-mechanical: $90 \%$ of the work is done manually from March to November. Weed management and spreading organic dung (farmyard manure, green manure, compost, stem and root remains) require the most amount of manual labour and costs. Production would be more profitable, if costly manual labour could be diminished. In the interviewed farmer- 
led CSAs this is done through employment of part-time workers, sharecropping, and transparent scheduling. However, these techniques do not necessarily translate into higher average income in most cases.

As for the weekly shares, CSAs in Hungary typically do not offer a full diet. A share typically extends to 8-10 vegetables, spices, herbal plants and some fruits, mostly organic and sometimes landraces. Relying on a diverse production assortment (e.g. 100 different vegetables, landraces, etc.) requires much more time and work from the farmer. For this reason, in certain CSAs voluntary coordinators help farmers to match the needs of local groups and manage the delivery. Collaboration of CSA farms also helps to provide a regular assortment of diversified produce throughout the entire season. To extend the variety, consumers primarily would prefer fruits, some grain (wheat, barley, buckwheat, and millet), meat, cheese and dairy products. Farmers or members also invite other producers with seasonal fruits to the drop off points. Stories of production procedures, recipes with simple technologies of cooking, processing, preservation and storing of given varieties are often pre-circulated in email by the farmers to give an insight into the weekly box.

The assortment can be improved by easy to grow complementary plants (chives, green spices, etc.) which would not sell in an online shop but can certainly offer some variability in the supply. Simplicity in logistics is a main competitive advantage in the CSA-model that directs a larger share from the entire value chain to the farmer. Selecting the assortment into the boxes is considered a creative task and farmers are proud and happy to do it. The weekly delivery of boxes is the principal act to develop strong relationship between producers and consumers. Money is involved only once in a month therefore the interactions at the drop off point are very convivial, which helps to establish long-term partnership between producers and consumers. To further enhance personal interactions, several farms collect direct feedback from their members through surveys, newsletters, and social media. Interviews revealed also that consumer feel they often get too much of the same thing during the growing season. All CSAs have begun to offer half or small boxes as a way to keep prices down and help people from being overwhelmed with too much produce.

Members are entitled to an equal share of the produce delivered in the weekly box. However the box is invitational, consumers are extrinsically motivated to offer boxes for present in their network, or to needy families to help spreading the CSA-model. Farmers offer further flexibility by meeting individual demands through pre-orders. Consumers also cooperate with each other in splitting share and home delivery. Excess produce can be offered to other members in an exchange box at the drop off point. Farmers encourage these exchanges between consumers through the mailing list.

\subsection{Financial aspects}

The innovative element in the CSA-model ensures that farmers can cut back on their sales (delivery, marketing, and packaging) cost and through the membership make better production planning and predict revenues. In such way they manage to completely avoid insecurities of conventional small scale farming: dependency and anonymity on single market outlets and food commodity price pressure. As one of the interviewees explained: "the leader of the organic market explicitly told us that we cannot enter the market to be competition for one of the main vendors... it would not be worth to come".

In principle, box prices or shares are calculated based on the operating capital needed to run the farms and accumulated from the full payment in advance of the growing season. However, farmers' self-reported assessments revealed that labour costs, rent, seeds and garden supplies are usually included, but improvements, maintenance, organisational and educational costs, as well as incidental costs are typically excluded from the calculation. In this way CSA farmers do not share the real costs of food production, and consequently consumers are not aware of the whole range of costs.

In practice, the pricing techniques are adjusted to the income level of the community. Some farmers try to further adapt their prices to competitors, vendors at the farmers' market and consumer-operated home delivery systems. The interviews revealed that consumers would flexibly pay higher price if needed, 
although they typically think that the box has a reasonable price, especially compared to the high quality of produce.

While the start-up does not require more investment than producing for and selling on the market, returns and operational costs are expected to stay much lower. Therefore all investigated business plans contain low-key calculations with a gradual increase in revenues. As the interviews pointed out, farmers calculate low revenues that do not even cover wage costs in the first three years. What is clear is that the CSA itself may not provide enough to live on for any of the farmers and in these circumstances each farmer relies on other sources of living. Extra-economic activities extend to gardening or part-time jobs in agriculture. Most farmers already have the necessary farming experience from the past and the capital as well to cover losses. CSA is regarded as an experimenting whereby they do not have much to lose.

Farmers also rely on their already existing trust-based social network to set up the vegetable community. Production risks are kept partly hidden from the consumers or at least not communicated and shared. Membership fees are also set very low: payments by the members only cover the monthly cultivation costs. Consumers also tend to shape the relationship with farmers to be more functional, service-oriented.

As for economic sustainability of the farmer-led CSAs, our research results provide some unexpected information for (potential) CSA operators. Many consumers are not familiar with the concept of CSA and are not willing to pay for positive environmental and social externalities but rather prefer a service-oriented functional CSA model. Farmers are concerned about offering low share prices not entailing to all costs for consumers to be CSA shareholders. It seems that for most consumers the pricing is not transparent. Whole season budgets are divided to be more attractive to low-income consumers.

Farmers invest a lot into community building. As interviews revealed, they regularly finance the operation of CSA from external resources. As a main consequence, farmers are not earning a living wage from their CSA operations and rely on different survival strategies. These include food processing to provide produce with higher added value (ratatouille, pumpkin seed, sea buckhorn for the market); season extension (by electrically or manure-heated hotbed, storage capacity for the winter); collaborative CSA (farmers team up to provide a full-diet assortment of diversified produce throughout the entire season); drop off points (develop infrastructure to reduce transport costs); involvement of members (volunteers for organising pickup points and work on the farm).

To sum up, CSAs integrated by the farmers may not be financially self-sustainable. They operate as nonprofit businesses which are basically regarded by the farmers, consumers and community organisers as social/community enterprises. The model requires labour investment from every participant. As formulated by a consumer, CSAs as social enterprises are rooted in the emotional relationship of farmers towards the land and farming. Beyond farming, operators create and animate communities, fostering a moral economy of human relationships. Solidarity is enhanced through interpersonal relations, community-level commitments and in its institutionalized form, the CSA contracts as well. Building a trusted customer base in alternative networks seems to be at least as vital for the survival of the farm as a more transparent sharing of costs. The more so since, according to the interviews, farmers are well aware that members' motivations change through their participation in CSAs. The expectation of growing members' commitment to the survival of local farms and to local economic activities might also explain, at least in part, the apparently "irrational" attitude of CSA farmers towards the sharing of costs if their CSAs are in an initial phase.

\subsection{Notions of community}

The interview and survey research assessed members' reasons for joining a CSA, as well as members' enduring experience of being members of a CSA community. The majority of members joined their CSA for convenient supply of fresh, healthy, local, organic produce from a producer they personally know. Though they tend to mention environmental protection issues (such as environmentally friendly production methods and less packaging), they rarely explicitly emphasize broader sustainability concerns as reason to pursue 
box schemes. Very few respondents joined their CSA for other ambitions: to build community of like-minded individuals, or solidarity with farmers.

It is also true that customers personally had much trust in farmers, even if they were only less engaged in the sustainability achievements of CSAs. Consumers like to describe their relationship with the farmers as solidarity or friendship. Farmers are considered the most authentic information sources on food quality issues. Conversations with CSA farmers improve cooperation and reinforce the rules of the vegetable community. Sense of community and solidarity with the farmers is reinforced through farm visits when consumers have an insight into the processes and socio-ecological impacts of farming, and the socioeconomic significance of production planning.

The consumer survey revealed an interesting pattern with regard to the enduring experience of being member in a CSA community. Examining the difference between the motivation of joining a CSA and the reported changes in experience of being member of a CSA pointed out the significance of the social: feeling of community membership, personal ties, and even friendship are reported as the main unexpected changes during a CSA experience. Respondents expressed their positive surprises by claiming, for example, of realising "the whole ideal of this initiative" of which "being part is extremely good". Furthermore, respondents reported positive feelings "of being one in the chain of production" and "providing a useful and meaningful time" as unexpected when deciding on joining a CSA. Though it cannot be claimed that very strong ties develop among members, but it seems justified to argue that a CSA initiative provides opportunities to (re-)learn community feeling and relations.

Farmers often feel that the CSA provides them with a desired lifestyle. They continuously look for opportunities to share this experience, offer activities beyond the basic transactions of box delivery. The organisational form (being a family business, a limited company or a cooperative) reinforces and pre-empts social boundaries and internal structure of CSAs. Farmers explore members' motivations and build up cooperative activities on mutual interests. Certainly, they all developed very good social and communicational skills and they actively organise and encourage members to take leading part in seasonal food preparation, exchanges of recipes, and various interactions at the drop off points to meet and socialize.

When talking about the members, farmers consciously avoid the concept of "consumers" and prefer to call CSA participants as "members" to foster community relations. To this end, virtual activities through newsletters, e-mails, blogs, and social media are gaining more and more importance in experimentally creating, recombining and distributing new knowledge for sustainable agriculture. Farmers tend to consider themselves as community developers continuously enhancing their members' commitment. They long for a more collaborative, partnership type of relationship.

\section{$4 \quad$ Discussion and Conclusion}

In sum, our research results point out that Hungarian CSAs are on the move from a functional to a collaborative model as they invest into creating their own community in urban and peri-urban areas (Feagan \& Henderson 2009). Though the CSA movement itself has no long tradition in the country, as we have shown some individual leadership efforts have a history of their own. While the economic significance of CSAs is still marginal in the country, it seems to have a growing future potential. Farmer-led CSAs emerged in the recent years in Hungary as a new type of local food systems. Previous research highlighted that this sector was in the phase of increasing development followed by national level acknowledgement. The empirical research reported here suggests that these relatively new and specific types of farmer-led CSAs can launch a learning process by educating members for consuming healthier and in a more environmentally friendly way on the one hand, and by assisting the development of community relations and solidarity feeling, on the other. In an attempt to live more sustainably, CSA - as Henderson (2003) pointed out - provides unique organizational solutions and reflects the needs, talents, and resources of the farmer and the community. In such farmer-controlled experiment stations the viability of a more local and socially just food system has been investigated (DeLind 1998; Henderson 2003). 
As a main line or argument the chapter showed that CSA farmers pursue a set of socio-economic practices (in production, assortment and delivery of boxes, investments and pricing, and community building) to reach beneficial socio-ecological outcomes on the community level. Cost sharing in farmer led CSAs are replete with paradox. Our findings suggest that for a successful business-rationale and the survival of the farm farmers need to rely on a trusted customer base; therefore in an initial phase they tend not to share all the costs with the expectation of growing members' commitment. Findings capture challenges that emerged as core experiences across the cases and illustrate an important point that has previously not received much attention in the literature. This led us to use the term "agriculture supported community" as a specific but previously unexamined form of moral economy whereby farmers create communities by relying on external financial resources and reaching out to trust based personal networks or ethical consumers (Psarikidou \& Szerszynski 2012). Following Flora and Bregendahl (2012), this chapter suggested that initiatives need to strengthen their economic basis to expand. Results have shown that farmers started to establish a market segment through the building up of new food communities (Hinrichs 2000; Lyson 2004). From the point of view of transition theories, we contend that farmers are the main actors in the protection and consolidation of an innovative CSA niche against predominant market forces. They rely on the help of engaged consumers and the emerging CSA platform.

Communities could survive in the long run if pricing would be more carefully done (involving higher membership fees) and strategies for survival based on outside sources would be harmonized. Policymakers aiming at ensuring sufficient revenues for small-scale sustainable farming may be interested in CSAs that potentially could reshape food chain supply and allow an alternative value repartition among agents. A collaborative network of cooperatively organised CSAs could represent a real and viable alternative to mass produced, homogenous, imported produce found in most supermarkets.

Following a qualitative research design, conclusions are derived from the specific experiences of interviewed farmers and consumers which may not be generalizable to other type of CSAs. Farmers invest into building up of food communities in the Hungarian context of low level of participative culture and weak civil society. With this risky community investment, consumers more easily engage themselves in local food systems. In such circumstances what makes these farmer-led CSAs unique is their potential for catalyse changes in dominant food system, reconnect consumers with producers by fostering a collaborative culture of sharing, gifting, bartering and donating.

Finally, as CSAs expect to get further public funding to extend their services and advocate work to develop community agriculture, it is helpful to highlight the most critical factor this study pointed at with regard to farmer-led CSAs, that is the pricing anomaly which involves unrecognised cost of developing a community. Practically, this calls for sharing best practices to ensure farmers fair return and secure income in the later phases. Further practice-oriented research would be also required to support the fruitful integration of farmers, members and expert-scientific knowledge necessary to solve such difficulties.

\section{References}

Balázs B. (2012) Local Food System Development in Hungary. International Journal of Sociology of Agriculture and Food, Vol. 19(3): 403-421.

Brunori, G., Rossi, A. and Guidi, F. (2012) On the New Social Relations around and beyond Food. Analysing Consumers' Role and Action in Gruppi di Acquisto Solidale (Solidarity Purchasing Groups). Sociologia Ruralis, 52: 1-30.

Hinrichs, C.Clare (2000) Embeddedness and local food systems: notes on two types of direct agricultural market, Journal of Rural Studies, Vol. 16(3): 295-303.

Cooley J.P. and Lass, D.A. (1998) Consumer Benefits from Community Supported Agriculture Membership. Review of Agricultural Economics, Vol. 20(1): 227-237.

Darányi Ignác Plan (2012) Framework programme for the implementation of the National Rural Development Strategy (NVS 2012-2020), Budapest. Published online: http://videkstrategia.kormany.hu/, accessed 31 May 2013. 
DeLind, L.B., 1999. Close encounters with a CSA: the reflections of a bruised and somewhat wiser anthropologist. Agriculture and Human Values, Vol 16: 3-9.

Dupuis, E.M. and Gillon, S. (2009) Alternative modes of governance: organic as civic engagement, Agriculture and Human Values, Vo. 26(1-2): 43-56.

Feagan, R. Henderson, A. (2009) Devon Acres CSA: local struggles in a global food system. Agriculture and Human Values, Vol. 2(3): 203-217.

Flora, C. B. and Bregendahl C. (2012) Collaborative Community-supported Agriculture: Balancing Community Capitals for Producers and Consumers. International Journal of Sociology of Agriculture and Food, Vol. 19(3): 329-346.

Hayes, M., és Milánkovics K. (2001) Community Supported Agriculture (CSA): A Farmers' Manual. How to Start Up and Run a CSA. Nyitott Kert Alapítvány, 2001. 87.

Henderson, E. (2008) Community Supported Agriculture." Encyclopaedia of Community. SAGE Publications. <http://www.sage-ereference.com/community/Article_n119.html>.

Izumi, B.T., Wright, W. and Hamm M. W. (2010) Farm to school programs: exploring the role of regionallybased food distributors in alternative agrifood networks. Agriculture and Human Values, Vol. 27(3): 335-350.

Kneafsey, M., Venn, L., Schmutz, U., Balázs, B., Trenchard, L., Eyden-Wood, T., Bos, E., Sutton, G., and Blackett M. (2013) Short Food Supply Chains and Local Food Systems in the EU. A State of Play of their Socio-Economic Characteristics. JRC Report 25911.

Kortwright R, Wakefield S (2011) Edible backyards: a qualitative study of household food growing and its contributions to food security. Agriculture and Human Values, Vol. 28(1): 39-53.

Kvale, S. (1996) InterViews: an Introduction to Qualitative Research Interviewing. London: Sage.

Lamine, C. (2005) Settling the shared uncertainties: local partnerships between producers and consumers. Sociologia Ruralis, Vol. 45(4): 324-345.

Lyson, T. (2004) Civic agriculture: Reconnecting farm, food and community. University Park: Penn State University Press.

Mariola MJ (2008) The local industrial complex? Questioning the link between local foods and energy use. Agriculture and Human Values, Vol. 25(2): 193-196.

Patton, M.Q. (2002) Qualitative evaluation and research methods, 3rd ed. Newbury Park, CA: Sage.

Psarikidou K. and Szerszynski, B. (2012) The Moral Economy of Civic Food Networks in Manchester. International Journal of Sociology of Agriculture and Food, Vol. 19(3): 309-327.

Renting H., Schermer M. and Rossi A. (2012) Building Food Democracy: Exploring Civic Food Networks and Newly Emerging Forms of Food Citizenship. International Journal of Sociology of Agriculture and Food, Vol. 19(3): 289-307.

Roep, D. and Wiskerke, H. (eds.) (2006) Nourishing Networks: Fourteen lessons about creating sustainable food supply chains, Rural Sociology Group of Wageningen University and Reed Business Information: Doetinchem.

Sík, E. (1992) From the Second to the Informal Economy. Journal of Public Policy, Vol. 12(2): 153-175.

Stagl, S. (2002) Local organic food markets: potentials and limitations for contributing to sustainable development. Empirica, Vol. 29: 145-162.

Vadovics, E. and Hayes, M. (2010) Open Garden - a local organic producer-consumer network in Hungary. System innovation on a number of levels. In: Tischner, U., Stø, E., Kjærnes, U. and Tukker, A. (eds.): System Innovation for Sustainability III. Case Studies in Sustainable Consumption and Production - Food and Agriculture. Greenleaf Publishing, UK. Chpt. 8.

Verhaegen, I., Van Huylenbroeck, G. (2001) Costs and benefits for farmers participating in innovative marketing channels for quality food products. Journal of Rural Studies, Vol. 17(4): 443-456.

Witkamp, M.J., Raven R.P.J.M. and Royakkers, L.M.M. (2011) Strategic niche management of social innovations: the case of social entrepreneurship. Technology Analysis \& Strategic Management, Vol. 23(6): 667-681.

Zsolnai, L., és Podmaniczky, L. (2010): Community-Supported Agriculture. In: Tencati, A. and Zsolnai, L. (eds.) The Collaborative Enterprise: Creating Values for a Sustainable World. Oxford: Peter Lang Academic Publishers: 137-150. 


\title{
Agri-food production in a Hungarian micro- region: Factors influencing farmers' practices
}

\author{
Boldizsár Megyesi ${ }^{1}$
}

\section{Abstract}

This chapter describes different models of agri-food production in a Hungarian rural micro-region. It proposes an analytical framework to understand the differences between these models, and presents the external factors and internal resources which influence farming technologies and practices. The theoretical background of the research is based on the concepts of alternative food networks. There are four types of farms in the study area: agricultural companies, medium-size farms small-scale, or semi-subsistence farms, and social farming, or community gardens. According to the case study mostly small scale farms are involved in alternative food networks. The agricultural methods of large-scale farms are defined by economic factors and market networks. Large scale farming is mostly influenced by agricultural and rural policies and subsidies, and the members of this group consider the less the societal or environmental consequences of their farming practices. This chapter argues that farming methods of these different stakeholders can be better understood using the presented analytical framework. There is difference among the farms regarding their specific networks, their knowledge, and resource use.

The first part of this chapter presents the theoretical background of my research: the changing role of foodnetworks in agricultural restructuring and the changes in land-use and agri-food chains in Hungary in the last two decades. This part also presents a theoretical framework to describe the different knowledge types used by the different farms, the most important resources and networks, and concludes with a possible analytical framework. After describing the methodology of the research, the case study area is presented. It is followed by the detailed description and characterization of farm types and a comparative analysis. Finally, conclusions are drawn.

Keywords: food networks, agricultural restructuring.

\section{Theoretical background}

Recent scientific literature on the changes of rural and agricultural production in Central and Eastern Europe focuses on the effects of privatization (Kovách 2012, Swain 2013), on new forms of cooperation (Chloupkova et al. 2003, Tisenkopfs et al. 2011), and on different types of small-scale farming (JehlickaSmith 2011), while the processes which lead to the concentration of land-use are neglected. In the first part of the theoretical background I shortly describe the recent changes of Hungarian agriculture. There are two main phenomena: the decreasing number of small-scale farms, and their continuously growing technological drawback on the one hand and the emergence of large and medium size agricultural enterprises, with improved infrastructure on the other hand. These processes are the results of land privatisation and development of production infrastructure financed by investors outside the agricultural sector, and the Common Agricultural Policy of the EU.

\footnotetext{
${ }^{1}$ Research fellow, Centre for Social Sciences, Hungarian Academy of Sciences, Budapest, Hungary; visiting research fellow, HÉTFA Research Institute, Budapest, Hungary. Email: Megyesi.Boldizsar@tk.mta.hu
} 
In this chapter I aim to link these changes to the theory of alternative food networks (Lamine 2005, Renting et al. 2012, Fonte 2010), and criticism of the alternative - conventional dichotomy (Morgan et al. 2006). Several authors argue that alternative food systems are not discrete movements, but are part of the agrifood production system (Morgan et al. 2006). Others argue that the dichotomy shadows the differences among the different types of the alternative food networks (Holloway et al. 2007). In this chapter I accept these criticisms, and argue that analysing the different dimensions of farming activity can help us to understand farming practices.

\subsection{Farm structure and land-use in Hungary}

According to certain estimations, in the late eighties around $40 \%$ of food production from small scale farming was self-provisioning. However, there are no reliable data on the proportion of self-provisioning among farmers. There are two ways to estimate the relevance of self-provisioning: on the one hand the number of self-provisioning farms can be assessed, on the other this can be indicated by the proportion of households engaged in agricultural activity. According to the most recent data (Central Statistical Office, Agriculture in Hungary (CSO - Agric in Hun (2010)), the number of farm units is continuously decreasing from 1396 thousand (in 1991) it fell to 960 thousand (in 2000) ${ }^{1}$, and now it is around 575 thousand in 2010. According to the data of the Agricultural and Rural Development Agency 186.126 farms received SAPS in Hungary; it is less than one third $(32,4 \%)$ of the number of total farm units. It means that $68 \%$ of the farms (as defined by the Central Statistical Office) produce on less than 1 hectare. Most of these small farm units are self-provisioning farms as several researches state (Kovách \& Megyesi 2006, Kovách 2012). There are very few data about the other perspective. According to a survey conducted in 2005, around one third (33.3\%) of the Hungarian population is engaged in any kind of agricultural activity (Kelemen \& Kovách 2007:17). According to the estimations of the Central Statistical Office, besides the farm units there are around 1.1 million households with some agricultural activity. It means that there are 1.667 million households actively involved in agriculture at least to some extent. It is around $40,6 \%$ of the households (HCSO - Agric in Hun (2010):2 and Bakos et al.)2.

Originally, there are two types of self-provisioning farms: traditional and leisure farms. Traditional farms, usually originating from peasant type farming are around the household. Leisure farms are the "product of socialism" (Kovách 1982). The site of production is far from the household itself, at the outskirts of the cities, and in frequented tourist areas. Both types used to sell their surplus at local markets and in certain areas also for food processors (Kovách \& Megyesi 2006).

Although land re-privatization in the early nineties resulted in quite dispersed and fragmented land ownership structure, and scholars then argued that it would hinder the development of productive and market lead agriculture (Burger 2001:261-263). Since then it turned out that land ownership and land use diverge: despite land ownership has remained fragmented, land-use is getting more and more concentrated in the last decades (CSO - Agric in Hun (2010)) and land lease prices are increasing continuously (Vranken \& Swinnen 2006: 486).

Statistical data seems to contradict the statement of land use concentration thesis presented above. Figure 1 shows that the proportion of the middle size farms (50-1000 hectares) increased in land-use, while the proportion of small-size farms (1-50 hectares) and large-farms (over 1000 hectares) decreased.

\footnotetext{
${ }^{1}$ http://www.ksh.hu/docs/hun/xftp/idoszaki/pdf/amo7.pdf http://www.mvh.gov.hu/portal/MVHPortal/default/kozerdekmenu/kozerdeku_adatok/tevekenysegi_adatok/kozzeteteli_I istak/Z20080910001.

${ }^{2}$ It is worth noting that even the data of the HCSO are contradictory (see Bakos et al 2011: 121-122).
} 


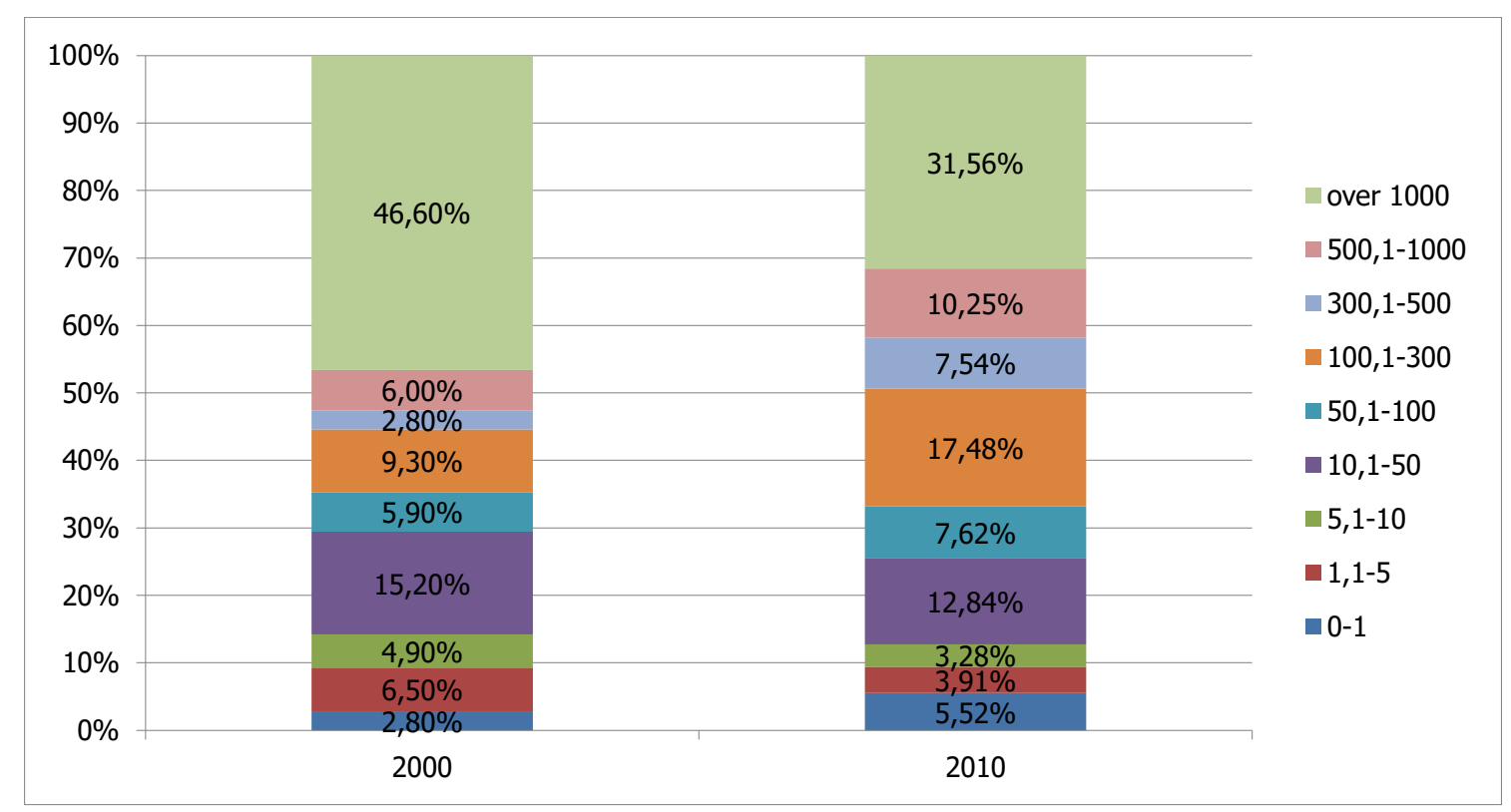

Figure 1. Changes of land use between 2000-2010: Proportion of farms according to the size of cultivated land (\%) (data source: CSO-Agric in Hun (2010)).

The concentration is typical in the middle category, between 100-1000 hectares: while in 2000 farms of this category used $18.1 \%$ of cultivated land, a decade later the farms belonging to this category used $35 \%$ of cultivated land. The proportion of farms over one thousand hectares decreased from $46,6 \%$ to $31,56 \%$. It is worth noting that the size of cultivated area decreased in two categories: in the case of farms using more than one thousand hectares, and in the case of farms cultivating less than 10 hectares, but more than one. The smallest farms (below one hectare) almost doubled their proportion.

To sum up, Hungarian agriculture profoundly changed in the last two decades, there are few new actors and a limited number of new products. Markets changed, product range transformed, so the networks among the producers, and relations between the farmers and the markets became different.

\subsection{Alternative food Networks}

Renting and his co-authors (Renting et al. 2003) describe three main types of non-conventional food networks: alternative food networks (AFNs), which definition focuses on the reflexivity of participating stakeholders, short food-supply chains (SFSCs), which definition focuses on actors and their networks and civic food networks (CFNs). The definition of the latter focuses on the role of (governmental) actors, discourses and the knowledge forms used in developing these networks (Renting et al. 2012:292-293). Although the three concepts refer to the similar phenomena, each emphasizes the role of different factors. In this chapter I aim to integrate these factors into an analytical framework and apply it to the agri-food system of the study area.

In the following I use their definitions as a starting point of the analytical framework, and argue that the uncertainties concerning the definitions are because of the complexity of the phenomena (Holloway et al. 2007). It is argued that the dichotomy of alternative and conventional food networks is problematic, because alternatives are diverse, and there are several factors which make such initiatives viable (not only the economic reasons) (2007:5). Based on the above arguments in the following I aim at presenting an analytical framework by which the different types of agricultural activities can be described and better understood. 


\section{The Analytical framework}

In this chapter, I analyse the different agri-food producers in a micro-region, describing the market relations, knowledge use, resources available to farmers, as well as the main stakeholders involved in farms and farmers' discourses on their own farming practices. In the analysis, I will distinguish three forms of knowledge: local/traditional, managerial and scientific knowledge (Tovey 2008). Analysing knowledge use we found in a previous article that these are interacting knowledge forms (Kelemen et al. 2008). The role of scientific and local knowledge in agricultural production seems to be well-discussed. Scientific knowledge provides overall concepts (e.g. climate change, sustainability), scholarly methods (e.g. modern production methods, or organic farming practices) and information that were previously gathered from different localities (e.g. ethnographical description), which can be used by local and non-local actors in their agricultural practice. However, this requires concepts, methods and information to be translated and adjusted to the local conditions that are best known by local people, which means the need for local (traditional) knowledge in the process. Thus local/traditional knowledge appears in agricultural methods (species, profile of the farm), and in everyday decisions concerning agricultural activity.

Managerial knowledge is neither really scientific nor local. Though it is explicit, specialized and learned in public education and training, it can be informal, experiential and person-bound (Bruckmeier \& Tovey 2008). Managerial knowledge carries site specific elements, albeit it does not belong to certain localities but to a wider institutional and economic environment. The growing importance of managerial knowledge can be related to the emergence of the phenomenon named as project class that mediates and redistributes "public and particularly private development funds and (...) materials, ideas, knowledge and power" (Kovách \& Kucerova 2006:4). However, not only project class members can use managerial knowledge but everyday people as well whose main activity is not related to projects.

In the previous work we argued that in rural development initiatives actors use a complex knowledge set (Kelemen et al. 2008). Without disputing this argument, in the present analysis I focus on the most important knowledge type used by the farmers. Analysing their networks, I differentiate between market networks, person-bound networks (family, neighbourhood), and local networks. Agricultural activities can be also analysed from the perspective of main stakeholders: whether they are initiated by entrepreneurs, civic organizations, or local governments. Reflection about own practice is also a part of the analytical framework. Social, ecological and ethical aspects of farming and farming methods can be mentioned here. Maybe the most problematic part is the one focused on analysing the main resource of a certain farm type. With this factor I aim at presenting the basis of farming. Financial capital, subsidies, land, and free labour force are the most important categories of this variable.

\section{Methods and the Case-study area}

The case-study was conducted as a part of a larger research ${ }^{1}$ on agricultural restructuring of the last two decades in Hungary. It is based on qualitative and anthropological methods: document-analysis, 14 semistructured, four narrative interviews, transect-walking and participatory observation (Yin 1994). We conducted interviews with farmers, local majors, entrepreneurs of food trade/production and agricultural input material traders, planners (at local and county level) civic activists and representatives of local initiatives to create short food supply chains. Most of the interviews were made at the home of the farmer; in the case of majors and civic activists - in their offices. The interviews were recorded and transcribed. The dense interview-guideline was used mainly as a check-list for the interviewer, and the stakeholders were asked to present themselves and their farm. The additional questions were focusing on the development of the farm, on the methods used by the farmers and their future plans. Most of the interviews covered also development projects of the farm (or the enterprise), and the changes of agriculture and land-use in the micro-region.

\footnotetext{
1 "Living from the land" project (100682 OTKA Program).
} 


\subsection{The case-study area}

The case-study was conducted in a small Western-Hungarian micro-region. A small river defines the geography of the area; the surface is highly diverse: acclivities, deep valleys, meadows and pastures lay along the small watersheds, while arable lands and forests can be found in other parts of the micro-region. The settlements of the micro-region belong to the same administrative unit since the late nineties (1887), despite they formed two different local development organizations. Although the county centre is near to the area its connections are weak both by roads and railway. The public transport is weak both within and outside the region, thus it cannot profit too much from the tourism of the neighbouring areas. Thermal waters and springs are the main natural resources of Zalaszentgrót. Churches, castles and peasant houses represent the built cultural heritage, while the elements of local cuisine and agricultural practices represent intangible cultural heritage.

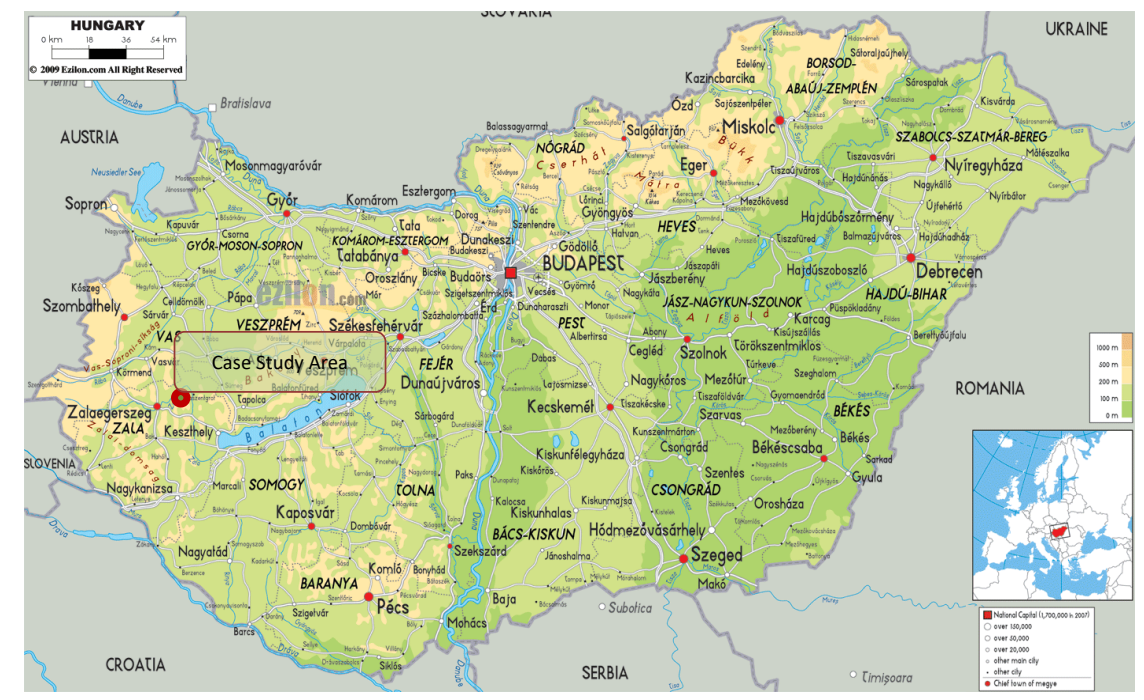

Figure 2. The case-study area

The micro-region consists of 25 settlements, the population is 18 744. There are seven villages with less than 200 inhabitants. The central town has 7823 inhabitants: "The centre of the micro-region is Zalaszentgrót. It can provide public services, and also other services are concentrated here" - as someone told. Depopulation is the major problem of the area; especially the proportion of active and educated labour force is decreasing. Young people with university degree do not come back to the area and in the last ten years also local skilled labour force has moved to Western Europe. As a result, there are several villages with less than 100 inhabitants. The number and ratio of civic organizations are around the county average. Most of them are active at one settlement. The most active organization is the ZalA-kar: it initiated several developments in the micro-region, among them a network to merchandise local food and a community garden in several settlements of the case study area. Also the Strategic Plan emphasizes the role of this association:

"The colourful activity of the civic organization is based on the work of a dozen of enthusiastic people. It is typical, that these people make a lot of efforts, but most of the locals do not notice it. The initiatives of the ZalA-KAR aim at solving this problem by creating community forum, civic groups, and conducting inquiries." (The Strategic Plan of the Micro-region 2007) Furthermore, the wine-route association, and the two main tourism associations are important actors of local civic society.

The economic conditions of the CSA are poor: "the area is an inner periphery of the region" - says a local. Most of the employees find work outside the micro-region, in the county centre, or at the nearby tourist area (Lake Balaton). The central town of the micro-region has now 4 bigger enterprises, but some of them employ workers only in the summer season. Industrial capacities were always low in the micro-region, but 
after the changes of the regime as the socialist type cooperatives collapsed, also their industrial activity disappeared. Once there were dairy, meat production, a mill, fruit and wine processing, nowadays only a mill and a recently established mineral water bottling company represents food industry. The share of industry is $46.6 \%$, while $46.1 \%$ works in the services, thanks to the continuously developing tourism, based on thermal waters. The share of agriculture is around $7.3 \%$. As an interviewee told:

"This is a micro-region, where the unemployment rate is over $12 \%$. Local governments are the major employers, the biggest private company has 250 workers. Most of the enterprises are small and medium size enterprises. It is necessary that civic organizations take the lead in development projects, and become employers themselves." (A local)

\section{The agriculture in Zalaszentgrót area}

\subsection{General characteristics}

The farm structure of the case study area (CSA) is diverse. There are lots of small and medium size farm, and a few large ones. Animal husbandry used to be very important, and it is still notable. Traditional products were fruits, vegetables, pork and dairy products. Now main products are arable crops, and poultry. The former state farm was privatized by the managers, and was sold in 2013 to a neighbouring large farm. There are new actors in agriculture: some townspeople moved here, or bought a second home in the area - according to a development plan. During the last two decades former socialist-types cooperatives and the system of household-farming collapsed. Also, the main markets changed profoundly. Despite the high relevance of agriculture, the quality of the fields was low. That was the reason for fodder and fruit production. The lack of processing industry makes fruit production (berries, apples, pears) impossible. As a consequence of it, former vineyards, and orchards became abandoned. Also the practice of gardening, which used to be widespread, has disappeared.

Different types of private farms became main actors of agriculture. New agri-food networks and new actors emerged: huge agricultural companies, integrated into the national and international agri-food market, medium and small scale family farms selling their products at national and local markets, former workers returning to the countryside and retired town's people starting household farming. Also farming methods became diverse: traditional, organic and high-tech agricultural methods co-exist in the area.

\subsection{Land-use in the CSA}

Table 1 below shows, that the proportion of farms in the case-study area is above both the county and the country average. But comparing the average farm size, the tendencies change: the farms in the case study use smaller lands. The proportion of arable crop farmers is high, more than double of the Hungarian average. In the following this chapter presents the four types of farms in the case study area: agricultural companies, medium-size farms, small-scale farms (semi-subsistence farms), and a new developmental initiative - the social farming or community gardens. 


\begin{tabular}{|c|c|c|c|}
\hline & $\begin{array}{l}\begin{array}{l}\text { Number of } \\
\text { farms (per } \\
1000 \text { inhab.) }\end{array} \\
\end{array}$ & $\begin{array}{l}\text { Average farm } \\
\text { size (ha) }\end{array}$ & $\begin{array}{l}\text { Ratio of arable } \\
\text { crop farmers (\%) }\end{array}$ \\
\hline Case-study area & 130,53 & - & - \\
\hline Companies & 1,24 & 111,89 & 0,06 \\
\hline Family farms & 129,29 & 3,24 & 7,27 \\
\hline Zala County & 89,40 & - & - \\
\hline Companies & 1,21 & 155,09 & 0,07 \\
\hline Family farms & 88,19 & 2,14 & 5,55 \\
\hline Hungary & 56,93 & - & - \\
\hline Companies & 0,85 & 216,57 & 0,05 \\
\hline Family farms & 56,08 & 3,42 & 3,11 \\
\hline
\end{tabular}

Table 1. The role of agriculture in the Case Study Area (HCSO-GAC, 2011)

\subsection{Agricultural companies}

Agricultural companies are specialized in arable crop production or animal husbandry, each using more than 300 hectares and applying conventional methods. These farms rent the land, thus land use and land ownership diverges from each other. They have long-term contracts and stable market-relations, use scientific and managerial knowledge. These farms can benefit the most from the EU-subsidies.

One of the biggest farms in the area is a limited company, the successor of the former State Farm. The State Farm was established in the 1949, it was privatized by the managers in the early nineties, and in 2012 it was sold to a foreign investor. Although it used to work on more than 6000 hectares, nowadays the company cultivates around 1300 hectares; the company have three main branches: plant growing, animal husbandry and pellet production (as fodder). Main crops are wheat, barley, sunflower, rape, and alfalfa. The company has 300 dairy cows. This branch of the farm produces loss since a few years.

Plant-growing is based on modern technology: the farm has all the necessary machinery; they can employ agricultural engineers specialized in plant protection, plant nutrition, and pay the tractorists. They also use qualified seeds; thanks to the favourable climatic and soil conditions the yields are higher than the microregional average. In the previous years the company developed plant-growing branch using own resources, and development founds. In the next years it aims at developing the stalls, and milk-house to make also animal husbandry profitable. Milk is sold to the same dairy company, but cereals, sunflower and raps are sold almost every year to different buyers.

There is another company of similar size: it is owned by a local famer and his family. They privatised the former socialist type cooperative and started plant growing on around 1100 hectares; the land used by them has been continuously growing in the last decades. They also used own financial resources and subsidies to develop their farm, and plan to start animal husbandry again. They employ tractorists, and cooperate with a free-lance agricultural engineer to discuss the problems of plant protection and nutrition. Apart of them, there are three actors using or owning more than 300 hectares: one of them is a farmer from Austria (commuting daily, and having here only few machinery and 3 workers), and two people from the capital, who do not farm actually, but lease their lands. 


\subsection{Medium-size farms}

There are two types of the medium size farms: on the one hand there are farms which have a diverse product range: from plant protection to animal husbandry. Their market relations are weak and uncertain, but have a dense, informal cooperation with neighbouring farmers, and they use a mixed knowledge set (Kelemen et al. 2008). There are farmers among them who seek to establish direct consumer relations. On the other hand, there are farms using 100-300 hectares producing wheat, raps and sunflower with usually one employee, hired machinery and fix buyers.

A typical medium size farm with animal husbandry has around 150 hectares land. Main crops are corn, wheat, alfalfa and other fodder plants. Such farms always have grasslands. The farmers are self-employed, involve family members and have one or two contract workers. They usually have stall-feed cows (20-50), or poultry, but there is a dairy farm also. This latter one is a special case: they also process the milk and sell dairy products at local markets. Most of them have some kind of agricultural education, and worked for the socialist type cooperative. They also use their local, traditional knowledge. The farmers of this group have no own resources - they can develop their farm using MADR resources and a bank loan. The failure of an investment risks the whole existence of the farm.

The second group of medium size farmers are specialized in arable crops. They produce wheat, corn and sunflower on 150-250 hectares. Such farmers have very old machinery and one employee (a tractorist). Although they do it as a main activity, they do not invest in farming and do not plan to develop their farms. Most of the farmer has a university degree and other family members do not work for the farm. They used to work for the cooperative. There activity is based on their professional and scientific knowledge.

In the micro-region, there are two integrator companies which are active in the wider region (in Transdanube). They have a special role as providers of input materials (machinery, seeds, nutrients, plant protection materials), owner of storage capacity, organizers of (bank)loans and buyers of arable crops. Mainly agricultural companies and medium size companies use their services. One of the integrator companies is the successor of a fertilizer-branch of a former cooperative. The other one was established in the early nineties as a small shop for fertilizers and pesticides. The owners are the managers themselves and they have eminent role in the organization of local agriculture, as they can introduce new fertilizers, pesticides, new plant protection methods.

\subsection{Small-size farms}

The group of small scale farms is mixed: the smallest farms are semi-subsistence farms, but the bigger ones are producing mainly for the market. The members belonging to the first category are locals who always produced some vegetables, fruits, some animal products. They used to be workers of local factories, former cooperative, or local institutions, but some of them moved here from bigger towns. Farmers belonging to the latter group are selling most of their products. They do not have other sources of income. Despite this diversity these farmers have some common characteristics: they farm on small plots, produce both for self-consumption, and sell their products at the local farmers' market, or from the farm gate, as they have weak market relations. The members of this group established a shop for local products and aim at developing a farmers' market. Their activity is labour-intensive, built mainly on their own labour force, and if necessary on family networks. The different sub-groups use different knowledge forms, and also their discourses on their farming practices are different.

The product range of semi-subsistence farmers is wide, very diverse and specialized: one of them produces goat-cheese, others produce honey, or pumpkin-oil, and there are producers and collectors of aromatic plants and herbs. The goat cheese producer ${ }^{1}$ started to farm in 2004 (ten years ago), as a hobby. Presently they use around 29 hectares; and offer different dairy products, young animals and agri-tourism services. They tend to use environmental friendly methods, and create an animal-friendly breeding method.

\footnotetext{
${ }^{1}$ http://www.nubiasaithaz.hu/magunkrol/
} 
They learned cheese production during the years. Their knowledge is based on scientific, traditional elements and own experience. The products are sold at the local farmers' market, and for their guests.

The bee-keeper has around 320 bee-families at two locations and a small shop for bee-keepers. He took his business from his father. Earlier he used to work, but since a few years he lives exclusively on bee-keeping. He has both traditional and scientific knowledge. He sells all his products at the local markets.

The oil-producer ${ }^{1}$ has very few land: only 0.7 hectares. She belongs to the group of semi-subsistence farms. Her main product is pumpkin oil, but she produces also nut-, poppy seed- and apricot-seed oil. She frequently refers to the health benefits of her oils. She sells her products at the local market, but this is only a secondary income.

The herb and aromatic plant producer, the herbarist, uses only 2.3 hectares land. He started his activity only two years ago (in 2012). Besides the production, he aims at organizing the collection of wide-herbs. To promote his idea and herb-production, he established a social cooperative, and to process the herbs he plans to build a herb-distillery. The products are sold at the local market, from the farm-gate, but he seeks to find new marketing channels. He gained his knowledge from books, thus it is a kind of scientific knowledge.

The analysis of the market relation of these farms shows that they use the most actively alternative marketing channels.

\subsection{Social farming}

Social farms are special forms of farming, organized by local governments to support landless locals. Similarly to the social-land programs, the initiative aims at encouraging locals to start (again) household farming. This form became popular after 2012, when the Hungarian government launched a program to support local social economy. Local governments are eligible for support from the program. They can cover some investment costs and the wages of the participating locals from it. Since then several such initiatives were launched in the case study area, as social cooperatives or community gardens. Local governments involved in these programs unemployed locals for low wages. Usually they use the land hired or owned by the local government. The product range is wide: usually different fruit and vegetables, but sometimes the organizers also offer poultry and pig keeping possibilities for locals. Originally social farming and community gardens were initiated by civic associations, but nowadays local governments took over the initiatives. In the case study area each initiative used professional and scientific knowledge. In one case the mayor had agricultural education, in another case they got advice from a retired agronomist.

In one of the small villages of the case study area the mayor decided to start a social farming initiative: the initiative hired the land from several elderly locals, who could not cultivate it anymore, and bought a plot in the village. They are producing different fruit: plums, raspberry and nuts, and jams and syrups. The nuts produced in social farming are sold together with the nuts originating from the own plantation of the mayor to Western-Europe. They also produce potatoes, corns and wheat for local consumption, and different vegetables. The production covers mostly local needs. The initiative started to develop an oil-producing unit using LEADER resources, aims at developing a small carpenter branch. They also plan to establish a local shop to sell their products. At the moment they employ 9 persons in agriculture, and 15 more in other branches. They use the local, managerial and scientific knowledge of the mayor, who has agricultural education. The mayor keeps this initiative as essential to provide employment for the locals.

\footnotetext{
${ }^{1}$ http://www.gastrolaj.hu/
} 


\section{Comparison}

In the following I compare the four main forms of agricultural practice of the case-study area, using the analytical framework presented above. The dimensions of the comparison are the resources, networks, knowledge forms used in farming, the reflexivity of the farmers and the main stakeholders.

In the case of the agricultural companies market relations are the most important influencing factor. Instead of medium and small-scale farms these companies react fast to the changes of market situation and change product structure according to it. They have established networks, they can rely on. Dense networks help these farms to choose new suppliers or buyers but, as an interviewee emphasized, do not substitute the attention of the managers.

Their most important resources are the land they can use, and the ERFA subsidies they can get. They use their relationships towards decision-makers to gain information (and to a less extent to influence decisions). They use scientific and managerial knowledge. Scientific knowledge is used in production: large-scale companies can afford to hire educated engineers specialized in plant protection and animal husbandry, while medium and small scale farms the owner or the only manager should have had all the specific knowledge. The access to scientific knowledge is mirrored also by the higher yields of large-scale companies. Managerial knowledge is important in the project activity of these farms, but as earlier researches showed, also rural development policies resulted that large scale farms were the most successful in gaining ERFA subsidies (see for example: Megyesi 2012).

The most important resource for the medium size farms are the complex knowledge set of the farmers, and to a less extent the family networks. Their weak market relations and the uncertainties concerning land-use make their activities vulnerable. For small-scale farms the free labour force of the farmers are the most influent factor of farming; as the farmer has more free-time, he or she seeks to work more. They mostly rely on local networks when asking for help, or selling their products. They use traditional and local knowledge. Usually small-scale farmers are reflective concerning their practices and emphasize the effect of farming on the environment, on animal well-being or on the health of the consumers. Social farming is initiated and lead by the local governances presently. They are built on the free labour force of the locals. In farming local and managerial knowledge is used. The managers of the initiative are reflective: they usually speak about the aims of their activity: to provide employment for locals and encouraging food selfprovisioning.

\begin{tabular}{llllll}
\hline Farming system & $\begin{array}{l}\text { Main } \\
\text { resource }\end{array}$ & $\begin{array}{l}\text { Main } \\
\text { networks }\end{array}$ & $\begin{array}{l}\text { Knowledge } \\
\text { form }\end{array}$ & $\begin{array}{l}\text { Reflex- } \\
\text { ivity }\end{array}$ & Stakeholders \\
\hline $\begin{array}{l}\text { Agricultural } \\
\text { companies }\end{array}$ & $\begin{array}{l}\text { Land, } \\
\text { subsidies }\end{array}$ & Market & $\begin{array}{l}\text { Scientific and } \\
\text { managerial }\end{array}$ & No & Entrepreneurs \\
\hline Medium-size farms & Land & Family & $\begin{array}{l}\text { Complex } \\
\text { knowledge set }\end{array}$ & No & Entrepreneurs \\
\hline Small-scale farms & $\begin{array}{lllll}\text { Free labour } \\
\text { force }\end{array}$ & $\begin{array}{l}\text { Neighbourh } \\
\text { ood }\end{array}$ & $\begin{array}{l}\text { Traditional / } \\
\text { local }\end{array}$ & Yes & Locals \\
\hline Social farming & $\begin{array}{l}\text { Free labour } \\
\text { force }\end{array}$ & Local & $\begin{array}{l}\text { scientific } \\
\text { managerial }\end{array}$ & Yes & Local governance \\
\hline
\end{tabular}

Table 2. Factors influencing farming system (most important factors are underlined) (own design)

According to the case study, mostly small-scale farms are involved in alternative food networks, but there are also medium-size farms and social farms using alternative channels. In the case of alternative food networks, free labour-force and local knowledge are the most important resources, while for large scale farming - financial resources and scientific knowledge. The agricultural methods of large-scale farms are defined by economic factors and market networks. 


\section{Conclusion}

Following the analysis, agricultural companies and social farming are mostly influenced by policy decisions. Large scale farming is mostly influenced by agricultural and rural policies and subsidies, and members of this group consider less the societal or environmental consequences of their farming practices. Decisions are based on economic calculations.

Social farms are influenced by state supports; without them they would not be able to pay their employees or invest in farming. Such farms are completely dependent on state policies, as they are not present at the free market. They do not build relationships with the alternative food networks, neither produce proper quantity to sell products for whole-sale traders.

Above, I argued that the farming methods of the different stakeholders can be better understood using the presented analytical framework. There is a clear difference between specific networks, in knowledge use, in involved stakeholder and in the relevance of the different resources. Policy formulation needs to take into account it to reach sustainability goals, as the different decisions has strong impact on each farm types.

Acknowledgements: This work was done within the "Living from the land" project (OTKA Program). The work on this study was supported by the Bolyai Postdoctoral Scholarship of the Hungarian Academy of Sciences and the European Union and the State of Hungary, co-financed by the European Social Fund in the framework of TÁMOP4.2.4.A/ 2-11/1-2012-0001 'National Excellence Program'. I would like to thank all interviewees for their help and participants of the SISA workshop for their comments.

\section{References}

Bakos et al. (2011) Magyarország [Hungary] Hungarian Central Statistical Office.

Bruckmeier K. - H. Tovey (2008) Knowledge in Sustainable Rural Development: From Forms of Knowledge to Knowledge Processes In: Sociologia Ruralis Special Issue: Special Issue on Rural Sustainable Development in the Era of Knowledge Society, Vol. 48(3): 313-329.

Burger, A. (2001) Agricultural development and land concentration in a central European country: a case study of Hungary, In: Land Use Policy, Volume 18(3): 259-268.

Chloupkova, J. - Svendsen, G. L. H. - Svendsen, G. T. (2003) Building and destroying social capital: The case of cooperative movements in Denmark and Poland. Agriculture and Human Values. Vol. 20: 241-252.

Fonte, M. (2010) Naming Food After Places. Food Relocalisation and Knowledge Dynamics in Rural Development. Ashgate.

Holloway L. - Kneafsey M. - Venn L. - Cox R. - Dowler E. - H. Tuomainen (2007) Possible Food Economies: a Methodological Framework for Exploring Food Production-Consumption Relationships. In Sociologia Ruralis Vol. 47(1): 1-19.

HCSO - Agric in Hun (2010) Magyarország mezőgazdasága, 2010 Általános mezőgazdasági összeírás (Végleges adatok), KSH 2012 (http://www.ksh.hu/docs/hun/xftp/idoszaki/gszo/amo10.pdf) In English: Agriculture in Hungary, 2010 - preliminary data based on the $12.5 \%$ of the questionnaires ((http://www.ksh.hu/docs/eng/xftp/idoszaki/amo/eamo10elo1.pdf).

Jehlicka, P. - J. Smith (2011) An unsustainable state: contrasting food practices and state policies in the Czech Republic. Geoforum Vol. 42(3): 362-372.

Kelemen E. - Megyesi B. - I. Nagy-Kalamász (2008) Knowledge Dynamics and Sustainability in Rural Livelihood Strategies: Two Case Studies from Hungary. Sociologia Ruralis Vol.4 8(3): 257-273.

Kovách I (1982) Termelök és vállalkozók (Producers and entreprenaurs) Budapest.

Kovách I. (2012) A vidék az ezredfordulón (Rural Hungary at the Millenium) Bp. Argumentum.

Kovách, I. - Megyesi, B. (2006): 4. Local Food production and Knowledge Dynamics in Rural Sustainable Development - In: Local Food Production Non-agricultural economy and Knowledge Dynamics in Rural Sustainable Development, the Polish, Hungarian and Czech cases; MTA PTI Digitális Archívum, Mühelytanulmányok, p. 24-38 (http://mek.oszk.hu/04000/04024/04024.pdf). 
Lamine, C. (2005) Settling Shared Uncertainties: Local Partnerships Between Producers and Consumers. Sociologia Ruralis Vol. 45(4): 324-345.

Megyesi B. (2012) Institutions and networks in rural development: two case studies from Hungary In: Stefan Sjöblom, Kjell Andersson, Terry Marsden, Sarah Skerratt (eds.) Sustainability and Short-term Policies: Improving Governance in Spatial Policy Interventions. 310 p. Surrey: Ashgate, pp. 217244.

Morgan, K. - T. Marsden - J. Murdoch (2006) Worlds of Food: Place, Power, and Provenance in the Food Chain. Oxford University Press, New York.

Renting, H., Marsden, T. and Banks, J. (2003) Understanding alternative food networks: exploring the role of short supply chains in rural development. Environment and Planning A Vol. 35(3): 393-411.

Renting H. - M. Schermer - A. Rossi (2012) Building Food Democracy: Exploring Civic Food Networks and Newly Emerging Forms of Food Citizenship. International Journal of Sociology of Agriculture and Food Vol. 19(3): 289-307.

Svendsen, G.H.L - Svendsen, G.T (2004) The creation and destruction of social capital, entrepreneurship, co-operative movements and institutions. Edward Elgar Publishing.

Swain N. (2013) Green Barons, Force-of-Circumstance Entrepreneurs, Impotent Mayors. Rural Change in the Early Years of Post-Socialist Capitalist Democracy. CEU Press Budapest-New York.

Tisenkopfs T. - I. Kovách - M. Lostak - S. Sumane (2011) Rebuilding and Failing Collectivity: Specific Challenges for Collective Farmers Marketing Initiatives in Post-Socialist Countries. International Journal of Sociology of Agriculture and Food. Vol. 18(1): 70-88.

Tovey H. (2008) Introduction: Rural Sustainable Development in the Knowledge Society Era. Sociologia Ruralis Vol. 48(3): 185-199.

Vranken, L. - J. Swinnen (2006) Land rental markets in transition: Theory and evidence from Hungary, In: World Development, Vol. 34(3): 481-500.

Yin, R. K. (1994) Case study research. Design and methods. Thousand Oaks/ London / New Delhi, Sage Publications. 


\title{
Understanding Trends in Consumer Food System Participation: Implications for Agri- food Movement Mobilization and Systems Change in the Northwestern United States
}

\author{
Marcia R. Ostrom ${ }^{1}$
}

\section{Abstract}

This chapter examines trends in the attitudes and behaviors surrounding food consumption and food sourcing in the northwestern United States, their social movement dimensions, and the potential outcomes for structural change. Research across the full spectrum of food system actors suggests promising opportunities to reshape conventional agri-food production and market relationships, however, it also reveals a complex array of motivations for participation in alternative food initiatives (AFIs) and key vulnerabilities and obstacles to lasting change. This chapter utilizes current theoretical understandings of the globalization of the food system and the dynamics of social movements as a basis for investigating the configurations, tactics, and effectiveness of locally driven initiatives and their outcomes for improving agrifood system sustainability Structural barriers to systems-level change are identified and the potential of various mobilizing frameworks to overcome them are discussed.

A social movements theoretical framework will be utilized to investigate the role of consumer ideological orientations and the effectiveness of local agri-food initiatives in driving larger food system innovation and institutional change. The results of random sample consumer telephone polling, farmer surveys, and participatory research with AFIs in Washington State will be analyzed to address underlying questions about the motivations and values-basis of food system participation. The motivational frames, behaviors, and movement orientations of various actors within the food system, including consumers, farmers, AFI organizers and institutional actors, will be analyzed to determine their degree of frame alignment with the goals of agri-food system sustainability and the potential for collective action.

Keywords: food system, food movement, social movement, food consumption, sustainable agriculture, food system regionalization, values-based food supply chains, alternative food initiatives, local food, food and environment, food democracy, consumer values, direct marketing, food sovereignty

\section{Introduction}

This chapter examines trends in the attitudes, behaviors, and meanings associated with food consumption and food sourcing in the northwestern United States and their social movement dimensions. Research across the full spectrum of food system actors suggests promising opportunities to reshape conventional agri-food production and market relationships, however, it also reveals a complex array of motivations for participation in alternative food initiatives (AFIs) and key vulnerabilities and obstacles to creating transformative systems level change. This chapter utilizes current theoretical understandings of the globalization of the food system and the dynamics of social movements as a basis for investigating common public perceptions about food and the configurations, tactics, and effectiveness of locally driven

\footnotetext{
${ }^{1}$ Associate Professor, School of the Environment and Center for Sustaining Agriculture and Natural Resources, Washington State University, Wenatchee, Washington, United States of America. Email: mrostrom@wsu.edu
} 
strategies for change in Washington State. This research will provide an overview of consumer views of food and agriculture, describe the landscape of alternative food initiatives in this region, and discuss some of the key barriers preventing more widespread adoption of such innovations. Finally, the potential for various mobilizing frameworks to overcome these obstacles is considered.

Export agriculture is a key driver of the Washington State economy, with over 9.12 billion USD (6.65 billion EUR) in farm sales, 80,000 people employed in agricultural production, and 37,249 total farms (USDA 2012). A diversity of micro growing zones, a temperate climate, and large-scale irrigation systems offer growing conditions suitable for over 250 different commercial crops on 15 million acres of farmland, making this among the most agriculturally diverse state after California. In particular, Washington is famous for orchards and wheat; it is the largest apple-producing region in the U.S. exporting to all 50 states plus 60 different countries. Over $85 \%$ of the wheat crop is exported internationally, primarily to Japan and other Asian countries. Other top commodities include dairy, vegetables, potatoes, beef, hay, legumes, and seed crops.

Despite this agricultural abundance, only a very small portion of the food that is consumed in Washington is actually grown in the state. Consequently, a wealth of independent local initiatives led by entrepreneurial individuals with a passion and personal commitment to sustainable foods have emerged to create alternative market channels that more closely link production and consumption. Alternative foods may be differentiated from the dominant commodity system by attributes such as place, origin, quality, production or labor practices, environmental values, or the identity of the producer, recognizing that, as pointed out by Follet (2009), some of these foods may only constitute "alternatives" to varying degrees.

The central research question is whether these spatially and organizationally disconnected initiatives to create alternative food supply chains through such channels as farmers markets, Community Supported Agriculture (CSA), food hubs, farm-to-chef programs, and institutional food buying can succeed in realizing any degree of democratic control or transformation of the conditions of food production and distribution within a region. It is challenging, however, to systematically analyze whether such present-day AFIs and their supporters can mount a meaningful counter movement to the intensifying reach and dominance of corporate-controlled global agri-food conglomerates (Heffernan 1999, Howard 2009a, b).

\section{Social Movements Theory as an Analytical Framework}

Attempts to circumvent, reshape or resist the dominant agri-food system are unfolding globally at a variety of arenas, scales, and locations. Good research has been amassed on the dynamics of global-level restructuring and the emerging transnational, corporate and political forces that currently compete to control the world's food supply (Heffernan 1999, McMichael 1994, Patel 2007, Roberts 2008, Howard 2009a,b). However, in many of these political-economic formulations the control of the global food system by monolithic, macro-level entities such as "corporate food regimes," "food system clusters," "agri-food complexes" and supranational world trade bodies appears inevitable, and grassroots movements for change, by comparison, appear weak and ineffective. Such accounts tend to be very good at conceptualizing the way the macro-level conditions the micro, but sometimes preclude our ability to comprehend with any depth, the significance of agency emanating from the ground up.

In contrast, a burgeoning new body of agri-food system literature focuses on concrete examples or case studies of food system change occurring in very specific, place-based, localized contexts (Alkon 2008, DeLind 1999, Follet 2009, Hayden and Buck 2012, Hinrichs 2000, Maxim 2006). These studies analyze, critique, and sometimes celebrate the progress of a particular CSA farm, urban farm, farm-to-school project, farmers market, restaurant, food hub or local branding project. When viewed autonomously, however, such community-based, entrepreneurial food and farming projects can easily be dismissed by critics as "feel good" success stories or isolated local struggles constituting no more than a "minor irritant" to the broader powers at work in the corporate-dominated, global capitalist system (Magdoff et al., 2000:188). What is missing is a systematic way of understanding how or whether these place-based initiatives that appear to be simultaneously emerging with increasing frequency across community, regional,

Published under a Creative Commons license 
and national landscapes are connected, and whether they, indeed, have any influence or oppositional power that extends beyond the diffuse and particularized solutions developed in specific local contexts.

Social movements (SM) theory offers an analytical framework for systematically assessing the significance of a broad spectrum of food system participation from the dominant commodity system, to values-based or "reflexive" purchasing by individuals and institutions, to engagement in AFIs, to explicit attempts to create social, economic, and political change through collective action. Benford and Snow have developed the concept of "framing," as originally set out by Erving Goffman (1974), as a construct for analyzing the "relationship between ideological factors - values, beliefs, and meanings - and identification with social movements and participation in their activities" (Snow and Benford 1988: 197, Benford and Snow 2000). Food, with its multi-layered symbolic, cultural, and material meanings, and profound implications for the environment, trade, and labor, provides a rich arena for such an analysis.

Frame analysis helps to identify the strengths and weakness of the organizational configurations, cultural shifts, identity networks, and negotiated outcomes characteristic of AFIs. Social movements that seek to reconfigure the agri-food system employ a variety of tactics and innovations aimed at changing farming and marketing practices, public policies and institutions, and, ultimately, the meanings and cultural understandings associated with what it means to eat (Ostrom 2007). When the discourse around food can be "reframed" to include a connection with farmers, the environment, community health or social justice, food begins to take on a larger meaning beyond a commodity or a purely economic good.

Because of their rapid proliferation, the state of Washington provides an interesting arena to investigate the dynamics of alternative agri-food initiatives. A focus on framing processes will be used to make sense of the changes taking place in Washington State and whether they have any larger significance in terms of a movement. After briefly describing our research methods, I will provide a broad overview of the landscape and extent of AFIs in the state. Next, I will share some highlights from our research findings. Finally, I discuss the significance of these findings for agri-food movement mobilization and the steps needed to address barriers and scale up sustainable, regional food sourcing.

\section{Methods}

This study utilizes a mixed methods research design that incorporates a variety of data collection approaches to assess trends and analyze the perspectives, roles and movement orientations of current actors in the Washington agri-food system. This chapter integrates data obtained from the three sources described below.

\subsection{Consumer Research.}

Dillman's Tailored Design Method was used for all consumer and farmer surveys ${ }^{1}$ (Dillman et al, 2009). Consumer data was gathered from two large-scale, geographically representative, random-digit dial telephone polls with Washington residents in 2002 (950 completed responses) and in 2010 (1027 responses). Response rates were $23 \%$ and $28 \%$ respectively, considered highly reasonable for a telephone poll. Data was also gathered using dot surveys at farmers markets with 4,720 shoppers between 2009 and 2011 (Ostrom and Donovan 2011).

\footnotetext{
1 The survey procedures known collectively as the "Tailored Design Method (TDM)" have been shown to significantly improve response rates through personalized communication strategies, user-friendly designs, mixed-mode options, and incentives. Both closed and open-ended questions are formatted to facilitate a response (Dillman et al., 2009: 304).
} 


\subsection{Farmer Research.}

A random sample of 3,718 farm addresses was drawn from the list of all farmers maintained by the Washington State Agricultural Statistics Service to understand the broad extent of farmer interest in testing alternative markets. Using Dillman's Tailored Design Method (Dillman et al. 2009), we used a mail survey to obtain an adjusted response rate of 49\% (see Ostrom and Jussaume 2007 for details). Second, using a mixed mode online and paper method, we surveyed a targeted group of 1200 direct market farmers comprised from lists provided by farmers market managers across the state. Again following the Dillman Tailored Design method, we obtained a response rate of $43 \%$ (Ostrom et al. 2012). Finally, U.S. Agricultural Census data was analyzed from 2002-2012 for farm numbers, characteristics, and direct market trends (USDA 2012).

\subsection{Participatory Action Research with Alternative Food Initiatives (AFIs).}

Research was carried out in partnership with AFls and non-profit partners from 2009-2014. Due to funding availability and their significance to food system stakeholders, farmers markets (FMs) were a central research focus. Together with stakeholder partners, we formed a "farmers market action team" to guide our research, analysis, and educational outreach. After working with non-profits to identify 169 markets in the state that met our definition of a farmers market, meaning there were five or more actual farmers present per market day selling their own products, all FMs were contacted for mail/online surveys and telephone interviews with managers. Because of our strong partnerships with farmers market leaders in the state, we were able to obtain an exceptionally good response rate of $78 \%$ (see Ostrom and Donovan 2013). A sample of markets was also studied using participant observation, focus groups, consumer surveys and participatory "Rapid Market Appraisal" techniques, again working with cooperative market managers and boards of directors (Lev et al. 2008). We also investigated numbers and characteristics of CSA farms, farm delivery services (box schemes), values-based supply chains (Ostrom and Stevenson 2013) and food hubs. Participant observations and secondary data were collected on emerging food policy councils, state and county-level regulatory frameworks, government agencies, and public agricultural support organizations. Non-profit food system organizations and organizers of AFls have been partners throughout the research process, an essential factor for gaining access to data and study populations.

Thus our data collection methods allowed us to sample a broadly representative sector of the general public and a representative group of the state's farmers. This breadth was complemented by targeted surveys and in-depth research with participants in AFIs and participatory action research with AFI leaders and non-profit groups.

\section{$4 \quad$ Findings}

Research findings will be reported from two levels of research: (1) the extent and types of alternative food marketing and distribution initiatives found in Washington and (2) consumer attitudes, beliefs, and values regarding the food system (frames), ranging from those held by the general public to those held by participants in AFIs. 


\subsection{Mobilizing Frameworks: The Landscape of Alternative Food Marketing and Distribution Initiatives in Washington}

\subsubsection{Extent of Farmer Engagement in Alternative Marketing}

In response to an agricultural export economy that has steadily squeezed out small and mid-sized farms and the moderate-scale processing, distribution, and retail infrastructure that supported them; various new forms of direct and regional food supply chain innovation are taking root in the northwestern U.S. Our research has shown widespread engagement and interest in alternative, direct-to-consumer market relationships by farmers. Because they involve personalized, direct relationships between producers and consumers, farmers markets and CSA are often seen as providing a framework that promotes civic engagement in agriculture (Lyson 2007). Such shortened supply chains are seen as noteworthy for their potential to capture economic value for farmers and to reengage and educate the public in agrarian concerns such as farm viability and farmland preservation while, at the same time, providing incentives for farmers to reorient their production towards agroecological approaches and the interests of local consumers.

Based on the random sample mail survey of the state's general farming population, Table 1 illustrates the extent to which different types of direct-to-consumer marketing strategies were being employed by Washington farmers.

\begin{tabular}{llll}
\hline & $\begin{array}{l}\text { Vegetable Growers } \\
(\mathbf{N}=\mathbf{1 1 8})\end{array}$ & $\begin{array}{l}\text { Fruit Growers } \\
(\mathbf{N}=\mathbf{3 3 2})\end{array}$ & $\begin{array}{l}\text { All Growers } \\
(\mathbf{N = 1 , 1 6 6 )}\end{array}$ \\
\hline Roadside Stands/Stores & $46.3 \%$ & $21.2 \%$ & $12.2 \%$ \\
\hline Farmers Markets & $35.2 \%$ & $15.3 \%$ & $8.2 \%$ \\
\hline You-Pick Farms & $23.4 \%$ & $12.9 \%$ & $6.8 \%$ \\
\hline CSA & $8.4 \%$ & $2.1 \%$ & $1.7 \%$ \\
\hline Use any of above methods & $59 \%$ & $30 \%$ & $20 \%$ \\
\hline Plan to increase direct & $48.8 \%$ & $22.6 \%$ & $25.3 \%$ \\
\hline
\end{tabular}

Table 1: Washington Farmer Participation in Direct Markets (Adapted from Ostrom and Jussaume (2007:242) based on a statewide random sample farmer survey).

The results displayed in Table 1 suggest that the use of direct marketing methods among farmers has become fairly common, especially among vegetable and fruit growers. Roadside stands or stores, followed by farmers markets and you-pick farms were the most common way that vegetable and fruit farmers sell their products directly to consumers. Almost 60 percent of vegetable growers reported using direct marketing and 46 percent said that they planned to increase their use of these methods (Ostrom and Jussaume 2007). Over one-fourth of growers overall said they planned to increase their use of direct marketing.

The U.S. agricultural census also found fairly widespread engagement with direct-to-consumer markets by the state's farming population, including farmers in predominantly commodity production areas (see Figure 1). However, our own farmer survey, found higher numbers of farmers participating in direct-to-consumer markets, possibly because of a higher response rate from these types of farmers. The volume of sales 
moving through direct market channels, as recently reported in the U.S. agricultural census at $45,124,000$ USD $(32,896,298)$ appears low (USDA 2012).

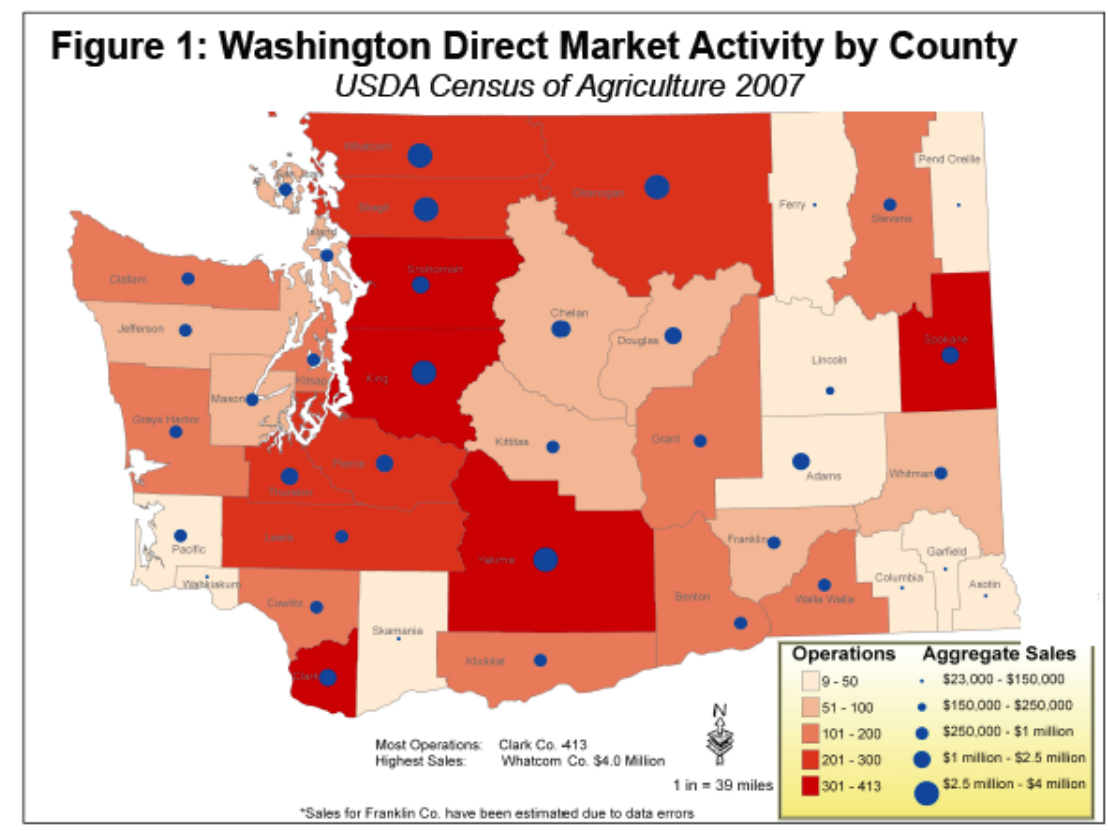

Mapped by Jeremy Sage 2010

It is likely that farmers are employing a "mix" of marketing methods, including a combination of conventional wholesaling and alternative marketing strategies to add income and reduce risk through market and crop diversification. Although these methods may be important to their overall business strategy they may not sell a high volume through any single channel (Ostrom and Jussaume 2007; Ostrom et al. 2012).

\subsubsection{The Role of Farmers Markets}

Farmers markets in the U.S. constitute a unique, material public space where farmers, consumers, and community organizers come together and interact. Nearly obsolete in Washington and elsewhere in the U.S. until a few decades ago, the revival of the community-based farmers market has become increasingly important to the profitability and survival of many small, beginning, and immigrant-owned farms and perhaps the most visible pillar of local food movements. They have also become increasingly popular with city governments and urban planners interested in revitalizing nearby business districts.

Based on our strict definition of a "farmers market" (meaning at least five farmers in attendance), the number of markets in Washington has exploded over the past four decades, increasing 10-fold, from just 16 markets in 1978 to 169 in 2011 (Figure 2). 


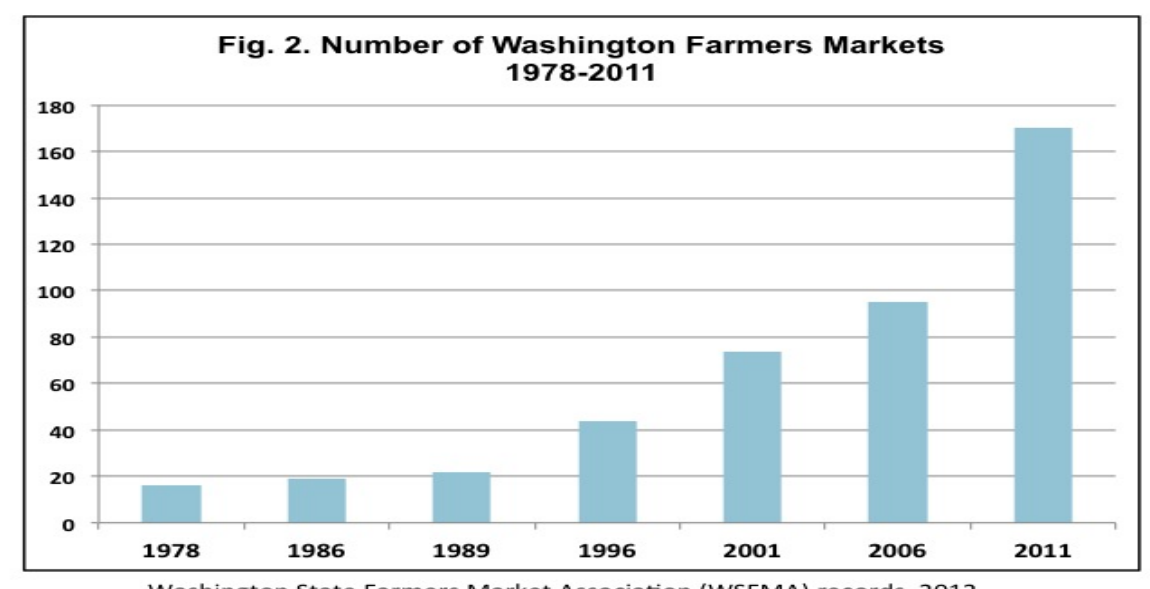

Washington State Farmers Market Association (WSFMA) records, 2012

Today these markets range in size from 5 to 100 farmers each, provide market outlets for an estimated 1,200 different farmer vendors, attract from 50 to 5,000 customers per day each, and have estimated combined sales of over $\$ 50$ million annually (Ostrom and Donovan 2013). Two markets in the state reported sales of over 5 million dollars per year (Ostrom and Donovan 2013). This rapid growth in the numbers of Washington farmers markets mirror national trends, where the United States Department of Agriculture lists 1,755 markets in 1994 as compared with 8,144 in 2013, a 364 percent increase in two decades (USDA AMS Marketing Services Division 2013).

As organizations, our market manager survey found that many FMs have a "mission" or social movement component. Three-fourths are organized as non-profits, while 14 percent operate under private business licenses, and another eight percent are supported by government agencies, such as parks and municipalities (Ostrom and Donovan 2013). When surveys asked FM managers to describe their organizational structure and share the primary goals of their organization, the highest numbers of responses were evenly split between the goals of (1) supporting farmers (38\%) and (2) providing community access to fresh and healthy foods (37\%). The next highest response category was to support community economic development, followed by bringing the community together (Ostrom and Donovan 2013).

The social movement oriented goals of many market organizations and their farmers are also evidenced by a commitment to making products available to low-income community members. Over $130 \mathrm{FM}$ organizations voluntarily participate in the Farmers Market Nutrition Program (FMNP), a federal government program to assist low-income shoppers obtain fresh produce, despite the fact that the added paperwork to accept these payments can outweigh any monetary benefits to the market. Likewise, farmer vendors at FMs express a firm commitment to serving low-income shoppers. Around $68 \%$ of individual farmers have been through an approval process to accept coupons from senior shoppers and WIC (women, infant, and children) food assistance programs. When questioned about their motives for going through this process, over $87 \%$ said it was important or very important to enable low-income consumers to buy their products (Ostrom and Donovan 2012).

\subsubsection{Other socially innovative alternative marketing initiatives}

While less common than farmers markets and farm stores, Community Supported Agriculture (CSA) is steadily growing in the Northwest, with 388 Washington farms reporting sales through this channel on the recent U.S. Census of Agriculture (USDA 2012). In 2001, there were only 80 known CSA farms in the state. Perhaps the most direct challenge to conventional market relationships (Ostrom 2007), the CSA model asks consumers to share in agricultural risks by paying a farmer in advance to receive a "share" of whatever is harvested from the farm each week. CSA farms in Washington may supply from 5 to 600 weekly farm shares, each designed to serve a family of four. Besides growing, harvesting, and distributing seasonal organic produce, CSA farms often emphasize public education, volunteerism, and community building. 
A variety of other creative market relationships are evolving among farmers and food cooperatives, independent grocers, health food retailers, restaurants, schools, and hospital cafeterias. Public schools appear poised to increase local food buying (WSDA 2014). The Washington State Department of Agriculture reports that at least 60 farmers are registered to sell products directly to schools (WSDA 2012). Of school districts surveyed in the state, over 90 percent say they are "very or somewhat interested" in purchasing Washington grown foods directly from farmers (WSDA 2012). Restaurants are providing increasingly dependable markets for locally and sustainably raised foods. The Seattle area is a national center of culinary innovation for seasonal and local foods. Around 50 area chefs belong to the Seattle Chefs Collaborative with a mission of supporting local farmers and sustainable farming practices (SCC 2012a). A number of directories and "farm finder" websites, some with regularly updated fresh sheets, have been developed to help chefs and institutional food buyers source local farm products. Recently, the Seattle Chefs Collaborative developed a "Road Map to a Greener Restaurant" guidebook to assist area chefs and beginning chefs with assessing and improving their local food procurement strategies (SCC 2012b).

Other collective marketing strategies and AFIs under development include a multi-farm CSA collective that serves over 1000 customers, a weekly home delivery service that aggregates organic produce from over 60 farms and delivers weekly shares to 20,000 households, and regional "food hubs" where products from large numbers of small and mid-sized farms can be aggregated, distributed, and collectively marketed to wholesale and specialty buyers. Five such "food hub" projects are under development in the state and 100 have been identified nationally (USDA 2012). Numerous food system assessments have been carried out by local community food organizations in the state and some have resulted in the formation of food policy councils, most notably the Puget Sound Food Policy Council serving the greater Seattle region.

\subsection{Consumer Food Purchasing Perspectives and Frames}

A comparison of our two sets of consumer telephone survey results from 2002 and 2010 with a broadly representative set of respondents offers a useful measure of how food buying trends and attitudes in Washington may have evolved during the past decade. Our results show a steady growth in the number of consumers who purchase food directly from farmers at farmers markets, at farm stores and roadside stands, at You-pick farms, and through CSA. In 2002, 31 percent of respondents said they never purchased directly from farmers, 43 percent said they did so once a month or less, and 26 percent said they did so twice a month or more. In the 2010 survey, the comparable figures were 19 percent who said never, 45 percent said once a month or less, and 36 percent said twice a month or more. Respondents in 2010 who never shopped at farmers markets, farm stores, roadside stands or You-pick farms were asked to identify the main reason for not doing so. In both surveys, the most common reason given $(32 \%$ and $43 \%$ ) was that there was no market nearby.

In both surveys, a large percentage of respondents expressed an interest in buying more local products. The percentage of those expressing interested in buying more of various products locally increased gradually over time (Table 2), suggesting that the potential for increasing local sales continues to steadily expand.

\begin{tabular}{lll}
\hline & $\begin{array}{l}\mathbf{2 0 0 2} \\
(\mathrm{N}=950)\end{array}$ & $\begin{array}{l}\mathbf{2 0 1 0} \\
(\mathrm{N}=1027)\end{array}$ \\
\hline Vegetables & $82 \%$ & $83 \%$ \\
\hline Fruits & $81 \%$ & $83 \%$ \\
\hline Eggs & $52 \%$ & $60 \%$ \\
\hline Beef & $36 \%$ & $42 \%$ \\
\hline Poultry & $34 \%$ & $40 \%$ \\
\hline
\end{tabular}


Table 2: Percentage of Washington consumers interested in purchasing more local foods (Random digit-dial telephone polls, Ostrom and Jussaume 2002, 2010)

At both time periods, Washington consumers were also asked to rate the importance of a variety of food attributes when making purchasing decisions. Again, there was a remarkable consistency across the different time periods. Figure 3 suggests that the intrinsic qualities of the food are highly important to consumers, regardless of where they shop.

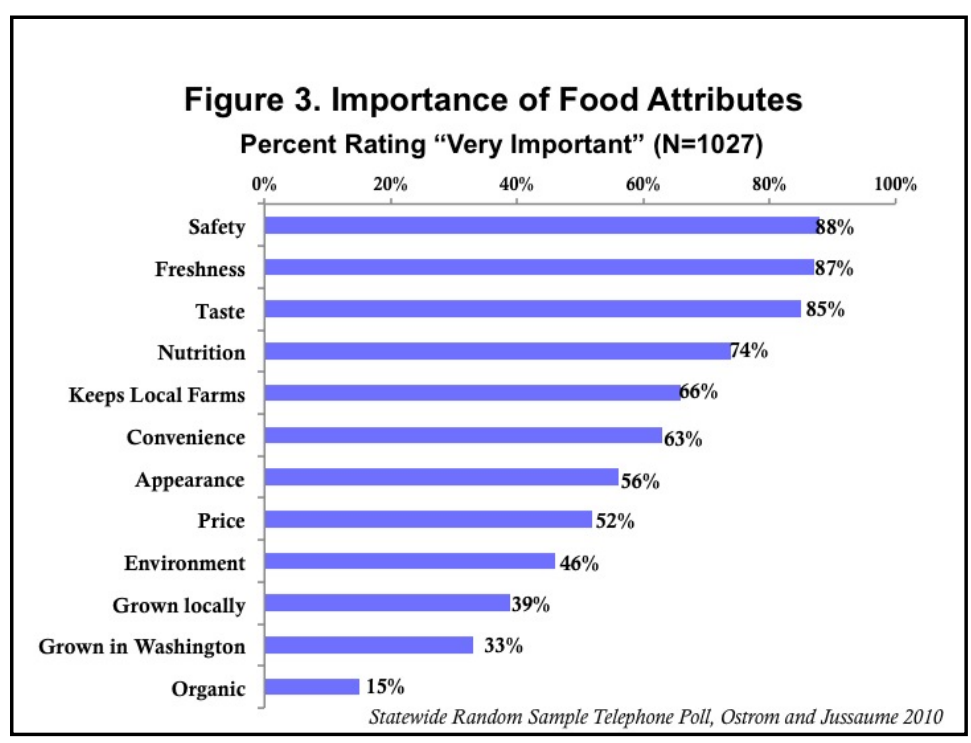

Similar to other consumer research results from the U.S. (see Hartman 2010), Figure 3 shows that consumers are highly concerned with safety, followed closely by the "quality" of the food in terms of freshness, taste, and nutrition. These are primarily self-interested motivations, however, other researchers have found that these criteria are interwoven with other ethical values in complex ways (Hartman 2010). Interestingly, in our research over eight years, both surveys found that the most important "civic" priority associated with food was a strong interest in helping to keep local farmers in business, with 66 percent of respondents feeling that this was very important. If this question is phrased differently, however, to simply ask how important it is for food to be "grown locally," only 39 percent feel it is "very important."

Consistent with other research, consumer motivations for food purchasing choices were found to be a complex mixture of self-interest and civic values (Ostrom 2006, 2007; Hartman 2010). While the results reported above come from random sample polls of the general population, these mixed motivations can also be seen among consumers who are already participating in AFIs. For example, in surveys of CSA participants, the top reasons for joining a CSA farm were listed as obtaining fresh and nutritious produce, an individualistic goal, followed by obtaining local produce and helping small farmers, a civic minded goal (Ostrom 2007: 109). When farmers market shoppers were surveyed about their single most important reason for being at the market, Figure 4 shows their top two choices were: "help a local farmer," followed by "healthy food." It could be worth conducting further research to investigate whether farmers market customers are distinct from other consumers in putting the farmer's interest before their own self-interest or whether this is an artifact of using a different survey method. 
Figure 4. Primary reason for shopping at a FM? WA Farmers Market Shoppers $(\mathrm{N}=4,720$ )

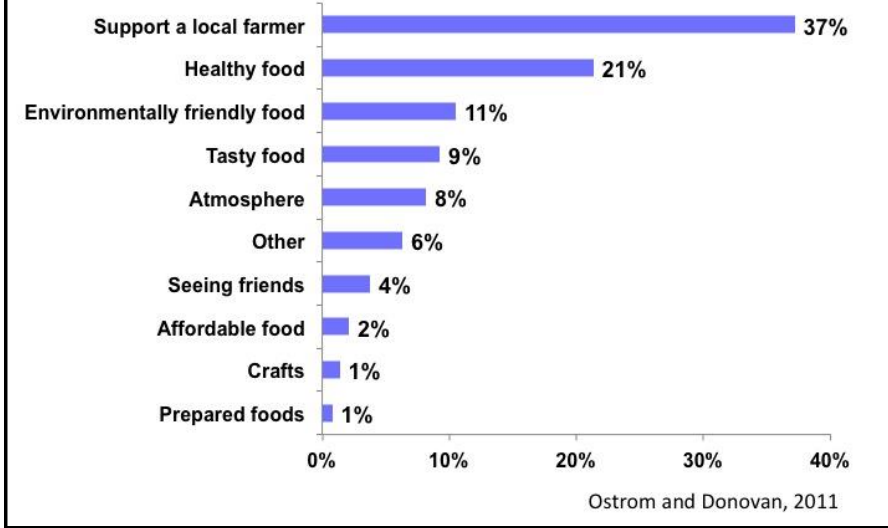

In spite of the variety of meanings that consumers associate with local foods (Ostrom 2006), research shows consistency across time in the willingness of consumers to pay more for them (Table 4). But, this willingness to pay has limits. A majority of respondents say that they are agreeable to paying slightly more: 10 percent. Around a fifth would pay 25 percent more. The willingness to pay more falls off quickly after this. Nonetheless, these results reinforce the overall interpretation that consumers in most parts of Washington feel committed to supporting local food and farmers monetarily to at least some degree.

\begin{tabular}{lll}
\hline & $\begin{array}{l}\mathbf{2 0 0 2} \\
(\mathrm{N}=950)\end{array}$ & $\begin{array}{l}\mathbf{2 0 1 0} \\
(\mathrm{N}=1027)\end{array}$ \\
\hline Not willing to pay more & $23 \%$ & $20 \%$ \\
\hline Willing to Pay 10\% more & $54 \%$ & $55 \%$ \\
\hline Willing to Pay 25\% more & $21 \%$ & $22 \%$ \\
\hline Willing to Pay 50\% more & $2 \%$ & $3 \%$ \\
\hline
\end{tabular}

Table 3: Percentage of Washington consumers willing to pay more for local foods (Statewide Random Sample Telephone Polls, Ostrom and Jussaume, 2002, 2010)

Thus, consumer commitment to alternative foods can be viewed as occurring along a continuum of motivational frames. As Figure 5 suggests, some consumer orientations show high civic and movement potential, while others are more self-serving. The survey research has indicated that shifts in favor of local food purchasing are occurring over time. Most consumer frames include an overlapping combination of practical and idealistic goals, with a core group that is explicitly pursuing systems level change in the food system (Ostrom 2007). 
Figure 5: Continuum of Consumer Interest in Alternative Foods

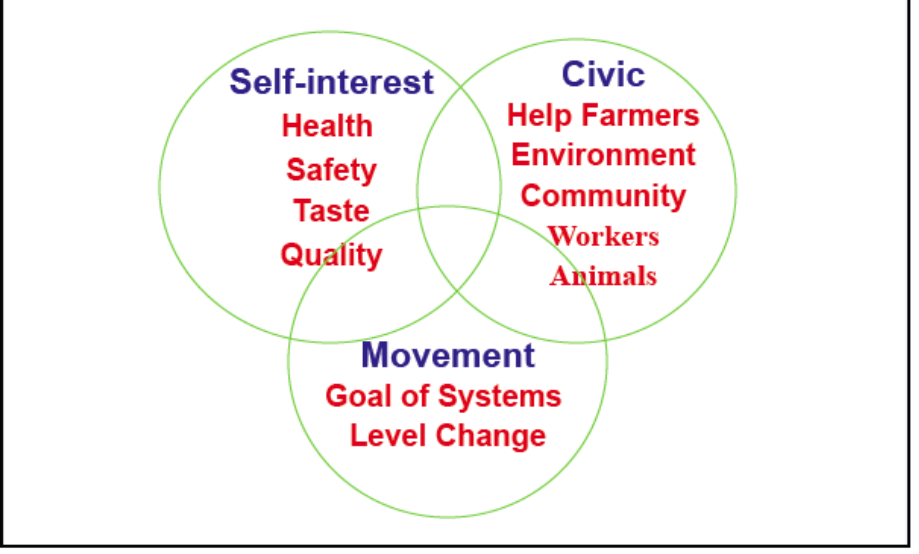

\section{Discussion}

As detailed above, citizens in the northwestern U.S. are engaged in alternative agri-food production, distribution, and marketing activities in record numbers. However, the rapid growth of interest and participation in alternative food value chains cannot be assumed to further the ideals of civic agriculture, environmental sustainability, democratic control of agri-food systems, or food justice (Hinrichs 2000, Allen et al. 2003, Ostrom and Jussaume 2007). How should we evaluate these new market forms in terms of their effectiveness as drivers of change towards more sustainable, democratic, or just food and farming systems? How do we assess their resilience and persistence in the face of powerful mainstream market forces? As Hinrichs (2000) and Allen et al. (2003) point out, direct marketing practices, while shortening the food supply chain, in and of themselves do not ensure that marketing or production practices are embedded in alternative social or ecological value systems that further sustainability, community food access, or food justice goals. Indeed, as discussed, from the standpoint of the actors, participation in alternative agri-food networks can involve mixed motives, simultaneously furthering both self-interest and civic interests.

Taken altogether, it is important to carefully consider what these new trends mean in terms of progress towards movement goals. At the farm level, the influence of alternative marketing structures and the incentives they provide to improve farm practices and environmental outcomes can be difficult to decipher. There is some evidence to show that participation in alternative markets has inspired farm management changes such as crop and livestock diversification, organic certification, and soil building (Ostrom and Donovan 2012), however, data still needs to be collected on the amount of acreage that is under cultivation specifically to supply direct markets and how it is being managed. As described above, the results of random sample consumer polling do not show the attributes of "organic" or "environmentally friendly" as high-ranking priorities so direct contact with consumers cannot be assumed to have the desired effect of incentivizing improvements to the ecological footprint of farming. On the other hand, random sample surveys of farmers show a statistically significant correlation between farmer participation in direct marketing and organic certification (Ostrom and Jussaume 2007). It seems likely that a strong consumer focus on food safety has resulted in increased organic food demand (Hartman 2010).

From the consumer side, we still need to know more about the ability of various AFls and popular media coverage to prompt consumer "reframing" of the issues around food. Do AFIs simply attract consumers who already hold particular food frames or do they inspire participants to transform their frames from individualistic health and safety values to civic values? We have some initial evidence from in-depth CSA studies and farmers market research that such transitions can happen as a result of participation (Hayden 
and Buck 2012, Ostrom 2007, Ostrom 2013), yet further research is needed to see how widespread these dynamics are.

Thus, our research results indicate a proliferation of alternative food production, distribution and marketing models and steady growth in the numbers of consumers, farmers, retailers, and institutional food buyers claiming support for alternative food supply chains. Nevertheless, despite vast agricultural production capacity, an increasingly sympathetic public, and widespread sustainability claims by public institutions, private companies, and policy makers; only a tiny fraction of the Northwest food supply chain is currently sourced from sustainable and organic regional producers. What are the most significant barriers to making alternative foods the mainstream?

Regional food system assessments and our research with farmers and consumers engaged in AFIs suggest a number of obstacles that still need to be addressed. Most critical is a serious loss of the appropriately scaled farming, processing, transportation, distribution, and marketing infrastructure needed for meeting local food demands; and the rising cost of farmland near population centers (Ostrom and Jussaume 2007, UW 2011). In Washington, as in other highly productive commodity agricultural regions of the U.S., the existing physical and regulatory infrastructure, the farm support policies, and the technical and educational systems are largely designed to support industrial scale, export agriculture (Ostrom 2006, Ostrom and Jussaume 2007). There has been a steady loss of small and mid-sized processing facilities over the past 20 years and those that remain are designed to handle large quantities of undifferentiated products for export. Especially in meat packing, it can be difficult for small, independent operators to even get through the door, let alone retain a unique identity and standards for their products. A lack of processing and distribution infrastructure is exacerbated by prohibitive food safety and health regulations that drive out processors and entrepreneurs with limited capital for meeting constantly changing facilities requirements.

The regulatory burden from local health jurisdictions, and state and national entities is far higher for diversified farms with multiple intensively farmed crops, low capital for infrastructure investments, and no administrative staff or record-keeping support. There is far more paperwork and permitting required to sell a value-added product to a neighbour than to take wholesale crops to the packing house or to the auction yard to ship out. Particularly in the meat processing industry, due to a lack of inspected facilities that accept small producers, local sales of meat cuts have been all but eliminated in some areas. Similarly, even in the most productive wheat regions, it is nearly impossible to find bread for flour or in the fruit growing regions, it is difficult to find products like ciders, fruit pies, jams and jellies, etc. made from local products. Small-scale producers oriented towards local food markets have a high need for assistance and education on how to comply with the demands of a complex in-state regulatory environment, however the State Department of Agriculture has been primarily focused on providing assistance for export crops.

The future expansion of alternative agri-food networks in Washington will depend on their ability to scale up regional food system linkages by addressing these infrastructural and regulatory barriers. Another key issue will be finding ways for aspiring producers in regional markets to access farmland and water. It remains to be seen whether struggles to bridge and coalesce the disparate players in alternative food systems can succeed in mounting coordinated, collective efforts to reform policy, address regulatory barriers to local trade, and amass the needed resources to rebuild missing processing and distribution infrastructure.

In a time of shrinking public investment in agriculture and increasing environmental crises, determining the most appropriate response of public agricultural universities and government agencies to citizen priorities related to the agri-food system has critical implications. While in general, citizen support for diversified, environmentally sustainable, regionally-based agricultural food production and distribution systems seems high, our findings suggest a misfit with the institutional priorities and directions of many publicly funded agricultural institutions (Ostrom and Jackson-Smith 2005). The next steps required for institutional and policy reform will require a new level of organization on the part of concerned citizens. It appears that, at least a minority of food system participants are involved with the "collective action" end of the spectrum and are designing strategies to target public institutions and policies. 
Over the course of this research, targeted citizen policy initiatives have resulted in a several observable, long-term institutional changes at the Washington State Department of Agriculture and Washington State University, the public agricultural college. Also, in response to citizen requests, the governor created a statewide Food and Farming Policy Roundtable that is engaging representatives from all state agencies in examining policies around local market development, processing infrastructure, farm and farmworker livelihoods, environmental issues in agriculture, and equitable food access. At the federal level, a recent publication by the U.S. Congressional Research Service speaks to the role of these citizen movements: "many community and farm advocacy groups have been arguing that such food systems should play a larger policy role within the next farm bill, and that laws should be modified to reflect broader, more equitable policies across a range of production systems, including local food systems" (Johnson et al. 2013). While goals of "more equitable policies" at the national level are still far from reality, these social movements for food system change have not gone unnoticed by state and federal lawmakers.

\section{Conclusion}

How long it will take to sufficiently address the structural barriers to scaling up alternative food production and distribution networks is unclear. However, it is clear that alternative agri-food movements have succeeded in opening up a new public discourse or conversation about food. Our research with the general public, government agencies, and with participants and organizers of AFls shows that for many Northwest residents, the way food is framed has been expanded beyond personal health and culinary preferences to include the economic and agroecological challenges of farmers and farm workers and the struggle to build equitable food access. A new dialogue about the meaning and politics of food appears to be occurring at local, regional, and national levels. New sets of meanings, ideas, and ideals have been set in motion and are being taken up and debated by the larger society.

Although it is certainly still true that the control of the agri-food system in the Northwest resides with highly concentrated, powerful global actors, the AFIs studied here have indisputably carved out new public spaces for democratic decision-making, knowledge creation, and problem solving to occur. The transformative potential of alternative food movement organizations appears to lie in their ability to catalyze cultural shifts and evolutions in the values, ideals, and meanings associated with food from the purely personal to wider societal concerns. Translating these emerging new value systems around food into systems-level change, however, will now require mobilizing collective action that is coordinated across individuals, movement organizations and institutions. The substantial policy and infrastructural barriers to sourcing any significant amount of food through sustainable regional food channels cannot be overcome by individuals or even institutions making informed purchasing decisions, but rather will require collective action strategies that bridge an emerging sense of individual agency with targeted political action strategies at multiple levels.

\section{References}

Alkon, A. (2008). Paradise or Pavement: The Social Constructions of the Environment in Two Urban Farmers' Markets and Their Implications for Environmental Justice and Sustainability. Local Environment 1.3 (3): 271-289.

Allen, P., FitzSimmons, M., Goodman M., and K. Warner. (2003). Shifting plates in the agrifood landscape: the tectonics of alternative agrifood initiatives in California, Journal of Rural Studies. 19: 61-75.

Benford, R. D. and D. A. Snow (2000). Framing processes and social movements: An overview and assessment. Annual review of sociology, 611-639.

DeLind, L. (1999). Close encounters with a CSA: the relfections of a bruised and somewhat wiser anthropologist. Agriculture and Human Values. 16:3-9.

De Schutter, 0. (2014). "The Transformative Potential of the Right to Food," Report of the Special Rapporteur on the Right to Food, United Nations General Assembly, Human Rights Council, twentyfifth session, January 24.

Dillman, D. A., Smyth J.D. and L. M. Christian. (2009). Internet, Mail and Mixed-Mode Surveys: The Tailored Design Method, 3rd edition. NJ: John Wiley and Sons. 
Follett, J. R. (2009). Choosing a Food Future: Differentiating Among Alternative Food Options, Journal of Agricultural and Environmental Ethics. 22 (1): 31-51.

Goffman, E. (1974). Frame analysis: An essay on the organization of experience. Harvard University Press.

Hartman Group. (2010). Beyond organic and natural report overview. An industry series report. Bellevue WA: Hartman Group Inc. Accessed 5-2012 at: http://www.hartmangroup.com/publications/reports/beyond-organic-and-natural

Hassanein, N. (2003). Practicing Food Democracy: A Pragmatic Politics of Transformation. Journal of Rural Studies. 19: 77-86.

Hayden, J. and D. Buck (2012). Doing community supported agriculture: Tactile space, affect and effects of membership, Geoforum. 43 (2): 332-341.

Heffernan, W. (1999) Report to National Farmers Union: Consolidation in the Food and Agriculture System. Department of Rural Sociology, University of Missouri, Columbia, Missouri

Hinrichs, C. (2000). Embeddedness and local food systems: Notes on two types of direct agricultural market. Journal of Rural Studies 16: 295-303.

Howard, P. H. (2009a). Consolidation in the North American Organic Food Processing Sector, 1997 to 2007. International Journal of Sociology of Agriculture and Food, 161), 13-30.

Howard, P. H. (2009b). Visualizing consolidation in the global seed industry: 1996-2008. Sustainability, 1(4), 1266-1287.

Johnson, R., Aussenberg, R.A., \& Cowan, T. (2013). The role of local food systems in U.S. farm policy. Congressional Research Service. 7-5700. R-42155. Accessed 4-2014 at: https://www.fas.org/sgp/crs/misc/R42155.pdf

Keane, J. and P. Mier. 1989. Preface in Alberto Mellucci, Nomads of the Present. Philadelphia: Temple University Press.

Lev, L., Brewer L. and G. Stephenson, 2008. "Tools for Rapid Market Assessments" Special Report 1088-E, Oregon Small Farms Technical Report http://smallfarms.oregonstate.edu/sites/default/files/small-farms-tech-report/eesc 1088-e.pdf

Lyson, T. A. (2007). Civic Agriculture and the North American Food System. In Remaking the North American Food System: Strategies for Sustainability. C.C. Hinrichs and T.A. Lyson. Lincoln and London, University of Nebraska Press: 19-32.

Magdoff, F., Bellamy Foster J., and F. Buttel (2000). Hungry for Profit. New York: Monthly Review Press.

Maxim, N. (2006). "Mission Possible." Gourmet. June.

McMichael, P. (Ed.). (1994). The global restructuring of agro-food systems. Cornell University Press.

Melucci, A. (1989). Nomads of the present. Philadelphia: Temple University Press.

Organic Farming Research Foundation (OFRF) (2012). Organic FAQs. Accessed 5-1-2012 from: http://ofrf.org/resources/organicfaqs.html

Ostrom, M. (2007). The Contribution of Community Supported Agriculture (CSA) to Movements for Change in the Agri-Food System. In Remaking the North American Food System: Strategies for Sustainability. C.C. Hinrichs and T.A. Lyson. Lincoln and London, University of Nebraska Press: 99120.

Ostrom, M. (2006). Everyday meanings of local food: Views from home and field. Journal of the Community Development Society. 37 (1): 65-78.

Ostrom, M. and G.W. Stevenson (2013). "Values-based food supply chains: Full Circle," case study series developed for USDA NIFA Agriculture and Food Research Institute, \#2010-85211-2057, "Multi-farm Business Strategies and Policy Considerations for 'the Middle' of the U.S. Agri-food System." http://www.cias.wisc.edu/values-based-food-supply-chain-case-study-full-circle

Ostrom, M. and C. Donovan (2013). "Summary Report: Farmers Markets and the Experience of Market Managers in Washington State," USDA National Institute of Food and Agriculture (NIFA), Agricultural Food Research Initiative, Grant \#2009-55618-05172, "Engines of the New Farm Economy: Assessing and Enhancing the Benefits of Farmers Markets." http://csanr.cahnrs.wsu.edu/wpcontent/uploads/2013/11/WSU-FMMS-report-Nov-2013.pdf

Ostrom, M. and C. Donovan (2012). Preliminary results of farmers market vendor survey, USDA NIFA, Agricultural Food Research Initiative, Grant \#2009-55618-05172, "Engines of the New Farm Economy: Assessing and Enhancing the Benefits of Farmers Markets." 
Ostrom M. and C. Donovan (2011). "Rapid Market Assessments: Dot Survey Results," USDA NIFA, Agricultural Food Research Initiative, Grant \#2009-55618-05172."Engines of the New Farm Economy: Assessing and Enhancing the Benefits of Farmers Markets."

Ostrom, M. and R. Jussaume (2007). Assessing the Significance of Direct Farmer-Consumer Linkages as a Change Strategy: Civic or Opportunistic? In Remaking the North American Food System: Strategies for Sustainability. C.C. Hinrichs and T.A. Lyson. Lincoln and London, University of Nebraska Press: 235-259.

Ostrom, M. and D. Jackson-Smith (2005) "Defining a Purpose: Agricultural Extension, Land Grant Research, and Diverse Farm Constituencies," Journal of Sustainable Agriculture. 27(3): 57-76.

Patel, R. (2007). Stuffed and Starved. Melville House Publishing: Brooklyn, N.Y.

Roberts, P. (2008). The End of Food. Houghton Mifflin: Boston and New York.

SCC (2012a). Seattle Chefs Collaborative. Accessed 5-15-2012: http://seattlechefs.org

SCC (2012b). Seattle Chefs Collaborative. "Road Map to a Greener Restaurant." Accessed 5-15-2012. http://courses.washington.edu/studio67/psrcfood/Food_studio_docs/Nol09_Green_Restaurants.p df

Snow, D. A. and R. D. Benford. (1988) Ideology, Frame Resonance, and Participant Mobilization. International Social Movement Research 1:197-217.

USDA (2013) "National Count of Farmers Market Directory Listing" USDA AMS Marketing Services Division, Graph: 1994-2013. Accessed 3-29-2014: http://www.ams.usda.gov/AMSv1.0/ams.fetchTemplateData.do?template=TemplateS\&leftNav=Wh olesaleandFarmersMarkets\&page=WFMFarmersMarketGrowth\&description=Farmers\%20Market\%2 OGrowth

USDA (2012). United States Department of Agriculture, U.S. Census of Agriculture. Accessed 5-2-2014: http://www.agcensus.usda.gov/Publications/2012/Full Report/Nolume 1, Chapter 2 County Lev el/Washington/

University of Washington (UW) (2011). Food Hubs Central Puget Sound. Vol. 6. Food system assessment prepared for the Puget Sound Regional Council, June. Accessed 3-20- 2012: http://courses.washington.edu/studio67/psrcfood/Food_studio_docs/Nol6_Food_Hubs.pdf

Washington State Department of Agriculture (WSDA) (2012). Personal correspondence with Tricia Kovacs, Washington State Farm to School Coordinator, WSDA, June 6, 2012.

Washington State Department of Agriculture (WSDA) (2014). "Participating Farms and Schools," Accessed 5-1-2014:

http://www.wafarmtoschool.org/Content/assets/Participating_Farms_and_Schools_Final.pdf

Washington State Farmers Market Association (WSFMA) (2012). Personal communication and data collection with Executive Director, Karen Kinney, http://www.wafarmersmarkets.com

Whitman, H., Desmarais, A. and N. Wiebe (2010). The origins and potential of food sovereignty. In Food sovereignty: Reconnecting food, nature and community. H. Witman, A. Desmarais and N. Wiebe. Halifax and Winnipeg, Fernwood Publishing; Oakland, Food First; Cape town, Dakar, Nairobi and Oxford, Pambazuka Press. 


\section{Part B}

Niche-regime interactions 


\title{
Identifying transition patterns at the regional scale. A Greek case study
}

\author{
George Vlahos, ${ }^{1}$ Pavlos Karanikolas ${ }^{2}$ and Alex Koutsouris ${ }^{3}$
}

\section{Abstract}

This chapter explores the pattern of transformative change in an emerging transition from an intensive, towards an integrated farming system in Northern Greece. The alternative system (niche-regime) has originated from within the incumbent regime. The study shows the validity of the critique on the analytical separation of the three levels in MLP, as most of the transition processes take place in an 'intermediate' area between the niche and the regime.

In this case, landscape developments created a series of tensions within the regional agro-food regime, which also manifested signs of stress. A major driving force behind the change of the incumbent regime was a policy change at the EU level, while central to the transition were the innovative activities of various regime actors. A sequence of top-down and bottom-up patterns of change have been identified, characterised as 're-constellation' and 'empowerment', whereas certain new co-ordination procedures have been identified. Eventually, the niche-regime developed a clear symbiotic relationship with the regime.

Keywords: Transition patterns, Integrated farming, Greece

\section{Introduction}

Transitions concern a substantial shift of a dominant socio-technical configuration (a regime). Transitions imply radical changes of complex societal systems, which have often been conceptualized in terms of interactions between different levels. In the context of the Multi-Level Perspective (MLP) these levels are defined as niche(s), regime and landscape (Geels, 2002; Elzen et. al., 2004; Grin et. al., 2010). Consequently, the existence of concrete patterns which those interactions follow is one of the important themes explored in transition literature during the last years (van de Poel, 2003; de Haan and Rotmans, 2011; Papachristos et. al., 2013).

Various analytical tools have been proposed in studying transition dynamics. Geels and Schot (2007) argue that transition pathways are defined as combinations of the timing and nature of multi-level interactions. In particular, four different transition pathways are developed by using these criteria: transformation, reconfiguration, technological substitution, and de-alignment and re-alignment. An additional, fifth proposition addresses the possibility of a sequence of transition paths, i.e. the case in which transitions start following one path, but later shift to others. By contrast, the 'zero proposition' concerns regime stability and reproduction.

Taking a different approach, Smith et al. (2005) argue that the change of the regime is a function of two processes. The first concerns the degree to which landscape pressures upon a regime are articulated towards a particular problem. The second one, the adaptive capacity of the regime, concerns the availability

\footnotetext{
${ }^{1}$ Agricultural University of Athens, Department of Agricultural Economics and Rural Development, Athens, Greece. Email: gvlahos@aua.gr

${ }^{2}$ Agricultural University of Athens, Department of Agricultural Economics and Rural Development, Athens, Greece. Email: pkaranik@aua.gr

${ }^{3}$ Agricultural University of Athens, Department of Agricultural Economics and Rural Development, Athens, Greece. Email: koutsouris@aua.gr
} 
of resources and the ability to coordinate responses. By combining these two processes, four transition contexts emerge: endogenous renewal, reorientation of trajectories, emergent transformation and purposive transition.

More recently, de Haan and Rotmans (2011) conceptualized transitions as regime shifts, expressed as sequences of various patterns that occur under certain conditions, thus producing transition paths. Conditions for transitional change involve tensions between the system and its external environment, stress, stemming from inadequacies or internal inconsistencies of the system, and pressure, stemming from the competition of the regime with viable alternatives. Hence, they have identified three basic patterns of interactions between levels: 'reconstellation', i.e. a top-down constellation change, 'empowerment', i.e. a bottom-up constellation change, when small scale initiatives become viable alternatives to mainstream, and 'adaptation', a constellation change which has been internally induced.

Another issue that has been the focus of recent research is the 'origin' of the regime change. It has been argued, for example, that many transformative dynamics occur amongst the 'micro-' and 'meso-level' where an 'empowered niche' (a niche powerful enough to attack the regime) is situated (Haxeltine et al., 2008). Other contributions suggest that "niches may also emerge within a regime and not only at the micro level" (Rotmans and Loorbach, 2010, p. 132). In this way, the relevance of the analytical separation between the three levels of the MLP model is questioned. Alternatively, some very important non-hierarchical representations have been proposed, challenging the existing hierarchical accounts of transition processes, such as: a complex, adaptive systems representation (Loorbach, 2007), a flat approach inspired by actornetwork theory (Jorgensen, 2012) and the identification of 'hybrid forums' in the framework of 'anchoring' (Elzen et al., 2012).

The present chapter aims at exploring the pattern of transformative change in an emerging transition at the regional level. By using the theoretical framework of de Haan and Rotmans (2011), we try to identify the pattern of interactions between the different levels espoused by the MLP, while we also try to identify the origin of regime change.

The case study concerns the introduction and establishment of Integrated Farming (IF) in Northern Greece, in an area characterised for a long time by an intensive agricultural system. This emergent transition is examined in the main producing region of canned peach, a sector in which Greece holds a dominant position in world exports. After a serious crisis of the regional agro-food regime, an IF standard was introduced in 2000; available data suggest that nowadays more than half of the peach producing land in the area is already cultivated under IF standards, having contributed to the reorganization of the whole sector.

The chapter is structured in seven parts. Following the introduction and the materials and method used, the initial state of the societal system is presented. Next, the conditions for transitional change as well as the emergence of the niche are analyzed, followed by the identification of transition patterns and their discussion. The chapter concludes with some remarks on the case study as well as on new theoretical insights.

\section{$2 \quad$ Materials and method}

The empirical material was collected at the regional department (NUTS 3) of Imathia, in the region of Central Macedonia, Northern Greece, in the context of FARMPATH EU project.1

In the spring of 2013, a total of 22 interviews have been conducted with representatives of institutions, local and regional governments and authorities, researchers, agricultural cooperatives' representatives, farmers as well as with advisors and agronomists-experts, in an attempt to analyse the implementation of

\footnotetext{
1 "Farming Transitions: Pathways Towards Regional Sustainability of Agriculture in Europe (FarmPath)", a collaborative research project funded through EU-7th Framework Programme, with seven EU participating countries (March 2011February 2014).
} 
Integrated Farming (IF) Standards by large fruit growers' producer groups (PGs) in this area. Interviews were taped, transcribed and analysed (exploratory analysis; Sarantakos, 2005, p. 294).

\section{The initial state of the societal system: The period of subsidised intensification}

Irrigated crops accounted for $93 \%$ of the research area, a far higher average than the national average of about $30 \%$. Historically, the area is mainly dedicated to the production of fresh fruit, almost exclusively peach, either as fresh or for canning. The area also constitutes part of the water catchment area of two rivers, of a NATURA 2000 protected area and, since 2006, of a Nitrate Vulnerable Zone.1

The starting point for the creation of the incumbent regime can be set in the early 1980s when Greece entered the, then, European Economic Community (EEC, nowadays the EU). Under the Common Market Organisation (CMO) for fruit and vegetables, implemented in Greece immediately after its accession to the EEC, subsidies were provided to producer groups (PGs) to withdraw large quantities of their production from the market as a means to stabilise producers' prices. Consequently, about 50 PGs have been established in the area to withdraw fruits. In this sense, it can be argued that the incumbent regime and its functions have largely been defined by the EEC CMO. Regime functions were confined only to the productive aspect, which was exercised in a very specific and rather conventional way, denoting a 'monofunctional' approach to farming. Hence an agro-food regime had been created, focusing exclusively on highly intensive production. However, the intensification of the production process had not been aiming at improving its competitiveness in the market. On the contrary, the main aim of farmers and their newly established collective organisations had been to exploit the full potential of their land in order to produce the largest possible quantities, thus increasing the subsidies received. And that was the distinctively important technical dimension of the regime in Imathia. The alienation of farmers from the market also created a seeming paradox, i.e. that local peach producers' groups linkages with the local market and the increasingly developed rural tourism initiatives were almost inexistent, contrary to the gradual integration of local winemakers in the local market.

Consequently, during the 1980's, due to its high profitability, peach gradually marginalised other land uses, including wine vineyards (see Figure 1) and cattle raising, otherwise important in the area. That was one of the elements of intensification that could be observed macroscopically, since the outcome was a change of the landscape of the area.

The intensification of production, however, found its main expression in (all aspects of) the technology used. First, the criterion for the selection of peach varieties planted, have been their high productive capacity, irrespective of the quality and the timing of harvest which, in the absence of subsidies, would be far more important in view of creating a slot in the market. This particular aspect of the shift to subsidy oriented productionism rendered redundant the function of the local public research institution (a pomology institute) which, until then, used to have a major role in the propagation material selection procedures. Before the accession to the EEC, the introduction of new varieties was made after consultation with this institute, founded in 1961 as a continuation of a vine nursery since the 1920s. The institute tested all new tree stocks for adaptation and suitability for local conditions, and subsequently offered technical support to farmers. According to a researcher currently working at the institute: "Before the EEC all varieties were tested here. Afterwards, the private nurseries, that dominate the market, suggested and actually promoted these varieties".

\footnotetext{
${ }^{1}$ NATURA 2000 is a European Network of areas under protection for biodiversity conservation, Nitrate Vulnerable Zones: areas designated by MS because of increased nitrate water pollution originating from agriculture.
} 


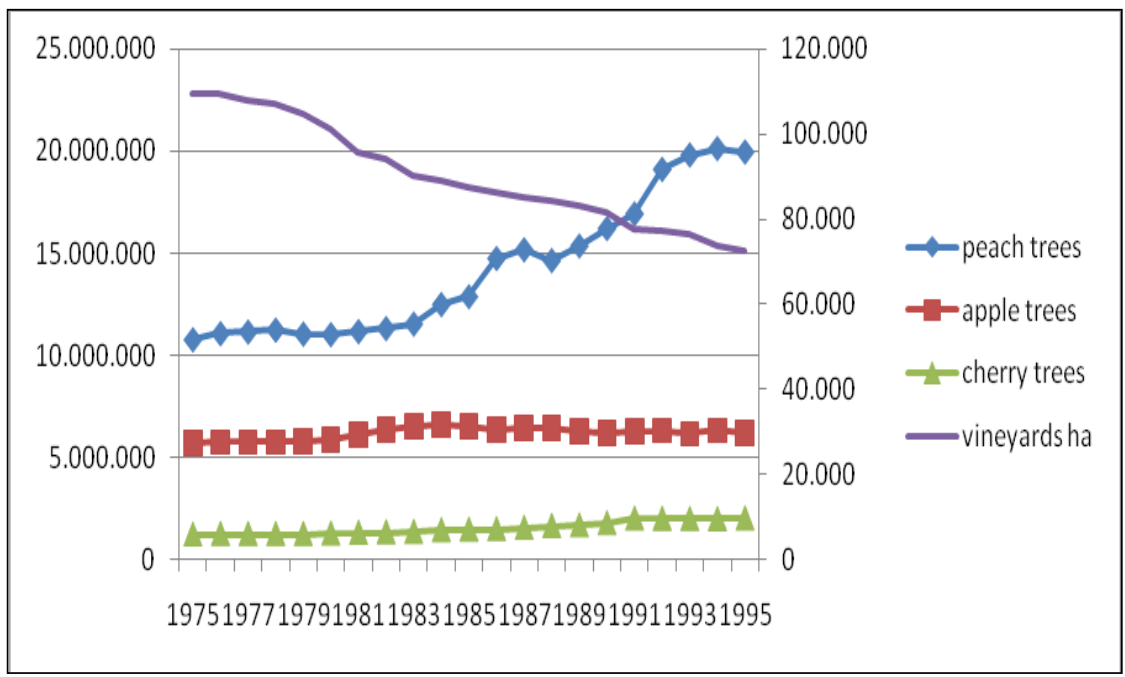

Figure 1: Evolution of selected permanent crops (1975-1995)

Legend: left axis = numbers of trees; right axis: ha. of vineyards

Another aspect of intensification, with a serious environmental impact, has been the increased use of fertilisers. The research area's farmers used to be among the ones who used the highest amounts of nitrogen fertilisers in Greece. According to Beopoulos (1996), the regional department of Imathia was at the top of the associated list. The increased use of fertilisers induced an increase of the use of irrigation water. These facts, combined with the expansion of irrigation in Imathia, may well explain the designation of the area as one of Greece's Nitrate Vulnerable Zones, thus pointing to the close relationship of the agro-food regime with the management of water resources.

Finally, another element characterising agricultural intensification processes all over Greece, i.e. the use of pesticides, mainly insecticides, was quite frequent in the area. A network of local professionals, mainly private agronomists, have been acting as retailers of agrochemicals. This network of input providers (fertilisers and mainly pesticides) has seen its role rapidly increasing after the Greece's accession to the EEC and the resulting acute increase in productivity. This has been complemented with a considerable presence of input companies' representatives, a fact denoting the importance of the area for the Greek chemical inputs market. The same network of professionals provided, in parallel, technical advice to farmers, with the assistance of the input companies. The latter frequently organised special events for the launching of new products, during which they made special offers to professionals and farmers to place agrochemicals. This informal information and advice network filled the gap created by the demise of public extension services, and rendered obsolete public research services otherwise available (Koutsouris, 1999). On the other side of the production chain, marketing decisions were in general left to elected leaders and the administration cadres of the PGs. They comprised a network that was linked to a large degree with partisan as well as local politics, as a remnant from interregional conflicts. This constitutes the most important institutional dimension of the incumbent regime: the existing direct linkages to parties and political networks mainly functioning through the 'PGs leaders' and thus influencing higher level politics, i.e. the Ministry of Agriculture.

At the same time, local level public administration (the Prefectural Directorate of Agriculture) was bypassed as obsolete. Although local administrators controlled subsidies, which constituted an important part of the local farming income (hence, the overall wellbeing of the area), any problem arising on subsidies were directly negotiated with the higher levels, national or even EU. The formation of clientelistic relations, through direct partisan linkages of the heads of farming co-operatives with central government and political party leaderships, bypassed local agricultural administration and, in many cases, disrupted linkages with local society. The other networks in the area (input providers/agrochemical companies) were connected to this policy network with an active role in the negotiation process at the central (national) level, due to the importance of the area for their overall performance in sales. 


\section{Conditions for transitional change}

A societal system could be compromised by various processes, stemming either from the relationships with its environment (tensions) or the composition of the system itself (stress or pressure) (de Haan and Rotmans, 2011).

A series of structural tensions influencing the area concerned derive from the global trend for intensification of agricultural production. In the case of Imathia, it seems that the local expression of intensification was towards the mere increase of production that would allow farmers to receive higher subsidies. Above, we already discussed the environmental impacts of such a process, and will now address important socioeconomic impacts. These include increased dependence of farmers on providers for inputs, often resulting, due to the high concentration of the input market, in higher costs for farmers. An additional indirect consequence of the intensification was the marginalisation of small family farms. Smaller households, not able to cope with the intensification process, abandoned farming, while specialised larger farms focussed their efforts on the most productive parts of the land.

Moreover, two important cultural tensions emerged. The first tension concerns an increased concern both of the wider public as well as of institutional actors like the European Commission, about negative externalities caused by intensive agriculture, i.e. the 'sectoral' expression of the widespread notion of sustainability. The second tension was created by an increasing de-legitimisation of the support provided to agriculture, especially due to environmentally harmful subsidies as is the case of the payments for the withdrawal of peach production. This resulted, i.a., from the spatial and temporal alienation of urban population from its rural origins. The expression "Farmers are producing for dumping areas" (chomateres in Greek) is still, almost 20 years later, a typical phrase used when the primary sector is discussed in Greece. Another element, closely related to the sustainability discourse, has been the increased degree of awareness for food safety, which has strongly influenced the initiative discussed here.

Moreover, given Greece's dominant position in the global canned peach industry, the fact that in some part of the EU compensation for the withdrawal of peach was used by certain PGs as a means to subsidise their canned peach produce and thus gain in competitiveness, caused market distortion effects in the global market (USDA, 2001). Hence, global competitors from Greece in the canned peach market issued a formal complaint to the EU, causing a radical shift in the CAP. In the CMO for fruit and vegetables, a gradual but severe restriction of quantities to be supported (1993-1995), had thus been introduced. This unusual change in EU policy, since prior CAP changes followed a more gradual process, found the producer groups of the area in a situation where they started losing export markets, as disguised export subsidies were no longer possible.

In addition to the abrupt change in CAP, global competitors also tried to counter the Greek industry with technical barriers. Using the ever increasing consumer concerns about food safety, especially pesticide residues in food, they were successful in imposing stricter residual limits. In this respect, an absolute prohibition of the use of a specific organophosphoric insecticide, commonly used in Imathia and other peach producing regions, was imposed by various importing countries, which was allowed under EU regulations. This, in turn, resulted in the rejection of shipments, due to the traces of methamidophos, the banned active substance.

All these changes compromised the functioning of the regime, which came under severe stress. Such tensions and stress have been accompanied by the pressure exerted on the regime after the emergence of the niche, as described in the next section.

One could thus infer that the main instigating factor behind the creation of the incumbent regime was the EU policy measure to provide subsidies for withdrawals. At the same time, a second regime factor, instigated by a landscape pressure, opened a window of opportunity for the creation of the niche, notably the radical change of the EU CMO for fruit and vegetables, which also stimulated a transitional change (see below). 


\section{The emergence of the niche}

The abovementioned crisis of the regional agro-food regime necessitated the search for alternative solutions. To overcome the aforementioned barriers, the only available option for the collective farmer organisations was to inspect and check all shipments before leaving the country for residuals. However, that ex post intervention was totally impractical to apply, due to the high number of farms and the lack of an effective tracing system. Thus, there was an urgent need to ensure that the final product, in its totality, would comply with the restrictions imposed by the respective clients to keep export markets, which, after the change of EU policy, had become an important outlet.

This crisis coincided with the establishment of Agrocert, a standardisation and certification organisation under the auspices of the Greek Ministry of Agriculture. The reason behind its establishment was to ensure a better functioning of organic certification systems. The initial plan, to replace private organic certification by a central system controlled by the government, was abandoned, thus resulting in the re-orientation of the organisation from merely fulfilling national and EU administrative duties towards the strengthening of farm produce links to the market and the improvement of farmers' competitiveness.

At the time, across Europe, the fresh farm produce value chain was at the focus of attention due to the formation of an alliance of big retailers and producers (Eurep-Gap) introducing a standard for controlling fresh products. This animated discussions and pressures towards the co-ordination of national and regional initiatives for an environmental friendly agriculture other than organic, e.g. Little Red tractor, Linking Environment and Farming (LEAF) in the UK, Agriculture Raisonnée in France, Producción Integrada in various Spanish regions. Drawing from these efforts, Agrocert issued an integrated farming standard (AGRO2: Management of the Rural Environment - System of Integrated Management in Agricultural Production) in two parts, Part1: Specification; Part2: Requirements for the application in crop production (AGROCERT, 2000).

The niche in Imathia, concerned the adoption by an increasing number of producer groups of the AGRO 2 standard. The technical dimensions of the standard have been of particular importance since the whole production process was changed. The implementation of the standard called for standardised procedures for the totality of the participants. These procedures covered all aspects of the production process i.e. the selection of the propagation material, irrigation, fertilisation, pruning, harvesting, post-harvest handling, biodiversity maintenance, safety procedures for farmers and crisis management plans. A critical issue was traceability and crop protection, as the main purpose of IF was to ensure that the pesticide residues would be low enough to allow the produce to re-enter the markets. A thorough plan for the organisational structure, functioning, monitoring and assessment of the system was a prerequisite for a successful auditing and finally certification.

The new technical arrangements of the production process necessitated new forms of co-ordination within and among existing networks. The input provider network was transformed into two new ones. Some of the professionals found a new role as private production management consultants assisting producer groups in setting up and implementing the management system's standardised procedures. This included internal auditing and advice on corrective actions, introducing new elements in the collective co-ordination for producer groups in the area. A second segment of the previous agrochemical retailers shifted towards technical advice, either as producer group employees or as free-lance technical experts collaborating with the PGs.

The detachment of technical advice from the provision of agrochemicals created a space for the reintroduction of public sector technical experts, such as researchers and highly specialised staff at various levels of public administration. Collaboration with PGs through the mediation of production management consultants was (re)established, thus acknowledging the valuable expertise and experience gathered in the public sector. Local public research institutions, invited by PGs and in collaboration with private management and technical experts, became gradually re-involved in relevant research projects. Input provision companies, after an initial negative stance, established and promoted links with the management 
consultants' network. According to a management consultant: " $M y$ condition for accepting the 'X'PG's request to consult them on their management system was that the $P G$ should take responsibility for selling pesticides to its members, to break the direct links of professionals and farmers with the companies."

Finally, a network of private certification companies was created. Agrocert, the quasi-public body that issued and ran the certification scheme, after an initial direct certification role, abandoned this role and currently limits itself to accrediting private certification organisations.

The role of advice has been of key importance in the creation of the niche, as major decisions by farmer's require consulting with and/or instruction from the supervising expert. As a Co-operative CEO stated: "The main result of IF is that it put science in production."

Additionally, it should be stressed that one of the prerequisites of the applied management system is that farmers have to follow short courses on subjects covering various practices throughout the production process. Farmers are also held responsible for the training of the farm workers they employ in various phases of production, even if this means having to translate basic food safety and workers security rules into the workers' native language. Furthermore, as it was indicated: "There is a two way process of learning. We [the consultants] learn together with the farmers from visiting other colleagues abroad (Italy, Spain, France), but we also learn from farmers (or local technical experts) their way of doing things and we circulate good practices to other farmers. "(Interview with management consultant)

Available data suggest that, currently, more than 6,200 small farmers participate in 26 PGs implementing the IF standards, covering over 10,000 ha which is more than half the peach producing land in the area.

\section{Discussion: Identification of transition patterns}

In the initial state of the regional agro-food regime, producers' adaptation to the Common Agricultural Policy (CAP) resulted in large production surpluses and, henceforth, market distortion effects due to the use of production withdrawal subsidies that functioned as disguised export subsidies. This, in turn, caused an abrupt shift in the EU policy measures, and consequently, a forced reorientation of farmers' focus towards the world market. Overarching factors such as the increasing degree of market concentration, stricter food quality and safety requirements, specific demands by retailers, etc., have been exercising strong influence, adding impediments to their strive for a share in a highly competitive global market.

In searching for alternatives to maintain the quality and overall fame of the main local product, i.e. peach, the chosen way to proceed was to regulate/manage the production process. Given that the high number of farms made the coordination of individual efforts an almost impossible task, an institutional change was a prerequisite to successfully manage the necessary technological changes. To reduce the cost of this institutional change, a novel institution was created, an IF standard, proposed by a newly established public actor (Agrocert), aiming at the protection of natural resources and biodiversity.

In this context, Agrocert played various critical roles. It acted as a regime actor (an organisation controlled by the Ministry of Agriculture) as well as a niche instigator. It also played another double role, that of standardisation organisation as well as that of certification entity. The latter was abandoned when private sector companies entered the certification market, an unconventional course of action for a regime actor, especially in the Greek context.

Furthermore, in an unconventional step, Agrocert used the existing network of private agronomists to gain access to, attract and finally enrol PGs to the niche. The usual path would be to address public administration and ask them to proceed (Koutsouris, 2008). According to a private management consultant: "When the whole process started, Agrocert decided to work with us, the private sector, and not the bureaucrats of the Directorate of Agriculture." 
Private agronomists, who previously dedicated themselves to input provision and associated technical advice, had been the first to adopt innovations and adapt to changes. Agrocert collaborated with the existing network of private agronomists to enrol PGs to the niche, unlike other attempts in Greece which focused on regime actors (Koutsouris, 2008). Thus a process of transformation of a well-established network took place, with private professionals (agronomists) shifting from input providers towards the provision of advisory services, because tensions with socio-technical landscape developments gradually rendered their activities obsolete. Changes in the $\mathrm{CMO}$ rules concerning the withdrawal of production and, almost immediately thereafter, a new set (and uncertainty) of rules for pesticide maximum residual limits, had affected their business directly.

Our case thus points to the 'origin' of the niche being not at the 'micro-' level, but at an intermediate area, where the public certification agency, producer groups, input providers, researchers and experts redefined their roles and changed their practices. Additionally, all those actors established, expanded and reorientated networks, playing thus a 'hybrid' role of being both regime and niche actors (Elzen et al., 2012). Similar findings in literature suggest that "niches are not bound to the micro-level but also occur and emerge at the meso-level" (Rotmans and Loorbach, 2010).

Concerning the dynamics of this emerging transition in terms of transition theory, it has been shown that landscape developments created a series of structural and cultural tensions with the regional agro-food regime. Also, the regime manifested signs of stress when it became inconsistent with the new broader environment. Of major importance was the policy change concerning CMO for fruits and vegetables, which was indeed the driving force behind the change of the incumbent regime. ${ }^{1}$ The launching, in 2000, of an IF standard by Agrocert, in the midst of a critical situation, was the triggering event for the transition. Thus, a policy change at the EU level, along with the critical role played by a quasi-state organisation, triggered a top-down pattern of constellation change, or 'reconstellation'(de Haan and Rotmans, 2011).

Furthermore, the initiation of the new standard and its rapid adoption by a large number of farmers resulted in a viable alternative to the conventional agro-food system. Hence, our case concerns a niche which has grown into a niche-regime (Rotmans and Loorbach, 2010). As this pattern of change shows characteristics of a 'bottom-up' process, it can be characterized as 'empowerment'.

Moreover, the initiative that triggered the creation of the niche, made certain adaptations necessary to accommodate the complexity of the situation at hand. More specifically, although its main aim was to enhance environmental friendly practices in agriculture, in our case AGRO2 was initially used to address an important deficiency of the existing production system: the failure to ensure an acceptable (by the market) level of residues on the final product. Thus a link to the local specificities was established and the niche was better adapted, while the new standard served as a 'perfect' instrument for the operationalization of the required shift from higher productivity to safe and quality products. The latter derived from the first part of the standard, calling for the existence of a series of standard procedures, their monitoring and control, which seemed appropriate to achieve a tightly controlled process, with an essential role of professionals in ensuring the control of this process.

Thus, it can be argued that this emerging transition unfolds with a concrete sequence of patterns, causing profound changes in structures, cultures and practices (Rotmans and Loorbach, 2008; Frantzeskaki and De Haan, 2009). The radical change in the technological aspects of the regime was accompanied by equally, if not more, important changes in the institutional and human/societal environment. Market power shifted from intermediaries (middlemen) to PGs, although the problem of a concentrated retail segment of the market still persists. Farmers' relationship with experts have changed as experts provide technical advice as such and not as an additional service only for the buyers of the inputs they deal with. Existing networks have been transformed (from input to service providers), new networks have been created, linkages

\footnotetext{
${ }^{1}$ The critical role of policy, is also manifest in all organizational and managerial innovations, which have been included in the EU supported management plans of the PGs. Furthermore, new technological developments, mainly in the field of spatially explicit methodologies and environmental friendly farming practices (advanced pesticide management methods) were undertaken via EU supported Research and Development projects, jointly run with local research institutes, PGs and private consultants.
} 
between actors and networks were broken (professionals - agrochemical companies), while new ones have been created (PGs - agrochemical companies, PGs - consultants), and weakened links have been restrengthened (research community - PGs).

Overall, the transition in this case is characterized by the strengthening of collaborative action and collective institutions. In the case of canned peach, the project can also be seen as a counter-oligopsony measure, with PGs trying to achieve a more balanced distribution of power in this specific value chain. PGs, that have participated in the niche, have seen their negotiating power within the value-chain increase, hence, private merchants have actually been following market trends set by the PGs.

The realization of the potential of the AGR02 standard, i.e. rationalization of management practices and increased role of advice, both technical and managerial, led to a reorientation of the Producer Groups' goals, since they could also economize on costs, reduce environmental impacts of production, as well as improve the quality of their products.

It should also be noted that this collective co-ordination scheme inoculated the agro-food regime with environmental elements, although the initial objective of the instigators was not environmental protection. On the other hand, the whole process relieved farmers' organizations from the previously existing burden of dependence on clientelism, by empowering them, strengthening their bonds with local society, and creating a new 'culture' of co-operation and commitment to a collective goal.

Fifteen years after the initiation of this emerging transition, the new state of the regime is characterized by a symbiotic relationship of the newly established IF niche-regime with the 'old' conventional farming regime (table 1).

\begin{tabular}{|c|c|c|c|c|}
\hline System State & Pattern & System State & Pattern & System State \\
\hline Regime & & $\begin{array}{l}\text { Regime and } \\
\text { Niche-Regime }\end{array}$ & & $\begin{array}{l}\text { Regime and } \\
\text { Niche-Regime }\end{array}$ \\
\hline $\begin{array}{l}\text { structural tensions } \\
\text { cultural tensions }\end{array}$ & Reconstellation $\rightarrow$ & $\begin{array}{l}\text { Tensions, stress } \\
\text { pressure }\end{array}$ & Empowerment $\rightarrow$ & $\begin{array}{l}\text { in a symbiotic } \\
\text { relationship }\end{array}$ \\
\hline
\end{tabular}

Table 1: Sequence of transition patterns

Such findings are in line with the relevant literature. For example, in the case examined here, some similarities with the socio-technical 'de-alignment and re-alignment' path (Geels and Schot, 2007) can be found in particular, with the argument that divergent, large and sudden landscape changes cause regime actors to lose legitimacy. Additionally, in this path, niches are empowered by the regime. Likewise, in the 'reconfiguration' path (Geels and Schot, 2007), as in our case, various innovations develop in niches and then result in a symbiotic relationship with the regime. Interestingly, those two paths ('de-alignment and realignment' and 'reconfiguration') seem to evolve concurrently, as regime actors undertake innovative activities, and the niche utilizes regime resources (such as factories for the canning of peaches and the marketing channels), resulting in a co-existence with the regime and triggering further adjustments in its basic structure. This finding points to the need for a more inclusive consideration of the interactions between the different MLP 'levels' (see also Elzen et al., 2012).

Furthermore, the processes identified in our case resemble some aspects of 'purposive transition' and 'endogenous renewal' as they are described in Smith et al. (2005), in which a high degree of co-ordination of resources is combined with conscious and planned efforts on behalf of regime actors. 


\section{Concluding remarks}

The aim of this chapter has been to explore the pattern of a transformative change in an emerging transition from an intensive towards an integrated farming (IF) system. The examination of the dynamics of this transition in Northern Greece, the main producing region of canned peach, a sector in which Greece holds a dominant position in world exports, reveals a series of notable processes at work.

The launching in 2000 of an IF standard by Agrocert, in the midst of a critical situation, was the triggering event of the transition. New networks were created, existing networks were transformed, while the whole process involved new organizational arrangements and learning processes. The alternative system (nicheregime) has originated from within the incumbent regime and has already developed a clear symbiotic relationship with it. It appears that the aforementioned critique on the analytical separation of the three levels in MLP is indeed valid, as most of the transition processes take place in this area of overlap.

In our case, landscape developments led to a series of structural and cultural tensions within the regional agro-food regime. Also, the regime came under stress when it became inconsistent with the new broader environment. A major driving force behind the change of the incumbent regime was a policy change at the EU level. Central to this transition were the innovative activities of a nationwide regime actor, who contributed in the creation of two critical new networks at the regional scale, one with PGs leaders and another with 'peripheral' actors of the established system of input-and-advice provision. The initiation of the new standard for agricultural production and its rapid adoption by a large number of PGs, and thus of their members-farmers, resulted in a viable alternative to the conventional agro-food system.

In terms of transition theory we have identified a sequence of top-down and bottom-up patterns of change, characterised as 'reconstellation' and 'empowerment'. Moreover, the initiative that triggered the creation of the niche necessitated certain adaptations to accommodate the abruptly changing institutional setup. This emerging transition followed a concrete sequence of patterns, causing profound changes in structures, cultures and practices. Finally, various transition 'paths' seem to unfold simultaneously, implying pluralistic patterns of change and pointing to the need for a non-hierarchical representation of the MLP.

Aknowledgments: Comments and suggestions by two referees and the editor are gratefully acknowledged.

\section{References}

AGROCERT (2000). AGRO2: Management of Rural Environment - System of Integrated Management in Agricultural Production Part1 Specification Part2 Requirement for the application in crop production. Athens, AGROCERT.

Beopoulos, N. (1996). The impacts of agricultural activities. In: Sp. Papaspiliopoulos, T. Papayiannis \& S. Kouvelis (eds.), Environment in Greece 1991-1996 (pp. 141-177). Athens, Bodosakis Foundation/ WWF Greece.

de Haan H. and J. Rotmans (2011). Patterns in transitions: Understanding complex chains of change. Technological Forecasting and Social Change, 78 (1), pp. 90-102.

Elzen, B., F.W. Geels, and K. Green, (eds.) (2004): System innovation and the transition to sustainability: theory, evidence and policy. Cheltenham: Edward Elgar.

Elzen, B., Leeuwis, C. \& van Mierlo, B. (2012). Anchoring of innovations: Assessing Dutch efforts to use the greenhouse effect as an energy source. Environmental Innovation and Societal Transitions 5, pp. $1-18$.

Fratzeskaki, N. and H. de Haan (2009). Transitions: two steps from theory to policy. Futures, 41 (9), pp. 593-606.

Geels F. (2002) Technological transitions as evolutionary reconfiguration processes: a multi-level perspective and a case-study. Research Policy 31, pp. 1257-1274

Geels, F.W. and J.W. Schot (2007). Typology of sociotechnical transition pathways. Research Policy, 36 (3), pp. 399-417. 
Grin, J. Rotmans, J. and J. Schot (eds) (2010). Transitions to Sustainable Developmen-New Directions in the Study of Long Term Transformative Change, London: Routledge.

Koutsouris, A, (2008). Learning and Innovation: Still an Enigma? Failing to Introduce ICM in a Greek Village. International Journal of Environmental, Cultural, Economic and Social Sustainability 4, pp. 77-84.

Koutsouris, A. (1999) Organisation of Extension Services in Greece. Options Mediterranneenes, Serie A: Seminaires Mediterraneenes, 38, pp. 47-50

Papachristos, G., Sofianos, Ar. and E. Adamides (2013). System interactions in socio-technical transitions: Extending the multi-level perspective, Environmental Innovation and Societal Transitions, Vol. 7 (2013), pp. 53-69.

Rotmans, J., and D. Loorbach (2008). Transition management: reflexive governance of societal complexity through searching, learning and experimenting. In J. van den Bergh and F. Bruinsma (eds.), Managing the transition to renewable energy, pp 15-46. Edward Elgar, Cheltenham, UK.

Rotmans, J. and D. Loorbach (2010). Towards a better understanding of transitions and their governance: a systemic and reflexive approach. In J. Grin, J. Rotmans \& J. Schot (eds.), Transitions to Sustainable Development- New Directions in the Study of Long Term Transformative Change, pp. 105-221. London: Routledge.

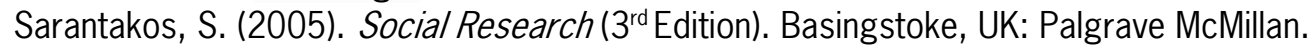

Smith, A., Stirling, A. and F. Berkhout (2005). The governance of sustainable socio-technical transitions. Research Policy, 34 (2005), pp. 1491-1510.

USDA (2001). Canned peach industry situation a history of EU subsidies and their effect on production and trade. Horticultural Tropical Products Division Foreign Agricultural Service. Washington, USDA.

Van de Poel, I. (2003). The transformation of technological regimes. Research Policy 32 (1), pp. 49-68. 


\title{
Exploring Diversity, Networks and Knowledge Regimes: Transitions and System Building in SRI in India
}

\author{
Shambu Prasad Chebrolu ${ }^{1}$ and Debashish Sen ${ }^{2}$
}

\section{Abstract}

This chapter explores transition and system innovation theory in a non-European context though the case of an agro-ecological innovation, the System of Rice Intensification (SRI) in India. SRI presents smallholder farmers with a radical alternative to productivity enhancement beyond the Green Revolution strategy of high external inputs and/or super-varieties. The chapter traces the dynamic evolution of SRI in India and compares SRI in three different states to highlight the diversity of technical and institutional arrangements in system innovation. The case highlights the importance of diversity and the role of networks in complex and multi-actor innovation systems. Technological lock-ins and institutional rigidities in existing policy regimes, we argue, provide little scope for user innovation and systematic learning of actors.

A better understanding of the politics of knowledge and contestations amongst actors is essential for managing sustainability transitions in developing countries where knowledge hierarchies are strong. Formal and informal networks play important roles in enabling the expression of the plurality of ideas. These networks, often in conjunction with institutional experiments such as learning alliances, act as 'sustainability brokers' and ensure greater horizontal linkages between experiments at micro-levels and between regimes at the meso-level. On the basis of this study we conclude that non-research actors comprehend complexity and show greater capacity for learning and experimentation than hitherto acknowledged. Therefore, we recommend that future policies need to focus more on the adaptive capacities and social learning of actors through processes of collective experimentation.

Keywords: System Innovation, Networks and learning alliances, SRI, User Innovation and Adaptation, Collective Experimentation, Knowledge Politics

\section{$1 \quad$ SRI and System Innovation for Sustainable Agriculture}

The Fifth Assessment report of the Intergovernmental Panel on Climate Change (IPCC, 2014) has confirmed an increasing ecological footprint of current agricultural practices, even as it warns of decreasing yields more rapidly and greater crop losses than earlier assumed due to climate change. The imperative to shift to more sustainable agricultural practices is particularly relevant for countries like India where farmers face acute distress with rapidly depleting groundwater resources, ever increasing costs of agricultural inputs, and increased vulnerability and risks due to weather and climate stress. Conventional responses to climate change have been largely technical, with focus on improved and super varieties of crops, and rarely enhance local adaptive capacities of farming communities.

In the last decade, the System of Rice Intensification (SRI) has emerged as a viable alternative to conventional approaches to enhancing food security and mitigating climate stress in India. SRI is an agro-ecological and climate-smart methodology for increasing the productivity of rice, and increasingly other crops (SRI Rice, 2014; Chopra and Sen, 2013). By changing the management of plants, soil, water and nutrients, while

\footnotetext{
${ }^{1}$ Professor, Institute of Rural Management Anand, India. Email: shambu@irma.ac.in

${ }^{2}$ Director, People's Science Institute, Dehradun, India. Email: debu_manu@yahoo.co.in
} 
significantly reducing external inputs, SRI is posited as an alternative paradigm to 'rebiologise' agriculture (Uphoff, 2013). It has rapidly spread from its early origins from the rice fields of Madagascar in the 1980s across 50 countries with over 10 million farmers experimenting with SRI principles on 3.5 million hectares of land, since the innovation moved beyond Madagascar in $1999 .{ }^{1}$ It is based on agronomic principles of establishing healthy early crop establishment, reduced competition between plants in healthy soils and through aerobic soil management. ${ }^{2}$ SRI practices enable growth of larger, better-functioning root systems, and farmers in different agroecological settings have attained higher yields with lesser inputs, and have witnessed greater adaptability to climate stresses (Kassam, Stoop, and Uphoff, 2011).

The agriculture sector presents special challenges in sustainability transitions due to the entrenched nature of the linear model of innovation that discourages feedback between research, extension and farmers, and privileges formal scientific knowledge from established disciplines over other forms of knowledge. This dimension of knowledge rigidities, we suggest, is widespread in agricultural policy and deters alternatives that emerge outside the agricultural research establishment. Thus despite its spread among farmers; policy makers and research establishments have for the most part been reluctant to invest in this innovation. Part of it is likely due to the debates and controversies engendered around its agronomic impacts and adoption rates. A few reputed agricultural journals dismissed SRI uncharitably as "UFOs", "curiosities and nonscience", ${ }^{3}$ and SRI struggles to find space in rice conferences. The quadrennial International Rice Congress in Bangkok recently had no more than 3 of the 152 articles on SRI, despite a large and increasing body of research on SRI (Styger, 2014). This led many SRI researchers to inviting the International Rice Research Institute and rice researchers for an open dialogue and collaboration through an Open Letter. ${ }^{4}$

Technological lock-ins (as suggested by Vanloqueren \& Baret, 2009) persists with the Green Revolution paradigm of input-intensification and official policy which, as we discuss later, does not favour the extension of knowledge and management-intensive practices of SRI. SRI presents a good case to understand institutional rigidities that often hinder sustainability transitions. In our chapter we focus on India as an interesting site where these challenges continue to be played out. India is a leader in both spread of SRI, as well as the number of research papers on SRI, yet SRI is not a mainstream strategy for agricultural food security, livelihoods and climate resilience.

In the particular case of SRI, the continued attempt of the dominant rice research establishment to dismiss SRI as nothing but its own Best Management Practices (BMP) reflects this deeper politics of knowledge, where rice scientists want to fit SRI into BMP, whereas farmers are commonly found to understand SRI and are either unaware of or have difficulty understanding a restricted researchers category like BMP. ${ }^{5}$ The

\footnotetext{
${ }^{1}$ Most of the spread of SRI has been to five countries in Asia i.e. China, India, Vietnam, Indonesia and Cambodia, which produce two-thirds of the world's rice output. (Uphoff et al. 2015)

${ }^{2}$ These translate into a set of practices (4-6) that differ from conventional rice cultivation and involve transplantation of young seedlings, widely spaced, in un-flooded but moist conditions, greater use of organic matter in soil and a hand or motorized weeder for weeding. Variation among specific SRI practices across different agro-ecological regions have been observed and reported. For details on differences between conventional and recommended SRI practices in the specific case of Uttarakhand of India see Table 2.

${ }^{3}$ A high impact journal Field Crops Research carried a series of articles in 2004-2008, that were critical of SRI. The papers revealed a clear asymmetry, with the journal editors accepting articles with controversial titles, which had no precedence in the journal's history, in a very short time with little review, even when counter arguments involved protracted reviews. This was after a debate in the International Year of Rice, also referred to as "Rice Wars" on SRI between its proponents and its opponents, largely from the International Rice Research Institute (IRRI) that was tied to a different research strategy on enhanced investments in genetic improvements. (Shambu Prasad, C. 2014., Shambu Prasad, C. (2014): "Uprooting rice science: Scientific controversies and SRl”. March 4. Unpublished presentation for the Science Studies Research Group, Cornell University).

${ }^{4}$ See "Open Letter to $4^{\text {th }}$ International Rice Congress" http://www.oxfamamerica.org/static/media/files/open-letter-to4th-IRC 1.pdf. For a comprehensive review of recent research on SRI in India refer to http://www.sriindia.net/event2014/research_2.htm (Accessed April 2, 2015).

${ }^{5}$ This is part of the controversy over SRI with IRRI, suggesting that SRI should be seen as BMP. After years of denial IRRI now has a page on SRI but wants SRI as part of its BMP http://irri.org/news/hot-topics/system-of-riceintensification-sri. For the SRI perspective see Norman Uphoff's paper "A decade's perspective on use and spread of SRI" for the WWF-ICSRISAT dialogue seminar on Dec 21-23, 2010 . http://www.sriindia.net/documents/A Decades Perspective on SRI Norman.pdf. Accessed April 1, 2015.
} 
politics of knowledge has important implications for understanding system transitions, and has a way of manifesting itself at the niche and regime level in everyday practice. ${ }^{1}$

The spread of SRI, as we show, has relied more on networks - local and global (with horizontal as well as vertical linkages) - rather than organisational design. Additionally, India presents greater challenges due to the diversity of practices across different states that reflect not only agro-ecological diversity but also institutional diversity in the nature of civil society and other organisations' involvement and their relation with the agricultural establishment. We highlight this diversity of institutional arrangements by contrasting three different states of India - Uttarakhand in northern India, Odisha in eastern India and Andhra Pradesh in the south. Through our empirical case study we suggest that the current system innovation and sustainable transition frameworks, while extremely useful for planning sustainable development, require modifications when applied to developing countries, with larger proportion of smallholders, and agricultural contexts where food systems are quite diverse.

This chapter draws from longer term work on the innovation and institutional history of SRI, participant observer methods in SRI conferences, and over a decade of policy dialogues at both national and state levels. We derive insights from a technographic account of SRI in Uttarakhand by one of the authors and insights from colleagues in other states, as part of an ongoing collaborative project on SRI as a sociotechnical movement in India. In section 2, after a brief introduction of SRI and system innovation in sustainable agriculture, we look closely at the complex evolution of SRI in India by delineating four phases of SRI spread in India, and highlighting the ebbs and flows of different stakeholders within the system of innovation, thus pointing to some challenges in system transitions. Section 3 focuses on the diversity in socio-technical regimes of SRI, while comparing its evolution and spread in the three different agroecological regions of Andhra Pradesh, Odisha and Uttarakhand. Section 4 highlights the role of user innovations and networks for sustainable transition in agriculture. In section 5 we conclude by drawing lessons from the empirical case for System Innovation Research and possible ways forward.

\section{The Complex Evolution of SRI in India: Beyond Conventional Interfaces and Boundaries}

The innovation history of SRI in India is rich and complex (Shambu Prasad, 2006). The lone Indian representation at the first international SRI conference at Sanya, China, in 2002 had modest yield results from the experimental plot in the state of Tamil Nadu. A decade since, India has been at the forefront of the global SRI movement. Few countries have had farmers experimenting with SRI principles in other crops and can match the sheer number of journal articles, books, training audio and video resources, or number of farmers who have tried out SRI. ${ }^{2}$ This unexpected lead is surprising because there has been no coherent and directed SRI policy at the central or federal level. While funding in agriculture, for both research and extension, is largely from the central pool, agriculture is considered a state subject and state governments often pursue different strategies based on local agro-ecological and socio-political factors. SRI spread in India reflects this diverse institutional character with different states providing a disabling or enabling environment for the spread of SRI.

The history of SRI can be broadly divided into four phases. In the early stages, 1999-2003, SRI was introduced in India via two distinct routes. Formal research on SRI began at the Tamil Nadu Agricultural University (TNAU) as part of a waterless rice project. Following talks and discussions with Prof Norman Uphoff of Cornell University, the state governments of Tamil Nadu and Andhra Pradesh, agreed to depute

\footnotetext{
${ }^{1}$ The use of niche, regimes and landscapes follows its definition and understanding in Elzen, Geels, \& Green, 2004.

${ }^{2}$ AnSRI Rice estimate of the spread of SRI in India indicates over 3.5 million farmers (38\% of world total) practicing SRI on 1.7 million hectares (51\% of world). Personal communications, April 2014. This would be of the order of $1-2 \%$ of total rice production in India. Also see special issue of LEISA India SRI: A scaling up success http://www.agriculturesnetwork.org/magazines/india/sri. A comparable estimate would be on hybrid rice that has had high state support for over two decades with rather poor adoption (Spielman, Kolady, \& Ward, 2013).
} 
officials to visit SRI Fields in Sri Lanka in 2002-03. These facilitated visits at an early stage were critical for Dr. T. M. Thiyagarajan, then Dean of the agricultural college in Tamil Nadu, and Dr. Alapati Satyanarayana, Dean of extension of the Acharya Ranga Agricultural University (ANGRAU), in Andhra Pradesh becoming 'system builders' in shaping the SRI innovation system. They undertook adaptive trial experiments on SRI and tried SRI across different agro-ecological regions in their respective states. ${ }^{1}$ In 2004 when the Nature journal carried a piece during the International Year of Rice on SRI, titled "Feast or Famine", research from India began to open up the debates on the controversies on SRI. Alapati wrote to Nature, providing evidence from different locations suggesting that SRI was not a niche innovation, as it was then being debated (Shambu Prasad and Basu, 2005). Simultaneously, SRI also spread among Civil Society Organisations (CSOs) in southern, central and eastern India, who heard of SRI through journals like ILEIA, and farmers started to experiment with SRI ideas almost immediately. ${ }^{2}$

The next phase of SRI in India, roughly from 2004-2007 indicates a broadening of the SRI agenda and a change in institutional character. A Dialogue Project on Water, Food and Environment by the World Wildlife Fund (WWF) in India based at ICRISAT (International Crop Research Institute of Semi Arid Tropics), Hyderabad, Andhra Pradesh saw an opportunity in SRI for water conservation. Playing the role of a "sustainability broker", to use Leach et al (2014)'s recognition of brokers in transforming innovation to sustainability, Dr. Biksham Gujja led the WWF project to embed the innovation of producing more with less through certain institutional changes. Gujja emerged as an important system builder by collaborating with Alapati, and funding ANGRAU in its trials and created innovation spaces where researchers were encouraged to dialogue with farmers, civil society organisations, extension personnel and local and national policy makers. A novel institutional platform, the National Symposium on SRI was established in 2006 at Hyderabad and continued for three years, enabling the meeting and spread of SRI as a movement. The active involvement of a CSO leading the agricultural research establishment towards new agendas, has little precedence in the Indian institutional context. WWF opened SRI to multiple actors, enabling their active role in shaping SRI through collaborative projects, dialogues, symposia, newsletters. Often, changes in location enabled changes in the nature of research questions as well. A dialogue on weeders in farmers' fields, rather than the research station, enabled the agricultural engineers to open up research on equipment for different kinds of soils and look beyond a centrally manufactured conoweeder, for instance. The WWF effort broadened the base of SRI by geographical expansion, with SRI being practiced in the remote hills of Uttarakhand, as well as moving SRI from researchers to farmers and CSOs. In a recent article, WatersBayer et. al. (2015) have reviewed the impact of CSOs in farmer-led research and have pointed to greater adaptation of locally appropriate technical innovations, greater peer to peer learning, and enhanced local capacity to innovation through informal networks and spaces facilitated by CSOs. We see many analogues of these trends in the SRI case as well.

The third phase of SRI, from 2007-2010, was one that witnessed a significant change in the location of SRI from irrigated green revolution areas to rainfed areas. While water conservation was the main focus for the southern states and SRI was promoted in the Rabi, or post monsoon crop, the rapid extension of SRI to central, eastern and Himalayan regions during this phase meant a shift from SRI for water conservation to SRI as contributing to local food security. A visit to the state of Tripura by a team following the first national symposium led to the second national symposium at Agartala in 2007. This shift from the centre to the periphery was a strategic one. On the one hand, it reflected the growing demand for SRI as an agroecological innovation in a different context, i.e. in regions where smallholders mostly use family or shared labour and have not much independent control over water management. Their farm sizes free them from the need for managing hired labour (for transplanting and/or weeding activities). On the other hand, the decline of SRI in Andhra Pradesh, with a change in guard at the helm and inability in some places to repeat some of the reported high yields, required a rethinking on SRI. Despite earlier collaborative research, the agricultural research establishment was reluctant to pursue SRI research on a consistent basis in the absence of external support. As has been pointed out by Water-Bayers (2015), support for CSO-led

\footnotetext{
${ }^{1}$ The idea of 'system builders' is used similar to Geels's (2004) usage, drawing upon the historian Tom Hughes's work. As pioneers TMT and Alapati built SRI in their respective states by entrepreneurially linking research, extension and policy, and were open to collaboration with civil society organisations too.

${ }^{2}$ Amongst early experimenters on SRI were Aurovilleans in Pondicherry in 1999, and organic farmers such as Selvam Ramaswamy and Narayana Reddy. See Shambu Prasad 2006: 47-59 for a detailed timeline of SRI in India.
} 
initiatives has been muted despite their potential. Of interest to sustainable transition management is the need to appreciate the role of actors who are often individuals within organisations who play the role of system builder. The small state of Tripura showed interesting possibilities by shifting the focus to regional food security and working through local government machinery in spreading SRI. SRI in Tamil Nadu continued with active state government supported by a new World Bank project on water management in river basins, with SRI being used as a means to enhance rice productivity.

A more significant change in this period was the spread of SRI to many of the poorer states of India through civil society organisations, largely supported by a new donor, the Sir Dorabji Tata Trust (SDTT) from Mumbai. The spread of SRI moved away from irrigated Green Revolution (GR) areas, to rainfed regions less impacted by GR such as Bihar, Odisha, Jharkhand, Chhattisgarh, Himachal Pradesh and Uttarakhand. Thus, while attempts were being made by WWF to consolidate the spread of SRI in different states and project acreage, the spread to these regions indicated a more important indicator, i.e. the number of small holder farmers taking to SRI in plots that were smaller in size as compared to more irrigated regions. While ideas and training on SRI continued to be inspired by the lead from Andhra Pradesh and Tamil Nadu, SRI in these regions was shaped locally by regional actors and their networks in diverse ways. In this phase we see networks collaborating both vertically within their respective regimes of the agricultural innovation system, and also horizontally across similar initiatives across regions. In some regions, local networks were able to gather support from state funded schemes on food security such as the National Food Security Mission. Institutionally, new mechanisms of extension, where communities were actively involved rather than public or private agents, were promoted. At the same time, the need to invest in human and institutional capacities of communities as experimenters and transmitters of knowledge was recognised.

The last phase of SRI, from 2010-14, is characterised by an open SRI innovation system. At the landscape or national level, SRI had attracted the attention of policy makers with some elements of SRI getting introduced in the National Food Security Mission (NFSM), a new scheme from the Department of Agriculture. There were round tables with policy makers from the Indian Council of Agricultural Research (ICAR) to examine closely the science related aspects of SRI. This was followed by the constitution of a sub-group of the Planning Commission on "Upscaling innovative technologies" that had recommended strategies for taking SRI in the Twelfth Five Year Plan (2012-2017). The Sub Group had pointed out the bankable aspects of SRI with agencies such as the National Bank for Agriculture and Rural Development (NABARD) and the Department of Rural Development through its livelihood missions, independently undertaking large scale pilots and projects on SRI. The institutional architecture suggested drew upon the diverse experiments across the country and sought to create alignment through a greater focus on peer-to-peer learning and extension, that had worked well in different SRI experiments. ${ }^{1}$

Despite repeated dialogues, scepticism concerning SRI within the agricultural research establishment continues to be high and there has been no independent initiative from national level bodies to examine SRI and shape it. The NFSM linked SRI with promotion of hybrid rice ${ }^{2}$ and invested more in the conventional extension approach of providing agricultural inputs through subsidies, rather than building human and institutional capacities. In the absence of a stamp of approval from research bodies, innovations in the linear model of agricultural innovation in India meant that public extension agents were unable to take up outside ideas for promotion. While some states like Tamil Nadu, Tripura, Odisha, Andhra Pradesh, and Bihar introduced SRI with some modifications in their extension systems, most others were unable to provide any thrust to SRI as they were unwilling to innovate institutionally. ${ }^{3}$

\footnotetext{
${ }^{1}$ See Shambu Prasad and Barah, 2013 for a description of the suggested institutional architecture of the sub-group.

${ }^{2}$ Hybrid rice is produced by cross-breeding different varieties that render higher yields and better profits for seed companies as farmers need to buy seeds every season and often avoid using it for home consumption due to poor taste and nutritional quality. The spread of hybrid rice in India has been modest (Spielman et al., 2014) and the seed saving costs through SRI provided a new opportunity for seed companies and the government.

${ }^{3}$ Some states were able to push for change due to key actors who played the role of system builders. In states like Odisha, the state government that initially began with SRI in whole villages chose to promote one aspect of SRI, namely line transplantation, and combined this with pushing hybrid rice and use of herbicides, much to the dismay of CSOs in the region. The Government was 'innovating' but the process revealed institutional rigidities, assuming that farmers could not adapt principles synergistically which was often not the case.
} 
During this phase, however, new organisations and networks emerged and were willing to take up ideas. A leading public policy innovator was the Rural Development Ministry's Livelihood Mission that has been open to SRI, especially in the state of Bihar. Following a successful pilot by a CSO, PRADAN (Professional Assistance for Development Action), SRI was chosen as one of the innovations for scaling up in a Development Marketplace contest in this World Bank supported livelihoods project. SRI was seen as an important livelihood enhancement strategy for poor women, who were organised into Self Help Groups (SHGs) through the livelihood mission. The focus on women, small and marginal farmers, and poverty reduction through the livelihood mission was in contrast to the conventional orientation towards men, large or progressive farmers and productivity aspects through the agriculture department. Increasingly, the policy agendas were being shaped at the state rather than the federal or national level. CSOs in different states organised state level workshops, learning alliances, to get greater buy-in from local actors with mixed results (Shambu Prasad, et al, 2007). More recently, SRI has been integrated into the new women empowered agricultural program of the Rural Development Ministry called the Mahila Kisan Sashaktikaran Pariyojana (MKSP). This program is a radical departure from conventional extension by working with groups of women farmers and through CSOs in different states. However, few agricultural departments have been supporting SRI indicating the need to look more closely at horizontal linkages in system innovation as suggested by Bai et al. (2009).

A review of the spread of SRI in the last decade in India (Shambu Prasad and Barah 2013, Thiyagarajan and Gujja 2013) indicates the following features:

- Productivity enhancement without varietal changes is possible through improved management practices as in SRI. Added benefits include better soil health, crop resilience and conservation of scarce resources, such as irrigation water and fossil fuel-based agri-inputs.

- These innovations and adaptations can go to scale with modest investments, but require different institutional mechanisms that are neither conventionally public extension nor private sector but community-led.

- SRI enhances farmer's capacities to manage changes in the external environment such as drought, and has greater potential in both mitigating and adapting to climate change. Upscaling SRI requires innovations in extension methodology based on improved knowledge, skills and management. Investments in farmers adaptive capacities is important and farmers are expected to enhance their on-farm management capacities (timing of operations, labour use, water management) and require support for at least 3 seasons/ years to enable a sustainable transition to SRI.

- Civil Society Organizations (CSOs) have an important role in enabling a shift in thinking on technological paradigms, regimes and extension systems. State governments, that have innovated their extension systems by working closely with Departments of Irrigation, Rural Development, and Panchayati Raj Institutions, have taken SRI much further than those that have relied only on conventional extension systems.

- Women farmers have played important roles in enabling this transition through community-based institutions in several states, while women's roles have conventionally been ignored by the State Departments of Agriculture.

- SRI can lead to diversification of farming systems providing greater choice for farmers and enhancing biodiversity. Indigenous varieties have responded well to SRI management, enhancing the scope for farmers to focus on varieties that improve household nutritional security in many parts of malnourished India.

- India has the potential of being a world leader in agroecological innovations like SRI.

This brief overview of a decade of evolution of SRI in India reflects some features of system innovation and transition management. First, the diversity of actors, their agendas and worldviews on how they see SRI needs to be appreciated. Second, is in understanding the fluidity of the institutional character of SRI. In the absence of a national policy on SRI, local and regional actors and system builders are able to enter the system, make changes and in some cases exit without damaging the adaptive capacity of the system as a whole. Thus, despite the failures of some established actors, new actors are able to enter and shape or renew the agenda for SRI. The institutional character is both fluid and dynamic, and often individuals in organisations can be system builders, even as the rest of their organisation is stuck with institutional 
rigidities. In some cases, the change of an individual at the helm can mean the return of conventional systems, as happened in the case of Andhra Pradesh.

Third, in the absence of formal organisational spaces for dialogue, new institutional mechanisms for dialogue become important. The National Symposia in 2006, 2007 and 2008 provided such opportunities while state level Learning Alliances (Odisha) and state level workshops enabled dialogue across departments and opened up the innovation and learning space (Shambu Prasad, 2009). In addition to these physical meeting spaces, networks in the form of e-groups have enabled sharing across partners. The SRI India e-group is one of the most active spaces on SRI and has attracted researchers from outside the country as well. A more focused group to discuss research, policy and practice of SRI, JAISRI, is facilitated by the National Consortium on SRI (NCS). NCS emerged as a network to promote conversations on science, policy and practice of SRI through dialogues, round tables and publications that seek to bring out perspectives from the field and from research to policy makers. NCS is a loose network that opportunistically engages multiple actors through discussions. ${ }^{1}$ There are, in addition, state level e-groups like Sriorissa and JAISRI-AP. Overall, networks have played an important role in the spread of SRI and have rendered some innovative 'sustainability brokering', to use Leach et al.'s (2012) phrase. Nemani Chandrasekhar, a programme officer from a CSO, is one such broker who, over the past seven years, has posted over 2500 items on SRI in different e-groups, thereby helping to connect researchers, equipment manufacturers, and others across states, regions and even internationally.

Nonetheless, knowledge rigidities and hierarchies continue to hinder open discussions. This is evident in the e-groups too, with CSOs being quite active in sharing and discussing while researchers and policy makers are often content with being passive spectators to the knowledge exchange instead of being active participants in knowledge dissemination through these informal spaces. Within this diverse institutional architectture of SRI we will address, in the following section, the features of SRI in the three states of Uttarakhand, Odisha and Andhra Pradesh, seeking to derive ideas for system innovation and system transition.

\section{Diversity in SRI practice: Evidence from India}

In this section, we briefly compare and contrast the spread of SRI in three different regions of India - the mountain farms of Uttarakhand, the coastal and hilly regions of Odisha, and the plains of Andhra Pradesh. Andhra Pradesh is among the top five states in terms of rice production and acreage. Productivity in Odisha is low, although it figures among top five in acreage. Rice cultivation in Uttarakhand is largely focused on household food security and does not rank high nationally, neither in yield nor acreage. All states have had more than seven years of experience with SRI. Historically Andhra Pradesh has been seen as a Green Revolution state and the state capital Hyderabad hosts the Directorate of Rice Research (DRR). Odisha has an older research centre in the Central Rice Research Institute (CRRI) at Cuttack and is recently the focus of a new scheme called "Bringing Green Revolution to Eastern India" (BGREI). Several districts in the state are covered under NFSM for productivity enhancement. Uttarakhand, by contrast, given the nature of rice farming in mountains, rarely figures in discussions on rice production nationally, even though rice farming is an important agricultural activity that is largely carried out by women. All states have agricultural universities with mixed experience in research and extension on SRI.

The initiation, incubation, expansion and acceleration of SRI in the three states has been summarised in Table 1. For the sake of brevity we focus more on the diverse institutional actors of SRI in the three states and skip the rich details of the actors. All states have good SRI presence and have multiple and diverse actors involved in its promotion. CSOs have primarily facilitated exchange of ideas and knowledge in the three states and have been at the forefront of local consortia, learning alliances and state level workshops. Important differences lie in the nature of institutions. In Uttarakhand, the same actors were involved in all phases of SRI spread, whereas this changed in Andhra Pradesh and Odisha. The latter have had collaborations with Departments of agriculture in the concerned states. However, reports from the field

\footnotetext{
${ }^{1}$ One of the more recent initiatives of NCS has been the international workshop on SRI with Wageningen University. See http://www.sri-india.net/event2014/home.htm for more details.
} 
indicate insufficient trust and lack of collaboration among the CSOs and their networks with agriculture departments in design of the SRI uptake.

\begin{tabular}{|c|c|c|c|}
\hline $\begin{array}{l}\text { Institutional } \\
\text { Attribute }\end{array}$ & dhra Pradesh & disha & Uttarakhand \\
\hline $\begin{array}{l}\text { (A) Initiation into } \\
\text { SRI }\end{array}$ & $\begin{array}{l}\text { Alapati Satyanarayana of } \\
\text { ANGRAU initiates trials across } \\
\text { state in 2003, Eenadu news } \\
\text { carries reports on SRI } \\
\text { actively, Focus on canal } \\
\text { irrigated areas }\end{array}$ & $\begin{array}{l}\text { Experiments by PRADAN in } \\
\text { Northern Odisha in 2003, } \\
\text { Taken up with vigour by CWS } \\
\text { (Centre for World Solidarity) in } \\
2005-06 \text { with inputs from } \\
\text { CSOs in Andhra Pradesh }\end{array}$ & $\begin{array}{l}\text { Ravi Chopra of People's } \\
\text { Science Institute (PSI)- a CSO } \\
\text { hears of it in 2005, Trials in } \\
2006 \text {, Inputs from WASSAN } \\
\text { and WWF program }\end{array}$ \\
\hline \multicolumn{4}{|l|}{$\begin{array}{l}\text { (B) Main Actor/ } \\
\text { Facilitator }\end{array}$} \\
\hline $\begin{array}{l}\text { Incubation of } \\
\text { Innovation Stage }\end{array}$ & $\begin{array}{l}\text { ANGRAU Extension leads trials } \\
\text { across the state, WWF begins } \\
\text { collaborative projects }\end{array}$ & $\begin{array}{l}\text { PRADAN and CWS in early } \\
\text { stages, } \\
\text { Research trials by CRRI and } \\
\text { DWD since } 2004\end{array}$ & SI with WASSAN \\
\hline $\begin{array}{lr}\text { Expanding or } \\
\text { Building the } \\
\text { innovation stage }\end{array}$ & $\begin{array}{l}\text { WWF creates innovation } \\
\text { spaces, CSO support, } \\
\text { WASSAN leads dissemination } \\
\text { and training, ANGRAU support } \\
\text { declines, Collaborations with } \\
\text { DRR and ICRISAT }\end{array}$ & $\begin{array}{l}\text { XIMB facilitates learning } \\
\text { alliance in Odisha, Partners } \\
\text { expand operations across } \\
\text { state with support from SDTT }\end{array}$ & $\begin{array}{l}\text { PSI, local partners; SDTT and } \\
\text { NABARD as donors, } \\
\text { Agriculture Department for } \\
\text { one year (2010) only }\end{array}$ \\
\hline $\begin{array}{l}\text { Acceleration } \\
\text { scaling up stage }\end{array}$ & $\begin{array}{l}\text { Dept of agriculture } \\
\text { reintroduces (modifies) SRI } \\
\text { with a mechanisation focus, } \\
\text { WASSAN spearheads a JAl } \\
\text { SRI AP consortium of actors } \\
\text { for uptake of SRI in selected } \\
\text { blocks with coordinated } \\
\text { action among research and } \\
\text { non-research actors }\end{array}$ & $\begin{array}{l}\text { Dept of agriculture creates } \\
\text { SRI villages initially; works with } \\
\text { CSOs in upscaling, later } \\
\text { promotes line transplanting } \\
\text { with hybrids CSOs unhappy } \\
\text { with 'unsustainable' turn, State } \\
\text { livelihood mission takes up SRI } \\
\text { in few districts }\end{array}$ & $\begin{array}{lr}\text { PSI leading } & \text { state level } \\
\text { workshops, } & \text { Research } \\
\text { community involved in } \\
\text { assessments, Agriculture } \\
\text { department not keen despite } \\
\text { SRI being included in annual } \\
\text { plan }\end{array}$ \\
\hline xtent & 99,048 & $\begin{array}{l}\text { armers in } 20,880 \text { ha } \\
\text { ent figures not } \\
\text { in } 2013\end{array}$ & $\begin{array}{l}\text { Around } 25,000 \text { farmers in } \\
2,000 \text { hectares in } 2013\end{array}$ \\
\hline $\begin{array}{l}\text { (D) Innovations in } \\
\text { SRI } \\
\text { (Technical) }\end{array}$ & $\begin{array}{l}\text { Coordinated trials by DRR, } \\
\text { good resource base for SRI } \\
\text { (trainers \& weeders sought by } \\
\text { rest of the country), AgSRI as } \\
\text { a social enterprise extends } \\
\text { SRI to sugarcane across India }\end{array}$ & $\begin{array}{l}\text { Stronger organic focus, } \\
\text { Leading research on science } \\
\text { of SRI by DWD }\end{array}$ & $\begin{array}{l}\text { Extension to wheat and other } \\
\text { crops, Less use of } \\
\text { agrochemical inputs }\end{array}$ \\
\hline $\begin{array}{l}\text { (User Adaptation } \\
\text { \&Experimentation) }\end{array}$ & $\begin{array}{l}\text { High awareness among } \\
\text { farmers though adoption not } \\
\text { as high, Agencies working on } \\
\text { incentives and support } \\
\text { structures }\end{array}$ & $\begin{array}{l}\text { Good spread among poorer } \\
\text { farmers in tribal regions, More } \\
\text { involvement of women in } \\
\text { weeding, Collective action } \\
\text { enhanced }\end{array}$ & $\begin{array}{l}\text { High level of farmers' } \\
\text { adaptations } \\
\text { experimentations, Community } \\
\text { level social organization }\end{array}$ \\
\hline $\begin{array}{l}\text { (Inst } \\
\text { Inno }\end{array}$ & $\begin{array}{l}\text { JAl SRI AP consortium } \\
\text { facilitates actors } \\
\text { collaborating, "field days' as } \\
\text { mechanisms for sharing of } \\
\text { results on SRI, Most active } \\
\text { presence in e-groups and } \\
\text { social media }\end{array}$ & $\begin{array}{l}\text { Learning alliance platform to } \\
\text { get actors together facilitated } \\
\text { by academic institution, } \\
\text { Collaboration between } \\
\text { agriculture department and } \\
\text { CSOs,Scope for collective } \\
\text { experimentation and learning } \\
\text { low }\end{array}$ & $\begin{array}{l}\text { Emergence of newer task } \\
\text { routines, Collective action, } \\
\text { Enhanced role of women, } \\
\text { Regular state level } \\
\text { workshops, Community based } \\
\text { extension model }\end{array}$ \\
\hline $\begin{array}{l}\text { (E) Collaboration } \\
\text { (Research and Non- } \\
\text { research Actors) }\end{array}$ & $\begin{array}{l}\text { Consortium enabling closer } \\
\text { collaboration and sharing, } \\
\text { More recent with IRRI by } \\
\text { WASSAN on water saving }\end{array}$ & $\begin{array}{l}\text { Knowledge sharing during } \\
\text { learning alliance meets, Some } \\
\text { experiments with research by } \\
\text { universities in collaboration }\end{array}$ & $\begin{array}{l}\text { Attempted but low key with } \\
\text { personal interest and little } \\
\text { institutional collaboration }\end{array}$ \\
\hline
\end{tabular}




\begin{tabular}{|c|c|c|c|}
\hline $\begin{array}{lr}\text { (CSOs } & \text { and } \\
\text { extension } \\
\text { departments } \\
\text { govt) }\end{array}$ & $\begin{array}{l}\text { Only in pilots of JAl SRI AP } \\
\text { consortium and some } \\
\text { collaboration with livelihood } \\
\text { mission }\end{array}$ & $\begin{array}{l}\text { Dept. of agriculture sub- } \\
\text { contracted SRI work to CSOs } \\
\text { though agenda set by } \\
\text { department on line } \\
\text { transplanting, Livelihood } \\
\text { mission more open }\end{array}$ & $\begin{array}{l}\text { Minimal, Failed after one year } \\
\text { because of development of } \\
\text { mistrust, and lack of } \\
\text { commitment r from } \\
\text { government department }\end{array}$ \\
\hline $\begin{array}{l}\text { (F) Sustainability } \\
\text { Agenda }\end{array}$ & $\begin{array}{l}\text { Sustainability not part of } \\
\text { official agenda, Compounded } \\
\text { by policy regimes such as } \\
\text { free electricity little incentives } \\
\text { for water saving, Little } \\
\text { systemic research across } \\
\text { actors and departments of } \\
\text { government }\end{array}$ & $\begin{array}{l}\text { Sustainability not part of } \\
\text { official government agenda, } \\
\text { very high on CSOs who have } \\
\text { promoted Jaivik SRI or organic } \\
\text { SRI }\end{array}$ & $\begin{array}{l}\text { High by CSOs } \begin{array}{r}\text { (avoided } \\
\text { inputs, }\end{array} \\
\text { agrochemical } \\
\text { encouraged local production } \\
\text { of bio pesticides), little } \\
\text { interest by agriculture } \\
\text { department on agendas } \\
\text { beyond yields }\end{array}$ \\
\hline
\end{tabular}

Table 1: Socio-technical Regimes of SRI in 3 States of India.

The comparison of the three states indicates some features that impinge on system innovation in diverse and plural socio-technical settings. These include:

a. Understanding and Planning for Diversity: Actors in the three states have a very diverse interpretation of SRI, reflecting plurality of ideas and contestation. Researchers and CSOs have different agendas on SRI. SRI is seen differently by farmers who depend on external labour like in Andhra Pradesh, who consider it as more labour intensive. In Odisha and Uttarakhand, labour is more easily managed within a family and it is more common to exchange labour. SRI principles become adapted locally due to bio-physical and socioinstitutional conditions. Attitudes of key actors like agricultural departments can vary both in space and over time. All of these have important implications for a system transition. This diversity in institutional arrangements needs to be recognised during planning by enabling local actors to adapt and build on this diversity that often gets reduced in upscaling and adoption processes. Enabling this expression of diversity and engaging across perspectives needs to become an important design feature of system innovation and sustainability transitions.

b. Sustainability and knowledge rigidities: Existing institutional structures in agriculture in India are too focused on yields alone. The multifunctional aspects of agriculture - its contribution to peoples livelihoods, its provision of ecosystem services or its ability to absorb stresses and shocks of industrial systems-are rarely recognised. Sustainable agriculture is increasingly embraced by farmers, not so much for its yield potential, but for its ability to enhance climate resilience, for reducing vulnerability and risks and enhancing capacities of collective action and community adaptation to climate change. The inadequate appreciation of these aspects often leads to regimes even seeking to fit an innovation such as SRI into existing yield paradigms. Given the power structures and hierarchies that exist, sustainability aspects of the innovation are not foregrounded. In fact, spaces for knowledge dialogues and discussions on how to foreground these ideas do not figure in planning. For instance, the three states show a clear mismatch between CSOs and formal research perspectives on sustainability issues.

c. Niche, regime and landscape: Stages or mental models: It is also evident from the experiences of the three states that key actors and facilitators often need to work simultaneously at niche, regime and macrolevels. In fact the ability of many CSOs to be part of formal and informal networks in other domains, such as natural resource management, watershed activities or sustainable agriculture, enables them to move across levels and draw from national and international experience and expertise. This ability to draw from horizontal linkages, as indicated by Bai et al (2009), is evident in the SRI case too. The case of SRI supports ongoing rethinking on MLP, as suggested by Genus and Coles (2008), who caution against the simplistic treatment of MLP leading to neat, mechanistic models of transition. They suggest that future MLP studies need to focus more on the contribution and interaction of diverse groups to socio-technical transformation and relook at supposed clear boundaries between niche, regime and macro levels. We suggest that the assumption that sufficient generation of novelties from protected niches would lead to regime changes 
does not recognise the difficulties in getting those in power and who have been promoting less sustainable practices, to think and work differently. ${ }^{1}$

Further, building on the work of Markard and Truffer (2008) we see the need for a greater focus on emergent institutions and the appreciation of competing and complementing technological innovation systems and landscape levels. We have shown how actors use or create emergent institutions such as learning alliances, consortia or sharing workshops to articulate alternative visions and that enable discussions on regime and macro levels even as they work at "niche" level. Elzen et .al. (2012) too have pointed to the need for better understanding processes that link niches to regimes. Current sustainable transition literature tends to focus on learning at the niche level, ignoring the need for systemic learning that needs to occur at the level of socio-technical regimes. Further, niches are not just spaces where technological innovations occur; a closer attention to what is happening at the 'niche' or local level indicates complex adaptation processes that should inform discussions at the regime level. We have shown that complexities are quite high at local levels and the absence of controlled laboratory type conditions in niches indicates a high level of adaptability and user innovation. It is a severe challenge to integrate these ideas at the local level with the regime and landscape levels, seeking to facilitate diversity in system innovation.

d. More space for social learning and collaborative experiments: The existing institutional environment favours maximizing single criteria objectives, such as yield, rather than locally optimizing multiple criteria. This frame diminishes the space for collaborative experimentation and does not allow the system as a whole to adapt to changes that can lead to sustainability transitions. That experiments can enhance the capacity to collaborate, work and learn together, especially outside the laboratories, is not sufficiently recognised by the research establishment. While some space has been created for knowledge sharing and dialogues through mechanisms such as consortia, learning alliances etc., there seems to be little support for investing in these mechanisms and enhancing human capacities to adapt and plan for system innovation. Experimentation has to happen at niche, regime and landscape levels and these are currently absent in the Indian policy environment. Greater investment is necessary to enable systemic thinking and modelling in these experiments.

\section{$4 \quad$ User Innovation, Networks and System Transition}

Problem-solving agricultural research towards more sustainable agro-food systems is, by its very nature, a critical but risky enterprise. The diversity of perspectives indicated above involves dialogue across disciplines, a nimbleness to dialectically link knowledge to action (and vice versa), and recognize the multiple sources of knowledge beyond research actors alone. Existing institutional arrangements in agricultural research centres are often hindrances to change. Few agricultural research organisations encourage new modes of professional behaviour associated with continuous learning and change (Watts et al., 2007). The case of SRI indicates that, despite large spread at the local level, knowledge politics and institutional rigidities hinder the wider spread innovation. We conclude this chapter by highlighting two areas of interest to transition management scholars (Loorbach and Rotmans, 2010) that have been relatively underexplored and that are important for sustainability transitions in agriculture, especially in developing countries - user innovations and role of networks.

\subsection{User Innovation and Adaptation in SRI}

Rice farming, and by extension sustainable agricultural practices, is not an individual practice but a sociotechnical practice where many operations (like nursery raising, land preparation, transplanting and water management) are performed in a collective way through informal social groups, and not just by individual farm households. Mountain farmers of the Western Himalayas follow a complex rice farming system,

\footnotetext{
${ }^{1}$ We suggest that following the important lead on system innovation and sustainable agriculture by Barbier and Elzen (2012), there is a need to look more closely on how and whether the MLP stages and the ideas of the niche in the literature are sufficient to understand the complexity of changes.
} 
growing multiple varieties of rice (along with other crops in the rainfed plots) collectively through different methods suitable to the scattered, marginal and diverse small farms. In 2006, when the People's Science Institute (PSI), a civil society organization based in Uttarakhand, tried to introduce SRI in the region with the help of other local CSOs, to enhance the household level food and livelihood security, they faced an uphill task as conditions were vastly different from both Madagascar and southern India, from where the PSI staff received training.

The scattered landholdings, small and irregular terraces, uncertainty in water availability, along with established agricultural routines and cultural practices like Dinbar, ${ }^{1}$ posed constraints on farmers, forcing them to adjust the recommended SRI practices to their own convenience (see Table 2). The diversity in socio-economic conditions of farm households in terms of ownership of land, proportion of un-irrigated and irrigated lands, labour, livestock, along with livelihood patterns, resulted in different farmers' responses to SRI, even within the same village. Farmers, along with the various other actors, performed a balancing act in modifying the recommended SRI practices, at the same time adapting conventional methods. This resulted in the emergence of new forms of rice cultivation. These technological adaptations were also accompanied and complemented by institutional adaptations in various social groups undertaking different activities right from nursery-raising to harvesting, along with changes in socio-cultural norms like Dinbar guiding rice farming.

\begin{tabular}{|c|c|c|c|}
\hline Parameters & $\begin{array}{l}\text { Conventional Practices } \\
\text { under Transplantation } \\
\text { from Bina or Saindhat }\end{array}$ & $\begin{array}{l}\text { Recommended } \\
\text { Practices }\end{array}$ & $\begin{array}{l}\text { Common Farmers' Modified } \\
\text { Practices }\end{array}$ \\
\hline $\begin{array}{l}\text { Age of Seedlings at } \\
\text { Transplantation }\end{array}$ & $\begin{array}{l}60-75 \text { days' old (Bina) } \\
45-60 \text { days' old (Saindha) }\end{array}$ & $8-12$ days' old seedling & 15 - 45 days' old seedlings \\
\hline Seedlings/hill & 4 - 10 seedlings/hill & 1 seedling/hill & 2- 4 seedlings/hill \\
\hline $\begin{array}{ll}\text { Plant to Plant } \\
\text { Spacing }\end{array}$ & $10-22.5 \mathrm{cms}$ & $25 \mathrm{cms}$ & $\begin{array}{l}15-25 \mathrm{cms}+\text { row spacing of } \\
25 \mathrm{cms} \text {, if marker is used; } \\
\text { otherwise even done by eye } \\
\text { estimation }\end{array}$ \\
\hline Water Management & $\begin{array}{l}\text { Flooded } \\
(10-15 \mathrm{cms})\end{array}$ & $\begin{array}{lll}\text { Alternate } & \text { Wetting } & \text { and } \\
\text { Drying } & & \\
\end{array}$ & $\begin{array}{l}\text { Flooded with less water depth } \\
(2-10 \mathrm{cms})\end{array}$ \\
\hline $\begin{array}{l}\text { Weed } \\
\text { Management }\end{array}$ & $\begin{array}{l}\text { Hand weeding as per } \\
\text { convenience }\end{array}$ & $\begin{array}{l}3 \text { intercultures with weeder } \\
\text { at } 10,20 \text { and } 30 \text { days after } \\
\text { transplanting }\end{array}$ & $\begin{array}{l}\text { Use of weeder, in case of } \\
\text { marking otherwise hand } \\
\text { weeding. First interculture } \\
\text { done with weeder, rest through } \\
\text { hand }\end{array}$ \\
\hline Nutrient Management & No Application & $\begin{array}{l}\text { Application of liquid } \\
\text { manures prior to weeder } \\
\text { operation }\end{array}$ & $\begin{array}{l}\text { Use of Panchagavya, a liquid } \\
\text { organic manure (optional) }\end{array}$ \\
\hline
\end{tabular}

Table 2: User adaptations to Innovations: Case of SRI in Uttarakhand.

SRI proved to be a complex system, various elements of which were interpreted differentially by various actors. The VLRPs (Village Level Resource Persons), who are farmers themselves, deputed by the SRI promoting CSO, attempted to enhance the capacities of individual co-farmers, seeking to enhance productivity with knowledge and acquired skills. The Master Trainers (extension personnel from the CSO) and the promoting CSO were more concerned with achieving the larger goal of addressing food security through upscaling SRI in the region. The farmers' focus was on minimizing risk and optimizing labour use and they thus experimented and tinkered with various elements of SRI, to establish local optimums based on their understanding.

\footnotetext{
${ }^{1}$ Dinbar is an auspicious date announced at the community level for initiation of transplanting activities in mountain villages of Uttarakhand. It takes into account suitable climatic conditions in terms of likely rains while encouraging diversion of labour from rainfed plots for collective local action.

${ }^{2}$ Bina: Dry bed nursery; Saindha: Direct wet bed.
} 
The case study from Uttarakhand shows that the dynamics of innovation is often not a simple progression of diffusion from a progressive to a laggard user, but a complex one of adaptation and re-innovation of components by users, involving experimentation and learning, selection and modifications, agricultural skilling and re-organisation, striving not only for technical but also for cultural and institutional improvisations through collective performance. Insights on users and technology from science and technology studies (Oudshoorn and Pinch, 2003) need to be drawn upon to appreciate user-technology relations better. A greater focus on users can help bring a shift from adoption at the individual farmer level to adaptations at field, community and landscape levels. In the future, innovation studies of diffusion therefore need to focus more on adaptation processes, rather than adoption as the former is essential for development innovation in diverse and complex agricultural systems. Innovation for sustainable development requires conceptualizing knowledge and skills as commons. These new commons have emerged in agriculture with CSOs and farmers playing an important role. Empowering communities by recognizing their role in innovation is critical for development of complex and increasingly vulnerable agricultural systems. CSOs can play an important role in this process of knowledge and skills dissemination, apart from facilitating socialreorganisation. One of their important roles is to create networks to break institutional rigidities and hierarchies.

\subsection{Role of Networks in System Innovation}

Studies of SRI in India have indicated that a heterogeneous 'support network', that transcends conventional agricultural networks, has played a significant role in the spreading of SRI (Basu and Leeuwis, 2012). Individuals within organisations have been strengthened by networks and have collaborated through 'creative dissent' by engaging with actors across conventional boundaries and scientific disciplines (Shambu Prasad 2006, Shambu Prasad et. al. 2012).

In the case of SRI, new forms of institutions have enabled knowledge flows via information and communication technologies, making it easy for actors to collaborate across disciplines and enable the coproduction of new knowledge by researchers and farmers. The increasing number of articles on SRI (journal articles were estimated at close to 100 in 2013 and cumulatively at 576, Styger (2014)) has spanned traditional disciplinary boundaries. Researchers have intuitively recognized that new knowledge often resides in the interaction of diverse actors facilitated through networks, aligned, but not necessarily in agreement, around common interests. Thus, while the number of journal publications on SRI has recently increased, this happened despite the absence of research programmes focused on SRI by most research establishments. Multiple actors have interacted with each other through informal networks like e-groups, regional networks, joint participation in sub-panels in mainstream rice conferences, wide sharing of newer manuals, power point presentations made for different forums, videos of innovations in rice production or equipment designs, and, more recently, specialized Facebook pages on equipment. All these contributed to the effectiveness of networks over conventional organizational forms. ${ }^{1}$

The role of networks in applying systems' thinking for sustainable agro-food systems has been insufficiently understood. Networks can create flatter organizational forms and can empower non-research actors (civil society organisations, farmers and their organisations and networks) whose knowledge often is ignored by researchers, even while they are often better in thinking systemically and managing complexity. In fact, the experience of the learning alliance in Odisha indicates that academic institutions can play this important knowledge dialogue and facilitating role, that is insufficiently understood. Complex social issues like sustainability transitions in agriculture require creative responses that can dwarf even the most wellresourced, well-managed organization. System thinkers, and sustainability science researchers, need to go beyond simply building their organizations, or their academic networks and concentrate on building capacity outside their organizations. Sustainability transitionists can leverage the strength of networks, formal and

\footnotetext{
${ }^{1}$ The proliferation of regional networks on SRI, strengthening the existing open-source dissemination of SRI from Cornell University, led to the creation of SRI Rice (The SRI International Network and Resources Centre). The information and resources page of SRI Rice shows the prevalence of diverse forms of knowledge creation and dissemination that shows journals as one amongst a larger set by which different actors globally use knowledge for action. http://sri.ciifad.cornell.edu/aboutsri/aboutus/index.html
} 
informal, to make sense of, and help solve complex problems. This requires a reorientation towards trust, not control, and towards enhancing cooperation as equal nodes in a constellation of actors, rather than relying on a central hub to command a node, and not a hub. Such institutions are few in agriculture and we suggest that investment in new institutional forms should be an important aspect of shifts towards sustainable intensification of food systems. ${ }^{1}$

\section{Conclusion: Implications for System Innovation Research}

In this chapter we reviewed the experiences of an agroecological practice, SRI, in India and showed that, despite a rich history of its practice and innovations over a decade by large number of farmers, the knowledge of SRI continues to lack policy support due to existing knowledge regimes that do not support agroecology. This challenge has been highlighted more generally by Vanloqueren and Baret (2009). We have argued how even the possibility of leadership in science in a new field does not necessarily evoke interest from the established scientific world. While the need to look at issues of knowledge at the regime and landscape level has been recognized in the system innovation literature, we suggest that the politics of knowledge has not received sufficient attention. Ignoring this aspect does not allow for transformations towards sustainability. Knowledge politics manifests in day-to-day practice in curious ways. Levidow et. al (2013) have shown the existence of rival visions to a master narrative of Knowledge Based Bio Economy (KBBE). In the SRI case, the onus of providing evidence and scaling up is often forced on the less dominant narrative of agroecology while resources for research and extension lie largely with the agricultural research establishments that are more aligned to the dominant narrative of agricultural intensification through genetic engineering.

Institutional rigidities and technological lock-ins do not allow for greater investment in human capacities and institutions that could enable experimentation and social learning locally in agroecological or sustainable agriculture based agro-food systems. Those involved in practicing alternate agriculture are often under pressure to prove, not only that agroecology works, but that it works fast. Support structures are often weak in developing country contexts and donor pressure to scale up provides little space for experimentation and innovation. Our case shows that the current categorisation of innovations transiting to sustainability from a protected niche to a regime, while good as mental model, does not necessarily translate as neat stages in practice. Practitioners of SRI have had to argue against SRI as being a niche innovation. The politics of knowledge of dominant paradigms tends to dismiss alternatives as niches with restricted scope, even when they claim universal spread and validity. Sustainable transition researchers need to avoid this trap and pay more attention to the mechanisms through which knowledge regimes persist.

The case study reiterates some insights from innovation studies in the literature, namely the role of system builders, or innovation champions, and innovation brokers. We showed that these actors can, and often do, change during the course of the innovation or sustainable transition and this can also vary spatially across regions. Transition management researchers need to appreciate this dynamics in complex systems, and the system of innovation needs to mapped periodically to be able to identify and invest in potential system builders. The case also suggests that some system builders can often be silent and less vocal and yet play their role as 'creative dissenters' (Shambu Prasad, 2014).

Two aspects that the case study of SRI brings out and need particular attention in future sustainable transition research, relate to diversity and the role of networks. We have shown, through the example of the three states of India, that it is often incorrect to assume a single replacement of the existing regime. Alternatives assume different characteristics in different institutional and bio-physical settings. Plurality

\footnotetext{
${ }^{1}$ These ideas are better discussed in fields other than agriculture or the systems thinking or sustainability sciences literature. Some leads from social entrepreneurship (Skillern and Marciano, 2008) and public administration (O'Toole, 1997) and sociology of science (Ynalvez and Shrum, 2011) can fruitfully be used by system thinkers.
} 
needs to be recognised as an important feature of sustainable agriculture and presents challenges for embedding this as a design principle. This has implications for system innovation researchers, particularly in understanding adaptation processes in innovation. Conventional economic theories on adoption dynamics of innovation tend to reduce the complexity of process innovations such as SRI and agroecology. Micro studies of adaptation processes, as we have shown in the case of Uttarakhand, can provide a better handle on designing system transitions. We have also tried to show how an excessive focus on the niche as the site of technological innovations detracts from institutional changes, transformations in work routines that happen locally in a niche. The ability of niche-actors to cope and deal with complexity is much higher than researchers give credit for and actually provides insight on institutional changes at the regime and landscape levels. We have also suggested that key actors often operate at niche, regime and landscape levels in a dynamic and even opportunistic manner. An approach, that presumes the need to build evidence from below before introducing changes at the meso and macro levels, is not only strategically unwise but can be ineffective as well. Knowledge rigidities and hierarchies are higher at the regime and macro levels and need to be opened up for democratic innovation at an early stage.

Networks, we suggest, open up spaces for institutional change by enabling actors to experience and behave differently. They play important roles in creating knowledge commons and dialogues and should not be used for project management purposes alone. They bring an inclusive character to complex knowledge discussions and can assume different forms, as in the case of SRI where learning alliances and state level workshops as newer institutions have worked in tandem with virtual learning and sharing groups through the Internet. Networks enable building of trust and strengthen creative dissenters and pioneers within the system who often do not find support within their existing organisations. Understanding and recognising diversity of systems of innovation, reflecting on knowledge rigidities and enabling and facilitating networks to create knowledge commons, and appreciating user adaptations and innovations, are insights that can enrich the repertoire of system innovation researchers and practitioners in sustainable agriculture.

Acknowledgements: We thank Ravindra Adusumilli and Sabarmatee for their useful inputs on SRI evolution and spread in the states of Andhra Pradesh and Odisha respectively. We are also grateful to Cees Leeuwis for suggestions on an earlier draft, and Harro Maat for his support and encouragement in the production of this chapter. We thank reviewers of the chapter at the SISA workshop in Paris and the participants that helped in revising the chapter. Finally, we acknowledge the financial support of the Dutch Organization for Scientific Research's Science for Global Development Programme (NWO-WOTRO) for supporting the study under a wider project "The System of Rice Intensification (SRI) as a socio-economic and technical movement in India", 2010-2014.

\section{References}

Abraham, B., H. Araya, T. Berhe, S. Edwards, B. Gujja, et al. 2014. The System of Crop Intensification: Reports from the field on improving agricultural production, food security, and resilience to climate change for multiple crops. Agriculture and Food Security 3 (1): 4.

Barbier, M., and Elzen, B. (eds), (2012).System Innovations, Knowledge Regimes, and Design Practices towards Transitions for Sustainable Agriculture. Inra [online], posted online November 20, 2012. URL: http://www4.inra.fr/sad_eng/Publications2/Free-e-books/System-Innovations-for-SustainableAgriculture

Bai, X., Wieczorek, A. J., Kaneko, S., Lisson, S., \& Contreras, A. (2009). Enabling sustainability transitions in Asia: the importance of vertical and horizontal linkages. Technological Forecasting and Social Change, 762), 255-266.

Basu, S., and Leeuwis, C. (2012): Understanding the rapid spread of System of Rice Intensification (SRI) in Andhra Pradesh: Exploring the building of support networks and media representation. Agricultural Systems 111: 34-44.

Chopra, R., and Sen, D. (2013): Golden wheat becomes more golden-Extending SRI to wheat, SRI: A scaling up success, LEISA India, 15 (1):30-32.

Elzen, B., Geels, F. W., and Green, K. (2004): System Innovation and the Transition to Sustainability Theory, Evidence and Policy, Cheltenham: Edward Elgar Pub. 
Elzen, B., van Mierlo, B., \& Leeuwis, C. (2012). Anchoring of innovations: Assessing Dutch efforts to harvest energy from glasshouses. Environmental innovation and societal transitions, 5, 1-18.

Geels, F. W. (2004). From sectoral systems of innovation to socio-technical systems, Research Policy, 33(6-7), 897-920.

Genus, A., \& Coles, A. M. (2008). Rethinking the multi-level perspective of technological transitions. Research policy, 379), 1436-1445.

Kassam, A., Stoop, W., \& Uphoff, N. (2011): Review of SRI modifications in rice crop and water management and research issues for making further improvements in agricultural and water productivity, Paddy and Water Environment, 9(1), 163-180.

Leach, M., Rockström, J., Raskin, P., Scoones, I., Stirling, A. C., Smith, A. Olsson, P. (2012). Transforming Innovation for Sustainability. Ecology and Society, 1 12 ).

Loorbach, D., \&Rotmans, J. (2010). The practice of transition management: Examples and lessons from four distinct cases. Futures, 42(3), 237-246.

Levidow, L., Birch, K., and Papaioannou, T. (2013): Divergent Paradigms of European Agro-Food Innovation: The Knowledge-Based Bio-Economy (KBBE) as an R\&D Agenda. Science, Technology \& Human Values, 38(1), 94-125.

Markard, J., \&Truffer, B. (2008). Technological innovation systems and the multi-level perspective: Towards an integrated framework. Research policy,374), 596-615.

Oudshoorn, N., and Pinch, T. J. (2003): How users matter: the co-construction of users and technologies. Cambridge, Mass.: MIT Press.

O’Toole, L. J., Jr. (1997): Treating Networks Seriously: Practical and Research-Based Agendas in Public Administration. Public Administration Review, 57(1), 45-52.

Shambu Prasad, C., Thiyagarajan,T. M., Rupela, O. P., Thakur, A., and Ramanjaneyulu, G. V. (2012): "Contesting agronomy through creative dissent: Experiences from India" in Jim Sumberg and John Thompson, eds. 2012. Contesting Agronomy: Agricultural Research in a Changing World. Routledge and Earthscan series on sustainability, London.

Shambu Prasad, C., and Basu, P. K. (2005):'Understanding Scientific Controversies: The case of the System of Rice Intensification in India", paper at the $4^{\text {th }}$ Annual IWMI TATA Partners Meet 'Bracing up for the future', Institute of Rural Management Anand, February 24-26.

Shambu Prasad, C. (2006): System of Rice Intensification in India: Innovation History and Institutional Challenges. Hyderabad: WWF-Dialogue Project at the International Crop Research Institute for SemiArid Tropics and XIMB.

Shambu Prasad, C., Beumer, K., \& Mohanty, D. (2007). Towards a learning alliance: SRI in Orissa. XIMB and WWF-Dialogue project, ICRISAT, Patancheru, India.

Shambu Prasad, C. (2009): Encounters, dialogues and learning alliances: The System of Rice Intensification in India, in I. Scoones \& J. Thompson, eds., Farmers First Revisited: Innovation for Agricultural Research and Development, Earthscan, London, pp 82-87.

Shambu Prasad, C. 2014. "Creative dissent: Linking vulnerability and knowledge in India". In Vulnerability in Technological Cultures: New Directions in Research and Governance. Anique Hommels, Wiebe Bijker, and Jessica Messman, eds. Boston: MIT Press.

Shambu Prasad, C. and Barah, B. C. (2013): Upscaling SRI: Unpacking innovation, investments and

SRI Rice (2014):The system of crop intensification: reports from institutions, LEISA India. 15(1): 16-19.

Spielman, D. J., Kolady, D. E., \& Ward, P. S. (2013). The prospects for hybrid rice in India. Food Security, 5(5), 651-665.

Thiyagarajan, T. M., and Gujja, B. (2013): Transforming rice production with SRI: Knowledge and practice. Delhi: National Consortium on SRI (NCS), India, 204 p.

Styger, Erika. (2014). System of Rice Intensification Research - A Review (1993-2013). Presentation at the $4^{\text {th }} \quad$ International Rice Congress, Bangkok, October 31.

http://www.slideshare.net/SRI.CORNELL/1424-system-of-rice-intensification-research-areviewAccessed April 2, 2015

Uphoff, N., Fasoula, V., Iswandi, A., Kassam, A., Thakur, A.K., 2015. Improving the phenotypic expression of rice genotypes: Rethinking "intensification" for production systems and selection practices for rice breeding. The Crop Journal, Special Issue: Breeding to Optimize Agriculture in a Changing World 3: 174-189. 
Uphoff, N. (2013): New approaches needed for another Green Revolution, Sci Dev Net, October 16, http://www.scidev.net/global/food-security/opinion/new-approaches-are-needed-for-another-greenrevolution.html accessed March 30, 2014.

Vanloqueren, G., and Baret, P.V. (2009): How agricultural research systems shape a technological regime that develops genetic engineering but locks out agroecological innovations. Research Policy, 38(6): 971-983.

Waters-Bayer, A., Kristjanson, P., Wettasinha, C., van Veldhuizen, L., Quiroga, G., Swaans, K., \& Douthwaite, B. (2015). Exploring the impact of farmer-led research supported by civil society organisations. Agriculture \& Food Security, 4(1), 4.

Watts, J. R., Mackay, D., Horton, A., Hall, Douthwaite, B., Chambers, R. and Acosta, A. (2007): (2nd Edition) Institutional Learning and Change: An introduction. ILAC Working paper 3, Rome, Institutional Learning and Change Initiative.

Wei-Skillern, J., and Marciano, S. (2008): The networked non-profit, Stanford Social Innovation Review, 6(2), 38-43.

Ynalvez, M. A., and Shrum, W. M. (2011): Professional networks, scientific collaboration, and publication productivity in resource-constrained research institutions in a developing country. Research Policy, 40(2), 204-216 


\title{
Resilient farmers' strategies and policy regulations: The quest for modernization on Dutch and Italian dairy farms
}

\author{
Paul Swagemakers, ${ }^{1}$ Pierluigi Milone ${ }^{2}$ and Flaminia Ventura ${ }^{3}$
}

\section{Abstract}

There has been much discussion on how the Multi Level Perspective (MLP) provides a framework for understanding a transition towards a more sustainable agro-food system. This chapter considers processes by which niches and regimes interact and are interdependent. It analyses how projects and practices developed by farmers and 'frontline' government representatives on how farming is to be organized, can help the wider sector to adopt resilient farmers' strategies. Such strategies entail the promise leaving the social-ecological crisis of the agro-food system while creating responses to the current, economic austerity in which many farmers are situated. Case study research focuses on dairy farming in the Netherlands and Italy, and analyses how farmers' organizations reconnect agriculture and food chains to environmental concerns, including climate change, unbalances in nutrient cycles, and biodiversity degradation. It draws conclusions on how farming in re-localized agro-food systems and supported by policy regulations might result in a sustainable deviation from the modernization trajectory.

Keywords: Institutional Arrangements, Niche and Regime Interactions, Step-by-step Innovation

\section{Introduction}

Environmental concerns like climate change, unbalances in nutrient management and biodiversity degradation call for a transition towards a more sustainable agro-food system (Darnhofer, 2014; Knickel et al., 2009; Marsden, 2013). Such a transition inevitably entails the gradual but continuous process of adaptation, as well as structural changes in the character of society (Geels and Kemp, 2000; Rotmans et al., 2000). This includes the production of competitive assets among farmers and small processing firms (Brunori et al., 2013) as often developed in niches, which are defined as incubation rooms for innovation. From a systems perspective, niches are "sources of systemic change if processes of other levels of the system are supportive" (Smith, 2007:427). This refers to the availability of resources as well as the adaptive capacity required for effective regime transformation at system level (Smith, 2005) and implies that, when sufficient compatible, niches can diffuse into the mainstream (Smith, 2007; Folke et al., 2010). Although over the past years transition theory has been applied to the agro-food system (Elzen et al., 2012; Klerkx et al., 2010; van Mierlo et al., 2010) limited attention has been paid to the particular direction of regime transformations that come along with agro-food systems that anchor in an agro-ecological tradition (Altieri, 1999; Sevilla Guzmán and Martínez Alier, 2006). Therefore this chapter focuses on farmers' strategies as they unfold at the interface of nature and society (Toledo, 1990). From a comparative case study perspective, it explores the theoretical and organizational implications of a regime shift towards agroecological food production, and points to the need for adaptive forms of policy regulations (Smith, 2005),

\footnotetext{
${ }^{1}$ University of Vigo, Department of Applied Economics, Faculty of Economic and Business Sciences, Vigo, Spain. Email: paul.swagemakers@uvigo.es

${ }^{2}$ University of Perugia, Department of Civil and Environmental Engineering, Perugia, Italy. Email: milonpie@tin.it

3 University of Perugia, Department of Civil and Environmental Engineering, Perugia, Italy. Email: flaminia.ventura@unipg.it
} 
both in the public and market sphere. In case studies on dairy farming in the Netherlands and Italy it examines how hybrid actors (Elzen et al., 2012) develop projects and practices on how farming is to be organized. With that, the chapter brings evidence on how farmers, government representatives, researchers, and semi-governmental innovation intermediaries transform the agro-food system in a step-bystep innovation process.

\section{Transition theory}

Farmers' strategies depend on and are shaped by larger frames of meaning and action (Long and van der Ploeg, 1994) and are embedded in the wider context of modernization, industrialization and globalization of the agro-food system. Over the past decades, this implied the increasing involvement in commodity markets as well as the transfer of externally designed (external to local farm practices) technology, knowledge, resources and organizational forms (Long and van der Ploeg, 1994). To regenerate the dramatic decline of attention for endogenous knowledge and to gradually ground the agro-food system in environmentally sound and socially fair production conditions again, new sustainability trajectories are taken (Milone, 2009; Oostindie, 2015). Thereby Wiskerke (2009) points to the co-existence of two paradigms that pursue a transition towards a more sustainable agro-food system: the agro-industrial food paradigm, anchored in the modernization, industrialization and globalization of the food system (Murdoch et al., 2000; van der Ploeg, 2003), and the integrated territorial paradigm (Marsden, 2003), anchored in re-localized food systems (Marsden and Smith, 2005; Brunori, 2007; McDonagh et al., 2015). Since the latter differs from the optimization patterns provided by external institutional bodies as in the more industrialized and globalized context, Wiskerke and van der Ploeg (2004) and Knickel et al. (2009) reflect on these processes as a rupture of existing routines. This, however, leaves open how the improvement of the efficiency and multifunctionality performance of productive systems by innovative farmers can diffuse into the more mainstream agro-food system.

To provide a better understanding of the gradual but continuous process of adaptation to the incorporation of environmental concerns and endogenous knowledge, various scholars applied the Multi Level Perspective (MLP) (Geels and Schot, 2007), which aims to provide a better understanding of transition processes. The MLP distinguishes between the level of the landscape, the regime and the niche. Although environmental concerns challenge the agro-food system to adapt to a more sustainable performance MLP studies show that regime actors resist change and for niche innovation to be scaled up, there is a need for a supportive structure (Smith, 2007). Scholars have argued that a regime shift results from a depletion of existing technological opportunities, when governmental policies dramatically change, and/or when new sets of social-cultural values emerge (Kemp et al., 1998). They distinguish two types of innovation processes: incremental innovation, which often stems from the rules set by the regime, and radical innovation, which stems from normative and cognitive ordering rules and often is induced by tensions within the regime (Geels, 2004; Rip and Kemp, 1998). Building upon MLP theory, this chapter therefore follows Elzen et al. (2012)'s theoretical standpoint that system innovation (SI) is the outcome of a complex processes in which the different levels mutually influence each other, and rules are sustained through multi-level and multi-actor interactions. This fits to how farmers improve the efficiency and multi-functionality performance of their production systems from an agro-ecological standpoint, namely through the gradual adaptation and optimization of agricultural production (Swagemakers et al., 2012), and the simultaneous construction of networks in which mutual translations take place between diverse actors (Swagemakers et al., 2009).

Although farm optimization trajectories in the integrated territorial paradigm radically differ from optimization patterns in the agro-industrial food paradigm, step-by-step innovation within niches and the step-by-step incorporation of niche innovations into the dominant regime imply that incremental innovation is the fundamental dynamic of successful system change at multiple levels. This relational character of $\mathrm{Sl}$ is emphasized in definitions of linking (adaptations and/or connections between niches and the regime) and anchoring (the initial making and breaking up of new connections within the niche and between niche and regime) (Smith, 2007; Elzen et al., 2012). From such a relational perspective, Moore and Westley (2011) examined how SI involves negotiations, renegotiations and, usually, the construction of institutional relations at the regime level (van der Ploeg et al., 2009). They point to the importance of agency, i.e. the capacity to 
transfer innovations and knowledge, in stimulating $\mathrm{Sl}$, as well as the importance of hybrid actors, i.e. actors who belong to niches as well as to the regime (Elzen et al., 2012).

\subsection{Resilience thinking}

If the successful integration of local knowledge and new organizational forms gradually develops in interaction with the regime, this implies that farmers' strategies, that perhaps initially have been constrained, finally might get supported and become mainstream. Since the neglect of endogenous knowledge for system optimization may result in the limited adaptive capacity of farmers' strategies (Darnhofer, 2010) and an increased vulnerability of the agro-food system (Marsden, 2013), there is the challenge to develop adaptive capacity from a system perspective. The reverse of ignorance of endogenous knowledge and vulnerability of the agro-food system consists of the systems' ability "to reconcile the impacts of human activity on the environment" (Murphey, 2000:2), which is determined by learning defined as a socially constructed (Raedeke and Rikoon, 1997) and negotiated process (Long, 1992; 1997; 2001). From this perspective, learning - including the incorporation of farmers knowledge in $\mathrm{SI}$ - is organized on small scales but can cause a transformation of the whole system, as is theoretically addressed in resilience thinking (Brand and Jax, 2007; Folke et al., 2010). From a wider theoretical study of resilience thinking, Darnhofer postulates that complex social-ecological systems need both "adaptive capability (the ability to bounce back) and transformative capability (the ability to bounce forward)" (Darnhofer, 2014:6). The term capability thereby denotes the "ability to identify opportunities, mobilize resources, to implement options, to develop processes, to learn as part of an iterative, reflexive process" (ibid:7). Adopting Darnhofer (2010)'s vision that resilience thinking goes beyond the, often applied, interpretation of unchanging stability in resilience literature, the central question is how the maintenance of ecological systems can support social and economic systems.

To contribute to answering this question, the argument in this chapter builds upon the Brundtland report's definition of sustainability as "the use of environment and resources to meet the needs of the present without compromising the ability of future generations to meet their own needs" (quoted in Berkes et al., 2003 , 2). The theoretical stipulation on how niches link up to a regime thereby brings the empirical challenge to study how farmers include environmental concerns in their farm practices and build organizational capacity for resilient farmers' strategies, both at the farm and in its wider institutional environment. To address this issue, the remainder of this chapter examines how projects and practices developed by farmers and 'frontline' government representatives on how farming is to be organized can help the wider sector to adopt resilient farmers' strategies, and demonstrates how farmers develop resilient strategies in re-localized agro-food systems, and resulting from it, how farming - further supported by policy regulations - might embark upon a deviation from the modernization trajectory.

\section{Intermediary organizations and institutions}

In our case studies from the Netherlands and Italy, farmers adopt resilient strategies when organizational and institutional arrangements align niche innovations that resolve biodiversity degradation. The innovations are translated into target indicators, in the case studies on biodiversity conservation (field birds and cow breeds), whereby the production process is optimized under local social and organizational conditions. E.g. field birds are linked to the reduction of nutrient losses and payment schemes for nature conservation and landscape protection, while cow breeds link to milk quality and distinctive characteristics of the cheese and opportunities for marketing and getting a better price.

If transition is understood - in line with the MLP framework - as a process that is "constantly reshaped by its own internal organizational and political dynamic and by the specific conditions it encounters or itself creates" (Long and van der Ploeg, 1994: 79), then a better understanding of transition processes, this chapter argues, lies in studying intermediary organizations that contribute to the incorporation of endogenous knowledge in modernizing the agro-food system. The descriptions in the case studies stem 
from primary and secondary sources. Materials have been collected in previous research projects and were derived from interviews, participatory observation and desktop studies. This existing information has been supplemented by additional desktop study (brochures, websites, research reports) and interviews with 15 key-informants in the case study areas (farmers, local leaders, researchers, frontline government representatives, project leaders) on how organizational and institutional arrangements facilitate farmers to adopt more resilient strategies.

\subsection{The territorial cooperative "Noardelike Fryske Wâlden"}

Grounded in 20 years of experience, the "Noardelike Fryske Wâlden" (literally: Northern Frisian Woodlands, in the northern part of the Netherlands) has been one of the Dutch pilot study areas for the Common Agricultural Policy (CAP) for the period 2014-2020. The case study region is characterized by a hedgerow landscape with small parcels (often between one and two, and in general less than five hectares) surrounded by an open landscape with larger plots (with parcels from five to ten hectares). In the region, dairy farming is the prevailing land-use. While most of the area is in use for grassland production, on some of the farms a limited proportion of the area (up to five percent) is in use for forage maize production. In the central part of the region, the biophysical farm and field characteristics, combined with regulations on landscape preservation, restricted a widespread conversion to large-scale agriculture.

In the 1990s, to reach policy targets more acceptable to the farmers than a top-down implemented regulation on the reduction of ammonia and nitrate emissions, farmers and scientists jointly reshaped and recombined the natural resource base for farming (Stuiver et al., 2003; Swagemakers and Wiskerke 2006; Swagemakers and Wiskerke, 2011). The initial focus of the farmers, who were organized in so-called environmental cooperatives, was on the reduction of nutrient losses by the optimization of the cattlemanure-soil-fodder balance (Verhoeven et al., 2003). Nutrient losses were reduced via a series of contextspecific measures, including permanent grasslands, alternative and less protein rich silage production, and the application of animal manure with a different nitrogen-carbon ration then in conventional manure (van der Ploeg et al., 2006; van der Ploeg, 2008). In the following years, the further internalization of environmental concerns in farm optimization trajectories resulted in the development of landscape preservation and nature conservation activities. While maintaining the dairy activities at the centre of farm configuration, farmers paid gradually more attention to developing the ecological system. The (often unintended) landscape amenities (biodiversity in the fields) that resulted from the optimization of agricultural production along agroecological principles turned into new income opportunities for farmers in the area. Instead of organizing agrarian nature conservation schemes at the individual level, like elsewhere in Europe, farmers in the area experimented with regional coordination and payment schemes.

In 2002, expecting to increase the possibilities to negotiate larger-scaled landscape and nature schemes through the improvement of administrative efficiency and effectively implementation of measures at individual farms, six environmental cooperatives (working area approximately 50,000 ha) merged into the territorial cooperative the "Noardelike Fryske Wâlden" (the territorial cooperative NFW). Until today, this cooperative is committed to maintaining the biological components of the ecological system that are part of the agrarian landscape, and organizes the acceptance among farmers to preserve the landscape as well as the financial support for this landscape preservation, including biodiversity conservation. With this additional source of income, farming in the area becomes strongly oriented towards multi-functionality performance (Swagemakers et al., 2009). To improve the interrelations between dairy production and the production of landscape amenities, and to inspire farmers in the area to adopt and further develop sustainable strategies in combination with the development of flexible, supportive policy frameworks, organizational and institutional arrangements of the cooperative ground in local social and organizational conditions. This refers to knowledge and experience that has been gained over the past 15-20 years: the creation of the first environmental cooperatives in the Netherlands in the early 1990s were followed by the application of scientific projects on the innovative ideas on the optimization of the farm configurations; the results of this research were applied in the fields of the farmers that were associated in the environmental cooperatives; further knowledge was gained from negotiations with the public administration on securing temporarily exceptions from general policies to experiment with the alternative patterns of farm optimization. 
Nowadays, the cooperative has over 1000 members, including 800-850 farmers who make up about $90 \%$ of the total farmers in the area. The remaining twenty per cent of the membership consists of private landusers, mostly households with a few hectares of land. The members of the cooperative manage $1,500 \mathrm{~km}$ of hedgerows of alder trees, $150 \mathrm{~km}$ of wooded banks of streams, 8,000 ha of land for field bird protection, 800 ha of botanic grassland, and over 100 'pingos' (pools created in the ice-age) and 'dobbes' (man-made pools). Its daily board consists of representatives from six environmental cooperatives in the area and a president. Various parties support the cooperative's objective of strengthening "gebiedskwaliteiten" (regional qualities) in relation to the perspective for farmers in the area in a so-called "gebiedscontract" (regional contract). These parties include the Ministry of Economic Affairs, Agriculture and Innovation (before 2010 the Ministry of Agriculture, Nature and Food quality) and the Ministry of Infrastructure and the Environment (before 2010 the Ministry of Housing, Spatial Planning and the Environment), the province of Friesland, the five municipalities in the area, Wetterskip Fryslân (the Water Board), De Friese Milieu Federatie (a federation for the protection of the environment in Friesland), the farmers' union, Landschapsbeheer Friesland (an organization that aims to improve landscape qualities in Friesland), de Bond Friese Vogelwachten (the Frisian field bird organisation) and Wageningen University. All support the cooperative to achieve its ambitious "Werkprogramma" (Program of Activities), in which longterm perspectives are combined with activities that can be carried out on the short term. The Program of Activities targets three major objectives:

- The incorporation of landscape, nature and biodiversity into the characteristics and dynamics of dairy farming in the area;

- The development of an endogenous "milieuspoor" (environmental trajectory) that corresponds to the characteristics and dynamics of dairy farming in the area and results into a jump in sustainability performance;

- The achievement of a significant level of self-regulation to be able to efficiently organise 1) agrarian nature management in combination with 2) environmentally sound farm practices.

To comply with expectations concerning the future and achieve a good position for the dairy farmers in the area, the Program of Activities is managed in the four thematic groups, notably Landscape and Nature, Field Bird Management, Agriculture, Environment and Water, and Regional Economy. The groups, each of them led by a farmer from the area, define and organize the activities, which fit to the general objectives and strategy of the territorial cooperative. The activities include scientific projects on finding evidence for claims and/or negotiations on the alternative farm optimization trajectories. To align farmers' interests with the overall objectives and strategy the thematic working groups are represented in an overall board, which is assisted by a Steering Committee. Members from this committee represent different administrative levels and control bodies (the parties in the Regional contract) and is consulted frequently, if needed on demand. As a consequence of the organizational structure and the Program of Activities, the production of ecosystem services - such as landscape, natural values, a healthy environment, clean water, mitigation of global warming and the production of agricultural commodities - are no longer separated (or at best "positioned alongside each other") but mutually reinforcing activities, with one being a condition for the other and vice versa.

From 2015 onwards, this newly developed and continuously further adapting organizational structure helps farmers in the area to adopt resilient farmers' strategies, for which opportunities are expressed in the new first and second pillar policies of the CAP for the period 2014-2020. Dutch policy makers aim to combine measures in the first pillar (greening) and the second pillar (rural development) at the regional level, and label payments to collective attempts to reconnect agriculture and food chains to biodiversity conservation. Such a deviation from farm modernization includes activities on nature conservation and landscape preservation, and implies the involvement of groups of farmers, rather than individuals. Instead of individual farmers implementing measures that avoid further biodiversity degradation, the new policy framework creates financial support for collective action and biodiversity conservation. In this process, the territorial cooperative plays an intermediary role, both between higher levels of administration as well as among farmers in the area, challenging them to improve the balance between productivity of dairy farm activities (e.g. milk production per hectare or cow) and biodiversity conservation (e.g. the hedgerow landscape, field bird protection), both at the farm and the regional level. This satisfies the aim of public financial support, 
which is to challenge and pay farmers to deliver societal performance. In this case study, public support is in line with Berkes' et al. (2003) suggestions for resilient strategies, that is, to provide opportunities for renewal while maintaining stability in the face of change. Thus, by building on farmers' requirements that anchor in an agro-ecological tradition, the territorial cooperative NFW is a good example of organizational and institutional innovation in the public sphere.

\subsection{The dairy consortium "Vacche Rosse"}

With a marketing experience of about 20 years, the dairy consortium "Il Consorzio Vacche Rosse" (CVR) in Emilia Romagna, Italy is a good example of organizational and institutional innovation in the private sphere. Among the many small Parmigiano-Reggiano (PR) cheese producers in Emilia Romagna, the second most important milk producing area in Italy, the CVR, like all producers in the area, follows the rules and regulations set by the Parmigiano-Reggiano Consorzio. A distinguishing characteristic in the CVR's business model is the use of the "Vacche Rosse di razza Reggiana" (VR), a traditional cow breed that is in danger of extinction. During the modernization and industrialization of agricultural production, the breed reduced significantly in numbers: from 140,000 heads in 1956, to less than 1,000 heads in the 1980s. An important feature of its obsolescence is its low milk production.

In a recent study by the Centro Ricerche Produzioni Animali (CRPA, Research Center for Animal Production, located in Emilia Romagna) the breed produced 5,729 kg per year, which is low compared to 7,468 kg for the more regular Frisona Italiana breed. With its slightly better percentages of protein $(3.40$ per $\mathrm{kg}$ in comparison to 3.25 for the regular breed) and fat (3.65 in comparison to 3.57), farmers associated in the CVR found other motivations for recovering the breed: its beauty, robustness, fertility, easy calving, high number of lactations per animal (long life-span), and its low needs in terms of fodder quality, make it an animal that in produces less but has strong other characteristics. These are translated into a marketing strategy: its high casein percentage in milk makes its milk suitable for long aging of the cheese, which brings outstanding organoleptic quality (flavour and aroma), high contents of calcium, phosphorus, protein, essential amino acids, and the absence of lactose in the cheese (Gandini et al., 2010). Through a marketing strategy in which the brand is related to the traditional cow breed and the specific product characteristics, the small group of farmers associated in and delivering milk to the dairy consortium CVR receive a milk price that is significant higher than famers who deliver milk to the mainstream circuit: approximately 78 euro per $100 \mathrm{~kg}$ of milk, compared to 53 euro for regular milk (Menghi et al., 2015).

Although the CVR represents a small business case, it finds its roots in local, historical and cultural dynamics in which skills, networks and the desire for self-employment are the main drivers (Picchi, 1994). Next to a mere geographical concentration of firms (including farms, often small-scaled processing industries, and supplying businesses), "the nature of economic relationships is decisive for the solidity and the competitiveness of the district" (de Roest, 2000:10). Since the production of quality cheese is labour intensive, (ibid) the question remains how globalization and industrialization of agricultural production impact the dairy sector and production techniques in the area. Like elsewhere, costs and benefits have to be carefully balanced, whereby price fluctuations on the world market affect the continuity of many of the dairy farms in the area. In response to increasing costs for the small-scaled milk processing and low milk prices in the regular PR circuit, farmers could easily get into the economic treadmill again. Surprisingly, the CVR and the use of the low productive breed have developed into a resilient farm strategy, which might serve as future strategy for thousands of other farmers in Emilia Romagna. Although the efforts of the consortium have resulted in the recovery of the breed, its milk production remains low and it is thus still relatively unattractive for many farmers in the area.

Currently, the CVR aims to improve the connection between food chains and biodiversity conservation by further developing the location-specific production features for agricultural production, while connecting small-scale production with the marketing of high value-added products. This has its roots in 1991, when in collaboration with CRPA and financially supported by the Ministry of Agriculture, farmers started to process their milk separately from milk from conventional cows. After two years of collaborative research on the recovery of the breed and marketing opportunities of selling milk with different product qualities, the 
farmers further developed the nested market. In line with the regular, and also regionally oriented Parmigiano-Reggiano Consorzio production regime - for example PR Consorzio regulations enforce that a large percentage of the feed intake should be regionally produced - the animals that belong to members of the CVR are fed with only fresh grass, hay and GMO-free feed, and become easily ten years old, which is a long life-span in comparison to the four to five years for conventional dairy farming. The marketing strategy is anchored in the use of the traditional cow breed, whose production features guarantee a level of production standards (like in the PR regime this standards are documented in a regulation that applies to the farmers associated to the CVR) that go beyond those from the Parmigiano-Reggiano Consorzio. It thus guarantees different product features to consumers. Consumers are an important lead in the development of the consortium, and the marketing and regulations that guarantee the consumers a certain standard are oriented towards consumer perceptions.

Since the breed is a crucial asset in this farmers' strategy, the reproduction and strengthening of the herd are collective concerns. Through the marketing strategy and supportive organizational and institutional structure, the number of breeds has increased from less than a thousand heads in the early 1990s to 2,424 productive cows and a total of 3,483 heads (including bulls and young cattle) registered by the breeding association ANaBoRARE, in 2014. The milk is processed at two small dairy plants and sold in farm shops, groceries, a cooperative online store, and overseas through principal sales channels and specialty shops in cities like New York, Montréal, Toronto and Tokyo. Next to Parmigiano-Reggiano cheese, the cooperative processes and sells butter and ricotta under the "Vacche Rosse" brand, therewith referring to the breed's red colour. For this reason, the case study is a good example of organizational and institutional innovation in the private sphere.

\section{From a comparative perspective}

The cases demonstrate how organizational and institutional arrangements contribute to and optimize dairy production features and biodiversity conservation. For example, in the Netherlands field bird protection relates to and results in rebalancing nutrient cycles. In Italy, the conservation of an indigenous breed relates to the improvement of casein contents in milk, and marketing opportunities for a more costly quality product. In analytical terms, the cases thus demonstrate how farmers adopt resilient strategies when organizational and institutional arrangements align target indicators (e.g. field birds, quality features of the cheese) to the optimization of the production process under local social and organizational conditions. Furthermore, the cases demonstrate that resilient farmers' strategies mutually build upon and conduct the further unfolding of contextual factors and structures that, in turn, determine how system innovation modifies the boundaries of systems and scales. Consequently, payments for farmers and the alignment of the target indicators for the optimization of the production process, are developed step-by-step and in interaction with policy regulations and market initiatives. In organizational-institutional terms, the cases demonstrate how knowledge institutions, business enterprises, grassroots organizations and/or public administration (Wellbrock et al., 2013; Welbrock and Roep, 2015) jointly increase adaptive capabilities and create opportunities to continue farming. Thereby, a key-question is how to continue to bring groups and stakeholders together who are not in the same organization (Ostrom, 1996), and diffuse niches and their agro-ecological ordering principles to the mainstream.

A more in-depth comparison of the relatively vulnerable niche innovations - one highly depending on public funds, the other highly depending of value added in a nested market - in terms of how niches link up to a regime leads to the conclusion, while satisfying Smith et al. (2007)'s condition that processes of other levels of the system have to be supportive, that the intermediary role of organizational and institutional arrangements is decisive for the connection of agriculture and food chains to environmental concerns. In the case studies, small groups of farmers, together with frontline government representatives and researchers, created the institutional organization and arrangements that - over a period of 20 years improved biodiversity: in the Dutch case through public funds and in the Italian case through the market. In the cases, the successful inclusion of - although differently expressed - environmental concerns into farmers' strategies highly depends on how various actors and parties organize themselves around how to 
build organizational capacity for resilient farmers' strategies, which is bound to local contexts. Although the innovations in the case studies rely on the interrelations between cow breeds, grassland management and milk production, the target indicators in the cases differ. In the Netherlands the optimization of the farming system relies on the quality of manure in relation to red-list bird species in the fields, while in Italy the optimization relies on casein levels in the milk and organoleptic quality of the cheese.

Finally, since the cases demonstrate different ways of dealing with the inclusion of environmental concerns, the comparative perspective allows postulating how system innovation can further inspire, conduct, and strengthen the resilience of farmers' strategies. This leads to the conclusion - and farmers' organizations in the areas are aware about this - that Dutch farmers would have to adopt an alternative market orientation while Italian famers would have to get into nature management schemes. As has been demonstrated in the cases this requires - again but in different fields - new organizational and institutional arrangements to build capacity to adapt to change (Berkes et al., 2003). Following Elzen et al. (2012), this first and foremost should be anchored in local social-ecological and organizational conditions.

Increasingly, policy frameworks prepare to facilitate heterogeneous farmers' strategies to adapt to numerous and heterogeneous environmental conditions. The cases illustrate renegotiated trajectories for farm modernization that deviates from making agriculture capital intensive, large-scale and using pesticides. Such a deviation of farm modernization complies with the OECD "Green Growth Strategy" for the coming decades (OECD, 2011), which implies solving environmental problems while creating economic benefits and human welfare; objectives which also have been taken as the EU position (Refsgaard and Bryden, 2012), which is recently implemented via of the Common Agricultural Policy for the period 2014-2020.

The adoption of trajectories that comply with sustainability characteristics, as outlined in this chapter, and which imply the further integration of public and private interests, bring along challenging organizational and technical change. Therefore, the question remains how policy regulations, under the condition that these are made to fit local institutional rules (Ostrom, 2010), can support a re-localization of agro-food systems, and thereby a sustainable deviation from the dominant modernization trajectory of the agro-industrial paradigm. Future research should, therefore, be oriented towards how environmental services can be organized and financed in local contexts. This would include studying the evaluation methods that accompany public and private payments for environmental services in farmers' strategies, and would imply the involvement of the wider farm community in building a sustainable agro-food system, one that reconnects agriculture and food chains to environmental concerns. In such an approach intermediary organizations and institutions enhance the opening up of the black box of endogenous knowledge, and hold the promise of encouraging sustainable farm modernization.

\section{Conclusions}

The Multi Level Perspective distinguishes between the levels of landscape, regime and niche, and examines how these (mutually interacting levels) influence a transition process. At the level of the niche, more radical change emerges. Together with other hybrid actors, farmers anchor and sustain novel farm optimization trajectories in the niche (Elzen et al., 2012), and gradually optimize the agro-food system through the creation of linkages between the levels of the niche and the regime in a step-by-step innovation process.

Based on empirical evidence from the cases, this chapter postulated how niches link up to a regime. Cases on re-localized agro-food systems in the Netherlands and Italy illustrate how newly evolving institutional arrangements help farmers to adopt resilient strategies. Thereby, new organizational and institutional arrangements anchor both public and private payments for agricultural production, and align the target indicators (biodiversity in the fields, organoleptic quality of the cheese) towards optimization of farmers' production processes under the local social and organizational conditions. The alternative farm optimization trajectories in the cases root in the experience and skills of pioneers, and are characterized by the capacity of hybrid actors like farmers, government representatives, and researchers, to create and adapt organizational structures that improve the optimization of agricultural production, food chains and environmental concerns. 
In the Dutch case, public payments for landscape and nature conservation stabilize farm incomes. Although the future of subsidy schemes is always uncertain, these payments do provide incentives for farmers to comply with environmental concerns. In the Italian case, consumers pay for biodiversity conservation. Farm incomes mainly depend on direct selling cheese and related dairy products, which all draws back on consumers' perceptions of production features that are translated into production regulations for the farmers. At local and regional levels, these alternative optimization trajectories bring benefits to the farmers. The cases demonstrate that sustaining the wider agro-food system along these lines remains highly dependent on policy support.

The Common Agricultural Policy for the programming period 2014-2020 provides attractive elements to help farmers to adapt their strategies to the type of deviation of farm modernization as described above. The case descriptions include environmental concerns and articulate farmers' drives to adopt production efficiency and cost reduction strategies that fit an agro-ecological system optimization. This offers a suggestion for public policies: a better understanding of transition processes lies in the equal allocation of research resources and policy support to intermediary organizations that contribute to the exploration and incorporation of endogenous knowledge in a future optimization of the agro-food system, and therewith help the wider sector to adopt resilient farmers' strategies.

Acknowledgements: The authors are grateful for the reviewers' comments and suggestions, which have been very useful to improve the theoretical argument that situates the case studies. In addition the authors thank the board members of the territorial cooperative NFW and dairy consortium CVR for their meaningful action and explications of the local dynamics and integration into higher scales of aggregation. The correct representation of the argument in this chapter and the contents of the case studies remain the authors' responsibility.

\section{References}

Altieri, M.A. (1999). Agroecología: Bases científicas para una agricultura sustentable. Montevideo, NordanComunidada.

Berkes, F., Colding, J. \& Folke, C. (2003). Introduction. In Navigating social-ecological systems: building resilience for complexity and change. F. Berkes, J. Colding \& C. Folke. Cambridge, Cambridge University Press: 1-20.

Brand, F.S. \& Jax, K. (2007). Focusing the meaning(s) of resilience: Resilience as a descriptive concept and boundary object. Ecology and Society 12(1): 23. [online] URL: http//:www.ecology and society.org/vol12/iss1/art23/

Brunori, G. (2007). Local food and alternative food networks: a communication perspective. Anthropology of Food 2 Available from http://aof.revues.org/index430.html Accessed 11 February 2015.

Darnhofer, I. (2010). Strategies of family farms to strengthen their resilience. Environmental policy and governance 20: 212-222.

Darnhofer, I. (2014). Resilience and why it matters for farm management. European Review of Agricultural Economics 41(3): 461-484.

de Roest, C. (2000). The production of Parmigiano-reggiano cheese: The force of an artisanal system in an industrialised world. Doctoral dissertation. Wageningen, Wageningen University.

Elzen, B., van Mierlo, B. \& Leeuwis, C. (2012). Anchoring of innovations: Assessing Dutch efforts to harvest energy from glasshouses. Environmental Innovation and Societal Transitions 5: 1-18.

Folke, C., Carpenter, S.R., Walker, B., Scheffer, M., Chapin, T. \& Rockström, J. (2010). Resilience thinking: Integrating resilience, adaptability and transformability. Ecology and Society 15(4): 20. [online] URL: http//:www.ecology and society.org/vol15/iss4/art20/

Gandini, G., Pizzi, F., Turri, F., Negrisolo, F. \& Musella, M. (2010). Razza Reggiana. Perchè gli allevatori allevano bovini di razza Reggiana. Available at http://www.consorziovaccherosse.it/wpcontent/uploads/perche-allevare-razza-reggiana.pdf

Geels, F.W. (2004). From sectoral systems of innovation to socio-technical systems. Insights about dynamics and change from sociology and institutional theory. Research Policy 33 (6-7): 897-920. 
Geels, F. W., \& Kemp, R. (2000). Transities vanuit sociotechnisch perspectief: Achtergrondrapport voor het vierde nationaal milieubeleidsplan (NMP-4). Maastricht, the Netherlands: Maastricht Economic Research Institute on Innovation Technology (MERIT).

Geels, F. W., \& Schot, J. (2007). Typology of sociotechnical transition pathways. Research Policy 36: 399417.

Kemp, R., Schot, J., \& Hoogma, R. (1998). Regime shifts through processes of niche formation: The approach of strategic niche management. Technology Analysis and Strategic Management 10: 175-196.

Klerkx, L., Aarts, N. \& Leeuwis, C., (2010). Adaptive management in agricultural innovation systems: the interactions between innovation networks and their environment. Agricutural Systems 103: 390 400.

Knickel, K., Brunori, G., Rand, S. \& Proost, J. (2009). Towards a better conceptual framework for innovation processes in agriculture and rural development: From linear models to systemic approaches. The Journal of Agricultural Education and Extension 15(2): 131-146.

Long, N. (1992). Introduction. In Battlefields of knowledge: The interlocking of theory and practice in social research and development. N. Long \& A. Long. London, Routledge: 3-15.

Long, N. (1997). Agency and constraint, perceptions and practices: A theoretical position. In Images and realities of rural life. H. de Haan \& N. Long. Assen, Van Gorcum: 1-20.

Long, N. (2001). Development sociology: Actor perspectives. London, Routledge.

Long, N. \& van der Ploeg, J.D. (1994). Heterogeneity, actor and structure: Towards a reconstitution of the concept of structure. In Rethinking social development. D. Booth. Harlow, Longman Group Ltd.: 6290.

Marsden, T. (2013). From post-productionism to reflexive governance: Contested transitions in securing more sustainable futures. Journal of Rural Studies 29: 123-134.

Marsden, T. (2003). The condition of rural sustainability. Assen, Van Gorcum.

Marsden, T. \& Smith, E. (2005). Ecological entrepreneurship: Sustainable development in local communities through quality food production and local branding. Geoforum 36: 440-451.

McDonagh, J., Nienaber, B. \& Woods, M. (2015). Globalization and Europe's rural regions. Ashgate, Aldershot.

Menghi, A., Ventura, F., Milone, P. \& Swagemakers, P. (2015). Costi di produzione e reddittività della vacca rossa Reggiana. L'informatore Agrario n. 20 Supplemento Stalla da latte: 34-38.

Milone, P. (2009). Agriculture in transition: A neo-institutional analysis. Assen, Van Gorcum.

Murdoch, J., Marsden, T. \& Banks, J. (2000). Quality, nature, and embeddedness: some theoretical considerations in the context of the food sector. Economic Geography 76: 107-125.

Murphey, J. (2000). Ecological Modernisation. Geoforum 31(1): 1-8.

Moore, M.L. \& Westley, F. (2011). Surmountable chasms: Networks and social innovation for resilient systems. Ecology and Society 16(1): 5. [online] URL: http//:www.ecology and society.org/vol16/iss1/art5/

OECD (2011). Towards green growth: Green growth strategy report. Paris, OECD Ministerial Council Meeting.

Oostindie, H. (2015). Family farming futures. Agrarian pathways to multifunctionality: flows of resistance, redesign and resilience. Doctoral dissertation. Wageningen, Wageningen University.

Ostrom, E. (1996). Crossing the great divide: Coproduction, synergy and development. World Development 24(6): 1073-1087.

Ostrom, E. (2010). Beyond markets and states: Polycentric governance of complex economic systems. American Economic Review 100: 1-33.

Picchi, A. (1994). The relation between central and local powers as context for endogenous development. In Born from within: Practices and perspectives of endogenous rural development. J.D. van der Ploeg and A. Long. Assen, Van Gorcum: 195-203.

Raedeke, A.H. \& Rikoon, J.S. (1997). Temporal and spatial dimensions of knowledge: Implications for sustainable agriculture. Agriculture and human values 14: 145-158.

Refsgaard, K. \& Bryden, J.M. (2012). Green innovation - Co-learning and conflict resolution. Paper presented at the 10th IFSA Symposium; 1-4 July, Aarhus, Denmark. Available at http://www.ifsa2012.dk/downloads/WS2_3/Refsgaard_Bryden.pdf. 
Rip, A., \& Kemp, R. (1998). Technological change. In Human choice and climate change. S. Rayner \& E.L. Malone. Colombus, Battelle Prêss Vol. 2: 327-399.

Rotmans, J., Kemp, R., van Asselt, M., Geels, F., Verbong, G., \& Molendijk, K. (2000). Transitions and transition management: The case of low-emission energy supply. Maastricht, International Centre for Integrative Studies (ICIS).

Smith, A., Stirling, A. \& Berkhout, F. (2005). The governance of sustainable socio-technical transitions. Research Policy 34:1491-1510.

Smith, A. (2007). Translating sustainabilities between green niches and socio-technical regimes. Technology Analysis \& Strategic Management 19(4): 427-450.

Sevilla Guzmán, E., \& Martínez Alier, J. (2006). New rural social movements and agroecology. In Handbook of rural studies. P. Cloke, T. Marsden \& P. H. Mooney. London, Sage: 472-483.

Stuiver M., van der Ploeg, J.D. \& Leeuwis, C. (2003). The VEL and VANLA cooperatives as field laboratories. NJAS 51(1-2): 27-40.

Swagemakers, P. \& J.S.C. Wiskerke (2006). Integrating nature conservation and landscape management in farming systems in the Friesian Woodlands (N-Netherlands). In From landscape research to landscape planning: Aspects of integration, education and application. B. Tress, G. Tress, G. Fry, \& P. Opdam. Dordrecht, Springer: 321-334.

Swagemakers, P. \& Wiskerke, J.S.C. (2011). Revitalizing ecological capital. Danish Journal of Geography 111(2): 149-167.

Swagemakers, P., Wiskerke, J.S.C. \& van der Ploeg, J.D. (2009). Linking birds, fields and farmers. Journal of Environmental Management 90: 185-192.

Swagemakers, P., Domínguez García, M.D., Símon Fernández, X. \& Wiskerke, J.S.C. (2012). Unfolding farm practices: Working towards sustainable food production in the Netherlands and Spain. Journal of Agriculture, Food Systems, and Community Development 2 (2): 1-17.

Toledo, V.M. (1990). The ecological rationality of peasant production. In Agroecology and small farm development. M.A. Altieri \& S.B. Hecht. Florida, CRC Press.

van Mierlo, B., Leeuwis, C., Smits, R. \& Klein Woolthuis, R. (2010). Learning towards system innovation: evaluating a systemic instrument. Technological forecasting and social change 77: 318-334.

van der Ploeg, J.D. (2008). The new peasantries: Struggles for autonomy and sustainability in an era of empire and globalization. London, Earth Scan.

van der Ploeg, J.D. (2003). The virtual farmer. Assen, Van Gorcum.

van der Ploeg, J. D., Verschuren, P., Verhoeven, F., \& Pepels, J. (2006). Dealing with novelties: A grassland experiment reconsidered. Journal of Environmental Policy and Planning 8(3): 199-218.

van der Ploeg, J. D., van Broekhuizen, R., Brunori, G., Sonnino, R., Knickel, K., Tisenkopfs, T. \& Oostindie, H. (2009). Towards a framework for understanding regional rural development. In Unfolding webs: The dynamics of regional rural development. J. D. van der Ploeg \& T. Marsden. Assen, Van Gorcum: 1-28.

Verhoeven, F.P.M., Reijs, J.W. \& Ploeg, J.D. van der (2003). Re-balancing soil-plant-animal interactions: Towards reduction of nitrogen losses. NJAS - Wageningen Journal of Life Sciences 51: 147-164.

Wellbrock, W., Roep, D., Mahon, M., Kairyte, E., Nienaber, B., Domínguez García, M.D., Kriszan, M. \& Farrell, M. (2013). Arranging public support to unfold collaborative modes of governance in rural areas. Journal of Rural Studies 32: 420-429.

Wellbrock, W. \& Roep, D. (2015). The learning rural area framework: a heuristic tool to investigate institutional arrangements which support collaboration in rural areas. Sociología Ruralis 55(1): 106124.

Wiskerke, J.S.C. (2009). On places lost and places regained: Reflections on the alternative food geography and sustainable regional development. International Planning Studies 14(4): 369-387.

Wiskerke, J.S.C. \& van der Ploeg, J.D. (2004). Seeds of transition: Essays on novelty production, niches and regimes in agriculture. Assen, Van Gorcum. 


\title{
Portfolio of promises: Designing and testing a new tool to stimulate transition towards sustainable agriculture
}

\author{
Boelie Elzen, ${ }^{1}$ Arni Janssen ${ }^{2}$ and Bram Bos ${ }^{3}$
}

\section{Abstract}

To stimulate innovation towards sustainability, the Multi-Level Perspective and the governance strategies based on it (like Strategic Niche Management and Transition Management), provide a number of useful tools. For the agricultural sectors, however, with its multi-variety of relevant sustainability aspects and its wide range of 'bottom-up' innovation initiatives by entrepreneurial farmers, these approaches have serious shortcomings. To address this, we have developed a 'Learning and Experimentation Strategy' (LES) in which a novelty is indicated with the term 'promise'. The term expresses that a novelty has attractive features from a certain sustainability perspective, but it has also problematic or unknown sides. Importantly, LES not only looks at individual promises but at a whole range of them, called the 'portfolio of promises'. Several of these may be connected as 'smart combinations' to address a variety of sustainability aspects. The PoP as a tool is basically a database that contains information on a number of aspects for each promise that we have applied in the animal production and glasshouse horticulture sectors. Hence, the tool can be applied in different sectors but it appears that a 'tailoring' towards the specifics of a sector is needed to increase its usefulness in practice. This chapter describes four tests that we have carried out with this tool in the animal production sector. This has led us to refine the strategies for using the LES approach, as well as change the architecture of the PoP to tune it to various specific applications in animal production. Although this is still work in progress, the tests indicate that the PoP can be used successfully as a tool in stimulating innovation towards sustainability.

Keywords: Niche, promise, portfolio of promises, combining novelties, animal production

\section{Introduction}

Building on the multi-level perspective, innovation scholars have proposed various approaches to stimulate innovation towards sustainability. Some well-known approaches include Strategic Niche Management (SNM; Hoogma et al., 2002; Schot and Geels, 2008) and Transition Management (Rotmans, 2003; Loorbach, 2007). We have sought to apply these approaches in the agro-food regime, specifically in the livestock sector.

Applying them, however, posed some serious challenges. Firstly, SNM and TM focus on alternatives with a specific 'technical nucleus', e.g. solar cells or electric cars. Livestock production, however, deals with complex bio-systems, with a wide range of functions that can be and are innovated upon, like feeding, housing, manure processing, tillage, etc. These are tackled by different and often distinct disciplinary groups of researchers and practitioners who hardly interact. Furthermore, SNM and TM focus on 'organized' learning and experimentation (top-down) with little attention for initiatives by practitioners (bottom-up). The great variety of practice initiatives by farmers in animal production would risk to be unrecognized in a top down approach.

\footnotetext{
${ }^{1}$ Applied Arable and Vegetable Research, WUR, the Netherlands. Email: boelie.elzen@wur.nl

${ }^{2}$ Wageningen Livestock Research, the Netherlands. Email: arni.janssen@wur.nl

${ }^{3}$ Wageningen Livestock Research, Wageningen, the Netherlands. Email: bram.bos@wur.nl
} 
To address these problems, we have developed a "Learning and Experimen-tation Strategy" (LES; Elzen and Spoelstra 2012) that is inspired by SNM and TM and combines the top-down and bottom-up routes towards change. The central concept in LES is 'promise', a novelty with certain attractive sustainability qualities, but also with problematic or unknown qualities. A range of such promises (called the 'portfolio of promises') is relevant when tackling the sustainability problems of the domain under study. Next to learning on individual promises, a major aim of LES is to combine learning from various promises in the portfolio so that they may add-up to lead towards more 'integrally sustainable' systems.

The portfolio of promises (PoP) is basically a database that contains initiatives with significant potential on one or more aspects of sustainability. The portfolio includes research projects, typically led by scientists, practice oriented projects carried out by networks of farmers, as well as individual farmer initiatives. On each initiative, the PoP contains practical information (description of the innovation, involved stakeholders) as well as an assessment of its 'sustainability potential' and opportunities and barriers in realizing this potential in practice. The concept of sustainability, of course, is far from straightforward and different actors will have different views on what it entails. Further below we describe how we have operationalized it in our case by taking into account the views of a variety of different types of actors, which led us to distinguish 15 different sustainability aspects in the PoP.

The development of the PoP will take place in a number of steps:

1. Development of a prototype tool;

2. Testing the tool with selected audiences;

3. Redesign of the tool;

4. Testing the tool with envisaged end-users;

5. Final design and actual use in practice.

The project is planned to take several years. In an earlier paper we described the general LES approach (Elzen and Spoelstra 2012) and in this chapter we focus on the PoP. We will describe the prototype and our findings on testing and redesigning it in the $2 n d$ and 3rd step. At the time of writing (mid 2015) we were working on the 4th step.

\section{The PoP Prototype}

\subsection{Multi-level Perspective}

The portfolio of promises builds on the multi-level perspective (MLP) on transitions (Rip and Kemp, 1998; Geels, 2002). The core of the MLP is that system innovations are shaped by interaction between three levels: the socio-technical landscape, the socio-technical regime and technological niches (figure 1).

Socio-technical systems are located at the meso-level of socio-technical regimes. These regimes indicate a set of shared rules that guide and constrain the actors within a production and consumption system in how they try to tackle various challenges they encounter. This typically leads to evolutionary patterns of innovation. The socio technical landscape is an exogenous environment of factors with a broader societal relevance like the need to reduce $\mathrm{CO}_{2}$ emissions. Technological niches are the breeding ground for radical innovations that initially poorly fit the regime. 


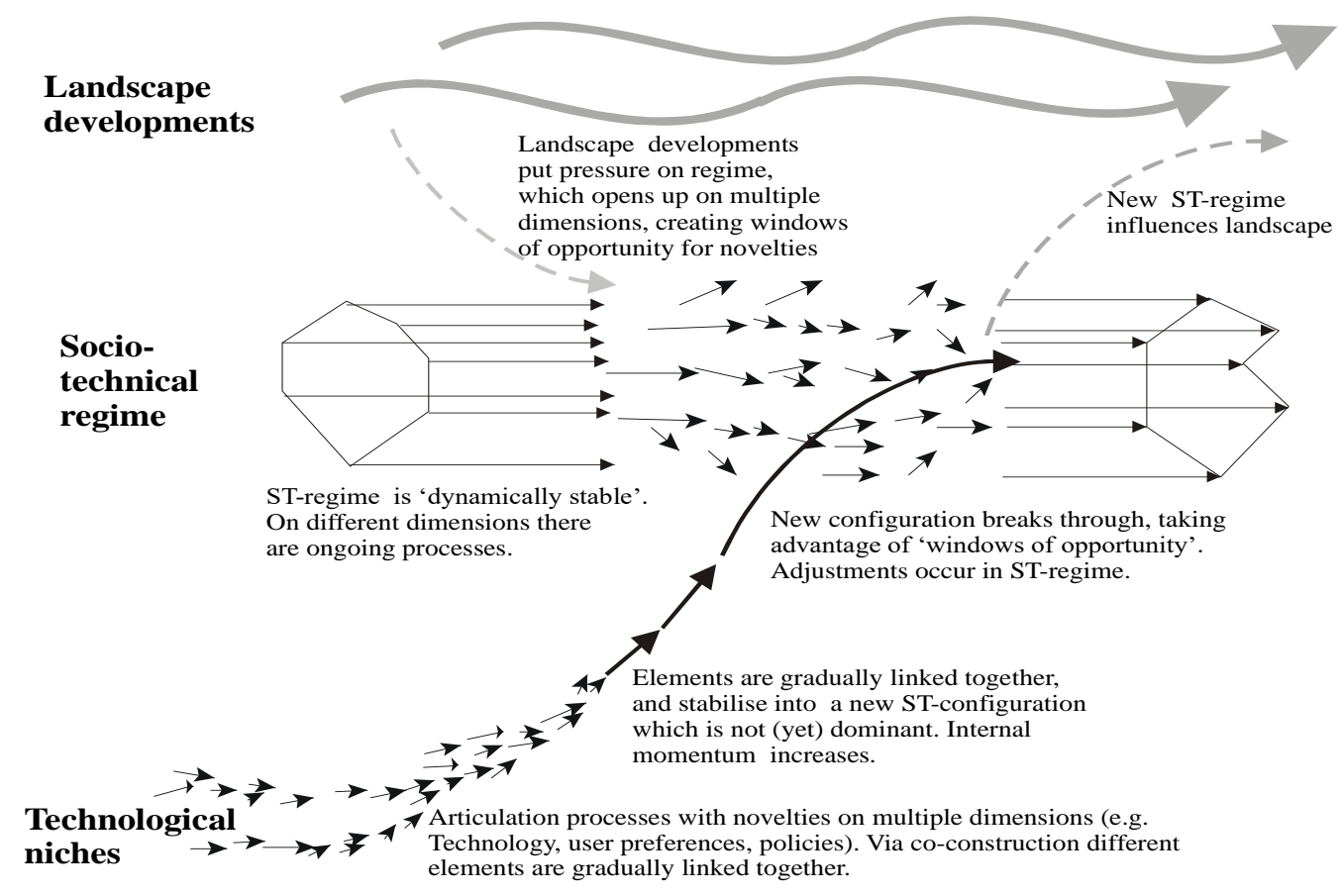

Time

Figure 1: A dynamic multi-level perspective on system innovation (Geels, 2005).

In the MLP dynamic, system innovations develop as follows. A novelty emerges in a local practice and becomes part of a niche when a network of actors is formed that share certain expectations about the future success of the novelty, and who are willing to fund and work on further development. Niches may emerge and develop partly in response to pressure and serious problems in an existing regime which can be either internal to the regime itself (such as animal welfare in industrial animal production) or come from the socio-technical landscape (e.g. the pressure to curb $\mathrm{CO}_{2}$ emissions which affects more than just the animal production sector). The further success of niche formation is on the one hand linked to processes within the niche (micro-level), and on the other hand to developments at the level of the existing regime (meso-level) and the socio-technical landscape (macro-level). Supported by actors willing to invest in the new concept (industries, R\&D organisations, government) and initially protected from competition at the market place (e.g. through subsidies), the technology is improved within the niche, broader networks are formed around it, and more is learned about directions for improvement and functions it may fulfil.

Following a certain degree of improvement of the technology, and after learning more about its use in practice, it may find its way in specific market applications, often typical segments that exploit new functional characteristics of the technology and focus less on cost structures (e.g. organic food). Through further improvement, increasing reliability, and cumulated experiences and learning about functionalities and potential applications, the technology can spread to other market niches and/or trigger an expansion of market niches. Processes of rule formation also play an important role, such as the development of standards and regulations for the technology, and processes to reduce the mismatch of the emerging technology with the rules of the dominant regime. As it starts to compete on or with main markets, the novelty may transform or substitute the existing regime and thus trigger a system innovation process.

This perspective allows for a very dynamic view on innovation processes as its application to a variety of historical cases has shown. These studies, however, tend to focus on the vicissitudes of a specific alternative technology to an existing system (e.g. sailing ships replacing steamships; Geels, 2002) although the new technology does not simply diffuse but changes in the process. This works fine for retrospective studies but it is problematic to use as a heuristic in a 'learning and experimentation strategy' seeking to contribute to system innovation. We do not know which alternative development will play a key role in the 
development towards a sustainable livestock sector. We need to acknowledge that 'innovation in action' is much messier than retrospective historical studies portray it (e.g. Elzen et al., 2012).

\subsection{Portfolio of promises}

In the MLP, niches are the locus to learn about and to further develop novelties. A niche consists of a variety of projects that share a technical nucleus, e.g. electric propulsion for cars (Hoogma et al., 2002). Using the niche concept in a sector like animal production, however, is problematic because innovative projects and practice initiatives are very diverse. For instance, they may relate to new types of animal feed, new manure collection technologies, new husbandry concepts, etc. Learning between these initiatives is often minimal and, therefore, they do not fit the definition of a niche in MLP.

To address such innovations we will use the term 'promise'. The term promise expresses that each of these novelties has attractive features from a certain sustainability perspective (e.g. lower $\mathrm{CO}_{2}$ emissions, or better animal welfare) but it has also problematic (e.g. more expensive) or unknown sides. Initially, a promise may just be an idea or a concept, explored in a single project or farmer's initiative. After a certain period of time more projects may be started in connection with the promise. When these projects start exchanging information and lessons learned, the promise may thus develop into a niche.

Historical cases (e.g. Geels 2005) show that system innovations are not the result of the 'massive diffusion' of a new technology but a lengthy process of combining and re-combining 'partial innovations'. This implies that, to induce or stimulate system innovations, attention should not go to a single novelty (or promise) but to range of novelties that we call the 'portfolio of promises'.

For each of these promises, a process of learning and experimentation is needed to find out in practice how the problematic sides may be solved and to explore whether it raises new problems. For an individual promise, even if it does not (yet) constitute a niche, the approach of Strategic Niche Management (SNM) provides valuable suggestions on how to do this (Hoogma et al., 2002; Schot and Geels, 2008). But SNM looks at the level of a single novelty and not at the portfolio level, i.e. across a variety of niches in MLP terms. To make a more encompassing contribution to system innovation, we need to addresses two levels, i.e. the level of individual promises and the level of the portfolio of promises.

- The individual promise level: because we are not only looking at technical innovations but also at new practices, new meanings, etc.; it is important to make various stakeholders, to whom the novelty may be relevant, part of the network exploring it and developing it further.

- The portfolio level: because a system innovation will result from a process of combining and recombining partial innovations it is important to analyse how various promises might be combined to create a full system that is more sustainable than the existing one. Such an analysis at the portfolio level (the 'portfolio integration') may result in starting new experiments with combined promises (thus creating a new, more encompassing promise) or in giving feedback to ongoing experiments to include certain aspects based on the portfolio integration. Because a variety of promise networks need to be running for a longer period, this portfolio integration should be a more or less continuous activity.

This combination of learning and experimentation at two levels we call the "Learning and Experimentation Strategy" (LES). It can be seen as an extension of SNM in two directions: (1) it addresses promises before they constitute a niche and (2) it looks across a range of promises (or multiple niches, in SNM terms).

\subsection{MLP revisited}

Promises may result from research projects ('top down'), as well as from practice initiatives by farmers ('bottom up'). This is captured in Figure 2 below, which gives a representation of the multi-level dynamic, focusing on the relationships between projects, practice initiatives, promises and the regime. 


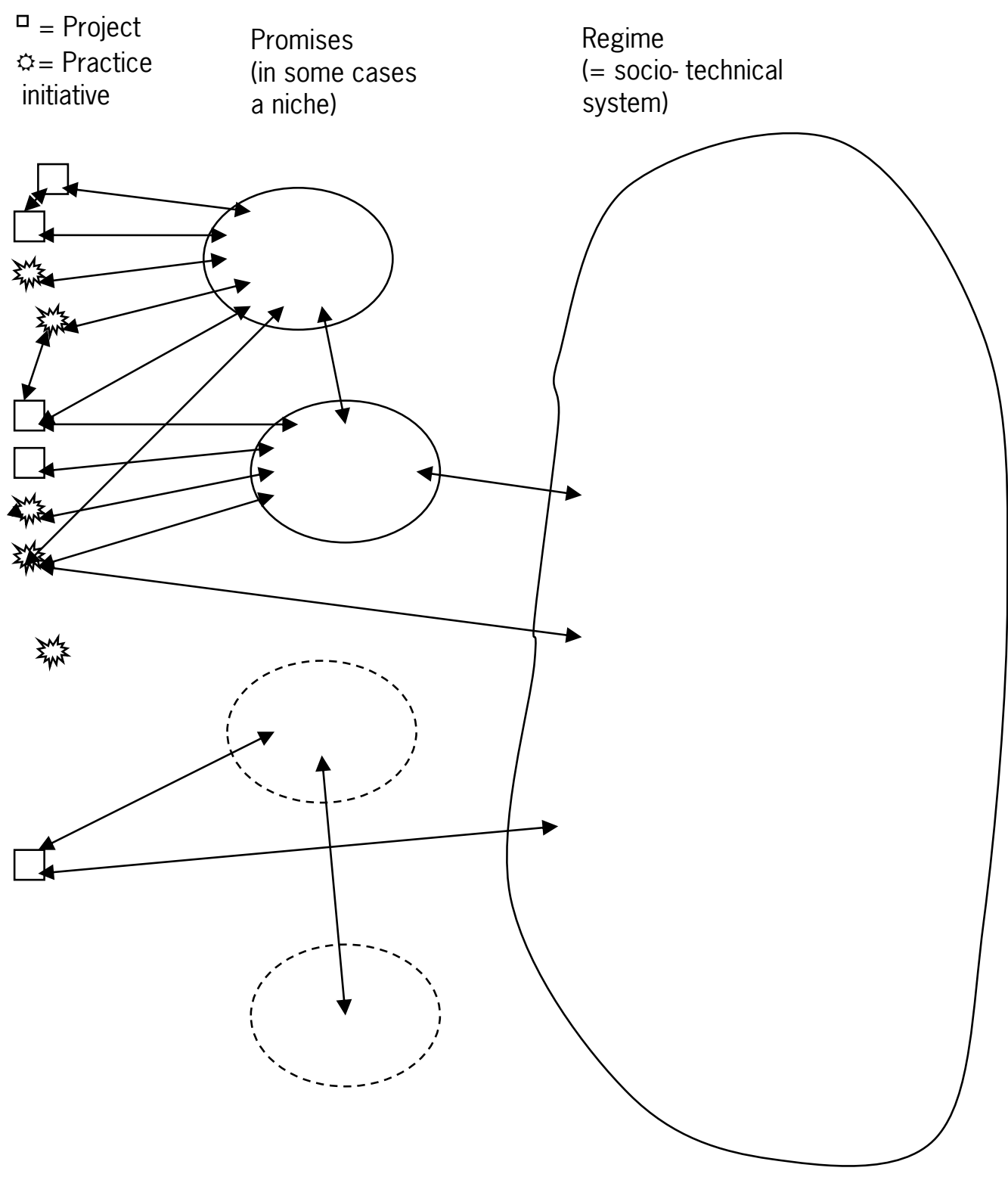

Figure 2: LES concepts in the multi-level dynamic (Elzen and Spoelstra, 2012).

Some explanatory remarks concerning the figure:

- Two-way arrows are used to indicate that influences may go both ways.

- $\quad$ Projects and initiatives may contribute to more than one promise.

- Some of the promises have been dashed, indicating they are (still) conceptual ideas that are not or hardly supported by a network. One of these is not supported by any project or initiative, indicating it is still just a conceptual idea.

- $\quad$ Projects and practice initiatives may influence each other directly.

- Projects and practice initiatives may also have an influence on the regime directly.

- Promises may also influence the regime.

- Promises may influence one another.

- One isolated initiative is not connected to any promise as an example of many such initiatives that do not fit the portfolio of promises. 


\subsection{Identifying and assessing Promises}

Farmers introduce novelties for a variety of reasons. There may be thousands of such initiatives, some of which may be inspired for sustainability reasons (e.g. because of societal pressure) while many others are motivated otherwise (e.g. for economic reasons). This begs the question how to assess which initiatives, and especially their constituent promises, might make a contribution to sustainable development.

We can approach this issue in various ways. Firstly, we might simply try to assess the actual 'sustainability' of the initiative as such, using a set of predetermined indicators. Although there is a range of systems in the Netherlands that try to do this (for farms or for the sector at large) in one way or the other, for instance in quality assurance schemes (cf. www.smk.nl), this assessment is cumbersome, laden with interpretation and almost impossible to do for initiatives, isolated from their context.

The second approach in assessing bottom up initiatives is to see them as part of an ongoing process. The question then becomes: "Which initiatives have a potential to contribute to sustainable animal production?" This requires a more thorough understanding of what makes the initiative special. In the PoP, we do this by identifying one or more novelties in the initiative, and qualitatively assess their respective potential contribution to 15 aspects of sustainability.

As a third approach, the question may be reversed. "How can we use these initiatives to learn about possibilities for sustainable animal production?" The initiatives are then seen as learning experiments to render knowledge on barriers and incentives for sustainable development. Thus, they can be made part of the 'portfolio of promises' within LES. This requires a process of continuous monitoring of which innovations are explored in the animal production practice and assess the relevance of the locally learned lessons within the broader portfolio.

In LES, the second and third approach are combined. This requires a tool to assess the various promises on their potential contribution to sustainable animal production.

\subsection{PoP Prototype}

As a tool, the portfolio of promises has the form of a database that contains an overview of initiatives that might make a sector more sustainable. This includes research projects, typically led by scientists, practice oriented projects including networks of farmers, as well as individual initiatives from farmers. On each initiative, the PoP contains practical information (description of the innovation, involved stakeholders) as well as an assessment of its 'sustainability potential'.

Different actors will have different views on what would be needed to make the sector more sustainable. In the Netherlands, these diverging views were discussed within a platform called the the 'Uitvoeringsagenda Duurzame Veehouderii' (UDV; "Action Plan for Sustainable Animal Production"; cf. section 3.5 below). UDV is a governance network with a broad range of stakeholders in and around the Dutch livestock production sector, ranging from NGOs to farmer representatives. UDV collectively agreed upon an agenda of 15 sustainability aspects that would have to be improved (Koole, 2013) and these were taken as an operationalization of the sustainability criteria for the PoP.

Table 1 below gives a selection of the main categories that are filled in for each initiative, together with a brief description of each category and guidance for filling in the PoP. The table only lists those categories that we focused on in the tests described below. Important other categories, that we will explore in depth in further work, are the barriers and incentives for developing a promise further, and the network of actors engaged in its development.

One of the listed categories in the PoP concerns the 'sustainability effects' which distinguishes 15 different aspects that are presented in Box 1 below the table. 


\begin{tabular}{|c|c|c|c|}
\hline Category & Description & Specification & Test questions \\
\hline Functional core & $\begin{array}{l}\text { The essence of what is done } \\
\text { differently from conventional } \\
\text { production methods, which } \\
\text { results in a substantial } \\
\text { sustainability improvement of the } \\
\text { system on one or more aspects. }\end{array}$ & $\begin{array}{l}\text { A farm can combine several } \\
\text { system innovative cores } \\
\text { What is done, not how it's } \\
\text { done specifically } \\
\text { Is concrete enough to be } \\
\text { combined with other functions } \\
\text { in the farming system } \\
\text { Is open enough to imagine } \\
\text { several possible solutions }\end{array}$ & \\
\hline Specific solution & $\begin{array}{l}\text { How the system innovative core } \\
\text { is being realized in the system }\end{array}$ & & $\begin{array}{l}\text { How is the system innovative } \\
\text { core being realized at the } \\
\text { farm? }\end{array}$ \\
\hline Other solutions & $\begin{array}{l}\text { Other ways of realizing the } \\
\text { system innovative core }\end{array}$ & & $\begin{array}{l}\text { How could you also realize the } \\
\text { system innovative core? }\end{array}$ \\
\hline Ambition & $\begin{array}{l}\text { The driving reason to rearrange } \\
\text { part of the production system } \\
\text { differently. Drivers can be } \\
\text { Internal (personal motivation } \\
\text { External (e.g. changing } \\
\text { legislation) }\end{array}$ & & $\begin{array}{l}\text { What drives the starter of the } \\
\text { initiative? What is the dream? } \\
\text { Which kind of 'energy' fuelled } \\
\text { the start of the initiative? }\end{array}$ \\
\hline System element & $\begin{array}{l}\text { Part of the production system } \\
\text { that is changed }\end{array}$ & $\begin{array}{cl}\text { Choose from: } \\
\text { - } & \text { Soil } \\
\text { - } & \text { Crop } \\
\text { - } & \text { Manure } \\
\text { - } & \text { Nutrients } \\
\text { : } & \text { Cow (/Animal) } \\
\text { - } & \text { Housing } \\
\text { - } & \text { Energy system } \\
\text { - } & \text { Labour } \\
\text { - } & \text { Productruct \& market } \\
\text { - } & \text { Capital } \\
\text { - } & \text { Rules } \\
& \text { regulations and } \\
\text { Several options may apply } \\
\end{array}$ & \\
\hline $\begin{array}{l}\text { Sustainability } \\
\text { effects }\end{array}$ & $\begin{array}{l}\text { Projected effect on sustainability } \\
\text { performance of the specific } \\
\text { solution for the system } \\
\text { innovative core. } \\
\text { See table } 1 \text { for sustainability } \\
\text { aspects taken into account. }\end{array}$ & $\begin{array}{l}\text { Only indicate when }>20 \% \\
\text { better/worse } \\
\text { conventional } \\
\text { Elaborate why performance } \\
\text { change is expected. }\end{array}$ & $\begin{array}{l}-1=\text { gets worse } \\
1=\text { gets better } \\
4=\text { uncertain if positive or } \\
\text { negative } \\
\text { Why do you expect the system } \\
\text { innovative core to have a } \\
\text { substantial effect on } \\
\text { sustainability performance? }\end{array}$ \\
\hline
\end{tabular}

Table 1: PoP main categories addressed in the tests and guidance for filling in the database.

The possible contribution of a promise to sustainable animal production is assessed on the following aspects:

1. Fossil fuel: Dutch livestock production at farm and chain level, will not use energy from non-renewable fossil fuels.

2. Climate: Dutch livestock production contributes proportionally to limiting the rise in global temperature to $2^{\circ} \mathrm{C}$ maximum.

3. Global biodiversity: Dutch livestock production contributes to conservation of species and restoration of global biodiversity

4. Local biodiversity: Local biodiversity is not being limited, but restored by Dutch livestock production.

5. Phosphate: Dutch livestock production at farm and chain level only uses phosphate from renewable, non-mined sources.

6. Soil quality: soil used for/by Dutch livestock production remains suitable for agriculture or other purposes.

7. Water reserves: Dutch livestock production does not deplete strategic water reserves. 
8. Water quality: Dutch livestock production keeps ground and surface water around the farm clean, so it can be used as a source for drinking water and aquatic ecosystems can thrive.

9. Animal welfare: animals in Dutch livestock production are able to meet all needs in their behavioural repertoire without pain or limitations. Interventions that violate the integrity of the animal are no longer executed structurally.

10. Animal health: Animals in Dutch livestock production remain healthy without structural medication.

11. Public health: Dutch livestock production and its products are safe for human health.

12. Relations with the local community: Dutch livestock farms are an accepted part of the community and do not cause local nuisance.

13. Profitability: Dutch livestock production is profitable.

14. Labour: Labour in Dutch livestock production is attractive, physically tolerable up to pensionable age and rewarding.

15. Knowledge, innovation and adaptability: Dutch livestock production is able to adapt continuously to changing conditions through a broad knowledge base and innovation.

Box 1: PoP sustainability aspects for animal production. These were agreed upon by the UDV platform, a governance network with a broad range of stakeholders in and around the Dutch livestock production sector (Koole, 2013; translation by the authors).

\section{Testing the PoP}

\subsection{Introduction}

In its general form, the PoP tool can be used in different agricultural subsectors and, together with colleagues from Wageningen UR, we have applied it in the greenhouse horticulture and dairy cow subsectors. In this chapter, we focus on the latter work.

In the $2^{\text {nd }}$ step of our long-term approach (cf. general Introduction) we discussed and tested the prototype with different types of actors. The overall objective of these tests and discussions was to gather feedback on the usefulness of the approach in various practical situations and use that as an input for redesign. These tests were carried out with the following actors:

- Various stakeholders in the province of Limburg engaged in a provincial sustainability initiative;

- Researchers engaged in various applied projects, working with stakeholders from the sector;

- Students at CAH Vilentum University of Applied Sciences who are the 'farmers of the future';

- The UDV platform, a governance network to stimulate transition to sustainable livestock production in the Netherlands.

The results of these tests are described below.

\subsection{Testing 1: Province of Limburg Innovation Agenda}

\subsubsection{Approach}

In 2010, the government of the Dutch province of Limburg and the LLTB (the provincial farmers representative organization) made an innovation agenda for sustainable animal production. They assigned us to use the PoP approach to assist them in their activities.

Our approach consisted of the following steps:

- Use the PoP to create an overview of provincial farmers initiatives to make animal production more sustainable in three main sub-sectors, i.e. pig fattening, dairy cattle, and poultry;

- Conduct a critical assessment of this portfolio to identify strengths and weaknesses;

- Identify possibilities for smart combinations;

- Discuss the results with stakeholders from the province, including farmers;

- Develop recommendations for our clients to realize the objectives of the provincial innovation agenda. 


\subsubsection{Results and consequences for PoP design}

The initial PoP design was comprehensive, and contained a lot of information on each initiative. As a result, the prototype was complicated with a variety of categories and sub-categories. The province, however, only had a limited budget and urged for a much simpler version that would be more easy to fill in. Therefore, a 'stripped' version of the format was developed.

Furthermore, because of time constraints, only a 'quick scan' could be conducted to identify farmers sustainability initiatives in the province and there was limited time to actually fill in the PoP. As a result, about a dozen initiatives from each of the three animal production sectors was included which was very limited. This was called an 'indicative' portfolio to stress its limited ambition.

Even with this stripped version, it appeared that filling in and scoring various initiatives was far from straightforward. There were numerous discussions on how to characterize a specific novelty, how to 'score' various sustainability criteria and how to identify possible barriers and incentives for its use. In a process of 'learning by doing', more specific criteria for filling in the various initiatives were developed.

The details from the critical assessment will not be discussed here, as the focus in this chapter is on aspects that affected the design of the PoP. Suffice to say, that various 'gaps' in the sustainability initiatives were identified and that the networks involved in these initiatives lacked specific stakeholders to facilitate orientation towards societal objectives. The provincial clients found these conclusions helpful in developing their further strategy for the innovation agenda.

The province was very interested in the idea of 'smart combinations'. On the basis of an analysis of the PoP, the project team would suggest a number of such smart combinations, which would subsequently be discussed in a workshop with provincial stakeholders.

On the basis of the content of the PoP, however, it appeared to be very difficult to actually identify smart combinations in a systemic way. In interaction with the province, three types of smart combinations were distinguished, i.e.:

- No obvious large barriers to realization; the combination might be realised immediately or in the short term.

- Serves a significant external (societal/political) or internal (in relation to husbandry) need but faces substantial barriers to realization; might be realised in the medium term.

- Large barriers to realization but offers interesting options to build upon further in the longer term.

For each of these types, 5-10 combinations were identified rather intuitively which were presented in a workshop with stakeholders, including farmers, LLTB-staff, representatives from the province, environmental NGO and others. Although the suggestions were a bit haphazard, the participants were enthusiastic about quite a number of them. Moreover, in breakout sessions they came up with a number of further smart combinations that some of them intended to explore further. The provincial clients were very happy with this result.

Although the research team was sceptical about the usefulness of a stripped version of the PoP, it appeared to be an effective tool to make recommendations for the provincial authorities and to stimulate creative thinking among provincial stakeholders. This led to the conclusion that the detailed design of the PoP would have to depend upon the specific objectives in using it. If it is used basically as a communicative tool, a rather simple version of the database ${ }^{1}$ and an intuitive identification of smart combinations will suffice.

\footnotetext{
${ }^{1}$ Actually, a little further down the project the province wanted us to make a 'quick and dirty' overview of sustainable animal production initiatives in the rest of the Netherlands. For this, we stripped the PoP even further, to its bare bones. Yet, this sufficed to present our client with an overview of what was happing elsewhere as input for determining their own strategy.
} 
If the objective is more scientific, however, a more systematic approach is needed. This especially manifested itself in the identification of smart combinations. It appeared that, in many cases, initiatives were not combined as a whole, but only certain elements of it. This led to a need, not to take an initiative at 'face value' but to break it down to its 'core' (or cores, if there are more). To allow making various combinations, it appeared to be easier if we did not see this core as a new solution, but as a new 'function' which was called the "functional core". For instance, emissions of ammonia can be significantly reduced by collecting urine and manure separately at the source. This 'early separation' we call the functional core which can be realized by various technical means. At face value, these technical means jump to the eye but for the PoP, an abstraction is made to identify this function, i.e. "separation of manure and urine at the source". This is entered as a 'promise' into the portfolio.

\subsection{Testing 2: Agriculture researchers}

\subsubsection{Approach}

The project team filled in the PoP with various novelties known to us that were developed by individual dairy farmers (which we call 'farmers initiatives'). These were discussed with six researchers from Wageningen UR Livestock Research, studying various aspects of dairy production (feed, housing, manure treatment, etc.), who were asked to complement the preliminary PoP with missing (details about these) initiatives. The goal was to develop an overview that would be representative for all types of novelties that are developed in Dutch dairy farming. With each expert, a meeting was held to discuss additions and how to analyze these for use in the PoP. Also, the application of the tool in research, farming practice and policy was discussed. The assessment of the sustainability performance of the novelties was not addressed in this test.

\subsubsection{Results \& consequences for PoP design}

The test resulted in several additions to the PoP: (reformulation of) promises, specific solutions for functional cores and listing of entrepreneurs that are experimenting with promises. The structure of the PoP was also slightly altered on the basis of the test.

One main issue, raised by dairy researchers, was to determine whether a promise is innovative enough to add to the portfolio. A selection from a huge range of promises needs to be made to keep the PoP manageable. Basically, every dairy farm is unique, consisting of a specific set of combinations of more or less common practices and solutions. How to determine, then, that a promise is sufficiently innovative to be included in the PoP? The answer to that question appeared to be largely subjective and the researchers disagreed on several occasions.

Seeking to develop criteria for this, the project team defined promises in the PoP as a new technology, new way of working, or new chain relations, that improves the performance of the farm on one or more of the sustainability aspects (cf. Box 1), by $20 \%$ or more. This definition, however, proved difficult to apply. For instance, the installation of PV-cells on the roof of the farm can significantly reduce on-farm fossil fuel use. This technology has been proven extensively already. Thus, the novelty does not fit the first part of the definition, but it does fit the second part. Furthermore, it opens up new possibilities on the farm when combined with small electromotor driven appliances, like manure robots. Therefore, this promise was included in the PoP and led to the conclusion that the definition should also include 'new combinations' of existing technologies, systems, relations, etc. Actually, this stresses the importance of 'smart combinations'.

Another complicating factor was that promises are embedded in a production system and their functioning can only be understood in this context. However, the 'whole production system' is not a useful unit of analysis to combine with other promises. It is difficult to isolate one specific promise from the system, since an innovative farmer usually changes several things at the same time and all these elements work interdependently. For instance, a farmer may combine a loose housing compost bedded pack barn with more space per cow than conventional, a mobile feeding system and a greenhouse foil roof. A specific part of this, e.g. a greenhouse roof construction, can be applied in any type of housing system, mainly to reduce 
costs. However, it is especially interesting to do so combined with a compost bedded pack, since the radiation from the sun and ventilation openings help evaporate the moisture (urine) that is absorbed in the packed bed. Thus, both promises together have a synergistic effect, but applying them separately can also be interesting for farmers.

There were 32 novelties in the initial PoP database that were extracted from 14 innovative farms. The dairy experts added names of entrepreneurs working on similar promises, which led to adding a column in the PoP to indicate that more farmers were working on the novelty. After the expert consultation, the PoP contained 52 novelties that 275 entrepreneurial farmers were experimenting with.

The experts found it important to also indicate what landscape and regime changes drive the development of novelties (e.g. increasingly strict environmental legislation), since it is a motivating factor for other farmers to change farm management. This was included in the PoP database under the title 'ambition'.

The experts consulted saw farmers as the main user group for the PoP. The experts work in applied research, aiming to develop knowledge that can be applied in farm practice. All agreed that the PoP has added value for their own work, because it provides a broad overview of novelties, also from outside their own area of expertise, which they are not usually exposed to. Going over the PoP periodically, would be a good way to evaluate current promises that researchers are working on, identify possible problems these promises might encounter, and develop a research agenda based on these problems.

Tables $2 \mathrm{a}$ and $2 \mathrm{~b}$ (cf. separate pages, after references) provide a sample of 8 promises as they are entered into the PoP to illustrate what it looks like.

\subsection{Testing 3: Agriculture students}

\subsubsection{Approach}

About 25 third-year students from CAH Vilentum University of Applied Sciences, doing the animal production/agricultural entrepreneurship educational program, were taken through a course consisting of four interactive lectures and a student assignment. In the first lecture, students were introduced to the PoP in the context of sustainability and transition management. Also, the student assignment was introduced: students (in groups of 2) had to choose a novelty from the database, find a farmer experimenting with it through their own network and find out from the innovative farmer a) how exactly the promise is put into practice on the farm, b) what motivates the entrepreneur to work on the novelty, c) what hurdles/incentives the entrepreneur encountered, d) what network he used to develop the novelty, and e) what the novelty yielded in terms of improved sustainability performance, as specified by the indicators in the PoP. The second lecture concerned an elaboration on the concept of sustainability, using the goals defined by the UDV platform (cf. section 3.5 below) to make the abstract concept of sustainability more concrete at farm level. In the third lecture, the findings of the students were presented, shared and discussed, providing the students with a broader overview of the innovation arena in dairy production and a deeper understanding of the relation between (aspects of) the farming system and its sustainability performance. In the fourth lecture, students were challenged to come up with an improved dairy production system, based on the weaknesses of the promise they had studied and inspiration from other promises. The ideas were pitched, the presentation was supported by a poster. Afterwards, the lectures and assignment were evaluated with the students via e-mail.

\subsubsection{Results and consequences for PoP design}

Some groups selected the promise to be studied based on their own unacquaintedness with the farming practice, i.e. as a learning opportunity, while others' choices were based on easy access to the entrepreneur through their network, i.e. on least amount of work. As in the test with agricultural researchers ('Testing 2'), a discussion point was how 'innovative' the promises in the PoP really are. Sometimes, uncertainty was due to how the novelty was formulated in the PoP. For instance, one of the novelties listed was to seed grass in an existing pasture, as opposed to tilling and newly planting the pasture. In the initial 
design of the PoP, novelties were formulated 'positively' (i.e. what is done, rather than what is not done). In the pasture case, many farmers improve its quality by seeding in the existing pasture if possible, since this induces lower cost than complete pasture renovation. Some innovative farmers, however, do not apply tilling at all anymore, which is the true promise. Novelties can therefore also be (most tersely) described as an abandoned practice from the existing regime.

The student assignment yielded additional entrepreneurs, working on novelties in the PoP database. The main result, however, was the learning effect for the students themselves. Most students grew up on a dairy farm, where farm management is executed according to tradition. Through this assignment, they were exposed to a wide range of innovative farming practices. The fact that a farmer, rather than a researcher, is motivated to apply a novelty and accept the risks associated, makes the students take the initiative more seriously.

The students made combinations between novelties, to improve a negative side effect of a new farming practice. The combinations did not always improve integrated sustainability performance however. One example of a combination made was to feed the packed bedding material from a loose housing system into a manure digester for energy production. The organic material in the bedding (straw) would increase the energy yield from the digester, making other co-products redundant. The original idea of farmers using organic bedding material, however, is to bind minerals from urine and manure to organic matter, creating a product that can be applied to improve soil quality. When digested, this effect cannot be sorted. Another example of a combination made was to guide visitors virtually through the farm instead of personally, to reduce the risk of zoonosis.

From the evaluation it can be concluded that students appreciated the overview of novelties and think that such an overview can be instrumental in exploring options for a farms development strategy.

\subsection{Testing 4: National UDV platform}

\subsubsection{Approach}

In the Netherlands, a formalized governance network (or transition arena) strives to stimulate sustainable development of livestock production. It is called the 'Uitvoeringsagenda Duurzame Veehouderii' (UDV; the name meaning "Action Plan for Sustainable Animal Production") and it consists of the national government, primary sector partners, chain partners, knowledge institutes and two NGOs (on animal protection and environmental issues). In 2009, the partners concluded a covenant for collaboration to make the sector fully sustainable by 2023 (Koole, 2013).

The project team had an open discussion with two representatives from the UDV platform to explore the potential of applying the PoP in the transition arena that they were setting up. Both representatives, one working for the Dutch Federation of Agriculture and Horticulture (a farmers' interest group), and the other working for "Stichting Natuur \& Milieu" (an environmental NGO), had recent experience with projects with a similar aim, yet different approach, named "Innovation in practice" and "Ranking the stars". Before the meeting, information about the status of each other's projects was exchanged to compare methods, results and hurdles encountered in the projects.

\subsubsection{Results and consequences for PoP design}

In both UDV projects, that worked complementary, pig farming, rather than dairy farming was the focus domain. Frontrunners in the pig sector were selected with a group of sector experts from the UDV platform. "Ranking the stars" analyzed four different strategies carried out by farmers to innovate and their characteristics (added value for innovation of the sector as a whole, challenges, entrepreneurs' attributes and partners involved). These frontrunner farms' performance was analyzed for a set of eight sustainability goals, based on expert opinion. The projects' results have been translated into a brochure for use by farmers and in education. 
"Innovation in practice" aims to stimulate entrepreneurs to develop certain aspects of farming practice by showcasing forerunners in the sector at farmers meetings. Such meetings were organized by sustainability theme (e.g. health) or innovative farm (full farm concept). The project's current main challenge is to position the forerunners' meetings in the communication towards farmers in such a way, that the meetings will attract enough attendants. There is much competition from study groups, workshops and seminars offered for free by commercial advisors (e.g. vets, feed companies). Communication is a sensitive matter, since the farmers' organization represents a wide range of farmers, some of whom might be offended when alternative farming practices are presented as being 'innovative' and 'sustainable', which implicitly disqualifies practices from other farmers as less sustainable, which might leave them feeling not supported.

The UDV representatives thought the PoP approach would have added value for the aforementioned two projects in several ways. For one, the functional analysis of novelties in the PoP allows for a more specific search for possible solutions, compared to the whole farm being taken as the unit of analysis. This added value was considered specifically interesting for advisors in the livestock sector, who encounter a wide range of entrepreneurs with strategic choices every day, whereas individual farmers only make these choices when making major investments, i.e. once every 5-10 years. The PoP is instrumental in providing an overview of possible solutions and their sustainability effect. Another added value mentioned is the in-depth evaluation of sustainability performance of initiatives. It was suggested to have this evaluation executed by university students as a standard assignment in their curriculum, as it would fit the learning objectives (Bloom et.al., 1956), would prepare students for future sustainability challenges and at the same time would guarantee sufficient quality of the analysis through supervision by university staff. Lastly, great potential was seen in comparing promises experimented with in different livestock sub-sectors. A quick scan shows that some aspects, like soil quality, are addressed in dairy production whilst not in pig production. This observation could urge the pig sector to explore strategies to improve on this hitherto unaddressed aspect as well.

As a consequence of the projected added value, the representatives thought the emphasis in the re-design of PoP should be on its use as a "morphological (i.e. function) chart". It would enable acquiring information concerning the solutions in the chart, like a description of inspirational initiatives from practice (including network, incentives, hurdles, etc.), where the novelty is applied, or sustainability performance of the novelty. An open access web-based relational database would allow the required functionality to be linked to information on each solution and make it available to a wide public. To keep maintenance cost of the PoP low, information/descriptions from other projects should be used as much as possible. The ambition of completeness was not considered realistic, nor necessary for inspiring advisors \& entrepreneurs to start experimenting with promises. Communication was seen as much more important, and an attractive and clear design of the user interface is therefore crucial.

\section{Redesign}

The results from the testing stage led us to redefine our objectives in using the PoP and make them more specific. As a result, three different types of main objectives were defined, notably:

a) to directly inspire stakeholders with novel farm practices;

b) to identify smart combinations, that potentially have synergistic effects;

c) to identify 'blank spots' in innovation programs and activities.

Each of these specific objectives sets its own requirements for the architecture of the portfolio. The requirements challenged us to partially redesign the PoP to address the more specific objectives. Below we discuss the three main objectives in using the tool, the requirements these have for the PoP, and the structural changes made in the PoP design. 


\subsection{Objective 1: Direct Inspiration}

The ultimate objective in using the PoP is to inspire farmers and other stakeholders to incorporate sustainable practices at farm and chain level to induce a transition towards sustainable agriculture (or animal production, in our specific case). The main purpose of the PoP is to provide interested stakeholders with inspiration and information on opportunities that are available, and to teach them about solutions \& initiatives that they might be interested in. The main users of the tool for this objective are advisors and innovative farmers.

This objective sets the following requirements for the tool:

- The tool needs to be freely accessible for all stakeholders in the sector, so that various target groups have open access to the information it contains.

- To keep the overview up-to-date, it should be easy to add information to the PoP. However, this should be done efficiently, re-using information generated within other projects when available. A thorough functional analysis of all novelties is too time consuming to perform and should therefore not be aimed for. Additions to the PoP should be made by an independent expert to ensure coherence of its contents.

- In communication about novelties in public, it needs to be clear who supports a certain novel practice that is showcased via the PoP.

- The information from the PoP needs to be presented in an attractive and clear way for the specified target group, using appropriate wording and indicating key information for the target group (e.g. expected investment costs).

\subsection{Objective 2: Identify smart combinations}

These are combinations of initiatives that are separate whilst, in combination, they could lead to synergistic effects. To meaningfully, systematically and traceably recombine novelties, it is essential to analyse initiatives on what is functionally done differently from common practice. This is problematic, since it requires an extensive knowledge of the system, is very time-consuming and thus costly for a practice tool. Alternatively, smart combinations can be identified more intuitively by farming system experts, and then discussed with advisors, innovative farmers and other stakeholders to explore their potential in practice. The main users of the tool in this case are researchers and advisors.

This type of application sets the following requirements for the design and use of the tool:

- Farming system knowledge (e.g. resource flows) to intuitively assess the potential of combining novelties within or between sectors.

- Frequent interaction with stakeholders (researchers/advisors/entrepreneurs) to test the viability of smart combinations. A large network in the sector is a precondition to be able to apply the tool in this way.

\subsection{Objective 3: Identify blank spots}

'Blank spots' are sustainability challenges that are addressed insufficiently. These can be used as input for innovation strategy and policy in the sector, to stimulate action to address these blank spots. Main users of the tool are researchers who use it to advice policy makers and strategic actors in the sector, i.e. actors who are responsible to carry out an innovation agenda or strategy.

The requirements associated with this objective are:

- The novelties in the PoP should be somewhat representative for the range of innovative activities in the sector, although completeness can never be obtained.

- Requires an assessment of the impact of novelties on various sustainability dimensions. The assessment needs to be of sufficient quality, e.g. by involving experts on the different aspects of sustainability. 


\subsection{Changes to PoP}

Based on these specific objectives and requirements, the PoP was critically evaluated. This led to small changes in the structure of the database and to more radical changes in the use of the tool.

Changes in the structure of the database were a description of a promise's functional core, listing of various entrepreneurs working on a promise (rather than just the one listed initially), and the option to identify several novelties per initiative when relevant.

Changes in the use of the tool were more substantial. Since a database as such does not provide a userfriendly overview for various user groups, researcher-processed content from the PoP is used in communication with relevant stakeholders. For instance, the information can be processed for interactive sessions with stakeholders, including farmers. It can be processed to make a morphological chart or spider web graph of sustainability performance, which can fuel a discussion on various options to realize certain functionalities. When the PoP is applied more as a communicative tool, ownership of the content of the PoP should get more attention, e.g. via the UDV platform.

\section{Discussion and conclusions}

The examples above clearly indicate that sustainable innovation in animal production is and needs to be multi-facetted. A range of novelties is needed and needs to be combined to achieve sustainability on a variety of dimensions, including animal welfare, emissions, profitability, etc. Many of such novelties are already being developed by a broad range of farmers who focus on application on their own farm rather than seeking to contribute to a broader transformation. A strategy to develop a more sustainable animal production should make use of this innovative power.

Although SNM provides a useful starting point for developing such strategies, the characteristics of the animal production regime imply that the approach needs to be transformed and extended. We have sought to realize this by developing, what we have called, the Learning and Experimentation Strategy - LES. Within LES, we use the term 'promise' to indicate a novelty, rather than 'niche' as in SNM, since many of these promises are in a stage of development and embedded in a network that do not (yet) satisfy the definition of a niche. A broad variety of these promises is currently being worked on, which we call the 'portfolio of promises' (PoP).

Crucial in LES, in contrast to SNM, is that it emphasises the importance of combinations of such promises (the 'smart combinations') to acknowledge the multi-variety of the ongoing innovation process and to be able to address a variety of sustainability dimensions within the same strategy.

In testing the prototype, it appeared that using the term promise provides a useful concept to create an overview of ongoing initiatives at the farm-level, but that it is too crude to develop suggestions for 'smart combinations'. It appeared that many initiatives by farmers consist of a combination of novelties addressing different aspects. Therefore, we chose to distinguish promises from (farmer's) initiatives. Furthermore, it appeared that there were various promises that were technically different but that served the same function (e.g. separating manure and urine at the source). It appeared that combining such functions provided a better stepping stone to stimulate innovation than combining solutions. The reason is that a combination of functions creates room for variety in solutions and, therefore, for a farmer to bring in personal preferences.

This led to the conclusion that we should not consider each farmer's initiative as a promise, but to take two analytical steps first, notably:

1. To assess whether an initiative constitutes a singular promise or a combination of several of them;

2. To break down each promise to its 'functional core'. 
It appeared, that these two steps are far from straightforward and led to various discussions on how to actually do this. By doing this in a wide range of situations in the future we will attempt to develop some guidelines for this.

Still, this provided a fruitful strategy to identify a number of smart combinations. This can be done rather intuitively, which proved to provide useful inputs for workshops with farmers and inspired them to explore whether they could actually realize them in their own practice. This also proved to be a good teaching tool, as the testing with students illustrates.

For strategic purposes, e.g. to identify 'blank spots', we think that we need a more systematic approach to identify smart combinations, e.g. to ensure that the full range of sustainability aspects distinguished in the portfolio is addressed appropriately. Our attempts in doing so, which are still ongoing, indicate that this is a labour intensive process. This may well be a serious handicap as we seek to use this tool in a practical situation where the budgets available for this type of work are limited.

Summarizing, our tests indicate that the simple version of the tool and the intuitive identification of smart combinations can already provide useful input for stimulating innovation towards sustainability. In the next phase we will develop this further in practical situations with stakeholders in the animal production sector and we encourage others to do this in other sectors as well.

Furthermore, we also seek to further develop a more advanced version of the tool for strategic purposes. It will be a challenge to do that in a cost effective way to increase the usefulness of the Portfolio of Promises in practical situations.

Acknowledgements: This paper is based on research conducted within the Programme "KB-16 Transitie \& Innovatie" (KB-16-002.02-003), financed by the Dutch Ministry of Economic Affairs.

\section{References}

Bloom, B.S. (Ed.), Engelhart, M.D., Furst, E.J., Hill, W.H., \& Krathwohl, D.R. (1956). Taxonomy of educational objectives: The classification of educational goals. Handbook 1: Cognitive domain. New York: David McKay.

Bos, Bram (2009). "Concepts and objects as boundary objects for sustainable animal husbandry: Anticipating regime transformations by design." Paper for 1st European Conference on Sustainability Transitions, Amsterdam, 4-6 June 2009

Elzen, Boelie, and Sierk F. Spoelstra. 2012. "Developing Sustainable Livestock Production Systems: Outline of a Learning and Experimentation Strategy (LES)". In Marc Barbier and Boelie Elzen (Eds.). Proceedings of the first international workshop on System Innovations, Knowledge Regimes, and Design Practices towards Sustainable Agriculture. Paris: INRA, pp.208-225. Downloadable from:

Elzen, Boelie, Cees Leeuwis and Barbara van Mierlo, 2012. "Anchoring of Innovations: Assessing Dutch efforts to harvest energy from glasshouses". Environmental Innovation and Societal Transitions, 5, pp.1-18.

Geels, F.W. (2002). Technological transitions as evolutionary reconfiguration processes: a multi-level perspective and a case-study. Research Policy 31 (8/9): 1257-1274.

Geels, F.W. (2005). Technological Transitions and System Innovations: A co-evolutionary and socio-technical analysis. Edward Elgar Publishing Ltd., Cheltenham.

Hoogma, R., R. Kemp, J. Schot and B. Truffer (2002). Experimenting with Sustainable Transport: the approach of Strategic Niche Management. London: Spon Press.

Koole, J. 2013. 4e Voortgangsrapportage Uitvoeringsagenda Duurzame Veehouderij. (Fourth Progress report UDV). The Hague: Uitvoeringsagenda Duurzame Veehouderij.

Loorbach, D. (2007). Transition Management: new mode of governance for sustainable development. PhDdissertation. Rotterdam:Erasmus University.

Rip, A., and R. Kemp (1998). Technological Change. In S. Rayner and E.L. Malone(eds). Human Choice and Climate Change. Columbus, Ohio: Battelle Press. Volume 2: 327-399.

Rotmans, J. (2003). Transitiemanagement, sleutel voor een duurzame samenleving. Assen: Van Gorcum. 
Schot, J., and F.W. Geels (2008). Strategic niche management and sustainable innovation journeys: theory, findings, research agenda and policy. Technology Analysis \& Strategic Management. 20: 537-554. 
Table 2a: Portfolio of Promises: sample of 8 promises for dairy production (for sustainability scores cf. table 2b)

\begin{tabular}{|c|c|c|c|c|c|c|}
\hline & $\begin{array}{l}\text { System } \\
\text { innovative core }\end{array}$ & Specific solution & Other solutions & Ambition & $\begin{array}{l}\text { System } \\
\text { element }\end{array}$ & Farmers working on the promise \\
\hline 1 & $\begin{array}{l}\text { Provide living } \\
\text { space without } \\
\text { obstacles and soft } \\
\text { bedding }\end{array}$ & $\begin{array}{l}\text { Loose housing system with } \\
\text { low cow density and } \\
\text { compost bedded pack } \\
\text { from wood chips }\end{array}$ & $\begin{array}{l}\text { Straw yard } \\
\text { Pasture based system }\end{array}$ & $\begin{array}{l}\text { Improve cow welfare } \\
\text { and increase culling age }\end{array}$ & $\begin{array}{l}\text { Housing } \\
\text { system }\end{array}$ & $\begin{array}{l}\text { Havermans/Wiersma/Hartman/de } \\
\text { Haan/Lubbersen/Groenwegen/Wilms/Neenho } \\
\text { uwer/Jensma/De } \\
\text { Regte/Hoogland/Bomers/Faes/ }\end{array}$ \\
\hline 2 & $\begin{array}{l}\text { bind animal } \\
\text { manure \& urine to } \\
\text { organic matter to } \\
\text { fertilize } \\
\text { crop/grassland }\end{array}$ & $\begin{array}{l}\text { Loose housing system with } \\
\text { low cow density and } \\
\text { compost bedded pack } \\
\text { from wood chips }\end{array}$ & $\begin{array}{l}\text { Loose housing system with compost } \\
\text { bedded pack from garden compost, } \\
\text { straw, reed, ditch sediment etc } \\
\text { (aerobic decomposition) } \\
\text { Straw yard (anaerobic decomposition) } \\
\text { Pasture based system }\end{array}$ & $\begin{array}{l}\text { Turn manure into a } \\
\text { valuable soil } \\
\text { improvement product }\end{array}$ & $\begin{array}{l}\text { Housing } \\
\text { system } \\
\text { Manure }\end{array}$ & $\begin{array}{l}\text { Havermans/Wiersma/Hartman/de } \\
\text { Haan/Lubbersen//Groenwegen/Wilms/Neenh } \\
\text { ouwer/Jensma/De } \\
\text { Regte/Hoogland/Bomers/Faes/ }\end{array}$ \\
\hline 3 & $\begin{array}{l}\text { Separate \& collect } \\
\text { urine and manure } \\
\text { in the barn to } \\
\text { fertilize } \\
\text { crop/grassland }\end{array}$ & $\begin{array}{l}\text { Concrete flooring system } \\
\text { with sloped slots and } \\
\text { drainage holes } \\
\text { Straw in cubicles \& manure } \\
\text { robot }\end{array}$ & $\begin{array}{l}\text { Flooring system consisting of a top } \\
\text { layer of filtering cloth, middle layer of } \\
\text { compressable material and under } \\
\text { layer of coarse drainage material } \\
\text { Autonomous manure cleaning } \\
\text { device(koeientuin) }\end{array}$ & $\begin{array}{l}\text { Turn manure into a } \\
\text { valuable soil } \\
\text { improvement product }\end{array}$ & $\begin{array}{l}\text { Housing } \\
\text { system } \\
\text { Manure }\end{array}$ & Kwatrijn \\
\hline 4 & Not dehorn cows & $\begin{array}{l}\text { Round house and more } \\
\text { space per cow }\end{array}$ & $\begin{array}{l}\text { Tie stall } \\
\text { Straw yard with more space per cow } \\
\text { Pasture based system }\end{array}$ & $\begin{array}{l}\text { Maintain physical } \\
\text { integrity of the cow }\end{array}$ & $\begin{array}{l}\text { Cow } \\
\text { Housing } \\
\text { system }\end{array}$ & De Groote Voort \\
\hline 5 & $\begin{array}{ll}\text { Maximize } & \text { milk } \\
\text { from grass } & \end{array}$ & $\begin{array}{l}\text { Pasture based system } \\
\text { All cows calve in spring }\end{array}$ & Summerfeeding & $\begin{array}{l}\text { Independence from the } \\
\text { bank, low variable cost } \\
\text { for landwork, vet, feed } \\
\text { concentrate and } \\
\text { artificial fertilizer. }\end{array}$ & $\begin{array}{l}\text { Crop, Feed, } \\
\text { Nutrients }\end{array}$ & Pure Graze (+/- 40 farms) \\
\hline 6 & $\begin{array}{l}\text { Producemilk with } \\
\text { special properties } \\
\& \text { processinto } \\
\text { specialty product } \\
\text { for niche market }\end{array}$ & $\begin{array}{l}\text { Jersey cow, special feed } \\
\text { (grass/clover/hay/herbs) } \\
\text { Cheese from raw milk with } \\
\text { Ghee crust }\end{array}$ & $?$ & Obtain higher milk price & $\begin{array}{l}\text { Crop, Feed, } \\
\text { Nutrients } \\
\text { Product \& } \\
\text { Market }\end{array}$ & De Groote Voort \\
\hline 7 & $\begin{array}{l}\text { Cows not owned } \\
\text { by the farmer }\end{array}$ & Consumers own cows & $\begin{array}{l}\text { Cooperative owns cows } \\
\text { Nature conservation organization } \\
\text { owns cows }\end{array}$ & $\begin{array}{l}\text { Involve citizens with } \\
\text { farm }\end{array}$ & Capital & Veld en Beek \\
\hline 8 & $\begin{array}{l}\text { Bring milking } \\
\text { parlor to cows }\end{array}$ & $\begin{array}{l}\text { Rapid exit milking parlor on } \\
\text { wheels }\end{array}$ & $\begin{array}{l}\text { Mobile milking robot } \\
\text { Hand milking }\end{array}$ & $\begin{array}{l}\text { Milk cows in nature } \\
\text { reserves }\end{array}$ & $\begin{array}{l}\text { Milking } \\
\text { System }\end{array}$ & Sjaak Sprangers \\
\hline
\end{tabular}


Table 2b: Portfolio of Promises: sustainability assessment of promises from the sample in table 2a (Aspects taken from Koole, 2013) (Meaning scores: -1 = gets worse; $1=$ gets better; $\boldsymbol{\zeta}=$ uncertain (might be either positive or negative)

\begin{tabular}{|c|c|c|c|c|c|c|c|c|c|c|c|c|c|c|c|}
\hline novelty & $\begin{array}{l}\text { Fossil } \\
\text { fuel }\end{array}$ & Climate & $\begin{array}{l}\text { Global } \\
\text { biodi- } \\
\text { versity } \\
\end{array}$ & $\begin{array}{l}\text { Local } \\
\text { biodi- } \\
\text { versity } \\
\end{array}$ & $\begin{array}{l}\text { Phos- } \\
\text { phate }\end{array}$ & $\begin{array}{l}\text { Soil } \\
\text { quality }\end{array}$ & $\begin{array}{l}\text { Water } \\
\text { reserves }\end{array}$ & $\begin{array}{l}\text { Water } \\
\text { quality }\end{array}$ & $\begin{array}{l}\text { Animal } \\
\text { welfare }\end{array}$ & $\begin{array}{l}\text { Animal } \\
\text { health }\end{array}$ & $\begin{array}{l}\text { Public } \\
\text { health }\end{array}$ & \begin{tabular}{|l|} 
Relations with \\
the local \\
community
\end{tabular} & $\begin{array}{l}\text { Profit- } \\
\text { ability }\end{array}$ & Labour & $\begin{array}{l}\text { Knowledge, } \\
\text { innovation and } \\
\text { adaptability }\end{array}$ \\
\hline 1 & & -1 & & -1 & & & & & 1 & 4 & 4 & 4 & & & \\
\hline 2 & & 1 & & 1 & & 1 & & & & & & & & & \\
\hline 3 & & 1 & & 1 & 1 & 1 & & & & 4 & & & 1 & & \\
\hline 4 & & & & & & & & & 1 & & & & & & \\
\hline 5 & 1 & & 1 & 1 & & & & & 1 & 1 & & 1 & 1 & & \\
\hline 6 & & & & & & & & & & & & & 1 & & \\
\hline 7 & & & & & & & & & & & & 1 & 1 & & 1 \\
\hline 8 & & & & & & & & & & & & 1 & & & \\
\hline
\end{tabular}




\title{
Role of NGOs in system innovation towards animal friendly pork production in the Netherlands
}

\author{
Jan Buurma, ${ }^{1}$ Anne-Charlotte Hoes, ${ }^{2}$ Karel de Greef $^{3}$ and Volkert \\ Beekman ${ }^{4}$
}

We do not intend to blame but to awaken the consumer.

Campaign leader of activist NGO

\section{Abstract}

This chapter analyses the dynamics between NGOs, researchers and sector organisations in system innovation towards animal friendly pork production in the Netherlands in the period 2005-2012. The findings are based on content analysis of 262 national newspaper articles in which a moderate NGO and an activist NGO addressed pork production topics. The content analysis shows that the two NGOs focused their attention on different issues and targeted different actors in the value chain. The activist NGO focused on campaigning against abuses in slaughterhouses and transport of livestock and against castration of pigs and mainly addressed consumers. Furthermore, they developed a consumer information system on animal welfare and environmental impact of various types of meat. The moderate NGO focused on developing a better housing system and an intermediate market segment for animal friendly pork. For that purpose they cooperated with researchers, pig farmers union, slaughterhouses and retail companies. In addition, the moderate NGO mainly addressed farmers in the articles. Despite these differences, the two NGOs supported each other in achieving a more animal-friendly pork production and consumption. While the activist NGO raised normative pressure on the current production and consumption system, the moderate NGO engaged in partnerships with the pork sector to experiment with alternatives. The study reveals the relevance of catching trends and incidents at landscape level, to strengthen pressure on the regime, in addition to multi-actor arrangements at niche and regime level.

Keywords: System innovation, animal welfare, pork production, NGOs, consumers

\section{Introduction}

NGOs can play an important role in system innovation processes because they can, among others, mobilise normative pressure to trigger regime change (Elzen et al., 2011; Geels and Schot, 2007). This chapter studies the dynamics between NGOs, research and sector organisations in innovation processes that aim to address sustainability issues, to get a better understanding of the role of NGOs in system innovation processes.

The subject of the study is the case of animal welfare in pork production in the Netherlands in the period 2005-2012. That period saw many campaigns, activities and efforts of various actors to address and reduce animal suffering in pork production. The selected period followed after several livestock crises caused by animal disease outbreaks in 1997 (classical swine fever), 2001 (foot-and-mouth disease) and in 2003 (avian influenza). In September 2003, the Minister of Agriculture started a fundamental debate on the

\footnotetext{
${ }^{1}$ Wageningen Economic Research, the Netherlands. Email: jan.buurma@wur.nl

2 Wageningen Economic Research, the Netherlands. Email: anne-charlotte.hoes@wur.nl

${ }^{3}$ Wageningen Lifestock research, the Netherlands. Email: karel.degreef@wur.nl

${ }^{4}$ Wageningen Economic Research, the Netherlands. Email: volkert.beekman@wur.nl
} 
future of intensive livestock industry (Veerman, 2003). He managed to get all value chain partners, including consumers, engaged in this debate. Following this debate many campaigns, activities and efforts took place in the pork sector. The chosen period of analysis ends with the introduction of a new intermediate animal welfare label on the pork market.

Our results show that two NGOs played a central role in triggering a system innovation in the pork sector and they both used different types of means and discourse for their quest to improve animal welfare (Vullings, 2009). One NGO focused on criticising the pork production chain while the other NGO sought partnerships with the pork sector to improve current conditions. The different roles that NGOs can play to further sustainable development has also been described by Elkington (SustainAbility, 1996). He distinguishes different types of NGOs that either focus on disrupting the status quo through confrontation (i.e. 'shark' NGOs) or NGOs that seek constructive collaboration with business, government and other stakeholders in order to change the status quo (i.e. 'dolphin' NGOs). In this chapter we use this distinction and refer to NGOs as either activist NGOs (i.e. shark NGOs) or moderate NGOs (i.e. dolphin NGOs). The objective of this study is to get a better understanding of the roles of and relation between such activist and moderate NGOs, in interaction with government, research and industry (primary producers, and other value chain partners), in system innovation towards animal friendlier pork production in the Netherlands.

\section{The role of NGOs in system innovation processes}

In order to put the NGO interventions into an innovation context, the multi-level perspective has been taken as a concept to delineate NGO activities and their effects (Figure 1) (Geels, 2002; Geels and Schot, 2007). The multi-level perspective makes a distinction between three levels (macro, meso and micro) that interplay during system innovation processes. The socio-technical landscape (macro) refers to the overall context of the regime and niches and contains aspects such as social values, political beliefs and economic or environmental circumstances. The socio-technical regime (meso) represents the established sector involving practices with shared routines, which are formalised through institutional rules or embedded as norms. Niche-innovations (micro) are the level at which alternatives for the status quo are developed. The multilevel perspective illustrates that landscape-, regime- and niche-developments influence each other. For example, 'changes at the landscape level create pressure on the regime and destabilisation of the regime creates windows of opportunity for niche-innovations' (Geels and Schot, 2007, p. 400). So, developments at landscape, regime and niche level may eventually amount to a fundamental change within the structure of the regime (i.e. system innovation).

Although NGOs are not depicted in the above representation of the multi-level perspective several system innovation scholars do address the issue of NGOs in system innovation processes (Figure 1). Some studies highlight that NGOs play an important role in creating normative pressure to trigger regime change (Elzen et al., 2011; Geels and Schot, 2007). When we relate the role to creating normative pressure to the multilevel perspective we place such activities at the border between landscape and regime level. Geels and Schot (2007) argue that these outside pressures need to be strong and prolonged in order to achieve regime orientation. Elzen et al. (2011) note that NGOs in the pork sector raised attention to a variety of issues and that this considerably weakened their normative pressure. This description of NGOs fits the description of the activist NGOs as mentioned in the introduction of this chapter.

Other scholars, in the field of sustainable development, describe the trend of partnerships between NGOs and industry to collectively work on sustainable development (Bitzer and Glasbergen, 2015; Harangozó and Zilahy, 2015). Such a partnership emerges and operates at the niche level or at the boundary between the niche and the regime level. Furthermore, this description of NGOs fits the description of the moderate NGOs as mentioned in the introduction of this chapter. 
Increasing structuration

of activities in local practices

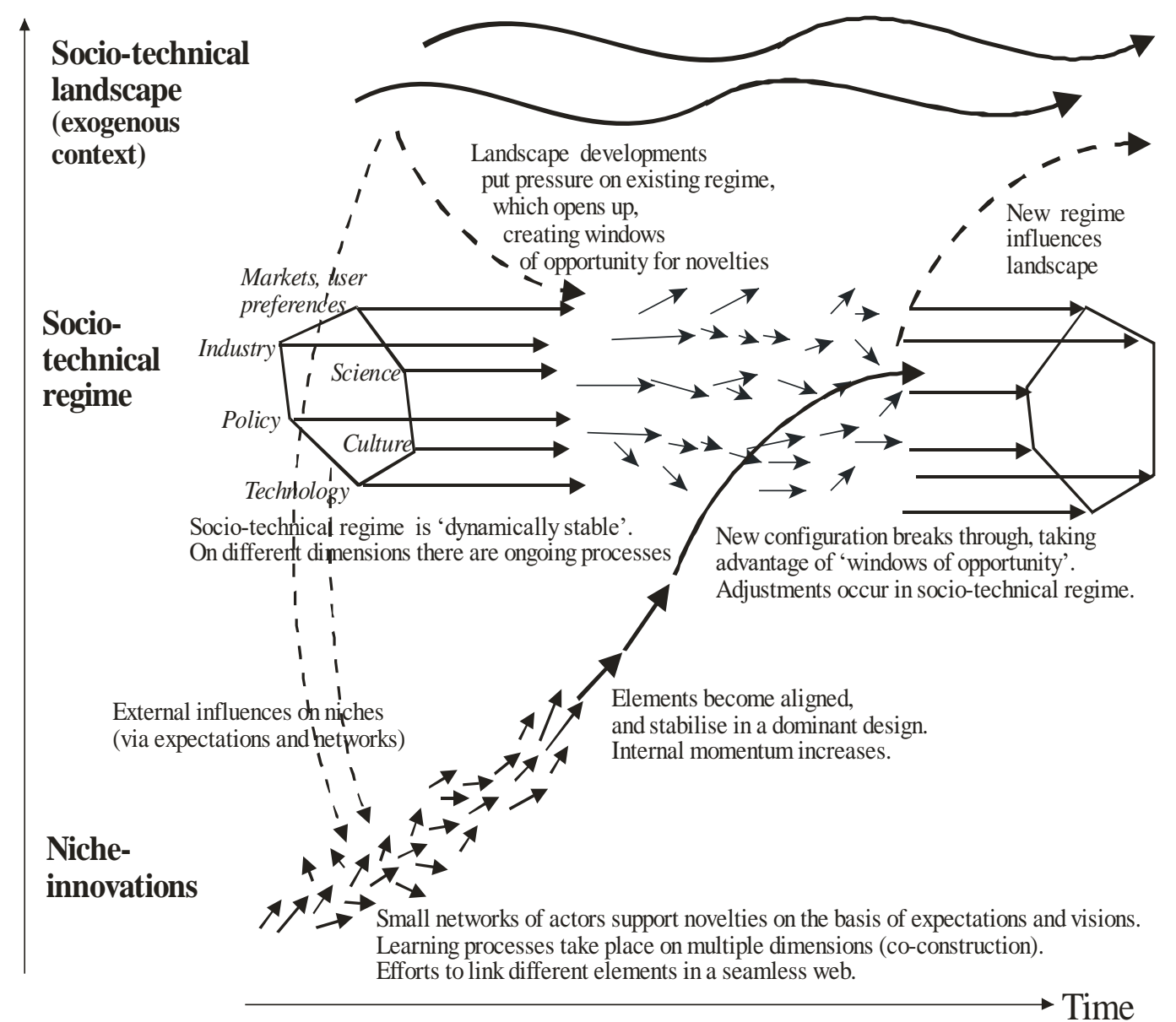

Figure 1: Multi-level perspective on transitions (adapted from Geels, 2002, p. 1263 (Geels and Schot 2007, p.401).

When we relate the descriptions of the roles of NGOs to the multi-level perspective, we expect that activist and moderate NGOs each play their own role in system innovation processes in which activist NGOs target their intervention at catching landscape developments that pressure regimes while moderate NGOs focus attention on developing alternatives in niches. In this chapter, we explore if activist and moderate NGOs in the case of the pork sector concentrate their activities on either the boundary landscape-regime or nicheregime level. To answer this question, we studied newspaper articles on the topic of NGOs and the pork sector in the period of 2005-2012 and question:

- Which issues were raised by activist and moderate NGOs?

- Which links of the production chain were addressed by activist and moderate NGOs?

- How did activist and moderate NGOs relate to each other in achieving animal friendly pork production in the Netherlands?

\section{Content analysis}

The contents of two sets of articles, showing the news coverage of an activist NGO and a moderate NGO in a selection of national newspapers, were analysed and compared. The next sections shortly describe the methodology. First the selection of newspapers and NGOs is explained, further data collection and analysis is explained and after that the contents of the two datasets are described and compared. 


\subsection{Selection of newspapers and NGOs}

The search machine LexisNexis (http://academic.lexisnexis.nl) has been used to discern which national newspapers, moderate NGOs and activist NGOs were most present (expressed in frequency of articles) in the public debate on animal welfare of pigs in the Netherlands. Table 1 shows the results.

\begin{tabular}{|c|c|c|c|c|c|c|c|c|c|}
\hline NGO & $\begin{array}{l}\text { Lexis } \\
\text { Nexis }\end{array}$ & $\begin{array}{l}: \frac{7}{0} \\
\overline{0} \\
\overline{0} \\
0 \\
\end{array}$ & 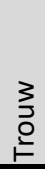 & 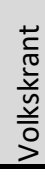 & $\frac{\mathscr{x}}{2}$ & 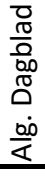 & $\begin{array}{l}\overline{8} \\
\frac{0}{\pi} \\
0 \\
\end{array}$ & 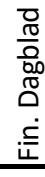 & $\begin{array}{l}\stackrel{ \pm}{ \pm} \\
\stackrel{ \pm}{0} \\
\end{array}$ \\
\hline Animal Protection Society & 202 & 75 & 30 & 29 & 12 & 8 & 7 & 9 & 32 \\
\hline Pigs in Distress & 170 & 58 & 22 & 19 & 17 & 13 & 14 & 2 & 25 \\
\hline Awake Animal & 133 & 41 & 19 & 26 & 7 & 6 & 4 & 2 & 28 \\
\hline Friends of the Earth & 125 & 31 & 17 & 19 & 9 & 4 & 4 & 7 & 34 \\
\hline
\end{tabular}

Table 1: Numbers of articles on animal welfare of pigs in Dutch national newspapers in 2005-2012, referring to specified NGOs. The highlighted cells mark the national newspapers, the NGOs and the resulting numbers of articles that were selected for further analysis.

The newspapers with the highest numbers of articles on the debate on animal welfare of pigs were Boerderij Vandaag, Trouw, Volkskrant and NRC. Boerderij Vandaag is an agricultural daily. The others are general newspapers. The agricultural daily was deliberately included in the selection, in order to cover the agricultural vision on the debate. The NGOs with the highest numbers of references in the debate were Animal Protection Society and Pigs in Distress. The Animal Protection Society ('Dierenbescherming') is known as a moderate NGO. They are inclined to improve animal welfare in cooperation with the livestock industry. Pigs in Distress ('Varkens in Nood'), Awake Animal ('Wakker Dier') and Friends of the Earth ('Milieudefensie') are known as activist NGOs. They are inclined to blame the livestock industry for animal suffering. The highlighted NGOs and newspapers in table 1 have been selected for further analysis. The highlighted cells contain 262 articles, of which 133 from the agricultural daily and 129 from the general newspapers.

\subsection{Analysis of newspaper articles}

With LexisNexis Academic the 262 articles have been retrieved and printed in full text. The reason for analysing printed articles has been to get as close as possible to the contents of the articles. Two sets of articles have emerged from the retrieval:

1. 146 articles mentioning Animal Protection Society

2. 116 articles mentioning Pigs in Distress

The overlap between the two sets of articles was small: merely 30 of the 262 articles mention both NGOs. Overlapping articles are included in the analyses of both the moderate and the activist NGO.

After printing, the contents of each article were analysed, according to the core questions of content analysis: who says what, to whom, why, to what extent and with what effect? (Lasswell, 1948). By doing so the actors (the 'who' question) and subjects (the 'what' question) have been identified. Next the reasons (the 'why' question) and targets (the 'to what extent' question) were recorded. The results were gathered in Excel files: one for the Animal Protection Society and one for Pigs in Distress. For each article, bibliographical (date, newspaper, editor, title and number of words) and content data have been recorded. When an article contained various actors and/or subjects, then actors and/or issues were summarised separately in the Excel file. On average each article resulted in three references. 


\begin{tabular}{|c|c|c|c|c|c|c|c|}
\hline \multicolumn{8}{|c|}{ Bibliographical data } \\
\hline dd & $\mathrm{mm}$ & yyyy & Newspaper & Editor & Title of article & & Words \\
\hline 30 & 11 & 2007 & NRC Handelsblad & Hans van der Lugt & End to castration harr & of piglets & 561 \\
\hline 30 & 11 & 2007 & NRC Handelsblad & Hans van der Lugt & End to castration harr & of piglets & 561 \\
\hline 30 & 11 & 2007 & NRC Handelsblad & Hans van der Lugt & End to castration harr & of piglets & 561 \\
\hline \multicolumn{8}{|c|}{ Content data } \\
\hline \multicolumn{3}{|l|}{ Actor } & Organisation & Subject & Reason & \multicolumn{2}{|l|}{ Target } \\
\hline \multicolumn{3}{|c|}{$\begin{array}{l}\text { Annechien ten Have } \\
\text { Theo Roos } \\
\text { Frank Dales }\end{array}$} & $\begin{array}{l}\text { Farmers' Union } \\
\text { Retailer Umbrella } \\
\text { Animal Prot. Society }\end{array}$ & $\begin{array}{l}\text { deal on castration } \\
\text { non-castration } 2009 \\
\text { spur Animal Prot. Soc. }\end{array}$ & $\begin{array}{l}\text { additional costs } \\
\text { more animal welfare } \\
\text { animal friendly prod. }\end{array}$ & \multicolumn{2}{|c|}{$\begin{array}{l}\text { paid by consumer } \\
\text { satisfied consumer } \\
\text { free range, groups }\end{array}$} \\
\hline
\end{tabular}

Table 2: Example of bibliographical and content data from the content analysis of newspaper articles on pig welfare.

An example is given in Table 2 (in the original spreadsheet bibliographical data and content data were placed next to each other). In this article, dated 30 November 2007, three organisations reflect on their deal with respect to castration under anaesthesia. The farmers' union, the retailer umbrella organisation and the Animal Protection Society each have their own perspective (subject, reason, target) on that deal. The subject is castration of pigs. The content data (especially the subjects) show that the Animal Protection Society struck a deal with retailers and pig farmers. The targets show that the retailers felt the pressure of the consumers and that the pig farmers tried to pass on the costs of castration to the consumers. The example shows that the Animal Protection Society addressed the retailers and the pig farmers (the 'to whom' question). The effects of the deal were progress in animal friendly production, satisfied consumers and farmers being paid for the costs of castration (the 'with what effect' question). This example shows how the core questions of content analysis come together in three references and how the references together provide a multi-actor picture of the event described.

After completing the basic work of summarising individual articles in one or more references, the animal welfare issue at hand in each reference has been identified and tagged to the reference. This has resulted in 8-10 animal welfare issues for each of the NGOs. Table 3 shows how subjects from Table 2 were clustered in animal welfare issues. The table shows a few examples of issues observed and the way in in which they were expressed in the newspaper articles.

\begin{tabular}{|c|c|c|c|}
\hline Issue & Subject expressions & Issue & Subject expressions \\
\hline Housing system & $\begin{array}{l}\text { animal friendly housing } \\
\text { creative toys for pigs } \\
\text { pigs in larger groups } \\
\text { better living conditions } \\
\text { pigs in Comfort Class stable } \\
\end{array}$ & Meat marker & $\begin{array}{l}\text { meat marker creates dilemmas } \\
\text { meat marker informs consumer } \\
\text { environmental impact of meat } \\
\text { truth behind bar codes } \\
\text { meat marker scientifically sound }\end{array}$ \\
\hline Interm. segment & $\begin{array}{l}\text { Better Life label } \\
\text { value added for consumers } \\
\text { closer relation with citizens } \\
\text { cost compensation for farmers } \\
\text { cooperation in value chain }\end{array}$ & Anaesthesia & $\begin{array}{l}\text { inspection on anaesthesia fails } \\
\mathrm{CO}_{2} \text { anaesthesia during slaughter } \\
\mathrm{CO}_{2} \text { methods unacceptable } \\
\text { stress during anaesthesia } \\
\mathrm{CO}_{2} \text { meets regulations }\end{array}$ \\
\hline Meat quality & $\begin{array}{l}\text { more attention for taste } \\
\text { good taste of Livar pigs } \\
\text { more intramuscular fat } \\
\text { increasing final pH of meat } \\
\text { consumer wants healthy food }\end{array}$ & Transportation & $\begin{array}{l}\text { abuses in animal transport } \\
\text { secret report Food Inspection } \\
\text { compliance with regulations } \\
\text { animal transport is in order } \\
\text { restrictions on animal transport }\end{array}$ \\
\hline Castration & $\begin{array}{l}\text { society against castration } \\
\text { castration under anaesthesia } \\
\text { conversion to non-castration } \\
\text { objections immunocastration } \\
\text { European ban on castration } \\
\end{array}$ & Animal suffering & $\begin{array}{l}\text { inconveniences of animals } \\
\text { images of burned animals } \\
\text { abuses in pig production } \\
\text { illegal practices on pig farms } \\
\text { suffering of circus animals }\end{array}$ \\
\hline
\end{tabular}

Table 3: Subject expressions representing the content of a selection of issues raised by NGOs 
The subjects express both what the NGOs aim(ed) to achieve as well as the problem they aim(ed) to tackle. The results of the content analysis are presented in the next sections.

\subsection{Issues of Animal Protection Society}

In this section, the issues raised in the newspaper articles mentioning the Animal Protection Society are presented. First a series of interrelated issues is presented, showing the course of the debate on housing systems. Subsequently, a series of separate issues is described. In both cases the issues are ranked according to sequence in time. Table 4 shows the interrelated issues. The core periods of the various issues (concentrations of references) are highlighted in the table.

\begin{tabular}{|l|c|c|c|c|c|c|c|c|c|}
\hline Issue & 2005 & 2006 & 2007 & 2008 & 2009 & 2010 & 2011 & 2012 & Total \\
\hline Welfare standards & 3 & 4 & 0 & 0 & 0 & 3 & 1 & 0 & 11 \\
Welfare criteria & 1 & 4 & 0 & 0 & 0 & 1 & 0 & 2 & 8 \\
\hline Housing system & 5 & 11 & 36 & 1 & 5 & 5 & 1 & 3 & 67 \\
Interm. segment & 0 & 0 & 3 & 5 & 7 & 23 & 13 & 11 & 62 \\
\hline Meat quality/taste & 0 & 1 & 2 & 0 & 0 & 2 & 3 & 7 & 15 \\
\hline Total & 9 & 20 & 41 & 6 & 12 & 34 & 18 & 23 & 163 \\
\hline
\end{tabular}

Table 4: Number of references in newspaper articles on animal welfare of pigs (interrelated issues) mentioning Animal Protection Society, classified into issues and years. The highlighted cells mark the core periods of the various issues.

In the years 2005-2012 the Animal Protection Society put much effort in the development of an animalfriendly housing system and later in the development of an intermediate animal welfare label for a segment in the market between conventional and organic pork. The process started with an exchange of trends, opinions and responsibilities with regard to welfare standards between a retail company, the Pig Farmers Union and social scientists in 2005/2006. In reaction to this diverging exchange, the Animal Protection Society together with the Pig Farmers' Union decided to define the basic needs of pigs and translate them into welfare criteria. The main work was done in 2006 by researchers of Wageningen UR.

Starting from these welfare criteria, researchers of Wageningen UR and representatives of both the Pig Farmers' Union and the Animal Protection Society (de Greef et al., 2011) designed an animal-friendly housing system (Comfort Class stable). In 2006/2007 the technical results of the Comfort Class stable received broad attention in the news, especially in the agricultural newspaper. However, the researchers and the representatives of the Pig Farmers' Union and the Animal Protection Society were reluctant to talk about the economic results. In 2009/2010 the researchers admitted that the costs were 10-15\% higher than in the conventional system. At the same time pig farmers told in newspaper articles that they needed compensation for the costs of distraction material, straw and additional labour.

The higher costs and the invisibility of animal friendly produced pork in the market were reason for the Animal Protection Society (Sligter, 2010) to develop the intermediate animal welfare label (Better Life label). The Better Life label was developed (2008/2009) and introduced (2010/2011) in close cooperation with slaughterhouses and supermarket chains. Through the introduction of the Better Life label pig farmers with animal-friendly production were able to get a price premium for their investments in animal welfare. The development of the intermediate animal welfare label was followed by requests of supermarket chains for improvement of meat quality/taste.

Apart from working on improvement of housing systems and development of market segments, the Animal Protection Society was also involved in a number of separate issues. These issues are specified in Table 5. Again, the core periods of the issues (concentrations of references) are highlighted in the table. 


\begin{tabular}{|l|c|c|c|c|c|c|c|c|c|}
\hline Issue & 2005 & 2006 & 2007 & 2008 & 2009 & 2010 & 2011 & 2012 & Total \\
\hline Castration of pigs & 1 & 8 & 7 & 3 & 7 & 4 & 0 & 0 & 30 \\
\hline High-rise pig farms & 0 & 8 & 1 & 0 & 1 & 1 & 0 & 0 & 11 \\
Mega-production & 0 & 0 & 3 & 3 & 0 & 2 & 2 & 6 & 16 \\
\hline Total & 1 & 16 & 11 & 6 & 8 & 7 & 2 & 6 & 57 \\
\hline
\end{tabular}

Table 5: Number of references in newspaper articles on animal welfare of pigs (separate issues) mentioning Animal Protection Society, classified into issues and years. The highlighted cells mark the core periods of the issues.

The Animal Protection Society rejected routine castration of male piglets and industrial production in highrise pig farms and mega-farms. In 2006 they explained to agree with castration under anaesthesia (den Blijker, 2006\%). After Pigs in Distress revealed that castration was twenty times more stressful than castration itself, the animal Protection Society stroke a deal on castration with the supermarkets and the pig farmers to stop selling meat of castrated pigs (den Blijker, 2010). In 2006 they -together with Friends of the Earth- entered protests against an 'agro-park' for pork production in the harbour of Amsterdam and explained their objections in newspaper articles (den Blijker, 2006 and den Blijker, 2006 ). In 2012 they refused to extend a Better Life star to a mega-farm with animal friendly production, because of the size of the farm (Moesker, 2012).

\subsection{Issues of Pigs in Distress}

In this section, the issues raised in the newspaper articles mentioning Pigs in Distress are presented. First the issues targeting consumers and retailers are presented and then the issues targeting the pork production chain. Table 6 shows the issues targeting consumers and retailers. The core periods of the various issues (concentrations of references) are highlighted in the table.

\begin{tabular}{|l|c|c|c|c|c|c|c|c|c|}
\hline Issue & 2005 & 2006 & 2007 & 2008 & 2009 & 2010 & 2011 & 2012 & Total \\
\hline Organic & 0 & 0 & 4 & 1 & 0 & 0 & 0 & 0 & 5 \\
Less meat & 1 & 0 & 5 & 0 & 8 & 1 & 0 & 0 & 15 \\
Meat prices & 0 & 1 & 6 & 7 & 3 & 6 & 3 & 0 & 26 \\
Meat marker & 0 & 0 & 0 & 0 & 31 & 4 & 0 & 26 & 61 \\
Interm. segment & 0 & 0 & 0 & 0 & 0 & 11 & 7 & 2 & 20 \\
\hline Total & 1 & 1 & 15 & 8 & 42 & 22 & 10 & 28 & 127 \\
\hline
\end{tabular}

Table 6: Number of references in newspaper articles on animal welfare of pigs mentioning Pigs in Distress, targeting consumers and retailers, classified into issues and years. The highlighted cells mark the core periods of the issues.

In 2007 and 2009 culinary journalists, together with Pigs in Distress, argued in favour of buying organic meat and buying less meat. They argued that animal welfare in organic production was much better than in regular production, and later that high levels of meat consumption were harmful for human health and for the environment. In addition, Pigs in Distress explained to citizens and consumers that low meat prices constrain farmers' investments in animal welfare. Subsequently the Party for the Animals asked the government to ban the import of cheap meat from abroad and to introduce standards for animal welfare in pork production. In addition, in campaigns they blamed supermarket chains for unethical behaviour by offering regular meat at record low prices, resulting in less demand for organic meat and less attention for animal welfare. Their statements were supported by experiences of pig farmers and findings of researchers and experts. Supermarket chains replied that the buying behaviour of the consumers forced them to decrease the prices. 
In the second part of the period Pigs in Distress introduced the so-called 'Meat Marker'. The 'Meat Marker' shows the consumer how different types of meat and protein products score in terms of animal welfare and environmental impact. The first version (2009) was a small card showing the scores of 18 types of meat on animal welfare and environmental impact. The second version (2012) was an app for iPhones enabling consumers to scan the barcodes of 16,000 meat products in supermarket shelves and to see the animal welfare quality and the environmental impact of these products (Lugt, 2009; Janssen, 2009; Postma, 2012; Moesker 2012). Moreover, Pigs in Distress supported the activities of the Animal Protection Society with regard to the intermediate segment in the market. They challenged supermarket chains to start selling 'Better Life meat' and thus reduce animal suffering and get a better reputation (Moesker, 2011).

Apart from challenging consumers and retailers to make a shift to animal-friendly produced meat, Pigs in Distress also denounced various abuses in the pork production chain. Table 7 shows the issues targeting pig farmers, livestock transporters and slaughterhouses. The core periods of the various issues (concentrations of references) are highlighted in the table.

\begin{tabular}{|l|c|c|c|c|c|c|c|c|c|}
\hline Issue & 2005 & 2006 & 2007 & 2008 & 2009 & 2010 & 2011 & 2012 & Total \\
\hline Housing & 0 & 1 & 6 & 1 & 1 & 0 & 0 & 1 & 10 \\
Anaesthesia & 0 & 14 & 0 & 2 & 19 & 0 & 0 & 0 & 35 \\
Transportation & 0 & 1 & 12 & 5 & 10 & 1 & 0 & 1 & 30 \\
Castration & 0 & 0 & 0 & 6 & 11 & 11 & 0 & 4 & 32 \\
\hline Animal suffering & 0 & 3 & 0 & 3 & 5 & 1 & 1 & 11 & 24 \\
\hline Total & 0 & 19 & 18 & 17 & 46 & 13 & 1 & 17 & 131 \\
\hline
\end{tabular}

Table 7: Number of references in newspaper articles on animal welfare of pigs mentioning Pigs in Distress, targeting the pork production chain, classified into issues and years. The highlighted cells mark the core periods of the issues.

The main issues (in terms of number of references) of Pigs in Distress targeting the pork production chain in 2005-2012 were anaesthesia in slaughterhouses, transportation of livestock, castration of piglets and animal suffering. They raised the issue of anaesthesia in slaughterhouses for the first time during the campaign for elections of the parliament in 2006. The issue then focused on the best method for anaesthesia $\left(\mathrm{CO}_{2}\right.$ or electric shock) and inspection by the Food Safety Authority. The debate was stirred up by researchers of Wageningen UR and representatives of the meat industry. In 2009, the issue was raised for the second time. The attention then went to animal suffering caused by $\mathrm{CO}_{2}$. Pigs in Distress showed videos with shocking scenes of anaesthesia with $\mathrm{CO}_{2}$ in slaughterhouses. The Minister of Agriculture explained in parliament that the slaughterhouses met the EU regulations.

Transportation of livestock was first raised in 2007. Focus was on violation of the regulations by transport companies. Pigs in Distress showed shocking scenes (blood on trucks) of livestock transports. Politicians asked for better inspection procedures. In 2009 the issue returned, again because of transport companies breaking the regulations. Pigs in Distress disclosed a secret report of the Food Inspection Authority on violations of transport regulations and intimidation of inspectors. Transport companies replied that most animal transports were in compliance with the regulations. Politicians again asked for better inspection procedures.

In 2008 castration of piglets became an issue for Pigs in Distress. They took out a summons against two supermarket chains in order to stop the sales of meat of castrated pigs. The retailers replied that castration was to be stopped in 2015 and that, in the meantime, castrations would take place under anaesthesia (ANP, 2008). In 2009 Pigs in Distress revealed research results showing that anaesthesia was twenty times more stressful than castration itself (den Blijker, 2009). This finding fuelled the discussion on castration. In this environment the Animal Protection Society succeeded to strike a deal (January 2010) with the supermarkets and the pig farmers to stop selling meat of castrated pigs as of January 2011 (den Blijker, 2010). 
In 2007, the national government issued a policy position on animal welfare in kept animals, including a report on discomfort issues in livestock husbandry (Leenstra, 2007). The resulting debate in parliament included criticism (and a plea for a ban) on circus animals and attention for living conditions of pets. In 2012 Pigs in Distress continued the debate on health problems of pigs (pneumonia) and measures to avoid tail biting (tail docking). A new issue was started in 2012 with the observation that animals in the meat industry are considered and treated as 'things' instead of being living creatures.

\subsection{Comparison of involvement in issues}

The previous sections showed in which issues Animal Protection Society (moderate NGO) and Pigs in Distress (activist NGO) were involved. The 'baskets of issues' of the two NGOs are shown in Table 8. The issues were classified into three links in the value chain: consumer/citizen, processing/retail and primary producers. Within each cell the issues were ranked according to the number of references in the content analysis. The overlap in issues between the two NGOs is highlighted in grey.

\begin{tabular}{|c|c|c|}
\hline $\begin{array}{l}\text { Addressees of } \\
\text { NGO activities } \\
\end{array}$ & $\begin{array}{c}\text { Animal Protection Society } \\
\text { (moderate NGO) }\end{array}$ & $\begin{array}{l}\text { Pigs in Distress } \\
\text { (activist NGO) }\end{array}$ \\
\hline Consumer/citizen & & $\begin{array}{c}\text { meat marker (61) } \\
\text { meat prices (26) } \\
\text { animal suffering (24) } \\
\text { less meat (15) } \\
\text { organic (5) }\end{array}$ \\
\hline \multirow[t]{4}{*}{ Processing/retail } & intermediate segment (62) & anaesthesia (35) \\
\hline & meat quality/taste (15) & castration of pigs (32) \\
\hline & & transportation (30) \\
\hline & & intermediate segment (20) \\
\hline \multirow[t]{6}{*}{ Primary producer } & housing system (67) & \multirow[t]{6}{*}{ housing system (10) } \\
\hline & castration of pigs (30) & \\
\hline & mega-production (16) & \\
\hline & high-rise pig farms (11) & \\
\hline & welfare standards (11) & \\
\hline & welfare criteria (8) & \\
\hline
\end{tabular}

Table 8: Comparison of involvement of moderate NGO and activist NGO in issues on welfare of pigs described in national newspapers in 2005-2012. The highlighted cells mark the overlap in issues between the two NGOs.

There is little overlap in the issues on welfare of pigs raised by the moderate and the activist NGO. The 'baskets of issues' only had 'housing system', 'castration of pigs' and 'intermediate segment' in common. The moderate Animal Protection Society had the lead in developing an alternative housing system and intermediate segment and Pigs in Distress joined them in these issues. The activist Pigs in Distress had the lead in putting the castration of pigs on the public agenda (with a focus on retailers), after which the Animal Protection Society struck a deal on this issue with retailers and primary producers.

Also, the overlap in parties addressed by the moderate and the activist NGOs was small. The moderate Animal Protection Society was mainly involved in issues targeting primary producers (e.g. housing system) and processing/retail (e.g. intermediate segment). The activist Pigs in Distress was mainly involved in issues targeting consumers/citizens (e.g. meat marker and meat prices) and processing/retail (e.g. anaesthesia and transportation). This means that the two NGOs focused on different levels in the value chain.

Furthermore, the overlap in approach of the moderate and the activist NGOs was small. The moderate Animal Protection Society mostly tried to create feasible solutions (e.g. housing system, intermediate 
segment). The activist Pigs in Distress were more inclined to denounce existing behaviours or practices in the value chain (e.g. anaesthesia, transportation, castration and low meat prices) and promote the reduction of meat consumption. An exception to this rule was the introduction of the meat marker. With this tool, Pigs in Distress tried to create a solution for the dark side effects (animal suffering and environmental impact) of meat consumption. This picture confirms the 'dolphin' character of the moderate Animal Protection Society and the 'shark' character of the activist Pigs in Distress.

The differences raise the question whether the activist NGO and the moderate NGO were antagonists or complemented each other's role. The content analysis revealed examples and evidence that the differences in issues, target groups and approach worked out well. One example was mentioned in the description of the debate on castration of pigs (under Table 5 and Table 7). The Animal Protection Society struck a deal with the retailers, after Pigs in Distress had fuelled the debate with inflammable information. The honour for the deal went to the Animal Protection Society, but Den Blijker (2010) explained that Pigs in Distress had dictated the agenda of the meat industry and the supermarkets in the years before.

In two newspaper articles, journalists confirmed the existence and need for combined action between activist NGOs and moderate NGOs. In the newspaper article of Lubbers (2009) a communication expert explained that each sector needs a 'bad guy' and a 'good guy'. The 'bad guy' applies an aggressive approach and puts abuses on the public agenda. The 'good guy' applies the dialogue model and takes care that arrangements are made. They get ahead by complementing each other. In the newspaper article of Lindhout (2010) a sociologist explained that activist NGOs and moderate NGOs urgently need each other. The small and versatile activist NGOs are effective in creating urgencies (stigmatising companies). The bigger and slower moderate NGOs are better in negotiating and striking deals with companies. In fact, they complement each other because of their differences in approach and competences.

\section{Reflection}

In this section the findings on the complementary roles of activist and moderate NGOs are (1) combined in a flow chart of activities leading to system innovation, and (2) positioned in the multi-level perspective.

\subsection{Flow chart of innovation process}

The findings on the succession of issues and complementary roles of activist and moderate NGOs gave rise to the idea that an innovation process can be depicted as a flow chart of phases and parties involved. Figure 2 is the result of our effort to compose this flowchart.

The flow chart starts with normative pressure (red arrow, bottom right) created by activist NGOs publishing confronting reports (e.g. on anaesthesia slaughterhouses or transportation of livestock) or observing disappointing trends (e.g. record low prices for regular meat or economic constraints of farmers). This normative pressure is pumped into the heart of the triangle, where the moderate NGOs have a central position between knowledge partners, primary producers and value chain partners. The moderate NGOs consult knowledge partners (researchers and pioneers) to develop technological and regulatory solutions (e.g. Comfort Class stable) for animal welfare problems. The results are discussed with NGO representatives and demonstrated to primary producers.

The normative pressure generated by the activist NGOs (through the heart of the triangle) moves on to the primary producers and (via consumer behaviour) to retail companies and their suppliers. The activity of the various partners is coordinated through the gear wheels of a process in which the most relevant partners are involved. This coordination process includes negotiations and striking deals. Such deals (e.g. between Animal Protection Society, retail companies and Pig Farmers' Union) result in new production systems and market segments, enabling (1) primary producers to sell animal friendly produced pigs, (2) retail companies 
and slaughterhouses to purchase animal friendly produced pigs, and (3) consumers to buy animal friendly produced pork in the supermarket.

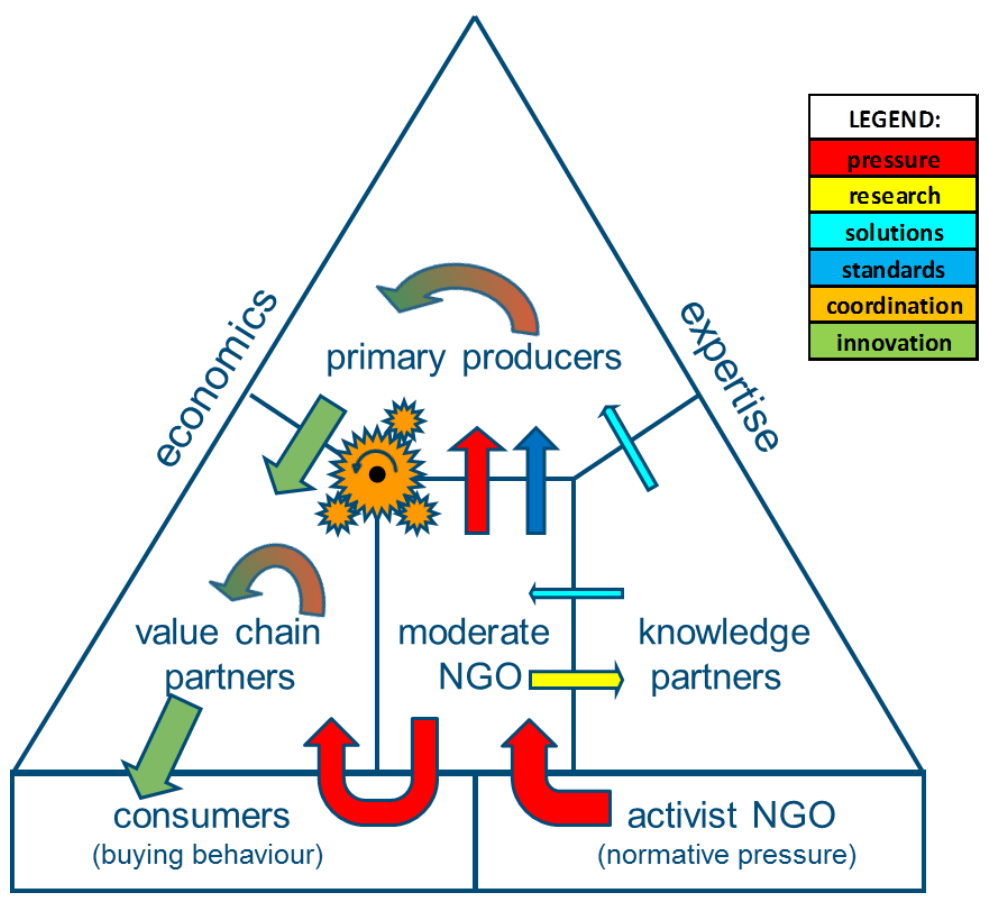

trends and incidents

Figure 2: Flow chart of system innovation towards sustainable agriculture

The flow chart shows the sequence of actors and activities involved in a system innovation such as the shift from low-cost production/marketing of pork to animal-friendly production/marketing of pork. This sequence is used for the reflection on the role of activist and moderate NGOs in the multi-level perspective.

\subsection{Positions in multi-level perspective}

Positioning the issues raised in the media by the activist and moderate NGO in the multi-level perspective, it shows that the activist NGO indeed operated on the boundary between landscape and regime level. The activist NGO was aware of the aversion of citizens and consumers against animal suffering in the meat industry. They started actions and campaigns with media-relevant information about trends and incidents (campaigning against anaesthesia methods in slaughterhouses or abuses in livestock transportation). In fact, the campaigns of the activist NGO revealed violations of existing laws. Apart from societal arousal, they triggered government agencies and politicians to take action against the abuses

Furthermore, we see that the activist NGO also operated at the niche level, e.g. the launch of the meat marker to inform the consumer about animal welfare and environmental impacts of various types of meat. The meat marker aimed at raising consumer awareness of morally relevant differences in meat or protein products. The marker intended to pull the consumer away from conventional pork and beef to organic meat and vegetarian alternatives. It also challenged retail companies to profile themselves with organic and vegetarian products. So, the activist NGO aimed at the pork regime from both catching landscape trends and working at niche level.

The moderate NGO operated on the boundary between the niche and the regime level in a different way than the activist NGO. The moderate NGO picked up the social unrest caused by publications and 
campaigns of activist NGOs. At the niche level, the moderate NGO developed an animal-friendly housing system (Comfort Class husbandry) and introduced their Better Life label to support an intermediate segment in the market. In addition, they sought strategic cooperation with the farmers' organisation. These initiatives stimulated pork producers to produce above legal minimum standards for animal welfare, acquire Better Life stars from the Animal Protection Society and get access to the intermediate segment in the market. They enabled retail companies to profile themselves by making the conversion to Better Life meat products.

When looking at the relation between activist and moderate NGOs we see that the activist NGO focused on making citizens and consumers aware of inconvenient truths in the pork production chain thereby increasing normative pressure on the pork regime. The activist NGO left it to regime-actors to solve the problem of occurrence of abuses and also paved the way for a moderate NGO to develop partnerships with actors of the pork regime to acquire support for animal-friendly pilots at farm level. The moderate NGO acted more constructively and participated in negotiations. Together they were successful in achieving changes at the regime level probably due to the pressure on the regime that was strengthened by the activist NGO. There were two main related changes at the regime level. First, the Comfort Class approach turned the producers' view on animal welfare from 'a set of conditions imposed by the government' to 'an ambition related to farmers' values but with economic hindrances' (De Greef et al., 2011). Secondly, the Better Life label became a new market arrangement that structurally changed the pig sector. Through this label one million pigs per year have improved husbandry conditions by technical facilities around the end of this study's window of attention (2010-2012).

So, although the activities undertaken and issues raised by the two NGOs differed, they supported each other in achieving changes at the regime level (i.e. a more animal friendly pork sector). Their differences in approaches and competences seem to have made it possible to achieve such change. The activist NGO focused on raising normative pressure without having to reconcile with regime players. The moderate NGO, focusing on less threatening issues, was able to keep good relationships with the pork sector. This perspective adds to current knowledge that a variety of issues does not necessarily weaken normative pressure on the regime (Elzen et al., 2011) but might make it possible for moderate NGOs to engage with regime players in order to work on possible solutions if the activities of activist and moderate NGOs complement each other.

\section{Conclusions}

The challenge of this study has been to better understand the roles of activist and moderate NGOs in system innovation processes. Our analysis shows that the moderate and the activist NGOs focused their attention on quite different issues in the newspaper articles on animal welfare in pork production and targeted different groups. The moderate Animal Protection Society focused on developing better housing systems and an intermediate market segment for animal-friendly pork. Furthermore, they rejected routine castration of piglets and the industrial production of pork in mega-farms. The activist Pigs in Distress predominantly focused on stimulating consumers to buy less meat. Simultaneously, they took action against record low meat prices and the related animal suffering in the meat industry. Furthermore, they introduced the so-called meat marker to show the consumer which types of meat are better for animal welfare and the environment.

In addition, the moderate and the activist NGOs both addressed different links in the pork production chain. The Animal Protection Society addressed primary producers, retailers and slaughterhouses. In collaboration with researchers and the pig farmers union they developed the Comfort Class approach. In collaboration with retailers and slaughterhouses they developed the Better Life label for animal-friendly pork. The activist Pigs in Distress, on the other hand, focused on citizens/consumers, livestock transporters and slaughterhouses. They pushed citizens/consumers in the direction of buying less meat and campaigned against record low meat prices. They denounced inadequate anaesthesia in slaughterhouses, long-lasting transportation of livestock and the stressful castration of male piglets. 
The work of the activist NGO supported the moderate NGO. The activist Pigs in Distress focused on making citizens and consumers aware of inconvenient truths in the pork production chain. They thus paved the way for the Better Life label of the moderate Animal Protection Society. Consequently, the activities of the two NGOs complemented each other. The activist NGO created a demand for better animal welfare. The moderate NGO (together with pig farmers and value chain partners) co-created a supply of animal-friendly pork. The resulting situation was a substantial second pork chain with improved animal welfare.

Positioning the case in the multilevel perspective we conclude that moderate NGOs focused their attention to the niche and the regime whereas activist NGOs operated mainly on the boundary between the landscape and the regime. The activist NGOs used the aversion of citizens and consumers against the suffering of pigs. They started actions and campaigns against the current regime when they got wind of trends and incidents. The moderate Animal Protection Society operated on the boundary between the niche and the regime level. By focusing on different levels, raising different issues and addressing different actors in the pork production chain, they managed achieving changes in the regime.

This study reveals the relevance of catching trends and incidents at the landscape level, to strengthen pressure on the regime, in addition to multi-actor arrangements at niche and regime level. Occurrence of trends and incidents and activist NGOs stressing these trends and incidents, create urgency for change and consumer awareness. The activities of activist NGOs are thus relevant for innovation because their claim of voicing the feelings of the general public affects market partners to take responsibility, creating room for partnerships with moderate NGOs. So, better listening to activist NGOs could enable researchers and policymakers to better attune the introduction of (technological) innovations to windows of opportunity. The collaborative activities of activist and moderate NGOs represent a form of social intelligence with their capacities for trend catching, development of novelties and never wasting a good crisis.

Acknowledgement: The work presented in this chapter has been sponsored by the Complex Adaptive Systems (CAS) programme of Wageningen University and Research Centre (Wageningen UR, 2014).

\section{References}

ANP Netherlands National News Agency (2008) Varkens in Nood daagt supermarkten, Amsterdam, Volkskrant, 6 Oktober 2008, Binnenland, page 5

Bitzer, V. and P. Glasbergen (2015) Business-NGO partnerships in global value chains: part of the solution or part of the problem of sustainable change? Current Opinion in Environmental Sustainability 12, $35-40$

Blijker, J. den (2006) Varkens zijn straks beter af in een flat dan nu op de boerderij. Amsterdam, Trouw, 8 November 2006. Vandaag, pages 2-3

Blijker, J. den (2006) Dierenbescherming denkt mee, maar varkensflat gaat toch echt te ver. Amsterdam, Trouw, 11 November 2006, Economie, pages 14-15

Blijker, J. den $\left(2006^{c}\right)$ Verdoving is beter voor de big, maar duurder voor de boer. Amsterdam, Trouw, 11 December 2006, Economie, page 8

Blijker, J. den (2009) $\mathrm{CO}_{2}$-verdoving bij biggencastratie omstreden, Amsterdam, Trouw, 19 May 2009, Economie, page 12-13

Blijker, J. den (2010) Varkens in Nood links ingehaald. Amsterdam, Trouw, 16 January 2010, Economie

Elzen, B., F.W. Geels, C. Leeuwis and B. van Mierlo (2011) Normative contestation in transitions 'in the making': Animal welfare concerns and system innovation in pig husbandry, Research Policy 40: 263-275

Geels, F.W. (2002) Technological transitions as evolutionary reconfiguration processes: A multi-level perspective and a case-study, Research Policy 31: 1257-74

Geels, F.W. and J. Schot (2007) Typology of sociotechnical transition pathways, Research Policy, Vol. 36, No. 3, pp.399-417.

Greef, K.H. de, H.M. Vermeer, H.W.J. Houwers and A.P. Bos (2011) Proof of principle of the Comfort Class concept in pigs. Experimenting in the midst of a stakeholder process on pig welfare, Livestock Science 139: 172-85 
Harangozó, G. and G. Zilahy (2015) Cooperation between business and non-governmental organizations to promote sustainable development. Journal of Cleaner Production 89, 18-31.

Janssen, C. (2009) Varkens in Nood en Milieudefensie maken vleeswijzer. Amsterdam, Volkskrant, 27 October 2009, Binnenland, page 3

Lasswell, H.D. (1948) Power and Personality. New York, W.W. Norton and Company

Leenstra, F.R., E.K. Visser, M.A.W. Ruis, K.H. de Greef, A.P. Bos, I.D.E. Dixhoorn and H. Hopster (2007) Discomfort among cattle, pigs, poultry, mink and horses. Inventory and prioritisation and possible solution strategies. Lelystad, Animal Science Group. Report 72

Lindhout, S. (2010) Wakker dier knalt de kilo's eruit. Amsterdam, Volkskrant, 12 August 2010, Binnenland, page 10

Lubbers, K. (2009) Actiegroepen moeten meer samenspannen. Amsterdam, Boerderij Vandaag, 13 June 2009, Agd. Extra, page 14

Lugt, H. van der (2009) Milieugroepen willen met vleeswijzer eetgedrag beïnvloeden. Amsterdam, NRC Handelsblad, 27 October 2009, Economie, page 12

Moesker, S. (2011) Brede aandacht voor duurzaamheid schept kansen in varkenshouderij. Amsterdam, Boerderij vandaag, 28 april 201, Actueel Achtergrond, page 11

Moesker, S. (2012) App voor inzicht in milieu en welzijnsaspecten. Amsterdam, Boerderij Vandaag, 8 May 2012, Intensieve Veehouderij, page 9

Moesker, S. (2012) Wakker Dier voert een hetze. Amsterdam, Boerderij Vandaag, 5 October 2012, Intensieve veehouderij, page 9

Postma, R. (2012) De waarheid achter de streepjescode. Amsterdam, NRC Handelsblad, 11 May 2012, Economie, page 2

Sligter, A. (2010) Kleine stapjes op weg naar een beter varkensleven. Amsterdam, Volkskrant, 12 June 2010, Economie, page 8

SustainAbility (1996) Strange attractor: The Business-ENGO partnership: Strategic review of BP relationships with environmental non-governmental organisations (ENGOs). London: BPSustainAbility

Veerman, C.P. (2003) Toekomst van de intensieve veehouderij. The Hague, Ministry of Agriculture, Nature Management and Fisheries. Letter to Parliament, nr 28973, 20 June 2003

Vullings, J. (2009) Het spagaat tussen actie en overleg. Amsterdam, Boerderij Vandaag, 13 June 2009, Agd.Extra, page 14

Wageningen UR (2014) website on Complex Adaptive Systems programme: http://www.wageningenur.nl/en/About-Wageningen-UR/Strategic-plan/CAS.htm 


\title{
Sustainable Practices, Sustainable Markets? Institutional innovations in agri-food systems
}

\author{
Allison Loconto, ${ }^{1}$ Anne Sophie Poisot $^{2}$ and Pilar \\ Santacoloma ${ }^{3}$
}

\section{Abstract}

This chapter investigates how sustainable practices interact and co-evolve with sustainable marketing initiatives. The research is based on an international survey of fifteen case studies of institutional innovations in linking sustainable agricultural practices with markets. We explore how farmers and organisations are moving toward more sustainable practices through the collective mobilisation of participants, technologies, resources, and capacity building. Each of the cases illustrates a unique approach to creating linkages to markets, such as the use of international standards, direct and institutional marketing techniques, and culinary education. We find trends in the linkages between the socio-technical controversies that spurred the innovation and the form of the institutional innovation. Initial results point to the importance of charismatic leadership, constructing a common vision for sustainable agriculture, and building collective commitments among actors, as is common in social movements. While the focus of many market arrangements is on building local networks, we find the influence of international value chains in each case. This suggests that both community and international dynamics influence the development of institutional innovations in developing countries.

Keywords: sustainability, markets, standard, multi-stakeholder, institutional innovation, agri-food system

\section{Introduction}

There is growing public consensus that agricultural production systems must develop within a model of sustainable intensification (Conway, 2012; FAO, 2011). However, how to intensify sustainably remains open to debate and there remain concerns about the feasibility of some proposed solutions to also meet societal grand challenges such as 'food security for all' (cf. Elzen et al., 2011; Garnett et al., 2013; Levin et al., 2012). For this reason, the sustainable intensification of agriculture provides a political space for making iterative improvements, or incremental innovations, to current agri-food systems (Busch, 2012; Grin et al., 2010).

Traditionally, agri-food system innovation has focused on developing and advocating the adoption and diffusion of productivity-enhancing technology, underpinned by improved research and development, but without much attention paid to system components beyond the technology (Lyson \& Welsh, 1993). Advances in theories of innovation and socio-technical change recognise the importance of institutions (including markets) and techno-economic networks in the adoption and diffusion of innovation (Callon, 1991; Grin, Rotmans, \& Schot, 2010; Smith, Stirling, \& Berkhout, 2005). Studies of grassroots and social innovations are beginning to illustrate the importance of organisational and spatial arrangements, identities, collective mobilisations, knowledge and practices in innovation (Moulaert, 2013; Smith \& Seyfang, 2013). If

\footnotetext{
${ }^{1}$ National Institute for Agricultural Research (INRA), Champs-sur-Marne, France; Institute for Research, Innovation and Society (IFRIS); Food and Agriculture Organization of the United Nations (FAO). Email: amloconto@versailles.inra.fr 2 Food and Agriculture Organisation of the United Nations (FAO), Rome, Italy. Email: annesophie.poisot@fao.org 3 Food and Agriculture Organisation of the United Nations (FAO), Rome, Italy. Email: pilar.santacoloma@fao.org
} 
we take this broader view of agri-food system innovation, we find evidence of smallholders who are able to link with other food system actors to innovate beyond technology, to become organized for accessing new market opportunities, to expand into processing activities and to increase their power in market negotiations (HLPE, 2012). Put simply, innovations for sustainable agriculture are necessarily both technological and institutional (Struik, Klerkx, van Huis, \& Röling, 2014).

Multi-stakeholder sustainability standards and their accompanying systems of certification have been referred to as: "one of the most innovative and startling institutional designs of the past 50 years" (Cashore, Auld, \& Newsom, 2004, p. 4). Often emerging from alternative agri-food networks (Allen, Fitz Simmons, Goodman, \& Warner, 2003; Bowen \& Mutersbaugh, 2014; Goodman, 2004; Goodman, DuPuis, \& Goodman, 2012), sustainability standards have become increasingly institutionalised through growing collaboration and recognition among a variety of actors and existing institutions (Loconto \& Fouilleux, 2014). Recent experimentation in these systems push the boundaries of the traditional roles of institutional and market intermediaries who are taking on a wider range of roles in linking farmers with markets for their produce (cf. Vorley, 2013). These intermediaries are part of local infrastructural and institutional environments and include a range of organisations that provide support to producers to learn sustainable techniques and market sustainably produced products and services. For example, within organic agriculture systems, an emerging approach is the participatory guarantee system (PGS), whereby the oversight systems are created by producers, researchers and consumers who collectively ensure that the sustainable practices are adopted (FAO, 2013; IFOAM, 2008). In other contexts, well-established farmer-supported marketing cooperatives are taking on new roles in supporting the adoption of more sustainable practices and technologies. We also see instances where public research and extension organisations are beginning to incorporate marketing aspects in the farmer field school (FFS) methodology and private traders are also beginning to invest upstream in their value chains to provide infrastructural and organisational support for small-scale producers. This study focuses on these types of innovations by asking: How do institutional innovations in sustainable agriculture occur?

This chapter attempts to provide an answer to this question based on an international survey of fifteen case studies of institutional innovations that link sustainable agricultural practices with markets. We define institutional innovations as novel changes in the arrangements among actors (including organizations), schemas, norms, regulations and material objects (including technologies). In this chapter, we are focusing specifically on innovations in the commercialisation of sustainably farmed products. We find that farmers and organisations are moving toward more sustainable practices through the collective mobilisation of technologies, resources, and capacity building. Each of the cases illustrates a unique approach to creating linkages to markets, such as the use of international standards, farm stalls, traditional markets, school canteens, and cooking schools among other techniques. We find trends in the linkages between the sociotechnical controversies that spurred the innovation and the form of the institutional innovation. Initial results point to the importance of charismatic leadership and a common vision for sustainable agriculture, as is common in social movements, but also to the building of collective commitments among other actors. While the focus of most market arrangements is on building local networks, we find the influence of international value chains in each case. This suggests that both community and international dynamics influence the development of institutional innovations.

This chapter proceeds as follows. We describe the conceptual framework based on the collective action model of institutional innovation (Hargrave \& Van De Ven, 2006) that provides an analytical approach to the tensions identified in studies of alternative agri-food networks and socio-technical change. We then present the case study method. The cases are then analysed according to the framing contests, the construction of the networks, the enactment of institutional arrangements, and the collective action processes, which are core processes in institutional innovations. Conclusions are drawn about how sustainable practices are being linked to markets in developing countries in innovative ways. 


\section{Institutional Innovations and sustainable agri-food systems}

In order to understand institutional innovations, it is important to establish why institutions are important for both constraining and facilitating transitions to sustainable agri-food systems. Generally, we follow North's (1991) definition of institutions as "humanly devised constraints that structure political, economic and social interactions" (p. 97). However, much has been written on institutions, particularly in theories of social movements and technology innovation management (see: Van de Ven \& Hargrave, 2004), that qualifies this generic definition with a more pliable version where an institution is an arrangement that consists of actors, schemas, norms, regulations and material objects that enable action for individuals and organisations. Cleaver (2002) argues that institutional contexts are better understood as 'bricolage', which is a multiplicity of formal and informal institutions (conventions) that sometimes conflict or converge depending on the context. In this sense, institutions can be seen as outcomes of agreements and concerted action that arise from interaction among the actors who can make a difference (Röling et al., 2012, p. 3).

Röling et al. (2012) suggest that the challenge is "to empirically study and analyse the scope for change" in institutions (p. 4). This is particularly important, Röling and colleagues argue, because of the "complex, messy, multi-level situations and relational configurations in which actors with diverse interests interact" in the context of smallholder innovation in developing countries. Classical and new institutional theory typically explain institutional change as a linear, evolutionary trajectory either toward a robust state or toward its imminent collapse (Cleaver, 2002). Yet, envisioning institutional change and innovation as a multidimensional, relational and dialectical process, including more actors than the state alone, provides a number of different possible entry points and trajectories for 'purposeful change' where learning, adaptation and experimentation are possible (Jiggins, 2012).

Van de Ven and Hargrave (Hargrave \& Van De Ven, 2006; Van de Ven \& Hargrave, 2004) and Geels and colleagues (Frank W. Geels, 2002; Frank W Geels, 2010; Grin et al., 2010; Schot \& Geels, 2008) focus on interpretations of Gidden's (1984) structuration theory as a way to enable an analysis of institutional change/innovation as contextually and historically contingent processes. Through the refinement of a multilevel perspective (MLP) heuristic, socio-technical systems are characterised by co-evolving relationships between actors and resources (e.g., supply and demand for innovations) and rules that co-ordinate their activities (Frank W. Geels, 2004). Diversity is considered to be present in these systems and resides in niches that offer alternatives and possible solutions to crises in the existing socio-technical regimes, which are comprised of rules, routines, and technological artefacts, and are influenced by landscape level pressures. One such pressure is the need for sustainable solutions to agricultural problems.

Within agri-food systems, scholars have focused on the emergence of novelties as 'seeds of transitions' (Wiskerke \& Van der Ploeg, 2004). That is, those ideas that modify or break with existing norms of the dominant agricultural socio-technical system. These can be focused on aspects of situated research activities, field practices or market organisation in situations of change that are governed by sustainable goals (Barbier, 2008). In all respects they are attempts to realign network actors towards existing public or private norms. Brunori et al. (2011) argue that alternative agri-food networks (AAFNs) are examples of niches, as they have stabilised beyond novelties through the creation of organizing visions and alternative techno-economic networks of food production, consumption and distribution. These are contingent relational activities where actors within AAFNs are interdependent on social actors within and outside the niche they are carving (Lamine, 2011). Some AAFNs, such as organic and fair trade, have adopted standards as a fundamental technology around which they organise diverse actors in a common vision of sustainability. 
The assumption is that socio-technical change is a long process, not manifesting before $20-25$ years. In the study of transitions there is thus a need for a methodology that can capture 'transitions in the making' (Elzen, Geels, Leeuwis, \& van Mierlo, 2011). That is the controversy, negotiations and path forging and breaking that necessarily occurs when transitioning between novelties, niches, regimes and even landscapes; particularly when considering multi-stakeholder issues like sustainability where transitions are instigated by regime outsiders as a way to influence normative orientations. Some scholars have argued that this can be found by rethinking transitions as realignments in networks following the tradition of actornetwork theory (Genus \& Coles, 2008). By focusing on the actors and strategic realignments, institutional innovation can be seen as a process of designing and re-designing the problem conceptualisation and the mechanisms to mobilise and guide collective action.

It is from the perspective of collective action that we find the analytical framework that we adopt in this chapter. In their review of the social movements, innovation systems and socio-technical change literature, Van de Ven and Hargrave (2004) identified four models of institutional change: institutional design, institutional adaptation, institutional diffusion and collective action. Each of these forms of change focuses on a different generative mechanism to explain change and can be seen as a progression over time of how academics have advanced our thinking about social change. Based primarily in the social movements literature, the collective action model is proposed as a way to understand how new institutions - or institutional innovations - emerge and develop through the political behaviours of multiple actors (Hargrave \& Van De Ven, 2006). These actors play different roles in an organisational field or network that emerges to support the development of a social movement or a technical innovation. The actors are characterised as being 'distributed, partisan and embedded' in both technological and institutional trajectories (Garud, Jain, \& Kumaraswamy, 2002). In other words, different actors play key roles and no one actor controls any pathway (distributed), actors participate based on their own interests and solutions emerge through partisan mutual adjustment (partisan) and actors become dependent on the paths they create and they learn as the process unfolds (embedded).

Hargrave and Van de Ven's (2006) approach takes 'problem formation' as an entry point for analysis, and examines how actors engage four dynamics of institutional change: 1) framing contests, 2) construction of networks, 3) enactment of institutional arrangements and 4) collective action processes. The framing contests initiated in the first dynamic are carried through the others in order to mobilize actors and inspire frame transformations, which are necessary for system-wide innovation). While this approach recognises the power and interests of a variety of actors (institutional entrepreneurs and other stakeholders), Hargrave and Van de Ven (2006) insist that we cannot eliminate the limiting factors that existing institutions play in institutional change, particularly in terms of the form and pace of change (i.e., path dependency). Nonetheless, analysing institutional innovations according these four dynamic processes will provide us with an account of how institutional innovations in sustainable agriculture emerged from interactions among interdependent partisan agents. From the analysis of the fifteen different cases of innovations that focus on changing not only the technologies of production, but also the institutions and networks that bring products to markets, we can begin to draw conclusions about the diversity of possibilities for transitioning to sustainable intensification.

\section{Methods}

Producing more with less by increasing efficiency and improving ecosystem services is the core concept of the Food and Agriculture Organization of the United Nation's (FAO) new paradigm for sustainable intensification, synthesised in the book "Save and Grow" (FAO, 2011). FAO's new paradigm is built upon lessons learned from the Green Revolution, taking into account its benefits and drawbacks. In 2013-2014 FAO conducted a survey of institutional innovations in order to recognise trends and the potential for markets in developing countries to contribute to the adoption of sustainable practices. Following a case study method of qualitative research (Maxwell, 2005), the authors launched a call for case study proposals on institutional innovations that link sustainable practices with markets for sustainable products. Proposals were evaluated according to the following selection criteria: 
- Relevance of the case to the request for proposals (describing an existing initiative, including sustainable practices, and including a link between sustainable practices and markets)

- Quality of the proposal

- $\quad$ Time that the innovative approach has been in use (more than two years)

- Author's institutional affiliation, with preference given to those directly linked to the implementers of the innovative approach

We received 87 proposals, of which 42 were considered relevant for the study. We then evaluated these based on 10 criteria that ranged from geographical priority to quality and innovativeness. This allowed us to prioritize those studies written by the innovators themselves, those that have been in successful operation for more than five years - which provided data for looking at the institutionalization process, and exciting new approaches.

Fifteen detailed case studies were finally selected from innovative approaches (public, private and/or civil society) designed to link sustainable agriculture practices with markets for sustainable products in developing countries. We sought geographic balance in our selection and in the end we arrived at four cases from Latin America and the Caribbean (Bolivia, Colombia, Ecuador, Trinidad and Tobago), six cases from Africa (Bénin, Namibia, Nigeria, Uganda (2), Tanzania), and five cases from Asia and the Pacific (India, Indonesia, Iran, Philippines, Thailand). The authors were primarily the implementing organisations (10), southern researchers with implementing partners (4), an implementing donor organisation (1) and a northern researcher with the implementing organisation (1).

Since the focus of the study is on understanding how institutions are changing in order to facilitate the linkages between sustainable agricultural practices and markets for their products, we categorised the cases according to the sustainable practices and the institutional innovations for linking farmers to markets. The cases span a variety of sustainable agriculture technologies, specifically: organic agriculture (10), integrated pest management (IPM, 2), and integrated production systems (IPS, 3). The bias towards organic agriculture in our case studies is a selection bias that comes from the distribution of the call for case studies, which was distributed through the organised organic networks as well as the sustainability standards and academic networks. ${ }^{1}$ However, the percentage of studies focusing on organic (69\%) reflects the distribution of sustainable agriculture practices found in the first round of submissions (46\%) and the short-list $(62 \%)$ of selected case studies. Nonetheless, we do recognise that certified organic represents only $0.87 \%$ of total agricultural land (Willer \& Lernoud, 2014) and thus is still very much a niche in the agricultural landscape. The institutional innovations examined in the study include participatory guarantee systems (PGS, 5), multi-stakeholder innovation platforms (IP, 6), and embedded networks (EN, 3).

The case development process was iterative where the authors developed a structured outline with guiding analytical questions for the case studies. The first drafts received detailed comments by the authors and follow-up consisted of either field visits (for eight of the cases), where the first author conducted interviews with the case study authors and the other institutional actors who were identified in each case, or by video conference with the authors. In the seven cases where field visits were not possible, local peer reviewers who were knowledgeable about the case and its context were identified to review the cases.

\section{$4 \quad$ Sustainable practices and markets}

In this section, we present the analysis of our 15 case studies according to the four processes of institutional innovation: 1) framing contests, 2) construction of networks, 3) enactment of institutional arrangements and 4) collective action processes. We draw upon insights from actor-network theory, as it is developed within the sociology of innovation, to explain how these processes work. This analysis enables us

\footnotetext{
${ }^{1}$ We announced the call through the following listservs: FAO departmental lists, ISEAL IMPACTS, IFOAM (PGS list), INRA (UMR-SADAPT, UR-SenS), CIRAD, EGFAR, Altersyal, Rural Finance Learning Centre, ISA RC40 (Research Committee on Agriculture), Food for the Cities, Prodarnet network, FFS Global Review, E-forum 2, POET Com, East Africa Organic Movement Organizations.
} 
to draw out the common elements of the institutional innovation process across the diversity of our cases. Annex 1 presents a summary table with the coding of each of the cases.

\subsection{Sustainable Practices and Markets: framing contests}

Framing processes call attention to the creation and manipulation of the meanings and issues at stake in the innovation process, as well as how a technology or a set of sustainable agriculture technologies is positioned within the dominant socio-technical regime. Frames have a role in both internal identity building and, externally, in establishing a world view that marks the innovation as a solution to an identified problem and something different from conventional approaches. Internally, frames make events and practices meaningful for the actors (Benford \& Snow, 2000), but they necessarily draw upon discourses and repertoires already circulating in society in order to establish themselves as different and innovative (cf. Swidler, 1995; Tarrow, 1993). According to the sociology of innovation, the framing of a controversial situation is an attempt by the actors to identify a problem and make it calculable (Callon, 1998). Actors do this by limiting the number of overflows (i.e., what the frame fails to explain) and can focus on not only proposed solutions to problems, but also to the means used to reach desired ends (Rukanova, Henriksen, Raesfeld, Stijn, \& Tan, 2007). In our cases, we identify a number of frames that are used to establish innovators as different from the conventional regime - thus solutions to the problems of unsustainable agriculture - and frames that are used to establish the means to achieve their desired ends.

In our cases we can distinguish between definitional framing (DF), which establishes the core identity for the actors, the objective (O) of the innovation, the solution (S) to the problem and the mechanism (M) through which to achieve it. We have identified four core ways of framing sustainable intensification as a solution: organic, commodity sustainability, community IPM and moral economy. We find that in the ten cases that use organic agriculture as their definitional frame there are contestations over what this means and the actors engage actively in definitional framing. We can divide our cases geographically and we find that the Latin American cases insist on a notion of agro-ecology, which includes a concept of food sovereignty and the promotion of a local economy. In the Bolivian case, it is defined as having the following dimensions: " 1 ) technological or productive, 2) social/cultural, 3) environmental, 4) economic and 5) political". In contrast, organic is used to refer to a weaker form of agro-ecology that is focused on the export markets and international organic standards. These debates were also present in Africa and Asia but these innovators did not mind identifying themselves as organic as opposed to agro-ecological. In the case of India, this is because the national "standards for organic production are geared towards specificities in India e.g. use of Ayurveda and Unani medicine systems in agriculture." Nonetheless, in these cases we found that the actors were not focused only on local markets but were also integrated into export-oriented value chains.

The three cases of commodity sustainability focused on creating cohesion within a specific sub-sector of the agricultural landscape: cocoa in Indonesia, tea in Tanzania, and agro-forestry in Trinidad. The justifications for these framings draw upon sectoral development and are attempts to shift the entire industry towards the innovative approach. There are also two additional definitional frames found in the cases. In Thailand, the Dharma Temple Garden frames its response to unsustainable agriculture in terms of the construction of a moral economy founded in Buddhist principles. In Iran actors are connected around the promotion of a specific agricultural technology - integrated pest management - which helps them to create a group identity based on shared experiences with the FFS methodology.

These definitional frames are accompanied by objectives or goals for a transition to a sustainable future. We can characterise these frames in terms of how actors explained the goals of their activities. The most prominent theme relates to health and safety, specifically in terms of safe food, consumer health and nutrition, and producer/worker health and safety. In India and Iran, there are nation-wide concerns over the excessive use of pesticides in conventional agriculture. Therefore the concept of 'safe food' carries a lot of traction with consumers who are looking for food that poses minimal risks to their health. In Bolivia, Ecuador and Uganda safety was expressed in terms of 'safe food' but also in terms of the safety of the farmers who must handle synthetic inputs. In these three countries, concerns for farmers' health were linked with consumer interest in nutrition. Here, consumers seek organic food also because the organic 
farmers are growing difficult to find varieties of fruits and vegetables that are known to have nutritional benefits. In Namibia, consumer health and nutrition was the key frame employed for an elite consumer base concerned about their local environment and animal welfare.

Livelihood promotion emerged as the second most salient objective of these initiatives. We saw a split between an individualistic notion of farmer livelihoods on the one hand (Tanzania and Indonesia) and community livelihoods on the other (Thailand, Trinidad and the Philippines). The Tanzanian and Indonesian cases are those where you have a strong presence of international standards and donors who are promoting sustainable agricultural practices in top-down, diffusion of innovation style projects - albeit with innovative techniques. Therefore, we believe that the focus on individual farmers emerges from this broader context. In the case of the community livelihoods, each of these is a community-initiated project that is focused primarily on a community-based market development. The case of the Songhai Centre in Benin is also focused on building local communities in the form of 'green rural villages', but they have a more ambitious plan for integrated rural development that is based in communities but linked into national, regional and international market networks. Finally, the Bolivian and Colombian cases have the objective of food sovereignty for producers. Food sovereignty is part of the public debate in both countries. It is enshrined in the Bolivian constitution and thus the innovation works to provide a means to achieve official policy. In Colombia, food sovereignty is hotly contested where official policy does not take it into account and thus the innovation plays an oppositional role by promoting it.

Each of the cases offers a different solution to the problem of sustainable agriculture. We can characterise the solutions more broadly into the categories of knowledge (youth training in Benin and Nigeria, FFS in Iran, and farmer-driven experimentation in Indonesia); market outlets (local economies in Bolivia, Ecuador, Namibia, Trinidad and Uganda and value chain management in Uganda and Tanzania); and access to biological resources (native seeds in Colombia and India, yield increases in India, and farmer-control over genetic resources in the Philippines). These solutions are delivered through three types of mechanisms: multi-stakeholder innovation platforms (IP), participatory guarantee systems (PGS) and embedded networks (EN).

An IP is "a multi-actor configuration deliberately set up to facilitate and undertake various activities around identified agricultural innovation challenges and opportunities, at different levels in agricultural systems (e.g. village, country, sector or value chain)" (Kilelu, Klerkx, \& Leeuwis, 2013, p. 66). There is no set configuration for an IP, it can be centralised or decentralised and focus on research and/or development activities. We see examples of this in our case studies. The Songhai Centre in Benin is a centralised model focused on research, training and development. It is composed of primary (an integrated production model of agriculture, aquaculture, livestock-raising, and biogas production), secondary (processing and packaging) and tertiary (food, marketing, information technology and transport services) production activities. This centre is linked to a network of satellite centres and alumni farmers who sell their products to the Songhai centres and promote learning exchanges. The Partisipasi Inovasi Petani (PIP) Project in Indonesia illustrates a hub-and-spoke model of innovation that provides a business-oriented farm extension outreach system where Cocoa Development Clinics (or CDCs) are the hubs and Cocoa Village Clinics (CVCs) are the spokes. The CDCs are centres for training, technology demonstration, developing regionally appropriate techniques and testing improved planting material. The CVCs are economically independent village enterprises that sell farm inputs, and provide agronomic advice based on their own demonstration plots.

The Community Based-Farming Scheme in Nigeria is another example of a centralised model whereby the University of Abeokuta has introduced organic agriculture curricula, student farms, community field visits and an organic kiosk to sell its produce. In Tanzania, we see national level government agencies collaborate with the tea research institute, private companies and NGOs to develop new technologies, exchange knowledge, provide financing and extension support to smallholder farmers for Rainforest Alliance certified production practices, which are sold locally to the tea processors who export the product. In Uganda, the Kangulumira Area Cooperative Enterprise (KACE) serves as a centralised IP for technology upgrading, knowledge exchanges and training in organic practices, access to finance and other development training for groups of farmers. Finally, the IPM Group in Iran is an example of a loose network IP. Here the network began in project-sponsored FFS but continued these FFS by creating a network of alumni and carrying on 
their own training of trainers. Now the IPM group also serves as a means to link its member farmers with markets by mobilizing other networks through exchange visits and renting farm stands.

PGS are networks created within local communities and consist of farmers, experts, public sector officials, food service agents, and consumers. "They certify producers based on active participation of stakeholders and are built on a foundation of trust, social networks and knowledge exchange." ${ }^{1}$ The role of this type of network is to create a local system of production and consumption whereby multiple stakeholders experiment with sustainable agriculture technologies (Rosegrant et al., 2014), but also collectively ensure that the techniques are adopted by setting standards and verifying their compliance (i.e., the governance arrangements) (IFOAM, 2008). PGS therefore both ensure the diffusion of the innovation and are the means through which the innovation process is governed. PGS emerged as experiments in organic agriculture in the 1970s in the US, Japan and Brazil, but are now found in 26 countries around the world. In developing countries they arose in response to protests against the dominant paradigm of standard-setting by corporate and Northern NGO actors who use third-party certification systems that were seen as too costly for many small-scale producers and not applicable to local agro-ecological and socio-technical conditions. PGS serve to provide a direct guarantee, through the formation of a market, for sustainably produced food and agriculture products. We have case studies of six PGS that are implementing organic agriculture in Bolivia, Colombia, India, Namibia, Philippines and Uganda. We can classify these into publicly promoted and recognised PGS (Bolivia and Philippines) and private sector PGS (Colombia, India, Namibia and Uganda).

EN refers to those innovations that are tied to the specific agro-ecosystems and socio-cultural contexts of their origin (Bair, 2008). In Ecuador, La Canasta Utopía is a community supported agriculture model whereby the core interactions are market-based, but support wider community mobilisation around healthy food and rural development. The markets and rural-urban exchanges take place in close proximity to the locus of action and they focus on ensuring rural food sovereignty. In Thailand, the Dharma Garden Temple is highly embedded in its community as it serves as the community religious centre and relies upon community volunteers for much of its training and outreach. The creation of a local radio station as a means to spread its message helps to embed the EN further into the community. Finally, the Brasso Seco Paria Community case demonstrates how an agro-tourism effort builds on existing community structures to introduce new technologies and markets that are necessarily located in their unique agro-ecosystem.

We find that each of these frames responds to debates that are circulating in national and international debates over sustainable agriculture. There are no fixed sets of problem frames, objectives, solutions and methods. In fact, each case has combined these in a different way, which provides evidence for the extremely contextual nature of these innovations. Nonetheless, we do find trends in the linkages between the socio-technical controversies that spurred the innovation and the form of the institutional innovation. In the PGS cases we see a reaction to controversies around food sovereignty and external expert control over practices. In the EN cases we see responses based on a moral economy that attempt to re-embed market transactions in to the community. In the IP cases, we see collaborative efforts to respond to crises related to agricultural technologies, particularly pesticide intensive farming, by encouraging collaborative learning.

\subsection{Sustainable Practices and Markets: the construction of the networks}

The construction of networks is fundamental to the extension of political, knowledge-based and market institutions. It is through the construction of networks that actors are able to transform the problems that they have framed into actionable solutions by mobilising actors, isolating themselves from conventional industries, and freeing themselves from some of the institutional constraints that constrict their growth (Hargrave \& Van De Ven, 2006). Network construction can be explained as a process of translation that includes the processes of problematisation, 'interressement', enrolment and entanglement of actors into the

\footnotetext{
${ }^{1}$ Official IFOAM PGS Definition, accessed 15 February 2014, http://www.ifoam.org/en/value-chain/participatoryguarantee-systems-pgs
} 
network, and mobilisation (Callon, 1986). In an innovation process, the construction of the network must include actors internal and external to the group in order to achieve both political and technical goals and be considered legitimate (Loconto \& Fouilleux, 2014). Therefore both vertical and horizontal mobilisations should be considered (Rukanova et al., 2007). These interactions can be collaborative or competitive and are not necessarily centrally planned, but more programmatically constructed where all of the actors concerned change their activities and ideas as a result of the interaction. In our cases we see examples of both vertical and horizontal network construction.

We see horizontal network construction occurring as a way to build cohesiveness within the group. This means that actors are enrolled and entangled as part of the core group of actors promoting the innovation. In all cases producers are the core group of actors, but what differentiates these innovations from conventional farmer groups or cooperatives is how producers are engaging with researchers, government officials, private companies, community members and consumers. In these horizontal relationships we see both market-based relationships and collective commitments between non-market actors. We see the emergence of a number of new hybrid actors, where responsibilities for different activities in the network emerge. The hybrid actors that we identify are consumer-citizens, farmer-experts, producer-auditors, producer-consumers, and producer-marketer. These hybrids represent a way for actors to take on multiple roles and identities in their networks. Producer-consumers are found in Bolivia, Colombia, Ecuador, Iran and Uganda where there is a primary focus on producing crops first for the farmers' own consumption and then for the local market. Farmer-experts, producer-auditors and producer-marketers are all ways to describe the changes in the roles of farmers in the Bolivian, Iranian, Indian, Namibian and Philippine networks. We see clearly the role of learning and knowledge exchange as producers take on more responsibilities beyond food production. Finally, there is an element of responsibilisation occurring in the Bolivian, Colombian, Ecuadorian, Namibian networks where we see consumer-citizens (cf. Spaargaren, 2011) who join the horizontal networks not only to consume organic food, but to also promote the social and political mission of the network.

Vertical network construction is used to create external alliances that ensure access to markets and/or provide a competitive pressure for improvement. In 12 of the 15 cases, we see a clear role for a charismatic leader (Zald \& Ash, 1966) in both mobilizing within the innovative group and by creating linkages with donors, NGOs, government officials and long value chains. In these relationships, knowledge and financial resources are exchanged between external and internal network actors. The leaders in these cases cover a range of types as we see a charismatic leader, based on a moral authority, in the case of Benin and in Thailand; and an organisation as a leader, based on market authority, in the case of Tanzania and Namibia. In Ecuador, Indonesia, and Trinidad, where do don't see a clear role for a charismatic leader, we find that these cases are small in size (and locally embedded in the cases of Ecuador and Trinidad) and the actors have not yet expressed clear intensions to expand their activities beyond their current geographically limited scope.

The focus on network construction highlights the importance of charismatic leadership and hybrid-actors as important for building collective commitments among actors. While the focus of many market arrangements is on building local networks, we find the influence of international actors in each case. This suggests that both community and international dynamics influence the development of institutional innovations in developing countries.

\subsection{Sustainable Practices and Markets: the enactment of institutional arrangements}

Institutional arrangements are those institutional and industrial infrastructures that provide political and market opportunities for the products produced through sustainable practices (Fligstein, 2001; McAdam, McCarthy, \& Zald, 1996). Van de Ven and colleagues (Hargrave \& Van De Ven, 2006; Van de Ven \& Garud, 1993) identify institutional regulations (IR) (e.g., laws, standards, agencies, associations, scientific/technical communities), resource endowments (RE) (e.g., knowledge, finance, insurance, training), consumer demand (CD) (e.g., creation of environmentally-socially-health-conscious consumers) and proprietary activities (PA) 
(e.g., quality products). These institutions are important because in order to have a market for sustainably produced products there must be ways to establish prices, inform customers and suppliers and to provide distribution arrangements. We find all of this occurring in our cases.

The ways in which prices are fixed follow one of three approaches in our cases. First, there are national level mechanisms which establish a price premium for organic or 'safe' food. These mechanisms dictate a set price or percentage above the market price (e.g., Philippines and Iran). Second, some arrangements set up their own private price negotiation between the producers and consumers in their network. This is the case in Ecuador where producers and consumers negotiate a fair price each season. This is based on the wholesale market prices and the prices are usually favourable to producers as the prices they receive are always higher than those from the wholesale markets. Finally, some arrangements do not specifically negotiate a price, but rely upon private contracts or the market prices to negotiate prices based on the quality of their products (e.g., Benin, Namibia, Uganda and Tanzania). In these cases, a price premium for sustainable products is not assumed and often is not received. In Benin, producers explained that they adopt this mechanism because they are making cost savings. In Uganda and Tanzania the cost savings were not as apparent.

We find differences in how customers and suppliers are informed across the cases. Direct interaction between producers and consumers through traditional or speciality markets are the preferred ways of communicating quality. However, we also find innovative ways of improving consumer awareness through product labelling that explains the health benefits of the product (Benin), Facebook updates (Uganda) and exchange visits in all cases. Large-scale consumer awareness campaigns are also occurring in all of the countries, but these are usually carried out by actors in the vertical networks (ministries, national organic movements, NGOs) and not directly by the innovators.

Distribution arrangements range from direct markets, through cooperative sales, long and short value chains to public procurement. In most cases, distribution arrangements pose challenges as it is in these instances where the existing institutions constrict behaviour. For example, the formalisation of informal networks (through tax registration and establishing formal enterprises) is necessary for accessing more formal markets such as export, public procurement and even having a market stall in the mainstream markets. In Tanzania, one of the innovative aspects of this case is how the different public and private organisations have mutually adjusted their practices in order to ensure timely distribution of certified products. This has worked as an incentive for the adoption of practices by farmers as consistency of logistical networks enables better planning of harvesting practices.

Finally, we found that the existence of a national policy or standard was not present in all of the cases. Instead, there seems to be a mix between national, regional and international standards that the farmers are using as a guide for their sustainable agriculture practices. There are no clear trends in the cases. For example, the EN cases comply with locally defined standards, but in Trinidad and Thailand we also see the farmers applying international standards for organic agriculture. Indeed, while well institutionalised cases, like Bolivia and the Philippines have national organic standards, those cases that are in the developmental phase of innovation (Tanzania and Benin) do not have any legislation related to the standards that they are applying. The status of these institutional arrangements is important for evaluating the outcomes of these collective action processes.

\subsection{Sustainable Practices and Markets: the collective action processes}

Hargrave and Van de Ven (2006) refer to collective action processes as the contested political process through which innovations emerge. These processes include the ways in which the solutions are framed, how the network of actors is engaged and the political and market opportunities that exist at a particular moment in time. Following from the information provided in the last three sections, we can consider the progress of collective action according to three phases: emergence, developmental and implementation (or 
convergence). We can thus discuss whether or not these innovations are currently considered legitimate solutions to the problem of unsustainable agricultural practices.

Building on the language from innovation studies, we characterise the current status of nine of the institutional innovations in our survey as being in an 'era of incremental change' (Anderson \& Tushman, 1990) or in the developmental phase. Based on a timeline from their official creation, the innovations have been in existence for about 10-15 years. Their forms and governance structures have converged over time towards more formalised organisations with delegation of rights and responsibilities assigned to professional staff (in most cases). They have markets, mostly on the local level which they are consistently supplying. There are projects in all countries to gain public recognition of their sustainable practices, which have been achieved through the mobilisation of networks. Private recognition, in terms of consumers and market actors, is also developing alongside the public recognition and is actually the driving force for pursuing political solutions that can facilitate access to market outlets.

The Indonesian, Namibian, and Nigerian cases are still in the phase of emergence as the sustainable agriculture practices are in the process of being introduced, the network linkages are weak, and the political project driven by the innovators does not have strong support from the public sector. On the other hand, we see Benin, Bolivia and Tanzania as entering into the implementation phase. In Benin, the model has been in existence for over 20 years. The agricultural methods are well established with a strong training curriculum. The model has been replicated outside of the country and Songhai just received a political commitment from the Ministry of Education to establish Songhai centres in each district of the country. In Bolivia, there is continued investment by public and civic actors over the past 20 years in the promotion of organic. Ten years ago a new national agency was created to provide training and support for the development of PGS; and to manage the institutional linkages with the food safety authority. Bio-fairs have become a mainstay in a number of urban centres and activities are ongoing to link PGS producers with school feeding programs in rural areas. The government has also made commitments to finance municipal level organic extension officers. In Tanzania the agricultural methods have only been taught over the past five years, but the institutional actors have been collaborating together for almost 20 years. Moreover, we see changes in national regulations and mandates for both public and private actors through the collaboration around sustainable agriculture practices. The current policy of the government agencies is to ensure that all smallholder tea farmers in the country will be practicing sustainable agriculture over the next five years. This is supported by the private sector and farmers, as sustainable products have become a de facto mandatory market requirement.

\section{Conclusion}

As Hounkonnou et al. (2012) argue "institutions cannot be transferred like technologies" (p. 81), change must occur from within the existing institutions in order to create new ones. Therefore, it is important to survey existing cases of where we see actors have already begun to invest in alternatives that have started to make changes in practices towards sustainable intensification. In our cases, sustainable intensification has taken many forms. For example, even within the organic cases, the practices that are considered to be sustainable and their institutional arrangements are varied. When international standards are used, the innovation lies in the mutation of 'control' mechanisms into 'learning' mechanisms. This allows for greater inclusion of local actors, but these innovations are not yet accepted in international markets. In many cases, there is reliance upon technological innovations ascribed to capital-intensive production systems, which illustrates that many of these examples are indeed incremental innovations within the sustainable intensification paradigm. This preliminary analysis of the case studies remains descriptive, but provides an overview of existing institutional arrangements that are effectively implementing sustainable agriculture practices, standards, and incentives.

The introduction of new ways of linking sustainable agricultural practices with markets, through new institutional arrangements, is neither necessarily robust nor enduring. These arrangements are likely to evolve over time as they receive more support and interest by additional stakeholders and existing 
institutional actors. What these innovations do emphasise, however, is that their emergence and development has been a result of a number of diverse institutional opportunities that have allowed ad hoc actors to invest in new organisational forms. As Cleaver (2002) argues, single purpose institutions are not favoured through institutional bricolage, which is a notion of institutional change that recognises both the structural constraints of institutions and actors' agency in changing them (though not a rational/instrumentalist agency). Indeed, we see this in our cases since while in their framing process each innovation may make claim to a key driver as the motivation for their innovation, the institutional development of the innovation has brought in complementary and contingent processes and functions that enable the innovation to persist over time. In this way, we have been able to explain how institutional innovations emerge from interactions and framing contests among partisan actors. By merging social movement theories with the sociology of innovation, we believe that we have been better able to capture the diversity of dynamics existing in our cases, but also to find similarities across the cases. This framework enabled us to ascertain a stage of collective action, which provides insights into questions of the legitimacy of these innovations in terms of resolving problems of un-sustainable agriculture. These insights are important for discussions of socio-technical transitions as they can shed light on the dynamics involved in moving these innovations from niche levels into wide-spread applicability and regime shifts (cf. Grin et al., 2010), which are clearly areas for further research on the institutionalization of these types of innovations.

Acknowledgements: The authors would like to thank the case study actors for their contributions and collaboration during the research process.

\section{References}

Allen, P., Fitz Simmons, M., Goodman, M., Warner, K., 2003. Shifting plates in the agrifood landscape: the tectonics of alternative agrifood initiatives in California. Journal of Rural Studies 19, 61-75.

Anderson, P., Tushman, M., 1990. Technological Discontinuities and Dominant Designs: A Cyclical Model of Technological Change. Administrative Science Quarterly 35, 604-633.

Bair, J., 2008. Analysing global economic organization: embedded networks and global chains compared. Economy and Society 37, 339-364.

Barbier, M., 2008. Bottling water, greening farmers: the socio-technical and managerial construction of a 'dispositif' for underground water quality protection. International Journal of Agricultural Resources, Governance and Ecology 7, 174-197.

Benford, R.D., Snow, D.A., 2000. Framing Processes and Social Movements: An Overview and Assessment. Annual Review of Sociology 26, 611-639.

Bowen, S., Mutersbaugh, T., 2014. Local or localized? Exploring the contributions of Franco-Mediterranean agrifood theory to alternative food research. Agriculture and Human Values 31, 201-213.

Brunori, G., Rossi, A., Malandrin, V., 2011. Co-producing Transition: Innovation Processes in Farms Adhering to Solidarity-based Purchase Groups (GAS) in Tuscany, Italy. International Journal of Sociology of Agriculture and Food 18, 28-53.

Busch, L., 2012. Standards governing agricultural innovation. Where do we come from? Where should we be going?, in: Coudel, É., Devautour, H., Soulard, C.-T., Faure, G., Hubert, B. (Eds.), Renewing innovation systems in agriuclture and food. Howe to go towards more sustainability? Éditions Quae, Paris, pp. 37-56.

Callon, M., 1986. Some elements of a sociology of translation: domestication of the scallops and the fishermen of St Brieuc Bay, in: Law, J. (Ed.), Power, Action and Belief. A New Sociology of Knowledge? Routledge \& Kegan Paul, London, pp. 196-233.

Callon, M., 1991. Techno-economic networks and irreversibility, in: Law, J. (Ed.), A Sociology of Monsters: essays on power, technology and domination. Routledge, London, pp. 132-163.

Callon, M., 1998. An essay on framing and overflowing: economic externalities revisited by sociology, in:

Callon, M. (Ed.), The Laws of the Markets. Blackwell, Oxford, pp. 244-269.

Cashore, B.W., Auld, G., Newsom, D., 2004. Governing through markets: Forest certification and the emergence of non-state authority. Yale University Press, New Haven.

Cleaver, F., 2002. Reinventing Institutions: Bricolage and the Social Embeddedness of Natural Resource Management. European Journal of Development Research 14, 11.

Conway, G., 2012. One Billion Hungry: Can We Feed the World? Cornell University Press, Ithaca, NY. 
Elzen, B., Geels, F.W., Leeuwis, C., van Mierlo, B., 2011. Normative contestation in transitions 'in the making: Animal welfare concerns and system innovation in pig husbandry. Research Policy 40, 263-275.

FA0, 2011. Save and Grow: A policymaker's guide to sustainable intensification of smallholder production. Food and Agriculture Organization of the United Nations, Rome.

FAO, 2013. Lessons learnt from field projects on voluntary standards: Synthesis of results, in: FAO-UNEP Sustainable Food Systems Programme (Ed.), Workshop on Voluntary Standards for Sustainable Food Systems: Challenges and Opportunities. Food and Agriculture Organization of the United Nations, Rome, Italy, 10-11 June 2013, pp. 1-27.

Fligstein, N., 2001. The Architecture of Markets: An Economic Sociology of Twenty-First-Century Capitalist Societies. Princeton University Press.

Garnett, T., Appleby, M.C., Balmford, A., Bateman, I.J., Benton, T.G., Bloomer, P., Burlingame, B., Dawkins, M., Dolan, L., Fraser, D., Herrero, M., Hoffmann, I., Smith, P., Thornton, P.K., Toulmin, C., Vermeulen, S.J., Godfray, H.C.J., 2013. Sustainable Intensification in Agriculture: Premises and Policies. Science 341, 33-34.

Garud, R., Jain, S., Kumaraswamy, A., 2002. Institutional Entrepreneurship in the Sponsorship of Common Technological Standards: The Case of Sun Microsystems and JAVA. Academy of Management Journal 45, 196-214.

Geels, F.W., 2002. Technological transitions as evolutionary reconfiguration processes: a multi-level perspective and a case-study. Research Policy 31, 1257-1274.

Geels, F.W., 2004. From sectoral systems of innovation to socio-technical systems: Insights about dynamics and change from sociology and institutional theory. Research Policy 33, 897-920.

Geels, F.W., 2010. Ontologies, socio-technical transitions (to sustainability), and the multi-level perspective. Research Policy 39, 495-510.

Genus, A., Coles, A.-M., 2008. Rethinking the multi-level perspective of technological transitions. Research Policy 37, 1436-1445.

Goodman, D., 2004. Rural Europe Redux? Reflections on Alternative Agro-Food Networks and Paradigm Change, pp. 3-16.

Goodman, D., DuPuis, E.M., Goodman, M.K., 2012. Alternative food networks : knowledge, practice, and politics. Routledge, Abingdon, Oxon ; New York.

Grin, J., Rotmans, J., Schot, J.W., 2010. Transitions to sustainable development : new directions in the study of long term transformative change. Routledge, New York.

Hargrave, T.J., Van De Ven, A.H., 2006. A Collective Action Model of Institutional Innovation. Academy of Management Review 31, 864-888.

HLPE, 2012. Investing in smallholder agriculture for food and nutrition security. V0 - DRAFT A zero-draft consultation paper, A report by the High Level Panel of Experts on Food Security and Nutrition of the Committee on World Food Security. Food and Agriculture Organization of the United Nations, Rome.

Hounkonnou, D., Kossou, D., Kuyper, T.W., Leeuwis, C., Nederlof, E.S., Röling, N., Sakyi-Dawson, O., Traoré, M., van Huis, A., 2012. An innovation systems approach to institutional change: Smallholder development in West Africa. Agricultural Systems 108, 74-83.

IFOAM, 2008. Participatory Guarantee Systems: Case studies from BRAZIL, INDIA, NEW ZEALAND, USA and FRANCE. International Forum for Organic Agriculture Movements (IFOAM), Bonn, Germany.

Jiggins, J., 2012. Diagnostic research in support of innovation. NJAS - Wageningen Journal of Life Sciences 60-63, 115-121.

Kilelu, C.W., Klerkx, L., Leeuwis, C., 2013. Unravelling the role of innovation platforms in supporting coevolution of innovation: Contributions and tensions in a smallholder dairy development programme. Agricultural Systems 118, 65-77.

Lamine, C., 2011. Transition pathways towards a robust ecologization of agriculture and the need for system redesign. Cases from organic farming and IPM. Journal of Rural Studies 27, 209-219.

Levin, K., Cashore, B., Bernstein, S., Auld, G., 2012. Overcoming the tragedy of super wicked problems: constraining our future selves to ameliorate global climate change. Policy Sciences 45, 123-152.

Loconto, A., Fouilleux, E., 2014. Politics of Private Regulation: ISEAL and the shaping of transnational sustainability governance. Regulation \& Governance 8, 166-185. 
Lyson, T.A., Welsh, R., 1993. The Production Function, Crop Diversity, and the Debate Between Conventional and Sustainable Agriculture1. Rural Sociology 58, 424-439.

Maxwell, J.A., 2005. Qualitative Research Design: An Interactive Approach, 2nd ed. Sage Publications, Thousand Oaks, CA.

McAdam, D., McCarthy, J., Zald, M.N., 1996. Comparative Perspectives on Social Movements: Political Opportunities, Mozilizing Structures and Cultural Framings. Cambridge University Press, Cambridge.

Moulaert, F., 2013. The International Handbook on Social Innovation: Collective Action, Social Learning and Transdisciplinary Research. Edward Elgar.

Röling, N., Hounkonnou, D., Kossou, D., Kuyper, T.W., Nederlof, S., Sakyi-Dawson, O., Traoré, M., Van Huis, A., 2012. Diagnosing the scope for innovation: Linking smallholder practices and institutional context: Introduction to the special issue. NJAS - Wageningen Journal of Life Sciences 60-63, 1-6.

Rosegrant, M.W., Koo, J., Cenacchi, N., Ringler, C., Robertson, R., Fisher, M., Cox, C., Garrett, K., Perez, N.D., Sabbagh, P., 2014. Food security in a world of natural resource scarcity : the role of agricultural technologies. International Food Policy Research Institute, Washington, DC.

Rukanova, B., Henriksen, H.Z., Raesfeld, A.V., Stijn, E.v., Tan, Y.-H., 2007. A Collective Action Perspective on Technological Innovation in Business/Government Networks, ECIS 2007 Proceedings Paper 194.

Schot, J., Geels, F.W., 2008. Strategic niche management and sustainable innovation journeys: theory, findings, research agenda, and policy. Technology Analysis \& Strategic Management 20, 537-554.

Smith, A., Seyfang, G., 2013. Constructing grassroots innovations for sustainability. Global Environmental Change 23, 827-829.

Smith, A., Stirling, A., Berkhout, F., 2005. The governance of sustainable socio-technical transitions. Research Policy 34, 1491-1510.

Spaargaren, G., 2011. Theories of practices: Agency, technology, and culture: Exploring the relevance of practice theories for the governance of sustainable consumption practices in the new world-order. Global Environmental Change 21, 813-822.

Struik, P.C., Klerkx, L., van Huis, A., Röling, N.G., 2014. Institutional change towards sustainable agriculture in West Africa. International Journal of Agricultural Sustainability, 1-11.

Swidler, A., 1995. Cultural Power and Social Movements, in: Johnston, H., Klandermans, B. (Eds.), Social Movements and Culture. University of Minnesota Press, Minneapolis, pp. 25-40.

Tarrow, S., 1993. Cycles of Collective Action: Between Moments of Madness and the Repertoire of Contention. Social Science History 17, 281-307.

Van de Ven, A.H., Garud, R., 1993. Innovation and industry development : The case of cochlear implants. Research on Technological Innovation, Management and Policy 5, 1-46.

Van de Ven, A.H., Hargrave, T.J., 2004. Social, Technical and Institutional Change: A Literature Review and Synthesis, in: Poole, M.S., Van de Ven, A.H. (Eds.), Handbook of Organizational Change and Innovation. Oxford University Press, USA, New York, pp. 259-303.

Vorley, B., 2013. Meeting small-scale farmers in their markets: understanding and improving the institutions and governance of informal agrifood trade. IIED/HIVOS/Mainumby, London/The Hague/La Paz.

Willer, H., Lernoud, J., 2014. The World of Organic Agriculture - Statistics and Emerging Trends 2014. IFOAM, FiBL, Bonn, Germany and Frick, Switzerland.

Wiskerke, J.S.C., Van der Ploeg, J.D., 2004. Seeds of Transition: Essays in Novelty Production, Niches and Regimes in Agriculture. Royal Van Gorcum.

Zald, M.N., Ash, R., 1966. Social Movement Organizations: Growth, Decay and Change. Soc. Forces 44, 327-341. 


\section{Annex 1: Qualitative codes for each case}

\begin{tabular}{|c|c|c|c|c|c|}
\hline Country & Title & Framing Contests & $\begin{array}{l}\text { Network } \\
\text { Construction }\end{array}$ & $\begin{array}{l}\text { Institutional } \\
\text { Arrangement }\end{array}$ & Collective Action \\
\hline Benin & $\begin{array}{l}\text { The Songhai } \\
\text { Model } \quad \text { of } \\
\text { integrated } \\
\text { production }\end{array}$ & $\begin{array}{l}\text { DF: Organic } \\
\text { O: Rural development } \\
\text { S: Youth training } \\
\text { M: IP }\end{array}$ & $\begin{array}{l}\text { Vertical: } \\
\text { Ministry of Education } \\
\text { Donors (South-South, } \\
\text { North-South) } \\
\text { Leadership } \\
\text { Horizontal: } \\
\text { Alumni network } \\
\text { Hotels }\end{array}$ & $\begin{array}{l}\text { IR: Scaling-up strategy } \\
\text { RE: Youth training } \\
\text { CD: Labelling strategy } \\
\text { PA: Quality products } \\
\text { and services }\end{array}$ & Implementation \\
\hline Bolivia & $\begin{array}{l}\text { The Ecological } \\
\text { Fairs of La Paz, } \\
\text { Cochabamba } \\
\text { and Tarija }\end{array}$ & $\begin{array}{l}\text { DF:Agroecology } \\
\text { 0: Food sovereignty, } \\
\text { Health (nutrition/safety) } \\
\text { S: Local economy } \\
\text { M: PGS }\end{array}$ & $\begin{array}{l}\text { Vertical: } \\
\text { Donors (FAO, Spain) } \\
\text { Leadership } \\
\text { Horizontal: } \\
\text { Producer-Auditor } \\
\text { Producer-Consumer } \\
\text { Consumer-citizen } \\
\text { School canteens } \\
\text { Municipal officials }\end{array}$ & $\begin{array}{l}\text { IR: National Organic } \\
\text { Law \& PGS standard } \\
\text { RE: Capacity building } \\
\text { CD: Local fairs } \\
\text { PA: Quality products }\end{array}$ & Implementation \\
\hline Colombia & $\begin{array}{l}\text { The Familia de } \\
\text { la Tierra PGS }\end{array}$ & $\begin{array}{l}\text { DF: Agroecology } \\
\text { 0: Food sovereignty } \\
\text { S: Native seeds } \\
\text { M: PGS }\end{array}$ & $\begin{array}{l}\text { Vertical: } \\
\text { Restaurants } \\
\text { Cooking school } \\
\text { Peasant movement } \\
\text { Leadership } \\
\text { Horizontal: } \\
\text { Consumer-citizen } \\
\text { Producer-consumer } \\
\text { University } \\
\text { District-level public } \\
\text { institutions }\end{array}$ & $\begin{array}{l}\text { IR: Organic Policy } \\
\text { Proposal, National } \\
\text { Association } \\
\text { RE: University seed } \\
\text { research } \\
\text { CD: } \\
\text { Consumers Gourmet } \\
\text { PA: Quality products }\end{array}$ & Developmental \\
\hline Ecuador & $\begin{array}{l}\text { Reinforcing the } \\
\text { Local Systems } \\
\text { of Healthy Food } \\
\text { of } \quad \text { Sierra } \\
\text { Centro }\end{array}$ & $\begin{array}{l}\text { DF: Agroecology } \\
\text { 0: } \\
\text { (nutrition/safety) } \\
\text { S: Fair trade (local } \\
\text { economy) } \\
\text { M: EN }\end{array}$ & $\begin{array}{l}\text { Vertical: } \\
\text { National NGOs } \\
\text { Horizontal: } \\
\text { Consumer-citizen } \\
\text { Producer-consumer }\end{array}$ & $\begin{array}{l}\text { IR: Food sovereignty } \\
\text { law, Nation Association } \\
\text { RE: Field visits } \\
\text { CD: Community } \\
\text { supported agriculture } \\
\text { PA: Quality products }\end{array}$ & Developmental \\
\hline India & $\begin{array}{l}\text { PGS and the } \\
\text { small holder } \\
\text { markets: Idea } \\
\text { of Trust and } \\
\text { Short Market } \\
\text { Chains }\end{array}$ & $\begin{array}{l}\text { DF: Organic } \\
\text { 0: Health (safe food) } \\
\text { S: Native seeds, Yields } \\
\text { M: PGS }\end{array}$ & $\begin{array}{l}\text { Vertical: } \\
\text { Donors (FAO, IFOAM) } \\
\text { Long value chains } \\
\text { Leadership } \\
\text { Horizontal: } \\
\text { NGOs } \\
\text { Farmer groups } \\
\text { Producer-Auditor } \\
\end{array}$ & $\begin{array}{l}\text { IR: National } \text { Organic } \\
\text { Law, Public PGS } \\
\text { standard, Private PGS } \\
\text { standard } \\
\text { RE: Field visits } \\
\text { CD: Short and long } \\
\text { value chains } \\
\text { PA: Quality products }\end{array}$ & Developmental \\
\hline Indonesia & $\begin{array}{l}\text { Partisipasi } \\
\text { Inovasi Petani } \\
\text { (PIP) Project: A } \\
\text { participatory } \\
\text { model for } \\
\text { promoting } \\
\text { farmer-driven } \\
\text { innovation }\end{array}$ & $\begin{array}{l}\text { DF: Commodity } \\
\text { Sustainability } \\
\text { O: Farmer livelihoods } \\
\text { S: Farmer-driven } \\
\text { experimentation } \\
\text { M: IP }\end{array}$ & $\begin{array}{l}\text { Vertical: } \\
\text { Donors (Mars, Inc.) } \\
\text { Long value chains } \\
\text { University } \\
\text { Horizontal: } \\
\text { Input providers } \\
\text { Farmer groups }\end{array}$ & $\begin{array}{l}\text { IR: Scientific/technical } \\
\text { community, GAP } \\
\text { standards } \\
\text { RE: } \\
\text { experiments } \\
\text { CD: long value chain } \\
\text { PA: Quality products }\end{array}$ & Emergence \\
\hline Iran & $\begin{array}{l}\text { The role of } \\
\text { CBOs in } \\
\text { sustainable } \\
\text { production and } \\
\text { marketing of } \\
\text { agricultural } \\
\text { products } \\
\end{array}$ & $\begin{array}{l}\text { DF: Community IPM } \\
\text { 0: Health (safe food) } \\
\text { S: Farmer Field Schools } \\
\text { M: IP }\end{array}$ & $\begin{array}{l}\text { Vertical: } \\
\text { Donors (FAO) } \\
\text { Leadership } \\
\text { Horizontal: } \\
\text { Producer-consumer } \\
\text { Farmer-expert }\end{array}$ & $\begin{array}{l}\text { IR: Development policy } \\
\text { RE: farmer field } \\
\text { schools } \\
\text { CD: } \\
\text { information consumer } \\
\text { PA: Quality products }\end{array}$ & Developmental \\
\hline
\end{tabular}




\begin{tabular}{|c|c|c|c|c|c|}
\hline Namibia & $\begin{array}{l}\text { The Namibian } \\
\text { Organic } \\
\text { Association's } \\
\text { Participatory } \\
\text { Guarantee } \\
\text { System }\end{array}$ & $\begin{array}{l}\text { DF: Organic } \\
\text { 0: Health } \\
\text { (nutrition/safety) } \\
\text { S: Local economy } \\
\text { M: PGS }\end{array}$ & $\begin{array}{l}\text { Vertical: } \\
\text { Allan Savory Institute } \\
\text { National Organic } \\
\text { Movement } \\
\text { National NGOs } \\
\text { Supermarkets } \\
\text { Leadership } \\
\text { Horizontal: } \\
\text { Consumer-citizens } \\
\text { Producer-marketer }\end{array}$ & 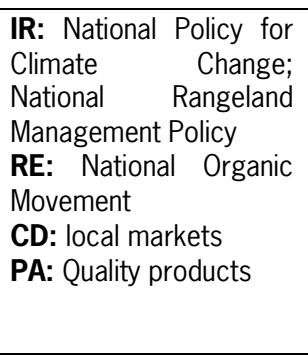 & Emergence \\
\hline Nigeria & $\begin{array}{l}\text { Impact } \\
\text { Assessment of } \\
\text { the Community } \\
\text { Based-Farming } \\
\text { Scheme in } \\
\text { Enhancing } \\
\text { Sustainable } \\
\text { Agriculture in } \\
\text { Nigeria }\end{array}$ & $\begin{array}{l}\text { DF: Organic } \\
\text { O: Sustainable farming } \\
\text { S: Youth training } \\
\text { M: IP }\end{array}$ & $\begin{array}{l}\text { Vertical: } \\
\text { Donors } \\
\text { Universities } \\
\text { Leadership } \\
\text { Horizontal: } \\
\text { Community engagement } \\
\text { Student training }\end{array}$ & $\begin{array}{l}\text { IR: International Organic } \\
\text { standards } \\
\text { RE: Student farms } \\
\text { CD: Organic kiosk } \\
\text { PA: Quality products } \\
\text { and services }\end{array}$ & Emergence \\
\hline Philippines & $\begin{array}{l}\text { The Innovative } \\
\text { Institutional } \\
\text { Approach: } \\
\text { QPGS }\end{array}$ & $\begin{array}{l}\text { DF: Organic } \\
\text { 0: Community livelihood } \\
\text { S: Farmer control over } \\
\text { genetic/bio-resources } \\
\text { M: PGS }\end{array}$ & $\begin{array}{l}\text { Vertical: } \\
\text { Provincial government } \\
\text { CSOs } \\
\text { University } \\
\text { Leadership } \\
\text { Horizontal: } \\
\text { Producer-marketer } \\
\text { Producer-auditors }\end{array}$ & $\begin{array}{l}\text { IR: National Organic } \\
\text { Act, Private PGS } \\
\text { standard } \\
\text { RE: University linkage } \\
\text { CD: local markets } \\
\text { PA: Quality products }\end{array}$ & Developmental \\
\hline Tanzania & $\begin{array}{l}\text { Sustainable } \\
\text { Agricultural } \\
\text { Practices by } \\
\text { Smallholders } \\
\text { Tea Farmers }\end{array}$ & $\begin{array}{l}\text { DF: Commodity } \\
\text { Sustainability } \\
\text { O: Health (safety) } \\
\text { Farmer livelihoods } \\
\text { S: value chain } \\
\text { management } \\
\text { M: IP }\end{array}$ & $\begin{array}{l}\text { Vertical: } \\
\text { Donors } \\
\text { Government agencies } \\
\text { SAGCOT } \\
\text { Leadership } \\
\text { Horizontal: } \\
\text { Farmer-Processor } \\
\text { linkages }\end{array}$ & $\begin{array}{l}\text { IR: Rainforest Alliance } \\
\text { standard, government } \\
\text { agencies } \\
\text { RE: extension } \\
\text { CD: } \\
\text { requirement Market } \\
\text { PA: Quality products }\end{array}$ & Implementation \\
\hline Thailand & $\begin{array}{l}\text { Moral Rice } \\
\text { Program: } \\
\text { Dharma Garden } \\
\text { Temple }\end{array}$ & $\begin{array}{l}\text { DF: Moral economy } \\
\text { 0: Community livelihood } \\
\text { S: Local economy } \\
\text { M: EN }\end{array}$ & $\begin{array}{l}\text { Vertical: } \\
\text { IFOAM } \\
\text { Long value chains } \\
\text { Leadership } \\
\text { Horizontal: } \\
\text { Community members }\end{array}$ & $\begin{array}{l}\text { IR: International and } \\
\text { local standards } \\
\text { RE: Volunteer, training } \\
\text { CD: Radio } \\
\text { PA: Quality products } \\
\text { and services }\end{array}$ & Developmental \\
\hline Trinidad & $\begin{array}{l}\text { The Brasso } \\
\text { Seco Paria } \\
\text { Community } \\
\text { Make } \\
\text { Agrotourism } \\
\text { Their Business }\end{array}$ & $\begin{array}{l}\text { DF: Commodity } \\
\text { Sustainability } \\
\text { O: Community livelihood } \\
\text { S: Local economy } \\
\text { M: EN }\end{array}$ & $\begin{array}{l}\text { Vertical: } \\
\text { Donors (IICA) } \\
\text { Horizontal: } \\
\text { Community members } \\
\text { Sister projects }\end{array}$ & $\begin{array}{l}\text { IR: International } \\
\text { standard } \\
\text { RE: } \quad \text { community } \\
\text { association } \\
\text { CD: Tourism } \\
\text { PA: Quality products } \\
\text { and services }\end{array}$ & Developmental \\
\hline Uganda & $\begin{array}{l}\text { Facilitating } \\
\text { social networks } \\
\text { through } \\
\text { FreshVeggies } \\
\text { PGS }\end{array}$ & $\begin{array}{l}\text { DF: Organic Health } \\
\text { O: (nutrition/safety) } \\
\text { S: Local economy } \\
\text { M: PGS }\end{array}$ & $\begin{array}{l}\text { Vertical: } \\
\text { Supermarkets } \\
\text { National NGOs } \\
\text { Donors (UN, Sida) } \\
\text { Leadership } \\
\text { Horizontal : } \\
\text { Producer-consumer } \\
\text { Farmer groups } \\
\text { SACCO }\end{array}$ & 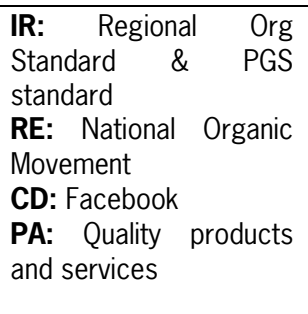 & Developmental \\
\hline Uganda & $\begin{array}{l}\text { The role of } \\
\text { cooperatives in } \\
\text { linking } \\
\text { sustainable } \\
\text { agricultural } \\
\text { practices with } \\
\text { market }\end{array}$ & $\begin{array}{l}\text { DF: Organic } \\
\text { 0: Farmer livelihoods } \\
\text { S: Value chain } \\
\text { management } \\
\text { M: IP }\end{array}$ & $\begin{array}{l}\text { Vertical: } \\
\text { Exporter } \\
\text { National NGOs } \\
\text { University } \\
\text { Leadership } \\
\text { Horizontal: } \\
\text { Farmer groups }\end{array}$ & $\begin{array}{l}\text { IR: Regional Organic } \\
\text { standard, IMO } \\
\text { certification } \\
\text { RE: University linkages } \\
\text { CD: long value chain } \\
\text { PA: Quality products }\end{array}$ & Developmental \\
\hline
\end{tabular}




\section{Part C}

\section{Regime transformations}




\title{
Sustainable development in education: are we ready for change? System innovation and higher education in life sciences
}

\author{
Erika Quendler ${ }^{1}$
}

\section{Abstract}

The role of system innovation is paramount when attempting to effect a change towards sustainable development. Education entities and employers are faced with the increasing need for a training on the manifold aspects of sustainable development to achieve a certain system change. The aim of this chapter is to give an indication on: (i) the discussions around the need for change in Higher Education Institutions; (ii) how the needs of the labour market regarding competences, skills and knowledge for sustainable development can be made transparent in the field of life sciences; and (iii) the role of system innovation in education towards reflecting and elaborating guidelines for further research. The use of multi-level perspective (MLP) helps to gain a holistic view on the interactions between education sector, stakeholders of educational system innovation and the market. As stronger focus on the needs of the market can make education and its approaches more viable in a changing world, at the same time contributing to the continued reinforcement of graduates' employability.

Keywords: System innovation, resilience, competences, knowledge, skills, sustainable development, employment, higher education in Agriculture

\section{Introduction}

All EU countries make substantial investments into education for ecological, social and economic reasons. One problem, however, with reliance on education involves the question of its sustainability. In particular, this concerns the lack of transfer of knowledge, skills and competences acquired in educational institutions to situations in the outside world of family, community, and work for a more sustainable world. Education is one of the main factors empowering individuals to rethink their behaviour, and to consider the idea of sustainable development (SD) within both private and occupational environments. While it is easy to see how such basic skills as reading and writing can be applied in a wide range of contexts, as the education becomes more specialised learning applicability to new situations becomes less apparent.

Contemporary higher education, especially in life sciences, is extremely specialised, yet only a small minority of graduates enter careers where their specialised knowledge, skills and competences can be used directly. The problem is further compounded by the rapidly changing nature of professional knowledge and practice, which makes a good deal of what is learned in formal education redundant or obsolete. Hence in a rapidly changing world, the idea that "more education is better" for a "knowledge society" seems a dubious prescription to foster the flexible learning skills needed to tackle a wide range of new, unforeseen, and increasingly complex problems. This raises the issue of the education for SD as an overall common goal for lasting prosperity, today and tomorrow, which depends on how many people are in work and how they handle SD.

The implementation of aspects and issues of SD in educational programmes in the field of life sciences as well as innovation for the sustainable future of our educational system assume that the market-relevant

\footnotetext{
${ }^{1}$ Federal Institute of Agricultural Economics, Vienna, Austria. Email: erika.quendler@awi.bmlfuw.gv.at
} 
competences, knowledge and skills related to SD have already been identified. However, an extensive review of literature indicated that, although there is a rich and converging debate going on (Grunwald, 2007; Martinuzzi and Zwirner, 2010; Sarewitz and Kriebel, 2010; Van Ackere, Larsen, Morecroft, 1993; Robert, 2000; Scott, Gough, 2003; Willard et al., 2010), such information is not available in the European or international context. Furthermore, high expectations are related to innovations in the educational sector in which classical teaching methods come to their limits and need target-group specific, innovative interventions, both technology-based and with other emphases. One such practical example is the Green Pedagogy (Hochschule für Agrar- und Umweltpädagogik, 2013). Different institutions and organisations have identified educational assessment as an important measure for a resilient development (cf. Saisana, D'Hombres, 2008; OECD, 2013; Tremblay, Lalancette, Roseveare, 2012) and also called for the system innovation and transition in education as a whole (cf. Lander, 2011; Smithers, 2010).

In this context of the on-going debates, the following chapter focuses on: (i) the discussions around the need for change in Higher Education Institutions (HEls); (ii) how the needs of the labour market regarding competences, skills and knowledge for SD can be made transparent in the field of life sciences; and (iii) the role of system innovation in education towards reflecting and elaborating guidelines for further research.

On the one hand, the dialogue between labour market and education begs to be strengthened, but on the other it is fraught with pitfalls. Using the approach of a multi-level perspective (MLP) can help to defuse these and provide a holistic view on the interactions between education, stakeholders of system innovation in education and the market. Looking at the needs of the market, it can help to make education more viable in a changing world. This would enable the emergent fields of education for SD to promote advanced efforts of mainstreaming SD by implementing concrete practices in the educational system, thereby contributing to the continued reinforcement of graduates' employability.

\section{The Need for change?}

According to HEFCE's (2009) vision, our starting point is that over the next years the higher education sector "will be recognised as a major contributor to society's efforts to achieve sustainability - through the skills and knowledge that its graduates learn and put into practice, its research and exchange of knowledge through business, community and public policy engagement, and through its own strategies and operations." For this reason education for SD has to become a central issue for Higher Education Institutions. As observed by the UNESCO Associated Schools (2011), Ministries of Education worldwide are currently examining how to introduce and reinforce the SD dimension throughout the curricula, in the training of teachers, in extra-curricular activities and in non-formal education. There is a need for innovation for several main reasons.

Firstly, education is a construct of the human environment. It should empower humanity in its capacity to act and in its ability to make decisions (Kaiser, 1985). The aim is not to provide an avalanche of "educational wares" but rather to enable informed, decisive, sensible and responsible action. In a professional situation this means conducting one's activities in a way that every development process is connected with the concept of sustainability and resilience. In this respect, our daily working life becomes an SD challenge and potential, that can be explored (cf. Figure 1).

Secondly, the continued reinforcement of employees' employability is essential for each society and its development. Moreover, the official stand point of the knowledge, skills and competence economy is that investment in employability will lead to the creation of highly-trained employees and contribute to eradicating poverty and social exclusion, thereby securing national competitive advantage and prosperity (cf. LeggattCook, 2007). Nowadays, employees are being confronted with changing requirements, such as technologies, procedures and definitions. They continuously have to find innovative solutions for new problems. In general, being in work means acting in complex situations. This requires that the workers, citizens and leaders of today and tomorrow are able to understand complexity and deal with it. 
Thirdly, people might be trained for a given occupation (nurse, engineer, auto mechanic, translator, etc.) in the form of qualifications. In the past a given level of qualification usually ensured a person a degree of lifelong job security. Nowadays, the advent of computers, outsourcing, temping, etc. offers much more viable options for the employer. This has led to massive changes in the employability landscape. The adjustment of knowledge, skills and competences at the right time and place goes along with enhancing employability. The extent, however, to which individuals are aware of their knowledge, skills and competences and its relevance to the employment opportunities available may affect their willingness to undertake training and other activities designed to upgrade their qualification. The European Qualifications Framework (EQF) uses the three qualifiers 'knowledge', 'skill', and 'competence' to describe learning outcomes and qualifications on several levels (see EC, 2008).

Fourthly, employability cannot only be focused on general qualifications. One may say that, in order to broaden our minds and to cope with upcoming duties and responsibilities, we have to include the principles of SD. In fact, in order to cope with the change to a sustainable future, knowledge transfer and skills training together with competence build-up are very important. What is meant here, is an education for SD in a life-long learning process which enables us to adapt quickly to different situations in daily work life as well as in private life, in order to shape a sustainable future (cf. Figure 1). With the background of the Brundtland report (UN, 1987) and the explanations above Martin's (2005) definition of an 'education for SD' might serve for orientation: "Education for SD is the provision of competences to manage and shape life in view of the global environmental, economic and social challenges with social responsibility for present and future generations". These challenges result from the complexity involved in satisfying the reciprocal dependencies of the environmental, economic and social circumstances of the present and future to be managed. The normative implication of such education is anchored in "social responsibility", which temporally also includes the future dimension (present and future generations). The chance of a good life reflects humanity's ability to adapt itself to each challenge that arises. The vocation of education for SD is based on the creation of awareness and identification with one's own immediate environment as well as with the world as a whole. Therefore, it not only consists of imparting knowledge but also of applied political learning (Eschig, 2005). This learning process ensures that people have more knowledge about SD (knowledge), are able to take a position by making an informed choice (ability), develop a preference for one choice over another (will), and have the resolution to make this choice in a real life context (courage).

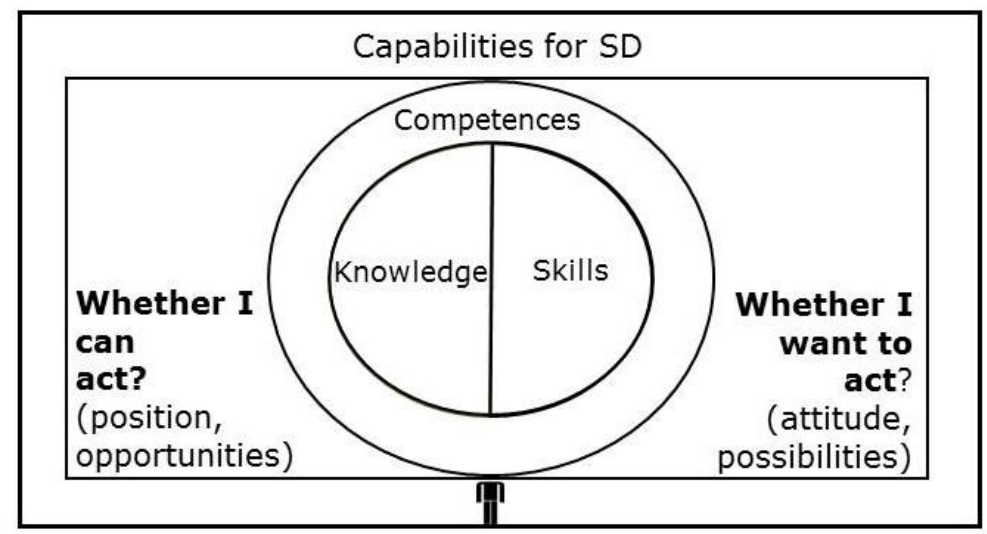

Figure 1: Capabilities for SD performance enablers: competences, skills and knowledge (Quendler et al., 2013a)

Given these capabilities the education for SD should add holistic value to the current university experience ensuring that relevant knowledge, skills and competences are offered, thereby better fulfilling the aspiration of those learning. The question remains: why does the current system continue to prepare the students for 'knowledge worker' jobs when there are clearly many demands and opportunities, as well as predilections for other competences and skills? There seems to be a need to revive the concept of apprenticeship and place more emphasis on learning competences and skills beyond the teaching area. Definitely, there is a need for better definitions about what students need to know from an employers' perspective, and more 
importantly, students need to be taught how to learn and how to teach themselves and others in a life-long learning process.

Nevertheless, there are difficult obstacles on this way. Since most educational systems are government monopolies rather than private enterprises, there is little innovation and little incentive for new entrants. Given the difficulty of starting alternative educational programs, and the rigidity of the existing educational bureaucracy, these experiments are too limited and there is a need for development. We are facing the situation that students have been taught inadequately and are unprepared for many of the roles and responsibilities they must take on. The state governments and localities could better act to allow for much more experimentation, and universities could demand more from people who want to teach, and create new teaching and educational paradigms. Otherwise, businesses will go back to the beginning and create their own schools, to ensure a consistent flow of knowledgeable students with excellent experience.

As a result, the educational system in Europe calls for improvements. In most rankings the European universities rank well down the list in terms of educational achievements (TES Global Ltd, 2014). Possibly, greater demand and political pressure could encourage more experimentation and innovation in this respect (cf. OECD, 2014). At this point we need a disruptive innovation - complete rethinking of the pedagogy, curriculum, technology and intent of education. It could be followed by a restructuring of when and how education is offered and consumed by considering the market's needs.

\section{Matching competences, knowledge and skills supply with labour market needs}

This research is meant to contribute to a better understanding of the complexity of competences, skills and knowledge for SD required by the labour market and to be taught at HEls. Deepening our insights into the context of competences, skills and knowledge for SD should shed light on whether there is a lack of information about competences, skills and knowledge for SD (required by labour market) and how innovation in our educational system can take place. The following section details the data collection, statistical analysis and interpretation used to answer the research questions.

\subsection{Questionnaire and data collection}

The selected dataset originates from two surveys, which were collected by the Innovation in the Teaching of Sustainable Development in Life Sciences in Europe (ISLE) network partners and serves as a basis for analysis. The target groups were HEls in life sciences and companies. The education survey gathered data from students, professors, staff and relevant partners in each of the network's member institutions, in order to identify the current status of the integration of SD into the institutions and studies, related to the field of life sciences. It was carried out from 10 May to 10 June 2011. The total number of replies in the raw database was 2,937 students and 852 academics. The company survey - aimed to map genuinely and comprehensively the tasks, functions and opportunities of education for SD in daily working life as already perceived by employers - was launched from 1 August till 7 October 2011. The total number of replies in the raw database was 959. The results indicate a trend for Europe. Its accuracy depends, inter alia, on the sample size and the number of answers collected. To evaluate and compare responses obtained from the HEls coherently (education survey: data on SD competences taught at universities or colleges) and those obtained from the employers (company survey: data on SD competences requested), the two databases had to be rearranged to allow a joint data-set with a good matching between the variables. The comparison of competences, knowledge and skills taught and required in daily work is based on the calculation of regression (Quendler et al., 2013, p31ff). 


\subsection{Statistical analysis and interpretation}

Responses in the questionnaire were expressed by the assignment of a score following personal beliefs of each respondent. The scores ranged from 1 to 5 (score 1 means that the topic is considered completely unimportant, while score 5 , on the other hand, indicates a very relevant concern). Each question is related to a particular SD "dimension", such as competences, skills and knowledge (Quendler et al., 2013, p24ff). Each "dimension" is described by several individual "attributes" that characterise it (for example: the dimension of "knowledge" is characterised, among others, by the following "attributes" or "descriptors": environmental justice, ecological economics, globalisation, human rights, and so on).

A simple and straightforward method to process this data statistically is to compute the average values of the score assigned to every attribute. According to this approach, no statistical inference can be drawn from the data and the analysis is limited to a simple description of the results. The degree of association or, in other words, the measure of dependence between the two quantities (scores assigned by 'company' and by 'education') was determined by calculating the correlation coefficient. The Pearson correlation is +1 in the case of a perfect positive (increasing) linear relationship, -1 in the case of a perfect negative (decreasing) linear relationship and some value between -1 and +1 in all other cases, indicating the degree of linear dependence between the two variables. A Pearson coefficient close to zero identifies the absence of correlation. The statistical analysis was run, using the Statistical Package for Social Sciences (SPSS 19.0) (Quendler et al., 2013, p26).

\section{Results}

According, to the survey results, a more educated and trained workforce is a more employable workforce. Generally, HEls need to impart the right mix of competences, skills and knowledge both to meet student needs and to match the requirements of the labour market. By comparing competences, skills and knowledge for SD at employers' level to responses from the educational side (Figure 2) shows that companies attribute more importance to all SD competences, skills and knowledge than universities do in their education. This is substantiated by a significantly higher average score of company (3.52), compared to education (HEIs) (2.79) results. Furthermore, 'future orientation' (C3) and 'social responsibility' (C1) are considered the most important competences in general, both by education (HEls) and companies. Companies also ranked 'system orientation' (C2) and 'analysing environmental impacts' (S1) as very important. However, skills like 'pollution trading' (S3) or 'reducing environmental impacts' (S2) are not considered very relevant. From the side of education, 'analysing environmental impact' (K3) and the 'social aspect of SD' (K7) are the most important ones; while 'general SD knowledge' (K1) and 'reducing environmental impacts' (K4) are the least relevant (Quendler et al., 2013, p62f). 


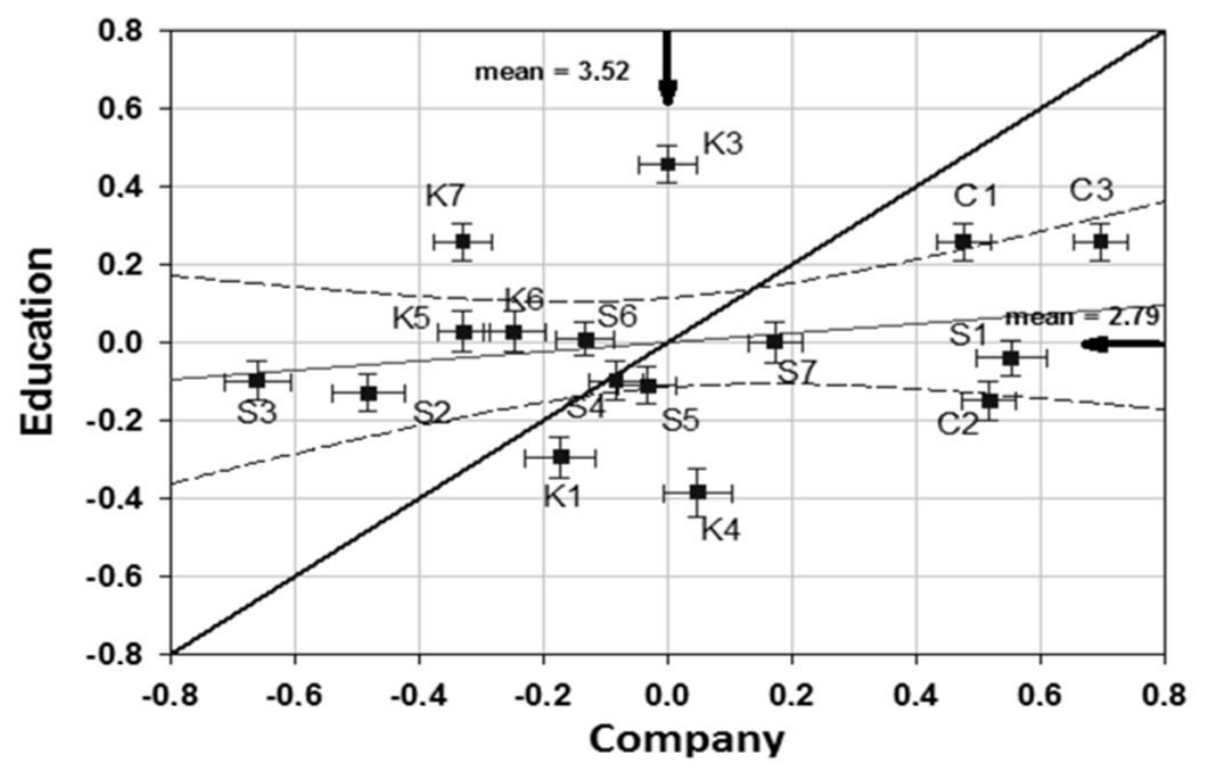

Figure 2: Comparison of the competences, skills and knowledge analysed in education (HEls) and at employment level (Quendler et al., 2013, p64).

Legend:

COMPETENCES (C): C1. Social responsibility, C2. System orientation, C3. Future orientation.

SKILLS (S): S1. Analysing environmental impacts, S2. Reducing environmental impacts, S3. Pollution trading, S4.

Economic optimization, S5. Communicating, S6. Implementing sustainability, S7. Leadership and teamwork.

KNOWLEDGE (K): K1. General SD knowledge, K3. How to analyse environmental impacts, K4. How to reduce environmental impacts, K5. Economics, K6. Value of nature, K7. Social aspects of SD.

It is a mixture of a lack of visibility and knowledge on the current and future supply and demand of issues, competences, skills and knowledge related to SD that prevents a better match between them. This is coupled with the inertia of education and training systems alongside labour market failures (Quendler et al., 2013, p68).

Nevertheless, there seems to be an overall consensus that in the future, SD would probably be a concept included well within the competences, skills and knowledge already required by the labour market. Moreover, currently only $26 \%$ of the respondents are looking at SD criteria when recruiting new employees. This notwithstanding, $71 \%$ of participants in the survey agreed that it is important that graduates have an excellent scientific/technological knowledge in their field of expertise (Quendler et al., 2013, p61).

The study (Quendler et al., 2013) finds that, although countries are moving towards a holistic and integrated approach to the provision of basic education, systems still have enormous difficulties in changing the fundamentals of teaching and learning in a way that proficiency in core competences, skills and knowledge can be acquired by all. Key challenges relate to the nature of pedagogical processes; the education and development of teachers; the effectiveness of educational leadership, supervision and professional support; the content and usage of materials and assessment systems; and the relationships between schools and the wider socioeconomic and cultural environment.

\section{Educational Innovation system for a sustainable future}

The ability of educational institutions and stakeholders to respond with innovation to the complex expectations inherent in education for SD can be supported by a multi-level perspective (MLP) on teaching and learning. The MLP has emerged as a fruitful middle-range framework for analysing socio-technical transitions to sustainability (Geels, 2011). The MLP promotes inter-disciplinarity as it addresses challenges 
to local or planetary sustainability at different levels. This is vital for innovation in education for SD and includes systems-thinking, intergenerational responsibility, the protection and enhancement of shared natural resources, the awareness of driving forces, and adopting strategic responsibility (McKeown and Hopkins, 2009; Gallagher and Hogan, 2000). The focus is on education for SD, its evolutionary transition path and the relevant stakeholders which shape its success. The results of the survey of higher education in the field of life sciences, as a case study, should help to generate high levels of innovative teaching for this education. By doing so, this allows students and employees to use knowledge, skills and competences in new and creative ways. More sustainable practices can be developed and better solutions to current issues may be achieved (Tilbury and Mulà, 2009, p7).

In this section we briefly review some recent perspectives on innovation systems from the MLP. For more information about the MLP and system innovation please see the relevant literature (e.g. Geels, 2002; Geels and Schot, 2007; Grin, Rotmans, Schot, 2010; Schot, 1998).

\subsection{System innovation in education}

But what do we mean by system innovation in education - and does it really matter? Is it simply the rebranding of things we have been doing forever? And most importantly, will it last longer than last year's headlines? Will it matter to our grandchildren someday?

Underlying the discussion on innovation systems is an understanding of innovation as an evolutionary process (cf. Barbier and Elzen, 2012; Foxon, et al. 2004; Geels 2004, 2005, 2011; Loorbach and Rotmans, 2006; Rotmans et al., 2003; Saadat et al., 2014) in which knowledge, skills and competences are combined enabling us to adapt quickly in the different situations in daily work as well as private life in order to shape the sustainable future. Professional ambition means being where the action is - and the action is happening in organisations that are creative, connected and cooperative. So an approach that considers all these aspects - and possibly also their interrelationships - is necessary (Chiodo, 2013).

In its essence, system innovation refers to new approaches and tools for solving system challenges for a sustainable future (cf. Edquist, 2001; Kemp and Rotmans, 2004; Lundvall, 1992; Smits and Kuhlmann, 2003; Rotmans et al., 2003). We have learned a lot over the past decade about what works and what does not in global education, development, sustainability, and many other challenging areas. Moreover, we have learned how to design and deploy interventions in organisational processes aiming toward changes. We should now have a clear perspective on which knowledge, skills, competences and interventions have the potential actually to alter the course of some of our dead end approaches (climate change, desertification, etc.), based on the evidence of actual outcomes. One may say that such changes typically involve the coevolution of a number of related elements, including technology, infrastructures, symbolic meanings, governance structures, scientific knowledge, industry and related institutions, etc. (cf. Foxon et al., 2004; Geels, 2004). But it is common that behind this there is education, a special need for knowledge, skills and competences for a sustainable future (cf. Figure 2). We believe that the very best system innovations, for instance e-learning, can transform our education system with new approaches to the complex challenges of the 21 st century.

However, achieving that kind of impact requires yet another step. Unless a program can be replicated and sustained on a large scale, it will not be transformational. Identifying and scaling our best solutions has become the sector's most important challenge. To meet that challenge, we can no longer evaluate programs simply based on how well they have performed in a given locality. Instead, we need to factor in the extent of their potential performance. We need to channel resources to the solutions that can produce the most goods for the most people. As Judith Rodin (in Norman, n.d.), president of the Rockefeller Foundation, has pointed out: "Solutions to many of the world's most difficult social problems don't need to be invented, they need only to be found, funded, and scaled."

It is mandatory for all of us to understand and vigorously address the barriers that prevent great ideas from turning into transformational changes. Unlike in the private sector, where successful product innovations 
have a clear process for gaining market share, the best educational innovations are not necessarily widely adopted. The challenges of education nowadays, and thus learning, are not only individual, they are also a social phenomenon concerning all stakeholders.

\subsection{The stakeholders of system innovation in education}

A multi-level perspective enables us to embrace this range of influences on innovation, and adopt a holistic view to the description and evaluation of an educational system in the field of life sciences. One definition of innovation for education in the field of life sciences is:

"Innovation within the teaching of sustainable development in the life sciences involves the creative process of combining up-to-date teaching methods, tools, and technologies recognising the opportunities and constraints inherent in the particular situation where learning is taking place" (cf. Weingirl, 2013, p33). Furthermore, system innovation for education is built on that set of distinct stakeholders which jointly or individually contribute to the development of a sustainable future and diffusion of sustainable practises and which provides the framework within which governments form and implement policies to influence the educational innovation process for a sustainable future. As such it is a system of interconnected institutions to create, store and transfer the knowledge, skills and competences for SD which defines the third mode type (cf. Metcalfe, 1997, p461ff).

Figure 3 provides one perspective on the set of stakeholders involved in higher education in life sciences and how they are related and work together. At the heart of the system are the key processes of knowledge, skills and competence generation, diffusion and exploitation which are shaped by the capabilities of employees in organisations or firms and the strength of their relationships. Supporting these activities are other aspects of the commercial, technological and regulatory environment within which education and firms (private industries) operate. The outcome of this complex set of capabilities and linkages is national innovative capacity, a key determinant of economic performance.

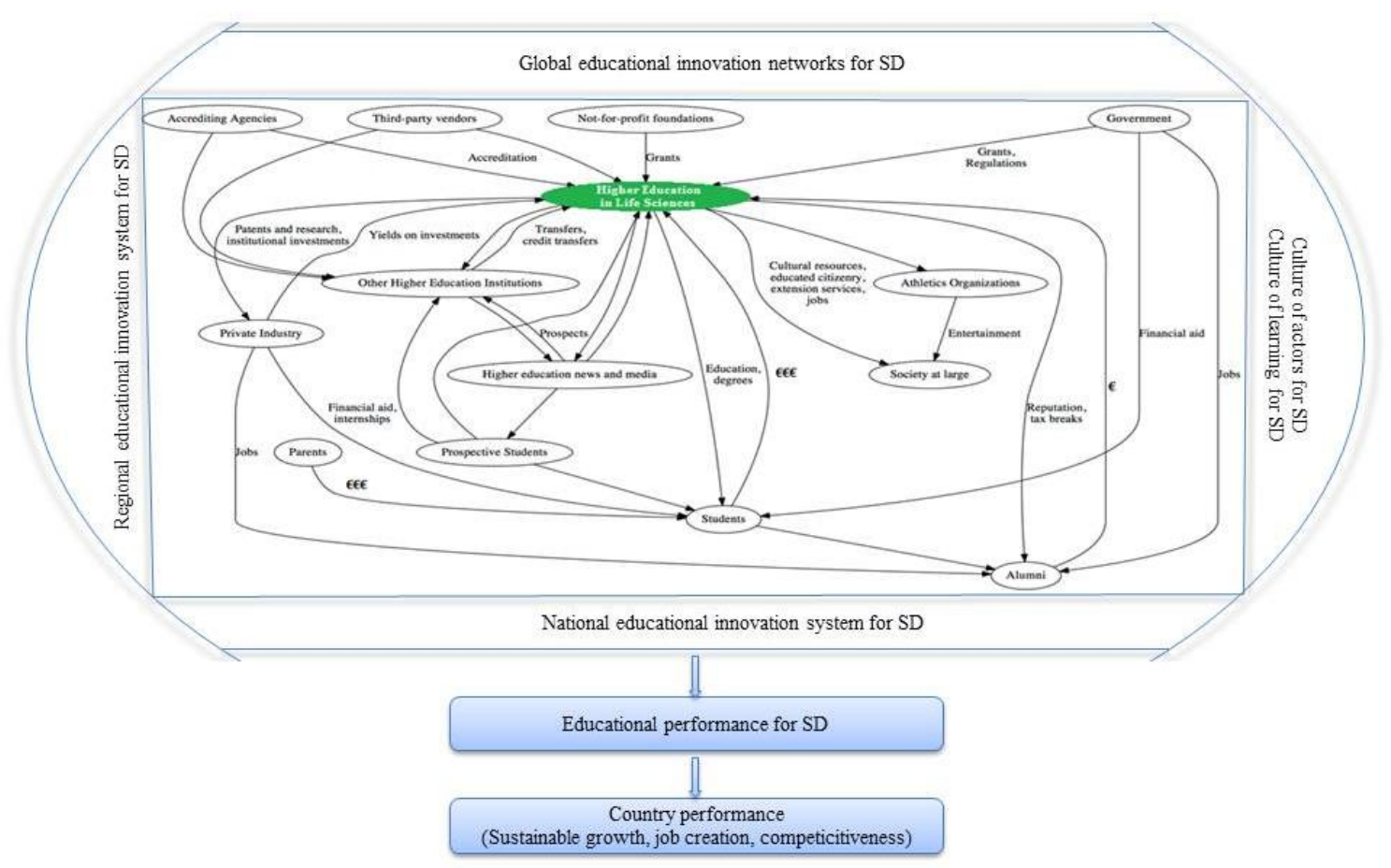

Figure 3: A map illustrating the relationships between various institutional stakeholders in higher education of life sciences (adapted from the OECD, 1999; Borwick, 2013). 
It is quite obvious that a multi-stakeholder and multi-disciplinary approach is very important. Therefore the identification of the stakeholders (and of their roles, motivation and mutual interactions), is a fundamental aspect in setting the proper conditions to support the transition process of educational innovation. In other words, the creation of a network made up of different socio-economical stakeholders is vital.

Nevertheless, it is important to remark that stakeholder involvement is a continuous and iterative activity throughout the entire educational process. This creates a need to define not only actors that are included but also when they need to be involved (in which phase of the transition process of educational innovation), and at what level they need to be involved. In other words, we are dealing with a stakeholder network which is not static, but dynamic, because the actors and also the related interactions could change dramatically along the way. A network needs to be capable of evolving in time and in relation to the specific needs. This evolution represents an important and fundamental element of the entire transition path.

\subsection{Characteristic phases in the 'evolutionary' transition path}

The key point is that educational system innovations come about through the interplay between dynamics at multiple levels. Several phases can be distinguished in transition (Rotmans et al., 2001). In the first phase, novelties emerge in the context of existing regime and landscape developments. One such practical example is Green Pedagogy (Hochschule für Agrar- und Umweltpädagogik, 2013). There is not yet a dominant design, and there may be various pedagogical concepts and technical forms competing with each other. Actors improvise, engage in experiments to work out the best design and find out what users want.

In the second phase the novelty is used in small market niches, which provide resources for technical specialisation. Gradually, a dedicated community of HEl's, teachers and students emerges, collectively directing their activities to improve the knowledge, skills and competences for SD in the form of the Green Pedagogy (new technology). Teachers develop new teaching methods, such as systemic constellations (Nikisch and Müller-Christ, 2013), and behavioural aspects in cooperation with the students, but also considering the market's needs. The new concept and teaching methods gradually improves, as a result of learning processes. As students interact and incorporate knowledge, skills and competences improvement for SD into their user practices as well as daily lives, they gradually explore new functionalities. This second phase results in a stabilisation of rules, e.g. a dominant design, an articulation of students and employers' preferences (A. novelties, that survive and develop into innovations).

The third phase is characterised by a breakthrough of the new concept and teaching methods, wide diffusion and competition with the established regime - going hand in hand with the growing numbers of alumni. On the one hand, there are internal drivers for breakthrough, e.g. higher employability, increasing number of students, and actors with interests that push for the further expansion of the new concept and teaching methods. On the other hand, breakthrough depends on external circumstances and 'windows of opportunity' (see Figure 4). The regime may come under pressure from changes at the landscape level or there may be internal technical problems in the regime, which cannot be met within the landscape level. Alternatively, there may be internal technical problems in the regime, changing user preferences (students, market's needs) or stricter regulations, which create problems for the existing concept and teaching methods. The key point of the MLP is that system innovations occur as the outcome of linkages between developments on multiple levels. As the new concept and teaching methods enter the mainstream educational market, they enter a competitive relationship with the established regime (B. regime changes, representing a system innovation).

In the fourth phase the new technology (i.e. concept, teaching methods) replaces the old regime, which is accompanied by changes in wider dimensions of the socio-technological regime. This often happens in a gradual fashion, because the creation of a new socio-technological regime takes time (C. landscape changes, representing a transition). 


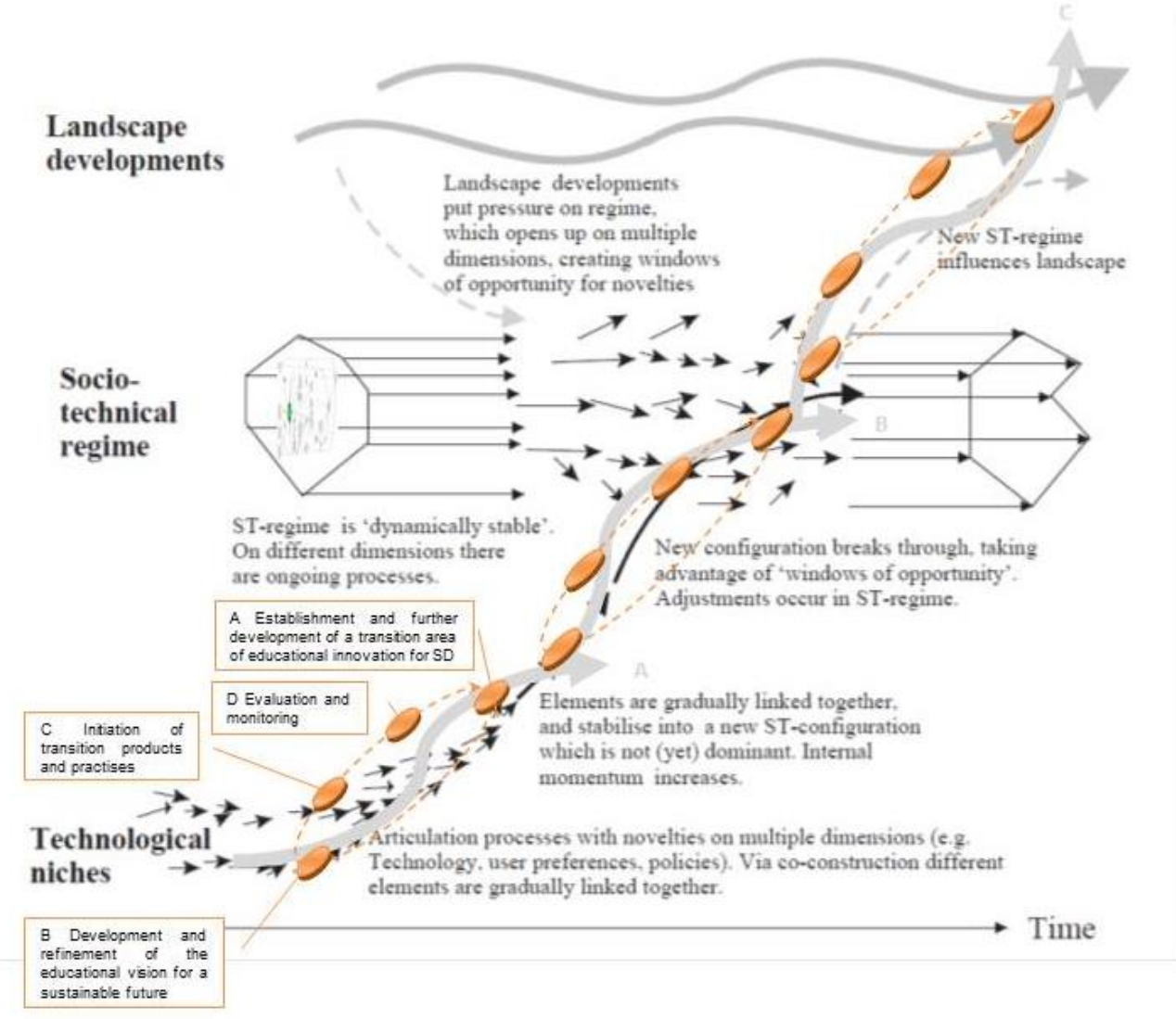

Figure 4: A dynamic multi-level perspective on system innovation (adapted from Geels, 2002; and Geels, 2005a).

"An important aspect of the MLP is to do away with simple causality in system innovations" (Geels, 2005a, p453), but consider that at each stage and in each phase there are several circles of revision in the form of (a) the Establishment and further development of a transition area of educational innovation for SD, (b) the Development and refinement of the educational vision for a sustainable future, (c) the Initiation of transition products and practises, and (d) the Evaluation and monitoring (see Figure 5). "There is no simple 'cause' or 'driver'. Instead there are processes at multiple dimensions and levels simultaneously. System innovations come about when these processes link up and reinforce each other ('circular causality')' (Geels, 2005a, p453).

Having seen the complexity of this dynamic process, it would be important to look at it in terms of educational outcomes and how the latter can contribute to the transition in practice.

\subsection{Key outcomes for employees from education for SD}

In order to deal with the dynamics of educational system innovations on multiple levels, it is possible to identify a series of six alumni or employee functions, which together contribute to the development of the innovation capability of education for SD. These are:

- Function 1 - Policy making - Employees working in organisations within this function will have broad social and economic agendas and a need to balance innovation for SD along with other policy priorities. At best such employees will take into account the potential impact of policy decisions on national innovation capability, and will act to strengthen the framework conditions within which system development for SD can take place. A key aspect of this element of the governance system is compliance between the different policy levels. 
- Function 2 - Innovation policy formulation and implementation for SD - Employees of organisations within this function will generally have an emphasis on local, regional, national or global SD but may also have specific objectives relating to innovation support. The focus is on the development and design of innovation support measures and other SD initiatives rather than their implementation. At best employees adopt a systemic perspective allowing them to address systemic failures or bottlenecks and resolve gaps or mismatches in system capabilities for SD.

- Function 3 - Support and direction of innovation, research and development - Dominated by publicly funded bodies, the key activities within this function are public support for knowledge, skills and competences creation, business innovation, research and development for SD. At best, employees provide responsive and flexible support for firms, adequate financial support for socially optimal levels of R\&D and innovation activity, and are accessible to firms in each sector and sub-region.

- Function 4 - Undertaking research and development - This function is dominated by organisations whose corporate objectives relate to knowledge, skills and competences creation (i.e. research organisations). This includes the universities, third-level colleges as well as public and industry research organisations. At best, this sub-system is populated by organisations with strong internal capabilities, dense and evenly distributed network links to other local organisations and 'open' external links to global centres of best practice (Braczyk et al., 1998). The key capabilities of this function for local innovation are threefold: the ability to generate new knowledge, skills and competences of employees applicable to local firms or markets; the ability to capture knowledge, skills and competences of employees with local applicability; the ability to provide training in knowledge, skills and competences for SD which are retained within the region.

- Function 5 - Facilitating and conducting knowledge, skills and competences diffusion Intermediate organisations whose function is knowledge brokering or diffusion. Key capabilities relate to the ability to identify valuable technologies or knowledge or skills or competences and to match this with appropriate (and local) exploitation mechanisms. Arguably such institutions play a particularly important role in mediating between knowledge generating organisations (e.g. universities) and smaller firms who may have less capability in identifying valuable technologies and a reticence to engage directly with knowledge, skills and competences generators.

- Function 6 - Knowledge, skills and competence exploitation - Primarily employees are linked through (vertical) local supply-chains and trading relations and (horizontal) collaborative networks. Here, the main objective is the exploitation of the knowledge-base to generate competitive products and services for SD, and so achieve enhanced profitability or business value. At best, firms have strong internal innovation capabilities. Local supply-chain linkages become robust and characterised by strong flows of knowledge, skills and competences between trading partners. Horizontal collaboration networks are ubiquitous.

\subsection{Linkages and spillovers}

System innovators recognise that there are also barriers, especially in the form of lack of knowledge or educational level, and are working to overcome them. A literature review (cf. Bowen, 2012; Coudly et al., 2000) points to four major opportunities that support our belief in the power of innovation in education for SD and provide insight into the path forward to scaling up the most promising solutions:

- Technology innovation: There has been a rapid development of products that can improve the transfer of knowledge, skills and competences from A to B in a very short period of time. Compared with other innovations that involve local social mobilization models, technology platforms designed for bottom-of-the-pyramid markets often scale remarkably well.

- Geopolitical shifts: Rapid economic development in some regions and countries, including India, China, and Brazil, is bringing new resources and perspectives to (system) innovation on a massive scale. China, for example, has moved the largest number of people out of poverty in the shortest period of time, in history. Tapping into the development lessons, increased resources, and powerful capabilities these countries are generating provides new and different fuel to the system innovation engine for education as well as useful insight into what could be effective elsewhere. 
- Cross-sector collaboration: We have moved beyond community solutions provided by churches, extended families, and government, to transformative innovations created through public, private, and non-profit collaborations. This includes new vaccines and diagnostics, new funding mechanisms such as social impact bonds, and new educational initiatives. Many collaborative approaches take advantage of economies of scale and market mechanisms to use resources more efficiently to produce positive outcomes on a greater scale.

- Knowledge, skills and competences sharing: In addition to creating partnerships, increased knowledge sharing between organisations and across sectors is helping to identify the most promising solutions. For the past several decades, the educational sector has been developing the capacity to evaluate and measure the impact of programs. This work provides the building blocks for the next phase of progress, in which innovators will be able to harvest the knowledge, skills and competences about what works and is currently distributed across the globe in companies. While these trends point to a tremendous flourishing of innovation, the work of the next generation of innovators will be to identify the ideas that produce results and ensure that limited resources are used to spread the best solutions. The vast impact could be achieved, if all the effort invested in addressing SD challenges were channelled to the widespread expansion of the most powerful programs. Bringing the best interventions - but also knowledge, skills and competences - to the people who need them most on a scale proportional to the size of the global problems we face is the major challenge facing the SD of our world.

\section{Reflections and guidelines for further research}

\subsection{General conclusions and remarks}

Competences, skills and knowledge form the bedrock of a country's economy and prosperity. They are not only linked to aggregate economic performance but also to each individual's success on the labour market. However, having competences, skills and knowledge is not enough. To achieve a sustainable growth, both for a society and an individual, not only these competences, skills and knowledge have to be put into productive use at work. They also have to be trained at an educational level.

This contribution reflects the growing interest in competences, skills and knowledge for SD and shows different patterns:

- $\mathrm{HEl}$ and company related: Firms attribute more importance to all SD competences than HEls do in their education. 'Future orientation' and 'social responsibility' are considered the most important competences, both by HEls and companies. In contrast, skills like 'pollution trading' or 'reducing environmental impacts' are not considered very relevant. The results also admit room for improvement.

- HEl related patterns: At present universities and research centres are good at limiting complexity. Most research is done on narrow issues, with simplified models, without looking at their real life implementation. This can even lead to an absolutely clear answer to an unrealistic question. This is expected to change: researchers could consider both a narrow issue and its broad application.

- Student related patterns: If one learns for SD, one wants to put the knowledge in practice. Students ask for applications. What can they do? Education for SD is about learning to know, learning to do, learning to be and learning to live together. In education for SD there should always be a prospect of action. It is important to look at the issue from different angles (theoretical, practical, social, economic and ecological). The difficulty is that it depends on the context. In the educational setting of a primary school complexity should be addressed in a different way than in an educational setting at a university or a company.

- Alumni related patterns: Professionals in SD will require new ways of thinking as well as certain competences, skills and knowledge to be able to contribute to the achievement of the goals of SD. This will also require changes in the training in life science of HEls. Thus, 'education and training' and 'work' will no longer be two separate entities. They will be much more integrated into a single 
lifelong learning process, open to innovation and accessible to everybody (cf. Green Pedagogy, systemic constellation).

The competences, skills and knowledge analysed go beyond those that individual alumni or professionals would have in order to provide a good quality work in their discipline. This set of competences, skills and knowledge is not a "minimum standard" to be met by all alumni or professionals, but rather a goal to which all alumni or professionals should aspire. It is not intended to prescribe behavioural outcomes. It rather provides a framework for the professional development of alumni or professionals and is of particular importance to individuals, groups and institutions that have a multiplier effect, such as the educators of alumni or professionals.

- Stakeholder-related patterns: It needs to be emphasized that, above all, educational efforts for SD could be based on cooperation between educational institutions, the authorities and companies. There could be a combination of initiatives which encourages companies towards new codes of practice that meet the needs for a continuous SD.

- Value-related patterns: The problem with this goal is that nowadays most people try to optimize their income. This could be refocused towards contribution to the society, i.e. that the majority are motivated to bring something into the society and make it better. Education for SD only works when we are able to focus on specific parts of the issue and at the same time able to look at the broad spectrum of the problem.

- Level-related patterns: The starting point for change can be found at the individual and regional level. Here all stakeholders can be brought together; here one can learn from formal, non-formal and informal learning settings.

- Culture- and ethics-related patterns: It also needs to be stressed that educational efforts for SD could reflect on the cultural and working ethics of a company in a country. Certain standards are developed in a society based on the cultural context of living and working. If the incorporation of the concept of SD in basic business decisions can be made both economically advantageous and a part of good business management, companies will be more active in this sense.

- System innovation-related patterns: In times of crises, society needs education or knowledge, skills and competences enabling innovative solutions and opening up new horizons. As Einstein put it, "problems cannot be solved by the same level of thinking that created them". Therefore, effective solutions need to be sought at a systemic level. Education plays a key role in raising awareness of social responsibility and SD that meets the needs of the present without compromising the ability of future generations to meet their own needs.

\subsection{Moving towards knowledge, skills and competences resilience}

"It is not the biggest, the brightest, the best that will survive, but those that adapt the quickest." (Charles Darwin in Jarche, 2007) This leads the discussion to the concept of what is needed to adapt: Resilience is defined as "an ability to recover from or adjust easily to misfortune or change" (Merriam-Webster, 2014). Perseverance is defined as "The continued effort to do or achieve something despite difficulties, failure, or opposition" (Merriam-Webster, 2014) and transition is defined as "the shift from an initial dynamic equilibrium to a new dynamic equilibrium" (Kemp and Rotmans, 2001). These definitions have the following common denominator: one has to adapt in order to evolve. Currently one talks about transition in terms of "modes" (cf. Doray et al., 2009; Geels, 2005, p687). 


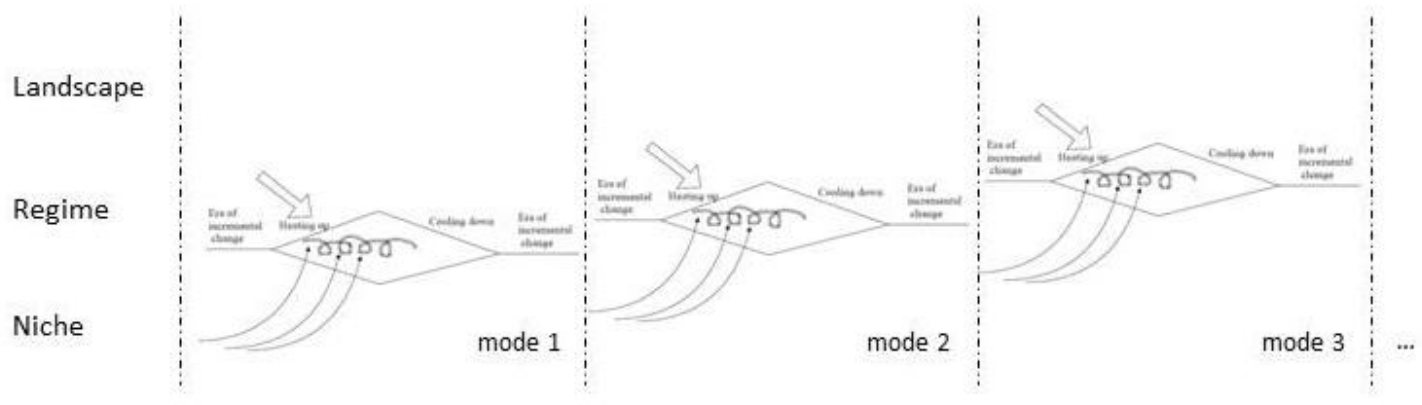

Figure 5: Wider transition routes as modes in system innovations (adapted from Geels, 2005, p688).

One may say, people take our current circumstances for granted. The author does not think that there is any doubt that we are shifting our educational systems and we are going to need new social-organisational structures to support how we live and work. Research on innovation, knowledge and design practices, for example in the field of the agro-food sector, can be considered as pivotal examples of what Gibbons et al. (1994) called a mode 2 type of knowledge production. Taking it a step further there is a need to rethink how we generate knowledge. What are the knowledge, skills and competences trained for a sustainable future in a way that innovation can take place in pedagogy, curriculum, technology and the intent of education? How do we restructure the way education is offered and consumed to align it to market needs with a view to a system change?

In a knowledge-based economy, educational performance (at university or in business) requires learning, all the time. Things like annotating, filing, reflecting, discussing and testing are already part of everyday student life and work. If one needs to be a creative problem-solver, then one will have to conversant with these tasks. A lot of students or workers are still not used to this, and those who want to be creative and flexible are often stymied by regulations and work structures.

Part of the transition strategy for any educational system that aims at building a third wave (or mode type), in the form of knowledge, skills and competences resilience, into its second wave structure will be the development of transition and system innovation in education. In this sense, system innovation cannot be designed in a top-down fashion because system innovations are the outcomes of the co-evolution processes. New knowledge, skills and competences are being created, new institutions and associations emerge out of processes of socio-technical alignment. System innovations involve various elements and processes, each of which is feeding on the other. There is an element of self-organisation: structure emerges out of interaction.

\subsection{Further research topics}

The following research questions could be addressed in the future, in order to foster sustainable education:

- How education for SD can, at all levels, best contribute to the transition process, building resilient individuals, resilient communities and resilient learning institutions?

- How can system innovation for sustainable education be influenced by different actors and cultural ethics, in particular by governments? Is there a need for capacity building for an institutional and cultural framework favourable to SD education?

- What are the lessons learnt from historical examples of transitions, and which instruments and policy tools can be used to stimulate future system innovations towards sustainable education?

- Transition, the adaptive capacity of individual workers, or their ability to deal with a dynamic environment, is built upon boundary controls that include sensory and response processes at work. Does an ever changing, complex (dynamic) environment require a feedback system to education? 


\section{References}

Barbier, M. and Elzen, B. (2012) System Innovations, Knowledge Regimes, and Design Practices towards Transitions for Sustainable Agriculture. INRA [online], posted online November 20. URL: http://www4.inra.fr/sad_eng/Publications2/Free-ebooks/System-Innovations-for-SustainableAgriculture (accessed August 2014).

Borwick, J. (2013) Mapping the system of US higher education. URL: http://www.heitmanagement.com/blog/2013/09/mapping-the-system-of-us-higher-education/ (accessed August 2014).

Bowen, G. (2012) The 'Cost Disease' in Higher Education: Is Technology the Answer? Transcript of two talks at The Tanner Lectures, Stanford University, October 2012.

Braczyk, H-J., Cooke, P. and Heidenreich, M. (eds.) (1998) Regional innovation systems: the role of governance in a globalised world. London and Pennsylvania: UCL.

Chiodo E. (ed.) (2013) Sustainable Development in Higher Education in Europe. Good Practices Compendium. ISLE Work Package 3 Final Report. Edizioni Homeless Book.

Coubly, D., Cowen, R. and Jones, C. (2000) Education in Transition. World Yearbook of Education 2000. First issued in Paperback 2012. Routledge 2012.

Doray, P., Comoe, É., Trottier, C., Picard, F., Murdoch, J., Laplante, B., Moulin, S., Marcoux-Moisan, M., Groleau, A. and Bourdon, S. (2009) Educational Pathways and Transition Modes in Canadian Postsecondary Education. Number $45 . \quad$ URL: http://www.cirst.uqam.ca/Portals/0/docs/projet_transitions/TransitionsNote4-en-Final.pdf (accessed August 2014).

Edquist, C. (2001) Innovation policy - a systemic approach. In: Archibugi, D., Lundvall, B-A. (eds.) The Globalizing Learning Economy. Oxford University Press.

Eschig, G. (2005) Dekade "Bildung für Nachhaltige Entwicklung". In: Linder, W. (Hrsg.). Bildung für Nachhaltige Entwicklung. Bundesministerium für Unterricht, Kunst und Kultur, http://www.bmukk.gv.at/medienpool/18309/bine_linder.pdf (accessed August 2014).

Foxon, T., Makuch, Z., Macarena Mata, M. and Pearson, P. (2004) Innovation Systems and Policy-Making Processes for the Transition to Sustainability. In: Jacob, K., Binder, M. and Wieczorek, A. (eds.) Governance for Industrial Transformation. Proceedings of the 2003 Berlin Conference on the Human Dimensions of Global Environmental Change, Environmental Policy Research Centre: Berlin: 96-112.

Geels, F. (2002) Technological transitions as evolutionary reconfiguration processes: a multi-level perspective and a case study. Res. Policy 31: 1257-1274.

Geels, F. W. (2004) Understanding system innovations: a critical literature review and a conceptual synthesis. In: Elzen, B., Geels, F. W., Green, K. System Innovation and the Transition to Sustainability: theory, evidence and policy. Cheltenham: Northampton: Edward Elgar: $19-47$.

Geels, F.W. (2005) Processes and Patterns in Transitions and System Innovations: Refining the Coevolutionary Multi-level Perspective. In: Technological Forecasting and Social Change 72: 681696.

URL: http://www.transitionsnetwork.org/files/Geels\%202011\%20EIST\%20response\%20to\%20seven\%2 Ocriticisms.pdf (accessed August 2014).

Geels, F.W. (2005a) The Dynamics of Transitions in Socio-technical Systems: A Multi-level Analysis of the Transition Pathway from Horse-drawn Carriages to Automobiles (1860-1930). Technology Analysis \& Strategic Management. Vol. 17, No. 4: 445-476, December 2005. URL: http://users.wpi.edu/ chamel/3.\%20Geels\%202005\%20automobile\%20transition\%20TASM\%20(1) .pdf (accessed August 2014).

Geels, F.W. (2011): The multi-level perspective on sustainability transitions: Responses to seven criticisms, Environmental Innovation and Societal Transitions, 1(1): 24-40. URL: http://www.transitionsnetwork.org/files/Geels\%202011\%20EIST\%20response\%20to\%20seven\%2 Ocriticisms.pdf (accessed August 2014).

Geels, F. and Schot, J. (2007) Typology of socio-technical transition pathways. Res. Policy 36: 399-417.

Grin, J., Rotmans, J. and Schot, J. 2010. Transitions to sustainable development. New directions in the study of long term transformative change. Routledge, New York, London. 
Gibbons, M., Limoges, C., Nowotny, H, Schwartzman, P.S. and Trow, M. (1994) The new production of knowledge: the dynamics of science and research in contemporary societies. London: Sage.

Grunwald, A. (2007) Working towards sustainable development in the face of uncertainty and incomplete knowledge. J Environ Policy Plan 9(3): 245-262.

HEFCE - Higher Education Funding Council for England (2009) Sustainable development in higher education. URL: http://www.hefce.ac.uk/media/hefcel/pubs/hefce/2009/0903/09 03.pdf (accessed August 2014).

Hochschule für Agrar- und Umweltpädagogik (2013) Grüne Pädagogik. Vom Theoriefundament bis zu professionsorientierten Lernarrangements. Wien: AV Astoria.

Jarche, H. (2007) Small steps toward knowledge resilience. URL : http://jarche.com/2007/08/small-stepstoward-knowledge-reslilience/(accessed March 2015).

Kaiser, A. (1985) Sinn und Situation. Grundlinien einer Didaktik der Erwachsenenbildung. Bad Heilbrunn/Obb.: Klinkhart.

Kemp, R. and Rotmans, J. (2001) The Management of the Co-evolution of Technological. Environmental and Social Systems, paper for the conference Towards Environmental. Innovation Systems, Eibsee, 2729 September 2001.

Kemp, R. and Rotmans, J. (2004) Managing the transition to a sustainable mobility, forthcoming. In B. Elzen, Geels, F., Green, K. (eds.) System Innovation and the Transition to Sustainability: Theory, Evidence and Policy, Cheltenham: Edgar Elgar: 137-167.

Kemp, R. and Loorbach, D. (20069 Transition management: A Reflexive Governance Approach. In: Voss, JP., Bauknecht, D. and Kemp, R. (eds.) Reflexive Governance for Sustainable Development, Edward Elgard, Cheltenham, UK: 103-130.

Kemp, R., Loorbach, D. and Rotmans, J. (2007) Transition management as a model for managing processes of co-evolution. The International Journal of Sustainable Development and World Ecology (special issue on (co)-evolutionary approach to sustainable development), 14: 78-91.

Lander, R. (2011) Transition in Action: Transition Edinburgh University. In: Hopkin, R. (2011). The Transition Companion: making your community more resilient in uncertain times. Chelsea Green Pub Co $(9$. November 2011). URL: https://www.transitionnetwork.org/ingredients/deepening/educationtransition (accessed August 2014).

Leggatt-Cook, C. (20079 Health, Wealth and Happiness? Employers, Employability and the Knowledge Economy. Working Paper No. $21 . \quad$ URL: http://md.massey.ac.nz/publications/working_paper_no_21.pdf (accessed August 2014).

Loorbach, D. and Rotmans, J. (2006) Managing Transitions for Sustainable Development. Understanding Industrial Transformation. Environment \& Policy Volume 44, 187-206.

Lundvall, B-A. (ed.) (1992) National Systems of Innovation: Towards a Theory of Innovation and Interactive Learning. Pinter Publishers, London.

Martin, H. (2005) Zeit für nachhaltige Bildung. In: Gruber, P. C. (Hrsg.) Zeit für Nachhaltigkeit. Schriftenreihe Bildung \& Nachhaltige Entwicklung, Monsenstein und Vannerdat, Münster, 147-177.

Martinuzzi, A. and Zwirner, M. (2010) Transformational CSR-Lern-und Dialogfähigkeit als strategische Wettbewerbsfaktoren nachhaltigen Wirtschaftens. Corporate Sustainability, Springer.

Merriam-Webster (2014) Online Dictionary copyright by Merriam-Webster, Incorporated. URL: http://www.merriam-webster.com/info/copyright.htm (accessed August 2014).

Metcalfe, S. (1997) Technology Systems \& Technology Policy in an Evolutionary Framework. In: Archibugi, D., Michie, J. (eds.) Technology, Globalisation \& Economic Performance, Cambridge, Cambridge University Press.

Nikisch, G. and Müller-Christ, G. (2013) Sustainable Leadership: Was müssen Führungskräfte können, um nachhaltigere Entscheidungen zu treffen? In: Keuper, F., Neumann, F. (Hrsg.) Sustainability Management. Nachhaltige und Stakeholder-orientierte Wertsteigerung. Berlin: Logos: 147-172.

Mulà, I. and Tilbury, D. (2009) A United Decade Education for Sustainable Development (2005-14): What difference will it make? Journal of Education for Sustainable Development, Vol. 3, No. 1: 87-97.

Norman, C. n.d. Mythmaking about speed and scale in social innovation. URL: http://censemaking.com/2013/07/18/mythmaking-about-speed-and-scale-in-social-innovation/ (accessed August 2014).

OECD (1999) Managing National Innovation Systems, Paris. 
OECD (2014) PISA 2012 Results in Focus. What 15-year-olds know and what they can do with what they know. URL: http://www.oecd.org/pisa/keyfindings/pisa-2012-results-overview.pdf laccessed September 2014).

Quendler, E., van der Luit, J., Monteleone, M., Aguado, P., Pfeiffenschneider, M., Wagner, K. and CunhaQueda, C. (2013) Sustainable development: an employers' perspective. AWI-Schriftreihe 104, Wien. URL: http://www.agraroekonomik.at/index.php?id=sr104 download\&L=1 (accessed August 2014).

Quendler, E., van der Luit, J., Monteleone, M., Aguado, P., Pfeiffenschneider, M., Wagner, K. and CunhaQueda, C. (2013a) Employers' needs on competences, knowledge and skills for sustainable development as a reference framework for higher education in life sciences. 4th International Conference on New Horizons in Education, Proceedings Book Volume 1/3, ISSN: 2146-7358, Rome: 1117-1139, http://www.int-e.net/publications/inte2013v1.pdf (accessed August 2014).

Robert, K.-H. (2000) Tools and concepts for sustainable development, how do they relate to a general framework for sustainable development, and each other? Journal of Cleaner Production, Volume 8 , Issue 3: 243-254.

Rotmans, J., Kemp, M. and Asselt, M. van. (2001) More evolution than revolution: transition management in public policy. Foresight 3 (1): 15-31.

Rotmans, J., Grin, J., Schot, J. and Smits R. (20039 Multi-, inter- and transdisciplinary research program into transitions and system innovations, Maastricht: ICES-KIS-research Program.

Saadat, S., Muffatto, M. and Shumaila,Y. (2014) A Multi-level Study of Entrepreneurship Education among Pakistani University Students. Entrepreneurship Research Journal, De Gruyter, vol. 4(3), pages 25, July.

Saisana, M. and D'Hombres, B. (2008) Higher Education Rankings: Robustness Issues and Critical Assessment. How much confidence can we have in Higher Education Rankings? European Communities. Luxembourg. URL: https://globalhighered.files.wordpress.com/2008/11/eur23487.pdf (accessed August 2014).

Sarewitz, D. and Kriebel D. (2010) The Sustainable Solutions Agenda. Consortium for Science, Policy and Outcomes, Arizona State University and Lowell Center for Sustainable Production, University of Massachusetts, Lowell.

Schot, J. (1998) The usefulness of evolutionary models for explaining innovation: the case of the Netherlands in the nineteenth century. Hist. Technol. 14, 173-200.

Scott, W. and Gough, S. (2003) Sustainable Development and Learning: Framing the Issues. RoutledgeFalmer, New York.

Smithers, R. (2010) Will students dig allotment soc? Among the clubs vying for freshers' attention at many universities this year is the allotment society. The Guardian. 4th October 2010. URL: http://tinyurl.com/2vukvvx (accessed August 2014).

Smits, R. and Kuhlmann, S. (2002) Strengthening Interfaces in Innovation Systems: rationale, concepts and (new) instruments. Report prepared on behalf of the EC STRATA Workshop New challenges and new responses for S\&T policies in Europe, Brussels. 22-23 April, 2002.

TES Global Ltd (2014) Worlds Universities Ranking 2011-12: Europe. URL: http://www.timeshighereducation.co.uk/world-university-rankings/2011-12/worldranking/region/europe (accessed August 2014).

Tremblay, K., Lalancette, D. and Roseveare, D. (2012) Assessment of Higher Education Learning Outcomes. Feasibility Study Report. Volume 1 - Design and Implementation. OECD. URL: http://www.oecd.org/education/skills-beyond-school/AHELOFSReportVolume1.pdf Iaccessed August 2014).

UNESCO (2011) Education for Sustainable Development. An expert review of processes and learning. URL: http://uneoc.unesco.org/images/0019/001914/191442e.pdf (accessed August 2014).

UN - United Nations (1987) Report of the World Commission on Environment and Development: Our Common Future. URL: www.undocuments.net/wced-ocf.htm (accessed August 2014).

Van Ackere, A., Larsen E. and Morecroft, J. (1993) Systems thinking and business process redesign: an application to the beer game. European Management Journal, 11(4): 412-423.

Weingerl, V. (eds.) (2013) Sustainable Development in Higher Education in Europe. INNOVATIVE PRACTICES COMPENDIUM. URL: http://www.isleproject.eu/images/stories/deliverables/Innovative_Practices_Compendium_VW_ISBN.pdf (accessed September 2014). 
Willard, M., Wiedmeyer, C., Warren Flint, R., Weedon, J.S., Woodward, R., Feldman, I. and Edwards, M. (2010) The Sustainability Professional: 2010 Competency Survey Report. International Society of Sustainability Professionals. ISSP, Portland (OR) United States. 


\section{From systematic to systemic: An experiment in systems analysis for agriculture and food}

\section{Frank Nevens, ${ }^{1}$ Erik Mathijs ${ }^{2}$ and Philippe Vandenbroeck ${ }^{3}$}

\section{Abstract}

In the realm of sustainable development, the need for holistic approaches and systems innovation -drawing on concepts such as transitions and transition management- is acknowledged, also with regard to agriculture and food. A basic precondition for such approaches is 'systems thinking': understanding systems' architecture and functioning. In this chapter, we present the main results of an interactive process in which we gradually crafted an analysis of the agri-food system in Flanders (considered representative for multiple developed regions). The multi-level perspective (MLP), adopted in transition theory, was used as a central methodological framework, combined with a causal loop design to visualise an underlying system narrative. The central 'regime' of the agri-food system was described in a way that highlighted a number of systemic hotspots: loci of tension that cause unsustainability concerns. In this chapter, we present a summary of the outcomes and we reflect on a number of assets that make systems analysis instrumental for effectively developing systems thinking (competences). We also share the lessons learned with regard to the deployed methodological tools and the processes in which they are deployed. In specific we treat the multi-level perspective on transitions.

Keywords: causal loop diagrams, Multi-level perspective, Sustainable Agriculture, Systems analysis, systems thinking, systemic hotspots

\section{Introduction}

When the myriad of unsustainability symptoms in contemporary societies is considered, it is clear that a prominent characteristic of the generic challenge is complexity. The multiple issues at stake (climate change, resource depletion, environmental degradation, etc.) relate to diverse activities and actors, combine multiple topics and sectors and address many (infra)structures and institutions; all of them strongly interrelated and intertwined. For tackling problems of this 'wicked' kind (Rittel en Webber, 1973), the need for more holistic approaches and systems innovation is acknowledged (e.g. Foley et al., 2011; Gallopin, 2003; Senge, et al., 2008; Tukker et al., 2008). Emerging system innovation discourses draw on concepts such as 'transitions': fundamental changes in cultures, structures and practices, aiming at more sustainable societal configurations (Freibauer et al., 2011; Grin et al., 2010; Loorbach, 2007; Rotmans et al., 2001). Also with regards to agriculture and food, 'systems' are under pressure (Marsden, 2012) and an appeal for more systemic innovation and transition-like approaches is observed (Elzen et al., 2012; Ikerd, 1993; Spaargaren et al., 2012; Uhlin, 1999; Veldkamp et al., 2008; Wilson,2007). This evolution should not surprise, when considering the grand challenge of feeding Earth's 9 billion people or more while facing many issues of unsustainability and acknowledging the multiple inter-relations with other sectors (FAO, 2011; Foresight, 2011; Godfray et al., 2010; Tischner and Kjaernes, 2007; Tukker et al., 2005; Wallgren and Höjer, 2009).

A basic precondition for deploying actually systemic action by the diverse actors involved lies in the competences and skills of understanding systems' architectures and functioning (Kalaugher et al., 2013;

\footnotetext{
${ }^{1}$ Department of Applied Biosciences, Ghent University, Belgium. Email: Frank.nevens@ugent.be

2 Division of Agricultural and Food Economics, Catholic University of Leuven, Belgium. Email: Erik.Mathijs@ees.kuleuven.be

${ }^{3}$ ShiftN Consultancy, Leuven, Belgium. Email: pv@shiftn.com
} 
Soroczynski, 2002). Exercises in the kind of 'systems analysis' are considered to enable and develop such systemic thinking capacity (Seiffert and Loch, 2005). A number of essential elements underpin the importance of analysing whole systems:

- mapping and relating multiple relevant issues inspire broader viewpoints than the typical ones of specific 'topics at hand' and thereby enlarge the scope of solutions and opportunities for sustainable practices (Meadows, 1994; Rotmans and Loorbach, 2009);

- describing systems makes explicit the loci of friction or conflict within current, 'normal' routines and/or institutions as well as between innovating frontrunners and resisting 'laggards' (Van Mierlo et al., 2010);

- $\quad$ uncovering a current systems' functioning informs on possible future scenarios (Shaw et al., 1992) and inspires the envisioning of desired, sustainable system configurations (Rotmans and Loorbach, 2009);

- developing skills in understanding system dynamics aids to recognize and induce essential issues for change, such as tipping points (Gladwell, 2000), leverage points (Meadows, 1999) and resilience (Blackmore and Ison, 2012);

- discussing system configurations helps to understand complex dynamics in a context of multi-level co-evolution and hence of interactions between 'niches', 'landscapes' and 'regimes' (Geels, 2011);

- exposing system 'mechanisms' enhances reflexivity in innovation projects and encourages system(ic) learning (Van Mierlo et al., 2013);

- $\quad$ analysing a system's functioning supports a better framing with regard to its very basic objectives and the related human needs; precisely these human needs are considered as the very essentials of sustainable development (WCED, 1987).

With the previous considerations, we follow Quade and Miser (1985) in their thinking that systems analysis is not primarily 'science', but more an interdisciplinary field that attempts to extend and deepen problem diagnosis and design of genuinely effective solutions (for sustainability). This field of systems analysis has gone through significant evolutions and evolved into an amalgam of different approaches, techniques and schools, exposing an impressive amount of diversity (IIGSS, 2001; Reynolds and Holwell, 2010). Therefore, actual systems analyses entail a significant amount of ad hoc work, intuition, creativity, emergence and pragmatism; finally aiming at a tailor-made integration of different approaches (Pereira and Funtowicz, 2006). In its bare essence, and in service of the specific mission of sustainable development, any resulting systems analysis outcome (content and process related) should be instrumental to initiate constructive discussion (Barreteau et al., 2010), and eventually inspire effective initiatives that accelerate sustainability oriented transitions.

Based on the empiricism of a systems analysis experiment that was run for the 'agri-food sector' in Flanders (Belgium), and enriched by a review of relevant literature, the major objective of this chapter is to reflect on enabling elements for genuine (collective) systems thinking. In particular, we draw attention on the use of the multi-level perspective on transitions in combination with an annotated causal loop visualization.

\section{Methodology}

\subsection{A systems analysis on request}

The systems analysis exercise, that we describe in this chapter, was run on request of the Flemish Environmental Agency, an government-linked organization that provides support on the preparation and implementation of policies for a better environment in Flanders (VMM, http://en.vmm.be/). In earlier strategic communications, VMM embraced 'transitions' and their governance as promising concepts for working at sustainable development. Observing that environmental problems are becoming more complex, it was acknowledged that more integrated approaches need to be deployed for accelerating the necessary system innovations towards effective sustainable development (Paredis et al., 2009). In that philosophy, and as a kind of test case (or experiment) for the actual workability of more systemic approaches, VMM asked three academic experts (the authors of this chapter) to establish a systems analysis of the Flemish 
agriculture and food system. The resulting 'Topic Report' and the interactive exercise behind it was envisaged as a potential trendsetter for collaboration and consultation between various policy domains (in this first case environmental and agricultural) and, by extension between all 'sectors' of Flemish society.

\subsection{Methodological grips}

\subsubsection{The multilevel perspective on transitions}

A structuring framework that was deployed for the systems analysis is the multi-level perspective on sociotechnical transitions (MLP; Geels, 2002; Geels and Schot, 2007; Rip and Kemp, 1998; Schot, 1998). This abundantly described concept in transition-like settings assumes that transformative changes of societal systems develop as a co-evolution and acceleration of dynamics at different levels.

The 'regime' (often used as a shorthand for 'the system') encompasses the deep, dominant cultures, structures and practices that establish an incumbent system's stable functioning; including the aspects of lock-in, inertia and path dependency (Geels, 2004; Hagelskjaer Lauridsen and Stissing Jensen, 2013). In our study at hand, and in agreement with Geels (2011), we considered the regime level of primary interest because transitions are defined as shifts from one regime to another. In that, we specifically addressed the challenge for systems analysts to investigate what lies underneath the activities of actors who reproduce the dominant system elements. However, since regimes ought not be considered as solely homogeneous or stable (Smith et al., 2005), we explicitly focused on making explicit those elements of tension (further referred to as 'hotspots') within the current regime setting of Flemish agriculture and food. The indication of these hotspots was inspired by (data supported) expertise and an interactive reflection process with stakeholders (see 2.3.). With this particular 'hotspot'-approach, we implicitly touched upon the major dimensions that shape a socio-technical regime (Geels, 2002) as well as the typical mechanisms that stabilise an incumbent regime (Walker, 2000).

Although a 'regime' is central in the MLP, there are strong influences from the accompanying levels of 'landscape' and 'niche'. In the 'landscape', major gradients of force are in play: dominant, exogenous trends and developments exert different kinds of pressure on the ruling systems, and trigger a sense of urgency for change (Bindraban and Rabbinge, 2012). 'Niches' are those loci where radical and systemic novelties emerge, by co-evolution of entrepreneurial impulses and in heterogeneous networks (Garud and Karnøe, 2001; Raven et al., 2010). Niches are considered as systemic alternatives that are embryonic for future new-regimes.

\subsubsection{A causal loop diagram and an underlying system narrative}

Visual models incorporate major potential to capture inherent systems complexity up to a level that allows for the enlightenment of tensions, trade-offs, leverages and intervention options; for that supporting capacity of articulating systems' architecture and functioning, visuals are frequently deployed as a typical 'language' for system description and analysis (Checkland and Scholes, 1990; Kim, 1995; Senge, 1994). Diagram-like devices reduce endless complexities to manageable simplicities with focus on the essential issues while avoiding endless searches for more details and hence drowning in ever proliferating abundant information (Pagani and Otto, 2012). An often used format is the causal loop diagram or influence diagram (Coyle, 2000; Kirkwood, 1998), which originates from the field of system dynamics (Forrester, 1958) and has proven to enable a workable externalization of mental models (Wolstenholme, 1999). In the systems analysis we present, we deployed a causal loop diagram that was annotated by a generic narrative. This approach was adopted owing to its explicit quest for interrelations and feedback structures between system elements; in that, we strived for a diagram that does not necessarily describe every detail of the system (processes), but does enlighten the logics and the mechanisms that lead to observed patterns of outcomes and impacts, desired and undesired ones.

In constructing the underpinning narrative of the established systems analysis, 'hard' and 'soft' systems thinking elements were combined (Maru and Woodford, 2007; Kalaugher et al., 2013). Drawing sound 
boundaries between 'hard' and 'soft' in these matters is not advisable (Pešsl and Hřebíček, 2003), and we had no intention on 'categorising' any of the deployed approaches. Yet, we explicitly avoided a track of solely -and rather typically- systems analysis bending on (exhaustive) use of quantitative, 'exact' formalisms and data that are taken to adequately represent a reality in a way that is assessed as measurable, demonstrable, rational, replicable and verifiable (often also referred to as 'scientific').

Qualitative ('soft') elements of systems analysis are considered desirable when the system under investigation is too complex for mere quantitative modelling (e.g. Grosskurth and Rotmans, 2005) or when the problem definition itself is a problem (Nidumolu et al., 2006). Approaches of the soft or conceptual kind (e.g. Checkland, 1981, 2000; Finegan, 1994) develop qualitative models that include the diverse values, beliefs, roles and power relations in which a situation is embedded (Reynolds and Holwell, 2010). In that and with intellectual rigor, soft systems approaches acknowledge and explicate the subjectivity that is a crucial and inherent characteristic of human affairs (Pešsl and Hřebiček, 2003). Therefore, they are a heuristic device for accommodation between different actors and viewpoints, for an integrated understanding of a system and its problems and for discussions on relevant cultural and political intervention (Barreteau et al., 2010; Ison, 2008). Also in agricultural contexts, the presence of intangible and intersubjective aspects and the need for their understanding is recognized (Hoffmann et al., 2007).

\subsection{An interactive and reflexive process}

The establishment of the systems analysis (and the coinciding report) was embedded in an iterative process that alternated desktop work (by the authors) and discussions on intermediate results in a twelve-headed reflection group that gathered representatives from the institutional triangle of state, market, civil society and science' (Grin et al., 2010):

- ' 'state': Flemish government administrators from the agricultural and the environmental departments $(n=3)$;

- 'market': sector federations delegates ( $n=2$, major agriculture federation and the federation of food industry companies);

- 'civil society': civil society organizations in the fields of environment, nature conservation, development aid, sustainable development $(n=4)$;

- 'science': during the establishment of the 'version 1.0', the three authors were the representatives of academia.

The expert desktop work was based on a systematic search in literature (scientific and) and assemblage of subsequent versions for the systems analysis. These onsets were thoroughly discussed during the five interactive sessions with the reflection group; the outcomes of which not merely yielded detail-like remarks, but also significantly influenced the further development of the analysis.

During a subsequent process, an additional group of lectors $(n=20)$ was invited for an online review of the report (amongst them additional members of academia). Based on the comments received, a revised version of the analysis was established and subsequently published. The major purpose of the publication was to demonstrate the 'client' Environmental Agency's aspiration to effectively experiment with more systemic approaches and to nourish further societal debate and envisioning on systemic solutions for sustainability (VMM, 2012).

\section{Results}

The process of the systems analysis at hand, resulted in a summarizing 100 pages book publication (in a Dutch and an English version) that was edited by the joint forces of the Flemish environmental and agricultural public administrations (MIRA, 2012). For any additional content details, we refer to this publication. Below, we present a summary. 


\subsection{The incumbent system (the 'regime')}

\subsubsection{The general picture}

The description of the agriculture- and food 'regime' was developed in a Flemish context, but with the underlying assumption of high similarity in other industrialised regions and including the relevant linkages with supra-regional levels.

The structuring causal loop diagram (Figure 1) holds the following rationale on the current system functioning: economic motives primarily drive the system (a reinforcing loop), social and ecological aspect are considered as limiting boundary conditions (a balancing loop) and technological fix is the exquisite track to maximise the economy and/or mitigate the ecological and social impediments. This agri-food system's 'archetype' is inspired by a view that commercial and economic dominance is persistent, also in practices related to sustainability efforts (Boons et al, 2013; McMichael, 2011). Placing natural resources in the centre of the system's functioning would have been a possible alternative (e.g. 'Ecologically Intensive Agriculture', El Ghali et al., 2012), yet such setting would already be indicated as 'alternative' for the actually dominant situation.

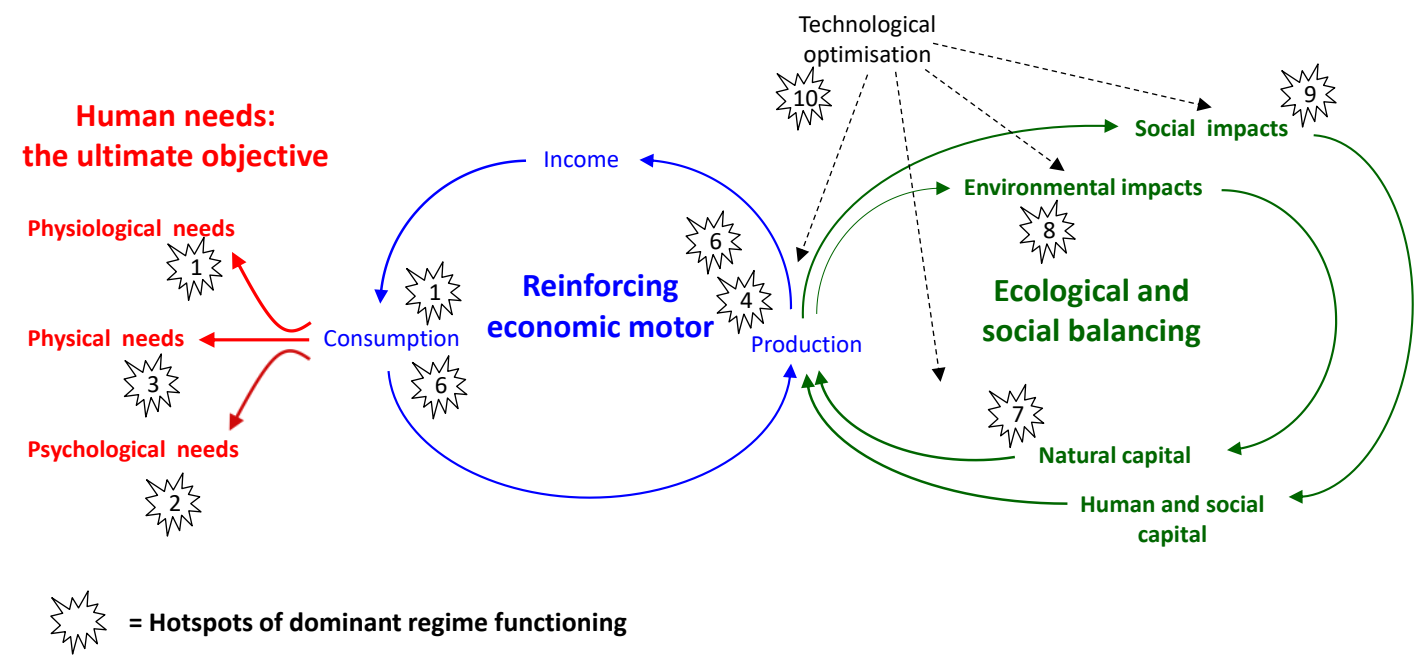

Figure 1. The basic causal loop diagram that summarizes the agri-food 'regime' functioning.

\subsubsection{Human needs: the ultimate system's objective}

In her saying that "a system is an interconnected set of elements that is coherently organized in a way that achieves something", Meadows (2009) stresses the importance of questioning the basic objective of a system when studying it. In that realm, drawing back on human needs as the very fundamentals of each production and consumption system is a precondition for sound systems analysis (D'Anna and Cascini, 2011); knowing that needs are also the very basics of the sustainable development concept (WCED, 1987). Acknowledging a lack of common definition of 'needs' in literature (Ericsson et al., 2009), even a simple concept such as Maslow's hierarchy of needs (Maslow, 1943) is workable, since it enables to question any system on that fundamental starting issue of its ultimate purpose. Many systems analysis exercises contain descriptions that 'end' at or even before the level of the final consumer/citizen (e.g. Gerbens-Leenes et al., 2003). Such practice seems to ignore the major steering factors for any system's functioning: consumer needs and behaviour (Grin, 2012; Heller and Keoleian, 2003). A majority of classic representations of agriculture and food systems start from a primary production side of the system and linearly develop towards 'end use'; in our approach, we start from the end consumer and his fundamental needs. 


\subsubsection{The reinforcing loop of economics}

The system of agriculture and food primarily provides food for consumers that pay for it by the living they earn from activities in the diverse sectors of the economic fabric (of which also the agriculture and food sector is part). This 'circular flow of income' is the basic cycle of macro-economics (Fischer et al., 1988). When consumers achieve a higher income, they are able to consume more, which at his turn, enhances production and hence economic growth. In semantics of system dynamics, this self-reinforcing loop epitomizes the very basics of the 'motor' of market economies (Jackson, 2009). This also comprises a typical price dynamic: wage hikes due to inflation cause companies to raise prices, leading to demand for further wage increases, and hence perpetuating a wage-price spiral (Kandil, 2007) as another reinforcing loop mechanism. The performance of the economic dynamic is based on the concepts of economic value added (e.g. Young, 1997), growth (Lucas, 1988) and competition (Porter, 1980). Agricultural entrepreneurs are in a strong competitive race, based on costs; to a large extent owing to relatively few powerful retailers and monopoly processors. In that realm, the dominant strategy of Western agriculture and food systems remains a large scale, productionist model that emphasises cost leadership by industrial efficiency (Hinrichs and Welsh, 2003; Ikerd, 1993) and that competes on a world market of bulk food commodities (Pretty, 2002). This strategic pathway created a landscape of specialisation (Gale, 2000), intensification (Stoate et al., 2001) and homogenisation (O'Hara and Stagl, 2001) as strategy enabling assets.

\subsubsection{Balancing loops of boundary conditions}

Like other systems, agriculture and food 'uses' the natural environment and its resources: the system needs them as inputs for the production processes (source); and the system generates waste, side streams, residues and emissions (sink). Both aspects have limitations: many natural resources are finite and hence exhaustible; and the natural ecosystems have a limited carrying capacity with regard to disturbance by unwanted impacts (Harris and Kennedy, 1999). Besides environmental aspects, a number of constraints to the dominant industrialised farming also draw back on social aspects, such as community building (Lobao and Stofferahn, 2007) and human well-being and health (Horrigan et al., 2002).

\subsubsection{Tensions in the system: 'hotspots'}

\section{Hotspot 1: Western world healthy food abundance. However, increasing food related health problems.}

Since the beginning of the industrial revolution, a gradually better performing Western agricultural system allowed to increase people's weight from underweight to 'normal', with positive impacts on life expectancy, fertility and at the same time the economic development of industrialising/industrialised societies (Fogel and Costa, 1997). Currently, developed regions have access to a never seen offer of diverse food, closely monitored for health and safety.

However, during the $20^{\text {th }}$ century some limits were obviously reached: for the first time, worldwide, the number of overweight and underweight people equalled. The developed countries even started showing signs of an obesity-epidemic (Caballero, 2007) and clearly increased risks for other 'welfare diseases' (e.g. type 2 diabetes, cardiovascular diseases, high blood pressure). Many of these counterproductive issues can be drawn back to ever growing food affluence (Erb et al., 2009), 'fattening food systems' (Sobal, 2008) and aspects such as fashion and style inspired over-consumption for entertainment (Lazarides, 2011).

\section{Hotspot 2: Western food choice redundancy. However, a resource intensive supporting system with significant burdens.}

The current Western food system provides ample possibilities for food choice in which almost unlimited wishes from the customer are met. Included convenience and hedonistic elements often go far beyond merely physiological assets and hence intrinsic qualities and functions (Costell et al., 2010; Grunert, 2006; Pohjanheimo et al., 2010). Such wishes are particularly at play in a culture of peer-to-peer comparison and 'mimetic desire' (Girard, 1965).

However, a far drifting consumerism (Wong and Bridges, 2008), whether or not created and reinforced by production and distribution actors (Sanne, 2002), asks for an ever expanding production apparatus, 
increased use of resources and coinciding impacts on the environment. A key issue is that food prices do not reflect social and environmental costs related to such an affluence (Weinzettel et al., 2013).

\section{Hotspot 3: Performing well on food production. However, increasing competition for other types of biomass use.}

Besides food, agricultural production systems traditionally also provided non-food products and commodities (Hardy, 2002), a task that had diminished during the rise of petro-chemical industry in the $19^{\text {th }}$ century.

However, with the rise of concepts like 'bio-based economy', there is regained interest from a myriad of actors for renewable resources for energy production or industrial raw materials (Baka and Roland-Horst, 2009). Hence, there are explicit issues of trade-off and tension, based on opportunities and constraints (Spiertz and Ewert, 2009) and owing to the competition with regards to limited available land and water for food production (Srinivasan, 2009). Already, the increased interest in the large potential of agricultural biomass for energy production has an indirect price increasing effect on food production (Esmaelli and Shokoohi, 2011; Von Braun and Pachauri, 2006); in a situation where consumers seem to adhere to food security yet low food prices (Skipper et al., 2009; Wu et al., 2012).

\section{Hotspot 4: Industrial chain efficiency. However, multiple loci of disconnection.}

The generic approach of specialisation, economies of scale and efficiency based cost leadership was successful in realising the great increases of industrialised agriculture and food production over the past 50 years (Stoate et al.,2001). Probably this very paradigm will be continuously important in the light of the foreseeable growing demand for food in the next decades (Tilman et al., 2011).

However, specialisation also caused segmentation of food chains in an increasing number of separated activities and responsibilities (Fresco, 2009; Infante Amate and González de Molina, 2013), with between them well defined relations in the kind of 'delivery'. At the same time, these links no or but few further awareness nor concern for down- or upstream consequences, also at social or ecological level.

Essentially linked ecosystem functions are separated in manageable agricultural production logics (e.g. plant and animal production; Björklund et al., 1999). Hence, even in a growing context of networked economies, there is a loss of commitment and co-responsibility for larger wholes (such as the broad ecosystem on which all actors ultimately depend; Morgan and Murdoch, 2000). This reflects in symptoms such as the 'shading' of up- or downstream costs (Princen, 1997). The loss of such tight connections between the different links in and between production and consumption also offsets essential feedback mechanisms (Sundkvist et al., 2005) and opportunity-rich multi-actor cooperations (Smith, 2013).

At the same time, power concentrations emerge in specialisation inspired agri-food chains (Hendrickson and Heffernan, 2002). Typical manifestations are the mechanisms of horizontal consolidation (firm merges or alliances) and vertical integration (buying up and controlling companies along the chain; O'Brien, 2004). Concentration occurs at the 'upstream' level of agricultural inputs (Marion, 1998; Busch and Bain, 2004) and processing (Hinrichs and Welsh, 2003) as well as the downstream distribution and retail level (Clarke, 2000; Oosterveer, 2012), where gaining market power appears a strong purpose, even more than efficiency (Aalto-Setälä, 2002). Concentration in (e.g.) agro-chemical transnational corporations limits the options for consumers and farmers to make informed and responsible decisions. This makes that safety and sustainability (e.g.) depend on the decisions of few actors, which might even increase the likelihood to consider unethical behaviour (Hendrickson and James, 2005).

\section{Hotspot 5: Diverse and abundant food availability. However, food illiteracy}

A specific aspect of systemic disconnection relates to the poor knowledge and awareness of consumers with regards to the origin of their food and the way it was produced (Gliesmann,2011). This aspect is also reinforced by the physical separation of the locations of production and consumption (Lambin and Meyfroidt, 2011). Hence, the connective role that food serves among personal health, environmental health and social well-being is also whisked away (Heller and Keoleian, 2003). Commoditisation of food (Weis, 2007) creates an illiteracy on the consequences of specific food patterns and hence hampers motivation 
for behavioural changes in favour of more sustainable food consumption (Aertsens et al., 2009). The rise in the plethora of food labelling schemes (Dendler, 2013) according to environmental or social standards is an illustration of the attempts to bridge the information gap distances in the food chain by communication, with regards to aspects of health (Grunert et al., 2010) as well as sustainability (De Boer, 2003).

\section{Hotspot 6: Food chain efficiency. However, considerable losses.}

In spite of the agri-food system's dominant rationale of intensification and efficiency, the total losses of edible food (agricultural production, postharvest, processing, distribution and consumption) are estimated roughly at about a worldwide quarter (Kummu et al., 2012) to one third (Gustavsson et al., 2011) of the total produce for human consumption. In developing countries, typically postharvest and processing losses by storage and transport conditions are the root causes. In industrial countries spoilage concentrates at the retail and consumer levels, where more than $40 \%$ of edible food may be wasted (Beretta et al., 2013). The estimated food losses (coinciding with the needs of 2 billion people) also entail the inefficient use of considerable amounts of valuable resources such as fresh water, cropland and fertiliser (Kummu et al., 2012). Reducing the food losses is considered as a major component of any strategy for sustainably and equitably feeding the growing global population (Foresight, 2011). In such a light, other 'typical' sustainability aspects could be re-framed: increasing food packaging - with increased environmental impact might be a sensible strategy when viewed from an angle of reduced food loss (Williams and Wikström, 2011).

\section{Hotspot 7: Increased resource use efficiency. However, resource scarcity becomes tangible.}

Natural resources (water, land, biodiversity, nutrients, fuels, proteins, etc.) are essential for the diverse processes in agriculture and food production systems. Supported by technological progress and following the industrial paradigm, productivity and resource use efficiency have increased significantly during the past decennia. Besides plant and animal breeding, the ever more efficient use of external inputs such as pesticides, mineral fertilisers and fossil fuels has enabled this valuable progress.

However, the continued growth of worldwide economies simultaneously increased (and will further increase) the total resource consumption. This makes higher productivity or efficiency no longer an univocally valid sustainability indicator (Steinberger and Krausmann, 2011). The increasing tangibility of resource scarcity and security of supply, reflects in increased prices and strategic mechanisms of protection. Hence, ever more pressure is put on a system with often 'artificial' primary production system support, such as subsidies (McKenney, 2002). As other industrial systems, agriculture and food highly depend on fossil fuels for direct and indirect energy use that is needed throughout the long food chains (Canning et al., 2010; Woods et al., 2010). Reinforced by climate change evolutions, an 'end of cheap oil' discourses urges to reduce fossil fuels urgently and pro-actively. This urgency is reinforced by the awareness that it will take time to implement energy savings and a switch to a system of renewable energy (Bardi et al., 2013) that will effectively bring about a global impact (Harding and Peduzzi, 2012).

\section{Hotspot 8: Environmental impacts diminish. However, carrying capacity remains delicate and environmental costs are not accounted for.}

Not unlike any other economic sector, agriculture and food activities generate emissions and residual flows that have negative impacts on the quantity and quality of natural resources that are necessary for the production systems (e.g. Engström et al., 2007; Hazell and Wood, 2008; Skinner et al., 1997). Hence these side effects are sources of long term instability and unsustainability, in their very nature of being biophysically counterproductive (Weis, 2010). Significant efforts to reduce negative impacts -building on innovative technologies and regulatory frameworks- have had positive results. Approaches in the kind of eco-efficiency improved overall environmental performance (OECD, 2008) and are the core of an 'ecological modernisation' of the industrial agriculture and food system (Archambault, 2004). Even ambitions towards 'zero discharge' are expressed (Lee and Okos, 2011).

However, in the future there are likely to be continuing concerns with the availability and quality of water, preservation of biodiversity, and the health of soils (OECD, 2012). Reinforced by the continuing economic growth paradigm, the absolute negative impacts are still of a magnitude which is beyond planet Earth's ecosystems' carrying capacity and concurrent regenerating power (Rockström et al., 2009; Steffen et al., 2015). An important issue is that the actual costs of undesired 'externalities', are not internalised in current 
market and pricing mechanisms of the economic motor logic (Pretty et al., 2000, 2005). In fact, these unaccounted externalities might even be interpreted as implicit subsidies to cheap industrial food production (Weis, 2010). As such -and depending on management practices- agricultural activities remain the source of numerous ecosystem 'disservices' (Power, 2010). Whereas, there are ample possibilities for agriculture to, on the contrary, reinforce or even produce a series of ecosystem services with substantial economic value (Costanza et al., 1997).

\section{Hotspot 9: Building on a well performing work force. However, threatening the social capital.}

Besides on natural capital, the agriculture and food system also builds on human capital. Related to this, during the past decades, farmers' labour productivity increased significantly, aided by technological progress, specialisation and increases in scale.

However, this evolution towards factory-farm-like approaches (Weis, 2010) has put a classic model of family farms under pressure (Moreno-Pérez et al., 2011). Coping strategies in the kind of multi-family partnerships might have allowed some survival (Calus and Van Huylenbroeck, 2005). Yet at the same time, intensively capitalised family farms became subject of a certain 'lock-in' with regards to change; potentially reinforced by a lack of understanding of farmers' rationalities with regards to flexibility and change (Milestad et al; 2012). Moreover, a system that increasingly functions in a global bulk commodities market with fierce competition is forced to continuously level up the demands from its labour force and hence addresses farm(er) liveability (Crawford et al., 2010). Besides an array of stressors related to the physical environment, manifestation of stress problems caused by economic difficulties and uncertainties, farmer's succession uncertainties and additional out-of-farm work indicate a rather precarious social position of farmers (Fraser et al., 2005; Lobao and Stofferahn, 2007; Thomas et al., 2003). A specific element of farmers' wellbeing is professional pride; in a context of increasing disconnection from consumers and citizens (see Hotspot 5), the coinciding loss of respect and recognition diminishes this important aspect of social sustainability (Dessein and Nevens, 2007).

\section{Hotspot 10: Technology optimises. However, there are drawbacks and limits.}

With the economic motor of industrial agriculture as remaining dominant driver of the agri-food system (Tamásy, 2013), the different elements of balancing loops are countered in a predominant mode of 'technological fix' (Rosner, 2004). This generic technological optimism based problem solving proved its ability to reduce negative impacts and to respond to scarcities: chemical fertilisers countered the relative soil mining, chemical crop protection and veterinary medicine solved vulnerabilities related to biological simplification and standardisation, mechanisation enabled high labour and land productivity (e.g. McKenney, 2002; Reid, 2011). Negative externalities of production processes were cost-effectively abated with ever evolving best available technologies (Brink et al., 2005). Aspects such as energy use efficiency (e.g. Alluvione et al., 2011) and nutrient use efficiency (Schröder et al., 2011) were significantly increased. Still remaining environmental pollution is neutralised 'as good as possible' by end-of-pipe technologies, making existing production methods more 'clean'. Acknowledging its large contribution to the historically increased outputs and productivity, further technological improvements are considered pivotal for future sustainability oriented developments (Burgess and Morris, 2009). In a continued realm of current market mechanisms (Aldy et al., 1998) and of technological solutionism (Morozov, 2013) they are considered as the source of solutions to challenges such as climate change (Smithers and Blay-Palmer, 2001).

However, there are warnings that also technological progress with regards to e.g. crop yields might have reached limits (Grassini et al., 2013). Additionally, new emerging technologies (e.g. genetic modification) are contested by public opinion, owing to factors such as (currently unknown) risks for humans and nature (e.g. De Krom et al., 2014). A specific element in that is the still significant vulnerability of high-tech animal production systems for outbreaks of animal diseases.

Concurrent with technology supported increased eco-efficiency, there is evidence of a rebound effect or 'Jevons paradox' (Polimeni et al.,2008), when an ever boosting driver of economic growth and consumption (over)compensates for the benefits made by more efficient practices. Also in the case of agriculture, such adverse effects of efficiency intentions is observed (Saunders, 2013). Another criticism is that technology supported optimisation might well mitigate unwanted externalities but at the same time helps to avoid the 
necessary fundamental changes (Tait and Morris, 2000; Tansey, 2013). In that way, it might even reinforce unsustainable practices, be it in a possibly more moderate way and at a slower pace. In a technology-fix paradigm, little attention is paid to innovations that address entire system configurations and that tackle the complex and wicked problems that contemporary societal settings face (EU SCAR, 2012).

\subsection{Landscape trends and developments}

During the interactive process of the systems analysis, ten headline landscape developments were indicated, as autonomous dynamics that influence the incumbent societal systems. The definition and selection was inspired by existing work on 'megatrends' (e.g. EEA, 2011) or key drivers of change of food systems (e.g. Foresight, 2011), For each landscape development, specific impacts on the agri-food system were described.

\subsubsection{Human population and its welfare level increase}

2050 UN-projections expect a 30 \% growth of the world population (from current 7 billion to 9 billion; UN, 2011), coinciding with a further increase of general human welfare (Asher and Daponte, 2010) and a particular catch-up from emerging economies and momentarily stay-behind regions (UNDP, 2012). As a result, it is foreseeable that the coinciding quantitative demand for food will rise by 70 up to $110 \%$ (Henningsson et al., 2004; Tilman et al., 2011; UNEP, 2012). At the same time, the worldwide dietary composition is expected to continue its shift from starch based ingredients towards fats, proteins ('meatification' in particular) and sugars ('Bennett's law', 1936). The impact of such an increased demand would offset land savings by expected agricultural productivity increases (Kastner et al., 2012), and hence urges for more, and more intensive production systems, worldwide (Spiertz and Ewert, 2009).

\subsubsection{Globalization continues}

Reinforced by enabling developments in information technologies, mobility and telecommunication, globalisation keeps inspiring the convergence of worldwide societies. More uniform patterns of economic, political and cultural organization (Guillén, 2001) and increasingly homogenous production and consumption patterns are established, also with regards to agriculture and food (O'Hara and Stagl, 2001). Globalization has multiplied opportunities for innovation (Rycroft, 2003) and reinforced economic growth (Dreher, 2006) but at the same time it induced drawbacks on agri-food systems: uncontrolled land use expansion (Lambin and Meyfroidt, 2011), global plunder of resources (Levidow, 2013), social inequality (Borghesi and Vercelli, 2003; Rees, 2002; Tisdell, 2001) and low-cost offsetting of environmental burdens (Roberts and Parks, 2007). International market forces may further threaten local food sovereignty, showing in loss of control on local markets for local actors with increased risks for poverty, famine and deterioration of rural structures and populations (Shiva, 2004).

\subsubsection{Western populations are ageing}

Ageing of the human population gradually faces industrialized regions (Dlugosz, 2011). Consequences are increased dependency ratio's Serban, 2012), the challenge of payable care systems (Tinker, 2002; Aysan and Beaujot, 2009) and workable inclusion of 'active ageing' elderly in society (Sidorenko, 1999; EC, 2009). A specific aspect is that rural communities tend to be more vulnerable to potentially negative outcomes of ageing, such as lower income and higher demand for care (Davies, 2011). The 'greying' trend reinforces discourses on the need for continued or increased activity of the motor of economic growth. An ageing population might also hold opportunities for new developments: elderly would show higher willingness-to-pay for environmental issues and establish a key market segment for high diversity consumables (amongst them food), locality and health aspects and consumption 'experimenting' (IGD, 2008).

\subsubsection{The world urbanises}

By 2050, 70\% of the world's population will be urban (Crossette, 2010), and this urbanisation trend will increasingly put claims on remaining open space areas and hence cause pressure on the amount and price of land available for agriculture (Kesteloot, 2003). Worldwide, cities are responsible for $75 \%$ of global 
resource consumption, and as a consequence for the coinciding impacts on natural environments (Grimm et al., 2008; Bellucci et al., 2012). Simultaneously, cities are seen as the ideal loci to effectively tackle unsustainability issues (Bulkeley et al., 2011) and hence to become the hubs of drastic innovation and sustainable development (Ernstson et al., 2010; Späth and Rohracher, 2012; Theodoridou et al., 2012). Specifically highlighted in this thought are urban opportunities related to climate neutrality programmes (Nevens et al., 2013), green structures architecture (Fikret and Huseynov, 2011), (peri-)urban agriculture (Barthel and Isendahl, 2012), civic agriculture (Delind, 2002), etc.

\subsubsection{The climate changes}

Human-induced climate change is expected to have major consequences on life on Earth (IPCC, 2007; Söderholm et al., 2011). Calls to reduce anthropogenic greenhouse gas emissions with up to $95 \%$, to be realised by all sectors (Lal, 2004; Alluvione et al., 2011) is a vast challenge, also for agriculture and food production (Norse, 2012). Besides this mitigation issue, actual climate change is expected to increasingly exert tangible pressure on many of our societal systems and hence urges for adaptation strategies. Effects of climatic changes will evidently influence worldwide primary agricultural production (e.g. Gohari et al., 2013; White et al., 2011). Strongly fluctuating agro-meteorology will cause elevated risks for crop yields, diseases and plagues (Rivington et al., 2013). A specific item is that of climate justice (Tonn, 2003; Page, 2007): the highest tangibility of climate change impacts will hit developing countries (e.g. regions of Africa), having contributed little to historic greenhouse gas emissions and having low capacity to cope or adapt (Bryan et al., 2013; Dasgupta et al., 2007; Fischer et al., 2005).

\subsubsection{Natural resources become scarce}

High and volatile prices indicate that an increasing number of scarce resources for human production systems is under pressure (IMF, 2012); multiple 'peaks' in production and economically feasible availability are to be expected (Lee et al., 2012; Prior et al., 2012). Regions such as Europe experience a resource squeeze by the relative poverty of own sources and the ever increasing claims on essential (mineral) resources by growing worldwide economic production and consumption systems. Roadmaps on efficient use of resources are on strategic agendas (e.g. EC, 2011).

In agricultural practice, a typical critical resource is mineral phosphate: finite and hence depletable, exploited outside Europe and under severe competition (Cordell et al., 2009). A drastically improved efficiency of its use is needed since an ever deceasing availability is to be expected (Schröder et al., 2011). Equally important are scarce resources such as water; food and agricultural 'licenses to produce' will increasingly be assessed by their water footprint (Liu et al., 2008; Marlow et al., 2009). Also biodiversity will gain attention as a critical resource: besides an intrinsic value, loss of biodiversity threatens ecosystem services that are vital to welfare and well-being of human societies (Melman and Van der Heide, 2011).

\subsubsection{Values and ethical stances of consumers and producers change}

The rise of reflexive modernisation (Giddens, 1991) feeds a growing undercurrent of engaged people with well-expressed and critical perspectives regarding new technologies, production paradigms, producerconsumer relationships, etc. (Ericson et al., 2009; Vergragt and Szejnwald Brown, 2008). This is also the case for food and the way it is produced (Goodland, 1997). That growing global civil society establishes (new) ethical norms (Martens et al., 2010) and consciously consumes more sustainable products (such as organic, fair trade, animal friendly, environmental friendly, locally produced, etc.), thereby expressing noneconomic values and considering ethics as 'product augmentation' (Crane, 2001; Klintman and Boström, 2012). Such moral and social concerns also gain attention in the context of farming and farmers' decisions (Mzoughi, 2011).

Also within business contexts, reflexive modernisation dynamics emerge in the deployment of concepts such as corporate social responsibility (McWilliams and Siegel, 2001), environmental management accounting (Gale, 2006) or sustainable business models (Bocken et al., 2014). 


\subsection{8 'Alternative growth' is an emerging discussion}

Beyond a critical level, the increase of Gross National Product (as the archetypical indicator of welfare; e.g. Safarzynska, 2013) no longer seems to contribute to an increased satisfaction of people (Inglehart and Klingemann, 2000; Easterlin et al., 2010). Observations of that kind increasingly put classically approached economic growth as vehicle for welfare and wellbeing in question as an axiomatic necessity (Kallis et al., 2012). There is an emergence of 'degrowth'-like discourses (Schneider et al., 2010; Sekulova et al., 2013). In an envisaged degrowth inspired society, there is high focus on values such as personal fulfilment, wellbeing, community building, etc. (Nierling, 2012). Discourses of the kind face major resistance and inertia from deeply rooted drivers such as material welfare, mimetic desire and property (expansion) as dominant inter-individual psychology and socio-economic processes (Girard, 1988; Lebreton et al., 2012; Van Griethuysen, 2010).

\subsubsection{Persistence of hunger and inequality in the world}

A number of 870 million hungry people in the world "remains unacceptably high" (FAO, 2012) and puts pressure on a (Western) food system that generates high losses and that shows a number of negative sideeffects that draw back on food affluence (Lazarides, 2011). Key obstacle for tackling hunger is not as much technological (agricultural productivity) but essentially draws back on accessibility of food. A remarkable observation is that three quarters of hungry people live in rural areas and hence they are often farmers themselves (UN, 2011).

Another point of attention is the rising number of people that are hungry in the prosperous Western world industrialised countries (Dowler and O'Connor, 2012). Together with aspects such as energy poverty (Bouzarovski et al., 2012) this reflects a general development of rising social inequalities (OECD, 2011); making poverty and social exclusion in all its symptoms major issues also in developed regions such as Europe (EC, 2010).

\subsubsection{Digital revolution continues}

The revolution of digital technologies rushed on in its sequence of personal computer (80s), world wide web (90s), mobile telephony (00s) and social networks (10s). Positive consequences are the world wide and 'on line' connections between people and hence never seen possibilities to communicate and to share information between like-minded in a network society (Falch and Henten, 2000). Without digital enabling, numerous economic opportunities of today would not exist: the digital era has increased productivity and performance of business significantly (Brynjolfsson and Hitt, 2003); there is a 'digital prosperity' discourse (Atkinson and Mckay, 2007). With specific regards to agriculture, ICT has provided farmers with productivity enhancing information and advisory services through SMS, voice, web portals, etc. (McNamara, 2008). ICTs offer ample new opportunities to develop sustainable solutions by (e.g.) supporting multiple efficiency increases, and spreading behavioural changes (Berkhout and Hertin, 2004). According to Rifkin (2011), an ICT supported communication revolution is essential for sustainability oriented systemic changes such as the 'energy internet', framed in networked and lateral power steered societal settings.

However, there is also a need for underpinned policies and regulations in order to avoid the potentially negative impacts of ICTs. With regards to the environment, direct impacts (e.g. material use and waste streams of electronic components) as well as indirect impacts (e.g. enhanced material consumption inspired by ICT) potentially counterbalance obvious advances (Berkhout and Hertin, 2004). Other negative consequences are information overload, internet criminality, social isolation and anonymity (Katz et al., 2001) as well as competitive disadvantages by non- or limited access, particularly in developing countries (Caspary and O'Connor, 2003).

\subsection{Niches: emerging system alternatives}

In the presented systems analysis, we described four 'niches' that were considered to provide radically different alternatives for the sketched dominant regime and in that establish (more) sustainable system configurations. 
There are many specific practices that combine under the niche 'urban agriculture', yet the most prominent shared characteristic is food production in and around a city. Additionally, there is a strong relationship of reciprocity between farmer and consumer, in the form of short chains and very often a multifunctional contribution of agricultural activities to diverse urban needs.

Organic agriculture still closely links to the existing regime, yet builds on a number of clearly deviating principles. Sustaining and enhancing soil, plant, animal, human and planet health are considered as one and indivisible. All practice is based on fairness with regard to environment and life opportunities, hence on the very basics of living ecological systems and cycles. The use of chemical fertilisers and pesticides is avoided.

'Eating differently' groups a number of consumption-driven sub-niches; the common essence is the fulfilment of 'new' needs in the areas of health, identity and sustainability. These are expressed in changes of dietary patterns, drawing back on i) reduction of animal proteins, ii) slow food and iii) customisable food.

New production paradigms is a cluster of sustainable alternatives for the aspects of standardisation, efficiency, and economies of scale as guiding principles of 'industrial' agricultural production chains. Four approaches are assembled in the niche: industrial ecology, bio-based economy, factories of the future and peer-to-peer production.

The chosen niches are considered as examples, to indicate diverse way in which alternatives for the incumbent system are being developed; and how these alternatives deal in a specific way with the determined hotspots of the current regime and the pressures from the landscape level. Considering different alternatives is a deliberate choice to avoid getting locked-in into single 'silver bullet solution' mind sets (Foley et al., 2011). Describing the niches and analysing their relation with the incumbent system and the identified hotspots enabled us to further refine and validate the latter. The niches were extensively described in VMM (2012). Here, we present the essential characteristics of each niche (Table 1). The characteristics (in columns) are presented in a way that relates them to the specific system hotspots (in rows) as they were described in section 3.1.5. 
Table 1. Niches and their assets with regards to systemic hotspots

\begin{tabular}{|c|c|c|c|c|}
\hline $\begin{array}{ll}\text { Hotspot } & \text { Niche } \\
\end{array}$ & Urban agriculture & Organic agriculture & Eating differently & New production paradigms \\
\hline $\begin{array}{l}\text { 1. Western world healthy } \\
\text { food abundance. } \\
\text { However, increasing food } \\
\text { related health problems. }\end{array}$ & $\begin{array}{l}\text { Fresh, affordable food } \\
\text { for vulnerable groups } \\
\text { in cities }\end{array}$ & $\begin{array}{l}\text { Natural' products } \\
\text { with no residues }\end{array}$ & $\begin{array}{l}\text { Customisable food } \\
\text { Low meat diet } \\
\text { Slow food: promote identity, } \\
\text { Mental well-being }\end{array}$ & \\
\hline $\begin{array}{l}\text { 2. Western food choice } \\
\text { redundancy. However, a } \\
\text { resource intensive supporting } \\
\text { system with significant } \\
\text { burdens. }\end{array}$ & $\begin{array}{l}\text { Short chains } \\
\text { Community building as damping } \\
\text { effect on unbridled consumer } \\
\text { requirements }\end{array}$ & $\begin{array}{l}\text { Traditionally more attention to } \\
\text { origin } \\
\text { than to outward appearance of } \\
\text { products }\end{array}$ & $\begin{array}{l}\text { Slow food: respect for } \\
\text { regional production }\end{array}$ & $\begin{array}{l}\text { Social innovation: actual needs as } \\
\text { basis for production } \\
\text { Peer-to-peer production to } \\
\text { promote social capital building }\end{array}$ \\
\hline $\begin{array}{l}\text { 3.Performing well on food } \\
\text { production. However, } \\
\text { increasing competition for } \\
\text { other types of biomass use. }\end{array}$ & $\begin{array}{l}\text { Options for diversification of } \\
\text { periurban } \\
\text { agriculture }\end{array}$ & & & $\begin{array}{l}\text { Bio-based economy: use of } \\
\text { agricultural products for } \\
\text { pharmaceuticals, chemicals, etc. } \\
\text { Industrial ecology/cradle-to-Cradle }\end{array}$ \\
\hline $\begin{array}{l}\text { 4.Industrial chain efficiency. } \\
\text { However, multiple loci of } \\
\text { disconnection. }\end{array}$ & $\begin{array}{l}\text { Short chains: local distribution } \\
\text { and } \\
\text { Consumption Reskilling of } \\
\text { consumers, } \\
\text { community building around food } \\
\text { production }\end{array}$ & $\begin{array}{l}\text { Small-scale (if not jeopardised } \\
\text { to some degree by upscaling and } \\
\text { conventionalisation) }\end{array}$ & $\begin{array}{l}\text { Slow food as answer to } \\
\text { anonymisation } \\
\text { of production and consumption, } \\
\text { and to } \\
\text { erosion of cultural and natural } \\
\text { capital }\end{array}$ & $\begin{array}{l}\text { Peer-to-peer: new production and } \\
\text { financing mechanisms by direct } \\
\text { contact } \\
\text { Industrial ecology/ cradle-to- } \\
\text { cradle as basis for integration and } \\
\text { exchange } \\
\text { 'Factory of the future' as } \\
\text { networked factory }\end{array}$ \\
\hline $\begin{array}{l}\text { 5.Diverse and abundant food } \\
\text { availability. However, food } \\
\text { illiteracy. }\end{array}$ & $\begin{array}{l}\text { Connection of citizens with food } \\
\text { and food production system }\end{array}$ & & $\begin{array}{l}\text { Building on knowledge and } \\
\text { appreciation of food and its } \\
\text { production }\end{array}$ & \\
\hline
\end{tabular}




\begin{tabular}{|c|c|c|c|c|}
\hline $\begin{array}{ll}\text { Hotspot } & \text { Niche } \\
\end{array}$ & Urban agriculture & Organic agriculture & Eating differently & New production paradigms \\
\hline $\begin{array}{l}\text { 6. Food chain efficiency. } \\
\text { However, considerable losses. }\end{array}$ & $\begin{array}{l}\text { Short chains: low losses } \\
\text { Seasonality } \\
\text { Small scale, demand-oriented }\end{array}$ & & Quality above quantity & Cyclic processes of production \\
\hline $\begin{array}{l}\text { 7. Resource use efficiency } \\
\text { increased. However, resource } \\
\text { scarcity becomes tangible. }\end{array}$ & $\begin{array}{l}\text { Intensive production units with } \\
\text { minimal } \\
\text { spatial footprint, agro-parks } \\
\text { Closing of loops } \\
\text { Reduction of transport distances }\end{array}$ & $\begin{array}{l}\text { Closed loops, avoidance of } \\
\text { exogenous inputs } \\
\text { Transition towns: self-sufficiency, } \\
\text { economical use of local resources }\end{array}$ & $\begin{array}{l}\text { Low meat diet as diet with lower } \\
\text { input of resources }\end{array}$ & $\begin{array}{l}\text { Industrial ecology as answer to } \\
\text { scarcity of natural resources } \\
\text { Bio-based economy as answer to } \\
\text { scarcity of fossil fuels } \\
\text { 'Factory of the future': energy and } \\
\text { material efficient }\end{array}$ \\
\hline $\begin{array}{l}\text { 8. Environmental impacts } \\
\text { diminish. However, carrying } \\
\text { capacity remains delicate and } \\
\text { environmental costs are not } \\
\text { accounted for. }\end{array}$ & $\begin{array}{l}\text { Reduction of transport distances } \\
\text { Improved quality of urban } \\
\text { environment }\end{array}$ & $\begin{array}{l}\text { Avoidance of externalities through } \\
\text { respect for and closing of natural } \\
\text { loops }\end{array}$ & $\begin{array}{l}\text { Low meat diet as diet with fewer } \\
\text { environmental impacts }\end{array}$ & $\begin{array}{l}\text { Industrial ecology, biorefinery as } \\
\text { ways of avoiding externalities }\end{array}$ \\
\hline $\begin{array}{l}\text { 9.Building on a well } \\
\text { performing work force. } \\
\text { However, threatening social } \\
\text { the capital. }\end{array}$ & $\begin{array}{l}\text { Short chains local distribution and } \\
\text { Consumption } \\
\text { Self-sufficiency } \\
\text { Cooperation }\end{array}$ & Human-nature relationship & $\begin{array}{l}\text { Consumer's sense of responsibility } \\
\text { Lower impact on Southern } \\
\text { hemisphere }\end{array}$ & $\begin{array}{l}\text { Cooperation for industrial ecology } \\
\text { Social innovation } \\
\text { Low-barrier manufacturing } \\
\text { industries }\end{array}$ \\
\hline $\begin{array}{l}\text { 10.Technology optimises. } \\
\text { However, there are draw } \\
\text { backs and limits. }\end{array}$ & $\begin{array}{l}\text { Intensive production units with } \\
\text { minimal } \\
\text { spatial footprint, agro-parks } \\
\text { Functional broadening of } \\
\text { agriculture, } \\
\text { ecosystem services }\end{array}$ & $\begin{array}{l}\text { Attention to cohesion human- } \\
\text { nature } \\
\text { system }\end{array}$ & $\begin{array}{l}\text { Increasing resilience through social } \\
\text { capital } \\
\text { (slow food) }\end{array}$ & $\begin{array}{l}\text { Increasing resilience through } \\
\text { exchange of energy and material } \\
\text { flows (industrial ecology) and } \\
\text { integrated information } \\
\text { management ('factory of the } \\
\text { future') } \\
\text { Peer-to-peer: increasing resilience } \\
\text { through social capital }\end{array}$ \\
\hline
\end{tabular}




\section{Conclusions and reflections}

Besides the tangible result of the described systems analysis (previous sections), we distinguish a number of more tacit outcomes. In this concluding session, we reflect on the major lessons learned with regard to the basic objective of performing systems analysis as an instrument for systemic thinking on sustainable development. Within each of these lessons, we also indicate how we assess the role of the applied methodological tools and the process that was run. These findings were established by continuous assessment during the work and by dialogue between the experts and the reflection group. This reflective track, in parallel to the actual systems analysis establishment, can be considered as 'reflexive monitoring' (Van Mierlo et al., 2010).

\subsection{Was systems thinking enhanced?}

What the presented agri-food systems analysis trajectory -run within the interactive setting of 'experts' and reflection group- essentially brought was discussion and reflection that effectively went beyond a typical approach of 'specific problems'. In fact, the process succeeded in giving detail issues a role of illustration for the more generic, systemic mechanisms in play. It was our experience that the 'reflection group' reached this depth of being genuinely systemic. It hence also transcended the role of a merely steering committee towards a co-constructing experimenting team, that inspired significant process and content adjustments. In hindsight, the analysis -in content and process- was a balancing act in combining parsimony and sufficiency: embracing as much simplicity as possible and as much complexity and 'completeness' as necessary (Binder et al., 2010; Leveson, 2011). Initially, the latter aspect gratuitously initiated (expected) remarks in the sense of "forgot this" and "overlooked that". Yet, the rather exemplary than exhaustiveness setting of detail information invited for close examination of the most fundamental systemic mechanisms and their drivers and hence drew attention to the eventual objective of discovering the generic systems functioning. For that challenge of 'simplexity' we gradually discovered the importance of 'synthesis' -as basis of mutual understanding- over that of 'analysis', which evokes extensiveness and even exhaustiveness. The applied methodological tools of the multi-level perspective and the causal loop proved to be valuable aids for not getting lost in traditional detail discussions and reaching the aspired level of systemic reasoning. It was a remarkable observation that for a number of the reflection group members the MLP was 'known' and considered as potentially valuable; yet it was never actively applied to the specific case of the Flemish agriculture and food system. And although, it was not always clear whether e.g. certain aspects belong to 'landscape', 'regime' or 'niche', this categorisation was not perceived as pinching issue. The essence of the effort was rather perceived in the actual consideration and inclusion of the diverse influences, topics, facts, etc. as relevant elements of an overall 'rich' picture (Checkland and Poulter, 2010) of essential loops, feedbacks and systemic logics. The aspects of landscape trends as well as niche development, turned out to be instrumental in describing the dominant functioning of the incumbent system regime and in determining and formulating the hotspots. The latter can be considered as what Geels (2002) indicates as 'tensions' in the regime. In our study, the explicit elaboration of the hotspots also allowed to go beyond a description based on classic 'dimensions' of a system (Geels, 2002) and/or the indication of mechanisms for system stabilisation (Walker, 2000). A specific strength of the adopted hotspot determination and description was the inherent dual consideration of 'on the one side' and 'however...': indicating that current potentially problematic issues may well originate from issues that once enabled the success of a system.

\subsection{Don't solely problematize!}

When introducing the 'hotspots' of the current system configuration, an important outcome was the acknowledgement that a number of elements of a system's initial success (e.g. productivity increase) can eventually turn out to be causal for long-term degradation (of e.g. the biophysical or socio-cultural environments; Bawden, 1991). Hence, initial success factors may gradually proof to cause adverse effects and contribute to the system's 'drift into failure' (Dekker, 2011). This very dual nature explains many of the 
hotspots' formulation as a positive introduction followed by a 'however ...' section. This outcome arose the awareness that in systems analysis for sustainability dynamics, there might be a tendency to enter the stage from a (perceived) preoccupied mind-set of 'problems'. We learned to consequently and simultaneously embrace the constructive merits of aspects that -currently- may be problematic. This notion also serves more mutual understanding (of diverse views) and constructive willingness in a typical setting where incumbent players turn out to be quite reluctant towards the idea of transitions being all about 'niches' that oppose to, break down and eventually take over 'bad' regimes (a 'de-alignment re-alignment pathway', Grin et al., 2010). We experienced that incumbent, powerful system actors are more comfortable in a system thinking setting in which the merits and potential of the dominant regime are part of the picture and of the discussion. In that context of a more 'transformation'-like pathway mind-set (transition dynamics where development paths and innovation activities are initiated and steered by the regime actors in place; Grin et al., 2010), there is more chance for constructive reflection that allows for niche and regime dynamics to be considered in a joint transition/transformation dynamic.

\subsection{Landscape trends and niches: not only about 'pressure'}

Also when considering landscape trends, a more 'opportunity'-oriented attitude was considered as instrumental for constructive system thinking. In the classic understanding of the multi-level perspective, the concept of 'landscape' coincides with the wide context and long term trends that "create pressure on the system" (e.g. Geels, 2011). The deployment of the MLP in the presented system analysis showed that the latter 'pressure' connotation of landscape developments can be broken up: besides a number of actually recognized pressures, there are also landscape developments that can reinforce the current regime and/or provide opportunities for regime change. A good example is the landscape trend of changing values and ethical stances of citizens (3.2.7.): this trend not only puts pressure on some of the current agricultural and food (production) practices, but is at the same time an evolution that provides plenty of opportunities to develop new value creation and production models that capitalise on that very development. In such reasoning, systems analysis has the potential to turn sustainability and transition discourses from problem towards opportunity orientations, that can also be transcribed to new, sustainable business models.

The same reasoning goes for 'niches'. Typically they are being viewed and described as dynamics or initiatives that start off 'below the radar', gradually scale up, conquer market niches and eventually overthrow and replace an incumbent regime and its dominant actors and structures (Weber et al., 1999). For such a success story, strategic management can be deployed (Kemp et al., 1998). From our experience in the presented systems analysis, we find reason to confirm the more workable character of aligning ongoing processes at different MLP levels: niche innovations remain important for sustainability transitions but should be considered as linking up with ongoing processes at regime and landscape levels. "The key idea is that change takes place through processes of co-evolution and mutual adaptation within and between the layers", according to Shove and Walker (2007). Niches are not that much a 'threat' to the incumbent regime, they equally provide inspiration and opportunity for transforming and creating win-win outcomes. In such a mind-set, we experienced more willingness for open-minded and constructive systemic reasoning. The deployed methodological grips - as might have done others - allowed for this constructive and co-evolutionary thinking.

\subsection{Dealing with normativity and 'scientific underpinning'}

In processes of the kind that we run, there is acknowledgement of the importance of the researchers' attitude with regards to the validity of different epistemologies or conceptualizations of knowledge (Barreteau et al, 2010; Kalaugher et al., 2013; Miller et al., 2008; Neef and Neubert, 2011). We are aware of the presence of normative elements in the presented systems analysis, a point that is not unfamiliar in whatever work on sustainable development, also with regards to agricultural systems (Bawden, 2012). As such, the work more than probably reflects some degree of the authors' (and reflection group members) personal interpretations on the dominant functioning of the current agri-food system, as well as on the relevant landscape developments and the choice of niches. The often invoked question on the 'scientific 
status' in matters of the kind well known and cannot unequivocally be answered (Majone, 1985). In that regard however, we do not pretend 'to be right'; we merely have the aim to initiate reasoning and dialogue on a genuinely systemic level. To avoid reserve due to the pitfalls of 'interpretation bias' or 'taken-forgranted' assumptions (Alvesson and Sköldberg, 2009), as much of the systems elements as possible were evidenced by scientific literature from a myriad of relevant domains and disciplines; an interdisciplinary combination that is not frequently found, even not in 'system' inspired work and publications. Yet, there is a remaining aspect of validity that reflects the general apparent paradox of the system analyst besides being a (scientific) crafts man, also being a change agent; and hence, besides the purely scientific (descriptive) there might also be prescriptive (advisory) and persuasive (argumentative-interactive) elements.

However, the process and analysis at hand was co-created in a reflection group with a diversity of actors and was later on reviewed by even more 'peers' from government, sectors, civil society and academia. That co-creative line of approach enabled to clarify elements of bias, yet also surfaced inherent divergences of views and opinions with regards to issues such as values and conceptions about sustainability. A major way in which these divergences were reflected in the analysis, were the described 'hotspots': they simultaneously hold a favourable and a problematic consideration. In that, their position is presented in a differentiated way that most often reflects the actually existing diverse opinions, yet at the same time invites for careful consideration and assessment with regard to the desired sustainable development. The fact that these elements were explicitly brought into the discussion and the results illustrates that a level of aspired profoundness of the systems analysis had been reached.

\subsection{Adaptive systems analysis}

The adopted elements of methodology as well as the eventual outcome of the presented work cannot be classified as 'standard'; a number of elements were considered pragmatically, critically questioned and rather organically combined in close interaction with the members of the reflection group. Thereby, potential drawbacks of particular elements may be still be present. For instance, we acknowledge that also in our study probably still too little attention was paid to the element of actors and agency, which was earlier argued with regards to the usefulness of the multi-level perspective (Ten Pierick and Van Mil, 2009). The actual approach emerged by the acknowledged deployment of cross-perception discursive meetings, iteration and negotiation, bolstering a more valid and reliable analysis (Wiek et al., 2008). And more, the approach as well as the results should not be considered as 'final' but rather as elements of a more continuous process of systems thinking that builds on ever advancing insights. An important element in that respect is the ongoing dialogue on the work at hand in an enhanced interaction and validation process with relevant stakeholders, both scientific and non-scientific. Additionally, the resulting systems analysis at hand is now being included in a process of "Transformation towards sustainable agriculture and food", supported by the Flemish Government and a consortium of incumbent regime players. In that way, the work might have inspired a further dynamic of systems thinking in a participatory dialogue, a core characteristic of systems (research) approaches (Darnhofer et al., 2009). It is precisely such continued backtracking and iteration (Pešsl and Hřebičcek, 2003) in favour of conditions for trust and reciprocity (Cramer and Loeber, 2004), that can lead to a social construct (Reynolds and Holwell, 2010) and to sufficiently encompassed diversity of actor viewpoints (Kalaugher et al., 2013). Systems exercises of the kind we presented may accommodate ontologies, discourses and knowledge (Miller et al., 2008) and eventually be instrumental for defining opportunities and action for systemic change (Van Mierlo et al., 2013). No matter how modest it might have been, we hope that the presented systems analysis has contributed to that very ambition.

Acknowledgements: For the financing and constructive collaboration, the authors cordially thank the Flemish Environment Agency and its MIRA team, and the Flemish Department of Agriculture and Fisheries and its Division for Agricultural Policy Analysis. 


\section{References}

Aalto-Setälä, V., 2002. The effect of concentration and market power on food prices: evidence from Finland. J. Retailing 78, 207-216.

Aertsens, J., Verbeke, W., Mondelaers, K., Van Huylenbroeck, G., 2009. Personal determinants of organic food consumption : a review. Brit. Food J. 111, 1140-1167.

Aldy, J., Hrubovcak, J., Vasavada, U., 1998. The role of technology in sustaining agriculture and the environment. Ecol. Econ. 26, 81 - 96.

Alluvione, F., Moretti, B., Sacco, D., Grignani, C., 2011. EUE (energy use efficiency) of cropping systems for a sustainable agriculture. Energy 36, 4468-4481.

Alvesson, M., Sköldberg, K., 2009. Reflexive methodology. New vistas for qualitative research ( ${ }^{\text {nd }}$ ed.). Sage, Los Angeles.

Archambault, S., 2004. Ecological modernization of the agriculture industry in southern Sweden: reducing emissions to the Baltic Sea. J. Clean. Prod. 12, 491-503.

Asher, J., Daponte, B., 2010. A hypothetical Cohort Model of Human Development. Human Development Research Paper 2010/40. United Nations Development Programme. URL: http://hdr.undp.org/en/reports/global/hdr2010/papers/HDRP_2010_40.pdf. Retrieved 2010-1025 (accessed March 2013).

Atkinson, R., McKay, A., 2007. Digital Prosperity. Understanding the Economic Benefits of the Information Technology Revolution. The Information Technology and Innovation Foundation, Washington, USA. URL: http://www.itif.org/files/digital_prosperity.pdf (accessed June 2013).

Aysan, M. , Beaujot, R., 2009. Welfare regimes for ageing populations: no single path for reform. Popul. Dev. Rev. 35, 701-720.

Baka, J., Roland-Horst, D., 2009. Food or fuel? What European farmers can contribute to Europe's transport energy requirements and the Doha Round. Energ. Policy 37, 2505-2513.

Bardi, U., El Asmar, T., Lavacchi, A., 2013. Turning electricity into food : the role of renewable energy in the future of agriculture. J. Clean. Prod. 53, 224-231.

Barreteau, O., Bots, P., Daniell, K., 2010. A framework for clarifying "participation" in participatory research to prevent its rejection for the wrong reasons. Ecol. Soc. 15, 1. URL: http://www.ecologyandsociety.org/vol15/iss2/art1/ (accessed June 2013).

Barthel, S., Isendahl, C., 2012. Urban gardens, agriculture and water management: sources of resilience for long-term food security in cities. Ecol. Econ. 86, 224-234.

Bawden, R., 1991. Systems thinking and practice in agriculture. J. Dairy Sci. 74, 2362-2373.

Bawden, R., 2012. How should we farm? The ethical dimension of farming systems, in: Darnhofer, I., Gibbon, D., Dedieu, B. (Eds.), Farming systems research into the 21th century: the new dynamic. Springer, Dordrecht, the Netherlands, pp. 119-139.

Bellucci, F., Bogner, J., Sturchio, N., 2012. Greenhouse Gas Emissions at the Urban Scale. Elements 8, 445-449.

Bennett, M., 1936. Wheat Studies of the Food Research Institute, vols. 12 and 18. Stanford University, California.

Berkhout, F., Hertin, J., 2004. De-materialising and re-materialising: digital technologies and the environment. Futures 36, 903-920.

Beretta, C., Stoessel, F., Baier, U., Hellweg, S., 2013. Quantifying food losses and the potential for reduction in Switzerland. Waste Manage. 33, 764-773.

Binder, C., Feola, G., Steinberger, J., 2010. Considering the normative, systemic and procedural dimensions in indicator-based sustainability assessments in agriculture. Environ. Impact Assess. Rev. 30, 71-81.

Bindraban, P. , Rabbinge, R., 2012. Megatrends in agriculture - Views for discontinuities in past and future developments. Glob. Food Secur. 1, 99-105.

Björklund, J., Limburg, K., Rydberg, T., 1999. Impact of production intensity on the ability of the agricultural landscape to generate ecosystem services: an example from Sweden. Ecol. Econ. 29, 269-291.

Blackmore, C., Ison, R., 2012. Designing and developing learning systems for managing systemic change in a climate change world, in: Wals, A., Blaze Corcoran, P. (Eds.), Learning for sustainability in times of accelerating change. Wageningen Academic Publishers, The Netherlands, pp. 347-363. 
Bocken, N.M.P., Short, S.W., Rana, P., Evans, S., 2014. A literature and practice review to develop sustainable business model archetypes. Journal of Cleaner Production, 65, 42-56

Boons, F., Montalvo, C., Quist, J., Wagner, M., 2013. Sustainable innovation, business models and economic performance: an overview. J. Clean. Prod. 45, 1-8.

Borghesi, S. , Vercelli, A., 2003. Sustainable globalisation. Ecol. Econ. 44, 77-89.

Bouzarovski, S., Petrova, S., Sarlamanov, R., 2012. Energy poverty policies in the EU: A critical perspective. Energ. Policy 49, 76-82.

Brink, C., van lerland, E., Hordijk, L., Kroeze, C., 2005. Cost-effective emission abatement in agriculture in the presence of interrelations: cases for the Netherlands and Europe. Ecol. Econ. 53, 59-74.

Bryan, E., Ringler, C., Okoba, B., Roncoli, C., Silvestri, S., Herrero, M., 2013. Adapting to climate change inKenya: household strategies and determinants. J. Environ. Manage. 114, 26-35.

Brynjolfsson, E., Hitt, L., 2003. Computing Productivity: Firm-Level Evidence. Massachusetts Institute of Technology (MIT) - Sloan School of Management; National Bureau of Economic Research (NBER), MIT Sloan Working Paper No. 4210-01, June 2003.

Bulkeley, H., Hodson, M., Marvin, S., 2011. Emerging strategies of urban reproduction and the pursuit of low carbon cities, in: Flint, J., Raco, M. (Eds.), The New Politics of Sustainable Urban Planning. The Polity Press, Cambridge,UK.

Burgess, P., Morris, J., 2009. Agricultural technology and land use futures: the UK case. Land Use Policy 26S, S222-S229.

Busch, L., Bain, C., 2004. New ! Improved ? The transformation of the global agrifood system. Rural Sociol. 69, 312-346.

Caballero, B., 2007. The Global Epidemic of Obesity: An Overview. Epidemiol. Rev., 29, 1-5.

Calus, M., Van Huylenbroeck, G., 2005. Attitude of Flemish farmers towards alternative business governance structures. Paper presented at the $94^{\text {th }}$ EAAE Seminar, Ashford, UK.

Canning, P., Charles, A., Huang, S., Polenske, K., Waters, A., 2010. Energy use in the US food system. United States Department of Agriculture. Economic Research Report, Number 94.

Caspari,G., O'Connor,D., 2003. Providing low cost information technology access to rural communities in developing countries: what works? What pays? OECD Development Centre, Working Paper $n^{\circ} 229$. OECD, Paris, France.

Checkland, P., 1981. Systems thinking, systems practice. Wiley, London, UK.

Checkland, P., 2000. Soft systems methodology: a thirty year retrospective. Systems Research and Behav. Sci. 17, S11-S58.

Checkland, P., Poulter, J., 2010. Soft systems methodology. In: Reynolds, M., Holwell,S. (Eds), Systems approaches to managing change: a practical guide. Springer, London, pp.191-242.

Checkland, P., Scholes,P., 1990. Soft Systems Methodology in Action. John Wiley \& Sons Ltd, Chicester,UK.

Clarke, I., 2000. Retail power, competition and local consumer choice in the UK grocery sector. Eur. J. Market. 34, 975-1002.

Cordell, D., Drangert, J., White, S., 2009. The story of phosphorus: global food security and food for thought. Glob. Environ. Chang. 19, 292-305.

Coyle, G., 2000. Qualitative and quantitative modelling in system dynamics: some research questions. Syst. Dynam. Rev. 16, 225-243.

Costanza, R., d'Arge, R., de Groot, R., Farberk, S., Grasso, M., Hannon, B., Limburg, K., Naeem, S., O'Neill, R., Paruelo, J., Raskin, R., Suttonkk, P., van den Belt, M., 1997. The value of the world's ecosystem services and natural capital. Nature 387, 253-260.

Costell, E., Tárrega, A., Bayarri, S., 2010. Food acceptance: the role of consumer perception and attitudes. Chemosens. Percept. 3, 42-50.

Cramer, J., Loeber, A., 2004. Governance through learning: making corporate social responsibility in Dutch industry effective from a sustainable development perspective. J. Environ. Pol. Plann. 6, 1-17.

Crane, A., 2001. Unpacking the ethical product. J. Bus. Ethics 30, 361-373.

Crawford, A., Nettle, R., Brightling, P., Hibburt, C., 2010. Enhancing the liveability of farm systems: Supporting new farm and advisory practices in the Australian dairy industry. In: Proceedings of the 9th European IFSA Symposium, Vienna, Austria, pp. 1109-1116.

Crossette, B., 2010. From conflict and crisis to renewal: generations of change. The state of world population 2010. UNFPA (the United Nations Population Fund), 
D'Anna, W., Cascini, G., 2011. Supporting sustainable innovation through TRIZ system thinking. Procedia Eng. 9, 145-156.

Darnhofer, I., Gibbon, D., Dedieu, B., 2009. Farming systems research: an approach to inquiry, in: Darnhofer, I., Gibbon, D., Dedieu, B. (Eds). Farming systems research into the 21th century: the new dynamic. Springer, Dordrecht, the Netherlands, pp. 3-31.

Dasgupta, S., Laplante, B., Meisner, C., Wheeler, D., Yan, J., 2007. The impact of sea level rise on developing countries: a comparative analysis. World Bank Policy Research Working Paper 4136.

Davies, A., 2011. On constructing ageing rural populations: Capturing the grey nomad. J. Rural Stud. 27, 191-199.

De Boer, J., 2003. Sustainability labelling schemes: the logic of their claims and their functions for stakeholders. Bus. Strategy Environ. 12, 254-264.

Dekker, S., 2011. Drift into failure: from hunting broken components to understanding complex systems. Ashgate, Aldershot, UK.

De Krom, M., Dessein, J., Ebout, N., 2014. Understanding relations between science, politics, and the public: the case of a GM field trial controversy in Belgium. Sociologia Ruralis 54, 21-39.

Delind, B., 2002. Place, work, and civic agriculture: common fields for cultivation. Agr. Hum. Values 19, 217-224.

Dendler, L., 2013. Sustainability Meta labelling: an effective measure to facilitate more sustainable consumption and production? J. Clean. Prod., in Press, corrected proof available online 18 May 2013.

Dessein, J., Nevens, F., 2007. 'I'm Sad To Be Glad'. An Analysis of Farmers' Pride in Flanders. Sociol. Ruralis 47, 273-292.

Dlugosz, Z., 2011. Population ageing in Europe. P. Soc. Behav. Sci. 19, 47-55.

Dowler, E., O'Connor, D., 2012. Rights-based approaches to addressing food poverty and food insecurity in Ireland and UK. Soc. Sci. Med. 74, 44-51.

Dreher, A., 2006. Does Globalization Affect Growth? Evidence from a new Index of Globalization. Appl. Econ. 38, 1091-1110.

Easterlin, R., McVey, L., Switek, M., Sawangfa, O., Zweig, J., 2010. The happiness-income paradox revisited. P. Natl Acad. Sci. 107, 22463-22468.

EC (European Commission), 2009. The 2009 ageing report. Economic and budgetary projections for the EU-27 Member States (2008 -2060). Joint Report prepared by the European Parliament, the Council, the European Economic and Social Committee and the committee of the regions, COM(2009)180.

EC (European Commission), 2011. Analysis associated with the Roadmap to a Resource Efficient Europe. Part I. Commission Staff Working Paper SEC(2011) 1067 final.

EEA (European Environment Agency), 2011. The European environment - state and outlook 2010: assessment of global megatrends. European Environment Agency, Copenhagen.

El Ghali, M., Daniel, K., Colson, F., Sorin, S., 2012. Towards an ecologically intensive agriculture. Paper provided by International European Forum on Innovation and System Dynamics in Food Networks in its series 2012 International European Forum, February 13-17, 2012, Innsbruck-Igls, Austria, 463485.

Elzen, B., Barbier, M., Cerf, M., Grin, J., 2012. Stimulating transitions towards sustainable farming systems, in: Darnhofer, I., Gibbon, D., Dedieu, B. (Eds.), Farming systems research into the 21th century: the new dynamic. Springer, Dordrecht, the Netherlands, pp. 431-455.

Engström, R., Wadeskog, A., Finnveden, G., 2007. Environmental assessment of Swedish agriculture. Ecol. Econ. 60, 550-563.

Erb, K.-H., Haberl, H., Krausmann, F., Lauk, C., Plutzar, C., Steinberger, J., Müller, C., Bondeau, A., Waha, K.,Pollack, G., 2009. Eating the Planet: Feeding and fuelling the world sustainably, fairly and humanely- a scoping study. Institute of Social Ecology, Vienna: Social Ecology Working Paper 116. URL:

http://www.ciwf.org.uk/includes/documents/cm_docs/2009/e/eating_the_planet_full_report_nov_ 2009.pdf (accessed May 2013).

Ericsson, Å., Müller, P., Larsson, T., Stark, R., 2009. Product-service systems - From customer needs to requirements in early development phases. Proceedings of the $1^{\text {st }}$ CIRP Industrial Product-Service Systems Conference, 62-69. 
Ernstson, H., van der Leeuw, S.E., Redman, C.L., Meffert, D.J., Davis, G., 2010. Urban Transitions: On urban resilience and human-dominated ecosystems. Ambio 39, 531-545.

Esmaelli, A., Shokoohi, Z, 2011. Assessing the effect of oil price on world food prices: application of principal component analysis. Energ. Policy 39, 1022-1025.

EU SCAR, 2012. Agricultural Knowledge and Innovation Systems in Transition - a reflection paper. Standing Committee on Agricultural Research (SCAR) Collaborative Working Group on Agricultural Innovation and Knowledge Systems (CWG-AKIS), EU, Brussels.

Falch, M., Henten, A., 2000. Digital Denmark: from information society to network society. Telecommun. Policy 24, 377-394.

FAO (ood and Agricultural Organisation of the United Nations), 2011. Energy-smart food for people and climate. Issue Paper. URL: http://www.fao.org/docrep/014/i2454e/i2454e00.pdf (accessed June 2013)

FAO (Food and Agricultural Organisation of the United Nations), 2012. The State of Food Insecurity in the World 2012. URL: http://www.fao.org/publications/sofi/en/ (accessed March 2013).

Fikret, E., Huseynov, O., 2011. Planning of sustainable cities in view of green architecture. Procedia Eng. $21,534-542$.

Finegan, A., 1994. Soft systems methodology: an alternative approach to knowledge elicitation in complex and poorly defined systems. Complexity International 1. URL: http://www.complexity.org.au/ci/vol01/finega01/html/ (accessed July 2013).

Fischer, G., Shah, M., Tubiello, F., van Veldhuizen, H., 2005. Socio-economic and climate change impacts on agriculture: an integrated assessment, 1990 - 2080. P. T. Roy. Soc. B 360, 2067-2083.

Fischer, S., Dornbush, R., Schmalensee, R., 1988. Economics. McGraw-Hill Book Company, New York, USA.

Fogel, R., Costa, D., 1997. A theory of technophysio evolution, with some implications for forecasting population, health care costs and pension costs. Demography 34, 49-66.

Foley, J., Ramankutty, N., Brauman, K., Cassidy, E., Gerber, J., Johnston, M., Mueller, N., O'Connell, C., Ray, D., West, P., Balzer, C., Bennett, E., Carpenter, S., Hill, J., Monfreda, C., Polasky, S., Rockström, J., Sheehan, J., Siebert, S., Tilman, D., Zaks, D., 2011. Solutions for a cultivated planet. Nature 478, 337-342.

Foresight, 2011. The Future of Food and Farming: challenges and choices for global sustainability. Final Project Report. The Government Office for Science, London. URL: http://www.bis.gov.uk/assets/foresight/docs/food-and-farming/11-546-future-of-food-and-farmingreport.pdf (accessed July 2013).

Forrester, J., 1958. Industrial Dynamics-A Major Breakthrough for Decision Makers. Harvard Bus. Rev. 36, 37-66.

Fraser, C., Smith, K., Judd, F., Humphreys, J., Fragar, L., Henderson, A., 2005. Farming and Mental Health Problems and Mental Illness. Int. J. Soc. Psychiatr. 51, 340-349.

Freibauer, A., Mathijs, E., Brunori, G., Damianova, Z., Faroult, E., Girona i Gomis, J., O’Brien, L., Treyer, S., 2011. Sustainable food consumption and production in a resource-constrained world. European Commission - Standing Committee on Agricultural Research (SCAR), The $3^{\text {rd }}$ SCAR Foresight Exercise. URL: http://www.scp-knowledge.eu/sites/default/files/knowledge/attachments/UmweltWissenschaft-EU-Landwirtschaft2050.pdf (accessed May 2013).

Fresco, L., 2009. Challenges for food system adaptation today and tomorrow. Environ. Sci. Policy 12, 378385.

Gale, F., 2000. Economic specialization versus ecological diversification: the trade policy implications of taking the ecosystem approach seriously. Ecol. Econ. 34, 285-292.

Gale, R., 2006. Environmental management accounting as a reflexive modernization strategy in cleaner production. J. Clean. Prod. 14, 1228-1236.

Gallopin, G., 2003. A systems approach to sustainability and sustainable development. CEPAL - SERIE Medio ambient y desarrollo. United Nations Publication, Santiago, Chile.

Garud, R., Karnøe, P., 2001. Path creation as a process of mindful deviation, in: Garud,R., Karnøe,P. (Eds.), Path dependence and creation, Lawrence Earlbaum Associates, pp. 1-38.

Geels, F., 2002. Technological transitions as evolutionary reconfiguration processes: a multi-level perspective and a case study. Res. Policy 31, 1257-1274. 
Geels, F., 2004. From sectoral systems of innovation to socio-technical systems. Insights about dynamics and change from sociology and institutional theory. Res. Policy 33, 897 - 920.

Geels,F., 2011. The multi-level perspective on sustainability transitions: responses to seven criticisms. Environmental Innovation and Societal Transitions 1, $24-40$.

Geels, F., Schot, J., 2007. Typology of socio-technical transition pathways. Res. Policy 36, 399-417.

Gerbens-Leenes, P., Moll, H., Schoot Uiterkamp, A., 2003. Design and development of a measuring method for environmental sustainability in food production systems. Ecol. Econ. 46, 231-248.

Giddens, A., 1991. Modernity and self-identity: self and society in the late modern age. Stanford University Press, Stanford, CA.

Girard, R., 1965. Deceit, Desire and the Novel : Self and Other in Literary Structure. John Hopkins Press, London.

Girard, R., 1988. Violence and the sacred. London: Athlone.

Gladwell, M., 2000. The Tipping Point: How Little Things Can Make a Big Difference. Little, Brown and Company; Boston, New York, London.

Godfray, H., Beddington, J., Crute, I., Haddad, L., Lawrence, D., Muir, J., Pretty, J., Robinson, S., Thomas, S., Toulmin, C., 2010. Food security: the challenge of feeding 9 billion people. Science 327, 812818.

Gohari, A., Eslamian, S., Abedi-Koupaei, J., Massah bavani, A., Wang, D., Madani, K., 2013. Climate change impacts on crop production in Iran's Zayandeh-Rud River basin. Sci. Total Environ. 442, 405-419.

Goodland, R., 1997. Environmental sustainability in agriculture: diet matters. Ecol. Econ. 23, 189-200.

Grassini P., Eskridge, K., Cassman, K., 2013. Distinguishing between yield advances and yield plateaus in historical crop production trends Nature Communications, 4, 2918.

Grimm, N., Faeth, S. \& Golubiewski, N., 2008. Global change and the ecology of cities. Science 319, 756760.

Grin, J., 2012. Changing governments, kitchens, supermarkets, firms and farms, in: Spaargaren, G., Oosterveer, P., Loeber, A. (Eds.), Food practices in Transition. Changing food consumption, retail and production in the age of reflexive modernity. Routledge, New York, London, pp. 35-59.

Grin, J., Rotmans, J., Schot, J., 2010. Transitions to sustainable development, New directions in the study of long term transformative change. Routledge, New York, London.

Grosskurth, J., Rotmans, J., 2005. The SCENE model: getting a grip on sustainable development in policy making. Environ. Dev. Sustain. 7, 135-151.

Grunert, K., 2006. How changes in consumer behaviour and retailing affect competence requirements for food producers and processors. EcoEconmía Agraria y Recursos Naturales 6, 3-22.

Grunert, K., Wills, J., Fernández-Celemín, L., 2010. Nutrition knowledge, and use and understanding of nutrition information on food labels among consumers in the UK. Appetite 55, 177-189.

Guillén, M., 2001. Is globalization civilizing, destructive or feeble? A critique of five key debates in the socialscience literature. Annu. Rev. Sociol. 27, 235-260.

Gustavsson, J., Cederberg, C., Sonesson, U., Van Otterdijk, R., Meybeck, A., 2011. Global food losses and food waste. Extent, causes and prevention, Food and Agriculture Organization, Rome.

Hagelskjaer Lauridsen, E., Stissing Jensen, J., 2013. The strictest energy requirements in the world: an analysis of the path dependencies of a self-proclaimed success. Energ. Policy 53, 97-104.

Harding, R., Peduzzi, P., 2012. The end of cheap oil: a threat to food security and an incentive to reduce fossil fuels in agriculture. Environ. Dev. 3, 157-165.

Hardy, R., 2002. The bio-based economy. Trends in New Crops and New Uses. Proceedings of the Fifth New Crops Symposium. ASHS Press, Atlanta.

Harris, J., Kennedy, S., 1999. Carrying capacity in agriculture: global and regional issues. Ecol. Econ. 29, 443-461.

Hazell, P., Wood, S., 2008. Drivers of change in global agriculture. Phil. Trans. R. Soc. B 363, 495- 515.

Heller, M., Keoleian, G., 2003. Assessing the sustainability of the US food system: a life cycle perspective. Agr. Syst. 76, 1007-1041.

Hendrickson, M., Heffernan, W., 2002. Opening spaces through relocalization: locating potential resistance in the weaknesses of the global food system. Sociol. Ruralis 42, 347-369.

Hendrickson, M., James, H., 2005. The ethics of constrained choice: how the industrialization of agriculture impacts farming and farmer behaviour. J. Agr. Environ. Ethics 18, 269-291. 
Henningsson, S., Hyde, K., Smith, A. Campbell, M., 2004. The value of resource efficiency in the food industry: a waste minimization project in East Anglia, UK. J. Clean. Prod. 12, 505-512.

Hinrichs, C., Welsh, R., 2003. The effects of industrialization of US livestock agriculture on promoting sustainable production practices. Agr. Hum. Values 20, 125-141.

Hoffmann, V., Probst, K., Christinck, A., 2007. Farmers and researchers: how can collaborative advantages be created in participatory research and technology development? Agr. Hum. Values 24, 355-368.

Horrigan, L., Lawrence, R., Walker,P., 2002. How sustainable agriculture can address the environmental and human health harms of industrial agriculture. Environ. Health Persp. 110, 445-456.

IGD (The Institute of Grocery Distribution), 2008. The Golden Generation. Identifying opportunities to meet the needs of a diverse older population, November 2008.

IIGSS (International Institute for Global Systems Studies), 2001. Some Streams of Systemic Thought, originated in 1996 by Dr. Eric Schwarz, Neuchâtel, Switzerland. URL: http://www.ilgss.net/files/gPICT.pdf (accessed June 2013)

Ikerd, J., 1993. The need for a systems approach to sustainable agriculture. Agric. Ecosyst. Environ. 46, 147-160.

IMF (International Monetary Fund), 2012. Primary Commodity Prices database. URL: http://www.imf.org/external/np/res/commod/index.aspx (accessed March 2013).

Infante Amate and Gonzalez de Molina, 2013. 'Sustainable de-growth' in agriculture and food: an agroecological perspective on Spain's agri-food system (year 2000). J. Clean. Prod. 38, 27-35.

Inglehart, R., Klingemann, H.-D., 2000. Genes, Culture and Happiness. MIT Press, Boston.

IPCC (Intergovernmental Panel on Climate Change), 2007. IPCC Fourth Assessment Report: Climate Change (AR4).

Ison, R., 2008. Systems thinking and practice for action research, in: Reason, W., Bradbury, H. (Eds.), The Sage Handbook of Action Research Participative Inquiry and Practice (2nd edition). Sage Publications, London, UK, pp. 139-158.

Jackson, T., 2009. Prosperity without growth. Earthscan Publications, UK.

Kalaugher, E., Bornman, J., Clark, A., Beukes, P., 2013. An integrated biophysical and socio-economic framework for analysis of climate change adaptation strategies: the case of a New Zealand dairy farming system. Environ. Modell. Soft. 39, 176-187.

Kallis, G., Kerschner,C., Martinez-Alier, J., 2012. The economics of degrowth. Ecological Economics 84, 172-180.

Kandil, M., 2007. The wage-price spiral: International evidence and implications. J. Econ. Bus. 59, 212-240.

Kastner, T., Ibarolla Rivas, M., Koch, W., Nonhebel, S., 2012. Global changes in diets and the consequences for land requirements for food. P. Natl Acad. Sci. 109, 6868-6872.

Katz, J., Rice, R., Aspden, P., 2001. The Internet, 1995-2000: Access, civic involvement, and social interaction. Am. Behav. Sci. 45, 404-419.

Kemp, R., Schot, J., Hoogma,R., 1998. 'Regime shifts to sustainability through processes of niche formation: the approach of Strategic Niche Management'. Technology Analysis and Strategic Management 10, 175-195.

Kesteloot, C., 2003. Verstedelijking in Vlaanderen: problemen, kansen en uitdagingen voor het beleid in de 21e eeuw, in: Schets L. (Ed.), De eeuw van de stad, over stadsrepublieken en rastersteden: Voorstudies. Ministerie van de Vlaamse Gemeenschap, Project Stedenbeleid, Brussel, pp. 15-39.

Kim, D., 1995. System Thinking Tools; The Toolbox Reprint Series. Pegasus Communications, Cambridge, Mass.

Kirkwood, 1998. System Behaviour and Causal Loop Diagrams, in: System Dynamics Methods: a quick introduction. URL: http://www.public.asu.edu/ kirkwood/sysdyn/SDIntro/ch-1.pdf laccessed March 2013)

Klintman, M., Boström, M., 2012. Political consumerism and the transition towards a more sustainable food regime, in: Spaargaren, G., Oosterveer, P., Loeber, A. (Eds.), Food practices in Transition. Changing food consumption, retail and production in the age of reflexive modernity. Routledge, New York, London, pp. 107-128.

Kummu, M., de Moel, H., Porkka, M., Siebert, S., Varis, O., Ward, P., 2012. Lost food, wasted resources: global food supply chain losses and their impacts on freshwater, cropland and fertiliser use. Sci. Total Environ. 438, 477-489.

Lal, R., 2004. Carbon emissions from farm operations. Environ. Int. 30, 981-990. 
Lambin, E., Meyfroidt, P., 2011. Global land use change, economic globalization and the looming land scarcity. P. Natl Acad. Sci. USA 108, 3465-3472.

Lazarides, H., 2011. Hunger and obesity: is this the best we - food scientists/engineers - can offer to the world community in the $21^{\text {st }}$ century? P. Food Sci. 1, 1854-1860.

Lebreton, M., Kawa, S., Forgeot d'Arc, B., Daunizeau, J., Pessiglione, M., 2012. Your goal is mine: unraveling mimetic desires in the human brain. J. Neurosci. 32, 7146-7157.

Lee, B., Preston, F., Kooroshy, J., Bailey, R., Lahn, G., 2012. Resources Futures. A Chatham House Report. URL:

http://www.chathamhouse.org/sites/default/files/public/Research/Energy,\%20Environment\%20an d\%20Development/1212r_resourcesfutures.pdf (accessed June 2013)

Lee, W., Okos, M., 2011. Sustainable food processing systems - Path to a zero discharge: reduction of water, waste and energy. P. Food Sci. 1, 1768-1777.

Leveson, N., 2011. Applying systems thinking to analyse and learn from events. Safety Sci. 49, 55-64.

Levidow, L., 2013. EU criteria for sustainable biofuels: accounting for carbon, depoliticising plunder. Geoforum 44, 211-223.

Liu, J., Yang, H., Savenije, H., 2008. China's move to higher-meat diet hits water security. Nature 454, 397.

Lobao, L., Stofferahn, C., 2007. The community effects of industrialized farming: Social science research and challenges to corporate farming laws. Agric. Hum. Values 25, 219-240.

Loorbach, D., 2007. Transition management, new mode of governance for sustainable development. International Books, Utrecht, the Netherlands.

Lucas, R. ,1988. On the mechanics of economic development. J. Monet. Econ. 22, 3-42.

Majone, G., 1985. Systems analysis: a genetic approach, in: Miser, H., Quade, E. (Eds.), Handbook of systems analysis. Volume 1: Overview of uses, procedures, applications and practice. NorthHolland, New York, Amsterdam, Oxford, pp. 33-66.

Marion, B., 1998. Changing power relationships in US Food Industry: brokerage arrangements for private label products. Agribusiness 14, 85-93.

Marlow, H., Hayes, W., Soret, S., Schwab, E., Sabaté, J., 2009. Diet and environment: does what you eat matter? Am. J. Clin. Nutr. 89, 1699S-1703S.

Marsden, T., 2012. Food systems under pressure. Regulatory instabilities and the challenge of sustainable development, in: Spaargaren, G., Oosterveer, P., Loeber, A. (Eds.), Food practices in Transition. Changing food consumption, retail and production in the age of reflexive modernity. Routledge, New York, London, pp. 291-311.

Martens, P., Dreher, A., Gaston, N., 2010. Globalisation, the global village and the civil society. Futures 42, 574-582.

Maru, Y., Woodford, K., 2007. Revisiting sustainability boundaries from a systems perspective. Conference paper presented at the MODSIM07, International Congress on Modelling and Simulation, held December 2007, University of Canterbury, New Zealand.

Maslow, A., 1943. A theory of human motivation. Psychol. Rev. 50, 370-396.

McKenney, J., 2002. Artificial fertility: the environmental cost of industrial fertilizers, in: Kimbrell, A. (Ed.), The fatal harvest reader: the tragedy of industrial agriculture. Island Press, Washington DC.

McMichael, P., 2011. Food system sustainability: questions of environmental governance in the new world(dis)order. Glob. Environ. Chang. 21, 804-812.

McNamara, K., (Ed.), 2008. Enhancing the Livelihoods of the Rural Poor through ICT: A Knowledge Map. Tanzania Country Study. InfoDev Working Paper No. 9. URL: www.infodev.org/en/Publication.517.html (accessed march 2013)

McWilliams, A., Siegel, D., 2001. Corporate social responsibility: A theory of the firm perspective. Academy of Management Review 26, 117-127.

Meadows, D., 1994. Envisioning a Sustainable World. Third Biennial Meeting of the International Society for Ecological Economics, October 24-28, 1994, San Jose, Costa Rica. URL: http://www.oasisdesign.net/design/legalizesustainability/files/D_Meadows_Envisioning.pdf (accessed March 2013)

Meadows, D. 1999. Leverage Points: Places to Intervene in a System. Hartland, VT, Sustainability Institute.

Meadows, D., 2009. Thinking in systems. A primer. Earthscan,London, UK. 
Melman, T., van der Heide M., 2011. Ecosysteemdiensten in Nederland: verkenning betekenis en perspectieven. Achtergrondrapport bij Natuurverkenning 2011. Wageningen, Wettelijke Onderzoekstaken Natuur \& Milieu, WOt-rapport 111.

Milestad, R., Dedieu, B., Darnhoder, I., Bellon, S., 2012. Farms and farmers facing change: the adaptive approach, in: Darnhofer, I., Gibbon, D., Dedieu,B . (Eds.), Farming systems research into the 21th century: the new dynamic. Springer, Dordrecht, the Netherlands, pp. 365-385.

Miller, T., Baird, T., Littlefield, C., Kofinas, G., Stuart Chapin, F., 2008. Epistemological pluralism: reorganizing interdisciplinary research. Ecol. Soc. 13, 46. URL: http://www.ecologyandsociety.org/vol13/iss2/art46/ (accessed March 2013)

MIRA (Environmental Report, Flanders), 2012. Transition to a sustainable agro-food system in Flanders: a system analysis. MIRA-AMS 2012 Topic Report. URL: http://www.milieurapport.be/Upload/main/0_topicrapporten/Topicrapport_Eng_webC2.pdf (accessed March 2014)

Moreno-Pérez, O., Arnalte-Alegre, E., Ortiz-Miranda, D., 2011. Breaking down the growth of family farms : a case study of an intensive Mediterranean agriculture. Agr. Syst. 104, 500-511.

Morgan, K., Murdoch, J., 2000. Organic vs. conventional agriculture: knowledge, power and innovation in the food chain. Geoforum 31, 159-173.

Morozov, E., 2013. To Save Everything, Click Here: The Folly of Technological Solutionism. PublicAffairs, New York, USA.

Mzoughi, N., 2011. Farmers adoption of integrated crop protection and organic farming: do moral and social concerns matter? Ecol. Econ. 70, 1536-1545.

Neef, A., Neubert, D., 2011. Stakeholder participation in agricultural research projects: a conceptual framework for reflection and decision-making. Agric. Hum. Values 28, 179-184.

Nevens, F., Frantzeskaki, N., Loorbach, D., Gorissen, L., 2013. Urban Transition Labs: co-creating transformative action for sustainable cities. J. Clean. Prod. 50, 111-122.

Nidumolu, U., de Bie, C., van Keulen, H., Skidmore, A., Harmsen, K., 2006. Review of a land use planning programme through the soft systems methodology. Land Use Policy 23, 187-203.

Nierling, I., 2012. "This is a bit of the good life": recognition of unpaid work from the perspective of degrowth. Ecol. Econ. 84, 240-246.

Norse, D., 2012. Low carbon agriculture: objectives and policy pathways. Environ. Dev. 1, 25-39.

O'Brien, D., 2004. Policy approaches to address problems associated with consolidation and vertical integration in agriculture. Drake J. Agricultural Law 33, 33-52.

OECD (The Organisation for Economic Co-operation and Development), 2008. Environmental performance of agriculture at a glance. OECD, Paris. URL: http://www.oecd.org/greengrowth/sustainableagriculture/40953155.pdf (accessed June 2013)

OECD (The Organisation for Economic Co-operation and Development), 2011. An Overview of Growing Income Inequalities in OECD Countries: Main Findings. In: Divided We Stand. Why Inequality Keeps Rising. OECD, Paris, 2011. URL: http://www.oecd.org/els/soc/49499779.pdf (accessed April 2013)

OECD (The Organisation for Economic Co-operation and Development), 2012. OECD Compendium of agroenvironmental indicators. OECD, Paris. URL: http://www.oecd-library.org/agriculture-andfood/oecd-compendium-of-agri-environmental-indicators_9789264186217-en (accessed June 2013)

O'Hara, S., Stagl, S., 2001. Global food markets and their local alternatives: a socio-ecological economic perspective. Popul. Environ. 22, 533-553.

Oosterveer, P., 2012. Restructuring food supply. Sustainability and supermarkets, in: Spaargaren, G., Oosterveer, P., Loeber, A. (Eds.), Food practices in Transition. Changing food consumption, retail and production in the age of reflexive modernity. Routledge, New York, London, pp. 153-176.

Pagani, M., Otto, P., 2012. Integrating strategic thinking and simulation in marketing strategy: seeing the whole system. J. Bus. Res. 66, 1568-1575.

Page, E., 2007. Fairness on the day after tomorrow: fairness, reciprocity and global climate change. Polit. Stud. 55, 225-242.

Paredis, E., Vander Putten, E., Maes, F., Larosse, J., Van Humbeeck, P., Lavrysen, J., Van Passel, S., De Jonge, W., 2009. Vlaanderen in transitie? In: Van Steertegem, M. (Ed.), Milieuverkenning 2030, 
Milieurapport Vlaanderen, Vlaamse Milieu Maatschappij, Aalst, pp 345-374 (in Dutch). URL: http://www.milieurapport.be/Upload/main/14.pdf (accessed November 2014).

Pereira, A., Funtowicz, S., 2006. Knowledge representation and mediation for transdisciplinary frameworks: tools to inform debates, dialogues and deliberations. Int. J. Transdisciplin. Res. 1, 34-50.

Pešsl, J., Hřebíček, J., 2003. Soft systems methodology applied to environmental modeling. Environ. Inform. Arch. 1, 261-266.

Pohjanheimo, T., Paasovaara, R., Luomala, H., Sandell, M., 2010. Food choice motives and bread liking of consumers embracing hedonistic and traditional values. Appetite 54, 170-180.

Polimeni, J., Mayumi, K., Giampietro, M., Alcott, B., 2008. The myth of resource efficiency: The Jevons Paradox. Earthscan, London, UK.

Porter, M., 1980. Competitive Strategy: Techniques for analyzing industries and competitors. The Free Press, New York.

Power, A., 2010. Ecosystem services and agriculture: tradeoffs and synergies. P. T. Roy. Soc. B. 365, 2959-2971.

Pretty, J., 2002. Agri-culture: reconnecting people, land and nature. Earthscan Publications Ltd, London, Sterling, VA.

Pretty, J., Ball, A., Lang, T., Morison, J., 2005. Farm costs and food miles: an assessment of the full cost of the UK weekly food basket. Food Policy 30, 1-19.

Pretty, J., Brett, C., Gee, D., Hine, R., Mason, C., Morison, J., Raven, H., Rayment, M., van der Bijl, G., 2000. An assessment of the total external costs of UK agriculture. Agr. Syst. 65, 113-136.

Princen, T., 1997. The shading and distancing of commerce: When internalization is not enough. Ecol. Econ. 20, 235-253.

Prior, T., Giurco, D., Mudd, G., Mason, L., Behrisch, J., 2012. Resource depletion, peak minerals and the implications for sustainable resource management. Glob. Environ. Chang. 22, 577-587.

Quade , E., Miser, H., 1985. The context, nature and use of systems analysis, in: Miser, H., Quade, E. (Eds.), Handbook of systems analysis. Volume 1: Overview of uses, procedures, applications and practice. North-Holland, New York, Amsterdam, Oxford, pp. 1-32.

Raven, R., van den Bosch, S., Weterings, R., 2010. Transitions and strategic niche management: towards a competence kit for practitioners. Int. J. Technol. Manage., 51, 57-75.

Rees, W., 2002. Globalization and sustainability: conflict or convergence? B. Sci. Technol. Soc. 22, 249268.

Reid, J., 2011. The impact of mechanization on agriculture. The Bridge 41, 22-29.

Reynolds, M., Holwell, S., 2010 . Introducing systems approaches, in: Reynolds, M. , Holwell, S.(Eds.), Systems Approaches to Managing Change: A Practical Guide. Springer, London, pp. 1-23.

Rifkin, J., 2011. The third industrial revolution. How lateral power is transforming energy, the economy and the world. Palgrave Macmillan, New York, US.

Rip, A. , Kemp, R., 1998. Technological Change, in: Rayner S., Malone E. (Eds.), Human Choice and Climate Change, Volume 2. Batelle Press, Columbus Ohio, pp. 327-399.

Rittel, H., Webber, M., 1973. Dilemmas in a General Theory. Policy Sci. 4, 155-169.

Rivington, M., Matthews, K., Buchan, K., Miller, D., Bellocchi, G., Russell, G., 2013. Climate change impacts and adaptation scope for agriculture indicated by agro-meteorological metrics. Agr. Syst. 114, 1531 .

Roberts, T., Parks B., 2007. A climate of injustice. Global inequality, North-South Politics and climate policy. MIT Press, Cambridge, UK.

Rockström, J., Steffen, W., Noone, K., Persson, A., Chapin, S., Lambin, E., Lenton, T., Scheffer, M., Folke, C., Schellnhuber, H., Nykvist, B., de Wit, C., Hughes, T., van der Leeuw, S., Rodhe, H., Sörlin, S., Snyder, P., Costanza, R., Svedin, U., Falkenmark, M., Karlberg, L., Corell, R., Fabry, V., Hansen, J., Walker, B., Liverman, D., Richardson, K., Crutzen, P., Foley, J., 2009. A safe operating space for humanity. Nature $461,472-475$.

Rosner, L., 2004. The Technological Fix: How People Use Technology to Create and Solve Problems. Taylor \& Francis, Oxon, UK.

Rotmans, J., Kemp, R., Van Asselt, M., 2001. More evolution than revolution: transition management in public policy. Foresight 3, 15-31.

Rotmans, J., Loorbach, D., 2009. Complexity and transition management. J. Ind. Ecol., 13, 184-196. 
Rycroft, R., 2003. Technology-based globalization indicators: the centrality of innovation network data. Technol. Soc. 25, 299-317.

Safarzynska, K., 2013. Evolutionary-economic policies for sustainable consumption. Ecol. Econ. 90, 187195.

Sanne, C., 2002. Willing consumers - or locked-in? Policies for a sustainable consumption. Ecol. Econ. 42, 273-287.

Saunders, H., 2013. Historical evidence for energy efficiency rebound in 30 US sectors and a toolkit for rebound analysts. Technol. Forecast. Soc. Chang., in press, corrected proof, available online 11 January 2013.

Schot, J., 1998. The usefulness of evolutionary models for explaining innovation: the case of the Netherlands in the nineteenth century. Hist. Technol. 14, 173-200.

Schneider, F., Kallis, G., Martinez-Alier, J., 2010. Crisis or opportunity ? Economic degrowth for social equity and ecological sustainability. J. Clean. Prod. 18, 511-518.

Schröder,J., Smit, A., Cordell, D., Rosemarin, A., 2011. Improved phosphorus use efficiency in agriculture: a key requirement for its sustainable use. Chemosphere, 84, 822-831.

Seiffert, M., Loch, C., 2005. Systemic thinking in environmental management: support for sustainable development. J. Clean. Prod. 13, 1197-1202.

Sekulova, F., Kallis, G., Rodríguez-Labajos, B., Schneider, F., 2013. Degrowth: from theory to practice. J. Clean. Prod. 38, 1-6.

Senge, P., 1994. The Fifth Discipline: the art and science of the learning organisation. Currency Doubleday, Ney York, USA.

Senge, P., Smith, B., Kruschwitz, N., Laur, J. and Schley, S., 2008. The Necessary Revolution, How individuals and organisations are working together to create a sustainable world. Nicholas Brealey Publishing, London.

Serban, A., 2012. Ageing population and effects on labour market. P. Econ. Financ. 1, 356-364.

Shaw, R., Gallopin, G., Weaver, P., Öberg, S., 1992. Sustainable Development. A systems approach. International Institute for Applied Systems Analysis, Satus Report SR-92-6; Laxenburg, Austria.

Shove E, Walker G, 2007. "CAUTION! Transitions ahead: politics, practice, and sustainable transition management". Environment and Planning A 39, 763 - 770.

Shiva, V., 2004. The future of food: countering globalisation and recolonisation of Indian agriculture. Futures $36,715-732$.

Sidorenko, A., 1999. From an ageing society to a society for all ages, in World Health Organisation (WHO), Ageing and Health: a global challenge for the $21^{\text {st }}$ century. WHO, Geneva, pp. 7-18.

Skinner, J., Lewis, K., Bardon, K., Tucker, P., Catt, J., Chambers, B., 1997. An Overview of the Environmental Impact of Agriculture in the U.K. J. Environ. Manage. 50, 111-128.

Skipper, D., Van de Velde, L., Popp, M., Vickery, G., Van Huylenbroeck, G., Verbeke, W., 2009. Consumers' perceptions regarding tradeoffs between food and fuel expenditures: a case study of U.S. and Belgian fuel users. Biomass Energ. 33, 973-987.

Smith, A., Stirling, A., Berkhout, F., 2005. The governance of sustainable socio-technical transitions. Res. Policy 34, $1491-1510$.

Smith, B., 2013. Developing sustainable food supply chains. P. T. Roy. Soc. B. 363, 849-861.

Smithers, J., Blay-Palmer, A., 2001. Technology innovation as a strategy for climate adaptation in agriculture. Appl. Geogr. 21, 175 - 197.

Sobal, J., 2008. Sociological analysis of the stigmatisation of obesity, in: Germov,J., Williams,L., (Eds.), A sociology of food and nutrition. The social appetite. Oxford University Press, UK.

Söderholm, P., Hildingsson R., Johansson B., Khan J., Wilhemsson, F., 2011. Governing the transition to low-carbon futures: A critical survey of energy scenarios for 2050. Futures 43, 1105-1116.

Soroczynski, T. 2002, Integrated Systems Analysis and Sustainable Development, in: Rizzoli, A., Jakeman, A., (Eds.), Integrated Assessment and Decision Support, Proceedings of the First Biennial Meeting of the International Environmental Modelling and Software Society, Volume 3, pp. 133- 138.

Spaargaren, G., Oosterveer, P., Loeber, A., 2012. Food practices in Transition. Changing food consumption, retail and production in the age of reflexive modernity. Routledge, New York, London.

Späth, P., Rohracher, H., 2012. Local demonstrations for global transitions - Dynamics across Governance Levels Fostering Socio-Technical Regime Change Towards Sustainability. Eur. Plan. Stud. 20, 461479. 
Spiertz, J., Ewert, F., 2009. Crop production and resource use to meet the growing demand for food, feed and fuel: opportunities and constraints. Neth. J. Agr. Sci. 56, 281-300.

Srinivasan, S., 2009. The food v. fuel debate: a nuanced view of incentives. Renew. Energ. 34, 950-954.

Steffen, W.; Richardson, K.; Rockstrom, J.; Cornell, S. E.; Fetzer, I.; Bennett, E. M.; Biggs, R.; Carpenter, S. R.; De Vries, W.; De Wit, C. A.; Folke, C.; Gerten, D.; Heinke, J.; Mace, G. M.; Persson, L. M.; Ramanathan, V.; Reyers, B.; Sorlin, S., 2015. "Planetary boundaries: Guiding human development on a changing planet". Science 347 (6223): 1259855

Steinberger, J., Krausmann, F., 2011. Material and energy productivity. Environ. Sci. Technol. 45, 11691176.

Stoate, C., Boatman, N.D., Borralho, R.J., Rio Carvalho, C, de Snoo, G.R., Eden, P., 2001. Ecological impacts of arable intensification in Europe. J. Environ. Manage. 63, 337-365.

Sundkvist, A., Milestad, R., Jansson, A., 2005. On the importance of tightening feedback loops for sustainable development of food systems. Food Policy 30, 224-239.

Tait, J., Morris, D., 2000. Sustainable development of agricultural systems: competing objectives and critical limits. Futures 32, 247-260.

Tamásy, C., 2013. Areas of intensive livestock agriculture as emerging alternative economic spaces? Appl. Geogr., in press.

Tansey, G., 2013. Food and thriving people: paradigm shifts for fair and sustainable food systems. Food Energ. Secur. 2, 1-11.

Ten Pierick, E., van Mil, E., 2009. Multi-level perspectief nader beschouwd; Aangrijpingspunten voor transitie richting biobased economy? LEl, Wageningen, the Netherlands, Rapport 2009-035.

Theodoridou, I., Karteris, M., Mallinis, G., Papadopoulos, A., Hegger, M., 2012. Assessment of retrofitting measures and solar systems' potential in urban areas using Geographical Information Systems: Application to a Mediterranean city. Renew. Sust. Energ. Rev. 16, 6239-6261.

Thomas, H., Lewis, G., Thomas, D., Salmon, R., Chalmers, R., Coleman, T., Kench, S., Morgan-Capner,P., Meadows, D., Sillis, M., Softley, P., 2003. Mental health of British farmers. Occup. Environ. Med. 60, 181-186.

Tilman, D., Balzer, C., Hill, J., Befort, B., 2011. Global food demand and the sustainable intensification of agriculture. P. Natl Acad. Sci. 108, 20260-20264.

Tinker, A., 2002. The social implications of an ageing population. Mech. Ageing Dev. 123, 729-735.

Tischner, U., Kjaernes,U., 2007. Sustainable consumption and production in the agriculture and food domain, in: Lahlou, S., Emmert,S., (Eds.), Proceedings: SCP cases in the field of food, mobility and housing, Proceedings of the Sustainable Consumption Research Exchange (Paris), June 2007, pp. 201-237.

Tisdell, C., 2001. Globalization and sustainability: environmental Kuznets curve and the WTO. Ecol. Econ. 39, 185-196.

Tonn, B., 2003. An equity first, risk based framework for managing global climate change. Glob. Environ. Chang. 13, 295-306.

Tukker, A., Huppes, G., Van Holderbeke, M., Nielsen, P., 2005. Environmental impacts of

products, Draft report of the European Science Techonology Observatory (ESTO). TNO, Delft, The Netherlands and JRC/IPTS, Seville, Spain.

Tukker, A., Charter, M., Vezzoli, C., Stø, E., Munch Andersen, M. (Eds.), 2008. System Innovation for Sustainability.1: Perspectives on Radical Change to Sustainable Consumption and Production Greenleaf Publishing, Sheffield, UK.

Uhlin, H.-E., 1999. Energy productivity of technological agriculture; lessons from the transition of Swedish agriculture. Agric. Ecosyst. Environ.73, 63-81.

UN (United Nations), 2011. World Population Prospects: The 2010 Revision.

UNDP (United Nations Development Program), 2012. Human Development Report 2011. Sustainability and equity: A better future for all. Palgrave McMillan, UK.

UNEP (United Nations Environment Program), 2012. The Environmental Food Crisis. Rapid Response Assessments. United Nations Environment Programme. URL: http://www.grida.no/_res/site/file/publications/FoodCrisis_lores.pdf (accessed December 2012).

Van Griethuysen, P., 2010. Why are we growth-addicted? The hard way towards degrowth in the involuntary western development path. J. Clean. Prod. 18, 590-595. 
Van Mierlo, B., Arkestijn, M., Leeuwis, C., 2010. Enhancing the reflexivity of system innovation projects with system analyses. Am. J. Eval. 31, 143-161.

Van Mierlo, B., Janssen, A., Leenstra, F., van Weeghel, E., 2013. Encouraging system learning in two poultry subsectors. Agr. Syst. 115, 29-40.

Veldkamp, A., Van Altvorst, A., Eweg, R., Jacobsen, E., Van Kleef, H., Van Latestijn, H., Mager, S., Hommaas, H., Smeets, P., Spaans, L., Van Trijp, J., 2008. Triggering transitions towards sustainable development of the Dutch agricultural sector: Transforum's approach. Agron. Sustain. Dev. 29, 87-96.

Vergragt, P., Szejnwald Brown, H., 2008. Genetic Engineering in agriculture: new approaches for risk management through sustainability reporting. Technol. Forecast. Soc. Chang. 75, 783-798.

VMM, 2012.Transition to a sustainable agro-food system in Flanders: a system analysis. MIRA Topic Report in collaboration with AMS, Department of Agriculture and Fisheries. Brussels. URL: http://www.milieurapport.be/Upload/main/0_topicrapporten/Topicrapport_Eng_webC2.pdf (accessed November 2014).

Von Braun, J., Pachauri, R., 2006. The promises and challenges of biofuels for the poor in developing countries. IFPRI, Washington DC.

Walker, W., 2000. Entrapment in large technology systems: Institutional commitments and power relations. Research Policy 29, 833-846.

Wallgren, C., Höjer, M., 2009. Eating energy - Identifying possibilities for reduced energy use in the future food supply system. Energ. Policy 37, 5803-5813.

WCED (World Commission on Environment and development), 1987. Our Common Future, World Commission on Environment and Development, Oxford University Press, UK.

Weber, M., Hoogma, R., Lane, B., Schot,J., 1999 Experimenting with Sustainable Transport Innovations: A Workbook for Strategic Niche Management. University of Twente Press, Twente, NL.

Weinzettel, J., Hertwich, E., Peters, G., Steen-Olsen, K., Galli, A., 2013. Affluence drives the global displacement of land use. Glob. Environ. Chang. 23, 433-438.

Weis, T., 2007. The global food economy: the battle for the future of farming. Zed Books, London, UK.

Weis, T., 2010. The accelerating biophysical contradictions of industrial capitalist agriculture. J. Agrar. Chang. 10, 315-341.

White, J., Hoogenboom, G., Kimball, B., Wall, G., 2011. Methodologies for simulating impacts of climate change on crop production. Field Crop Res. 124, 357-368.

Wiek A., Lang, D., Siegrist, M., 2008. Qualitative system analysis as a means for sustainable governance of emerging technologies: the case of nanotechnology. J. Clean. Prod. 16, 988-999.

Williams, H., Wikström, F., 2011. Environmental impact of packaging and food losses in a life cycle perspective: a comparative analysis of five food items. J. Clean. Prod. 19, 43-48.

Wilson, G., 2007. Multifunctional agriculture. A transition theory perspective. CABI, Oxfordshire, UK.

Wolstenholme, E., 1999. Qualitative v. Quantitative modelling : the evolving balance. J. Oper. Res. Soc. 50, 422-428.

Wong, L., Bridges, J., 2008. Consumerism: Overview. International Encyclopaedia of Public Health, 2008, pp. 1-7.

Woods, J., Williams, A., Hughes, J., Black, M., Murphy, R., 2010. Energy and the food system. P. T. Roy. Soc. B. 365, 2991-3006.

Wu, F., Zhang, D., Zhang, J., 2012. Will the development of bioenergy in China create a food security problem? Modelling with fuel ethanol as an example. Renew. Energ. 47, 127-134.

Young, D., 1997. Economic value added: a primer for European managers. Eur. Manage. J. 15, 335- 343. 


\title{
Reflexivity, reflection and learning in the context of system innovation: Prying loose entangled concepts
}

\author{
Pieter J. Beers ${ }^{1}$ and Barbara van Mierlo ${ }^{2}$
}

\section{Abstract}

System innovations towards sustainability invariably involve learning. In experiments, participants learn about how innovations can change their institutional and biophysical environments. To enrich such approaches in-depth insight in the relation between reflexivity, learning and reflection is needed. However, reflexivity is seldom clarified conceptually and as a consequence its relations with learning and reflection have hardly been studied so far. In this chapter, we first conceptually disentangle the concepts of reflexivity, reflection and learning and then present an exploratory case study on their relations. The case study shows that as expected in literature, learning indeed may increase reflexivity. However, the relation we found was rather loose-in many cases changes in reflexivity preceded learning, instead of resulting from learning. Furthermore, much learning was unrelated to reflexivity. These findings show the importance of conceptually distinguishing learning, reflection and reflexivity and of studying their relations and interactions in future empirical research. We shortly discuss the implications for the facilitation of learning and system innovation.

Keywords: Reflexivity, learning, reflection, system-innovation

\section{Introduction}

System innovations towards sustainability invariably involve learning. In local experiments, participants learn about how they can change their institutional and physical environments. Local learning experiences with social and technical novelties and innovations, are translated into more generic rules and hence foster sustainability transitions in the making (Smith \& Raven 2012). Such learning takes place in a situation of actors collaborating within and across social networks, in an ever-changing environment. The associated learning processes are fraught with uncertainties, value differences and different time horizons.

In recent years, researchers have started to develop learning concepts that are relevant to complex problems or, more specifically, system innovation, in terms of the importance of its systemic context and its inherently reflexive nature. The concept of system learning for instance has recently been developed further as a process by which actors learn to redefine external barriers in the dominant system into opportunities and are thus inspired to design activities that would contribute to system change (Van Mierlo et al. 2013). Reflexivity is seen as a major asset of such learning processes. These new orientations have given rise to methodologies that support learning for system innovations, such as Reflexive Monitoring in Action (RMA). Learning is thought to require reflection on the assumptions underlying proposed actions, on perceived boundaries between project and context (or in transition terms: between niche and regime / system), and on the actions of external actors which may be perceived and handled as barriers or windows of opportunity. A conducive learning process, in turn, may stimulate the reflexivity of a system innovation project which is regarded as an emergent systemic property. This perspective on reflexivity acknowledges specifically the institutional character that is typical for change processes towards sustainability. Reflection, learning and reflexivity hence are assumed to be separate but positively related concepts.

\footnotetext{
${ }^{1}$ Dutch Research Institute for Transitions, Erasmus University Rotterdam, Netherlands. Email: beers@drift.eur.nl

2 Knowledge, Technology and Innovation Group, Wageningen University, Netherlands. Email: barbara.vanmierlo@wur.nl
} 
For approaches aiming at system innovation, in-depth insight in the relation of reflexivity with learning and reflection is needed. All three concepts themselves are loaded with positive connotations and the concept of reflexivity is seldom clarified (Popa et al., in press). As a consequence, its relation with the other concepts has hardly been studied so far. This led us to pose the following research question: Is it possible at all to recognize reflexivity in a system innovation initiative separately from learning, and if so how? A second question is: To what extent can changes with regard to reflexivity be attributed to learning outcomes?

In this chapter, we aim to explore the presumed relations between the concepts of reflexivity and learning more critically in the case of a system innovation initiative in the Dutch greenhouse sector. We first broadly describe the ideas about reflexivity, with specific attention to the context of sustainability transitions and infer that it is conflated with the notion of reflection. Next, we develop a conceptual framework to study the relation between reflexivity and learning in a system innovation initiative more systematically. We illustrate the value of this model with a case study in the greenhouse sector in the Netherlands, by presenting the findings in terms of changes in reflexivity and the associated outcomes of learning. In the end, we conclude that at times learning indeed contributed to reflexivity. However, reflexivity seems to be the outcome of multiple processes rather than learning among initiators of a system innovation project alone. As expected, it indeed may be regarded as a positive emergent systemic property of a system innovation initiative.

\subsection{Reflexivity}

In the most general sense, reflexivity entails "some sort of recursive turning back" (Lynch 2000:34). A very broad distinction can be drawn between reflexivity as a human condition and reflexivity as a human capacity, something one may or may not be (i.e., being reflexive). In the former meaning of the word, it concerns how every person, or humanity as a whole, acts in a (socio-physical) context that changes over the course of human action, and subsequently comes to change persons, or humanity. In this sense, people always are reflexive, whether desired not, comparable to Heidegger's notion that people are always "thrown into the world"- they cannot be without being there. In the latter meaning, reflexivity can be seen as a virtue-the more one is aware of one's ties to the environment and how it changes, the better one's goals, interests and actions can be attuned to (changes in) this environment. In this sense, being reflexive can be seen as an intentional act of reflection.

Beck and colleagues related the concept of reflexivity, as a condition, to persistent societal problems (Beck et al. 2003). In their perspective, reflexivity mainly concerns how modern society has come to (unintentionally) impact itself negatively through modernisation processes. While simple modern society "started out from" simple distinctions between society and nature, between insiders and outsiders, and between knowledge and other beliefs, in the process of modernisation people became more and more interconnected, blurring lines between nature and society, ever changing who's in and who's out, and rendering one set of beliefs just as true as any other set. This then is reflexivity': the process of modernisation has undercut its own basic tenets, that is, the simple distinctions between for instance society and nature, insiders and outsiders, and knowledge and beliefs. For example, the accelerated burning of fossil fuels has led to possibly irreversible climate change, which in turn forces to rethink many aspects of society, primarily the way energy is produced, food is grown, dwellings are built-all these developments were never intended when people started to produce energy with fossil fuels and as such they are all examples of how the environment is turning back on society. Beck et al. (2003; cf. Smith \& Raven 2012) write that such reflexive change involves co-occurring changes in economy (markets, dominant user/consumer practices), politics (rules and regulations, policy networks, power), technology (infrastructure, technical standards), culture (value orientations, symbols), and science (knowledge in perspective, questioning the value of science). In other words, reflexivity then is the nature of any modern society. This is what Voss et al. (2006) call first-order reflexivity.

\footnotetext{
${ }^{1}$ For reasons of clarity, the main concepts used in this chapter are printed in italics.
} 
Being reflexive refers to having an awareness of the reflexivity of one's situation in reflexive society. This entails knowledge of how society is changing, how those changes may impact oneself, and how one contributes to changing society, as well as attuning one's goals and interests to those changes. In that sense, it goes beyond "merely" reflecting on society, because it also involves drawing consequences from those reflections for oneself. A "reflection-on-reflection", so to speak (Beck et al. 2003:16). Being reflexive thus allows people to act more in accordance with their societal environment and in this way to increase their chances of "success" (in quotes, because what counts as success will remain open for debate among the reflexive), and for society to become more sustainable. In this sense, reflexivity is a human (group and/or individual) capacity, that may be present to a varying extent, and which can be supported, for instance, to foster sustainable development. This is what Voss et al. (2006) call second-order reflexivity. It is inherent in approaches such as reflexive governance (Voss et al. 2006).

Reflexivity is an ambiguous concept with various meanings (Lynch 2000). With each meaning of the term, what is turning back, and on what, varies. For instance, the object of reflexivity for Beck is modern society. Or, consider the example of reflexive governance:

"... refers to the problem of shaping societal developments in the light of the reflexivity of steering strategies - the phenomenon that thinking and acting with respect to an object of steering also affects the subject and its ability to steer. One calls into question the foundations of governance itself, the concepts, practices etc. by which societal development is governed and that one envisions alternatives and reinvents and shapes those foundations. E.g. modern ways of problem solving (rational, specialised) may change when trying to deal with problems that are the outcome of these problem solving practices. Externalities should no longer be seen as externalities. ..." (Voss et al. 2006:4).

Reflexive research, another example, is advocated as an adaptive change process from interdisciplinary research to transdisciplinary research, involving a structural change of the division of labour between scientists, experts and others (Popa et al., in press). In reflexive monitoring, a third example, dominant ways to conduct evaluation studies (goal oriented or purely learning oriented) are being transformed in an experimental and learning approach while supporting innovation initiatives to contribute to the change of a specific socio-technological system (Van Mierlo et al. 2010a). Although such meanings seem dissimilar, the different meanings tend to include the other. For instance, the first of five key elements of reflexive governance is defined as transdiciplinary knowledge production (Voss et al. 2006) which covers reflexive research.

In most perspectives, reflexivity is about fundamental change. However, reflexivity is often described as an activity, a specific kind of reflection, that is, critical reflection or the scrutiny of the assumptions and values underlying current governance approaches, ways of conducting research and evaluations, including the presumed categories of for instance facts versus values (Hendriks \& Grin 2007; Keen et al. 2005; also see several contributions in Wals 2007). For instance, in one of the rare empirical studies in which the term is operationalised, reflexivity is described as critical reflection on the assumptions, normative orientations and values underlying mono- and interdisciplinary research practices which requires a social setting of deliberation so as to enable change towards transdisciplinary research (Popa et al., in press).

Many authors use the terms reflection and reflexivity interchangeably. Beck et al. (1994) in contrast, warn not to conflate reflexivity with reflection. They fear the inherent optimism of a conceptualisation of reflection as a conscious activity: the system is expected to open up with more experts, more self-criticism, and more knowledge, while in their view such assumptions themselves are major causes of modern societies' problems.

In our opinion, it is better to regard reflexivity only as a social condition - see our further explanation in the next section - and not conflate it with reflection-on-reflection, or as is often suggested, reflecting at the deeper level of issues, the underlying assumptions and values. It is also very important to distinguish between reflection-on-reflection and reflection in general. Many authors appear to suggest that facilitation of reflection (in general) will stimulate learning and innovation. As a consequence, reflection, while necessary, is interpreted too optimistically. And while facilitating reflection-on-reflection might contribute to reflexivity, it 
is more realistic to expect this to happen rather unexpectedly and to be dependent on many more conditions.

\subsection{Conceptual framework}

Many scholars in natural resource management and sustainability transitions relate reflexivity explicitly to a systems perspective, acknowledging the complexity of change processes, the blurring of boundaries between in and out, overlapping network configurations et cetera. In this chapter, we are concerned with the reflexivity of initiatives that aim to contribute to system innovation; the change of existing sociotechnological regimes towards a more sustainable direction, including a change of user preferences, market structure, physical infrastructure, symbolic values, et cetera (Geels \& Kemp 2007; Smith \& Raven 2012).

We define reflexivity of a system innovation initiative as an emergent systemic property, that is, its ability to interact with and affect the institutional context in which it operates. It is the result of multiple actions and interactions. In this way and in contrast to most literature on reflexivity, we see it as a possible outcome of rather than a condition for (or asset to) learning. In the practice of system innovation initiatives, reflexivity can be recognised as the emergence of new (semi-coordinated) practices of participants in the initiative as well as their wider networks, and as new associated rules enabling and constraining these practices. This is in line with, for instance, ideas about reflexive governance involving a change of assumptions, practices, and institutional arrangements (Hendriks \& Grin, 2007).

With regard to learning in the context of system innovation, especially social learning scholars mention the importance of reflexivity in learning in complex contexts related to diversity in values, interests and knowledge. They place reflexivity at the core of an interactive learning process engaging multiple actors in issues of sustainability and Natural Resource Management, as a condition for or main asset to social learning: "social learning requires reflection and reflexivity throughout the entire process, if only to monitor change and progress throughout" (Wals 2007:500). As said before, the perceived relation between learning and reflexivity, however, tends to remain unclear in the many articles and chapters that elaborate on only one of the two concepts (e.g. Bastrup-Birk \& Wildemeersch 2011; Dewulf et al. 2005; Pahl-Wostl 2006).

For Keen et al. (2005) reflexivity (or reflection, Keen et al. use the terms interchangeably) makes up one of the five strands of a social learning process, in addition to system orientation, participation, negotiation and integration. Reflective learning, which involves reflecting on the origins and value of people's knowledge is supposed to lead to new understandings, which is essential in an iterative social learning process turning into a double or triple loop learning process (Argyris \& Schön 1978). In line with these scholars, we regard reflection as the mental or communicative activity of considering knowledge, ideas, the outcomes of actions, goals and more. As such, reflection is a conscious individual or social / collaborative activity, that can, to some extent, be organised, facilitated and planned. We propose however to distinguish it more clearly from reflexivity as described above and learning to which we now turn.

In order to be able to separate learning as an outcome of interaction from reflexivity as the condition of a system innovation initiative, we take a discursive perspective on learning (see Beers et al. 2014; cf. Edwards \& Potter 2001). We see learning as a communicative interaction process of giving meaning to problems, new technology, social innovations, societal developments, et cetera (cf. Dewulf \& Bouwen 2012; Leeuwis \& Aarts 2011; Sol et al. 2013). This means that learning may occur during regular project meetings as well as special learning occasions like workshops.

A learning process in communicative interaction that contributes to system innovation is assumed to include knowledge, actions as well as relations (Beers et al. 2014). Knowledge concerns among others individual or shared information and ideas, but also new problem definitions, ideas for how to solve problems, shared / common values, et cetera. In the learning process, knowledge refers to the content that participants exchange and produce: new insights, ideas, changed views, and new visions, while they are pursuing their goals (Wals 2007). 
A second aspect of learning concerns action. With action, we indicate the agreements, decisions, and other forms of action that are voiced during communicative interaction about the proposals for real-world actions as they are contributed during meetings or otherwise, including when they are rejected, and the decisions that may ensue.

A third aspect concerns relations, including roles and identities. Authors like Pahl-Wostl (2006), Leeuwis and Aarts (2011) and Van Mierlo et al. (2010a) have noted that interactive learning does not only produce knowledge, but also new relations between actors. This may happen, for example, when external actors are discussed and put in a certain light that changes their relational status. Similarly, when a previously unknown resource or capability of a participant comes to the fore, this may change his / her status within a network.

Not only the learning process, but also its outcomes take place in a discursive setting. A learning outcome occurs when knowledge (the what), actions (the how) and relations (the who) become substantively intertwined (cf. Argyris \& Schön 1978). The interweavings themselves are the learning outcomes. It is important to note that this definition yields a rather straightforward distinction between learning outcomes and the real-world actions that possibly follow.

\section{Research design}

For a preliminary empirical analysis of the relations between reflexivity and learning taking place in discursive interaction, we conducted a case study of an innovation initiative in the Dutch greenhouse sector that aimed to change a complete sector. Our view of learning has several methodological consequences. First of all, although facilitated interaction can be part of a larger learning process, we see it essentially as a process that takes place over longer time periods within various configurations within and across the network of an innovation initiative. Therefore, we studied the communication at different types of meetings over a longer period of time in chronological order. Second, our predominant view of learning as a process taking place in communication (leading to learning outcomes) suggests that the moments of interaction as organised by initiatives themselves are the main source of data. This could be in the form of extensive notes, audio recordings or full transcripts of meetings. The data for this chapter are nine meetings of the general board and of the related chain knowledge platform in the period from January to July 2013, all but one attended by the first author. The other meeting was attended by another project member. We collected extensive notes on six meetings as well as complete transcripts for another three.

These data were used to analyse the moments at which knowledge, relations and actions became interwoven, that is, learning outcomes. First, transcripts and notes were segmented into interaction episodes related to one topic. An episode was coded as having resulted in learning if 1 ) it contained conceptual content, relational content and actions, 2) clear conceptual relations existed between these content types, and 3 ) at least one action discussed concerned a decision, meaning that an intention existed to carry out that action.

We first identified the episodes in which a decision was taken, those being the segments with the highest probability of having a learning outcome. Next, we coded the learning content of each of these episodes, distinguishing the three main content categories-conceptual content, relational content, and actions. The details of the coding procedure are described in section 2.1 below. This procedure led to the identification of 14 episodes with a learning outcome. 


\subsection{Coding the three dimensions of learning outcomes and reflexivity}

Action content was coded for any statement that included an actual decision or an opportunity for action. In that sense, action content does not necessarily entail a concrete decision. Many options for action can be mentioned ("We'll organise an event, preferably with live cases.") without an actual decision being taken ("Okay, so we'll organise that meeting.") In our coding, we distinguished between action content as options for action and action content as decisions. A decision includes an explicit or entailed commitment to a future (material) action by one or more participants in the meeting. Furthermore, a proposal for action is sometimes put on the agenda, while during the meeting it becomes clear that the proposal has insufficient backing. Such content was coded action, even though the proposal, as is, was not accepted.

Conceptual content was coded for any statement describing the initiative, its context, its problem orientation, et cetera, such as "There is a difference between producing for bulk or producing for Japan: Japan has much higher quality standards." Conceptual content, as we coded it, included the current state of affairs in the initiative, problems and challenges confronting the initiative, and goals, visions, strategies and ways of working towards change. Other examples of conceptual content include illustrative stories about cases. Sometimes, conceptual content really concerns discussion about the meaning of a concept, e.g. "What do we mean by communication?"

Relational content was coded for data fragments about actors. Usually, this concerned actors outside the initiative, and their relations with (the goals of) the initiative. Relational utterances concern actors and their 1) activities and development, 2) constituency, 3) disposition towards (the goals of) the initiative (roughly: insiders vs. outsiders), 4) importance for the initiative, and 5) the desired position towards the initiative. Furthermore, aspects such as culture and practice of other actors were coded relational content, such as when someone remarked that we should speak the language of growers. Participants could be members of multiple groups and they also could change groups over time (cf. Akkerman et al. 2008).

Reflexivity was operationalised in terms of 1) rules guiding actors' practices (organisationally, legally, politically, symbolically), 2) relations between actors, and between initiative and context, 3) practices (common ways of working) and 4) discourse related to the future of the initiative's sector. These four analytical aspects of reflexivity are based on Grin's work on reflexive governance (Grin 2006) and Van Mierlo et al.'s (2010a) on reflexive monitoring, which point at all of these aspects. It was analysed by comparing changes in these four dimensions over time with the initial state of the initiative (the baseline).

As sources of evidence we used statements about such changes in the meeting transcripts which were triangulated with the documents that were prepared for the meetings and informal talks with key persons in the initiative. Our analysis of rules, was guided by Klein Woolthuis et al. (2005; also see Van Mierlo et al. 2010b), who include standards, laws and the legal system as a whole (e.g. contracts, intellectual property rights), the political culture, and social norms and values. Applied to our case, we categorised the establishment of a new platform as institutional change, as well as the policy changes announced in a new policy letter from the Dutch Minister for Agriculture.

With regard to relations, the analysis focused on interpersonal and interorganisational relationships and strategic alliances / coalitions, in other words, changes in organisational ties (cf. Klein Woolthuis et al. 2005). This included also analysis of how actors are related to each other in terms of (dis)alignment of values and interests, as well as the way in which the initiative positioned itself towards others. Applied to our case, for instance the changes with regard to which body within the initiative is in the lead were categorised as a change in relations.

Practice was characterised rather broadly, concerning not only practice in the sense of a shared enterprise of a community with an associated repertoire of actions (Wenger 1998) but also decisions and developments that changed the potential practice of the initiative. For instance, when an option for a range 
of future actions disappeared, because of changed networks or institutions, this change in options was categorised as changed practice.

For discourse, we concentrated mainly on changed terminology, 'language' and elicited common future perspectives (Van Mierlo et al. 2010b; cf. Beers et al. 2010; cf. Grin 2006). In other words, the way in which the initiative speaks or writes of, or treats its main challenge and how to overcome it. This can be recognised in explicit comments on writings about the greenhouse sector, but also implicitly in the case of materials and anecdotes. Note that this concerns 'shared' expressions, to the extent that the individuals appear to agree, or at least that the expression is non-controversial. An example from our case was the main challenge in question, when it was reframed from being insufficiently market oriented to being insufficiently society oriented.

Sometimes these categories overlapped, for instance when a culture within a sector is indicative for mutual relations, the same fragment would be coded as both institutions and relations. The resulting case history constitutes an account of increases and decreases in reflexivity, based on changes in rules, relations, practices and discourse.

As the final step of the analysis, we identified whether the contents of the learning outcomes related to the changes in reflexivity and in what chronological order. In each period of a reflexive turn, for each of the reflexive changes (in a rule or relation for instance) we explored whether they could be traced back to any of the 14 learning outcomes. This enabled us to detect which learning outcomes were and which were not represented in a reflexive change, and which reflexive changes could and could not be traced back to a learning outcome.

\subsection{Case}

STAP is an innovation initiative of greenhouse growers. STAP means Foundation for Strengthening the Sales and Marketing Position of Greenhouse Vegetable Producers in the Netherlands (in Dutch: STichting versterking Afzetpositie Producenten van glasgroenten in Nederland). It was founded a few months after the so-called EHEC crisis in March 2011 when fresh greenhouse vegetables were contaminated with enterohemorrhagic Escherichia Coli (EHEC), causing a syndrome (haemolytic-uremic syndrome, HUS) in consumers as a complication of infection. In Germany 53 people died because of HUS (Wikipedia). Although Dutch produce was not infected with EHEC, the crisis strongly affected growers' market position when consumers turned away from tomatoes and cucumbers. Because the initiators had been concerned about their market position for a long time, they used the momentum created by the EHEC crisis to stimulate greenhouse growers to innovate. STAP was founded around August-September 2011, to strengthen the market position of greenhouse growers and to prevent another EHEC crisis from happening.

STAP is a network of various greenhouse growers, researchers, educational institutes and intermediaries. At the beginning of our study (January 2013) STAP consisted of an executive board with three members and a larger general board, both mainly of greenhouse growers. Some of them were also active as salespersons and traders. Meetings of the general board were also attended by representatives of the Dutch Federation of Agriculture and Horticulture. In February 2013, STAP additionally established a platform of research and education institutes and intermediaries: the chain knowledge platform (henceforth: STAPCKP). See Figure 1. 


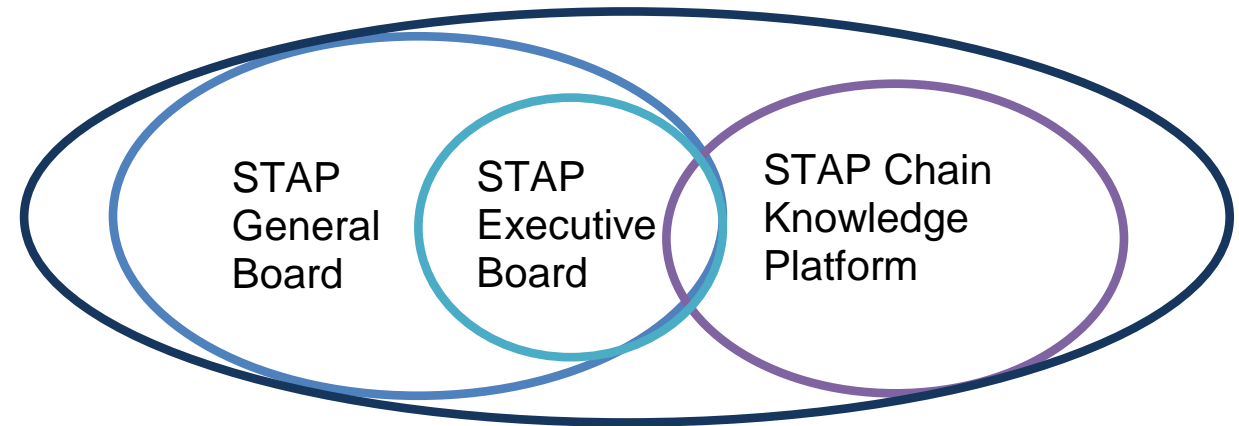

Figure 1: STAP organisation

To give an idea of the participants of STAP, we describe the main members of the knowledge platform. One is the representative of the Executive Board: a large greenhouse grower with a strong ambition to produce what society will require in the future. His company has implemented several innovations to save energy in the greenhouse, and is one of the most innovative businesses in the sector. Another CKP member represents a Higher Professional Education institute. A third member is a researcher from the Agricultural Economics Research Institute that studies innovative business models and who facilitates innovation processes among greenhouse growers. A fourth member also facilitates innovation processes, working for Syntens, an innovation institute in the public sector.

The various members of STAP have a large network in the wider sector, including several other innovative greenhouse growers but also representatives of businesses further down the production chain such as sales organisations and growers. Furthermore, some have contact with politicians at the national level, including the Dutch Minister for Agriculture.

\subsection{Role of the researchers}

We used Reflexive Monitoring in Action (RMA: Van Mierlo et al. 2010c; Van Mierlo et al. 2010a) not only to study learning and reflexivity, but also to support it. RMA is a form of action research in which the researcher acts as a monitor for an innovation initiative. In RMA, monitoring concerns stimulating reflection among initiators, so that they may learn, evaluate the outcomes of activities in the name of the initiative in the light of the system innovation ambition and adapt its actions to increase reflexivity. The first author acted as reflexive monitor in STAP. This was not an official role, rather, we conducted the research while supporting and advising on STAP's innovation process. The STAP members were aware that our main scientific interest concerned their communication and their learning processes.

\section{Reflexivity changes and learning}

In the period of study, three reflexive turns could be distinguished (see Figure 2). After sketching the situation at the start of our study, about two-and-a-half years after STAP had started, we present the three periods in STAP distinguished by the reflexive changes that demarcate them. For each period, we first describe the reflexive changes that herald that period and then we describe which learning outcomes were substantively related to these reflexive changes. Below, we describe each reflexivity turn and for each which learning outcomes around these turns were substantively related to the turn and which seemed to be unrelated. 


\subsection{Baseline}

At the beginning of 2013 , the start of our analysis, STAP exists as a formally established organisation, consisting mainly of greenhouse growers. STAP's context is that of production- and efficiency-oriented growers with a bad market position. Product chain partners are seen as both part of the problem and the solution for improving the market position of greenhouse growers. STAP conceives of its role as working towards the transformation of the whole greenhouse sector to become more consumer-oriented. It understands the necessity of good relations and collaboration with the other organisations in the production chain. STAP does not officially represent all greenhouse growers. Rather, it is an initiative of specific greenhouse growers who see themselves as innovative and who worry about the future of the sector as a whole. STAP does not have a clear strategy at that time, since an approach with workshops has not succeeded and no alternative approach is available yet.

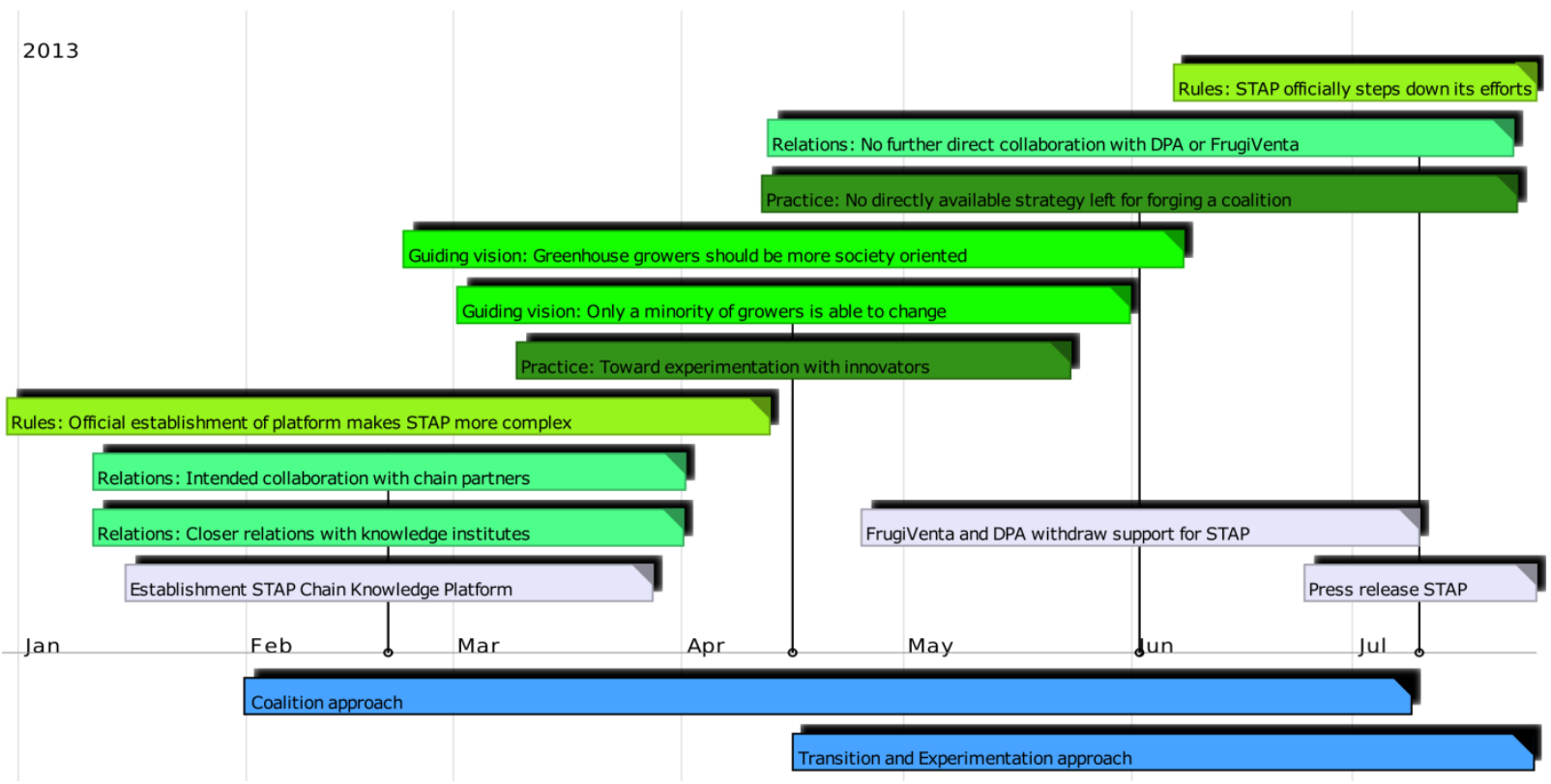

Figure 2. Reflexive turns in STAP: mid-February to mid-April (establishing the Chain Knowledge Platform); mid-April to June (experimentation approach); and June to July $10^{\text {th }}$ (failing network strategy).

For both the general and executive boards (the CKP was not established yet) the main issue of STAP is the bad market position of greenhouse growers. In their view, growers are too much oriented at decreasing production costs, lack a market orientation and also because financial margins are low. STAP Executive: "The central issue: a more competitive position for greenhouse growers" (2013-02-12). However, because the workshops had not resulted in change and a separate initiative for horizontal bundling in bell peppers had failed, STAP searches for other, more effective strategies. The executive board concludes that it cannot effect this change on its own, because sales and trade parties possess knowledge about the market that growers need to be able to become more consumer-oriented. STAP therefore needs to collaborate with other parties in the sector.

\subsection{Increased reflexivity: Established Chain Knowledge Platform}

In a general board meeting on February 20, STAP officially establishes the Chain Knowledge Platform (CKP). The idea is that such a platform, bringing together educational and research institutes, will be able to provide knowledge in answer to questions of entrepreneurs and in this way stimulate them to innovate. The board expects the platform to have a catalysing effect on the innovative capacity of the sector as a whole. 
The members of the CKP include Inholland, a higher agricultural education institute, the Agricultural Economics Research Institute, Syntens, an institute that facilitates innovation (innovation brokerage) and Wageningen University (i.e. the authors of this chapter). Furthermore, STAP seeks collaboration with traders and sales organisations and plans to form a coalition with the organised trade organisations (FrugiVenta) and sales organisations (DPA). These chain organisations are intended to give direction to the activities of the CKP, together with STAP. Hence, the platform is established with a position in mind for these two organisations in the production chain. This is a new step towards closer organisational relations with these partners.

With the establishment of the Chain Knowledge Platform, the organisation of STAP becomes more complex. In effect, this is a spin-off of STAP, representing a more official relation between STAP entrepreneurs and related knowledge institutes. In that sense it represents an increase in reflexivity, with regard to rules (the official establishment of the platform) as well as relations (strengthening the relations with knowledge institutes). In addition, the CKP is intended to be a platform by and for the greenhouse sector as a whole. This can be seen as another way in which the CKP increases reflexivity in terms of relations.

The first learning outcome related to this increase in reflexivity concerns the topic of "bundling". In an earlier meeting on February 12 with the future members of the CKP the participants first explore the differences between "horizontal bundling"-more collaboration within each of the links of the production chain, especially greenhouse growers, to get a stronger competitive position, and "vertical bundling"-more collaboration across the links of the production chain, growers, sellers and traders working together. Many growers have advocated horizontal bundling, but in this meeting vertical bundling is seen as more important. A decision is taken to do a small-scale study of different interpretations of bundling to learn about obstacles to bundling. This learning outcome precedes the reflexivity change in relations in this period.

A second learning outcome during this meeting, about the idea to organise student projects to support small-scale growers, does not seem to be related to the changes in reflexivity.

The main learning outcome in this period emerges during the general board meeting when it is decided to establish the platform. Discussions focus first on what STAP's next step should be. Board members conclude that there is a need to address questions by growers to help them forge more market-oriented production chains. The Chain Knowledge Platform is seen as the answer to these challenges. The board members explicitly see this platform as guided by both STAP and FrugiVenta, an important chain partner. Practically, the role of the CKP is to work on knowledge in a pre-competitive manner, to answer questions to benefit the sector as a whole, not individual growers' questions. This learning outcome offers a one-toone mapping to the observed changes in reflexivity.

\subsection{An experimentation approach}

Mid-April, as evidenced by transcripts of a meeting on April 16, STAP reconsiders its own position due to changed (perceptions of) relations with chain partners, institutional obstacles (insufficient number of good salespersons) and relations with growers. The discussions at this meeting focus on transition issues. This is the first moment of seeing STAP's challenge in a broader, societal light with a long-term perspective, as opposed to the more consumer-oriented short-term market perspective taken within STAP's general board. STAP executive in the CKP: "Growers should think in much broader terms. They used to think that they were sustainable when they had a combined-heat and power-installation" (2013-05-13). Furthermore, STAP-CKP members mention that only a small part of the growers will be able to make the necessary changes, and that the obstacles for change are much more pervasive among sellers (DPA especially) than previously thought. Several contributions during the discussion together shape the contours of an alternative innovation strategy; a situation in which radical product changes are necessary but the majority of growers is not able to create these on its own, which calls for an approach of experimenting with innovation and sharing of successful examples of innovation. These changes in proposed goals and practice of STAP are indications of an increase in reflexivity. 
Indications of reflexivity thus include a change of goals and activities (practice), in light of a changed perspective on relations with other actors and the relation with society (citizens) as a whole. However, this increase in reflexivity only concerns the CKP and not the STAP general and executive boards.

An important learning outcome seems to be related to these reflexivity changes. In a later CKP meeting on May 13, a small note on bundling is discussed, a follow-up to the earlier discussion. The note includes a reflection on horizontal and vertical bundling and suggests that vertical bundling better fits STAP's purposes than horizontal bundling, and that horizontal bundling could even pose a risk to vertical bundling. While STAP previously held a neutral position on this issue, the note advises STAP to explicitly favour vertical bundling over horizontal bundling. The CKP agrees. In contrast to our expectations, this substantively related moment of learning does not precede the reflexivity turn, but follows them. Interestingly, also several other learning outcomes occur during this period (since April 16) that refer to earlier changes in reflexivity, suggesting that the reflexivity turn precedes the learning outcome instead of the other way around. These learning outcomes involve 1) that meeting with the chain partners would be urgent and 2) that using a number of exemplary marketing cases for publicity purposes would be helpful.

\subsection{Decline in reflexivity: failing network strategy}

The first five months of 2013 are characterised by various actions towards more collaboration with other sector organisations, with entrepreneurs in the STAP General Board, and with the partners in the Chain Knowledge Platform. At first, FrugiVenta's director indicates in bilateral meetings with STAP executives that FrugiVenta will collaborate with STAP and the CKP, and that DPA is expected to do so later. At times however, FrugiVenta seems to be withdrawing. As time goes by, STAP tries to force a breakthrough by issuing a position statement with an analysis of the challenges of the greenhouse sector and the need for STAP and the chain partners to collaborate. This strategy seems to succeed at first, when at a meeting the $14^{\text {th }}$ of May several prospective partners state their support for STAP's position statement, including Frugiventa and DPA. But about two weeks later DPA and FrugiVenta withdraw their support, marking the end of STAP's efforts toward a coalition with them. This also marks a breakdown of STAP's strategy: making the greenhouse sector, as a whole, more market-oriented, necessitates support from and collaboration with DPA and FrugiVenta. Now that these organisations have withdrawn their support, this strategy is no longer viable, and STAP, again, is without a clear strategy forward. In response, STAP announces in a press release July 10, 2013 to become less active in innovating the greenhouse sector, among others because of a lack of collaboration from the chain partners.

The period from February to June can be marked as a stagnation regarding reflexivity, due to uncertain relations and partnerships. Furthermore, the beginning of June 2013 can be seen as a clear decline of reflexivity, because when the strategy to collaborate with chain partners failed (relations), STAP left its previous strategy (practice). The press release is a clear indication of the reduced reflexivity, because it explicitly states that STAP has few real activities left and it publicly establishes that relations with chain partners have cooled down. In terms of reflexivity, this period is marked by changes in relations and practice.

No related learning outcomes occur that precede this decrease of reflexivity. However, learning outcomes do occur in a CKP meeting June 3 that follows the previous reflexivity decline. First, a discussion takes place about the mandate of the CKP in relation to STAP. The question is whether the CKP can start collaborations with chain partners after STAP has announced that FrugiVenta and DPA will not collaborate with STAP. The discussion ends with the conclusion that the CKP is related to STAP but also has sufficient independence to set up its own contacts with partners from the chain.

Secondly, a discussion takes place on how to reach the goals of STAP. CKP members state that collaboration with the chain partners is necessary to reach STAP's goals. And even though FrugiVenta and DPA have just closed the door on future collaboration, CKP members say that it should not change their problem analysis. FrugiVenta and DPA should be able to join later on, if they want to. This position is reinforced by some notions about moving beyond the goal of a market-oriented sector towards the goal of 
a society-oriented sector that will also be able to respond to citizens' concerns and deal with environmental issues. This would necessitate even stronger relations between STAP and the chain partners. This learning outcome seems to follow up on the earlier increase in reflexivity in the CKP, and might have been given room by the decline in reflexivity at the level of the whole STAP initiative

\section{$4 \quad$ Conclusions and discussion}

In this chapter we set out to critically discuss the often presumed tight, intrinsic relation between reflection, learning and reflexivity, in order to better inform approaches and methodologies that support system innovation initiatives. Our preliminary conclusions build on a review of the literature on reflexivity and a tentative analysis of the relation between learning and reflexivity in a case study. Since the data used cover a short period with just one obvious reflexive turn in which the reflexivity had increased, our conclusions about the relation between reflexivity and learning are preliminary with the aim to inform further study.

The literature review revealed that reflexivity has hardly been operationalised and seems not to have been studied empirically. The main conclusion is that given the general meaning of reflexivity it should be distinguished from reflection and learning and could perhaps best be seen as a property of the social object to which it relates (monitoring, research, governance or the learning). In the light of the ambition of initiatives to change complete socio-technological systems, we operationalised their reflexivity as changes in rules, discourse, practices and relations.

The preliminary empirical analysis suggests that learning outcomes are indeed not linearly related to increased reflexivity. A few of the 14 observed learning outcomes can be argued to have increased the reflexivity. Surprisingly, some other relevant learning outcomes seemed to be following on a reflexivity turn rather than preceding it. Furthermore, the other observed learning outcomes (seven in total) are mainly in line with the dominant rules that guide participants' practices and interaction, without an apparent stimulus to increase the reflexivity. This indicates that not all interactive learning outcomes contribute to system innovation. Furthermore, whereas sometimes learning indeed contributes to an increase of reflexivity, other learning outcomes are directed "inwardly," at substantiating reflexivity, rather than at (further improving) the initiative's position vis-à-vis the wider societal context.

This result leaves various questions to be answered. First, how is it possible that reflexivity changes occurred in the initiative that could not be traced back to learning outcomes of its members? A first explanation may be methodological. We were present in all board and CKP meetings of STAP during the study period, but learning could also have taken place in informal moments of meeting, phone calls, email exchange, maybe in the wider networks around the STAP initiative et cetera. Also, with the definition of learning as the interweaving of new ideas, relations and actions visible in communication, we left out relevant discussions on only one or two learning aspects, preceding the reflexivity turn. Furthermore, another approach to analysing learning outcomes, such as asking the stakeholders to define them, might have yielded different results. However, that would not help to critically address and investigate the assumptions regarding the possibilities to facilitate learning in collective settings of meetings and workshops.

Secondly, since there are signs that reflexivity of an initiative can increase without any internal learning preceding it, a second question is how these reflexive changes come about, if not through learning? Obviously, the position of FrugiVenta and DPA is not under STAP control. The ongoing changes in the relations with the chain partners are illustrative of the fact the innovation initiatives have only limited control over their environment, and that they are affected by changes occurring around them. While this is no new insight, our study indicates - to be validated later - that the reflexivity of an initiative is not only relatively independent of learning, but also a contingent outcome of both internal as well as external developments. This confirms our conceptualisation of reflexivity as a systemic property of a system innovation initiative. 
In conclusion, our study suggests that it is possible as well as relevant to distinguish learning and reflexivity and investigate their relationship and interaction more in-depth ${ }^{1}$. It provides initial evidence of the rather loose relation between the two; as two rivers springing from the same mountain following their own flow to the same sea and at times intersecting. Reflexivity of a system innovation initiative can best be understood as a systemic property, or condition of the initiative that may follow, but may just as well precede important learning moments. This conceptualisation links to ideas of reflexivity as a condition or property of a social network or societies rather than a human capacity and awareness. Hence, it is close to Beck's first meaning of the reflexive society, albeit as its positive counterpart, not undermining modern society further, but changing its basic assumptions.

To notions such as reflexive governance, reflexive research and reflexive monitoring, the study contributes the insight that conscious reflection on assumptions, values and the basic premises of the system that is supposed to be in need of change may not be the sole leverage to work towards system change. The familiar strategies of supporting reflection and learning in workshops and other special learning events are likely to be a hit-and-miss strategy. Scholars of learning perhaps have overestimated the relation between organised learning and transformative change and collective action. Our results suggest a more modest expectation regarding the importance of organised learning within an innovation network or group.

Tracking learning in the discursive interaction of a system innovation along the way of the innovation trajectory, and combining it with an analysis of the reflexivity turns and their relations with learning, may provide an intensive, but valuable way to stimulate learning towards system innovation. We think (and at this point we recognise in our thinking the same ambiguity as in the literature we criticise) that collective reflection of the initiators on the reflexivity history of an initiative, will help to increase its reflexivity.

Acknowledgements: This work is part of the research programme Responsible Innovation, which is (partly) financed by the Netherlands Organisation for Scientific Research (NWO).

\section{References}

Akkerman, S., Admiraal, W., Simons, R.-J., \& Niessen, T. (2008). Considering diversity: Multivoicedness in international academic collaboration. Culture \& Psychology, 1244), 461-485.

Argyris, C., \& Schön, D. A. (1978). Organizational learning: a theory of action perspective. Massachusetts: Addison-Wesley.

Bastrup-Birk, H., \& Wildemeersch, D. (2011). Navigating the tides of change: revisiting the notion of reflexivity in the context of social learning for transboundary collective experimentation. Studies in Continuing Education, 33(3), 219-234.

Beck, U., Bonss, W., \& Lau, C. (2003). The theory of reflexive modernization. Problematic, hypotheses and research programme. Theory, Culture \& Society, 2a2), 1-33.

Beck, U., Giddens, A., \& Lash, S. (1994). Reflexive modernization: Politics, tradition and aesthetics in the modern social order. Stanford, CA: Stanford University Press.

Beers, P. J., Hoes, A.-C., \& Van Mierlo, B. (2014). Towards an integrative perspective on learning in innovation initiatives: The case of the Dutch greenhouse sector. Paper presented at the 11th European International Farming Systems Association.

Beers, P. J., Veldkamp, A., Hermans, F., Van Apeldoorn, D., Vervoort, J., \& Kok, K. (2010). Future sustainability and images. Futures, 42, 723-732.

Dewulf, A., \& Bouwen, R. (2012). Issue framing in conversations for change: Discursive interaction strategies for "doing differences". The Journal of Applied Behavioral Science, 48(2), 168-193.

\footnotetext{
${ }^{1}$ Since we used the transcripts as the basis for the analysis of both learning outcomes as well as reflexivity, there is still some overlap between the two. In the next step, we intend to 1) use date over a longer period with more and more clear-cut reflexivity turns in practice; 2) analyse two cases in a similar way to look for counterevidence; and 3) focus only on clear-cut reflexivity turns in practice, and validate this analysis more firmly on evidence with interviews and documents.
} 
Dewulf, A., Craps, M., Bouwen, R., Taillieu, T., \& Pahl-Wostl, C. (2005). Integrated management of natural resources: Dealing with ambiguous issues, multiple actors and diverging frames. Water Science \& Technology, 526), 115-124.

Edwards, D., \& Potter, J. (2001). Discursive psychology. In A. McHoul \& M. Rapley (Eds.), How to analyse talk in institutional settings. London, UK: Continuum.

Geels, F. W., \& Kemp, R. (2007). Dynamics in socio-technical systems: Typology of change processes and contrasting case studies. Technology in Society, 29, 441-455.

Grin, J. (2006). Reflexive modernisation as a governance issue, or: designing and shaping restructuration. In J.-P. Voss, D. Bauknecht \& R. Kemp (Eds.), Reflexive governance for sustainable development. Cheltenham, UK: Edward Elgar.

Hendriks, C. M., \& Grin, J. (2007). Contextualizing reflexive governance: the politics of Dutch transitions to sustainability. Journal of Environmental Policy \& Planning, 93-4), 333-350.

Keen, M., Brown, V. A., \& Dyball, R. (2005). Social learning in environmental management. Towards a sustainable future. London, UK: Earthscan.

Klein Woolthuis, R., Lankhuizen, M., \& Gilsing, V. (2005). A system failure framework for innovation policy design. Technovation, 256), 609-619.

Leeuwis, C., \& Aarts, N. (2011). Rethinking communication in innovation processes: Creating space for change in complex systems. Journal of Agricultural Education and Extension, 171), 21-36.

Lynch, M. (2000). Against reflexivity as an academic virtue and source of priviliged knowledge. Theory, Culture \& Society, 173), 26-53.

Pahl-Wostl, C. (2006). The importance of social learning in restoring the multifunctionality of rivers and floodplains. Ecology \& Society, 11(1), art.10.

Popa, F., Guillermin, M., \& Dedeurwaerdere, T. (in press). A pragmatist approach to transdisciplinarity in sustainability research: From complex systems theory to reflexive science. Futures.

Smith, A., \& Raven, R. (2012). What is protective space? Reconsidering niches in transitions to sustainability. Research Policy, 41, 1025-1036.

Sol, J., Beers, P. J., \& Wals, A. E. J. (2013). Social learning in regional innovation networks: trust, commitment and reframing as emergent properties of interaction. Journal of Cleaner Production, 49, 35-43.

Van Mierlo, B., Arkesteijn, M., \& Leeuwis, C. (2010a). Enhancing the reflexivity of system innovation projects with system analyses. American Journal of Evaluation, 31(2), 143-161.

Van Mierlo, B., Janssen, A., Leenstra, F., \& Van Weeghel, E. (2013). Encouraging system learning in two poultry subsectors. Agricultural Systems, 115, 29-40.

Van Mierlo, B., Leeuwis, C., Smits, R., \& Klein Woolthuis, R. (2010b). Learning towards system innovation: Evaluating a systemic instrument. Technological Forecasting and Social Change, 7Л2), 318-334.

Van Mierlo, B., Regeer, B., Van Amstel, M., Arkesteijn, M., Beekman, V., Bunders, J., et al. (2010c). Reflexive monitoring in action: A guide for monitoring system innovation projects. Oisterwijk, The Netherlands: Boxpress.

Voss, J.-P., Bauknecht, D., \& Kemp, R. (Eds.). (2006). Reflexive governance for sustainable development. Cheltenham, UK: Edward Elgar.

Wals, A. E. J. (Ed.). (2007). Social learning towards a sustainable world. Wageningen, The Netherlands: Wageningen Academic Publishers.

Wenger, E. (1998). Communities of practice: Learning, meaning and identity. Cambridge, UK: Cambridge University Press. 


\title{
Role of intermediation in the management of complex socio- technical transitions
}

\author{
Patrick Steyaert, ${ }^{1}$ Marc Barbier, ${ }^{2}$ Marianne Cerf, ${ }^{3}$ Alix Levain ${ }^{4}$ and \\ Allison Loconto ${ }^{5}$
}

\section{Abstract}

In this chapter, we analyse intermediation activities at play in situations of sustainability transitions and in relation to what we call the 'environmental paradox'. While sustainability transitions are strongly related to political or social expectations in terms of efficiency and measurement, they are characterized by some generic attributes of 'wicked problems' that make these expectations partly unachievable. We argue that the core properties of wicked problems related to environmental issues (interdependency, complexity, uncertainty and controversy) are conditioning the understanding and the concrete achievements of intermediation activities. As a consequence, we argue that these activities imply to favour processes of transformational change and social learning asking to better articulate both positivist and interpretative perspectives of knowledge, which we respectively define as objectification and inter-subjectification processes. We draw upon four narratives of complex situations of change involving intermediary actors to propose a comprehensive analysis of intermediation activities in context of action. The confrontation of our cases allows us to identify some key functions fulfilled by intermediation activities involving strong articulation of objectification and inter-subjectification processes. We finally identify some key properties that can help to understand how intermediation activities become efficient.

Keywords: sustainability transitions, intermediation, wicked problems, transformational change, objectification, inter-subjectification

\section{Introduction}

Intermediation has been studied across a variety of scholarly fields and in a variety of contexts (Howells, 2006; Meyer and Kearnes, 2013). Myriad terms are used to name individuals or organizations involved. They are mainly described as 'match-makers' aligning two (or more) entities and bringing them into contact to address business information and knowledge gaps or technological issues occurring in system failures or innovation networks. They are named: 'innovation intermediaries' (Burt 2004; Hargadon, 1998; Howells 2006), 'knowledge or innovation brokers' (Gassmann and Reepmeyer, 2005; Klerkx and Leeuwis 2008; Lomas 2001), 'systemic intermediaries' (Klerkx and Leeuwis, 2009), 'boundary spanners' in education (Stevens, 1999), public management (Willimas, 2002) and in business organization management (Aldrich and Herker, 1977).

\footnotetext{
${ }^{1}$ INRA, UR1326 Laboratoire Interdisciplinaire Sciences Innovations et Sociétés (LISIS), F-77420 Champs-sur-Marne, France. Email: psteyaert@grignon.inra.fr

${ }^{2}$ INRA, UR1326 Laboratoire Interdisciplinaire Sciences Innovations et Sociétés (LISIS), F-77420 Champs-sur-Marne, France. Email: Marc.barbier@grignon.inra.fr

${ }^{3}$ INRA, UR1326 Laboratoire Interdisciplinaire Sciences Innovations et Sociétés (LISIS), F-77420 Champssur-Marne, France. Email: cerf@agroparistech.fr

${ }^{4}$ INRA, UR1326 Laboratoire Interdisciplinaire Sciences Innovations et Sociétés (LISIS), F-77420 Champssur-Marne, France ; and Museum National d'Histoire Naturelle, Paris, France. Email: alix.levain@gmail.com

${ }^{5}$ INRA, UR1326 Laboratoire Interdisciplinaire Sciences Innovations et Sociétés (LISIS), F-77420 Champssur-Marne, France. Email: amloconto@versailles.inra.fr
} 
By naming intermediaries, scholars mainly try to identify the new actors (individual or organizational) working at the boundary of organizations and the ways they act as a third party in one-to-one or many-tomany relationships. Some authors, such as Bussant and Rush (1995), Howell (2006), Guston (1999) or Klerkx and Leeuwis (2009) go further and characterize the functions that intermediaries fulfil within innovation and knowledge systems. Nevertheless, other theoretical foundations of intermediation can be found in the sociology of science and technology with the notion of 'boundary object' as introduced by Star and Griesemer (1989) or in anthropology of development with the idea of 'development brokers' (Olivier de Sardan, 1995) or 'knowledge brokers' in medicine (Ward, House and Hamer, 1997) and 'knowledge intermediation' in science shops (Meyer and Schlierf, 2013). Such studies pay more attention to the diversity of perspectives that people have on a reality and their diverse ways of building interpretation and of acting in situation.

Extending this point of view, this chapter is a contribution to a stream of enquiries that particularly investigates the functions and properties of intermediation activities in sustainability transitions, with an attention to learning processes in situations of change (Van Mierlo et al., 2010; Elzen et al., 2012.; Klerkx et al., 2012; Barbier et Elzen, 2012). Focusing on intermediation in transition studies requests to associate the study of learning processes, the exploration of governance principles and institutional arrangements or evaluation instruments in order to cope with issues for which various narratives and innovation pathways are explored at both local and global levels (Smith \& Stirling, 2007). Indeed, what can be considered to be obviously innovative by some is often ill defined or contested by others. In this context, developing the conditions for social learning in sustainability transition appears to be key but tricky as socio-political choices are made in transition pathways. Intermediary actors can hardly claim their neutrality as they capture and embody many tensions at play. As a consequence, intermediation in sustainability transitions cannot only be described as providing new flows of knowledge and objects within a given network of interests for technological innovation. Nor can it be described as a functional role of filling knowledge gaps in system failures. Rather, intermediation performs specific functions that are related to the kinds of problems that are at stake and therefore plays a political role by supporting the interactive work of problem framing, goals definition, means setting and solution finding within a dynamic set of relations. Therefore its epistemic dimension is to be acknowledged. To achieve this, we assume that we need to study the practices of intermediary actors from the perspective of their underlying assumptions regarding the relationship between knowledge and action, what Baert \& Rubio (2012) called the 'politics of knowledge'. We claim that this type of politics of knowledge needs more attention in transition studies.

In this chapter, we first explain our interpretative perspective and provide the main reasons for which we believe research on intermediation activities must be renewed while crossing social learning backgrounds and politics of knowledge insights about sustainability transitions. After some important methodological concerns that explicate our interpretative position, we present the four case studies about intermediation taking place in different situations of change. Based on a crosscutting analysis of those case studies, our discussion section reflects on the role of intermediation in fostering transformational change and we follow up on this by analysing the functions that actors of intermediation fulfil in that process. We then propose three main generic properties, which we identify as key for intermediation activities to become efficient. We conclude by arguing that the analysis of the systemic interplay between these functions and properties can become a basis for the development of new research on intermediation.

\section{Sustainability transitions as transformational change to address wicked problems}

Sustainability has become a public problem that entails a large array of contradictions (producing climate change vs adaptation to climate change, biodiversity conservation vs compensation for biodiversity loss, food security vs food securing, etc.). Thanks to -or because of- many local or global conflicting political arenas, its recognition in decision making layers occurs once actors begin to ask questions about how their environment evolves and is transformed under both natural and anthropogenic conditions. The claim for the 
recognition of anthropocene as a new geological age echoes this recognition pattern in the realm of science. In other words, the biophysical, technical or economical dimensions of sustainability are definitively known to be socially constructed. Sustainability is then a kind of public problem that recognises the necessity and the complexity of a reconciliation between the many and specific dramaturgies of the wide range of issues that contribute to its definition (Gusfield, 1981). Within this framework, sustainability can be described as a 'wicked problem' (Batie, 2008; Levin et al., 2012); that is problem which cannot be tamed by the solely legitimating chorus of techno-science and administration together because of inherent contradictions and changing requirements.

If one takes the concept of 'wicked problems' seriously, sustainability transitions are better explained as processes of re-assembling the Social, the Technical and the Natural (Barbier, 2010). We assume that reassembling these dimensions relies on processes that need to be analysed in the specific circumstances of situations of change and during collective experiments through which the establishment of the matters of concern and matters of facts are simultaneously materialized in specific promising organizational arrangements. Based on these assumptions, we propose that dealing with sustainability transition problems related to natural resources involves four types of emerging features: (i) bringing to the fore existing but previously invisible interdependencies, (ii) confronting stakeholders with complex issues of change, (iii) revealing numerous uncertainties and (iv) generating controversies about the goals and means of action. These features - interdependencies, complexity, uncertainty and controversy - can be identified as the conditions and context in which intermediation activities take place once we consider sustainability transitions as a process in the making dealing with 'wicked problems' that are particularly difficult to handle within a managerial perspective (Rotmans et al., 2001). Those features are intertwined but have to be specified for our analytical purpose.

\subsection{Interdependencies}

The agriculture modernization, which took place on large scale during the last century, resulted in a lack of consideration - if not deny- of what has been described as negative externalities. Environmental issues (like pesticides use reduction, water protection or landscape management for wildlife, etc.) became public issues at the end of the last century and practitioners or stake-holders started to become aware of the connections between what they did and knew about their own activity and the ecological processes which take place at various spatial and temporal scales. As a result local interdependencies between the social, natural and technical became visible and now constitute the core of what has to be managed. But, at the same time, these environmental issues cannot be separated from a broader context made of policies, markets, norms and organizations. To put it differently, the increase in nature and number of interdependencies in every local level leads to an increase in nature and number of local-global interdependencies, phenomenon labelled by Robertson (1994) as 'glocalisation'.

\subsection{Complexity.}

Snowden (2002) makes a useful distinction among the complicated and the complex nature of systems and its consequences for management issues. The former are so termed because "cause and effect can be separated and by understanding their linkages we can control outcomes" (ibid p.116). The latter are irreducibly complex systems in which "the components and their interactions are changing and can never be quite pinned down" (ibid p.116). Adaptive properties, feedback loops, and threshold effects leading to irreversibility of a trajectory are some of the phenomena, which make it very difficult to pin down the underlying dynamics. Increased complexity results from interdependencies and their dynamic interactions over time. 


\subsection{Uncertainty.}

From a 'techno-scientific' perspective, to increase the available knowledge in order to be able to objectify the underlying processes of ecosystem functioning (i.e., the interplay between biophysical and technical processes) is often considered as the key activity needed to manage sustainability problems. However, uncertainties result from the radically unaccomplished character of the scientific representation of nature or human activities. What is done here and now can lead to consequences elsewhere and later; acting on a specific dimension of a problem may lead to unexpected effects on another. Therefore, the scientific enterprise involved in much problem definition or problem solving processes contributes as much to release uncertainty than to raise new challenges and new issues.

\subsection{Controversy.}

Finally, sustainable transitions are highly disputed because of definitional struggles, co-ordination stakes and goal definition issues. They lead to confrontations of various systems of interest by demanding that actors identify and implement 'win-win' solutions, when contradictions are driving forces. But more importantly, they result from the various conceptions people have of their own actions and from their level of acceptance of the inherent uncertainties that sustainable transitions cover (Stirling, 2014). Controversies can reveal the role in transitions that people assign to knowledge mobilization and production and the ways in which they take over this knowledge as a resource for their own action. For example, do such processes lead to struggles around knowledge production and possession in order to reinforce particular social positions? Are they used to inform and convince people about the relevance and need of public decisions? Or should they also be used to support people in exploring controversies and building new arrangements?

While the management of sustainability transitions confronts people with the wickedness of problems and the lack of means to even frame them, at the same time action is goal-oriented or purposive (Smith \& al., 2005). Put differently, action is strongly related to political or social expectations in terms of efficiency (management performance) and measurement (measurable results and effects) of the pressing environmental issues. To a certain extent, this constitutes a kind of 'environmental paradox': the generic characteristics of environmental problems make these expectations partly achievable. But, concomitantly, as Connors and Dovers (2004) observe, there is a "need for policy discourse and learning, especially in the case of sustainability as a profound social goal pervaded by complexity and uncertainty' (p.226). Therefore, if one calls for a more holocentric approach of sustainability transitions (Bawden, 2003), an understanding of how people are involved in processes of 'transformational change' is needed. Hence, we assume that this needs to be analysed in the specific circumstances of situations of change and during collective experiments through which the establishment of the matters of concern and matters of facts (Latour, 2004) are simultaneously materialized in specific promising organizational arrangements.

Under such assumptions (which target the wickedness of problem and the need of transformational change) and in local experiments to deal with the 'environmental paradox', intermediation activities can be defined by their main purpose: situational articulation. This articulation concerns two main communicational processes. On one side intermediation activities support some clarification and coordination processes that are meant to objectify the issues that are at stake, based on the instrumental mobilisation of proofs and evidences with denial of subjectivity. After Nussbaum (1985), we call it objectification. On the other side, intermediation activities recognise and empower elicitation processes of actors' viewpoints (their own subjectivity) based on the exchange and confrontation of opinions and arguments of those who shape the problem and are concerned with its solving. There, the attention is put on the development of interpersonal meanings that requests concern about how the self-image of actors is addressed in discourses. After Traugott (2010), we call it inter-subjectification. Finally, since the issues that are at stake are partly unknown, objectification and inter-subjectification have to be built through deliberative processes involving not only the mobilisation of knowledge but also the confrontation of various points of view, values, and perceptions, which can lead to social learning processes (Steyaert \& Jiggins, 2007). Thus, intermediation activities are performed to manage both objectification and inter-subjectification processes, as well as their interplay to support people in expanding their understandings of the situation and in working and reworking 
the stock of available knowledge used to analyse and transform this situation. In so doing, intermediation activities have to cope with the various ways people think about action and knowledge and, as a consequence, their various expectations regarding the ways to link knowledge to action.

The four above mentioned features and the recognition of transformational change ground our analytical perspective through which we expect to deliver new insights about intermediation as an activity, which enables objectification and empowers inter-subjectification. In order to mobilize this interpretative model, we shall now present some methodological considerations of our empirical understanding of intermediation in agricultural sustainability transition.

\section{Methodology}

As advocated in the special issue edited by Meyer and Kearnes (2013), analysing intermediation activities implies studying empirical questions such as: how and why intermediary actants (individuals, organizations, and objects alike) mobilize, reframe, structure and condense expertise or policy imperatives? How do they foster and facilitate interactions between deliberative arenas in which sustainability issues are framed and addressed? How do become performative the discourses of intermediary actors, says produce effects in the 'real'? Those empirical questions have been at play to set up the empirical materials needed to establish narratives of the four case studies to be presented hereafter. It is to be noticed that each case study had its own field research dynamic, i.e. based upon a specific set of shared research methodologies like participatory observations, interviews, interventions, but also some documentary analysis of reports, coverup and documents that trace the socio-political dynamic at play.

Each case study has developed over a significant period of time (from three to ten years), allowing us to capture the dynamics of transformation. Thanks to this duration, each offers a relevant example of the interplay that takes place between intermediary actors and transformational change in collective settings. Three of them concern agricultural adaptation to environmental concerns: water pollution due to intensive use of inputs (nitrogen, pesticides) in an arable crop farming area; nature preservation and land use in the French Atlantic Coastal Wetlands; struggles against green algae proliferation in French Brittany. The last case encompasses many dimensions of sustainable agriculture through the study of standards development at transnational and local levels.

The methodological challenge was then to assemble basic empirical questions and materials, and finally to bring these research experiences together in order to compare and contrast them. For that purpose, we have first built a narrative of each case in order to put light on the process of transformational change and the way intermediation activities fostered it/them. Those narratives are built upon the knowledge and understanding we have of the situation and its transformation. They are built in order to identify "critical events', e.g. "events, incidents or factors that help promote or detract from the effective performance of some activity or the experience of a specific situation" (Butterfield et al., 2005: 482). Critical events therefore are those which led to the reorientation of goals and means of collective action and might also reorient intermediation activities. The narratives also point out the 'deliberative arenas' in which political action occurs as a result of the confrontations and interactions of a potentially large number of actors between or inside different social worlds (Dodier, 2003). By tracing actions in deliberative arenas as part of specific situations, we can account for the framing of problem and the reorientation of goals and means of collective action. This is a process that involves not only exploring natural or technical phenomena, but also challenging the legitimacy, power relationships and identity of human communities, as many works of ActorNetwork-Theory have pointed out (Latour, 1999; Callon et al., 2001).

In a second step, we have iterated between those narratives and the interpretive conceptual model several times in order to confront our model with a variety of cases in the tradition of grounded theory (Glaser \& Straus, 1967; Olivier de Sardan, 2008; Detienne, 2009). The output of this iterative reflection was a common grid to be used to cut across our case studies. Following symbolic interactionism (Strauss, 1978), the study of those arenas enables to understand how humans interact and how meaning is created and 
interpreted in and through interactions (Blumer, 1971). We then used our conceptual model to cut each narrative into phases by systematically identifying the critical events and illustrating how (i) the generic dimensions of the wicked problems (i.e. interdependencies, complexity, uncertainties and controversies) were redesigned and tackled; and how (ii) intermediation activities operated the interplay between objectification and inter-subjectification processes. Therefore each case can be described according to the grid proposed in Table 1.

Evolution of the perceived dimensions of the wicked problems
\begin{tabular}{|l|l|l|l|}
\hline $\begin{array}{l}\text { Critical event leading } \\
\text { to reorient goals and } \\
\text { means of action }\end{array}$ & $\begin{array}{l}\text { Critical } \\
\text { event 1 }\end{array}$ & $\begin{array}{l}\text { Critical } \\
\text { event 2 }\end{array}$ & $\begin{array}{l}\text { Critical } \\
\text { event 3 }\end{array}$ \\
\hline Interdependencies & & & \\
\hline Complexity & & & \\
\hline Uncertainties & & & \\
\hline Controversy & & & \\
\hline
\end{tabular}

Situational articulation in process

\begin{tabular}{|l|l|l|l|}
\hline Critical incidents & $\begin{array}{l}\text { Critical } \\
\text { event 1 }\end{array}$ & $\begin{array}{l}\text { Critical } \\
\text { event 2 }\end{array}$ & $\begin{array}{l}\text { Critical } \\
\text { event 3 }\end{array}$ \\
\hline Objectification & & & \\
\hline Inter-subjectification & & & \\
\hline
\end{tabular}

Table 1: Intermediation activities in situ

Each case study has thereby been mangled (Pickering 1995) through this interpretative work. As a result, we issued a synthetic table like the one presented in Appendix I. Finally we have conducted a crosscutting analysis of the four cases in order to identify generic functions and properties of the intermediation work in processes of transformational change. The results of this analysis are given after the presentation of the case studies.

We are aware of the very interpretive nature of our work, which may be contested. Apart from the consistency of our conceptual model, a way to improve its relevance is to discuss our interpretative analysis and findings with intermediary actors involved in our cases. While this was partly done, not in all cases, it constitutes a logical development of this research and a relevant way to consolidate our interpretive framework.

\section{$4 \quad$ Intermediation activities observed in four case studies}

\subsection{Case study $n^{\circ} 1$ : developing low-input cropping systems for arable farming in the Parisian Basin}

\subsubsection{Presentation}

This case study accounts for a long-term dynamic that started during the 1990's in one arable cropping (wheat, rape seed and barley) area, the Parisian Basin, where the intensive use of inputs (nitrogen, pesticides) is still very common. Local public authorities pointed out the need to reduce nitrogen pollution of the aquifer by farming practices within the auspices of the new public management focus on meeting environmental objectives. At the time, a new national public instrument was institutionalized (PDD for "Plan de Développement Durable"), enabling contracts to be signed between the State and single farmers through which the latter expressed some means and goals to achieve sustainability at the level of the farm, in line with local objectives for environmental achievement. The farmers' board and the managers of the Chamber 
of Agriculture proposed to hire a new advisor (B.0) to provide advice to the farmers who were contracted to reduce the use of inputs; the intermediary in this case. This case study is based on a longitudinal approach of tracking advisors as practitioners of change (Maxime et al., 2002; Cerf et al, 2011) and explains the specific role of the B.O. in networking various activity systems at both local and national levels in order to support the search and development of on-farm pathways towards sustainability.

\subsubsection{Intermediation as practice and process}

After the PDD was launched, few farmers signed such contracts. Nevertheless, a group of farmers and advisors was formed constituting a socio-technical arena in which low-input practices were discussed. The B.O. bridged this local socio-technical arena to two others: an administrative and political one involved in the follow-up of the contracting process at the national level; and a techno-scientific arena called the "hardy wheat network" in which experiments were developed for arable crop areas, in order to assess integrated production methods. In these arenas, a systemic approach at the field level was promoted. The B.O. proposed that the group ground the design of low-input practices in such an approach and invited some of the people of these networks to feed the discussions among farmers. Managing the nitrogen pollution problem was in the background, but was not addressed as such by the group. The B.0. also encouraged it in order to keep an eye on the proposals of a national scientific committee delivering recommendations on how to reduce nitrogen pollution.

In 2001, the State stopped its support to the PDD, and at that time, the "hardy wheat network" also faced some legitimacy and financial problems as a techno-scientific arena supported by public authorities. At the local level, farmers were nevertheless keen to continue exploring low-input cropping systems and asked the board of the Chamber of Agriculture to support the process by dedicating a part of the B.0.'s time to their experimental initiative. It was quite an issue as the practices explored were seen as more political than technical in a local context of intensive farming systems. One farmer of the group was part of the board of the Chamber, and acted as an intermediary and promoted the opening of the group to newcomers willing to develop environmental-friendly practices as well. Indeed the group expanded, and newcomers started to develop low-input practices. The B.0 sought to create a renewed techno-scientific network in order to feed the group with a broader systemic approach, e.g. at the agricultural landscape level and with a longer time span (crop rotation). This was particularly helpful when, in 2005, the group identified that farmers were facing a problem of weed invasion, which resulted paradoxically to a rather high level of herbicide use. The B.O. suggested the group to start redesigning their cropping systems and he introduced a methodology, which he had just built within a new techno-scientific network which he had suggested to become involved. This network (called "RMT SdCi" for Mixed Technological Network towards Innovative Cropping System) was mainly composed of agronomists belonging to various organizations of the French agricultural knowledge and innovation system. It was meant to develop innovative and sustainable cropping systems and, primarily, methods to design and assess them. The B.0. adapted these methods and the group started a process of co-designing and co-assessing new cropping systems for each farmer within the group. More time was allocated by the collective to support each farmer in his pathway towards his targeted cropping system, e.g. in identifying weak and strong features of each cropping system, in designing monitoring indicators, and in suggesting alternative solutions whenever failures were pointed out. This deliberative arena was viewed by the B.O. and the group as a "safe" space in which debates about the professional norms of farmers could take place. Additionally, farmers started to discuss initiatives taken by some of them individually. For example, one farmer was involved in a network seeking recognition of the role of pesticides in the development of professional diseases and another began exploring agroforestry solutions. Therefore, discussions about their shared values took place as the practices developed by the farmers became more and more controversial among the local farmers and were met with suspicion by farmers on the board of the Chamber.

In fact the group had to face the controversial debates which were amplified when the Grenelle de l'Environnement, (a national political process in 2007 to frame sustainability objectives across many sectors), created a new political agenda under which the intensive use of pesticides was addressed, if not discarded. This resulted in tensions among different professional norms and values within the agricultural world both at the national and local levels. But the main tensions were found along the pathways of sustainable development in terms of pace and depth. In the follow-up to this Grenelle, but mainly as a 
consequence of the Pesticide European Directive, a national action plan (named Ecophyto 2018) was designed by the Ministry of Agriculture. The goal is to reduce pesticide use by $50 \%$ between 2008 and 2018. The Ecophyto Plan was composed of 115 actions to support a transition to reach this $50 \%$ reduction goal. One action, labelled FERMECOPHYTO, was setup to create a large network of farmers' groups (a total amount of 2000 farmers) in which farmers would experiment with pathways of pesticide-use reduction with the part-time support of an advisor paid for. In the first stage, the design of this network was supported by the knowledge produced within the national techno-scientific arena in which the B.0. was involved (the "RMT SdCi"). But the national organizations of the French agricultural knowledge and innovation system contested the target and the chosen frame for FERMECOPHYTO network. As one of those actors involved in the first stage, the B.0. had to deal with this controversy. Nonetheless, his position was clearly reinforced in the subsequent stages, thanks to the work he undertook in between 2008 and 2011. During this period, he took part in various R\&D projects through which arenas were built to invite advisors to discuss and reflect upon their advisory practices in facilitating change of agricultural practices. He played the role of facilitator in these arenas and developed his ability to support advisors to reflect upon their own practice. Right from the beginning, he was hired to join the national facility point, which was designed to support the FERMECOPHYTO network and kept this role even after the controversy took place. His legitimacy was two sided: first the group of farmers was involved in the national FERMECOPHYTO network, and their practices were involved and discussed as credible solutions for reaching the goal; second, he was seen as a person who had the ability to support the work of the other advisors who were supporting the farmers' groups within the network. This new position and the dynamic of his group resulted in a greater emphasis on supporting farmers to cope with uncertainties. These were: i) those that take place in monitoring change at a systems level (cropping and farming system); ii) those that appear while assessing the impacts of the change on the environment; and iii) those that remain around the target and professional identity the farmers wish to assume. This case highlights how local and national intermediation appears more and more intertwined over time.

\subsection{Case study $n^{\circ} 2$ : implementing Natura 2000 Directive in the Rochefort Marshland}

\subsubsection{Presentation}

This case study deals with the Territorial Collective Action Device implemented under the Natura 2000 policy framework (Steyaert, 2006). Its aim was to build an action plan for preserving wildlife biodiversity in the marshland area of Rochefort (13.500 ha), in the West of France. It brought together a set of various institutional stakeholders and land users deliberating in formal and informal arenas in order to identify goals and means of action. Two people have coordinated the design of this action plan: one was a member of an environmental protection association, the other one was appointed by the Chamber of Agriculture. In this chapter, we analyse their joint activity as an intermediation activity, which has played a significant role in the deliberative process that successfully issued the local Natura 2000 action plan. Both were mandated by the regional public services for environmental protection of the Poitou-Charentes region. The design process assigned and involved a set of deliberative arenas with the following objectives: to inform and enrol citizens into the working process through public meetings (arena 1); to design practical proposals in thematic working groups (arena 2) in order to elaborate the items of the action plan; to follow the process and validate its outcomes within the steering committee (arena 3 ).

\subsubsection{Intermediation as practice and process}

During the first information meetings and the first steering committee meeting, crop farmers and land owners contested the Natura 2000 policy framework by addressing the problem of area delimitation. With the help of a national Deputy who became their spokesperson, they created a landowners association to block the whole process through legal means. They mainly contested the inclusion of cropping land in the protected area because these parts of land could not correspond to the nature conservation specifications that environmentalists used for area delimitation (i.e. CORINE biotopes classification). This first stage of the process led to concerns about the legitimacy of one of the intermediary actors. Although the one appointed 
by the Chamber of Agriculture had been designated to play a main role in coordinating the process, the extensive use he made of biological knowledge to convince people of the relevance of the Natura 2000 policy reinforced claims and contestation. In this way, by coining the problem as it is defined within the policy (to preserve natural habitats and their biological richness) the coordinator turned himself into a spokesperson for nature. His local legitimacy decreased in favour of the other coordinator, the member of the Chamber of Agriculture, who took the main responsibilities and initiatives in what will be described hereafter.

To reduce contestations, the coordinators decided to adapt the deliberative process. While the work in thematic groups started, they implemented so-called "cartographic" and "open marshland" meetings. Organized at the municipality level and involving all land owners and farmers holding a plot in the area, the goal of the first meetings was to integrate into the map's legend some agricultural categories like permanent and natural grasslands, cultivated grasslands and fallow land. In doing so, they corrected some errors in land classification, but more importantly they created the pedagogical conditions that opened up the whole process to deliberative practices. They reduced fears, provided more precise and adapted information to all, and individually invited everyone to take part in working groups. Afterwards, many of the people they met decided to be involved, which led to a change in the social configuration of those arenas by increasing the number of land users compared to institutional stakeholders. The second series of meetings were organised to challenge the problem that most of the marshlands users did not know what ecologists were speaking about when they were speaking about nature. These meetings consisted of visiting some interesting parts of the marshland to encourage an ecological point of view. Land users asked ecologists to explain what a habitat is, why they believe that some species are important to preserve, how to recognize biological richness, what a biological inventory is, and so on. This led to a sharing of the scientific knowledge held by ecologists with other people: what was considered initially as "bizarre" or unimportant became mundane and was recognized. This has clearly helped to build a common understanding of the ecological dimension of wetlands.

Being reinforced in their facilitators' position and having gained confidence from all parties, the coordinators were mainly involved in facilitating the deliberative processes during those meetings. Rather than focusing exclusively on nature protection goals, they opened space and time to take account of the diversity of social preoccupations that were linked to the development of human activities and water management. In some way, they left out the policy framework of Natura 2000, so to be better involved in the stake-holding processes (Steyaert \& Jiggins, 2007). Each of the stakes was discussed and gave rise to action proposals and rules, which progressively constituted the content of the action plan. When heavy controversies arise, like for example concerning allowance and management of hunting areas, they helped people to explore those controversies rather than closing them down. When knowledge was made available, about the spatial distribution of hunting ponds, their owners and users, and hunting pressure, for instance, they created the conditions to make this knowledge public and shared. Finally, they built a progressive support of the diversity of actors involved in the working process.

All this was possible because of the social structure of the deliberative arenas, which were made up of institutional stakeholders mixed with diverse and heterogeneous land users. However, despite the progress made in establishing an action plan, contestation around the area delimitation was still alive during the steering committee meetings where power relations were perennial and fierce. To overcome this impasse, the coordinators made use of a scientific concept classifying wetlands according to their functional ecological potential (Steyaert, 2008). That led to a qualification of the area in a way that is different from how administrative services were used to do it up to that point in time. The use of this concept in several arenas, especially in the land owners association, and its blending with local knowledge, led to the total dissolution of social contestation into deliberations oriented toward the construction and appropriation of the action plan. As a result of the work completed and the trust of all participants in its outcomes, the national Deputy became the spokesperson for the process, playing an intermediary role between collective action and administrative services. While administrators insisted on a strong conformity of action rules with the policy, he asked for an integral validation of the action plan while accepting modifications only if they would have been discussed and negotiated earlier with the people involved. 


\subsection{Case study $\mathrm{n}^{\circ} 3$ : Preventing green tides in Brittany}

\subsubsection{Presentation}

Based upon a three-year long ethnography in Brittany (Western France), this case study focuses on the local co-construction of action plans to reduce nutrient flows released by farming activities in a rural watershed severely affected by coastal eutrophication phenomena. In Lannion Bay, massive algal blooms appeared in the 1970s' simultaneously with the rise of intensive livestock farming and major disruptions within the social organization of rural communities (Canevet, 1992). "Green tides" have hence been part of local life in some bays for two generations. The amplification of public policies dedicated to the reduction of blooms and agricultural nutrient leaks challenges the effects of agricultural modernization on public goods like water resources. In the early 90s', local representatives and local leaders of the main farmer union engaged in a dialogue with local authorities, which aim was to avoid both resignation and rising conflicts and criticism towards the environmental impacts of farming: they could neither give up the idea of agriculture contributing to the common good, nor ignore the coastline affected by what was largely perceived as an environmental disaster, compromising tourism and local development. This commitment gave birth to successive action programs, aiming mostly at adjusting fertilization practices, managing structural evolutions of the landscape and reducing the dependency of dairy farmers to external inputs.

As green tides affected other bays in the region, local means for action were limited and European policies on water quality were implemented, specific programs progressively emerged at the regional and national levels, which became more and more stringent in the 90s' and 2000s'. Local intermediaries including farmers, elected representatives, multiple advisors as well as researchers faced successive changes that transformed their role, the nature of the interactions between stakeholders and the meaning they gave to the dialogue they all tried to maintain under increasing external pressure. The empirical work has specifically shed light on the reduction of dissonance in situations of change during sustainability transitions (Levain, 2014), and therefore has particularly paid attention to public management settings and collective action at the level of watersheds. Within the scope of this chapter a focus is put on the functions of intermediary actors in settings that were dedicated to reducing dissonance between agricultural modernization on the one hand and sustainability goals in policy-making processes on the other hand.

\subsubsection{Intermediation as practice and process}

Lannion Bay is known for its high sensitivity to algal blooms, which generated great concern of local representatives and the population in general since the 70s'. In the $80 s^{\prime}$, the bay received much attention of scientists and experts, who first hesitated in their analysis of the causes of the phenomenon (What was the limiting factor, nitrogen or phosphorus? Why there, whilst local farming practices were less intensive than in neighbouring areas? Was the responsibility to allocate to domestic wastewaters or to farms? Etc.). Green tides proved to be highly dependent on nitrogen availability in water, mainly emanating from fertilization. Thus, in 1995, the local representative of the main Farmers Trade-Union (FDSEA) and one elected politician representing the municipalities of the watershed initiated and institutionalised an Agricultural Professional Committee (Comité Professionnel Agricole, CPA). This committee had been intentionally shaped as an arena for incumbent professionals, with the purpose of organizing and concretizing the contribution of farmers to the "fight" against green tides. Institutionalization of such a cooperation system required accepting the idea of sharing, beyond the main "union family", the concerns that environmental issues posed for Breton agriculture. These sharing concerned two fronts: on the one hand, the CPA brought together farmers who belonged to different professional unions, with different political leanings and agricultural practices; on the other hand, a sound partnership between professional and political representatives was established. For the local stakeholders - elected representatives and, even more, environmental activists and tourism operators - who were largely excluded from agricultural politics and had very few levers to change agriculture, the CPA was a gamble that opened an unprecedented field of possibilities, since the organization guaranteed them stable spokespersons representing the diversity of the farmers. The establishment of this committee was a clear signal that any improvement would come from farmers themselves and that something was lacking in the incumbent farmers' contributions to coastal management. It also paradoxically meant that 
conventional farming organisations could not be directly involved, as new local structuration had to be performed.

The setting up of this committee opened two controversial "fronts": one among the farmers (the advocates and antagonists of "green agriculture"), and the other between environmental stakeholders and the committee itself considered by some of the former as "too agricultural", which meant they feared that the protection of mainstream intensive agriculture would prevail in the end, whereas the situation required radical change in farming systems.

At the end of the 90s', the committee initiated a "Watershed Programme" based on voluntary commitment of farmers and the organization of collective actions (pasture management, peer-to-peer training etc.). It aimed at articulating public action, environmental mobilization and farmers' efforts with the intent of negotiating change and enhancing collective action. A situated "exploration regime" of coordinated actions through deliberations was established between various intermediaries acting at the level of Lannion Bay, that consisted of the local representative of the Farmers Trade-Union (FDSEA), one elected politician representing the municipalities, farmers' advisors, watershed management facilitators, and representatives of the water resource agency. The local stakeholders initiated the participation of researchers at an early stage by involving them in the reflection and diagnosis that was part of the first so-called "preventive" control programs in the late 1990s. This partnership provided support for new developments in agricultural practices - optimization of fertilization, for example - and access to new knowledge (Levain et al., 2014, 2015).

After 10 years of this "exploration regime", it was noticed that, if they produced significant results on nutrient leaks and on local dialogue, all the actions undertaken were ineffective as regards to their final target, since algal blooms remained massive. This led in 2007 the local authorities in charge of water quality and the CPA to look for more science-based action programs, more systematic action and to consider radical changes in farming systems. To do so, they asked for the support of research scientists from the National Institute for Agricultural Research (INRA) for a structured action-research program. Considering the characteristics of the watershed, mechanisms for action compatible with the technical, economic and environmental sustainability of farming were sought and proposed. The defined agronomic framework leaving farmers with a space for personal reflection and choice was innovative and facilitated the design and implementation of various measures, leading to several types of systems, which in turn could inspire other livestock farmers. A group of 'pilot farms' was settled, as well as a collective objective of reducing nutrient leaks. Two main mechanisms were selected: i) reducing nitrogen inputs and ii) promoting its recycling in the system, to increase nitrogen use efficiency. The reflection led to proposing the development of permanent crops (without bare soils) suitable for feeding ruminants, for example developing grass-based production systems in cattle farms. Both the characteristics of farming systems and the experiences of the stakeholders were quite specific for the watershed: many farmers already complied with technical specifications that allowed them to qualify for agri-environmental support, thus subscribing to voluntary EU agri-environmental plans. Their attachment to a "bottom up" approach and their wish to avoid further undifferentiated regulations also kept them in these plans. But the aim to contribute to a major reduction in nitrogen flows and, ultimately, in green tides, also placed them on the edge of result-oriented plans. Since farm capital was usually quite low in the area, the project was part of a collective attempt to reduce cognitive uncertainties and risks associated with technical and economic transition, and to help farmers find their own way between these two approaches (Levain et al., 2015).

Though this technological solution and transition pathway promoted by the CPA was at the beginning consensual, it triggered many professional debates within the farmers' community. The issue raised by farmers was more about the techno-economical risks of shifting from maize to grass than on the acceptance of changes due to environmental pressure. The raising of this issue showed the significant uncertainty about the effects of such a transition for farmers and the effectiveness of grazing systems in the reduction of algal blooms was once again questioned. The farmers challenged the legitimacy of the CPA and the activities of intermediaries had to shift from a regime of exploration and negotiation based on "soft schemes" to a regime of conviction and change, because a collective transformation had to be managed. Intermediaries were involved in its promotion. The introduction of this regime opened channels for stronger 
contributions of researchers that were convened by the CPA to "measure" risk and uncertainty, at the level of farms. Therefore, researchers joined the setting as knowledge brokers, through expert meetings or dedicated action-research projects with the network of pilot farms accompanied and monitored by agricultural advisors.

Suddenly a disruptive event challenged the process of objectifying the pathways for a sustainability transition in July 2009. On the beach, the leakages of sulphuric gas produced by beached algae killed a horse and injured its horseman. This event was covered by local and national media, and became proof that algal blooms could be extremely dangerous. Green tides suddenly became a matter of national health security and the Prime Minister ordered a Govermental Action Plan to fight against "green algae". This event directly questioned the local consensus established by the CPA and challenged the goals of the transformative setting. The Lannion bay became a "template", which concretely implied that, as much had already been done there, it had to rapidly comply to the new framework and to serve as an example for other bays, and the regime of conviction was turned into a regime of public evidence making with objectives and subsidies established by this new "Green Algae Plan". The process of voluntary engagement by farmers shifted to a forced process of participation in change, before regulatory measures were taken by public authorities. Under this pressure, farmers felt stigmatized ("we did not sign up for that at the beginning", they claimed). Intermediary actors were bounded to a different type of rationalized action, reinforcing evidence-based public action: they had to quantify the expected effect of each measure they proposed to governmental authorities, to prioritize them, and to engage in an obligation of results within five years. Actors involved found themselves caught in an operational plan, with external assessment. The network of pilot farms was de-legitimated in its role of actionable knowledge production. The CPA was also affected and its President himself considered that the reorientation of the setting towards a new external objective was a fundamental change, since the participants were obliged to drive their collective action differently. Intermediary actors thus were trapped in a very different situation of boundary-work, since their function henceforth became to interact between two organisational and political levels, the Lannion pilot-bay and the regional stakeholders of the "Green Algae Plan", while preserving the local partnership which was the result of 10 years of negotiations. Their aims and functions turned to sustaining their initial programme, and to keep farmers in. Thanks to the very meticulous intermediary work of advisors that bridged the maintenance of local commitment and the technical support to pilot farms, the local programme was signed as a "Territorial project" that responded to the public authorities' objectives. But after a difficult discussion, the CPA also decided to stop its collaboration with researchers, as a meaningful way to clearly put "public knowledge" at a distance: the feeling prevailed that to preserve local dialogue and to keep farmers involved, a limit to external assessment and to prescriptive and judgemental interventions had to be reaffirmed.

\subsection{Case study $\mathrm{n}^{\circ} 4$ : "Intermediating the good certifier for sustainable standards supported by ISEAL"}

\subsubsection{Presentation}

The context of the problem of defining the 'good certifier' is situated within debates that occurred in the 'sustainability field' (Dingwerth and Pattberg 2009; Loconto and Fouilleux 2014) over the legitimacy of private instruments of governance - sustainability standards. Specifically, there are debates over the legitimacy of different models of certification as a means to both create trust in private standards systems and to enforce the compliance of producers (mostly agricultural) with the values and practices encoded in the standards (McDermott 2012; Hatanaka 2010). These debates began in the 1990s when a number of social and environmental standards became formalized through the creation of certification schemes (e.g., Fairtrade International, Marine Stewardship Council, Forest Stewardship Council, Rainforest Alliance and national Organic regulations). During this period, each scheme developed its own standards, its own verification system and trained its own auditors. This first period was then marked by severe competition between schemes and accusations of 'greenwashing' based on the methods that some standards development organizations (SDOs) used to verify compliance with their standards. 
Beginning in 2000, with the creation of the International Social and Environmental Accreditation and Labelling Alliance (ISEAL), the five largest SDOs began to work together to reduce this competition. Since 2005, ISEAL has focused a portion of it work on encouraging its SDO members to work together to find solutions to common problems such as certification. This was possible because at the time most of the SDOs were relying upon the same certification bodies to carry out audits for each individual standard. It was during this period that the collaboration and collective action began to take place within the sustainability field and it is where we find the intermediation activity of certifiers exemplified in this case.

\subsubsection{Intermediation as practice and process}

Within this context, the deliberative arena consisted of the technical and steering committees setting standards between 2010 and 2012. The author conducted participant observation by sitting on the technical and steering committees for the entire standard-setting process. These two committees met as one group for the majority of the meetings. In this arena, multiple stake-holders (SDOs, certifiers, accreditation bodies, consultants, researchers, retailors and NGOs) came together to create a standard for conformity assessment systems (i.e., systems of certification and oversight). This means that the actors in this situation were discussing technical requirements for how to set up verification, audits and oversight for enforcing standards. This specific context is important to the intermediation process for two core reasons. First, the actors are mission-driven. This means that how they frame their problems is within the context of trying to influence change towards a more sustainable society. Second, they assume that there is something unique about their work that separates them from mainstream practices. Therefore, they are seeking to make their systems of control different from the dominant paradigm that relies upon multiple and not connected levels of third-party certification and accreditation (Loconto and Busch 2010).

The SDOs in the group were dissatisfied with some of the results of third-party certification, meaning that they had to rely on an externally appointed certifier. They complained about conflicts of interest between certifiers and farmers that influence the certification decisions taken by the SDOs. The SDOs also accused some certifiers of outright fraud and others of incompetence. All participants, including the certifiers, were quick to insist on oversight (including accreditation and market surveillance of labelled products) to combat fraud. They developed a nuanced understanding of conflicts of interest recognizing that such conflicts were a risk that could hardly be avoided in all cases.

Therefore, the core problem that the actors needed to solve was that of the auditor competency. The results of initial scoping showed that: "auditor competence has been the top challenge" (authors' notes). Therefore, the challenge posed to the group was to create criteria within the broader standard for conformity assessment systems for the 'good certifier' who would be able to competently and efficiently deliver credible audit results and thereby testify to the credibility of farmers. The starting point for intermediation was the current practices of certification bodies and the existing International Organization for Standardization (ISO) standards for conformity assessment systems and auditor competence (17065 and 19021 respectively). The key question was: who should take responsibility for ensuring that auditors are capable of conducting credible audits: the SDO who hires the certification body, the certification body who hires its audit staff or the auditors themselves? Answering this question entailed debates around the knowledge that different actors had. For example, how can one judge whether an auditor will be competent and how can you measure if the auditor has been competent? These questions are directed at individual skills and knowledge of auditors.

The SDOs in the arena argued that they maintain a systems' focus (meaning that they are looking at how audits fit into a whole system of standards, conformity assessment, technical assistance, etc.). Therefore, they argued that ISEAL advice should be to focus SDO attention away from generic competencies of certification bodies and their personnel, and instead towards other types of knowledge and skills. The reason given was that the ISO 17065 and 19021 standards require a 'competencies approach' that is based on a prescriptive set of personality traits that can be identified through a human resources evaluation. In contrast, the SDOs took a qualifications approach based on the experience and education of the auditor rather than on their actual performance. An accreditor argued that: "ISO did not give us enough guidance, so we became more prescriptive. The new standard (17065) is better in auditor competency. But we trained auditors when we started our system because no one else was doing it!" 
The intermediation by ISEAL and certifiers brought the debate back towards performance, but of a different kind. They achieved agreement that auditors must be able to 'audit to the intent' of the standard (subject matter content) and not just to the criteria on audit checklists (generic audit competency). The result of this intervention is that all stake-holders came to recognize that auditors must truly know the content and the intent of the standard, which links the problem of auditor competency to the SDOs' missions of influencing societal change towards a sustainable future. The idea is that even the auditors who are not part of these standards systems must share the mission of the SDOs. This poses a problem to the practice of auditing, as many of the auditors are hired on an ad hoc basis and therefore conduct audits for numerous standards systems, not just one standard. Traditionally, the SDOs have dealt with this, as the above quote notes, through auditor training. Indeed, the main criterion for training for each standard was undisputed and was reinforced through the recommendation by the accreditors and certifiers that SDOs should put a system of 'auditor calibration' into place. In other words, like machines, auditors' knowledge and competence should be tinkered with until they are calibrated to produce consistent results over time (Loconto and Barbier, 2014).

The intermediary actor in this debate was actually not the designated facilitator for the code development. Rather, after about a year's debate over what to do with the generic requirements proposed by the ISO regime, a certifier stepped up to influence the direction of the debate. He was a director of a mission-driven certification company. This 'capture' was possible because the nature of the arena was promoting reflexive rather than defensive discussions. The other actors in the room argued their positions in a very passive manner, such as "well we do this and we want this...". Therefore, when the certifier voiced his dissenting view on auditor competence, he was able to push everyone in the desired direction as an intermediary. This occurred particularly on the issue of defining a 'good certifier'. The 'good certifier', according to this intermediary actor, is a person, who has first-hand experience in the region; one who can speak the local language. "A young person, it does not matter what education or qualification, but one who is a critical thinker" (author's notes). The important competencies of the 'good certifier' are thus based on an inquisitive personality and a desire to 'learn-by-doing'. The certifier argued that ensuring this type of a 'good certifier' also means focusing on the moral fibre and personality of the auditor him/herself that can be cultivated through a mentor-mentee relationship within the certification body.

By advocating this approach, the intermediary actor argued that the responsibility sits with an organized certification body, which could properly train an auditor in both the intent of the standard and the practicalities of audits. This resulted in an annex to the standard that explains in detail the types of personality traits and qualitative competencies (such as interviewing and report writing) that auditors should have and is based on the justifications provided by the intermediary. The required criteria switched the responsibility from being solely held by SDOs to a division of responsibilities for different aspects of the certification process between SDOs and certifiers.

In this case, the intermediation process took place between the standard for conformity assessment that was being developed by ISEAL and its members, and the localized practices of conducting certification audits. Here certifiers were seen as taking on the role of interpreting/translating the standard in the face of real agricultural and agro-forestry practices. Their contributions modified the requirements for how auditors will be judged as competent and who must take the responsibility for this. It represents a major change in these systems as the increased accountability of more actors in the network, beyond just the SDO, distributes the responsibilities for sustainable agriculture more broadly and ties certification bodies more closely to SDOs than was previously the case. 


\section{$5 \quad$ Crosscutting comparisons}

\subsection{A heterogeneous set of case studies}

Our set of case studies offers a variety of situations of transformational change meant to address sustainability issues in agriculture. All have involved intermediation activities. In Table 2, we summarize the main characteristics of these situations and we roughly outline the intermediation activities, which took place in the process of transformational change.

\begin{tabular}{|l|l|l|}
\hline & $\begin{array}{l}\text { Forms of sustainability transition } \\
\text { situations }\end{array}$ & $\begin{array}{l}\text { Characteristics of intermediation } \\
\text { activities }\end{array}$ \\
\hline CS 1 & $\begin{array}{l}\text { A goal oriented action (reduce the use of } \\
\text { chemical agricultural inputs), framed by } \\
\text { successive public policies, involves an } \\
\text { increasing number of crop farmers into } \\
\text { transformational change processes }\end{array}$ & $\begin{array}{l}\text { An advisor taking stock of his working } \\
\text { experience starts to play an } \\
\text { intermediary role among set of } \\
\text { heterogeneous social arenas and is } \\
\text { involved in 'outscaling and 'upscaling' } \\
\text { processes }\end{array}$ \\
\hline CS 2 & $\begin{array}{l}\text { A sectorial public action framework } \\
\text { (N2000) is transformed, through its } \\
\text { implementation, in a territorial } \\
\text { development plan of a marshland }\end{array}$ & $\begin{array}{l}\text { Named and mandated coordinators by } \\
\text { public authorities build their own } \\
\text { legitimacy through a set of initiatives in } \\
\text { order to produce a management plan } \\
\text { for the area }\end{array}$ \\
\hline CS 3 & $\begin{array}{l}\text { An ecological disaster (algal bloom) leads } \\
\text { to a local public action implementation } \\
\text { covering various, successive, collective } \\
\text { action regimes due to ineffectiveness, } \\
\text { uncertainty and regulatory frames }\end{array}$ & $\begin{array}{l}\text { A heterogeneous group of local } \\
\text { stakeholders plays an active role in } \\
\text { enrolling local farmers to adapt their } \\
\text { farming activities and practices }\end{array}$ \\
\hline CS 4 & $\begin{array}{l}\text { A search for greater legitimacy of private } \\
\text { sustainability standards brings a set of } \\
\text { stakeholders to redesign the definition of a } \\
\text { 'good certifier', which leads to educational } \\
\text { and organizational changes }\end{array}$ & $\begin{array}{l}\text { A certifier shifts the debates from } \\
\text { impersonal to personal traits that } \\
\text { enable the standard-setters to reframe } \\
\text { certification activities in line with their } \\
\text { missions }\end{array}$ \\
\hline
\end{tabular}

Table 2: A synthetic account of situations and intermediation activities in each case study (CS)

Despite the variety of goals and social configurations, our cases show that sustainability transitions always involve some public or collective action, defined as "a set of relations, practices and representations which contribute to the production of politically legitimated regulatory patterns of social relationships" (Dubois, 2009). Initiated under community based or local policy but also under private initiatives, these situations are dynamic and evolve over time under internal and external conditions. They are made of relations between the natural, the technical and the social, and are goal-oriented and purposive in the sense that social expectations are very high and intense with regards to what has to be reached (fighting against biodiversity erosion or algal bloom, reducing water pollution, implementing sustainable agricultural production through standards).

In all cases, we observed practices dedicated to intermediation. Some intermediary actors were designated and had to gain legitimacy through their actions; others decided to play such a role based on what is needed in the given situation and founded in their own professional experience; still one other emerged as being the most suitable person in the context of how the situation was evolving. So, intermediation may be carried out by a specific intermediary actor (CS 1 and 2) or by a group of people building alliances and sharing a common perspective about how change can be facilitated (CS 3), or even by the agency of human and non-human agents (a certifier and a code of conduct, CS 4). 
How can we better understand intermediation activities as a practice and as a process that support efficient collective action in situations of transformational change? We will first discuss some characteristics of intermediation situations before developing functions and proprieties of intermediation activities.

\subsection{A common trait of situations of intermediation: dealing with 'wicked problems' in the flow of action.}

In all our cases, an 'environmental paradox' is clearly at stake for intermediary actors that have to face the concomitance of high expectations in discourses and institutional arrangements and of low effectiveness in the concretization of sustainability in practice. The ineffectiveness of action against algal bloom, nonmeasurable effects of changes in practices on water quality, a disputed role of certification in fostering sustainable agricultural production and an unknown role of human activities in increasing the quality of wildlife habitats provide some evidence that these goals remain more or less immediately 'unreachable'. Intermediary actors, who have to address a given environmental issue, are reflexively conscious that it cannot be pre-set by some external authority, even if environmental regulations might provide a direction and frame for how to reach it. Unreachable goals are constitutive of intermediation work in our situations of transformational change. In many cases, these unreachable goals relate to the four features of wicked problems that we have identified: they are complex management problems where cause-effect relations cannot be pinned down. In that sense, when sustainability transitions are not depicted as a simple technological innovation to be adopted, promoted and implemented, actors find themselves in messy situations where uncertainty prevails.

This invites us to pay attention to the way intermediation activities take on board the key features of wicked problems and to the way these dimensions evolve over time. All our case studies demonstrate that these key features cannot be separated from the flow of actions: interdependencies and complexity are sometimes reduced; sometimes they increase and change in nature.

For example, the main focus on a descriptive appraisal of nature in CS 2 led to a reinforcement of blocking strategies. In that case, opening the black box of how human activities influence ecological functioning was needed to allow for the exploration of the controversy and to build management agreements, even if that kind of relationship remained mostly unknown and if the aim of collective action was displaced from nature preservation to territorial development. In CS 1, an exploration of how agricultural practices could be redesigned to reduce chemical pollution of water led to a more systemic appraisal of farming activities and finally questioned the way farmers could be involved in transition pathways towards sustainability and cultural changes. In CS 3, it appeared that ineffectiveness of action related to the complexity of the problem and the techno-scientific uncertainty has framed the successive involvements (or resistances) of all actors in public action regimes: search, conviction and change, and finally evidence-based regimes. Yet, no one knows how that public action will evolve in the future, with what outcomes. In CS 4, it seems that prescriptive conceptions of auditors' competency struggled with more comprehensive appraisals based on a wider recognition of knowledge and skills. The challenge was to accept auditor's field-based knowledge as proof of competency and to allocate responsibility away from SDOs and towards certification body management. In other words, to take on board the complexity within which auditors are practicing their activity and the ways certifiers must act to inter-relate standards and existing practical realities of standards in the making.

\subsection{Key functions of intermediation activities}

Does intermediation activities mainly consist of 'working and re-working the stock of knowledge' (Barnett, 2004, Hall et al., 2003) and in networking the places where it is produced with those where it is used? While this is clearly a part of intermediary actors' practices, in the case of sustainability transitions, our case studies illustrate that intermediation activities foster interactive processes in which goals and means definition are at the core of public or collective action and in which transformational changes might take 
place. In order to go beyond a restrictive cognitive interpretation of these practices, we propose some generic functions fulfilled by intermediation activities, which we abstracted from our case studies. : (I) building an efficient collective action on one side, (II) maintaining the dialogue and social interactions among participants who do not necessarily value the same politic of knowledge on the other one. This interpretation put forward the dialectic nature of intermediation activities while performing it over time to overcome the 'environmental paradox' in situations of transformational change.

(1) Building an efficient collective action relates to the objectification process and the problem that must be managed. In this context, certified knowledge mobilization and evidence-based decisions are meant to objectify the problem at hand and identify how changes in human practices and activities will influence the interdependencies that the problem reveals. As such, this type of knowledge is often missing, is incomplete or very partial for implementing it in a singular situation. Those involved have to explore the surface of the problem, which is never totally stabilized: what questions does the problem of nature preservation recover and how does that problem meet other social preoccupations of people at territorial level (CS 2)? What are the consequences, constraints and opportunities of changes in farming practices to reduce chemical pollution and how could this be thought of and practiced at a more systemic level (CS 1) or at the territorial level of a watershed (CS 3)?

Without pretending here to be exhaustive, our case studies enable us to identify and propose a set of functions (table 3a) that intermediation can fulfill to foster efficient collective action.

\begin{tabular}{|l|l|}
\hline Functions & Outputs \\
\hline Boundary work around problem definition & Stabilized agreements \\
\hline Problem finding and problem solving & $\begin{array}{l}\text { Permanent iteration between goals and } \\
\text { means of action }\end{array}$ \\
\hline Co-generation of knowledge & $\begin{array}{l}\text { Reduced uncertainties and explored } \\
\text { controversies }\end{array}$ \\
\hline Networking of human and cognitive resources & $\begin{array}{l}\text { Enhancement of collective action } \\
\text { capabilities }\end{array}$ \\
\hline $\begin{array}{l}\text { Problematizing the existence of adequate } \\
\text { deliberative arenas }\end{array}$ & $\begin{array}{l}\text { Out-scaled and up-scaled outcomes of } \\
\text { action }\end{array}$ \\
\hline
\end{tabular}

Table 3a: Functions of intermediation to build an efficient collective action

(2) Maintaining the dialogue relates to the inter-subjectification processes and the functions to fulfil in order to support social interactions over time in situations of transformational change. Indeed, processes of problem finding and solving not only rely on available knowledge but more importantly on the knowledge incumbent or new actors construct in action, individually and through processes of social interaction. While generic knowledge may be used in such deliberative processes, it is always adapted, reframed and redesigned to align with the natural, technical and social specificities of the local. The three regimes of action that were identified in CS-3 provide a particular appropriate illustration of how knowledge is used and the consequences of its mobilization for collective action. In the search regime, a collective dynamic was organized around identifying cause- effect relationships of algal bloom over a long period of time. But the ineffectiveness of undertaken actions led to the promotion of an exclusive livestock farming model based on grazing through a conviction regime, with unknown consequences on farm income and even more, on algal blooms. Finally, the contingent incident of sulfuric gas leakage led public authorities to implement an evidence-based action regime whereby knowledge was used to provide proof of environmental damage and force farmers to change. Nobody could really know beforehand which regime would be more effective. But according to each regime, the way people interact can change. In this case, it moved from cooperation to conflicts and contestations, requiring different abilities to maintain the dialogue over time. Table $3 \mathrm{~b}$ proposes a set of functions that intermediation can fulfill to support it. 


\begin{tabular}{|l|l|}
\hline Functions & Outputs \\
\hline Convince people through pedagogy & $\begin{array}{l}\text { Enrollment of stakeholders and } \\
\text { ownership of action }\end{array}$ \\
\hline $\begin{array}{l}\text { Reduce fears, resistances and contestations } \\
\text { and contain overwhelming processes }\end{array}$ & Space and time for deliberation \\
\hline Build new interpretative frames & $\begin{array}{l}\text { Transformation of identities, legitimacies } \\
\text { and social asymmetries } \\
\text { Changes in values and systems of } \\
\text { interest }\end{array}$ \\
\hline $\begin{array}{l}\text { Stimulate individual and collective reflexive } \\
\text { consciousness }\end{array}$ & $\begin{array}{l}\text { Build a shared understanding of the } \\
\text { situation }\end{array}$ \\
\hline
\end{tabular}

Table 3b: Functions of intermediation to support dialogue and social interactions in collective action

In all our cases, intermediation activities support the enrollment of stake-holders into collective action according to this dialectic of goals (between I and II). To create space and time for new meanings to emerge (Snowden, 2002), intermediation activities take place to convince, reduce social fears and contestations, gain adhesion by its contribution to the framing of the deliberative process containing overflowing processes. In some way being aware of the complexity of the context within which collective action takes place, intermediary actors develop the capabilities to 'hold together' the various and numerous components involved in collective action. In CS1 for example, despite changes in public policy frameworks leading to more coercive ways of action, intermediation is at the core of actors' willingness to follow-up and deepen the work undertaken in the past and to expand their ideas, findings and change proposals beyond the group. Thus by taking care of the social process and by stimulating individual and collective reflexive consciousness, intermediary actors help transform social identities and legitimacies of collectives.

\section{Discussion}

\subsection{Intermediation work to foster transformational change: articulating objectification and inter-subjectification processes}

Often, knowledge is considered as a thing within what Cook \& Brown, (1999) called an epistemology of possession. It is viewed as something that can be appropriated, owned, stocked and circulated, in order to be used for innovation. This kind of conception dominates in techno-centric or eco-centric approaches of action (Bawden, 2003), in which already available and science-based knowledge is considered to be sufficient for defining reachable goals, the way to assess the undertaken action as well as the means to be implemented. As shown in our case studies, knowledge can also be seen as a "flow", a process that emerges in action, encompassing both objective and subjective representations (Whitehead, 1929). Intermediation activities are then more about helping people to transform their own interpretative frameworks of the reality (Muller, 2010), that is their understandings, worldviews, opinions, conceptions of action and values. This is where learning takes place.

Therefore, we suggest that intermediary work can be seen and understood as an activity that articulates processes of objectification with processes of inter-subjectification. The latter term does not mean a radical relativistic approach of reality. On the contrary, it insists on the confrontation of interpretative perceptions people construct on a same reality. As political narratives can inform "about how people make sense of their lives, about how they construct disparate facts and weave them together cognitively to make sense of reality" (Patterson and Monroe, 1998), inter-subjectification is key in fostering heterogeneous people to 
make sense of a shared reality. The key functions that we identified in our case studies are those that contribute to achieving this articulation between objectification and inter-subjectification processes.

Some intermediary actors are designated as such by their profession (like advisors), but it does not mean that this professionalization systematically enables such actors to achieve a functional performance of objectification and inter-subjectification. To reach this position they have to gain legitimacy in the course of action and to signify, by their commitment, their attachment to a certain community of practice in interorganizational settings. Others do not have a professional commitment to be intermediary actors, such as scientists or consultants. Their practices of intermediation often emerge through the momentum in a process of transformational change. Their background plays a role in the way legitimacy is gained as they develop their transformative stances. Such legitimacy relies also on their capabilities to develop a new regime of action where existing goals and means are questioned in order to reassemble differently existing heterogeneous practices. Our case studies have illustrated how such capabilities are built by intermediary actors. In our view, these findings can be understood as contributing to a theory of intermediation, which encompasses the diversity of intermediary activities in sustainability transitions.

\subsection{Intermediation activities: the properties at play to foster transformational change}

Our interpretative perspective put emphasis on intermediation activities meant to support transformational change and to tackle sustainability issues that are defined as wicked problems. We suggest here that the efficiency of intermediation activities relays on three interlinked constitutive properties which will need further investigation in a strong research program on intermediation: performativity, contextualization, and reflexivity.

The concept of performativity has been developed earlier by Austin (1962) in the field of philosophy reflecting on the meaning and consequences of speech acts. According to this approach, the performativity of speech acts indicates that the enunciation of utterances is already the realization of an action, the effects of which are to linger in the future. The effectiveness of discourses and performativity analysis have become a common practice in many fields like economic sociology, critical management studies, science and technology studies, and rural sociology (Michael, 2000; Mol 2002; MacKenzie et al. 2007; Busch 2007; Callon 2010; Strati, 2007; Law 2008; Loconto 2010). We take here discourses as collections of interrelated texts that produce both meanings and effects in the real world ${ }^{1}$. This vision of achieving performance through the enunciation of discourses "focuses attention not only on the rhetoric and narrative of the performance itself but also on the way the performance expresses - and is embedded in - modes of information control' (Hilgartner 2000). In this perspective, many scholars have paid attention to enrolments of both material devices and their users into collectives after the utterance being delivered, and to the meaning that these collectives produce beyond the initial interaction (Callon, Méadel, and Rabeharisoa, 2002). They have not so much paid attention to the way a given regime of action gains legitimacy, which in turn gives strength to an utterance and supports its performativity. We propose to consider that such legitimacy is built through the articulation of objectification and inter-subjectification processes that intermediation activities fulfil in order to perform transformative change in sustainability transitions. We thus recognize performativity as a property of intermediation.

The second property we would like to stress is contextualization. In our case studies, we showed that intermediation activities are deeply related to a problematic situation, but also act as a translator between various deliberative arenas in which the problem at stake and the desired futures are framed.

\footnotetext{
${ }^{1}$ As Maguire and Hardy (2009: 150) phrases it their enquiry about discourses in the DDT Ban: discourses "define "who and what is 'normal,' standard and acceptable" (Merilanen, Tienari, Thomas, \& Davies, 2004: 544), as well as acceptable ways to think, talk, and act (Hall, 2001). Discourses thus shape "the strategies and rules by which we can speak about and act on a domain . . . in such a way that certain possibilities and outcomes are realized rather than others" (Reed, 1998: 196). As a result, discourses produce "power/knowledge relations, linguistically communicated, historically located, and embedded in social practice" (Heracleous \& Barrett, 2001: 757)'...
} 
Contextualization refers here to this ability to elaborate a transformative purpose, which is sustained in an argumentative discourse. The latter is established in order to support and to frame a promising and deliberative setting within a web of interests and social positions assembled in institutional arrangements. This approach relies on a semiotic perspective like the one developed by Latour (1990) and Akrich \& Latour (1992) to give an account of scientific work and scripts of innovation. The construction of successive utterances in deliberative arenas can be taken analogically as a text with a transformative purpose. The translations achieved by the intermediary actors maintain the consistency of utterances in deliberative arenas through time and thus creates a context. The production of a text and of a context expresses the meaning and the practicability of the transformative purpose at work; it shapes a promising future and reframes collective action simultaneously. This is what we label as "contextualization".

The third property is reflexivity, and it has to deal with learning in processes of change. Much has been said about reflexive practitioners in the area of social learning, following Argyris (1995: 17) famous pragmatic intuition: "we know we learnt something when we are able to realize what we assert we know". The reflexive consciousness (Giddens, 1984) of intermediary actors about their own position in reflexive modernization settings (see Bos and Grin, 2008) is based on a sense of caring about the (un)intentional effects of their practices in a process of change. This is central to sustaining intermediary activities but also to accommodate their legitimacy in deliberative arenas. The ability to develop this attitude has also been labeled as 'second order reflexivity' (Voß and Kemp, 2006). An earlier contribution (Elzen, et al., 2012) has established that various misfits within an existing sociotechnical regime require reflexivity - a questioning of both the taken for granted characteristics of the regime and the beliefs of stake-holders. This reflexive stance is clearly at work within our four case studies.

\section{Conclusion}

Through an interpretative process based on a crosscutting analysis of four case studies of various types of sustainability transition we have proposed to identify key functions fulfilled by intermediary activities and we have suggested that the efficiency of these activities needs to be analysed as the combination of three properties which we have termed: contextualization, performativity and reflexivity. These findings reflect our iterative and grounded approach of theorising intermediation. In light of some critiques proposed early in this chapter, they also represent a way of doing research with a comprehensive approach of intermediary actors to build a first interpretative model, which must be validated through further research. Despite this potential weakness, the study of both intermediation functions and properties constitutes a contribution to the research agenda for ongoing research about intermediation. Our results seem consistent with results already published by authors who have the intention of creating changes for sustainability drifts in agricultural innovation systems (Klerkx and Leeuwis, 2009; Klerkx et al., 2010). What our theoretical framework adds is the aspect of 'unintentionality' and a more fine-tuned understanding of the functions of intermediation.

To conclude we advocate for the development of a strong research program on intermediation as practice and process. In our view, such a program should target the three following issues.

1) The way intermediation acquires its legitimacy. To what extent does it depend upon an intentional longterm engagement of intermediary actors with their own visions of transformative change to address wicked problems within institutional arrangements? How does such legitimacy rest on the intermediary's ability to develop a regime of action in which goals and means are questioned together in order to reassemble existing heterogeneous practices in the field?

2) The objectification and inter-subjectification processes and the way they are articulated through the different functions of intermediation activities so to achieve transformational change. How this articulation is promoted or, on the contrary, constrained if not refrained by organizations and institutional arrangements? How to design processes for transformational change if one wishes to put intermediation efficiency at first? 
How researchers involved in field research could take into account their mobilization in objectification processes and in inter-subjectification processes as well?

3) The constitutive properties of intermediation remain quite invisible in sustainability transitions. How the interlinked, constitutive properties of intermediation (performativity, contextualization and reflexivity) are actualized in the course of action, and could they be traceable? What could be the consequences of focusing on these properties in professional training and teaching programs?

By opening these three lines of enquiry, we might be able to increase our understanding of intermediation in sustainability transitions.

Acknowledgements: This chapter has received the stimulating and demanding comments of Barbara van Mierlo and Bart Bremmer. Our thanks go to them.

\section{References}

Akrich, M. and Latour, B., 1992. A summary of a convenient vocabulary fot thr semiotics of human and nonhuman assemblies, in Bijker W.E. and Law (ed.), Shaping Technology/building society, Cambridge, Massachusetts: The MIT Press.

Aldrich, H. and Herker, D., 1977. Boundary Spanning Roles and Organization Structure, Academy of Management Review, 2 (2): 217-230.

Anderson, D. and Ackerman-Anderson, L., 2010. What is Transformation, and Why is It So Hard to Manage? On line access http://changeleadersnetwork.com/free.resources/.

Argyris, C., 1995. Savoir pour agir. Surmonter les obstacles à l'apprentissage organisationnel. Paris : InterÉditions.

Austin J.L. 1962. How to Do Things with Words: The William James Lectures delivered at Harvard University in 1955, (ed. J.0. Urmson and Marina Sbisà), Oxford (published posthumously in 1962).

Baert, P., and F. D. Rubio, F.D., 2012. The politics of knowledge. London ; New York, Routledge.

Barbier, M., and Elzen, E., 2012. System Innovations, Knowledge Regimes, and Design Practices towards Transitions for Sustainable Agriculture, Paris : INRA Editions, 374p.

Barbier, M., 2010. The ecologization of agricultural development and the treadmill of sustainable development, a critique in a state of transition. Przeglad Socjologiczny (Sociological Review), 59(2) :9-28.

Barnett, M.L., 2004. Are globalization and sustainability compatible? A review of the debate between the World Business Council for Sustainable Development and the International Forum on Globalization. Organ. Environ. 17 (4), 523-532.

Batie, S.S., 2008. 'Wicked Problems and Applied Economics', American Journal of Agricultural Economics, 90 (5), 1176-91.

Bawden, R., 2003. The Essential Learning \& Inclusive Cognition'. A workbook.

Bessant, J., Rush, H., 1995. Building bridges for innovation: the role of consultants in technology transfer. Research Policy 24, 97-114.

Blumer, H., 1971. Social problems as collective behavior. Social Problems 18, 298-306.

Bos, A.P., and Grin, J. 2008. "Doing" Reflexive Modernization in Pig Husbandry: The Hard Work of Changing the Course of a River. Science, Technology, \& Human Values, (33) 480-507.

Bourblanc M. (2007). Les politiques de reconquête de la qualité de l'eau face aux pollutions. Thèse, Université de Rennes.

Burt, R., 2004. Structural holes and good ideas, American Journal of Sociology, 110: 349-99.

Busch, L., 2007. Performing the economy, performing science: from neoclassical to supply chain models in the agrifood sector, Economy and Society, 36, 437-466.

Butterfield, L. D., Borgen, W. A., Amundson, N. E., and Malio, A.S.T., 2005. Fifty years of the critical incident technique: 1954 - 2004 and beyond. Qualitative Research, 5 (4): 475-497.

Callon, M., 2010. Performativity, Misfires and Politics, Journal of Cultural Economy 3(2):163-69.

Callon, M., Lascoumes, P., and Barthe, Y., 2001. Agir dans un monde incertain: Essai sur la Démocratie Technique. Seuil, Paris. 
Callon, M., Méadel C. and Rabeharisoa V.,2002. The Economy of Qualities, Economy and Society, 31, 194217.

Canévet C., 1992. Le modèle agricole breton. Rennes, Presses Universitaires de Rennes.

Cerf M., Guillot M.N., Olry P., 2011. Acting as a change agent in supporting sustainable agriculture: how to cope with new professional situations? Journal of Agricultural Education \& Extension, (17), 7-19.

Connor, R., Dovers, S., 2004. Institutional Change for Sustainable Development. Edward Elgar Publishing, Cheltenham.

Cook, S.D.N., Brown, J.S., 1999. Bridging epistemologies: the generative dance between organizational knowledge and organizational knowing. Organization Sci. 10 (4), 381-400.

Detienne, M., 2009, Comparer l'incomparable, Paris, Le Seuil.

Dingwerth, Klaus, and Philipp Pattberg. 2009. World Politics and Organizational Fields: The Case of Transnational Sustainability Governance. European Journal of International Relations 15 (4):707743.

Dodier, N., 2003a. Leçons politiques de l'épidémie du SIDA. Editions EHESS, Paris.

Dodier, N., 2003b. L'espace et le mouvement du sens critique. Colloque Convention et Institutions: Approfondissements Théoriques et Contributions au Débat Public. CNRS, Université' Paris X, Paris, Décembre 2003.

Dubois, V., 2009. L'action publique. In Nouveau manuel de science politique, Cohen (A.), Lacroix (B.), Riutort (Ph.). (Ed.), pp.311-325.

van Eemeren, FH, 2011. In Context Giving Contextualization its Rightful Place in the Study of Argumentation, Argumentation, 25 (2): 141-161

Elzen B., Barbier M., Cerf M., Grin J., 2012. , Stimulating transitions towards sustainable farming systems., In Ika Darnhofer, David Gibbon, Benoit Dedieu (Eds.), The farming systems approach Into the 21st century: The new dynamic, Springer, 2012.

Gassmann, 0. and Reepmeyer, G., 2005. Organizing pharmaceutical innovation: From science-based knowledge creators to drug-oriented knowledge brokers', Creativity and Innovation Management, 14: $233-45$.

Geels, F.W. 2002. Technological transitions as evolutionary reconfiguration processes: a multi-level perspective and a case-study, Research Policy, 31 (8-9), 1257-74.

Geels, F.W., 2011. The multi-level perspective on sustainability transitions: Responses to seven criticism. Environmental Innovation and Societal Transitions, 1: 24-40.

Giddens A., 1984. Theory of structuration, Cambridge, Polity Press.

Glaser, B. and Strauss, A., [1967\} 2008, La production de la théorie à partir des données, Enquête (on line).

Gusfield, J.R., 1981. The Culture of Public Problems, Chicago, University of Chicago Press.

Guston, D.,1999. Stabilizing the boundary between US politics and science: The role of the Office of Technology Transfer as a boundary organization, Social Studies of Science, 29: 87-111.

Hall, A., Rasheed Sulaiman, V., Clark, N., and Yoganand, B., 2003. From measuring impact to learning institutional lessons: an innovation systems perspective on improving the management of international agricultural research. Agric. Syst., 78: 213-241.

Hargadon, A. B., 1998. Firms as knowledge brokers: Lessons in pursuing continuous innovation, California Management Review, 40: 209-27.

Hilgartner S., 2000. Science on Stage. Expert advice as public drama, Stanford University Press

Hatanaka, M. 2010. Governing sustainability: examining audits and compliance in a third-party-certified organic shrimp farming project in rural Indonesia. Local Environment, 15 (3): 233-244.

Holling, C. S., 2001. Understanding the Complexity of Economic, Ecological, and Social Systems. Ecosystems 4: 390-405

Howells, J., 2006. Intermediation and the role of intermediaries in innovation. Research Policy, 35: 715728

Klerkx, L. and Leeuwis C., 2009. Establishment and embedding of innovation brokers at different innovation system levels: Insights from the Dutch agricultural sector. Technological Forecasting \& Social Change, 76: 849-860.

Klerkx, L. and Leeuwis, C., 2008. Balancing multiple interests: Embedding innovation intermediation in the agricultural knowledge infrastructure, Technovation, 28: 364-78. 
Klerkx, L., Aarts N., Leeuwis. C., 2010. Adaptive management in agricultural innovation systems: the interactions between innovation networks and their environment, Agric. Syst., 103: 390-400.

Klerkx L., Van Mierlo B., Leeuwis C., 2012. Evolution of systems approaches to agricultural innovation: concepts, analysis and interventions in Farming Systems Research into the 21st century: The new dynamic, Springer, pp. 457-483.

Latour, B. 1987. Science in Action: How to Follow Scientists and Engineers through Society. Milton Keynes, England: Open University Press.

Latour B. 1990. Drawing things together, in Lynch M. et Woolgar S. (ed.), Representation in scientific practice, Cambridge, Mass. : The MIT Press.

Latour, B., 1999. Politiques de la nature. Comment faire entrer les sciences en démocratie. La Découverte, Paris.

Latour, B., 2005. Reassembling the social : an introduction to actor-network-theory. Oxford ; New York, Oxford University Press.

Law, J., 2008, On sociology and STS, Sociological Review, 56: 623-649.

Levain, A., 2014. Vivre avec l'algue verte, Médiations, épreuves et signes, Thèse de doctorat en anthropologie Muséum National d'Histoire Naturelle, Paris.

Levain, A., Vertès, F., Ruiz, L., Delaby, L., Gascuel, C. Barbier, M., 2015. 'I am an intensive guy': The possibility and conditions of reconciliation through the ecological intensification framework. Environmental Management, in press.

Levin, K., B. Cashore, S. Bernstein, and G. Auld, 2012. Overcoming the tragedy of super wicked problems: constraining our future selves to ameliorate global climate change, Policy Sciences, 45 (2): 12352.

Loconto, A. 2010. Sustainably performed: Reconciling global value chain governance and performativity. Journal of Rural Social Science 25 (3): 193-225.

Loconto, A., and Fouilleux, E., 2014. Politics of Private Regulation: ISEAL and the shaping of transnational sustainability governance. Regulation \& Governance 8(2): 166-185.

Loconto, A., and Busch, L., 2010. Standards, techno-economic networks, and playing fields: Performing the global market economy. Review of International Political Economy 17 (3): 507 - 536.

Loconto A., and Barbier M., 2014. Transitioning Sustainability: Performing 'governing by standards', in S. Borraz and J. Edler (ed), The Governance of Socio-Technical Systems - Explaining change, Edward Elgar Publishing: 70-95.

Lomas, J. (2001) 'The in-between world of knowledge brokering', BMJ, 223: 129-32.

MacKenzie, D. A., F. Muniesa and L. Siu (2007), Do economists make markets? : on the performativity of economics, Princeton, NJ: Princeton University Press.

Maguire S and Hardy, C., 2009. Discourse and deinstitutionalization: the decline of DDT, Academy of Management Journal, 52 (1) 148-178.

Maxime F., and Cerf M., 2002. Apprendre avec l'autre : le cas de l'apprentissage d'une relation de conseil coopérative. Education Permanente, 151, 47-68.

McDermott, C. L. 2012. Trust, legitimacy and power in forest certification: A case study of the FSC in British Columbia. Geoforum 43 (3):634-644.

Meyer, M., and Kearnes, M., 2013. Introduction to special section, intermediaries between science policy and markets, Science and Public Policy, 40 (3): 423-429

Meyer, M., and Schlierf K., 2013. Situating knowledge inter-mediation: insights from science shops and knowledge brokers, Science and Public Policy, 40 (3): 430-441.

Michael, M., 2000. Futures of the Present: From Performativity to Prehension, in N. Brown, Rappert, B., Webster, A. Contested Futures - A sociology of prospective techno-science. Aldershot, Ashgate: 2139.

van Mierlo B., Leeuwis C., Smits R., and Woolthuis R.K., 2010. Learning towards system innovation: Evaluating a systemic instrument, Technological Forecasting and Social Change, (77), 2: 318-334.

Mol, A., 2002. The Body Multiple: Ontology in Medical Practice. Durham: Duke University Press.

Muller, P., 2009. Les politiques publiques. Coll. Que sais-je ? Editions PUF, Paris.

Nussbaum, M.C. 1985. Objectification. Philosophy \& Public Affairs 24 (4): 279-83.

Olivier de Sardan, J.-P. , 1995, Anthropologie et développement. Essai en socio-anthropologie du changement social, Paris, Karthala (translate in English in 2005). 
Olivier de Sardan, J.-P., 2008. La rigueur du qualitatif. Les contraintes empiriques de l'interprétation socioanthropologique. Louvain-La-Neuve: Bruylant.

Pickering, A. (1995). The mangle of practice: time, agency, and science. Chicago, IL, University of Chicago Press.

Robertson, R., 1994. Globalisation or glocalisation?, The journal of International Communication, (1)33-52

Rotmans J., Kemp R., and van Asselt M., 2001. Transition Management: a promising policy perspective, Interdisciplinarity in Technology Assessment / Wissenschaftsethik und Technikfolgenbeurteilung, $11: 165-197$.

Schlierf, K., and Meyer, M. 2013. Situating knowledge intermediation: Insights from science shops and knowledge brokers, Science and Public Policy, 40(4): 430-441.

Smith, A., Stirling, A. and F. Berkhout, F., 2005. The governance of sustainable socio-technical transitions, Research Policy, 34 (10), 1491-510.

Smith, A., and A. Stirling, 2007. Moving outside or inside? Objectification and reflexivity in the governance of socio-technical systems. Journal of Environmental Policy \& Planning, 9: 351-373

Snowden, D., 2002. Complex acts of knowing-paradox and descriptive self-awareness. J. Knowl. Manage. 6 (2), 100-111 (special issue).

Sonnenwald, D. H. 1996. Communication role that support collaboration during the design process. Design Studies, 17: 277-301.

Star, S.L., and Griesemer, J. (1989). Institutionnal ecology, 'Translations' and Boundary objects: amateurs and professionals on Berkeley's museum of vertrebate zoologie, Social Studies of Science. 19(3): 387-420.

Stevens, D., 1999. The Competent Boundary Spanner, Teaching and Teacher Education, 15(3): 287-299.

Steyaert, P., 2006. Dispositif d'action collective : un concept pour comprendre la gestion concertée de l'eau à l'échelle de bassins versants. In Ph. Mérot (éd.) Qualité de l'eau en milieu rural. Savoirs et pratiques dans les bassins versants. Quae Editions, INRA, Paris.

Steyaert P., 2008. Des concepts intermédiaires producteurs de sens pour la gestion environnementale : une étude de cas sur les zones humides côtières en France. In F. Mélard (éd.), Écologisation : Objets et concepts intermédiaires, Editions P.I.E.-Peter-Lang, coll. Écopolis, Bruxelles.

Steyaert, P., Jiggins, J., 2007. Governance of Complex Environmental Situations through social learning: a synthesis of SLIM's lessons for research, policy and practice. Environ. Sci. \& Policy 10(6), p. 575586.

Stirling A., 2014. Towards More Reflexive Governance of Vulnerability, In A. Hommels, J. Mesman and W. E. Bijker (Eds.) Vulnerability in technological cultures: new directions in research and governance. MIT Press, Cambridge, MA.

Strati, A., 2007. Sensible Knowledge and Practice-based Learning, Management Learning, 38(1): 61-77

Strauss, A., 1978. A social world perspective. Stud. Symbolic Interact. 1, 119-128.

Traugott, E.C., 2010. Revisiting subjectification and intersubjectification, in Kristin Davidse, Lieven Vandelanotte, and Hubert Cuyckens, (eds.), Subjectification, Intersubjectification and Grammaticalization, 29-70. Berlin: De Gruyter Mouton

Voß, J.-P. and Kemp, R., 2006. Sustainability and reflexive governance: Introduction. In J.P. Voss, D. Bauknecht and R. Kemp (Eds.). Reflexive governance for sustainable development. Cheltenham: Edward Elgar, pp. 3-28.

Ward, V., House A., and Hamer, S., 2009. Knowledge Brokering: The missing link in the evidence to action chain?, Evidence Policy, 5(3): 267-279.

Whitehead A.N., 1929. Process and Reality: An Essay in Cosmology, corrected edition, edited by David Ray Griffin and Donald W. Sherburne, Free Press. (Ed. 1979).

Williams, P., 2002. The Competent Boundary Spanner, Public Administration, 80(1): 103-124,. 


\section{Appendix 1: Sample of the use of the analytical GRID}

\begin{tabular}{|c|c|c|c|}
\hline $\begin{array}{l}\text { Critical Events } \\
\text { Features }\end{array}$ & $\begin{array}{l}\text { 1. Heavy } \\
\text { contestation about } \\
\text { the limits of the } \\
\text { nature } \\
\text { preservation area. }\end{array}$ & $\begin{array}{l}2 . \quad \text { Get round } \\
\text { institutional } \\
\text { contestation } \\
\text { diversifying by } \\
\text { deliberative arenas } \\
\end{array}$ & $\begin{array}{l}\text { 3. Struggle between local } \\
\text { actors involved in collective } \\
\text { action and administrative } \\
\text { agents }\end{array}$ \\
\hline Interdependencies & $\begin{array}{l}\text { Unexplored and } \\
\text { limited to a } \\
\text { "descriptive" } \\
\text { approach of nature }\end{array}$ & $\begin{array}{l}\text { Increases by the } \\
\text { integration of social } \\
\text { preoccupations linked to } \\
\text { human activities (livestock } \\
\text { farming, hunting, fishing, } \\
\text { water management, } \\
\text { invasive species, etc.) }\end{array}$ & $\begin{array}{l}\text { Between the local (collective } \\
\text { action and what it produced) } \\
\text { and the global (political } \\
\text { framework and its translation } \\
\text { by administrative services) }\end{array}$ \\
\hline Complexity & $\begin{array}{l}\text { Reduced to the } \\
\text { description of nature } \\
\text { and land use } \\
\text { focusing on area } \\
\text { delimitation }\end{array}$ & $\begin{array}{lr}\begin{array}{l}\text { Diversification } \\
\text { components }\end{array} & \text { of } \\
\text { interactions. } & \text { Shift } \\
\text { marshlands' } & \text { description } \\
\text { to } & \text { marshlands' } \\
\text { functioning } & \end{array}$ & $\begin{array}{l}\text { Reduced to political and } \\
\text { administrative } \\
\text { (validation, funding) }\end{array}$ \\
\hline Uncertainties & $\begin{array}{l}\text { Socio-political about } \\
\text { the consequences of } \\
\text { nature protection } \\
\text { policies and their } \\
\text { future development } \\
\text { on human activities }\end{array}$ & $\begin{array}{l}\text { Techno scientific: cause- } \\
\text { effect relationships } \\
\text { between human activities } \\
\text { and ecological functioning } \\
\text { of the marshes are } \\
\text { unknown }\end{array}$ & $\begin{array}{l}\text { Political about the acceptance } \\
\text { of the action plan and its } \\
\text { funding through a set of } \\
\text { administrative and political } \\
\text { frameworks }\end{array}$ \\
\hline Controversy & $\begin{array}{l}\text { Quality of biological } \\
\text { inventories is } \\
\text { contested in order to } \\
\text { exclude crop land } \\
\text { from the area }\end{array}$ & $\begin{array}{l}\text { Specific around } \\
\text { management stakes and } \\
\text { related technical objects } \\
\text { emerging from } \\
\text { deliberations (e.g. hunting } \\
\text { areas, water levels, etc.) }\end{array}$ & $\begin{array}{l}\text { Related to how public action is } \\
\text { conceived and implemented } \\
\text { (deliberative vs prescriptive) }\end{array}$ \\
\hline
\end{tabular}

\begin{tabular}{|c|c|c|c|}
\hline Objectification & $\begin{array}{l}\text { Extensive use of } \\
\text { descriptive } \\
\text { knowledge: habitats' } \\
\text { presence and } \\
\text { richness. Agricultural } \\
\text { data (typologies, } \\
\text { maps) }\end{array}$ & $\begin{array}{l}\text { Validation of land use } \\
\text { maps and new map's } \\
\text { legend. } \\
\text { Use of a new concept to } \\
\text { qualify different } \\
\text { marshland areas }\end{array}$ & $\begin{array}{l}\text { A shared and collective action } \\
\text { plan defining stakes, } \\
\text { management goals and a set } \\
\text { of means for achievement }\end{array}$ \\
\hline $\begin{array}{l}\text { Inter- } \\
\text { subjectification }\end{array}$ & $\begin{array}{lr}\text { Confrontation } & \text { of } \\
\text { conflicting } & \text { social } \\
\text { interests. } & \end{array}$ & $\begin{array}{l}\text { Technical debate } \\
\text { develops leading to build } \\
\text { a shared understanding } \\
\text { of stakes and to restore a } \\
\text { so called "marshland } \\
\text { integrity" }\end{array}$ & $\begin{array}{l}\text { Confrontation of values around } \\
\text { top-down and bottom-up } \\
\text { approaches of public action }\end{array}$ \\
\hline
\end{tabular}




\title{
Conclusion: a Curiosity Cabinet of Agro- Ecological Transition Studies
}

\author{
Marc Barbier ${ }^{1}$, Boelie Elzen², Barbara van Mierlo ${ }^{3}$ and Anna Maria \\ Augustyn ${ }^{4}$
}

\section{Introduction}

The final chapter in this volume teases out some general lessons. It summarises the main findings of each of the preceding chapters and ends with a number of general reflections on the study of agroecological transitions-in-the-making. Each of the preceding chapters describes practical experiences in stimulating transitions towards sustainable agri-food systems. Many of these studies draw upon the agroecological agenda, meaning the bio-politics of access to resources that define the people in their humanity with a sense of distributive justice. Most studies in this volume focus on how to sustain a biological and biophysical capability, says a living soil, to generate bio-resources as a surplus for animal, vegetal and human systemic relations. A limitation, that needs to be acknowledged, is that the majority of the chapters concern countries of industrialised agriculture, although there are some noticeable exceptions. Despite this limitation, however, these studies do provide a far more 'integral' analysis of sustainable agri-food systems than in a wide variety of other studies and do provide a good stepping-stone to tackle the enormous sustainability challenge that lies ahead.

The form taken by agroecological agenda in the cases analysed is largely inspired by the organic farming movement but cannot be reduced to it. Many relevant initiatives explore other sociotechnical promises that are based on value systems which are more or less shared with the agroecological agenda. This agroecological turn is not only paved with good intentions but also with many traps stemming from the inner tensions. Paradoxes emerge when practices confront diverging values in transition processes. But this turn cannot avoid facing the incumbent system of norms, actors, routines and lock-in of agri-food-chains. Therefore, studying transition-in-the-making in this context needs to liaise with the stream of research that studies sociotechnical regimes and that sheds the light on multi-actor networking and learning loops in fostering agroecological transitions. This concluding chapter thus also provides input for a research agenda on agroecological transitions-in-the-making.

\section{A Curiosity Cabinet displaying three strands of Transition Studies}

Seeking to draw general lessons from the preceding chapters constitutes a challenge, since these chapters have varying epistemological and theoretical backgrounds. Yet, they do represent the state-of-the-art of research on sustainability transitions in agro-food systems. Drawing general lessons from what at first sight seems a very heterogeneous collection, we have divided up the collection into three parts corresponding with the three analytical strands as explained in the introduction to this volume. To acknowledge this

\footnotetext{
${ }^{1}$ INRA, UR1326 Laboratoire Interdisciplinaire Sciences Innovations et Sociétés (LISIS), Champs-sur-Marne, France. Email: marc.barbier@grignon.inra.fr

${ }^{2}$ Applied Arable and Vegetable Research, WUR, the Netherlands. Email: boelie.elzen@wur.nl

${ }^{3}$ Knowledge, Technology and Innovation Group, Wageningen University, Netherlands. Email: barbara.vanmierlo@wur.nl

${ }^{4}$ Groupe de Bruges, the Netherlands. Email: annamaria.augustyn@yahoo.com
} 
heterogeneity, we use the term 'Curiosity Cabinet' for the collection as a whole. The three analytical strands are (1) learning in niches, (2) niche-regime interactions, and (3) regime transformations.

The three analytical strands represent three different foci in how researchers are currently tackling the issues of agroecological transitions, while they are situating their own analysis in rather specific loci of human action where actors are engaged in transformational change processes. This emphasis on field work certainly reflects a value that the authors of this volume share with many social scientists, including giving a reflexive account of engagement with the situations analysed and an openness towards transdisciplinary research. As a result, several of the authors address questions like: how to foster learning in niches? How do niches link up to regimes to start a change process? How to stimulate this with methods like co-design or action research? How does this lead to a transformation of the regime (massive uptake of novelties) and how to accelerate this?

Below, we seek to develop (tentative) answers to such questions by revisiting all the chapters of this volume. We are doing so under three headings that reflect the three analytical strands indicated above. In this synthesis of the chapters, we hope readers will find some echoes of their personal or collective interests thanks to our 'guided visit' through the Curiosity Cabinet.

\subsection{Learning in Niches: Nursing the seeds of transition}

In transition studies, niche projects are often considered the "seeds of transition" (Wiskerke and Van der Ploeg 2004) that, following an evolutionary process, could induce further regime transformations. Experiential knowledge, ex-post analysis and giving feedback are then important to help participants and scholars to learn about how innovations or changes can transform views on their institutional and biophysical environments. Six chapters focus on these issues from two different angles: (1) agricultural production per se and (2) agricultural production in its wider societal embedding.

\subsubsection{Exploring path-breaking agricultural innovations}

Three chapters take specific problems of the incumbent regime as a starting point to develop and/or explore new forms of agriculture that might solve these problems. They provide insights in transitions in-themaking and the collective design of possible transition pathways by analysing how certain actors try to realise purposeful changes by experimenting with breakthrough alternatives to the dominant agro-food regime. In one case, the strategy for change is rooted in reflexive processes of niche actors that interact with regime actors to explore possible pathways for change, based on anchoring and a permanent negotiation of ambitions. In another case, changes are promoted by niche initiatives that operate independently from the mainstream agricultural knowledge system. Yet, this chapter also describes that niche and regime developments do influence one another. The third case describes how changes may also occur in paradoxical situations where sustainability goals are pursued by both consumers and producers, but where inertia and prevailing power relationships create barriers for the regime change. Despite this lock-in, a combination of co-construction and advocacy strategies may induce changes towards a more sustainable system. Below we take a closer look at these three chapters.

Reflexivity and anchoring. The chapter by Bart Bremmer and Bram Bos provided an analysis of network building in the design of new animal husbandry systems (the RIO approach) in the Netherlands over the past 15 years. By documenting the vicissitudes of these new initiatives they shed light on three distinctive ways to support niche development, notably shielding, nurturing and empowerment. They argue that innovations, that are carried out by individual farmers, are not likely to result in niche development, as innovative farmers generally only aim for changes on their own farm, and do not seek to make others adopt these changes. In practice, in many of these initiatives, that were initially path breaking, farmers chose to decrease the level of ambition by adapting their choices to the existing environment that remained unaltered. In other examples, however, a wider network was involved in implementing new systems that resulted from the RIO projects and these altered the direction of regime developments to some extent, thereby providing more space and support for radically different innovations. The RIO approach and its 
outcomes did result in path-breaking new husbandry systems which, however, (thus far) have only been realized on a small scale in local initiatives.

Boundary work and adaptive interactions. In their study, Julie Ingram and Damian Maye described an emerging group or 'sub-niche' that promotes and develops permaculture initiatives and analyse how this group interacts with the mainstream agricultural knowledge system (AKS). Going beyond identity claims and contentions, their analysis showed that a new knowledge system has emerged in this community to support learning independently from the existing AKS. They also showed that this learning process has cohered around the community's social system. Interestingly, rather than finding a dichotomy of the permaculture knowledge system challenging or invigorating the incumbent system, they identified a subtle set of overlapping processes that involve some contested diffusion of permaculture ideas into the AKS. There is a certain degree of co-learning, resulting in the emergence of fresh perspectives and opportunities for innovation. As a result, there is a clear influence from a niche with transformative ambitions on the regime. In this situation, intermediaries between the knowledge systems, rather than playing a purely functional role of communicating objective knowledge, engaged in a process to negotiate, interpret and represent different values, epistemologies and visions of the future. In the case of permaculture, these intermediary processes have been $a d$ hoc and opportunistic and the relative merits of such emergent and adaptive interactions, compared to formalised approaches, need further attention in the context of sustainability transitions.

Strategizing transitions in a sociotechnical system. Recent developments have led to the emergence of new multi-actor 'transition arenas'. The chapter by Claire Lamine takes a paradox as a matter of enquiry: how to understand that societal pressures for sustainability have had virtually no impact on cultivar breeding in the French peach and apricot industry, although the quality of modern cultivars is often disappointing to both consumers and farmers? She shows that, despite inertia and prevailing power relationships, a combination of co-construction and advocacy strategies within three different kinds of arena (mainstream, alternative and transition arenas) might form a basis for a collective design of pathways towards sustainability. These emerging transition arenas stem from the alliances between a diversity of stakeholders who embody the different components of the socio-technical system (research, experimentation networks, breeders, economic stakeholders, policy makers, civil society), although they do not represent them in an official, mandatory way. This co-presence can provide a way to tackle (or to redefine) the interdependencies that tie them together.

\subsubsection{Societal embedding of novel agricultural practices}

The first three chapters discussed above all addressed niche developments in which agricultural production is the focus of attention. Three further chapters also dealt with the development of niches but in these, agricultural practices were analysed as part of a wider system. These chapters also consider agriculture's regional role with moral concerns about linking production to food provision in alternative food networks and intermediation support for sustainable development. They thus provide informed insights on transitions-inthe-making when the reconnection of production and consumption is grounded in a moral economy carried by communities and social movements. Although the focus is on niches, in which a collective exploration takes place at a rather small scale, this should not lead to viewing these practices solely as fancy subcultures of alternative food provision. While infrastructural barriers to sourcing food through sustainable regional food channels will not be overcome by individuals or small organizations alone, these initiatives do provide stepping stones to target political action strategies at multiple levels.

A culture of reconnection. From the point of view of transition dynamics, Bálint Balázs, György Pataki and Orsolya Lazányi described how farmers became the main actors in the protection and consolidation of an innovative reconnection of producers and consumers. 'Community Supported Agriculture' (CSA), that has developed outside the industrial regime of food provision, relies on the help of engaged consumers and an emerging CSA platform. CSA members put extra effort into bringing together and nurturing bonds of affinity with their customer base and, furthermore, educate them about sustainable diets. CSA appears as a specific form of the moral economy whereby farmers seek to create communities relying on external financial resources and reaching out to trust-based personal networks or ethical consumers. CSA can be 
seen as a collective exploration to catalyse changes in a dominant agro-food system, reconnecting consumers with producers by fostering a collaborative culture of sharing, gifting, bartering and donating.

Small scale farming as alternative. Building on the concept of 'alternative food networks', Boldizsár Megyesi described different models-in-use of agri-food production in a Hungarian rural micro-region. He assessed various forms of knowledge (local/traditional, managerial and scientific knowledge) and types of farming (agricultural companies, medium-size farms, small-size farms and social farming). Exploring the factors and resources that determine framing technologies and specific practices that inspire different models of agri-food production, it appears that small scale farming is able to liaise with alternative food networks, while the other types of farming remain inside the incumbent agricultural regime. The latter abide by existing rural policies and subsidy arrangements and tend to minimize their attention for the societal or environmental consequences of their farming practices.

The transformative potential of alternative food movements. Compared to the two previous chapters, Marcia Ostrom went a step further by showing how niche level developments may start change processes at the regime level. She described a new dialogue on the meaning and politics of food that takes place at local, regional, but also national levels. New sets of meanings, ideas, and ideals have emerged and have been taken up and debated by the larger society. She concluded that the transformative potential of alternative food movement organizations depends on their ability to catalyse cultural shifts and evolutions in the values, ideals, and meanings associated with food from the purely personal to wider societal concerns. Translating these emerging new value systems around food into systems-level change, however, will require mobilizing collective action that is coordinated across individuals, movement organizations and institutions. Substantial policy and infrastructural barriers to sourcing any significant amount of food through sustainable regional food channels cannot be overcome by individuals alone or even small institutions making informed purchasing decisions. In addition, this will require collective action strategies that bridge an emerging sense of individual agency with targeted political action strategies at multiple levels.

\subsection{Governing sustainability by linking niche and regime developments}

The six papers discussed in this section focus on driving forces that govern sustainability transformations, either through public support and policy making or through organised action and initiatives that intend to govern sustainability by institutional arrangements or market instruments.

\subsubsection{Niche-regime linking affected by policy making}

The first three chapters discussed below addressed the linking processes between niches and regimes that are required to make a new technology or a new farming practice influence regime developments to become more sustainable. These chapters focused on tensions within systems of knowledge, the status and role definition of intermediary organizations and overcoming biases in resources for different types of research.

Pluralistic patterns of change in a niche-regime. The chapter by George Vlahos, Pavlos Karanikolas and Alex Koutsouris addressed the interaction between niche and regime in canned peach production in Northern Greece. They used the concept of niche-regime to analyse how Integrated Farming has originated from within the incumbent regime. This study identified an area of overlap between niche and regime in which the authors identify a sequence of top-down and bottom-up patterns of change, characterised as 'reconstellation' and 'empowerment'. The emerging transition seems to follow a concrete sequence of patterns, causing profound changes in structures, cultures and practices. Rather than an evolutionary dynamic of niche expansion, the dynamic in the area of overlap shows various and sometimes diverging transition paths that seem to unfold simultaneously. The chapter thus identified pluralistic patterns of change, the study of which, the authors argue, will require a non-hierarchical representation of the multilevel perspective (MLP). 
Competing narratives for research and extension. In contrast to the preceding chapter, the chapter by C. Shambu Prasad and Debashish Sen described a case where a global niche has been firmly established and recognised: the System of Rice Intensification (SRI) in India. The chapter argues that the success of SRI relies on the conjunction of institutional experiments and experiments at micro-levels, and the role of non-research actors who show a capacity for learning and experimentation. Nevertheless, the knowledge and experiences with SRI continue to lack policy support due to existing knowledge regimes that do not support agroecology. While the AKIS (agricultural knowledge and innovation system) and the MLP literature have addressed issues of knowledge at the regime and landscape level, the authors argue that the politics of knowledge has not received sufficient attention. Resources for research and extension lie largely with the agricultural research establishments that are more aligned with the dominant narrative of agricultural intensification through genetic engineering, rather than a 'low-tech' alternative like SRI, despite its evident successes.

Allocation and policy support to intermediary organizations. The chapter by Paul Swagemakers, Pierluigi Milone and Flaminia Ventura also considered the interdependency of niches and regimes in two case-studies on alternative practices in dairy farming in the Netherlands and in Italy. Their analysis of the organization of projects and practices developed by farmers and government intermediaries showed the importance of organizational structures that remain highly dependent on policy support. This support is crucial to address environmental concerns and articulate farmers' drives to adopt production efficiency and cost reduction strategies that fit an agroecological paradigm. The authors demonstrated that a better understanding of transition processes lies in the equal allocation of research resources and policy support to intermediary organizations. These contribute to the exploration and incorporation of endogenous knowledge in a future optimization of the agro-food system, and therewith help the wider sector to adopt resilient farmers' strategies.

\subsubsection{Niche-regime linking through strategizing and governance}

The three chapters discussed above focused on how the linking of niches and regimes is affected by policymaking and public support at the national or regional level. The three chapters discussed below target a different level of enquiry. They focus on organised action and initiatives that stimulate such linking by means of entrepreneurial strategies. These chapters describe the strategies of collective action and social movements, and analyse the role of intermediaries and market standards as instruments for sustainable development. The respective studies are clearly transdisciplinary since the researchers themselves were actively engaged in the transitions-in-the-making that they described.

Portfolio of Promises as a transition tool. The chapter by Boelie Elzen, Arni Janssen and Bram Bos described a tool that can be used to stimulate transition processes. It built on the recognition that in agricultural practice there is a wide range of 'bottom-up' innovation initiatives that are carried out by entrepreneurial farmers. The authors used the term 'promise' to describe a novelty with attractive features but that has also problematic or unknown sides. To help entrepreneurial farmers to reflect on the sustainability potential of a range of novelties, the authors have developed a database called 'portfolio of promises' which contains information on a large number of these promises. This tool can be used by farmers to take decisions on changes they want to make on their farm, as well as by strategic actors and policy makers to inform a broader innovation strategy. Although the underlying database structure of the portfolio of promises may be general, specific interfaces are needed to make the tool useful for farmers, strategists in the sector, policy makers or researchers. Each of these envisaged user groups has different requirements concerning the level of detail of the information they need and the comprehensiveness of the available information.

Variety in social movements strategies. The chapter by Jan Buurma, Karel de Greef and Volkert Beekman focused on the ways in which social movements can trigger change processes in a regime by analysing the dynamics between two types of NGO, researchers and sector organisations in the domain of pork production in the Netherlands. In the MLP terms, the study argued that a 'moderate' NGO focused on the overlapping area between niche and regime while an activist group targeted the overlapping area 
between regime and landscape. In terms of effectiveness, one strategy is not systematically more effective than the other while both can support each other's effectiveness. The authors underlined that an effective strategy for change should make use of trends and incidents at the landscape level, but also increase pressure on the regime, in addition to multi-actor arrangements at the niche and regime level. The occurrence of trends and incidents, combined with an activist NGO stressing these, create urgency for change and consumer awareness. The activities of an activist NGO are thus relevant for innovation because their claim of voicing the opinions of the general public stimulates market partners to explore changes, thus creating room for partnerships with moderate NGOs to define and implement such changes.

Standards linking local practices and global markets. As in the previous chapter, Allison Loconto, Anne Sophie Poisot and Pilar Santacoloma also built on social movement theories, combining these with the sociology of innovation. This chapter described 15 cases of creation of various market arrangements in developing countries, based on local networks linking sustainable agricultural practices to global markets. Although smallholders have a limited influence in setting standards, such standards do play an important role in facilitating this linking. The findings showed the entrenchment of both local communities and international dynamics that determine the development of institutional innovations. The role of standards in connecting sustainability niches and globalized markets is complex, as they are only one factor at play in the social dynamics. Other important factors include direct marketing techniques used by groups, charismatic leadership, constructing a common vision for sustainable agriculture, culinary education linking the origin of food and its preparation. These factors all reflect important distributed capacities that help farmers and their organizations to move gradually toward more sustainable practices.

\subsection{Knowledge and knowing in regime transformations}

The last part of this volume addressed the issue of regime transformations by focusing on cognitive frameworks and narratives that guide action. The cases described different types of social research (sociology of education, system thinking, communication studies and practised based approach) that question the transfer of knowledge as it is practised in the dominant regime. However, the way these four chapters approached knowledge and knowing does not simply consist of replacing one set of values and norms by another, more sustainable set. On the contrary, the authors used very nuanced approaches to study knowledge acquisition, knowing processes and reflexivity in relation to action in transitions.

Improving sustainability training in higher education. In this volume, Erika Quendler had a unique take on the sustainable development by focusing on the role of education. She analysed how education providers and employers have been training students on the manifold aspects of sustainable development with a view towards stimulating systemic change. An important overall observation was that Higher Education Institutions (HEls) training programmes have been suffering from the same inertia as incumbent systems towards changes. Yet, societal pressure, but also the demands from firms, call for significant changes in training programmes, e.g. more attention for sustainable development in general; training in handling complex situations; more attention for the prospect of action, for putting knowledge into practice; and more attention for lifelong learning in a rapidly changing world. Proposing to refresh the current discussion on the role of system innovation in education, this chapter utilised the MLP to tackle the issue of improving graduates' employability, based on improved sustainability knowledge and skills. It thus framed interactions between the education sector, actors striving for educational system innovation and the market in a new and promising way.

Niche as collective experience of opportunity. In their chapter drawing on the concepts of system thinking and transition management, Frank Nevens, Erik Mathijs and Philippe Vandenbroeck discussed an interactive process in which they have gradually crafted an analysis of the agri-food system in Flanders. The chapter discussed the use of system analysis as an instrument to assess problems that originated from phenomena that once marked the success of a system, such as productivity increase. A variety of lessons were drawn from the analysis, contesting or nuancing starting points and findings from earlier MLP work. One finding was that landscape pressures may not only cause regimes to change, they may also reinforce them. A further lesson is that, compared to 'weaker' actors, powerful system actors are more comfortable 
in a system thinking setting in which the potential of the dominant regime is part of the picture and of the discussion. From such a position, niches may not necessarily be seen as a threat to the incumbent regime, but also as a collective experience that provides inspiration and opportunity for transforming.

Reflexivity and learning outcomes. The study described by Pieter J. Beers and Barbara van Mierlo started with observing that reflexivity is seldom clarified conceptually and that its relation with learning and reflection have hardly been analysed. From a literature review they concluded that that reflexivity has been rarely operationalised and not seem to have been studied empirically at all. In a case study on an innovation initiative on the Dutch greenhouse sector, they predefined 14 learning outcomes. They concluded that of these learning outcomes, only a few have increased reflexivity. Half of the observed learning outcomes were mainly in line with the dominant rules that guide participants' practices and interaction, without an apparent stimulus to increase reflexivity. This lead to the conclusion that not all interactive learning outcomes could be expected to contribute to system innovation. The authors proposed it as possible as well as relevant to distinguish learning and reflexivity, and investigate their relationships and interaction more in-depth. But they also warned that scholars of learning may have overestimated the relation between organised learning and transformative change.

Intermediation as a complex activity. The chapter by Patrick Steyaert, Marianne Cerf, Marc Barbier, Alix Levain and Allison Loconto focused on intermediation activities at play in situations of sustainability transitions and in relation to what the authors call the 'environmental paradox'. The authors suggested that these activities need to be analysed as the combination of three levels of engagement from intermediaries: contextualization, performativity and reflexivity. On the basis of a crosscutting analysis of case studies they observed that, while sustainability transitions are strongly related to expectations in terms of efficiency and measurement, they are also characterized by some generic attributes of 'wicked problems' that make these expectations partly unachievable. Therefore, the core properties of wicked problems related to environmental issues need to be taken into account: interdependency, complexity, uncertainty and controversy, since these properties condition the understanding and the potential impact of intermediation activities. As a result, initiatives to make agriculture more sustainable should be aimed less towards goals achievement and more towards the process dimension of transformational change. In conclusion, the chapter argued for a research program on intermediation as practice that should address the following three issues: (1) the way intermediation acquires its legitimacy; (2) the objectification and intersubjectification processes and the way they are articulated through the different functions of intermediation; and (3) the working of the constitutive properties of intermediation, i.e. contextualization, performativity and reflexivity.

\subsection{Three research strands on agroecological transitions}

The six papers discussed in section 2.1 above all focused on how various actors are tinkering with new agricultural practices in niches or with new social practices of food provision. Three of these chapters considered agricultural production per se and the collective design of possible alternatives that address shortcomings of the incumbent sociotechnical regime, while the other three analyse agricultural niches as part of wider local or regional change process for sustainable development. These chapters clearly illustrated that the production of novelties does not occur in an isolated bubble of values, action and intentions. The transformative ambition of those initiatives leads them to develop ties with contextual incumbent systems which they seek to change.

The following six papers discussed in section 2.2 explored linking processes between niches and regimes to support transitions. Three chapters concerned new technology and sociotechnical standards which mobilise public attention and policy making to transform existing systems. This causes tensions in prevailing systems of knowledge, questions the status and role definition of intermediary organizations and requires a different allocation of resources. Three other chapters described a gradual process of transformation by means of strategizing and market standards, focusing on organised action and initiatives that seek to govern sustainability via entrepreneurial strategies and market instruments. These chapters thus provided a distinctive perspective on transitions, one that emphasizes the transformative potential of civic actors, of 
liberal market institutions and that is less depending on public support and policy attention for rural and agricultural development.

The final set of four papers discussed in section 2.3 addressed the issue of regime transformations by focusing on narratives, cognitive frameworks and reflexive consciousness that guide action for sustainable development. They analysed a variety of concrete cases, including a chapter on the role of education in sustainable development. Moreover, explored the conditions under which a novelty, that has successfully linked up to the regime, is becoming more widely used. As a result, the incumbent practice of the regime may gradually loose its dominance, which may eventually result in a transition towards sustainable agriculture. These chapters offered empirically grounded insights to set up methods, guidelines and visions to foster transformative changes. Yet, many issues are still open and call for a discussion of scientific frameworks that have been used or challenged in the chapters in this volume.

\section{Challenges in the study of agroecological transitions}

\subsection{Articulating and contrasting seminal research frameworks}

A large number of publications have already resulted from applying the MLP to the analysis of transitions in various sectors. By using the concept of 'transition pathways' (Geels and Schot, 2007), more insight has been gained into the governance of the discontinuation of problematic sociotechnical regimes (Stegmaier et al., 2014). This attempt to re-think sociotechnical regimes as large evolutionary reconfiguration processes that also have polities, policies and politics, has been connected to more critical perspectives on the politics of transition management (Smith and Stirling, 2010). However, few studies have addressed transitions-in-the-making in the agricultural sectors or the agri-food system. Seeking to close this gap, this volume presented several chapters that use the MLP to analyse a variety of practical attempts to trigger or stimulate transitions.

All chapters in this volume used a systems perspective and either implicitly or explicitly build on the legacy of 'Farming Systems Research' (e.g. Darnhofer et al. 2012) to structure debates and innovation processes in response to the shortcomings of linear innovation models and technology transfer approaches. From the beginning, and also inspired by the studies of development in rural areas in developing countries, the main principle of Farming Systems Research has always been to consider the need for partnerships between farmers and researchers, including both technical and social scientists. More recently, these analyses also started to include extension agents and policy actors, attempting to involve farmers in the design of novel solutions to tackle sustainability challenges (Norman 2002; Pant and Hambly-Odame 2009).

System thinking in the domain of food and agriculture is certainly not new. Some system perspectives have resulted from critiques on earlier, dominant perspectives on agricultural innovation that consider innovation as a social phenomenon that first spreads via communication in social systems through networks of personal contacts. In later stages of the diffusion process, according to this perspective, mass media play a key role when large groups are spurred to adopt a new technology or product (Rogers 1995). The critique of the diffusion paradigm was carried further by the Agricultural Knowledge and Innovation Systems (AKIS) approach that extended the boundaries of analysis to the whole sector and webs of national and international institutions. Adopting a soft systems perspective, AKIS approaches emphasize that a system and its boundaries should be understood in diverging ways to acknowledge the diversity of actors' objectives and situations. In this interpretation, the focus is on the diversity of actors who are part of a 'human activity system' (Röling 1992) that negotiates the arbitrary boundaries established by institutions and regulation. Thus, the systems concept became used as an action-research strategy to make people think of themselves as being part of a system, which would require novel forms of coordination (e.g. Engel 1995). 
Concomitantly, Agricultural Innovation Systems (AIS) thinking emerged (Assefa et al. 2009; Pant and Hambly-Odame 2009) that was influenced by ideas and concepts on 'national systems of innovation' as developed by Lundvall (1992) and pioneered in the agricultural domain by A. Hall and others (e.g. Hall, 2006). AIS thinking has further broadened the scope by addressing complex interactions between a multitude of institutionalised players and infrastructures. The chapters of this volume did not advocate a convergence of those approaches, but together they provided a testimony of the diversity in studying, analysing and interpreting transitions in agro-food systems.

The authors of this volume shared the common vision that much contemporary research naively assumes a general need of enhancing innovation or stimulating the knowledge economy through improving the functioning of the 'system'. Such studies tend to neglect that the goals, interests and perspectives of interdependent actors in agro-food systems diverge widely. This results in conflicts in processes of change, implying that there is no general acceptance of what constitutes a system or structure. This is where the sociotechnical regime approach (MLP) certainly has provided a refreshing method to address transition processes.

In our view, the notion of system or regime in sustainability transitions literature is well equipped to contribute to the agroecological agenda, since it acknowledges the multiplicity of values, conflicts and contestation. Moreover, it supports transformative change since it addresses questions of the emergence of new sociotechnical arrangements, the simultaneous reconfiguration of incumbent systems by overcoming path-dependencies. The multi-level perspective forms the backbone of this approach in which systems are regarded as the whole of actors, their relations and recurrent practices, which are heavily influenced by the regime of cognitive and normative rules. Socio-technical novelties that hold a promise to radically change these regimes can only survive if they are protected in the early stages of development, nurtured, and empowered vis-à-vis the dominant regime. If they are, they may eventually develop into new systems of their own and either take over the dominant regime or transform it. Yet, however relevant it seems, using a sustainability transitions perspective in the agricultural domain is still rare, and has not received the attention that it deserves.

\subsection{Transition and agroecology: governing reconnection}

To connect issues of transition with the agroecological turn requires addressing how transition processes are both matters of scientific enquiry and matters of action. The objectivation of 'transitions' - as normative pathways of governing sociotechnical regimes - brings back contentions and discussions between those who reify sociotechnical regimes to purposefully discuss the management of change ('governance on the outside') and those who take a more reflexive and political stance towards governance of change, bearing in mind the indeterminacy of sociotechnical arrangements ('governance on the inside'; cf. Walker and Shove 2007; Smith and Stirling 2007).

As far as agriculture is concerned, such debates about change and transition management (on the outside versus on the inside) are as ancient as the critique of the modernization process of agriculture (Weber 2013). We need to acknowledge that the agricultural sector features a permanent process of change of both techniques and farmers' practices and the correlated adaptation of agricultural policies to food security goals. However, over the past fifty years, farming has become a matter of serious societal concern: food provision, food quality and sustainable diets have progressively emerged as problematic issues related to problematic modes of agricultural production, echoing critiques of the treadmill of production (Barbier 2010). Simultaneously, academic notions of 'the system' in agricultural innovation processes have widened from primarily encompassing farms and farmer groups within their direct biophysical and socioeconomic context, to encompassing wider innovation systems, including organizations like agro-food companies, public research institutes and governmental entities, and, in some cases, consumers, as well as technical infrastructure and their relations. Within this perspective, learning and change extend beyond agricultural research institutes and extension systems (Klerkx et al. 2012). 
Meanwhile, the launch of the European Innovation Partnership (EIP) on 'Agricultural Productivity and Sustainability' has spurred the AKIS approach to rethink interactive links between agricultural research and innovation by incorporating policies, rules and regulations, as well as Operational Groups that depend heavily on brokering activities, intermediaries and boundary type of work. While this approach is not new for those who have studied rural and agricultural development initiatives, this recognition is seen as a contribution to a more effective European policy on innovation in agriculture and rural areas, to counterbalance the Knowledge Based Bio-Economy (KBBE) approach (Knickel et al., 2009). In research, two streams have recently evolved in agricultural and rural studies: one on the ecologization process of agricultural production, and another on the transformation of food systems and consumption. These two streams have initially developed rather separately, except for those who pioneered the analysis of organic or peasant farming and agri-food networks (Lamine et al. 2012; Chiffoleau 2009) and who have questioned the reorganization of connecting the production of food to space (Campbel 2009).

The progressive alignment of separated visions of agriculture and food provision - either in dialectical, systemic or actor-network frameworks - has certainly been an intellectual challenge, that received more attention after the BSE (mad cow disease) crisis. It lies also at the heart of the agroecological agenda to reconnect agriculture and food provision, thus enriching a productivist Farming System perspective with considerations on learning and change in a context of environmental and food quality concerns (Cerf et al. 2000). This systems research epistemic community has lingered until recently (Darnhofer et al. 2012) and clearly harnessed research on the alignment of agricultural systems and agroecological challenges. But it has also roots in systems thinking theory and its application to agriculture (Bawden and Packam 1993) that has fostered a critique of technocentric or ecocentric approaches of action (Bawden 2000). In these approaches, knowledge is supposed to objectify reality which enables goal oriented action. But knowledge can also be considered as a 'flow' in action, which calls for a holocentric (human centred; Bawden 2000) approach of sustainability transitions to support transformational change. It leads to a cross-fertilization of systemic and pragmatist approaches to be able to give a full account of transitions of agri-food systems (Lamine et al. 2015).

Despite the existence of more holistic evolutionist frameworks to capture knowledge dynamics in action and transformation, we still face a complex challenge: the notion of agri-food systems, which purposefully reassembles the ecologization process of agricultural production and the transformation of food provision and consumption into one perspective. By consequence, this could lead to a reification of agri-food regimes, i.e. regimes to be governed 'on the outside'. However, a wide variety of studies warn against this and stress a need to seriously address 'governance on the inside'. The debate about the conventionalization of organic farming provides a good example of such tensions (Buck et al. 1997), while warnings have also been voiced against the possible absorption of agroecological innovation into one big corporateenvironmental food regime (Levidow 2015). Another emblematic contention concerns the research system itself (Vanloqueren and Baret, 2009) and the re-association of agroecological innovations as matters of fact for the agronomic knowledge regime. As analysed by Ollivier and Bellon (2013), different labels of ecologized agriculture have appeared over the past decades within an opposition between holistic approaches (sustainable agriculture, integrated agriculture, eco-agriculture, multifunctional agriculture, agroecology, alternative agriculture, organic agriculture) and technology centred approaches (precision agriculture, conservation agriculture).

\subsection{Studying transformative change as a scientific challenge: regime shifts and paradigmatic conflagration}

The contributors to this volume all lean on some form of evolutionary and systemic approach to analyse the sociotechnical dynamics in a variety of cases, whatever the level of their enquiry. Understanding those processes as a distributed manifestation of the co-evolution of tension streams, either at the heart or at the fringes of the agriculture and food regime, requires a certain variety in approaches to analyse pathways of change, causality, lock-in and performativity. Certainly, at present this enquiry may be divided up into too 
many fragments of research interests, or a curiosity cabinet. But this volume can also been seen as an effort to organize and somewhat focus the study of agri-food transitions-in-the-making.

One thing the authors of this volume share is that the institutionalisation process of making agriculture more sustainable is at the same time a de-institutionalisation process of the sociotechnical traits that have made it so un-sustainable. The ecologization of agricultural policy has become less and less sectorial, making ecological critiques and proposals less local and more global. The initial greenwashing response to sustainability concerns has become increasingly criticized, resulting in more systemic and systematic approaches in practice. We witness a reorientation of research, development and production that treats the ecologization of farming as a major bottleneck for sustainable agriculture. At the same time, changes take place in the links between food provision and food consumption. This is supported by a variety of insights on food security or (un)healthy food habits, and can be observed in the consumption movement as well as in transformative processes that target changes of agricultural production in relation to short circuits or alternative food networks.

These changes, although important, do not necessarily mean we are on the right track. We can observe changes that may result in two very different types of transition pathways: a modernisation of mainstream and intensive agriculture for which the KBBE paradigm presents a roadmap; and an agroecological redesign of intensive farming that is supported by the organic movement. These paradigmatic transition pathways compete in many ways, but may also co-operate since some farming technological issues or problem definitions are shared in the same institutional arenas and may even be at work at the level of new farming practices. Also, both pathways are based on a vision that deviates from the prevailing 'productivist' paradigm: more incremental in the first case, more radical in the second, and of course with different visions of sustainability.

Therefore, considering a pure opposition of paradigms would not only be simplistic but would also make a caricature of the ongoing changes. The critiques of the absorptive capacity of the dominant regime of productivist agroindustry, with its emphasis on profit, growth and modernization, should not obscure the studies of transformative changes. Transition studies of agriculture and food provision should start with the analysis of changes of practices, since radical or incremental innovation and resistance towards productivism do not operate in a vacuum but are embedded in systems of actors, routines, technology and regulation. Different actors have also different capacities to foster and absorb innovations (Nemes and Augustyn 2017). Here, some of the burning questions may be: How can the critique of the productivist 'milky-way' be translated into practical challenges rather than utopian visions? Does the absorptive capacity of the dominant regime operate like a mangle for initiatives for change? What are the effects of absorption and according to what type of transition pathway and learning processes? These are complex questions, for sure, but they also provide inroads to deal with the systemic nature of transitions.

With this volume we take an agnostic stance towards change processes. The reference to the canonical MLP model of niche-regime-landscape dynamics should not lead to a simplistic divide between, on the one hand, a global vision of the modernisation of the regime via incremental innovation pathways and, on the other hand, a local account of the many agroecological niches that nourish great expectation outside the dominant regime. Important research themes have blossomed in the area of transition studies, and many of them take the MLP as a heuristic to organise research questions on the dynamics at play. As a result, this heuristic has nourished the justification and framing of purposeful transition management issues. The proposal for a social science agenda on the dynamics of agri-food systems by Thompson and Scoones (2009), and the necessity to recover narratives on productivism in agriculture in line with contemporary of even future challenges of food provision (Marsden, 2013), together present a challenge for many scholars concerned with agri-food systems. The efforts to congregate scientists with different disciplinary backgrounds to deliver research insights on transformation and system innovation within the agri-food sociotechnical regime, thus contributes to the objective of fostering a distributed and collective enquiry of transition processes (Barbier and Elzen, 2012).

The purpose of the present volume is to keep the ambition high for this perspective. This is reflected in the chapters in this volume that are not necessarily confined to a specific programmatic vision of transitions, 
nor are they bound to a specific reflexive account of doing transitions research. But they might be captured under the umbrella of 'social studies of transition-in-the-making'. Together they represent a collection of transition studies and not a set of proofs to defend a specific theoretical framework. Rather, this Cabinet of Curiosity of transition studies provides a collective enquiry based on empirical investigations to compare and contrast practices, and analyse innovation efforts towards changes and breakthroughs that are grounded in a critique of the incumbent agri-food system.

\section{References}

Assefa, A., Waters-Bayer, A., Fincham, R., Mudahara, M., 2009. Comparison of frameworks for studying grassroots innovation: Agricultural Innovation Systems (AIS) and Agricultural Knowledge and Information Systems (AKIS). In P. Sanginga, A. Waters-Bayer, S. Kaaria, J. Njuki, C. Wettasinha (eds.). Innovation Africa: Enriching farmers livelihoods. London: Earthscan, 35-56.

Barbier, M. and Elzen, B. (eds.), 2012. System innovations, knowledge regimes, and design practices towards transitions for sustainable agriculture. http://www.inra-ifris.org/activites/openscience/system-innovations-knowledge-regimes-and-design-practices-towards-transitions-forsustainable.html

Barbier, M., 2010. The ecologization of agricultural development and the Treadmill of sustainable development. A critique in a state of transition, Przegląd Socjologiczny, 59 (2), 9-28.

Bawden R.J. and Packam R., 1993. Systems praxis in the education of the agricultural systems practitioner. Systems Practice, 6, 7-19.

Bawden, RJ., 2000. Valuing the Epistemic in the Search for Betterment. Cybernetics and Human Knowing, 7, 5-25.

Buck, D, Getz, C., Guthman, J., 1997. The Organic Vegetable Commodity Chain of Northern California. Sociologia Ruralis, 37 (1), 3-20.

Campbell, H., 2009. Breaking new ground in food regime theory: corporate environmentalism, ecological feedbacks and the 'food from somewhere' regime? Agriculture and Human Values, 26, 309-319.

Cerf M., Gibbon D., Hubert B., Ison R., Jiggins J., Paine M., Proost J., Röling N. (eds.), 2000. Cow up a tree, Learning for change in agriculture - Case studies from industrialised countries. Paris: INRA.

Chiffoleau Y., 2009. From politics to cooperation: the dynamics of embeddedness in alternative food networks. Sociologia Ruralis, 49 (3), 218-235.

Darnhofer, I., Gibbon, D., \& Dedieu, B., (2012). Farming systems research: an approach to inquiry. In I. Darnhofer, D. Gibbon and B. Dedieu (eds.). Farming Systems Research into the 21st century: The new dynamic. Dordrecht: Springer, 3-31.

Engel, P. G., 1995. Facilitating innovation: an action-oriented approach and participatory methodology to improve innovation social practice in agriculture. http://www.wur.nl/en/Publicationdetails.htm?publicationld=publication-way-3238393332

Geels, F. W., and J. Schot, 2007. Typology of sociotechnical transition pathways. Research Policy, 36, 399417.

Hall, A., 2006. Public-private sector partnerships in an agricultural system of innovation: concepts and challenges. International Journal of Technology Management \& Sustainable Development, 5 (1), 320.

Klerkx, Laurens, Barbara Van Mierlo, and Cees Leeuwis, 2012. Evolution of systems approaches to agricultural innovation: concepts, analysis and interventions. In I. Darnhofer, D. Gibbon and B. Dedieu (eds.). Farming Systems Research into the 21st century: The new dynamic. Dordrecht: Springer, 457-483.

Knickel, K., Tisenkopfs, T., and Peter, S., 2009. Innovation processes in agriculture and rural development. Results of a cross-national analysis of the situation in seven countries, research gaps and recommendations. In-Sight project report.

Lamine C., Renting H., Rossi, A., Wiskerke, J.S.C., Brunori, G., 2012. Agri-Food systems and territorial development: innovations, new dynamics and changing governance mechanisms. In I. Darnhofer, D. Gibbon and B. Dedieu (eds.). Farming Systems Research into the 21st century: The new dynamic. Dordrecht: Springer, 229-256.

Lamine, C., Bui, S., \& Ollivier, G., 2015. Pour une approche systémique et pragmatique de la transition écologique des systèmes agri-alimentaires. Cahiers de recherche sociologique, 58, 95-117. 
Levidow, L., 2015. European transitions towards a corporate-environmental food regime: Agroecological incorporation or contestation? Journal of Rural Studies, 40 (August), 76-89.

Lundvall, A., 1992. National systems of innovation. London: Pinter.

Marsden, T., 2013. From post-productionism to reflexive governance: Contested transitions in securing more sustainable food futures. Journal of Rural Studies, 29 (January), 123-134.

Norman, D. W., 2002. The farming systems approach: A historical perspective. Proceedings of the 17th Symposium of the International Farming Systems Association in Lake Buena Vista, Florida, USA, 1720.

Nemes, G. and Augustyn, A., 2017. Inclusive Innovation in a European context - the experiences of two Learning and Innovation Networks for Sustainable Agriculture from Hungary. Innovation and Development, 1(7), 1-20.

Ollivier, G., \& Bellon, S., 2013. Dynamiques paradigmatiques des agricultures écologisées dans les communautés scientifiques internationales. Natures Sciences Sociétés, 21 (2), 166-181.

Pant, L. P., \& Hambly-Odame, H., 2009. Innovations systems in renewable natural resource management and sustainable agriculture: a literature review. African Journal of Science, Technology, Innovation and Development, 1 (1), 103-135.

Röling, N., 1992. The emergence of knowledge systems thinking: a changing perception of relationships among innovation, knowledge process and configuration. Knowledge and policy, 5 (1), 42-64.

Rogers E, M., 1995. Diffusion of innovations. New York: Free Press.

Smith A., and Stirling, A., 2007. Moving Outside or Inside? Objectification and Reflexivity in the Governance of Socio-Technical Systems. Journal of Environmental Policy \& Planning, 9 (3-4), 351-373.

Smith, A., and Stirling, A., 2010. The politics of social-ecological resilience and sustainable socio-technical transitions. Ecology and Society 15 (1): 11

Stegmaier, P., Kuhlmann, S., Visser, V.R., 2014. The discontinuation of socio-technical systems as a governance problem. in S. Borrás and J. Edler (eds.). The governance of socio-technical systems: explaining change. Cheltenham: Edward Elgar Publishing.

Thompson J., Scoones, I., 2009. Addressing the dynamics of agri-food systems: an emerging agenda for social science research. Environmental Science \& Policy, 12 (4), 386-397.

Vanloqueren, G., and Baret, P., 2009. How agricultural research systems shape a technological regime that develops genetic engineering but locks out agroecological innovations. Research Policy, 38 (6), 971-983.

Walker, G., and Shove, E., 2007. Ambivalence, sustainability and the governance of socio-technical transitions. Journal of Environmental Policy \& Planning, 9 (3-4), 213-225.

Weber, M., 2013. The agrarian sociology of ancient civilizations. Verso Books.

Wiskerke, J.S.C. and Van der Ploeg, J. D., 2004. Seeds of Transition: Essays on novelty production, niches and regimes in agriculture. Assen: Royal van Gorcum. 


\section{Author Biographies}

Anna Maria Augustyn (1982) originally from Poland, graduated in applied social sciences from the Warsaw University and works as a free-lancer. She has over 10 years of experience of research and consultancy in various projects across Europe. Her main areas of expertise are sustainable agriculture, rural and community development, facilitation of participatory and multi-stakeholder processes, impact assessment and evaluation. Among others, she worked with the European Commission, European Network for Rural Development, LEADER Local Action Groups, University of Ljubljana and Hungarian Academy of Sciences. In 2015 she was elected a vice-president of the Groupe de Bruges - an international think-thank dedicated to sustainable agriculture and rural areas.

Bálint Balázs (1975) has an MA in history (Central European University) and sociology (Eötvös Loránd University), and is a $\mathrm{PhD}$ candidate in environmental sciences. He is a senior research fellow of the Environmental Social Science Research Group (ESSRG) and lecturer of environmental sociology at the Institute of Nature Conservation and Landscape Management, St. István University, Gödöllö, Hungary. He is a board member of the Environment \& Society Research Network of the European Sociological Association. He is country contact person for 'Living Knowledge', the International Network of Science Shops.

Marc Barbier (1964) is a Senior Researcher in Sciences and Technology Studies at the National Institute for Agricultural Research (INRA) and co-editor of the Revue d'Anthropologie des Connaissances. He manages the CorTexT Platform of the LISIS Unit in Paris. His research interests and works contribute to the fields of social studies of knowledge regimes in agriculture and of the governance of sustainability transitions under various pressures for change, such as pesticide use, emergent diseases, bioenergy and ecosystem services.

Volkert Beekman (1968) has a background in sociology (MSc) and philosophy (PhD). He works as a senior researcher at Wageningen Ecnomic Research, and is involved in projects that focus on the social appraisal of emerging science and technologies in agriculture and food production. The projects in which he participates typically go beyond science as a merely analytical endeavour to also practically co-design networks and platforms to open-up dialogue and cooperation between various societal actors. He has an established track record in applying qualitative social science research methodologies and is an experienced coordinator of European projects.

Pieter J. Beers (1977) is senior researcher at DRIFT, the Dutch Research Institute for Transitions (Erasmus University, Rotterdam) and professor of applied science at HAS University of Applied Science. During the study described in this volume he worked at the Knowledge, Technology and Innovation Group of Wageningen University. His main research interests concern new business models for agricultural transitions. He is an expert on learning processes and monitoring in the context of societal transitions and sustainable development. He has studied and facilitated initiatives towards transition in both education and agriculture. In addition, he has developed and taught various courses about learning and transitions.

Bram Bos (1968) has a background in biology and STS (MSc) and philosophy (PhD). He works as a seniorresearcher at Wageningen Livestock Research and is involved in projects that aspire to contribute to sustainable animal husbandry. The projects in which he participates transcend the technical, and involve animal, social, organizational, cultural and even philosophical aspects of keeping animals. Together with colleagues, he developed the Reflexive Interactive Design (RIO) approach. RIO combines insights from Engineering Design, STS and systems thinking, and looks for convergence rather than trade-offs between interests and values, and converts this into visionary as well as plausible designs of sustainable animal production systems. Several of these were realized in practice.

Bart Bremmer (1984) works as a self-employed innovation sociologist. He advises governments and research institutes about the social aspects of sustainability and innovation in agriculture. His focus lies on the big puzzle (system perspective) on the one hand, the perspectives of individual farmers, advisors, civil 
servants, etc. on the other hand, as well as the interaction between these perspectives. He combines his background in Rural Sociology with a keen interest in Behavioural Economics and Social Psychology.

Jan Buurma (1953) has a background in agronomy and agricultural business economics. He works as a senior researcher at Wageningen Economic Research. He has an international track record in economics and innovation of plant production. Since 2000 he gradually moved to sociology of innovation, with a special focus on analysing and understanding the dynamics of public debates. For that purpose he developed the dramaturgical approach in addition to content analysis and successfully applied this approach on issues like pesticides and crop protection, regional transition processes in horticulture and animal welfare in the livestock industry. Based on this empirical knowledge he now, together with colleagues, works on agent-based modelling of complex adaptive systems.

Marianne Cerf (1960) is an agronomist with a PhD in cognitive psychology and is senior researcher at the National Institute for Agricultural Research (INRA). She is assistant head of the INRA Research Department "Science for Action and Development". She developed researches on farmers' decision making and learning processes as well as action-research projects on design activities and extension work with various advisory, $R \& D$ as well as research organizations. She is involved in a French multi-stakeholder network dedicated to the design and the assessment of innovative sustainable cropping systems and contributes to study intermediation and to support French policy makers on issues related to sustainability transitions.

Shambu Prasad Chebrolu (1967) is an engineer who pursued his doctoral work on science, technology and society studies from the Indian Institute of Technology (IIT) Delhi after stints in the industry, a masters in science policy and an active engagement with a civil society organisation in between. He brings to his research, teaching and strategic consulting multidisciplinary insights on innovation and public policy and has been involved in knowledge dialogues and learning alliances with practitioners and academics working together to enhance innovation capacities of communities at the margins. His work encompasses the domains of innovation management, social entrepreneurship, public policies and public system management, rural livelihoods, sustainable agriculture and ecosystem and sustainability management. He coordinates various networks of actors on rural livelihoods, sustainable agriculture and science policy. He has been a Senior Fulbright Research Fellow at Cornell University (2013-14).

Boelie Elzen (1953) was trained as an electrical engineer and holds a PhD in STS. Until recently, he worked at Wageningen Livestock Research, where he participated in some of the projects described here. Currently, he is partially affiliated with Wageningen UR, Applied Arable and Vegetable Research. For the other part, he is affiliated with the Science, Technology and Policy Studies department at the University of Twente, and has his own company (called Alnus) for research and consultancy on sustainability transitions. His general interest is to create bridges between research insights on the one hand, and sustainable development in practice on the other. His dual goal is to make the latter more effective while, based on these practical experiences, broadening and deepening scientific insights. He has published widely on his research, including a frequently cited volume on sustainability transitions for which he was the lead-editor.

Karel de Greef (1963) was trained as an animal scientist at Wageningen University. He did his PhD in modelling growth and body composition in pigs and was subsequently active in several disciplines at Utrecht University and Wageningen Research institutes. Since the early 2000s, he is active in projects where animal science is combined with innovation theory and interactive work to address social unease in farm animal production. The Pigs in Comfort Class was an early effort to integrate analysis, design and stakeholder participation into an innovation approach. Currently, his prime activities for Wageningen Livestock Research deal with systems changes in the pig and in the rabbit production chains.

Anne-Charlotte Hoes (1982) works as an action-researcher in the area of social innovation at Wageningen Economic Research. Her expertise in (system) innovation, process monitoring and communication enables her to further our understanding on innovation processes and to assist innovation initiatives such as Sustainable Dairy Chain. She studied biology (BSc), management, policy analysis and entrepreneurship (MSc) at the Amsterdam VU University and finished the graduate programme of "Science, Technology and Modern Culture". During her PhD she addressed issues such as the social acceptance of novelties, the 
diffusion of innovations and research-practice co-creation. She also participated in the research team that developed the 'Reflexive Monitoring in Action' approach.

Julie Ingram (1958) is a reader of sustainable agri-environmental systems at the Countryside and Community Research Institute (CCRI), University of Gloucestershire, UK. Her main research interests are learning, and knowledge and innovation systems within the context of sustainable agriculture and natural resource protection, with particular reference to soil. Most recently she has lead work packages in the following EU Framework 7 projects: SOLINSA (Support of Learning and Innovation for Sustainable Agriculture), SmartSOIL (Sustainable farm Management Aimed at Reducing Threats to Soils under climate change) and VALERIE (Valorising European Research for Innovation in Agriculture and Forestry).

Arni Janssen (1977) has studied biology and STS (MSc) and holds a teaching certificate in biology (MSc, first degree). She works as a lecturer in Biosystems Design at the Farm Technology Group of Wageningen University, the Netherlands, and is linking design, research and education for permaculture and agroecology initatives around the world. She has worked for six years at Wageningen UR Livestock Research, where she contributed to co-design projects applying the method of "Reflexive Interactive Design" in several animal husbandry sectors. Alongside that, her task was to involve researchers, students and teachers from agricultural vocational education in dissemination, circulation and co-creation of knowledge about sustainable livestock production.

Pavlos Karanikolas (1964), Ph.D. is an agricultural economist and assistant professor in the Department of Agricultural Economics and Rural Development at the Agricultural University of Athens. He teaches undergraduate courses on political economy and agricultural policy, as well as a graduate course on EU agricultural and rural development policies. His research interests and published work include political economy, transition theory, agricultural economics and rural development. He has taken part in a series of research projects, such as "FarmPath-Farming Transitions: Pathways Towards Regional Sustainability of Agriculture in Europe" (EU-FP7).

Alex Koutsouris (1959) is associate professor at the Department of Agricultural Economics \& Rural Development at the Agricultural University of Athens. He has a strong general background in agricultural and rural development and is specialist in agricultural extension and agricultural education/training as well as in sustainable rural development with emphasis on participatory methods. Currently, he is member of the steering committees of IFSA (International Farming Systems Association), the European Group and ESEE (European Society/Seminar of Extension Education and associate editor of the Journal of Agricultural Education \& Extension. He has participated in several research and collaboration projects including "A cognitive approach to rural sustainable development - the dynamics of expert and lay knowledge" (CORASON); "Learning in European Agricultural and Rural Networks: Institutions, Networks, Governance" (LEARNing) and "Space for Innovations in Agriculture" (AgriSPIN). He also collaborated with "Prospects for Farmers' Support: Advisory Services in European AKIS" (PRO-AKIS).

Claire Lamine (1970) holds a PhD in sociology. After practical experience in rural development and diverse research experiences, she was hired by INRA in 2005 to develop interdisciplinary approaches to pesticide reduction issues and organic agriculture. Her main research themes are: transitions towards ecological modes of production; transformation, distribution and consumption within the agri-food system at large; promises and controversies of the agro-ecological paradigm; and evolution and possible ecologization within the breeding industry and research.

Orsolya Lazányi (1987) has an MSc in regional and environmental management from Corvinus University of Budapest, and studied sustainable territorial development in Brazil at the Federal University of Santa Catarina. She is currently PhD student at Corvinus University of Budapest on interdisciplinary research on sustainable land-use and heritage management, as well as junior research fellow at the Environmental Social Science Research Group (ESSRG) and the Gyula Forster National Centre for Cultural Heritage Management, Hungary. 
Alix Levain (1978) is a social anthropologist and a post-doc research fellow at INRA (LISIS: Interdisciplinary Laboratory for the Study of Science, Innovation and Society), and is an affiliated research scientist at the French National Museum of Natural History. Her research focuses on environmental change as lived experience, on intermediary activities and on the social construction of environmental risks and disasters, which she addresses mainly through ethnographic methods and participatory research. She is currently involved in the "Governance of Discontinuation in Socio-technical Systems" European research project, where she studies the socio-technical regime and governance of pesticides.

Allison Loconto (1978) is a research fellow at the National Institute for Agricultural Research (INRA, UMR LISIS). She is also a visiting expert at the Food and Agriculture Organization of the United Nations (FAO). She holds a PhD in sociology from Michigan State University and an MA in international affairs and development from The American University in Washington, DC. Her research and publications focus on governance by standards, innovations in certification systems, regulatory and innovation intermediaries, social innovation, and the governance of transitions toward sustainable agriculture. She is currently President of the Research Committee on Sociology of Agriculture and Food (RC40) of the International Sociological Association.

Erik Mathijs (1968) has an MSc in agricultural economics and sociology (1991) and a PhD in agricultural economics (1998). He is professor of agricultural and resource economics at the Department of Earth and Environmental Sciences of the University of Leuven, Belgium. His research focuses on innovation processes and more particularly on how to enable the transition towards a sustainable agricultural and food system. $\mathrm{He}$ is chair of the Expert Group of the 4th Foresight Exercise of SCAR, the EU's Standing Committee on Agricultural Research.

Damian Maye (1978) is a reader in agri-food studies at the Countryside and Community Research Institute (CCRI), University of Gloucestershire, UK. He has longstanding research interests in the geography and sociology of alternative and local food networks, food supply chains and food security. Recent research projects include an analysis of learning and innovation networks in Europe, a multi-dimensional assessment of global and local food chain performance in Europe, an examination of short food supply chains, waste recycling and multifunctional land use in European city regions, and an assessment of sustainable finance strategies for sustainable agriculture and fisheries. He edited (with James Kirwan) a major special issue of the Journal of Rural Studies on food security in 2013. He currently serves on the editorial boards of the Journal of Rural Studies and Moravian Geographical Reports.

Boldizsár Megyesi (1976) holds a PhD in sociology from Eötvös Loránd University, Budapest and an MSc. in horticultural engineering. He is research fellow at the Institute for Sociology, Centre for Social Sciences, Hungarian Academy of Sciences, Budapest, Hungary and visiting fellow at the Hétfa Research Institute, Budapest, Hungary. His main scientific interests cover social and economic changes of rural spaces, effects of development policy on rural communities, organic farming, new models of food-production, and ageing in rural Europe.

Pierluigi Milone (1971) is a researcher at the University of Perugia and holds a PhD in rural sociology from Wageningen University. His research interests include agricultural and rural sociology and economics, development intervention and rural transformation, contemporary rural politics and governance. He was a member of the technical cabinet of the former Italian agricultural Minister in the period 2002-2006. Since 2009 he is coordinator of the technical advisor group in the Molise Rural Development Program. He coedited an Emerald and a Routledge book publication on developmental practice and practitioners in relation to new markets with structurally different characteristics than mainstream markets.

Frank Nevens (1967) was educated at Ghent University as an agronomist, specialised in plant production. After a PhD on nitrogen use efficiency in ley-arable rotations and fodder crops, he broadened his perspective to whole farming systems sustainability. This resulted in embracing the dedicated study of systems innovation and transitions for sustainable development. He currently teaches the latter topic to students of Ghent University and keeps an ongoing interest in the logics of sustainability dynamics - or the 
lack of them - and the societal processes that could trigger acceleration of systemic changes towards sustainable agriculture and food practices.

Marcia Ostrom (1962) is associate professor in the School of the Environment and the Center for Sustaining Agriculture and Natural Resources at Washington State University, U.S. She teaches courses on sustainable food systems analysis and leads interdisciplinary research and education projects on agri-food system sustainability. She holds a PhD in environmental studies from the University of Wisconsin and an MS in rural sociology from Cornell. Research interests include agri-food movements; values-based food supply chains; participatory knowledge creation for ecologically-based farming systems; and food system regionalization. She recently completed a university teaching curriculum on values-based food supply chains.

György Pataki (1969) has an MSc in economics and a PhD in organisational science. He is research director at the Faculty of Business Administration and associate professor at the Department of Decision Sciences, Institute of Business Economics, Corvinus University of Budapest, and senior research fellow of the Environmental Social Science Research Group (ESSRG), Hungary. He has international research experience in EU-projects in the field of social innovation, valuation of ecosystem services, biodiversity governance and climate change adaptation. He is committed to participatory action research, sciencesociety and science-policy dialogues. He is an Eastern European member of the Multidisciplinary Expert Panel of the Intergovernmental Science-Policy Platform on Biodiversity and Ecosystem Services (IPBES) and a board member of the European Society for Ecological Economics.

Anne-Sophie Poisot (1973) is deputy coordinator of the Integrated Production and Pest Management Programme at the Crop Production and Protection Division of FAO. She holds a Masters in political science and economics from the Institut d'Etudes Politiques de Paris. Her work has focused on promotion of sustainable agriculture through discovery-based adult education such as farmer field schools, support to farmer organizations, strengthening producer-buyer linkages for sustainable products, pesticide risk reduction, quality standards and certification, and support to agriculture policies. She has recently coordinated the publication of several training guides on sustainable agriculture.

Erika Quendler (1971) is a researcher at the Federal Institute of Agricultural Economics. She holds a PhD in agricultural economics from the University of Natural Resources and Life Sciences in Vienna. Her research is focused on sustainable development, quality of life, evaluation for rural development programmes, young farmers' and family farms' issues, value chain and economic accounts for agriculture. In 2014, she won the Best Paper Award at the international conference „Resilience - The New Research Frontier" organised by the ISDRS (International Sustainable Development Research Society) in Trondheim with her contribution entitled "Resilience as an inclusive approach for sustainable, good life - a concept".

Pilar Santacoloma (1963) is an agribusiness economist working at the Agroindustry Division at the FAO. She holds a PhD in agriculture economics from the Hohenheim University, Stuttgart, Germany, and an MSc in agriculture economics from the National University, Bogotá, Colombia. Her work has focused on value chain development, strengthening producer-buyer linkages, analysis of agribusiness capabilities needs, food security through the commercialization of agriculture, food safety and quality standards, fostering agroentrepreneurship and assisting Ministries of Agriculture in formulating implementation plans for agricultural sector development. Her most recent publication is a series of 13 country case studies on agribusiness public-private partnerships.

Debashish Sen (1965) was born in Kharagpur, West Bengal in India. He holds a bachelor of technology degree (1988) in agricultural engineering from Allhabad Agricultural Institute (now Sam Higginbottom Institute of Agriculture, Technology \& Sciences), India. After his graduation, he started his career as a research assistant at the People's Science Institute (PSI), a non-profit research and development organization based at Dehradun, India. He took over the responsibility of heading the Centre for Participatory Watershed Development (CPWD) at PSI in 1996. Since 2006, he has been actively involved in the promotion of "System of Rice Intensification" (SRI) in the mountain states of India. This is what inspired him to enroll for a doctorate programme in 2010 at the Wageningen University, The Netherlands, to do 
research on the issue of farmer-SRI interactions. He is presently the Director of PSI. He has research interests in sustainable livelihoods, natural resources management and environmental impact assessments.

Patrick Steyaert (1959) is senior researcher in livestock science and sociology at the National Institute for Agricultural Research (INRA). He has an extensive research experience in Africa and in France. His work focuses on understanding the role of knowledge mobilization and production in processes of transformational change and social learning. His special field of research is agro-environmental public action related to water protection and nature conservation policies. He mainly practices intervention research in various multi-stakeholder networks related to the sustainable management of Atlantic coastal wetlands and to the governance of water on regional scale (French Brittany).

Paul Swagemakers (1974) is researcher at the Department of Applied Economics at the University of Vigo, Spain. He holds an MSc and PhD in Rural Sociology from Wageningen University, the Netherlands. His special interest is in farming in relation to rural development, agro-ecology and transition processes. From 2000 he published on farm innovation and continued his research interest as PhD student analysing the multi-functionality performance of dairy farmers in the Netherlands. After that he worked in European research projects in the Netherlands and Spain. In Spain he obtained a grant for the period 2013-2016 to continue his research interest from a comparative, international perspective.

Philippe Vandenbroeck (1965) has an MSc in agricultural engineering, an MPhi in philosophy and an MSc Human Settlements. He is co-founder and partner at the consultancy network shiftN, based in Leuven, Belgium. In his work he aims to support decision-makers in government, civil society and in the corporate world to handle complex, long-term strategic challenges through systems and futures approaches. He is affiliated with the Advanced Consortium on Cooperation, Conflict and Complexity at Columbia University.

Barbara van Mierlo (1964) is associate professor at the Knowledge, Technology and Innovation Group at Wageningen University, the Netherlands. She develops and conducts research on learning in system innovation for sustainability. The line of this research revolves around bounded initiatives of groups who aim for the transformation of socio-technological systems, including the rules that have emerged with earlier unsustainable practices. While acknowledging the limited contribution of single initiatives, the aim of the work is to study as well as enhance their significance and role in transformative change towards sustainability. New insights directly feed into the further development of the methodology of Reflexive Monitoring in Action (RMA), which aims to contribute to the emergence of new social practices and rules, by stimulating reflection and learning. RMA has a wide international uptake in among others agriculture, natural resource management and health.

Flaminia Ventura (1958) is researcher at the University of Perugia, Italy. She holds a PhD in Rural Sociology from Wageningen University. Her research interests include agricultural and rural sociology, development intervention and rural transformation, contemporary rural politics and governance. She was the head of the technical cabinet of the former Italian agricultural Minister in the period 2002-2006, and from 2008 is a coordinator in the National Rural Network in Italy. Recently she co-edited an Emerald and a Routledge book publication on developmental practice and practitioners in relation to new markets with structurally different characteristics than mainstream markets.

George Vlahos (1964) is assistant professor at the Department of Agricultural Economics and Rural Development, Agricultural University of Athens. He has collaborated in several research projects that focused on rural and agro-environmental policies, and authored articles and book chapters on these issues. He has been a member of the Thematic Working Group on 'Public goods and Public Intervention' of the European Rural Development Network, and is currently chairman of the Board of Trustees of WWF, Greece. He has participated in a large number of research projects on agro-environmental indicators and the implementation of rural development programmes. 